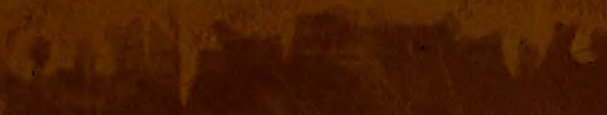

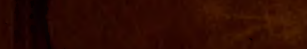




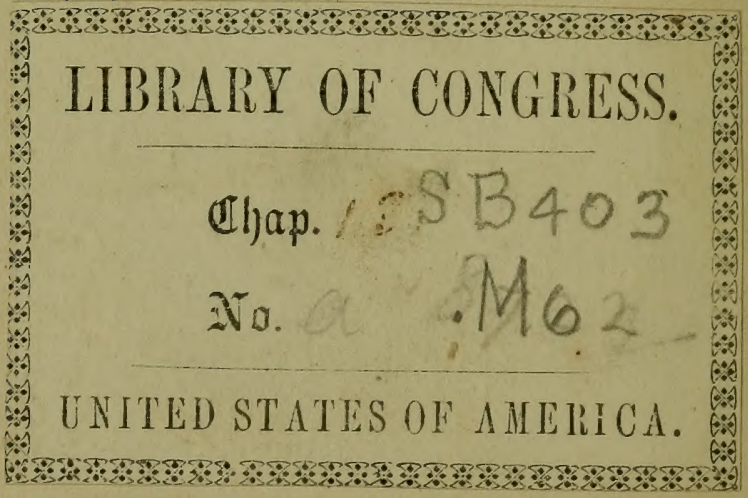






THE

\section{I D L A N D F L O R I S T,}

AN D

\section{SUBURBAN HORTICULTURIST.}

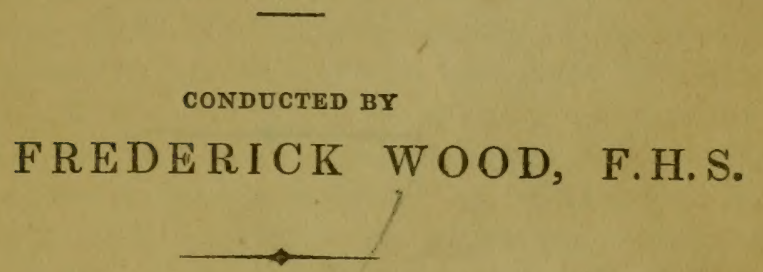

\section{JOHN FREDERICK WOOD, F.H.S.}

VOL. VI.

JANUARY TO DECEMBER, 1852.

"To study culture, and with artful toil,

To meliorate and tame the stubborn soil ;

To give dissimilar, yet fruitful lands,

The grain, or herb, or plant that each demands ;

To cherish virtue in an humble state,

And share the joys your bounty may create;

To mark the matchless workings of the power

That shuts within its seed the future flower;

Bids these in form of elegance excel,

In colour these, and those delight the smell;

Sends nature forth, the daughter of the skies,

To dance on earth, and charm all human eyes;

To teach the canvass innocent deceit,

Or lay the landscape on the snowy sheet.-

These, these are arts pursued without a crime,

That leave no stain upon the wing of time."

COWPER,

\section{LONDON :}

SIMPKIN, MARSHALL, \& CO., STATIONERS' HALL COURT, 
$\$ B_{40}$ 
THE

\section{MIDLAND FLORIST.}

\section{弱art}

ORIGINAL COMMUNICATIONS.

REPLY TO MR. R. DIXON'S ARGUMENTS IN FAVOUR OF RESTRICTIVE CLASS SHOWING.

WHEN I entered my protest against what I considered the unwise restriction generally adopted in class showing, namely, in only permitting one variety to be placed, I did not conceive that any further explanation from me would be necessary; such, however, appears not to be the case.

My attention has been directed to the observations made by Mr. R. Dixon, of Manchester, who having expressed an adverse opinion to my own, at the concluding part of his article, expresses a wish that I should reconsider the papers I have cast upon the sea of public opinion, and that if I wish to be thought a real friend to floriculture, to openly admit that what I have advanced was published without due consideration, and be as ready to retract as $I$ have 
been to propagate opinions which, if acted upon, cannot fail to be injurious to the true interests of floriculture. With all due deference to Mr. D.'s suggestion, I beg to say, that so far from retracting one iota of what I have advanced, I am induced to contend more strenuously for the adoption of my plan, and more earnestly urge the removal of secondrate varieties, being fully assured that my suggestions are based upon correct principles, and that they must, ere long, be generally adopted. And here let me remark, that the ground of my protest remains unshaken. The opinions I promulgated, were to the effect, that any restriction preventing the best flower from winning in the classes was mischievous in its tendency, unfair in its operation, and incompatible with the true interests of floricultnre, the patrons of which ought, without reference to long-established customs, to abandon so unwise a policy, when the evil tendency of the same had become so powerfully. apparent.

In reply to Mr. D.'s first question, whether the term beautiful, as applied by me to the memorable display at Derby, " did not rather belong to the varied excellence of the stage, than to the isolated excellence of some half-dozen varieties?" I beg to say, that it was intended to apply to the exhibition generally; and the question of regret, to the beautiful specimens of rejected varieties the judges were compelled to set aside, in order to fill up the classes from inferior flowers. This fact alone is sufficient to illustrate my previous assertion of the unwise mode at present pursued in class showing.

I do not acquiesce in Mr. D.'s statement that my plan will "have the effect of removing from our exhibitions all this interesting variety." That it will remove all flowers of questionable character is certain; but the real gems of our collections will remain undisturbed, while the inferior varieties will be brought to their proper level, $i$. $e$ removed from the prize stage altogether. 
If the principle I am advocating might "with some propriety be applied to the pink and to the carnation," on the ground of their easy reproduction, I am at a loss to imagine why the tulip should be an exception; for if the time required to bloom tulips from seed is protracted, the facility and almost certainty of procuring seed at any time, coupled with the fact of its increasing during its progress to maturity, reduces the distance to a mere nominal distinction. But I have yet to learn that carnation seed from choice varieties can be secured to a certainty.

Mr. Dixon's opinion and mine is not in unison on another point. He contends that no honour is done to any variety by giving it a second place. As a cultivator and raiser of tulips, he must know that the merits of three or four leading flowers in each class are now so nearly balanced, that a variety placed even third, in unrestricted class shoming, is neither dishonoured nor yet removed from class A.; but they do present an insurmountable barrier to the admission of seedlings of second-rate quality, and thus incontestably prove the real use of class showing.

Whether I am the propagator of " new-fangled and impracticable theories," the public will be the best judge. I have shown that it has already been carried out; and from the district where it is in operation some most exquisite gems have emanated. I admit myself to be the cultivator of what I style the queen of the garden, and am also excessively jealous lest any intruder having the least tinge of impurity, should be seen within the royal circle. I praise her beauties, and those who are personally acquainted with me, know that $I$ also am an unflinching advocate for purity in the fullest extent of the term; and I feel certain the time has arrived when the presence of the queen of beauties will not be tolerated at our popular exhibitions, unless she is in untainted splendour. The meditated destruction on ms part, can therefore only apply to such varieties 
as are unworthy of being retained, unless the restrictive clause provides a place for them.

Mr. D., in conclusion, asserts, "I am not fearful of any bad effects from the propagation of such opinions, and therefore have no counter advice to offer ;" which I presume implies that after all "we're not so bad as we seem ;" and if such be the case, I hope I shall, ere long, see many of Flora's votaries (who now hold different opinions) converts to the plan I have before suggested, and which I still adhere to.

Leicester, 6th December, 1851.

ROBERT MARRIS.

CLASS SHOWING.

I Do not know if my good friend, Mr. Dixon, anticipated any response to his reply to Mr. Robert Marris and my humble self, on this subject; but if he did, and if he really did wish it might be a long time before Mr. Marris were gratified in his wishes, I cannot help thinking he has taken a most unfortunate course for the maintenance of his views. First, because the subject is one which, in popular parlance, especially requires "ventilation;" and secondly, Mr. Dixon has totaliy failed to offer any reply to the only point on which the subject hinges. It may be, that Mr. Marris may be " in error as regards the wishes of florists generally," and it may be, that "you do not do honour to any variety by giving it a second place in the class ;" granting this, though something might easily be said on both points, these are secondary only, and in no way touch the vitality of the question. The sole point at issue, and the only one of any importance to be determined, is, does the rule restricting judges to the placing a variety once only in its class lead to the cultivation of secondary varieties, and is the cultivation of secondary varieties beneficial to floriculture? (In using the word sew 
condary, of course it is to be taken in an extencled sense; if any doubt as to the interpretation exists, let the question read, third, fourth, and fifth-rate varieties.) To this point Mr. Dixon does not offer one word of reply, and surely it cannot be necessary again to refer to the abundant testimony contained in the reports of our floricultural exhibitions, that secondary, and grossly secondary, varieties are kept in cultivation by the rule-or again to exhibit the unanimous testimony of seedling raisers, that no advance will be obtained by seeding from an inferior parent?

What then is the bugbear which leads to this "hope" that Mr. M. may not be gratified in his wishes? Here it is. "Would not a regulation (a discretion, mind, vested in the hands of judges, presumed to be men, best informed of their class) such as he (Mr. M.) advocates, have the effect of removing from our exhibitions all their present interesting variety?" Certainly it nould not. All that is intrinsically interesting, all that is consistent with a correct and refined taste, all, in fine, that is " intellectually improved," would be retained, to be all the more enjoyed, becanse of its removal from that on which a correct eye cannot dwell with pleasure.

But should it still be questioned that an " interesting variety" would be absent from exhibitions (and I by no means underrate the importance of variety; I have always considered that my successes, trifling in themselves, have been greatly aided by the strict attention I have always given to the effect of contrust, - not the contrast of good and bad, but the contrast of habit, and colour, and delineation), what have we to do but offer prizes for dissimilur varieties? Depend upon it such a provision will amply check any inclination there may be to reduce our exhibitions to an "insignificant display" of "a few varieties."

In conclusion, I can assure my friend I am duly sensible of my own insignificance, ard equally sensible of the consideration conceded to me on that 
ground, but in the absence of all logical deduction, and with a distinct admission that the discretion contended for, may with some propriety be applied to such flowers as are easily produced (I should contend that the more difficult, or less ready, the reproduction, the less laxity is tolerable in all pertaining to such reproduction), I cannot allow him quietly to dub me a "propagator of new-fangled and impracticable theories." That which has long been practised, cannot be either "new-fangled" or "impracticable." Neither can I accept the assurance he gives me, that Mr. M.'s protest had astonished the WHOLE floral community. Quietly to ignore the existence of all opposed to us, is never just, and rarely politic; and as I presume Mr. D. does know the restriction has never obtained in the south, and that he has noted the stringent condemnation given to it by Mr. Wood, at page 260 of the present year's volume (the subject being tulips, and the expression far more severe than any emanating from me, and Mr. Wood's knowledge of the tulip is at least not insignificant), and as further, many eminent dissentients to the restriction might be adduced from the north itself,-York, for example,-I presume that these expressions have been hastily uttered, without a proper refiection, and that it is Mr. Dixon, and not myself, who must "reconsider the paper he has cast upon the sea of public opinion," and if he would be thought a " sound practical florist, and friend to floriculture," must "openly admit he has published without due consideration."

Derby, December, 1851.

E. S. DODWELL.

GROUPING OF COLOURS IN A TULIP BED.

I kNow that you, Mr. Editor, with myself, and many of our friends, are passionately fond of the tulip,that we can never hear too much about it, if well 
said. Of this I feel more convinced than ever, from the firm and majestic strides the tulip fancy is taking through the length and breadth of our island. I may mention one circumstance as a striking proof of thisthat parties (first-rate growers) ordering my seedling rose breeder, Juliet, have preferred to pay in cash, rather than with good varieties from their collections, which they might have done. Indeed it is erident that the demand for really good varieties has been beyond that of former years. Such being the case, and so large a host of veterans having entered the field, and lifted the gauntlet, to fight for the claims of the tulip, as respects its shape, purity, marking, \&c. that hitherto undecided boundaries and distinctions of classes may now be set at rest, as well as whether the so called absurd practice of giving a prize to an inferior flower, because a better variety has been already once placed in the class, shall continue.

I'hese, however, are not the points I wish to rouch upon. I would rather listen to those who have already entered the lists of competitors, on these points of deep interest, and draw my pencil across a field hitherto, so far as I know, untouched, if haply I may so colour it as to add another beauty to the beantiful.

Now however beautiful the old mode of growing and arranging the heights and colours of the tulip may be in the eyes of some, and however strongly bound around by old associations, first a root of one colour and then one of another, all through a bed, is to me very much wanting in bold effect, when compared with what I would term grouping of the colours or classes.

More than twenty years ago, serving as knife-man in the Gateshead nursery, then perhaps the most general nursery in Britain, my attention was drawn to the subject of grouping, the cultivation of which, of late years, has very much improved the appearance of our flower gardens. I then noticed an effect produced by massing which I had never observed in 
the mixing of colours; for it was easy to see that many solitary plants were quite ineffective, until massed, as is common in a nursery, where beds of one kind of plant are put together, when an effect of no ordinary beauty and brilliancy is produced, as, for instance, a bed of the fine double blue larkspur, the old double white rocket, and the Lobelia fulgens. Although all these are fine in solitary plants, what are they when compared with a mass of them?

Having thus far premised, I must come at once to the subject, which is to show the advantage of grouping tulips in a bed over the system of dotting a bed all over with different kinds. In no way can I do it better, or be more clearly understood, than by describing my own bed, which would be, in the estimation of small growers, more properly a land of tulips than a bed. Its length is thirty-eight yards, and its width six feet, containing two hundred and forty-seven lines, with thirteen bulbs iu each. Now, to plant such a bed in the ordinary way, would be an immense trouble, to arrange and tally every bulb. My method is this, to commence with byblcemens, planting them as far as they will reach, then bizarres, and next a large batch of selfs, which contrast well with the painted flowers; next in turn come the rose tulips, and then the tricolours. Again, I commence with another class or group of colours, say bizarre breeders; as a further contrast, the scarlet bizarre is planted, which, by the by, is a very distinct and gay tulip, and it is my opinion, with many other growers, that it ought to form a separate class in every society. I finish my bed with a group of byblœmen and rose breeders. I must now say one word or two on the difficulty which may arise in some minds as to how $I$ manage the heights of the tulips. This is done with comparative ease. Say that I have fifty-two roots each of Polyphemus and Triomphe Royale (and I grow more than that number), this plants four lines of each. I select the largest roots for the centre of the bed, placing the smallest blooming bulbs at each side 
of the bed, and the intermediate bulbs between, at the same time raising the centre of the bed a few inches higher than the sides. In this way, the appearance of my bed, viewed from any quarter, when in fine bloom, is so imposing, that it requires to be seen fully to appreciate such an arrangement.

WILLIAM WILLISON.

Flower-gate, Whitby, Dec. 11, 1851.

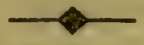 \\ ON WINTERING THE PINK.}

Av experience of more than twenty years has satisfied me that some provision is needed to meet the various mishaps of winter and early spring; and after trying different expedients, I have adopted the following, as the readiest and most effective, premising that my. situation is somewhat damp in winter, and open to the wind from south-east, but sheltered from the north.

I plant in pairs, in rows, across the bed, and get the plants in as early as I can, to have them well established. As soon as bad weather may be expected, say from the middle to the latter end of November, I draw the soil up towards the plants in ridges. This assists materially in keeping them free from wet, and preventing them being blown off by wind, or lifted by frost. As soon as the plants begin to grow at spring, the surface of the soil, as far as its nature is exhausted, is removed, the bed moderately stirred, and a covering of a suitable compost given.

$\mathrm{My}$ additional winter protection is a covering of the small branches of spruce fir, the trimmings of young plantations. When these have lain one year, and lost their leaves, the light structure of the branches, and their having a natural curve upwards, renders them admirably adapted to the purpose. Laid over the bed, with the curve downwards, they afford protection without pressing on the plants. 
With care, they will serve for several seasons, and where accessable, will be found very effective. But as a matter of precaution, it is good policy to winter a few of the more delicate sorts with carnations, in a frame, and pot or bed them out as early in spring as the season will permit. The same treatment will apply to the pansy bed in every respect.

$$
\text { H. J. D. }
$$

\section{DESCRIPTIVE LIST OF PINKS. \\ BI ALPHA.}

Colcutt's Sappho.-This was recently sent out by Mr. C. Turner, and fully maintains the general character of the flowers which he patronizes. In colour it approaches nearer to Hodges's Melona than any flower I am aware of. It is perfectly smooth, while a slight serrature is observable in that flower. It is an excellent lacer, has a good pod, and appears a free grower. No collection ought to be without it. It approximates to the desired standard, intermediate between north and south.

Smith's Huntsman is from the same cultivator, but it had well nigh been consigned to oblivion, in consequence of one of my plants spindling soon after I received it, which produced a distorted pod, and bloomed in a confused manner, with scarcely a redeeming property about it. I, however, headed it down, thus inducing a rapid growth of increase, all of which produced flower stems ; and now observe the contrast -instead of a distortion, the pod was excellent, the blooms, although late, came well, and gave me some of the most beautiful specimens of the pink it has been my lot to witness. Its colour is rich rosy purple, edges beautifully smooth, and altogether extremely attractive. Its habit is unfortunately similar to several of Mr. Smith's varieties, straggling in growth, with long joints. 'This variety should not be overgrown, or it will come too heavy in colour. The necessity of not condemning a flower from its first appearance is fully exemplified in this instance. I once heard the editor of the Midland Florist remark, that if only one good leaf appeared in a flower, it ought not to be discarded without a further trial, and the soundness of this advice is here strikingly apparent.

Read's Countess Rossi is a flower raised by the same party who originated the beautiful variety known as Read's Jenny Lind. 
The Countess appears to be a seedling from it, partaking much of its character, but expanding better; the colour is a dark rosy lilac, and it is worthy of being admitted into select collections.

Read's Kate.-Also sent out last year, by the above raiser. This takes the precedence, in my estimation, over the last described flower, although I cannot yet dispense with either. Kate has a style of marking which, for regularity, combined with a finely formed petal, gives her the advantage over her attractive rival. This also appears to have emanated from the same source as Countess Rossi, but is a decided improvement on it.

Mr. Read has, this autumn, sent out another seedling, which he has named "Kossuth," and which he states will supersede those I have noticed above. I have obtained this variety, and if spared another season, may report on its merits.

Looker's Rosalind.-This I received new last season, anu on its first appearance, it indicated great promise. That it will be useful to the raisers of seedlings is beyond question, but for competition it must succumb to many of our popular varieties. The outer row of petals is excellent, but the inner ones are too confused, and much smaller than I like. It produces abundance of pollen. I have obtained two fine pods of seed from Keynes's Hon. Mrs. Herbert and Marris's Sir Harry Smith, through its agency. I intend to retain it as an invaluable seeding variety.

Smith's Dianthus. - This is another of Mr. Smith's flowers, but unfortunately, it is of straggling growth, and produces but little increase. The petals are very smooth, and it appears to be a constant lacing flower. The colour is rather dull. It must be placed in the red-laced class, and may be grown for the preseut.

Looker's Prince of Wales.-This, I believe, ranks amongst the best of Mr. Looker's flowers sent out last year. There is one remarkable feature in nearly all the pinks raised by this cultivator, the white is generally exceedingly pure, and it is strikingly so in the present variety. It has a fine petal, is in colour a deep purple, the lacing constant, and although the marking is not laid on in so even a manner as in his Countess of Waldegrave, still it will find a place in our collections for the present.

I apprehend the past season will prove to have been a fertile one in producing new varieties. Mr. G. Lighthody, of Falkirk, reports some gems; Mr. Marris, of Leicester, has some half-dozen varieties; 
our friend, Mr. Smith, is scarcely ever withont; and Messrs Kirtland, Colcutt, Read, and others are sure to have their share in producing new faces. They must be good too, for hearsay will not now suffice, as we have a National ordeal, as well as effective local ones, to submit our pets to. In conclusion, I will communicate, for the benefit of the uninitiated, a very simple mode of support for the plants, during the winter months, when violent winds often threaten the destruction of our favourites. In planting, I have found the greatest support given by inserting three or four small twigs in the ground, in a triangular manner, bringing the same close to the heads of the plants, thus keeping them in an upright position, and to a certain extent preventing the worms from destroying their roots. The supports can also be removed in a few minutes, when no longer required.

FRUITS OF THE MIDLAND COUNTIES.

BY THE EDTOR.

[Continued from vol. 5, p. 358.]

PLUMS

ARE being much more extensively cultivated than formerly, and from the numerous new varieties in. troduced, public attention has, within these few past years, been especially directed towards them. Among large plums may be enumerated the following :-

Caledonian. - A rather coarse but very handsome and productive variety, colour dark purple. When trained against a wall, it attains a very large size. On a north wall, it bears and ripens its fruit well with us. Its season may be quoted the early part of September.

Diamond.-We were particularly struck with the appearance of the fruit of this variety, the past season. It is large, rather long, and the colour, when ripe, intensely dark, approaching to black. Like the Caledonian, it is very handsome, though of a different cast of beauty, and certainly not first-rate. We should class it as an excellent market plum. It is under. 
stood to have been raised by a farmer, named Diamond. Very productive.

Washington.-A fine greenish yellow plum, of peculiar growth and appearance. Against a wall it bears excessively, the fruit being as large as middle-sized apricots. Our standard trees produce a great quantity of blooms each year, but do not appear to set their fruit well. Ripe in the early part of September, and is of superior flavour to the two preceding varieties.

Huling's Superb is another yellowish green variety. Our trees are remarkable in their growth, being readily told, either with foliage or without, from any other sort in the nurseries. The branches are produced thickly, and the wood is very shortjointed. The fruit is as large as the Washington or Caledonian, and of much better flavour than the latter, though as a market plum not so good, purple sorts always selling best.

Columbia, a splendid American variety, of the largest size. We have planted this pretty extensively as pyramids. It is of excellent flavour, form of an apricot, and a rich dark purple. One of the best large plums grown.

Coe's Golden Drop appears in this part of the country to require a wall to bring it to perfection, and if ever a plum deserved one, this very fine variety does. It grows vigorously, and bears profusely; the fruit will hang very late on the tree, shrivelling, and is then extremely luscious and excellent. It abounds in rich saccharine juice, and ought to be grown wherever possible.

Orange Plum. A fine yellow fruit, of great size, equal to any previously described; second-rate in flavour, but will be extensively cultivated when better known.

Dovebank-A very fine and handsome purple plum, raised in a locality which is a guarantee of its hardiness, namely, at Lord Waterpark's, in the upper part of Derbyshire. It is very productive in this neighbourhood, and is extensively planted.

Prince of Wales. (Chapman).-Somewhat in the style of the Orleans. Bears remarkably well, young trees, only two years from the bud, being often covered with bloom. It is tolerably well flavoured, and is well adapted for a market fruit.

Jefferson.-At last there is a variety which rivals the Greengage in flavour; it is of large size and very beautiful, an American variety, but bears well in this country. The late Mr. Wilmot, of Isleworth, noted for his judgment, planted a considerable number of this excellent sort only a short time before his death. Colour rich orange, tinted on the sunny side with purple.

Reine Claude de Bavay.-This is of the Greengage family, larger than that fine plum, and having a more yellow cast. JANUARY-VOL. VI. 
It is a thrifty and vigorous grower, extremely productive and well worthy of extensive cultivation.

Denyer's Victoria.-Rather long, deep orange, tinged with red next the sun, of vigorous growth, and on our strong loam bears heavily and regularly. Second.rate in flavour, but worthy of attention, from its extreme productiveness.

Orleans. - This well known plum is extensively grown in the midland counties, and, through its blooming late, generally brings a crop ; consequently it is considered one of the best market plums, which character its good colour, form, and flavour sufficiently carry out.

Greengage still has but few equals, the Jefferson, before alluded to, being one of its most formidable rivals. Bears remarkably well here on standard trees which are very old. When the fruit is ripe, it ought to be immediately gathered, as a shower of rain at this period will cause the plums to burst. We once had a few bushels of this fine fruit rendered wholly unfit for market, owing to a heavy rain.

The whole of the plums enumerated are now grown more or less in the midlands. We cultivate them as pyramids, a plan we would strongly recommend in garden orchards. Ours are on a gentle slope to the soutl-east, the spaces between the rows being cultivated as nursery ground, the soil a strong deep reddish loam, and no trees can be more luxuriant and beautiful.

\section{A WORD OR TWO ON THE NOMENCLATURE OF TULIPS.}

A sHoRT word with Mr. Macefield. Firstly, admitting Polyphemus to be Hamlet, and vice versa, how is it that a LONDON JUDGE did pass them as being dissimilar? the gentleman himself lately saying that he was considered the first amateur grower in England, and is so considered by most London growers. So says my friend, Mr. M. but who perhaps refers to the senior gentleman.

Secondly, admitting 'Triomphe Royale to be Heroine, and vice versa, ditto, ditto, ditto, ditto, ditto, ditto. 
Thirdly, the rule requiring an equal proportion of bizarres, byblœmens, and roses was most strictly complied with, or at least so proves Mr. Macefield.

\section{$\left.\begin{array}{l}\text { Polyphemus } \\ \text { Hamlet }\end{array}\right\}$ Bizarres.

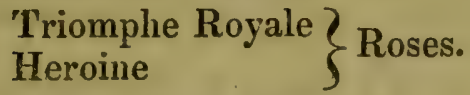

Queen of the North

And the good old By bLEMEN, Byblœmens.

Trion phe de LisLe

If Queen of the North be byhlœmen, Mr. M. converts the bad strain of Rose Camuse into a good old bybloemen. What is in a name? may be here truly applied to Primo bien du Noir. Who would translate these words other than FIRST MUCH OF THE BLACKS? Every school boy tyro wonld so construe their magic meaning. 'To call red NoIr is to say black is white. What say you, Mr. Editor? Primo bien du Noir, I find, was also placed by the censors as a flamed byblœmen. The correctness of nomenclature has been doubted amongst the London growers for some years, and I, for one, thank $\mathrm{Mr}$. M. for expounding a mystery, and standing sponsor, when others, who profess to be highly taught, were unable or unwilling so to do.

A LONDON GROWER.

\section{$\longrightarrow$ \\ COP PICEANA.}

No. XVIII.

Amongst beautiful evergreens may be enumerated the alaternus, or, if we use the scientific designation, the rhamnus. It bears the climate of this part of the world very well, with the exception of the gold and silver-striped varieties. These are of more slender and less robust growth than the other sorts, 
and are with difficulty preserved so far north as Nottingham, during severe winters. The other varieties also are amongst the greatest ornaments of our shrubberies.

$\boldsymbol{R}$. Hispanicus is very robust, and a lighter green than the $R$. Alaternus. It grows somewhat in the same style, forming a beautiful pyramidal evergreen bush.

R. Alaternus.-There are many fine specimens of this well known plant in this neighbourhood, and, with its oval dark shining green foliage, it is very attractive and desirable. It is raised by layers of the previous year's wood. These should be kept in pots, as it is difficult to move when it attains any size.

R. Alaternus Aurea Maculata. (The Gold-blotched Alaternus.) -A variety of the preceding, to which it will often revert, when planted in rich and moist soil. It is extremely handsome, rivalling the aucuba and gold-edged holly in richness of colour. It will assume quite the appearance of a tree. Our specimen has a trunk quite free of branches for at least seven feet from the ground, with a compact head of foliage, mottled with rich yellow, and having a most beautiful effect. R. Hybrida.-This is a plant of wholly different character to any of the preceding, with long pointed foliage, destitute of that beautiful glossiness which is so apparent in the varieties previously named. It is, however, a good addition to our hardy evergreens.

\section{RHODODENDRON.}

Of this splendid family it is almost impossible to say too much, differing, as they do, so amazingly in the colour of their flowers, their foliage, and general habit. It was formerly supposed that they could only be cultivated successfully in peat soil, and perhaps this impression is not yet quite worn away; but, provided the situation is suitable, they may be grown in great beauty, in strong loam, as may be seen any day, by visiting our nursery. They are raised easily from seed, which is produced in great abundance, and may also be successfully propagated by layers, or more readily still by grafting and budding. They will grow either in shade or sun, in pots or out; they will force well, and at the same time many of them will withstand the most rigorous winters. Their magnificent trusses of flowers vary from pure white 
to vivid crimson, spotted with various shades, whilst others, which have been crossed with the yellow azalea, have produced yellow flowers; and, from this systematic hybridizing going on, we may anticipate many rich additions to the numerous varieties already raised. Some new sorts lately introduced from India, and known as the Sikkim rhododendrons, will afford ample scope for those who are fond of experimenting in this beautiful path of floriculture. Having said thus much in their favour, we will describe those cultivated here, premising that they are all perfectly hardy.

Rhododendron Imbricata.-A very neat plant, with rather small rounded foliage. The flowers are rosy pink, but neither of very good form nor conspicuous in beauty. The habit of the plant is its chief recommendation.

R. Cartoneana.-This is a most delightful plant, apparently a hybrid of the azalea. The flowers are small, but produced in great profusion, in fine trusses, all over the plant; the foliage is narrow and light in colour; the flowers are shaded lilac, and are well adapted for bouquets.

$R$. Ennendria.-Another small-growing variety, raised (if our recollection is right) by the Rev. W. Herbert, being one of the many hybrids originated by him. The flowers are small, reddish pink, something like those of $\mathrm{R}$. ferrugineum. A neat and desirable sort.

R. Foxii-Originated by Mr. F. Fox, of Cliff Vale, near Leek, Staffordshire. It flowers most profusely, and is of excellent habit. Colour delicate lilac.

R. Everestianum. - This is a delicate and very beautiful variety. The truss of flowers is large, and it forces remarkably well. The flowers are waved and slightly serrated, giving it a very distinct character.

R. Catawbiense Variegata.-Flowers like the common R. catawbiense, but the foliage of the plant is mottled with rich yellow, in the style of the aucuba.

12. Catawbiense Illuminator.-This is a brilliant variety, being bright rosy crimson, very free-blooming, and a great addition to the class.

R. Fastuosum Plenum.-Very singular, having double flowers. These are light purplish pink, and are produced freely.

R. Dauricum Atrovirens.-A really beautiful plant, flowering early in the spring, with rich deep pink flowers. The foliage is small, and the plant is of neat growth. This should most certainly be in every collection. 


\section{邺art 秋E。}

\section{NEW, RARE, OR GOOD FRUITS, FLOWERS, PLANTS, TREES, AND VEGETABLES.}

FR UITS.

Belle de Fontenay Raspberry.-A new variety, and a prodigious bearer. It is of rather bushy habit, of good flavour, large, and continues producing fruit till late in the season. It is high in price yet.

\section{HARDY PLANTS.}

Phlox Napoleon.-A rival to $\mathrm{V}$ an Honttii, being a most beautiful striped variety, of excellent shape, and producing a large spike. Ground colour creamy white, distinctly ribboned with bright violet.

Phlox Roi des Nains.-A very compact and pretty variety. Brilliant rose, with scarlet eye.

Phlox Imperialis Major.-Beautiful lilac, shaded with white.

Mimulus Elegance.-Light yellow ground, with very dark blood-coloured blotches. Fine.

Mimulus Rubinus Perfecta.-An improvement on Rubinus, being larger, fine in form, and margined with rich crimson.

Antirrhinum Soliel D'Or.-A very fine yellow variety, contrasting beautifully with the darker sorts.

Antirrhinum Giantess.-Yellow, striped with dark crimson. Pretty. 
Antirrhinum Quees of the Whites.-One of the best of its colour.

Hesperis Coccinnea Flore Pleno. (Double Crimson Rocket.) - This very beautiful herbaceous plant is letting out this season. What an excellent plant it will make for the border, and how nicely it will contrast with those old favourites, the Double White and the Double Pink. It is a great acquisition.

\section{GREENHOUSE PLANTS.}

Erica Losgiflora.-The foliage of this fine heath is peculiarly beautiful. It blooms when very small. The flowers are tubular, large, and of a rich yellow.

Epacris Hyacinthiflora Candidissina.-These plants are general favourites, and this new white variety will prove a welcome addition to any collection.

Azalea Indica Extranir.-With most beautifully formed flowers, of a rich and intense crimson.

Azalea Indica Magnifica.-This is a continental variety, of excellent habit, the petals thick, and the flowers large. Pure white.

Pelargonium Mount Hecla (Gaines.)-A most striking variety, and will make a splendid stage plant. Colour bright scarlet, upper petals blotched, with a light centre.

Pelargonium Standard Bearer (Henderson). - A very attractive flower. Lower petals salmon, upper rich shaded crimson. Large and free.

Pelargonium Reine des Fleurs (Henderson).This is a fancy variety. The ground colour is white, with well defined plum-coloured blotch, the lower petals veined with purple. Of excellent habit, and a most beautiful show variety. 


\section{BEDDING PLANTS.}

Verbenas.-New varieties of this very pretty family increase on us fast. Great quantities are raised on the Continent. The following are amongst the best which have come under our notice during the past season:-

Dufay's M. Paquin.-This forms a large truss. The flowers also are large; they are blue, with a distinct white centre.

Turner's Beauty.-This we have bloomed very finely. It is somewhat in the style of Princess Alice, except that the centre of pink is more decided. It forms a large and flat truss.

Louise Miellez (Lebois).-A striking variety, of large size, pink, margined with white.

La Nymph (Dufoy).-This, on the contrary, is white, raargined with rose. Very delicate and pretty.

Jules (Chauviere).-Rich purplish rose, immensely large, and flowers very profusely. Fine for either pot culture or for massing.

Calceolarias.-The following are fine for border cultivation:-

Conway's Florabunda.-Of very compact habit, producing large trusses of bright yellow fluwers.

Albiflora. - The flowers are a very clear white. It is figured in Van Houtte's Flore, and has proved itself an excellent bedding plant in this country.

\section{EXTRACTS, HINTS, AND RECOLLECIIONS.}

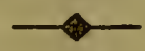

A CHEAP PIT FOR GREENHOUSE PLANTS.

I TAKE it for granted that there are a good many among our readers who, like myself, love gardens, and are too poor to have all the luxuries that belong to them. Among these luxuries I count greenhouses and hothouses. Now, as I don't spend fifty dollars a year on my garden, besides my own labour, it is not 
to be supposed that I have any such "crystal palaces." Yet I contrive, by the aid of cheap pits or frames, sunk in a dry warm part of my garden, under the south side of a broad fence, to keep through the winter all the half hardy plants, such as tea roses, carnations, petunias, heliotropes, and most of the hard-wooded greenhouse plants that adorn the garden and keep it gay in summer. Chinese azaleas do even better in these pits than they do in greenhouses. To make such frames, it is only needful to choose a piece of ground that is well drained, to have a few good hotbed sashes, to make a frame or bottomless box out of some rough boards, as wide as the sashes are long, as long as the sum total of feet that your sashes will cover, if laid side by side. Sink the frame in the ground to its level, within two inches at the front and three inches at the back, so as to make the needful slope to carry off the rain. Dig out the soil two feet deep, spread a couple of inches of small stones or coal ashes at the bottom, and set the pots upon this. Give as much light and air as you can, until severe frosty 'weather sets in. In downright winter weather keep the frames shut up pretty close, covering the glass at night with several thicknesses of matting or old canvass bagging, and in very bard frost, with a few bundles of straw in addition. Water only when the pots appear somewhat dry, but then water freely, especially if the weather is such that you can keep the frame open for an hour or more. In this way almost all the popular and showy greenhouse plants may, as I have said, be wintered in excellent condition, at very trifling expense, no artificial heat whatever being required. Wishing, however, last winter, to do something new, and have a few really tender exotics in a pit, I hit upon a cheap and simple sort of warming apparatus, which succeeded quite to my satisfaction, and I must therefore describe it to you. My heating apparatus was a large flat tin lamp, with a common candle wick, the lamp large enough to hold a pint of alcohol, for this was to be 
my fuel. Over this lamp, at the distance of an inch and a half, was suspended or fixed my boiler, about six by eight inches, and also tin. Out of the side of this boiler, abont one-third of the way down, started a tin pipe, one inch in diameter, tightly soldered to the boiler, and also at every joint. This pipe ran quite round the frame (suspended a little way from the board by a wooden bracket), and finally entered the boiler again, near the bottom, on the side opposite where it went out. The boiler itself was soldered quite tight, and the whole pipe was quite tight, with the exception of one place; this was the first elbow after it left the boiler, one-third of the way round. Here it had an upright joint soldered on, reaching up to near the glass, say two inches higher than the level of the water in the boiler. This upright joint was open at the top, and into this opening I daily poured the water, to fill the boiler, pipe and all, for you see it was in fact all one boiler. I had then, as our readers well versed in hot water heating will see at a glance, a modern hot water apparatus on a miniature scale, at a very low price, such as can be made in a few hours, by any tinman. Sixpence worth of alcohol would carry my hot water apparatus through the coldest night, and warm the frame admirably, without any danger of over-heating; and in ordinary nights (the frame being well covered) I needed no fire. Soon after the lamp was lighted, the warm water began to rise in the boiler, and to flow off through the topmost pipe, and as it became cooled it returned to the bottom of the boiler, by the lower part of the same pipe; and although, of course, the water never became hot, it was quite warm enough, not only to raise the temperature of the frame, but to keep it raised, as the water, once heated, remained so a long time after the lamp went out. I ought to add, that at the end of the frame, where the lamp was fixed, I had a little box, or double door, by which I could light and feed the lamp, without letting cold air into the frame. 
I have sent you this account of my simple experiments, which will appear insignificant enough to many of your readers, thinking that some few of those to whom "necessity is the mother of invention" might find a useful hint for their own practice.

American Horticulturist.

TO IMPROVE THE PRESENT RACE OF HOLLYHOCKS BY CROSS-BREEDING.

LET us suppose, then, that we are about to plant a seminary, and hare decided that it shall contain twelve varieties; how shall we select them? The following have been chosen with a view to embrace every important feature of the flower in the greatest perfection.

1. Attraction-Chocolate and white, very prettily veined. Not a fiower of first-rate properties, but distinct, and regarded as the type of a strain of veined flowers.

2. Black Prince.-Flowers nearly black, petals opaque and very glossy. The object to be gained here is larger and better flowers of the same colour.

3. Commander in Chief.-Flowers rose colour, edged. A poor variety, but an elegant branching habit, with improved flowers, are a desideratum.

4. Comet.-Flowers bright crimson, very large, of excellent form. The petals are of great substance, the habit noble, but rather tall. This is certainly one of the best, and we should like to see flowers of every colour equal to it, with the improvement of a dwarfer habit.

5. Delicata.-Fiowers French white. This variety, when not hybridized, comes true from seed, hence we should have great confidence in crossing for the attainment of a given end.

6. Magnum Bonum.-A fine rich dark-coloured variety, of the habit of Comet.

7. Napoleon.-Flowers red and buff, showy, but not good. A good flower of this colour is still wanted.

8. Obscura.-Flowers shaded puce. This is a very distinct and finely-formed flower, very soft and silvery in appearance.

9. Queen.-Flowers blush. Seedlings from this variety often come true. Delicata and Model of Perfection have also been raised from it. Habit fine. 
10. Rosea Grandiflora.-Flowers pink. One of the finest, both in flower and habit. It often comes true from seed, sometimes produces Surprise, and occasionally Delicata.

11. Sulphurea Perfecta.-Flowers sulphur, the finest of this colour. Varieties of a deeper tint would be a great acquisition.

12. White Perfection.-The best pure white known. More varieties of this colour are wanted.

With these materials and a camel hair pencil we are prepared for crossing. The best time for carrying on this work is the inorning, and as soon as the dew passes from the flowers. There are, perhaps, no varieties, however double, which will not yield stamens or styles to a close inspection. It is only necessary to collect the pollen from the stamens by passing the brush lightly over them, and to convey it to the flower required to produce seed.

Paul's Hour with the Hollyhock.

\section{THE EVERGREEN PLUM OF CALIFORNIA.}

The evergreen plum is the Cerasus ilicifolia of Professor Nuttall; but it certainly has but little resemblance to a cherry (cerasus), or plum (prunus), for its flowers are produced in small racemes, somewhat like the common berberry, or bird cherry (padus), but the fruit is as large as a middling-sized plum, has a soft pulpy flesh like a cherry, and the plant is as good an evergreen as the common holly; the stone inside the fruit is rather large, with a very thin shell, and quite smooth on the outer surface, like the stone of a cherry; the kernel is sweet, and forms an important part of the indians food, in autumn ; they first bake and pound up the kernels into a powder; and afterwards make gruel of it, which they very much esteem, and for which purpose they plant the evergreen plum round their huts, living on the ripe fruit while in season, and afterwards on the kernels, which are large and sweet, and easily obtained, the 
shells being so very thin. The plant was first introduced by the Horticultural Society, in 1848, through their collector, Hartweg, who found it growing on the lofty coast range of mountains called San Antonio, and San Luis Obispo, or Bishop's mountains in Upper California, in company with Pinus Sabiniana, and the beautiful evergreen oak of California (Quercus agrifolia). It grows from ten to twelve feet high, in its native mountains, with a compact habit and thickly set foliage; the leaves are of a dark glossy green, quite round, heart-shaped at the base, finely toothed round the edges, much undulated, and have, when bruised, a very powerful smell of bitter almonds. Mr. Hartweg compares it to a large bush of the common holly, thickly studded over with middle-sized bright red plums. Its native name is "islay." If the plant is not botanically distinct from the cherry (cerasus) it certainly forms a very distinct section of that genus, which might have the name Ilicocerasus, or Holly Cherry, given to it; and when its fruit gets improved by cultivation, it will greatly improve the barren appearance of our orchards during the winter months, by its beautiful foliage. It now grows freely in any good garden soil, and is said to fiower in April or May, and ripen its fruit in September. It is increased by cuttings, or by eyes, like the vine, in heat, and is quite hardy.

George Gordon, A.L.S., in Beck's Florist, $\& c$.

At the Royal South London exhibition, held in the Zoological Gardens, on the 25th of June, Mr. Foster had some very fine seedling pelargoniums. The following had certificates of merit awarded to them :-

Optimum.-Splendid crimson scarlet, with black blotch in the top petals, and lighter scarlet margin. It throws very large trusses of flowers, and is extremely showy. It will make a first-class plant for exhibition.

Ariadne.-This is a robust variety, of pretty habit. Colour rosy purple, with fine blotch.

JANUARY - VOL. VI. 
Enchantress. -A decided improvement on Gipsy Bride, being the same rich and attractive colour, but twice the size.

Rubens.-Rich crimson, with dark blotch, and a neat margin of scarlet.

Not only were these fine flowers rewarded at this exhibition, but the next day, at the National Floricultural Society's rooms, 21, Regent-street, they were similarly honoured.

We are glad to see, by an advertisement in the present number, that onr friends, the florists of Snenton, near Nottingham, have thrown open their shows to amatenrs residing in the county; and, moreover, that at each of their two exhibitions, a silver cup, value five pounds, will be competed for, one with twelve dissimilar blooms of roses, the other with six carnations and six picotees, one of each class. This is as it should be. Twelve roses only will cause a great number to be staged, and will ensure a large attendance and a keen and spirited competition. It also gives the cultivator of two dozen plants a chance with him who grows thrice the number. 'There are in the vicinity of Nottingham an immense number of gardens, and few towns can boast of so many rose growers, or of producing better flowers. Thirty-six blooms are all very well for nurserymen, but by confining the number to twelve, we think the Snenton committee have acted wisely; and we trust that very many of our amateur townsmen will have a cut-in for the cup, and by their entry give evidence that they appreciate the exertions made to get up a first-rate exhibition of these splendid flowers.

I SEE that several of your correspondents have asked for a descriptive list of good auriculas. Now I would suggest, that if there were a show of these flowers, open to the United Kingdom, held in some town, say Derby, Nottingham, Birmingham, or any other that might be agreed upon, it would be the best 
way to test the merits of the blooms which would be brought from different counties; and I should feel much obliged if Mr. Wood would take an active part in getting up an exhibition of this kind, that the lovers of the auricula might have an opportunity, like the tulip and carnation growers, of seeing gqod blooms of their favourite flowers.-ROBERT HALL, Alkrington, Middleton.- [We think the idea a good one, and would propose Manchester as the first place in which to hold such an exhibition.-ED.]

At the great south Lancashire tulip exhibition, we were glad to see in the stand of flowers which gained our friend, Mr. John Naylor, a silver cup, his seedling, Joan of Arc. We believe this will be a teazer for Heroine. In the same stand was Edgar, raised by the same gentleman. We notice this more particularly, because we had a bulb of that variety from MIr. Naylor, and, as we have observed elsewhere, it bloomed beautifully with us, but was disqualified at Nottingham, though the best feathered flower in the room, in consequence of stained stamens. In the feathered byblœmens, we see a flower calleả Salvator Rosa takes a sixth prize. Is this correct? Does Salvator come occasionally feathered? Perhaps some of our friends will enlighten us on this head.

\section{R E V I E W S.}

The Gardener's Almanack, for the Year 1852. By G. W. Johnson.

THIS is the only almanack we have received, therefore we cannot, by comparison, say how much better it is than others; but we can aver, and that without much fear of contradiction, that it is a most excellent work. The directions for every month in the year are most copious and practical: ererything required 
to be done is here pointed out, and that too in the best manner and in the plainest way. We very strongly recommend it to our garden loving friends.

\section{An Hour with the Hollyhock. By Wm. Paul.}

This little brochure emanates from the Cheshunt nurseries, and treats on a flower now coming very much into fashion. Mr. Paul enters into the early history of the plant, the preparation of the soil, planting, and propagation, with lists of the best flowers, and the opinions of some of the leading cultivators of the day. We much like his idea of planting "a seminary" (that is one or two of certain sorts to save seed from), an extract from which we give in another place. The work is written in a popular style, and cannot fail to please all who are admirers of these noble flowers. We have spent a very pleasant " hour with the hollyhock."

\section{仹art JE-EEE。}

\section{QUERIES.}

I have long been an amateur carnation grower, but from the dampness of the situation of my house, have never yet been able to save any seed. If any of your readers could supply me with a little, I would pay their price, and should feel much obliged.

A Subscriber.

I have a number of geraniums and fuchsias, which I have grown in a cold frame. I cover them up well at night, and during frosty weather, giving them plenty of air when fine. Shall I have any chance of preserving them by these means through the winter? or should I be more likely to succeed by using some fermenting material to create heat in the frame? An answer in your next publication will oblige a constant subscriber.

F.

Will you give, in your next number, the names of six tulips in each class, bizarres, bybloemens, and roses, irrespective of price? 
How and in what way are tree pæonies propagated? I see several varieties named in "Coppiceana," which I should much like to obtain; and I have two or three sort of my own, that I wish to increase. As the time for the operation will possibly be getting on, perhaps you will give me some information on the subject. AN Old Subscriber.

[The tree pæonies, from their slow propagation, are yet scarce. As soon as we have plants, of which due notice will be given, we shall be happy to supply them.]

\section{ANSWERS TO CORRESPONDENTS.}

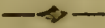

Brougham Hall Melon, when well grown, retains its excellent character.

Mirls's Canampion Cucomber.- Yes, it is a most prolific and handsome variety.

Oxon.- Save your coronillas, by all means; it is possible you may get a new variety. Both the cases you cite are hurtful to the carnation, to the foliage especially, if kept in a closed frame.

\section{CALENDAR OF OPERATIONS, FOR JANUARY.}

THE attention requisite to be bestowed on florists' flowers, this month, will not be very great. The chief preparation will be in forming beds for the ranunculuses. One great secret is that the beds should not be above the level of the paths, and the compost should be formed of good well decomposed loamy turf, to which may be added a tenth part of sharp river sand, and a fourth part of three or four year old rotten cow manure. These should be well incorporated, throwing the compost up in ridges, to be acted on and mellowed by the frost. Pansy beds, particularly those planted out late, ought to be hooped over and protected, when requisite, for, though the plants are hardy, they will be all the better for being sheltered from cutting frosty winds. Ir mild weather, worms are apt to work and sometimes loosen the plants: it will be necessary to have an eye to this, and to fasten them as required. Tulips, if the grower do not mind a little trouble, ought also to be covered in severe weather. We have a small ient, which is placed under our permanent 
one, and over this a large-meshed net is spread; this, again, is covered in severe weather with mats, which appears to answer the purpose very well; though many amateurs in this neighbourhood hoop their beds, and then stretch over them a piece of damaged lace, which is fastened close down on all sides, and remains on till the plants are so far advanced that the top cloth is required. Auriculas and polyanthuses in pots will require to be kept from wet. Both are apt to throw up precocious blooms; these should be removed, as they tend to weaken the plant considerably at this season of the year.

In the fruit garden, considerable attention will be required at this season, however small the plot of ground may be. Some people place manure round their trees. We would apply it some dislance from the stem, for the small rootlets, the feeding fibres, do not lie there. We are convinced that fruit trees, particularly in orchards, require a regular and copious top-dressing of manure. If this were more attended to, and the branches kept thin, and the roots pruned, orchards and fruit gardens would be much more productive than they are. Give a good dressing of manure also to gooseberry and currant trees, using Lyndon's digging fork. This will be found an invaluable instrument, and in many cases will supersede the common fork. Train fruit trees whenever there are fine sunny days. Take care to lay in as much young wood as possible, bringing it up, when practicable, from the bottom of the tree. $8 y$ this means, large unsightly blanks are avoided.

In the kitchen garden, let all unoccupied land be manured and trenched; in fact, at this time of the year, it is a symptom of bad gardening not to attend to this. Also put all refuse and vegetable matter together, for future use. Small salaaiing may be sown in boxes, where there is the convenience of a pit or hotbed. Seakale should be covered with pots, and surrounded with warm dung. The same plan may be pursued with rhubarb. Peas may be sown on a warm border. Select such sorts as the Early Frame and Warwick, and rub them well with powdered rosin previous to sowing: we have found this a good preservative from mice.

In the greenhouse, abundance of air must be given, when favourable, with an occasional fire. As a matter of course, in severe weather, constant fires will be requisite, but then only sufficient to keep out the frost. Fumigate when required. Damp and insects are the amateur's two worst enemies. Constantly hand pick the plants, a little care and attention of this kind is amply repaid. Tilley's Superb Russian and the tree violet are nice things. Camellias will also be blooming. The Aggeratum cœlestinum blooms abundantly and beautifully; our plants, which had been in the open border, during summer, are now (Dec. 22) one mass of bloom, flowering from every side shoot. 


\section{FLORAL EXHIBITIONS.}

TULIP SHOW,

At the Griffin Inn, Wakefield, May 26, 1851 .

Premier Bloom.-Lady Stanley (feathered rose), J. Gill.

Pans of Six Blooms.-1. Dovers, Napoleon, Comte de Vergennes, Black Baguet, Edmund Kean, Clark's Clio, and Duchess of 'Tuscany, S. Hartley. 2. Duc de Savoy, Gibbons's Lady Stanley, Black Baguet, Polyphemus, Triomphe Royale, and Duchess of 'Tuscany, J. Gill. 3. Surpass Catafalque, De Maroc, Heroine. Charbonnier, Triomphe Royale, and Bienfait, C. Boocock.

Fcathered Bixarres.

1 Surpass Catafalque, C. Boocock.

2 Duc de Savoy, J. Gill.

3 Charles X., J. Cato.

4 William Pitt, S. Hartley.

5 Duke of Clarence, J. Gill.

6 Leonatus Posthumous, ditto. Flamed Bizarres.

1 Polyphemus, J. Gill.

2 Count Platoff, ditto.

3 Waterloo, ditto.

4 Napoleon, ditto.

5 Charles X., J. Cato.

6 Prince of Orange, J. Gill. Feathered Byblomens.

1 Black Baguet, J. Gill.

2 Lewold, ditto.

3 Washington, ditto.

4 De Maroc, C. Boocock.

5 Voorhelm's, ditto.

6 Hugobert, J. Gill. Flamed Bybloemens.

1 Roi de Siam, J. Gill.

2 Alexander Miagnus, ditto.

3 Waler's No. 71, S. Hartley.

4 Bienfait, J. Gill.

5 La Belle Narene, S. Hartley.

6 Countess of Harrington, J. Gill.
Feathered Roses.

1 Gibbons's Lady Stanley, J. Gill.

2 Heroine, C. Boocock.

3 Gibbons's Lady Flora Hastings,J,Gill

4. Walworth, ditto.

5 Duchess of Newcastle, ditto,

6 Lady Crewe, C. Boocock. Flamed Roses.

1 Lady Stanley, J. Gill.

2 Aglaia, ditto:

3 Lady Middleton, ditto.

4 Triomphe Royale, ditto.

5 Lady Crewe, ditto.

6 Lord Hill, ditto. Bixarre Breeders.

1 Polyphemus, S. Hartley.

2 Paul Pry, J. Cato.

3 Dentonian, ditto. Bybloemen Breeders.

1 Grace Darling, S. Hartley.

2 Maid of Orleans, J. Gill.

3 Lancashire Hero, ditto. Rose Breeders.

1 Nuchess of Sutherland, J. Gill

2 Lady Flora Hastings, ditto.

3 Anastasia, ditto.

1 Cotherston, S. Helfs

2 Min d'Or, J. Gill.

3 Golden Hero, S. Hartley.

\section{WAKEFIELD FLORAL SOCIETY PINK SHOW.} July $5,1851$.

Premier Bloom.-Huntsman, J. Steel.

Pans of Six Blooms.-1. Huntsman, Greensides, J. Sturge, Rachael, Blackeyed Susan, and Superior, J. Gill. 2. S. Hartley. 3. J. Steel.

Dark laced.

1 Huntsman, J. Steel.

2 Pilgrim, ditto.

3 Susan, S. Hartley.

4 Rebecca, ditto.

5 Masterpiece, J. Gill.

6 Pilot S. Hartley.

Red-laced.

I J. Sturge, J. Steel.

2 Huntsman, J. Gill.

3 Seedling, S. Hartley.
4. Rebecca, S, Hartley.

5 Susanna, C. Boocock.

6 Prodigal, S. Hartley. Black and White.

I Elizabeth, J. Steel,

2 Blackeyed Susan, S. Hartley.

3 Queen of Whites (seedling), J. Steel.

4 Beauty of Blackburn, S. Hartley.

5 Miss Jessop, ditto.

6 Beauty of Clayton-le.Moor, J. Gill.

WAKEFIELD FLORAL SOCIETY CARNATION SHOW. August 11, 1851 . CARNATIONS.

Premier Bloom -Lady Ely, J. Steel.

Pans of Nine Blooms, -1. Sir R, Peel, Lord Milton, Mango, Brilliant, Lady Ely, Portia, Mrs. Horner, Juliet, and Seedling, S. Hartley. 2. Jolly Dragoon, 
Lord Milton, Earl Spencer, Lord Nugent, Flora's Garland, Nulli Secundus, Mrs. Horner, Queen Victoria, and Mrs. Sykes, J. Gill. 3. Seedling No. 12, Bloomsbury, Seedling No.4, Bellerophon, Lady Ely, Nulli Secundus, Mrs. Potter (seedling), Enchantress, and Picnic, J. Steel. Scarlet Bizarres
1 Jolly Dragoon, J. Gill.

2 Seedling No. 12, J. Steel.

3 Old Frank, J. Gill.

4 Lord Pollington, ditto.

5 Seealing No. 13, J. Steel.

6 Duke of Sutherland, J. Gill. Pink Bizarres.

1 Lord Milton, J. Gill.

2 Gladiator, ditto.

3 Paul Pry, ditto.

4 Bloomsbury, J. Steel.

5 Robert Burns, ditto.

6 Duke of Bedford, ditto. Scarlet Flakes.

1 William IV., J. Steel.

2 Cherry Cheek Patty, S. Hartley.

3 Brilliant, ditto.

Heavy-edged Purple.

1 Nulli Secundus, J, Gill.

2 Mrs. Lilly, J. Steel.

3 President, ditto.

4 Portia, S. Hartley.

5 Susanna, J, Gill,

6 Princess Alice, ditto. Light-edged Purple.

1 Enchantress, S. Hartley.

2 Queen Victoria, J. Gill.

3 Juliet, S. Hartley.

4 MIrs. Fenton, J. Steel.

5 Elegahns,'J. Gill.

6 Jenny Lind, S. Hartley.
4. Madam Maria, J. Steel.

5 Beauty of Brighouse, S. Hartley.

6 Firebrand, ditto.

Purple Flahes.

l Earl Spencer, J. Gill.

2 Seedling, S, Hartley.

3 Beauty of Woodhouse, J. Gill.

4. Blue Ribbon, J. Steel.

5 Seedling, S. Hartley.

6 Bellerophon, J. Steel. Rose Flakes.

1 Lady Ely, J. Steel.

2 Flora's Garland, J. Gill.

3 Lovely Mary, J. Steel.

4 Lady Flora Hastings, ditto

5 Lady of the Manor, J. Gill.

6 Apollo, ditto.

\section{MIDDLETON FLORAL AND HORTICULTURAL SOCIETY.}

At Mr. John Harrison's, Masons' Arms Inn, Middleton, Monday, August 25.

The extra prize, given by Mr. John Holland, for the best pan of seven, five carnations and two picotees, was won by W. Taylor, with Admiral Curzon, Lord Milton, Maid of Athens, William IV., Mayor of Oldham, Nulli Secundus, and Duchess of Cambridge.

\section{CARNATIONS.}

Scarlet Bizarres.

1 Admiral Curzon, A. Gant.

2 British Hero, J, Boardman.

3 Duke of Sutherland, $\mathbf{L}$. Ashmole.

4 Unknown, J. Marsden. Pink Bizarres.

1 Paul Pry, R. Lancashire.

2 Nulli Secundus, W. Taylor.

3 Cartwright's Rainbow, ditto.

4 Lord Milton, L. Ashmole. Scarlet Flakes.

1 Brilliant, J. Marsden.

2 Rob Roy, J. Heap.
3 Middleton Hero, M. Partington.

4 William IV., J. Heap. Pink Flaties.

1 Hepworth's Maid of Athens, W. Taylor.

2 Ariel, L. Ashmole.

3 Lovely Ann, J. Marsden,

4 Miss Walker, R. Bourghall. Purple Flates.

1 Bonny Bess, J. Heap.

2 Squire Meynell, $\mathbf{R}$. Lancashire

3 Mango, L. Ashmole.

4 Beauty of Woodhouse, W. Taylor.

\section{PICOTEES.}

Heavy-edged Red.

1 Duchess of Cambridge, W. Taylor.

2 Mrs. Horner, Light-edged Red.

1 Maid of Honour, W. Taylor.

2 Yorkshire Hero, J. Fitton.

Heavy-edged Purple.

1 Nulli Secundus, W. Taylor.

2 Princess Alice, J. Bamford.

Light-edged Purple.

1 Delicata, A. Gant.

2 Hepworth's MaryEilien, R.Lancashire 


\section{嗮art $x_{\text {. }}$ \\ ORIGINAL CONIIUNICATIONS.}

A YOUNG FLORIST'S OPINION ON TULIP SHOWING.

I AlI a young tulip grower, who feels happy to observe the discussion now going on in the pages of the Midland Florist, and who thinks, if that discussion (as I fondly hope it will be) is conducted in a becoming spirit, all tulip fanciers will be benefitted thereby. I trust, therefore, that everyone who writes, will plainly and fully give his opinion, and if he should see fit, combat the opinions that others have advanced, but let it be done with soft words, however hard may be the arguments. Let us always remember that "many men have many minds," and that all knowledge does not dwell in the mind of any one man; and also, that every man hath as good a right as we have to hold his own opinion. If this were always borne in mind by florists, we certainly should not have so many captious fault-fiuders, or so much

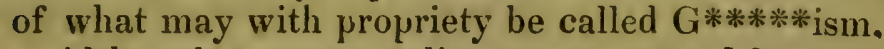

Although a young tulip grower, may I be allowed to respond to the request of $\mathrm{Mr}$. Turner, in giving my opinion. If so, I would with all humility, as becomes a young man, say, I agree with him, that in a stand of tulips there ought to be no restriction in regard to feathered or flamed. The only restriction that I would wish to see is, that each exhibiter shall have in his stand of six, nine, or twelve blooms, an equal number of DIsTINCT varieties, of bizarres, byblomens, and roses, whether feathered or flamed, just as it suits the taste or the bed of the exhibiter. Anything short of this, in my opinion, must have the effect of curtailing ANY exhibition.

FEBRUARY-VOL.VI. 
As to class showing, whether there be two or three classes, I think it would matter very little, provided we have yet enough of flowers to form a third class. But as to the manner or mode of slrowing in the classes, I think it does matter, and I fondly trust, with all due deference to the opinion of Mr. Dixon, that I shall soon have the pleasure of seeing in your pages, that the classes are to be shown in accordance with the rules of Messrs. Dodwell and Marris; and where they are not shown so, I shall assuredly pay little attention to them. It is impossible for me to understand what Mr. Dixon means when he states "that such rules may with some propriety be applied to the pink and carnation, but not to the tulip." Why one would have thought that "what was sauce for the goose might. be sauce for the gander ;" for if such a way of showing, according to Mr. Dixon, is calculated to improve one class of flowers, why not all? Can the mere point of time make wrong for the tulip what with "some propriety" is right for the pink? Assuredly not. But why "s some propriety?" Surely Mr. D. had left his logic behind him when he penned these words, for a rule such as this must either be wholly right or altogether wrong; and if right, why some? if wrong, why at all? It seems to me perfectly evident, that if second to tenth-class fiowers (of which I think we have far too many already) are what are wanted, then by all means let tulip fanciers support Mr. Dixon; but if they wish to save their pockets, and at the same time raise the standard of the "queen of the garden," by all means let Messrs. Dodwell and Marris have their support. And no "persevering and intelligent raiser of seedlings will have cause to fear the propagation of newfangled and impracticable theories," for by that yery means he will be led to see what is the standard aimed at, and when successful, he will assuredly be rewarded. But I have no doubt that selfish men will have reason to fear; for if such rules had been in existence a few years ago, we should not have had so 
many of those "improved tulips" that have sprung up like mushrooms, and yet the standard would have been as nearly gained. Not quantity, but quality, is the thing wanted. Let every florist, therefore, decide in his own mind which is the better plan for improving the quality, and when he has decided, let him act accordingly.

I am also happy to see that Mr. Dodwell's views have "astonished the whole floral community." It is well that it is so, for before the astonishment calms down, Mr. D. will find many more than Mr. Marris of his way of thinking. A little agitation, and a few more such correspondents as Mr. Dixon, and the work is done; for in my opinion he has done much to damage the side he has taken, and if he tries again, perhaps you will find him converting himself.

R. C.

Carney, Dec. 15, 1851.

If you, Mr. Editor, or any of your correspondents, would give a paper or two on the various names applied to one variety of tulip, I think a great service would be done to the floral community, and especially to young florists like myself, for I have been led to get not a few varieties, while I had plenty of the same in my bed, under a different name.

\section{ANOTHER WORD ON THE NOMENCLATURE OF TULIPS.}

IT appears to me that your correspondent, "A Londun Grower," is either unable or unwilling to read, or he would not so have twisted and perverted what appeared from me in your December number.

I have yet to learn that a London judge did pass the stand in question, having always understood that the majority of censors decided; and there being three northerns to one southern, it is only fair to presume he was outvoted. 
With regard to his assertion, that the London judge said he was considered the first amateur grower in England, and that I confirmed such opinion, I beg distinctly to deny it, so far as I am concerned; and to call upon this said London Grower to say when and where the gentleman himself ever made such declaration, as, from my knowledge of him, I believe him to be utterly incapable of such egotism.

I never denied there being an equal number of bizarres, byblœmens, and roses in the stand exhibited by Mr. Turner, at Derby; but according to your report of prizes, both $\mathrm{Mr}$. 'Turner and $\mathbf{M r}$. Edwards showed Triomphe de Lisle, and called it Primo Bien du Noir. I would ask whether any other London grower would have committed snch an error, both flowers having been well known here for forty years past at least.

I beg to inform "A London Grower" that I never converted one flower into another, as he assumes; nor do I ever allow a flower to be called by a wrong name, where I can prevent it; for I well know instances where men who would have been ornaments and acquisitions to the fancy, have been driven disgusted from it by unprincipled individuals havirg rechristened old fiowers and brought them out as new.

What is in a name? For the information of "A London Grower," if he will take the trouble to search the Dutch catalogues for forty years back, he will find Rose Primo Bien du Noir, which I translate "First good Rose from the Blacks," and which was explained to me some twenty years ago, by an old French florist, who, I believe, knew the raiser, to mean, the best rose at that time ever raised from the seed of a byblomen. If any of you readers should send to a London dealer for Primo Bien du Noir, they would most assuredly not receive the byblœmen exhibited by Messrs. Turner and Edwards, but a bad strain of Rose Camuse.

In conclusion, why the writer should thank me 
for expounding a mystery and standing sponsor, th a mystery to me. I can assure the gentleman that there are two things that I would not stand sponsor for, viz. miscorrect reading and translating.

\section{J. MACEFIELD.}

\section{HARDY PERENNIAL PLANTS.}

BY THE EDITOR.

PO'TENTILLAS.

Considerable improvement has of late been made in potentillas,-numerous seedlings have sprung up,and certainly there are few plants which afford a more constant succession of bloom during the summer and autumn. Their strawberrylike leaves, and flowers of all shades, or nearly so, excepting blue and purple, are very attractive and ornamental. As far back as we can recollect, $P$. atrosanguinea, with its dark scarlet flowers, and $\boldsymbol{P}$. formosa, with deep pink, were, with some few yellow rarieties, the chief surts cultivated. Then came that rery great improvement, $\boldsymbol{P}$. Hopwoodiana, with its large wellformed flowers, white, shaded with rose. This was so distinct and beautiful, that it was in great request, and it still retains its place as one of the rery best. $\boldsymbol{P}$. Tonguii is a neat and very pretty sort, buff, with a dark crimson spot at the base of each petal. The flower stems lie prostrate, and the blossoms are produced in great profusion. It is peculiarly adapted for rockwork. This, we believe, was originated somewhere in the neighbourhood of Garstang, in Lancashire, at which place, several new seedlings have lately been raised, which promise to become popular perennial plants. Amongst parti-coloured sorts, there is $P$. Smouthii, introlluced of late years, and said to be striped. We confess we were disappointed in this plant, the ground colour of the flower is buff, veined with dark brown, and it has E 2 
a dingy appearance at the best of times. It grows rather tall, and we want more compact habit, and now the flowers are so much improved, attention must be directed to this point. O'Brienii is buff or pale yellow ground, with a crimson undefined tinge at the base of the petals ; and though pretty, $P$. Garneriana is a decided beat on it, having similar ground colour, with a well defined crimson spot at the base of the petals, looking somewhat like Cistus formosa. This last is a very nice thing, and ought to be in every garden. Our friend, Mr. Willison, has raised soine good shaded varieties, blooms of which we saw and reported on last season. Perhaps some of the most striking flowers are raised in our native county, for a namesake of ours, Mr. D. Wood, of Welton, near Hull, has added four or five good ones. Among the shaded or parti-coloured varieties, there is $P$. Woodiana, with a brilliant deep yellow petal, edged with scarlet, very constant in its marking, and occasionally semidouble. $\boldsymbol{P}$. bicolor grandiflora is also in this way, and very beautiful. $P$. picturata is also a yellow-ground flower, with rich blotch, very handsome. Amongst yellow-flowering varieties, there are $P$. pedata, insignis, and leuchrocora, calling for no particular comment, insignis being the best. Mr. Wood, before alluded to, has obtained a very fine yellow from seed, $\boldsymbol{P}$. lutea, which he informs us is of much better habit than the generality of the flowers of this colour, and will, doubtless, be an acquisition. $\boldsymbol{P}$. Antwerpensis is a beantiful semidouble orange, very attractive. In darks, Mr. Willison has some very good seedlings, large, and of fine form, which we noticed during the summer. Then there is $\boldsymbol{P}$. Pennonii and Fintlemanii, which, thongh large and of fine colour, shows the green calyx through the petals. It is certainly inferior in form. $P$. Bainesiana, the exterior of the petals yellow, whilst the interior surface is crimson. P. Menziesii, shaded crimson, is very attractive, of gond habit, and worthy of extensive cultivation; but perhaps one of the best 
in this class is $P$. sanguinea maxima, of immense size, the flowers often measuring two inches across, and for stontness of petal and brilliancy of colour, certainly very far in advance.

The potentilla is easily cultivated, and may be propagated by division of the root, in March. It appears to be at home on any soil, thriving alike in light and in heavy land. Perhaps no flower offers so good a chance of raising new varieties, as the anthers are easily extracted, and pollen can be applied to the stigmas. The best support for the flowers is a small wire guard, about a foot high. This should be placed over the crown of the plant, and the stems then take an easy and natural direction, and appear far better than when tied to a stick, which destroys the greater part of their beauty.

\section{CHRYSANTHEILUIS.}

Durixg the past autumn, I visited several of the finest collections of chrysanthemums in the neighbourhood of Lundon, and, believe me, Mr. Editor, I was most highly delighted with the beautiful display of these splendid autumnal flowers. Not only is there a manifest improvement in the larger-flowering varieties, but there are those "pets of pompons, or miniatures," which are so neat in habit and so suitable for window culture, that I do not wonder at their becoming general favourites. On consulting my memoranda, I find the following as having struck me as worthy of a place in any collection. First, there was

Salter's Miss Kate, perhaps not so novel in colour as some, being a light pink, but the form of the flowers individually, and their profusion, render it a nice addition to the numerous varieties already sent out by that gentleman.

Taillard's Rossini is very attractive, being a fine rich yellow, striped with red; the form was hardly so good as the preceding, but, nevertheless, it is an interesting and novel sort. 
Erinne (Pele) is a charming kind, the flowers patting one in mind of gigantic daisies, with snowy petals, tipped with light crimson; a very lively and pretty sort. This, I fancy, will become a general favourite.

Astre Brilliant caught my eye in a moment, amidst a large assemblage of beauty. It is a stout grower, with peculiar deep orange flowers, of a large size. This must be grown not only for its good form, but for the beautiful contrast it makes with the other varieties.

Pio Nono was a distinct sort likewise, the preponderating colour being dark red, and the tip of each petal yellow. I saw several in this style, but this took my fancy most.

Bernet's Arc en Ciel was a decided novelty, and though the plant was not in very good health, still I could see well enough that it would be a popular variety. The ground was pale yellow, margined with a coluur closely approximating to purple.

\section{Another tipped flower was}

Mange, also a continental variety, and differing from many others. Colour lilac, edged with yellow.

Now, though those previously mentioned were very beautiful, new, and distinct, the miniatures took my fancy most, for I was not prepared to see plants not more than a foot high, covered with a profusion of particoloured flowers, of almost every hue. As a pot plant it is certainly one of the very best, and, from its hardiness and comparative easy cultivation, may be grown by everyone, however small their pretensions to floriculture nay be.

Daphne (Bonamy), a neat deep pink, with a purple tinge, was a decidedly beautiful variety.

Elegantissima (Smith), was not only singular, but very handsome, having a dark centre, and the other part of the flower shaded yellow.

Ninon (Pele) - A nicely formed variety, blooming very profusely. Pure white, the lower part of the petals being pink.

The two best yellows that I saw, and very good they were, being dwarf, compact, and rich in colour, were

Sacramento and Solfaterre, both, as I understood, raised by Pele; the former being deepest in colour, a bright shining orange, whilst the latter was a fine and delicate light yellow, or canary. 
La Fiancee I thought by far the best white. A nice sort for a wedding bouquet!

And last, though not least,

Elise Miellez.-Rosy purple, with white tips.

These, Mr. Editor, were all of them really excellent, and being a tolerable grower, and having added them all to my own collection, I thonght perhaps their description might be of service to others, who may be desirous of obtaining a few new sorts.

W. SIMPSON.

\section{THE AMERICAN HIGH BUSH BLACKBERRY.}

Is Hovey's Magazine, for January, 1851, there is a woodcut and notice of the above. Hearing so much about it, I went to all the principal gardens around, this last summer, to see if it maintained its great bearing qualities. Not a place I went to that I did not think it grew finer and finer. It is, without doubt, one of the finest of the small fruits. When quite ripe, if not superior, it is as good as any raspberry, twice as productive, and double the size. Mr. Hovey made a plantation of twelve vines, two years ago, and this summer, nothing could equal the crop. He assured me, that from these twelve vines, he gathered forty-three quarts of fine large berries, each of them from one and a half to one and threequarters of an inch in height. I was with him inyself, one day, and we gathered four quarts in about a quarter of an hour. 'Though it has been known four or five years, it has never drawn any particular attention till the last two years. People thought it was nothing more than the common blackberry under cultivation. It has now been fully proved to be a seedling, raised at Dorchester, about five miles from Boston. It was, this year, exhibited every Saturday, for five weeks, at the Massachussets Horticultural Society, and obtained a prize each time, and 
in the market they fetch from fifty to seventy-five cents. (equal to two and three shillings British) a quart. It is of the easiest culture, delighting in a rich sandy loam, and merely requiring the old wood to be cut out every winter. I am sure, if it were once in the cottager's garden, it would be quickly disseminated, and the first thing you heard of it would be that it was exhibited as well as any raspberry or goboseberry.

Only that I am known to you, many of your readers might think I was speaking too highly, and giving it a Yankee puff. No such thing; it is my firm belief that it is a first-rate fruit, and all the English gardeners that I have met with say the same.

Boston, U.S.

B. F.

\section{FRUITS OF THE MIDLAND COUNTIES.}

BT THE EDITOR.

[Continued from page 16.]

PEARS.

$\mathrm{W}_{\mathrm{E}}$ have named a few apples and plums grown in the midlands, and now come to pears. The mania for new Belgian varieties has somewhat cooled down in this part of the world, from the circumstance that many of them, though fine in a more southerly latitude, have failed here to be so excellent as was anticipated. The sorts most commonly cultivated are,

Jargonelle.-This is a highly esteemed dessert pear, bearing well either on a wall or as a standard. The branches weep, and it grows strong and luxuriantly. On a wall, the fruit attains a large size, long in form, and greenish yellow when ripe. Its season is the beginning of August.

Striped Catherine. - This is extensively grown in some neighbourhoods, and though only a third-rate pear in flavour, still, from its handsome appearance (yellow and scarlet) and great produce, it is found to be a profitable market variety.

Brougham.-This is one of the seedlings of the late Andrew Knight, Esq. and, from its hardiness and other good quali- 
ties, will be extensively planted when better known. As a standard, the fruit is very russety. It is a melting pear, of fine flavour.

Hessel.-One of the most productive and regular bearers grown. Unfortunately it does not continue long in perfection, but for profit there are few like it. The tree is a fine pyramidal grower, with pendulous branches. Fruit oblong, and covered with brownish russet.

Beurré de Capiaumont.-This, like the preceding, bears profusely, but is far from being so handsome in its mode of growth. Many old trees of the Huntingdon or Lammas pear have been regrafted with this variety, and speedily made large and well-formed drooping heads. The fruit is mediumsized, greenish yellow, with red next the sun, and keeps rather better than the Hessel, but should be disposed of as soon as ripe. Its season is September.

Marie Louise.-One of the most awkward-growing varieties, twisting and twirling any way but right, unless supported for the few first years. It is rather getting out of favour here, not because its fruit is bad, for that is most excellent, but we cannot stand a crop only once in five or six years. The fact is, it blossoms su very early, that the bloom is frequently cut off. When it does "HIT," the tree is full, and on standards the fruit is most excellent. It is a sort that well deserves a wail, and where there is convenience for shading the trees when in blossom, they will amply repay the extra trouble. Fruit rather long, greenish yellow, and of a rich and exquisite flavour.

Fry's Seedling.-A new and very prolific pear, medium size, and very hardy; colour greenish yellow, erect in habit, and the foliage has a greyish downy appearance. The flesh is melting, and in flavour approximates to that fine old pear the Swan Egg.

The Welbeck, or Welbeck Bergamot.-This variety was raised at the seat of the Duke of Portland, in Nottinghamshire. It is of very large size, rather more round than long, deep russet, with a dark red cheek next the sun. It is erect in growth, and bears profusely ; the fruit too is large, but un. fortunately it is rather coarse, though in this paricular it varies much. It grows to a very large size on a wall, and is then a good second-rate melting pear.

The Althorpe Crassanne, raised by the late Andrew Knight, Esy. like the other varieties originated by that gentleman, is very hardy, bears well, and is of fine flavour, keeping till December. The fruit is rather round, greenish yellow, occasionally covered with russet.

The Dunmore is one of the best of Mr. Knight's seedlings, bearing regularly and well. To this is added large size and excellent flavour. 


\section{COP PICEANA.}

No. XIX. "

$\mathrm{W}_{\mathrm{E}} \mathrm{continue}$ our descriptive list of rhododendrons.

R. Van Houtti.-Singular, from having semidouble blue flowers.

$\boldsymbol{R}$. Glennyana.-Of very neat growth, blooming profusely, with large trusses of deep pink or light scarlet flowers; flowering early, but not so soon as to be destroyed by frost.

R. Augustum.-Foliage rather coarse, but the flowers very beautiful. Delicate peach bloom, with intensely dark spots.

R. Invictum.-Pretty habit, flowers crimson, spotted with black.

R. Pyramidale Flore Pleno.-Double rhododendrons are now beconing plentiful. This is one of the best. Flowers rosy purple.

R. Catawbiense Corulea.-A continental variety, the flowers approximating to blue. We have several seedlings which we consider quite equal to this variety. It affords a good contrast to others.

R. Grandiflorum. - Of robust habit, with splendid foliage, and immense heads of large purplish lilac flowers.

$\boldsymbol{R}$. Victoria. - A very beautiful variety, raised, we believe, by Messrs. Pince \& Co. of Exeter. The foliage is dark and fine, flowers deep claret, produced freely and in large clusters.

$\boldsymbol{R}$. Albertii. - This, as a matter of course, should accompany the preceding variety. It is of another class of beauty, being a richly spotted and beautiful pink.

R. Ponticum Puniceum.-A free-blooming variety, with crimson flowers, very hardy and pretty. The flowers are not, however, of the best form in the world.

R. Caucasicum Album.-Of dwarf and compact habit; does not bloom very freely; the flowers are creamy white, and produced early, often being cut off by spring frosts.

R. Catawbiense Atropurpurea--Belonging to the hardy American section, but the flowers hardly of so dark a purple as its name would imply; they are produced in magnificent heads.

R. Hirsutum.-A dwarf and neat grower, with small leaves, hairy round the margin, bearing clusters of red flowers. There appears to have been little done in the way of improvement with this variety, the only other sort is one with the leaves prettily margined with yellow.

R. Feringinea.-Another very dwarf sort. The leaves underneath are of a rusty colour. This and the preceding form excellent companions for Daphne cneorum, Rho. daurica, and some other short-growing peat earth plants.

\section{RuBus. (The Bramble.)}

Most of these are coarse-growing straggling shrubs. We have often thought that if attention were turned 
to the common wild variety of the hedges, in course of time, by crossing the flowers with the raspberry, a valuable fruit might be obtained. It will be perceived, in another part of our number, that already there is an American blackberry, which is attracting notice, and likely to become a very useful fruit. Of the sorts cultivated,

$R$. Variegata is one of the most handsome. The leaves are very distinctly variegated with white. It makes a good pillar plant, bearing fruit abundantly, often having clusters in which are ripe black fruit, red, or only partially so, and green at the same time, which has a very pretty effect.

$\boldsymbol{R}$. Flore Albo Pleno, with very double white flowers. Rather an untidy plant, but the flowers are pretty.

R. Rubra Flore Pleno.-This is a double pink bramble, and is a distinct and handsome sort.

These are all easily propagated by layers, and we think there are many places where they might be advantageously planted; on the tops of banks, for instance, where they would make a fence which few people would like to face.

There is a different style of plant, putting up canes like raspberries, which belong to the same family. Of these,

$R$. Spectabile, with pink flowers, is perhaps the handsomest.

$R$. Oderatus.-Also in the same style.

RHus. (The Sumach.)

R. Cotinus is a branching shrub, often reaching six or seven feet in height, and bearing a very beautiful lilac featherlike bloom.

This plant ought to be seen much more frequently than it is.

\section{HUFTON'S LORD RANCLIFFE POLYANTHUS.}

WHO WAS ENTITLED TO NAME HUFTON'S LORD RANCLIFFE ALIAS CLEGG'S GOLDEN HERO POLYANTHUS.

OwING to statements having been made in the Durham Advertiser and elsewhere, by Mr. John Slater, FEBRUARY-VOL. VI. 
of Cheetham Hill, near Manchester, that the florists of the midland counties had renamed a polyanthus bought of the late John Hufton, of Heanor, by Mr. Joseph Clegg, of Manchester, the untruth of which we at the time pointed out, and the statement having been repeated, we considered it necessary to make further inquiries.

We stated in the Durham Advertiser, that it was of our own knowledge, and likewise notorious among all classes of florists in the neighbourhood, that John Hufton never did sell the stock of any flower that he raised. We also stated, that long after the flower had been shown at Nottingham, and named by Hufton, Mr. Clegg came to Beeston, and bought two dozen large plants, of Mr. Joseph Oldham, of that place, and that too at the time when there were plenty of the sort in the hands of florists round Nottingham.

In order that we might make no mistake, we wrote to Mr. Brown, of llkeston, requesting all the information he could give on the matter, for we are aware that we have all sins enough to answer for, without being calumniated and falsely spoken of. We subjoin Mr. Brown's reply.

Dear Sir,--Not long after I received your letter, Samuel Pollard came to my house, and I read it to him. And I can tell you that we both saw Hufton's Lord Rancliffe polyanthus growing on the seedling bed of James Fisher, of Cotmanhay, in the parish of Ilkeston, the first year of its blouming. A week after this, he sold the plant to John Hufton, for ten shillings and sixpence, and John gave it the name of Lord Rancliffe, a popular man at the time. In two or three years after, Hufton sold it out at twelve shillings per plant. Mr. Pollard says, after it had been let out, Clegg, of Manchester, came to Benjamin Wade's, at the Queen's Head, Ilkeston, and sent for him, to go over to Ned Hufton's (the son of John), who lived at Marpool, near Heanor. Clegg and Pollard went together, to buy Earl Grey (now Clegg's Lord John Russell) and this Lord Rancliffe, two plants of each sort, at five shillings each.

At this time, both the sorts had been sold out several years, and the reason why they went to Ned Hufton was that they expected to get them cheaper of him than of his father. You may depend on this statement being correct.

I remain yours respectfully, JOHN RAWDEN BROWN. 
We now leave it to the florists of the world to judge whether the charge of the midland florists renaming these flowers is correct or not. We have put these observations on record, to counteract the effect of the mischievous statements alluded to, merely observing, that we make a point of never attacking anyone: ours is purely a defensive system.

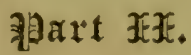

\section{NEW PLANTS.}

Silver-Striped Weeping Holly.-It is but few years since the common weeping holly was discovered, in a garden at Derby, and it has now become generally known. We noticed last year, that a shoot on one of our plants had several leaves blotched with cream colour. Last spring, we grafted the shoot, and it has again produced rariegated foliage, so that we hope we have fixed the sport. Should it prove so, it will be a singular addition to our hardy weeping trees.

Chrysanthenum Hexpersonit.-One of the great drawbacks to the enjoyment of these beantifni antumnal flowers has been the late season at which they bloom. We are glad to find that a new variety (originated in Italy) has been introduced, which is very considerably earlier than the Chinese sorts already in cultivation. The flowers are described as being double, well formed, and of a rich orange yellow. It is expected to be a favourite bedding plant, from its dwarf habit and abundant blooming.

The Wellington Hero Calceolaria, to be let out this spring, is another fine plant also for bedding. The flowers are very fine, rich golden yellow. 
New Pansies.-The following new pansies are letting out this spring :-

Kossuth.-A finely-formed black self, with extremely stout petals.

Sir Joseph Paxton.-This also is excellently formed. Ground colour canary, with rich bronze margin.

Duchess of Perth.-A purple-belted flower, very stout, excellent form, with splendid eye.

The above are Scotch varieties, and by good judges are pronounced first-rate.

EXTRACTS, HINTS, AND RECOLLECTIONS.

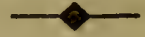

RAISING ROSES FROM SEED.

[From the Gardeners' Chronicle.]

Some of our best and latest new roses have been produced from seed gathered from hybrids-Athelin and Celine--two varieties which seed abundantly, even in unfavourable seasons; and from these have sprung a portion of that beautiful class termed hybrid perpetuals. Presuming then there are good reasons to believe that varieties of standard merit may be raised here, let us mention a few kinds which seed freely in England, and appear well suited for female parents. First amongst the hybrid Chinese are, Athelin and Celine, Ne plus ultra, Duke of Devonshire, Chatelaine, Princess Augusta, Henri Barbet, Globe, White Hip, General Allard, Aurora, and others. These might be crossed with some of the freest-blooming damask perpetual or Bourbon roses, to endeavour to obtain an increase and an improvement among the hard autumnal roses. The Ayrshire and Sempervirens, amongst which there is a paucity of high coloured flowers, might be fertilized with the farina of some dark varieties, selected from those which approach nearest to them in natural character. 
Here Ruga, Splendens, and Leopoldine d'Orleans might form the female parents. Among the moss, the Single Crimson, Du Luxembourg, and Eclatante occasionally seed; among the briers, the Double Yellow and Harrisonii; among the Bourbons, the Old, or De Lisle, Augustine Lelieur, Du Bourg, Gloire, De Rosamenes, Emile Courtier, and Bouquet de Flore; among the Chinese, Camellia Blanc, Fabvier, Therese Stravius, Alba, Belle Elvire, Henri Cinque, and Madame Buteau; among the tea-scented, Odorato, Jaune, Hamon, Lyonnais, Hardy, Lady Granville, Caroline, Gaubult, Belle Allemande, and Bardon. Many of the least double Gallica roses also seed freely. These, and many others which, by seeding, have doubtless at some time struck their posséssors, may be taken as female parents, and crossed with whaterer varieties the fancy of the operator may suggest. How far the experiment of crossing the different sections may be carried into effect, it is not easy to determine; but the peculiarity of certain features existing in some varieties, and readily traceable to their parents, leads us to think that the scere of action will not be found very limited. As a female parent will in many cases be semidouble, we should endeavour to counteract the probable results of this, by crossing with farina gathered from the most doubie varieties that we can collect it from. Thie plants intended to seed should be selected in a good state of growth, and never allowed to suffer from drought. Where they bloom in trusses, the backward flower buds should be cut out, learing not more than six of the plumpest and most perfect buds on one flower' stalk. We are, no doubt, indebted to accidental crossing, in a great measure, for the various novelties and improvements in the rose tribe. Artificial crossing, however, appears the only probable method of obtaining an end in view; and althongh this is at first somewhat tedious, it will be found to increase in interest as we become familiar with its application. Just as the flowers intended to 
be crossed are expanding, it will be necessary to remove the anthers, or they will burst, and the flower thus become self-impregnated. They may be re- : moved early in the day, with a small pair of scissors; and in a sunny hour, flowers should be gathered from . the variety we intend to cross with, and the pollen dusted on the stigmas of the flowers of the opposite parent. A truss of flowers may be crossed with one kind, and a gauze bag drawn over each truss when the operation is completed, to prevent the perversion of our designs by the countless millions which swarm in the air at this season of the year. The dusting of the pollen may be repeated once or twice, to make our purpose sure. If we wish to know the result of our crossing, and whence the seedlings spring, leaden numbers may be attached to each flower stalk, and corresponding numbers, with the names of the parents, written in a book. Probably, after crossing, the seeds have seldom been kept separate, on account of the trouble it would occasion; nevertheless, raisers have been able, by tracing a little and guessing a great deal, to acquaint us with the progenitors of their seedlings. But what might be known for certainty, thus often becomes a matter of speculation. In autumn, as soon as the seed is ripe, it should be gathered, and placed, with the nnmber, in the gauze bags previously used, and left in the seed vessel till required for sowing. We may sow the seed as soon as ripe, or in spring, when some will germinate immediately, but the greater part not till the year following. If the seed be kept a twelvemonth before sowing, it should be buried in the seed vessels, in boxes of sand or light earth, kept moist, and not exposed to the extremes of temperature. It may be sown either in seedpans, in a frame, or in the open border. If the latter, an eastern exposure is most favourable; and in all cases, the soil in which it is sown should be rich and light. We should sow thin, that the plants, when growing, may not crowd each other and become weak. The seed should not be 
sown too deep, and after sowing, the surface of the soil may be strewn with a light covering of moss. As the seeds break through, this may be removed, and protection afforded against slugs and birdş. It will also be advisable to shade and water them, and where too thick, to transplant the weakest at an early stage of growth. Transplanting should, however, be avoided, if possible, as it ordinarily retards the period of flowering. Some of the seedling Indicas will flower in the autumn of the same year, but for the mass, we must wait one or two subsequent seasons. As winter approaches, some plan must be devised to protect them from frost, as the plants in general being young are more than usually tender. One advantage gained by sowing in pans or in a frame, is the efficient mode in which we can accomplish this, by removing the former to a pit or greenhouse, and affording protection to the latter in the usual manner. When sown in the border, they must be covered with moss, or some protecting substance, to shield them from the frost.

Nurseries, Cheshunt, Herts.

$$
\text { W PAUL. }
$$

\section{ROT IN THE AURICULA.}

[We extract the following from the Scotlish Gardener, elsewhere noticed. It is from the pen of Mr. George Lightbody, of Falkirk, one of the most successful cultivators of the auricula in Scotland.]

THERE is one fatal malady to which this fine flower is liable - that is the rot. 'I'his may be attributed to two causes, viz. improper compost and allowing water to lodge in the hearts of the plants. An experienced cultivator can instantly perceive, by the peculiar smell, when disease is in a collection. When a plant is seen with its head leaning to one side, and the outer leaves assuming a purple hue, having also a strong disagreeable smell, then rot lias commenced. 
Plants so infected must be immediately removed to a distance from those in health, otherwise the whole collection may be swept off in a very short time. I tried every sort of experiment to cure this scourge. The only remedy that was successful was to take the plant out of the pot, wash it well, and with a sharp knife cut away all infected parts, and dust the wounds with charcoal; and after allowing the plant to dry for a few hours, repot it in a mixture of leaf mould, loam, and sharp sand.

To guard effectually against the rot, never allow the plants to have any heavy rains; and purchasers cannot be too careful in having their plants from a healthy stock. I lately saw large collections in such a state that I would not have taken the whole in a compliment, knowing that I should only be introducing the plague into my own stock.

\section{TULIP JUDGING IN THE MIDLANDS.}

Is the numbers of the Midland Florist, for September and January last, you allude to Edgar being disqualified, in consequence of stained stamens, though the best feathered byblomen in the room. Now I am not an advocate for what you call smudgy bottoms, neither am I for stained stamens, but you may judge of my surprise when I saw the return of the Nottingham show, in the October number, and found that in the very class where Edgar was disqualified is placed La Belle Narene, with long cup, narrow petals, smudgy bottom, and stained stamens; next Van Amburgh, smudgy altogether nineteen times out of twenty; next Bienfait, with both stained bottoms and stamens; and also Sancta Sophia, alias W ashington, with yellow bottom and stained stamens. (In this latter case, as well as at Derby, I think the judges were very much to blame for allowing a flower to pass in a wrong name, knowing, as they do, that 
Sancta Sophia is nothing but Washington.) Now I know the above description to be true, as I grow all the sorts $I$ have named; and it is such anomalies as this, that makes the northerns think the midlanders are partial. I do not say Edgar is first-rate, but I do say it is better than any of the above; for when in bloom, and properly managed, it will make a good cup, and for white and marking it is not surpassed by any, but it has that unfortunate drawback the stamens, and I have no doubt that if it had been a midland seedling it would have been at the top of the class. I hope these few remarks will not be thought offensive, for I am sure I do not intend that they should, but merely to point out the inconsistency of judgment.

\section{Denton, Jan. 10, 1852.}

JOHN NAYLOR.

[Edgar was our own flower, and very much annoyed we were that it was not placed before the sorts named by Mr. Naylor; but when we put our flowers into the hands of men who have been selected as judges, if they make a mistake, it is our misfortune, and we endeavour to look as charitably on the blunder as we can. We do not, however, think that the midland counties are the only places in the world where flowers have aliases. It would appear, from our correspondent's letter, that they alone were guilty. We could enumerate a few flowers that certain parties in other quarters have renamed and sold at a high price, but it would engender bitter and angry feelings, which our correspondent, we are quite sure, will think with us, had better be avoided.]

Mr. Hovey, of Buston, U.S. had seeds sent to him last year from Central Mexico. Amongst them, he has bloomed a new globe amaranthus, a brilliant orange colour, about two feet high, and double the size of the old purple or white. It makes a beautiful contrast. 
On Saturday evening, the 16th of August, we called at the florists' meeting, held at Mr. Wasnidge's, the Crown Inn, Nottingham, and were much pleased with what we both heard and saw. The members are chiefly working men, who have gardens in the vicinity of the town, and every Saturday night, at eight o'clock, after the week's work is concluded, they meet to enjoy a few hours in conversation, on those subjects most congenial to their tastes, namely, the productions of their gardens. They have a welllighted room to themselves, in the centre of which is a table, on which are displayed flowers or vegetables that are thought worthy of attention, each member bringing what he chooses. The merits of these are discussed, interchanges or sales are made, drc. \&c. Amongst other things exhibited, we noticed in particular a stick of Cole's red celery, which was trimmed and fit for use, and weighed six pounds and an ounce. When it was got up, before any leaves or fibres were taken away, it weighed seven pounds eight ounces. We also ubserved a seedling passion flower, raised by Mr. Wasnidge, from Passiflora cœrulea. It was somewhat in the same style, but much lighter. We hope it will prove hardier than the parent, as a passion fiower that would bear the winters of Nottingham would indeed be an acquisition. On the table were cut specimens of roses, dahlias, verbenas, and fuchsias. There was a good spike of Lupinus Foxii ; also blooms of the fine white hollylock, Belladonna, besides pentstemons, delphiniums, and most of the best perennials out. The subscription for each member is one penny per week. Various periodicals are purchased-Beck's (now Turner's) Florist, the Cottrge Gardener, the Cabinet, the Midland Florist, Gardener's Chronicle, \&c. Now we would ask our moneyed friends who love their gardens whether such a spirit amongst the industrious artizans of Nottingham ought not to be encouraged: books, we know, would be thankfully received, and any seeds of new vegetables, which many in the 
higher classes could give without loss to themselves, we are sure would be highly prized and well grown. The secretary, Mr. Marshall, would acknowledge the receipt of any of these things we have alluded to.

Our American correspondent says, people are dissatisfied with all the English nurserymen, for not knowing how to pack plants. They mostly come half dead, if not more. It would require a person to see how we pack them for a month's journey, and not a plant dead when they arrive at their destination. When packing trees, shrubs, \&c. never put moss, straw, or hay through them, only partly dry moss through the roots, and pack tight, with air to the limbs. Turn plants out of the pots, roll them up tight in canvass, and place tier above tier, with a lath between each tier, nailed at each end, to keep the plants in place. We could send plants to England as fresh and healthy as if they had only travelled ten miles.

Delphixium Magrifica.-We insert the following testimonial to the merits of this splendid perennial herbaceous plant, and can truly say it accords precisely with our own opinion of it, and glad should we be to get similar notices of new plants from various parts of the country. This is from an amateur of this beantiful family, in Scotland, but we will give his own words:- "Last year, I saw D. magnifica advertised at $10 \mathrm{~s} .6 \mathrm{~d}$. and I at once ordered a plant; and although the price was "rather saut" (salt), as we say in Scotland, I do not grudge it, for it has turned ont one of the very few things that well deserved all the character given it by the adrertiser. This plant commenced flowering with me about the middle of June, and continued an object of very great attraction, even to the "rabble," for a long time.-[Ours has been so attractive, that some of the ladies (?) who visited our grounds could not leare it alone, but gathered part of the flowers, to 
our great mortification.-ED.]-I was kind to it, and it put up two very strong stems, which were not well done flowering until several more shoots appeared, and at this moment (Aug. 11) they are in all their glory, and nearly as attractive as the first. I suppose it is no uncommon thing for delphiniums to flower twice, and I hope the plant will not be the worse for it." Our correspondent then names and describes some other varieties, as D. Barlowii, D. Hulmii, \&rc. which have been before referred to in the Midland Florist; but as there is one we have not seen, and neither perhaps have many of our readers, we will add the description. "D. Velutinum.-Of dwarf habit, with large geranium-shaped leaves, very hairy. Flower stem and flowers also hairy. A most drolllooking flower, dark in colour, and looking out of its rough woolly cowl like a baboon!"

I perceive one of your correspondents complains of the dampness of his situation, and thinks it is the cause of his not saving any carnation seed. It is eighteen years since I commenced growing this favourite flower, and the first season I got a thimbleful of seed, and then I was fourteen years and did not save a single grain. I read the article on impregnation, in the Midland Florist, and when the time of pink and carnation blooming came on, I set to work attentively, and the result has surprised me, as the seed is much finer, and there is double the chance of producing good varieties. I anticipate having something to send you, during the blooming season, that will make you smile at the fruits of my impregnation; and I have a fine stock of seed from Cant's Criterion, crossed with his Sturge, and other sorts as well; but you must refer your correspondent to the article alluded to (vol. 2, page 164), and I have no doubt but he will succeed in obtaining seed.-S. H.

American Vegetables.-(From our American cor: respondent.)-We have nothing new, or that would 
be of use to your readers. Tomatoes, squash ( $\mathrm{Cu}$ curbita melopepo),-these two, with their rarieties, constitute the principal American regetables. So fond are the Americans of tumatoes, that they have them for breakfast, dinner, and supper, roasted, boiled, stewed, for sauces, and in pies, \&c. ; squash pies also. In fact, I cannot enumerate one-half the varions methods they have of cooking them. When I first came here, I fancied I should have the cholera if I eat a mouthful of either; but, after a time, I got Americanised, and I now think they are two of the finest regetables grown. Nothing can be better than tomato sauce, and squash, mashed like turnips, is far superior to that vegetable. Lima beans are great favourites, and a regular Yankee would not think Sunday was Sunday, unless he had baked pork and Lima beans. The cabbage tribe is bad, tough, and insipid. No boiling can make them mellow, though they grow quickly, and attain a large size in a short time. Melons and cucumbers, with a few early radishes and lettuce, are also grown well.

Marshal Soult Tulip. - Some say that this flower is stained at its base. If so, why is it considered a good sort? Perhaps some good frieud in the south will give us the names of "what to aroid" in this particular, so that in improving our beds in the north we may only get those which are pure.

\section{Lotus Corniculatatus Flore Pleno.}

(The Double-flowering Birdfoot Trefoil.) - This is a very interesting procumbent perennial, with double yellow flowers. We are hlways glad to get hold of any little anecdote like the following, for which we are indebted to our indefatigable friend, Mr. Willison, of Whitby:-About ten or twelve years ago, when walking by the side of our high Whitby cliffs, I discovered this plant growing by the pathway. Apparently it might have been there for a century. With great pleasure I removed it to a more secure locality, where it was safe from a watery grare; for FEBRUARY - VOL. VI. 
what is very remarkable about this pretty little plant is, that after growing for so long a time in the place from which I removed it, in about ten days after, the plot of ground was carried away into the sea.

Hovey"s Seedling Verbena (A merican).-One of the finest whites yet raised. It is extremely pure, of good substance, beautiful habit, and the largest flower I have yet seen, each pip being the size of a shilling, forming a splendid conical truss, in fact, $a$ snon-white bouquet. Foliage strong and luxuriant, like Scarlet Defiance (its parent). If it blooms as well with you as with us, depend on it, money will be made of it.-American correspondent.

Seedling Caneldias are raised in America in great quantities. Our correspondent says, Mr. Hovey has eight or ten extremely fine and novel, one in particular, darker even than Rivers's George IV. rose, in form like the double white, fine thick petal, lasting till you are tired of looking at it.

THE POLITE GARDENER ON THE CHARACTER OF HIS BRIDE.

MY Kate, she bid me cull a flower, The best within the garden bower,

Which should herself describe.

A rose I sought, but roses fair,

Though born to deck her shining hair,

I felt could never half declare

The merits of my bride.

I brought in place a flower rare,

The pride of all the gay parterre, Gay Flora's golden cup.

Reluctantly Kate took my prize,

Regarding me with scornful eyes,

Yet seeming anxious to disguise

The tremour it call'd up.

A tulip's then the emblem true

Of her, she cried, who was to you

Once geritlest of her race :

I little thought these looks of mine,

You oft have praised, were near so fine!

So gay! so bold! - but truth sublime,

To you I must give place! 
O Kate! I cried, a tulip graind,-

Its points, did you but understand,

The rarest gifts portray:

O listen, then, nor pout thy lip,

From which the gods would gladly sip,

But let sweet smiles disperse full quick

That cruel look away.

A tulip, Kate, first you must know,

Is bright-eyed Flora's gayest beaux, And you're a florist's belle;

(A simile less trite than fine)

For Florist, sure, is masculine

For Flora, in the Latin line,

As all good classics tell.

But next, its form's an hemisphere,

And you are en bon point, my dear,-

Of circular outline:

Its petals, too, are stiff and stout,

Which all acknowledge hereabout,

Are merits which in you throughout

Particularly shine.

Again, when it's superbly good,

By florists all 'tis understood,

To be without a stain :

Though others err, and ill forget

How soon a character is let,

$O$ never has foul slander yet

Attacked my Kate's fair name!

But chiefest does the likeness hold,

In what we always have been told,

In a fair maiden's seen:

For both alike to gratify,

To warm the heart, and please the eye,

They each must have the quality

Of being pure and clean.

\section{R E V I E W S.}

Turner's (late Beck's) Florist, Fruitist, and

Garden Miscellany.

WE are sure that Mr. C. Turner makes bis debut with the good wishes of all who know him, and, with others of his friends, we most heartily desire his success. If the most successful florist in England cannot give instructions, and make a delightful and readable book, who can? If he does not succeed, no other person need try. 'The articles are well 
written. One particularly, on the culture of the hollyhock, will, we think, be highly esteemed. The illustrations are very good. The pink, Optimus, appears the ne plus ultra of this favourite tribe of plants; whilst Optimus pelargonium is as gorgeous as can well be conceived.

The Scottish Gardener, a Magazine of FloriculTURE AND Horticulture.

$\mathrm{W}_{\mathrm{E}}$ heartily welcome our north country friend across the border. Looking through its pages, we find several articles of sterling merit, and we feel confident that extensive popularity will be gained, if such are brought forward monthly. The floricultural articles are, On the Cultivation of the Auricula, by Mr. G. Lightbody, of Falkirk-Pansies in Pots, by Mr. C. Turner, Royal Nursery, Slough-On the Culture of the Cineraria, by Mr. E. A. Henderson, London-and are very excellent.

The Journal of the Horticultural Society of London. Vol. vii. Part 1.

THERE is a most valuable and interesting paper " $\mathrm{On}$ the Climate and Vegetation of the Temperate and Cold Regions of East Nepal and the Sikkim Himalaya Mountains," in which is a full description of the newly-introduced rhododendrons, \&c. "Mode of Heating adopted at Porthgwidden, near 'Truro." It is a combination of hot water pipes and open tronghs, and is said to answer admirably.

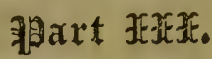

\section{QUERIES AND ANSWERS.}

If you will tell me, in your next number, where and at what price the Irish peat charcoal is to be obtained, you will greatly oblige

A Constant Reaner. 
We have an inquiry as to the merits of Heprorth's President (C.B.) and Superior (S.F.), the former stated to excel Jeniny Lind. Will our friend, Mr. Jonathan Jackson, or other friend in the neighbourhood of Huddersfield, inform us as to these flowers?

Will you state, in an early number, the best way of striking and dividing dahlia roots, where $n$ number are recinired?

\section{G. R., A New Subscrtber.}

I find in the answers to correspondents (vol. 5, page 281), that you mention Lord Suffield apple as being a very prolific bearer; and in your descriptive list of apples (pange 355 ), you do not mention the sort under that name, as worth or not worth growing. I should like to have your opinion about it; and also to know whether you have got a sort called Grenadier in your neighbourhood. W. M., A Constant Reader.

[We have other apples to allude to, as well as plums, pears, \&c. and Lord Suffield will be included amongst them. We hold a high opinion of its precocity and abundant bearing. We have not a sort called Grenadier. What is it like? Perhaps it is a synonyme.]

I am desirous of becoming a subscriber to the National Tulip Society; but before I subscribe, I wish to know if the southern system of class showing, advocated by Messrs. Marris and Dodwell, is to be adopted by that society, at their future shows. If so, I must decline subscribing to it, as I consider the northern system the best. For example, the southern system would allow three tulips to take (i.e. monopolize) the whole of the prizes, seventy-two in number, provided there were twelve flamed and twelve feathered of each flower, sufficiently good; when on the contrary, the northern system would allow only one prize to the best flower of each variety in its class; at the same time allowing seedlings to be exhibited with the old flowers. A better test for seedlings cannot be. It is better than a certificate of merit, as it gives the juvenile florist the exact worth of the seedling, from the rank it takes with the older flowers. The only improvement required, would be to disqualify all dirty flowers, and the aliases of every description. Then, in my humble opinion, it would be complete, and by far the best system of the two. Although I admire the northern system of class showing, I differ with them in what constitutes a flamed flower. The best specimen of flame is generally to be found in Holmes's Kring. A Southers Florist.

[We suppose that the Birmingham florists will state in their schedule how the flowers are to be shown. Then, we imagine, florists will subscribe, or not, as it meets their views, and according to the chance they may have of winning. Should the exhibition be held at Leeds, Liverpool, Manchester, 
York, Darlington, \&c. in 1853, the committee for that year may, if they like, establish such rules as seems to them best. In a few years, experience will settle the question, and we hope unity will then prevail.]

Spring is the best time to plant asparagus, just when it is be. ginning to grow. The roots will often rot, when planted in autumn, especially on cold and wet land. If the gentleman plants in March, he will succeed.

\section{CALENDAR OF OPERATIONS, \\ FOR FEBRUARY.}

GREENHOUSE.

Cleanliness should prevail in this department. All plants infested with scale, aphis, or other insects, should be carefully cleaned before they commence growing. Remove dead leaves as they appear, stir the surface soil, and let everything appear neat and clean at this dull season, when flowers are comparatively scarce. Give plenty of air when the weather is favourable, and occasionally light a fire, to expel damp, as this is a great enemy to many plants.

Cinerarias, calceolarias, pelargoniums, \&c. which have been kept in small pots during the winter, may be shifted on, using a generous soil ; let the pots be well drained, and clean, inside and outside. Fuchsias, which have been kept under the stages, in cold frames, or any other convenient place, during the winter months, may be shook out, roots and shoots pruned, and repotted in smaller pots; place them in the warmest part of the house, water sparingly until they have commenced growing freely. Fuchsia seed may be sown, also a few pots of mignonette, ten weeks stocks, nemophillas, schyzanthuses, Rhodanthe Manglesii, \&c. Water sparingly all plants except those which are showing symptoms of growth: these may be encouraged by repotting, and a more liberal supply of water. Where mats, asphalie felt, wooden shutters, or any other covering can be used, but little fire will be needed to keep out frost.

Derwent Bank, Derby. JOHN BAYLEY.

\section{FLOWER GARDEN.}

In fine weather, turn over the soil of those beds intended for grouping, that it may sweeten, and add a little thoroughly decomposed manure, where necessary. Fork over all beds or borders carefully, where there are herbaceous plants, bulbs, \&c. Increase such plants as are desirable by division at the root. 
If there are any patches of hardy annuals, they may be thinned. Prune creepers, roses, \&c.; nail or tie neatly such us are required to cover walls or trellises. Plant box edgings, lay turf, cut neatly grass edgings, and complete all alterations as soon as possible. Sweep and roll grass on fine dry days. Clean, turn, and roll gravel walks. Plant ranuuculuses.

\section{Derwent Bank, Derby.}

JoHN BAYLEY.

Carnations and Picotees. - The requisites for the successful development of these flowers are plenty of light, plenty of air, and plenty of attention. Add to this, that fine blooms are the result of a growth, progressing without a check from the first gentle movement to its culminating point, and I believe the amateur, experienced or inexperienced, has before him the whole mystery attending their cultivation. It will be my business to state how I endeavour to comply with these conditions in my practice, and whilst I do this, I shall be obliged if instructions are given to me how to improve it. Assuming the plants to have been healthy and well established when placed in their winter quarters, they will now be full of vigour, and daily give increasing indications of their spring start. To keep this growth healthy, and judiciously support the p!ant in the race it is now entering upon, must be our object. Let them be completely open at every favourable moment, and have any gentle showers which may fall from the south or south-west. Shield from heavy or cutting winds, but never quite close the frames, not even in frost. Calm cold is quite innocuous; not so keen frosty winds. Should severe frost be apprehended, let the plants have the protection of a mat or two, and keep them on until the thaw is complete, should Master Jack have reached the plants; don't, however, forget that air must be given, though light for a few hours is withheld. Continue carefully to remove every decayed or decaying leaf from the plants, and brush out any dust or other matters which may be lodged in the axils of the leaves. Let these be at once removed to their place in the compost yard, and not untidily cumber the ground around the frames, to the annoyance of every person possessed with a love of neatness, and to the great hindrance of surface draingge during wet weather. Promptly despatch any order necessary to replace questionable plants, or others needed to complete the collection, as getting them in at this time and in the autumn is a very different thing; and early orders only are likely to get attention; besides which it is almost certain death to the plant to subject it to the evil of travel, and (possibly) violent disrooting, when active growth has commenced. We have heard of cultivators who thought it a matter for congratulation that their loss through the winter was not more than six or seven in a hundred. We should think such an event a certain evidence of 
our inattention. The compost for hlooming should be at once placed in the potting shed, if not already there. Where this convenience does not exist, a temporary protection must be devised. None but a sluggard will have left his pots unwashed till this moment; but if not done, let them be forthwith attended to, and placed where they can be kept dry.

E. S. DodweLL.

\section{Derby.}

Tulips are peeping fast. We would advise an immediate covering of some light material, which will prevent the effects of cutting winds, and also be a good protection from frost.

Auriculas may be top-dressed towards the latter end of the month; but this should be performed with great care, as the fibres are apt to be seriously injured in loosening and removing the surface soil.

Polyanthuses, at this time of the year, often have the crown of the plant bare. The beds should be carefully cleaned, and a top-dressing of equal parts rotten cow or sheep manure and vegetable mould given. This will be found very beneficial to them.

Pinks and pansies require similar treatment, as a preparation for a more genial season.

Hollyhocks may he transplanted with safety, and towards the end of the month cuttings strike readily in gentle heat.

W. M.

\section{VEGETABLE GARDEN.}

The beginning of the month, make preparations for sowing onions. Dig in a good quantity of very rotten manure, leaving the soil in ridges, so that it may be levelled down when opportunity serves.

Those who have room, and are desirous of raising fresh sorts, should now sow rhubarb seed.

Early peas may be sown. Rub the seed with powdered rosin, before putting it into the ground. This will be found a great preventive of the attacks of mice. There are several early peas, very similar, and of little use as varieties. Perhaps the best are Warner's Early Emperor, Ringwood Marrow, and the Early Auvërgne.

Plant early kidney potatoes at the commencement of the month, and the main crop of Regents, Shaws, or Flourballs at the latter end.

Sow radishes and small salading in warm situations. Garlic too, where required, as it is by many foreigners, should be put in. Parsnips, spinach, \&c. should be sown.

Cucumbers should be kept in a brisk heat, taking care that a succession of plants is kept up, by sowing, \&c.

I. $\mathrm{H}$. 


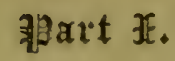

\section{ORIGINAL COMMUNICATIONS.}

RENARKS ON THE BEST NETHOD OF ARRANGING A TULIP BED.

W ITH your permission, Mr. Editor, I beg to offer a few remarks on the best and most effective method of arranging a tulip bed, which, in the opinion of so many devoted florists, so much enhances the charms of a good collection. I have been induced to make these observations at the present time, in consequence of the remarks of your experienced correspondent, Mr. Willison, of Whitby, on "grouping" colours in a tulip bed. I offer them not in a spirit of contradiction or controversy, but certainly with the hope of partly counteracting the effects of Mr. W.'s remarks on young amateurs, who are now forming and arranging their collections; and as they are written in the pure spirit of brotherly good will, I trust that they will be received with the same friendly floral feeling.

It was with much surprise and disappointment that I read the suggestions in question, as they turned my memory back over a period of about twenty years, when $I$ was a novice in floriculture, and when the good old fathers of our floral society used to point out with pride and descaut at length on perhaps halfa-dozen blooms of Count de Vergennes, huddled together in one place, four or five Triomphe Royales in another, as many Triomphe de Lisles in a third, and so on, to the end of the chapter. This was the happy period of the golden age in $\mathrm{my}$ floral life. "I Ignorance was bliss," and perhaps I am not singular in the feeling now, that it has sometimes been "Folly to be wise." But more of this anon.

MARCH-VOL. VI. 
Well! This system of planting continued general in the northern counties (and as Mr. Willison knows the Gateshead nursery, no doubt he has seen it there) till Mr. Glennv's luminous articles on the subject were disseminated through the floral world. No sooner were these read than enterprising amateurs saw at once what additional charms their beds would have both for themselves and their visiters, if the colours were CONTRASTED; and many immediately set abont a reformation of the old-fashioned system of planting in masses, which $\mathrm{Mr}$. W. recommends for the adoption of the young florist now, in this advanced age of floriculture.

But to plant a bed of seventy, or even thirty rows, in the regular arrangement of rose, byblœmen, and bizarre throughout, would be a most tedious affair, if the amateur marched out to his tulip ground on the planting day with his whole stock tied up in paper bags. He would most likely begin to plant himself, but he would require an amanuensis to write out his catalogue for him, as he planted row after row. He would go on from bag to bag, seeking different varieties, and bulbs of sufficient strength to rise the proper heights, till he grew weary and sick of the herculean task, and the probability is, that before he had got half-a-dozen rows arranged to please himself, he would give the matter up in despair, and fall back at once to the "grouping system."

Now the planting day should be a day of planting ALONE. Fvery bulb should be studied and arranged beforehand, not only as to colour and height, but also as to contrast. To do this, a tulip cabinet is indispensably necessary, and the amateur who is now forming a collection, should order such a cabinet at once sufficient to contain a bed of seventy rows. It ought to consist of seven drawers, each drawer containing ten rows, and seven bulbs in each row. Each drawer is thus divided into seventy little squares or compartments, the partitions between which should be of sufficient thickness to allow the name of the 
variety to be pasted on the top, and then the amateur can begin and arrange his stock as his fancy prompts him. One great advantage attends the pasting of the name of each variety on its square, as you can then read over your bed when taken up just the same as if you had them in bloom before you ; and if you should happen to lose your tulip book, your stock is still safely catalogued in your cabinet. Many a happy hour is spent during the summer season in looking over the bulbs thus arranged, cleaning them, altering a row here and there, introducing a new bulb, putting a heavily flamed byblœinen near a Holmes's King, or any such arrangement as is found necessary.

We shall now see that, with a stock regularly arranged in this manner, the planting becomes a very plain and simple affair. The amateur cautiously draws out his first drawer, walks deliberately to his tulip bed, plants his first ten rows withont trouble, and then returns his empty drawer to its proper place. He then takes out his second drawer in the same manner, and plants from the tenth row to the twentieth, and so on through the whole bed, without stop or difficulty.

Surely then the young and enterprizing amateur will not grudge the trouble of this first arrangement of his stock, which may last for years, except any little changes that he may think necessary, as he improves his stock from year to year. I must contend that a judicions arrangement of rose, byblœmen, and bizarre, throughout a whole bed, produces the most varied and delightful treat that is to be met with in all the various fields of floriculture; for in criticising a tulip bed, we must take one individual cup after another, and then, where can be the charm of contrast, if we are to stoop down and look over forty or fifty blooms all of the same colour and variety together? It is only the glorious mingling of the beauteons tints in the different classes that fills 
up the gorgeous picture which raises our admiration to the highest pitch, and teaches us to

$$
\text { "Look through Nature up to Nature's God." }
$$

Having trespassed so long on your space, I would only add, that a fresh tulip book should be made at leisure every year, copied from the cabinet, writing the names of the flowers on the left hand page only, and leaving the right hand one vacant for remarks, thus:

TENTH ROW.

REMARKS.

I Triomphe Royale ....... pure bottom, good cup, light flame

2 Addison..................., g.c., grand feather.

3 Duke of Northumberland. . p.b., g.c., grand flame.

4 Anastasia ................. g.c., fine dark ro. feather.

5 Lawrence's Friend .......p.b., g.c., dark f. and fl.

6 Polyphemus .......... p.b., g.c., light fl.

7 Lady Crewe ........... small, fine f.

This keeps a correct account of the different strains of the varieties in your possession, and is an interesting record to refer back to in future years. The following abbreviations may be used, as they occupy little space, and are sufficient to show the character of the different flowers:-p.b. means pure bottom, g.c. good cup, f. feather, fl. flame, l. light, h. heavy, d. dark, s. stained stamens, p s. pure stamens, \&dc.

I have been induced to trespass on your space, as I do not recollect any description of a tulip cabinet in the pages of the Midland Florist; and as I think it may be interesting to the young tulip collector, I shall be glad if you will give it an early insertion.

WM. HARRISON.

West Thirston, near Felton, Jan. 15, 1852.

\section{CLASS SHOWING.}

I HAVE been much intercsted on the subject of "class showing," that has been discussed in your admirable monthly during the pas: year, and I think that those 
able generals in floriculture, Messrs. Marris and Dodwell, have completely silenced the advocates of the extreme restrictive class showing system. But how far the system that they have advocated will meet the requirements of amatenrs and dealers, as exhibiters, is another question. Mr. Marris has recorded in your $\mathbf{J}$ uly number, that " the main question at issue appears to be this, and on its merits or demerits let it stand or fall:-W What is the legitimate purpose of class showing? Every unprejudiced mind must admit it to be the only sure method of testing seedlings singly, and to give full effect to the same, the best variety should be admitted in competition against them, unrestricted and without limit." I admit that this reads very well, but let us try it in practice. At the exhibition held at Derby, between the north and south cultivators, was shown a seedling scarlet flake, called the Duke of Devonshire, which carried away all the prizes in its class. What did it beat? In what estimation does it stand now? I believe none, for it has scarcely been heard of since. Again, at the Derby open show, last year, in the scarlet bizarres, Admiral Curzon took all the prizes, the first four prizes being taken by one exhibiter. Consequently, I, as an amateur, shall in future, only have occasion to grow Admiral Curzon, to win all the prizes in that class. Let the trade notice this particularly. In the same paragraph, Mr. Marris says, "This is no theory: the plan has for some time been practically carried out at Cambridge, where Headly's King James and Venus both monopolized a considerable portion of the class, and have they not realized the expectation formed of them ?" Let it be remembered, that at the same place, Don John made its first appearance, and out of twelve blooms set up for competition, it was awarded the first ten prizes in its class, and in consequence was sold out at two guineas per pair. $W$ as it the best flower of the day? Decidedly not: at the same time, Martin's Splendid and Gameboy were out; but the 
Cambridge exhibiters could only see Don John, and next season, at the Crown and Anchor Tavern, Strand, an exhibition open to all England, one bloom of Martin's Splendid beat a whole stand of Don Johns. I would ask, has Don John, under the "unlimited system, realized the expectation formed of it?"

I agree with Mr. Marris, that a young cultivator, with a few approved varieties, shonld have a chance in class showing, as well as those who grow a large collection. But I deny that the system he advocates will effect that object. 'Take the case of a young cultivator growing a few approved varieties of carnations, suppose he has got Admiral Curzon "well done," and in the pride of his heart takes it to Derby open show, thinking to take a prize with it,-in steps Mr. Marris with a dozen blooms of a first-rate seedling that he has not yet let out, in the same class, and carries off all the prizes. Would that be encouragement for a young cultivator? Yet I think it is much like the manner in which the system advocated by Mr. Marris would work, a system that can only benefit extensive seedling growers.

I will now lay before you a plan which I believe will be more approved of. It lias been worked by the Northampton society for some time, and has been found to answer well, giving satisfaction both to amateurs and dealers. We will call it the "intermediate system," to distinguish it from the others.

Each exhibiter is allowed to stage as many blooms in each class as he chooses; but not two blooms of the same variety. It might so happen by this arrangement that all the blooms placed in one class might be of the same variety, but they would be by different cultivators, and it would only go to prove the estimation in which that variety was held, besides testing the skill of each individual cultivator upon that particular variety. Suppose the best bloom on the table be Admiral Curzon, it shall take the first prize; if the same exhibiter can prodnce Lord Rancliffe, or any other variety, better than any other 
exhibiter can produce Admiral Curzon, or any other variety, he would get placed second, and so on to the end of the class. Should an exhibiter take all the prizes in a class, it would only be by different varieties. If an exhibiter can produce a superior bloom from an old or inferior variety, so as to take a prize in the class, he is as much entitled to merit as if he had produced a good bloom from a superior sort. By this system, a seedling taking the first prize in its class must be enhanced in value in the estimation of all amateurs, because it is clearly seen what rarieties it has beaten, and by what cultivators they were produced.

Newland, Northampton, Jan 21, 1852.

HENRY GOODALL.

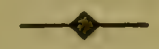

\section{CLASS SHOWING.}

\section{TO MESSRS. MARRIS AND DODWELL.}

Gentlemen,-I cannot admit the force of arguments which are advanced rather for the purpose of maintaining a simply assumed position, than of proving its propriety and advantages, and fully expected that if the public were to hear anything more on the subject of class showing, it would be illustrated in such a manner as to leave no doubt on the mind that the system, as at present practised, was injudicious as well as injurious to the true interests of floriculture. However, in this I have been disappointed, and find that you have, as it were by common consent, satisfied your minds by taking a simply negative course. In the following observations I will endeavour to place before you the proper consideration of the question at issue. In speaking of the tulip, a class is understood to mean all such varieties as come under the same denomination; and class showing to be a competition of those varieties; and in order to encourage the improvement of the classes, in the true sense of the word, that is in form, purity, and marking, the practice of giving prizes at our exhibitions to a certain number of the best varieties in each class was generally agreed upon as the surest means to that end. This method of class competition has, up to the present time, been almost universally acted upon, and with the most satisfactory result, for as new and improved varieties were introduced the inferior ones gave way, and thus by a method of encouragement at once simple and just, has 
floriculture advanced and improved, and as far as I can learn, to the entire satisfaction of all interested.

I will now take a glance at what may be termed Mr. Marris's proposed method of class showing, and if I fail to prove that it is contrary to the interests of floriculture and the practice of florists generally, it will not be for the want of means, but the ability to do it.

First then, I will suppose an exhibition at which it is announced that prizes shall be given to the ten best flowers in each class. How many varieties would any experienced florist expect to find placed as wortliy of a prize in the feathered bizarre class? I have no hesitation in saying that the whole of the prizes in that class would be awarded to one variety, and thus affording, as Mr. Marris correctly observes, an insurmountable barrier to the admission of second-rate seediings-nay, even a barrier to all other varieties. Is this the way to encourage the growth of seedlings, and consequently the improvement of the classes? I am quite sure that every unprejudiced mind will exclaim with me in the negative; and here I may repeat what I inserted in my last, that it would have the effect of throwing out of cultivation nearly all the present varieties, without the slightest chance of supplying their places with better. But it must be observed, if ever our exhibitions are thus paralysed, and reduced to a competition like the above, it is no longer class showing; it is a competition between flowers of the same variety, and not different varieties, which class showing implies. What I have said of the feathered bizarre class, is equally applicable to all the other classes. I have therefore no hesitation in saying that Mr. Marris's theory is new as far as my experience goes, and impracticable to any good result. I have not the remotest expectation that what I have said, or may say, will have the effect of altering Mr. Marris's opinion on the subject of class showing, for he emphatically adds that he is induced to contend more strenuously for the adoption of his plan, and urge more earnestly the removal of second-rate varieties. What Mr. M. may mean by second-rate varieties may to some appear vague; however, it seems to imply inferiority in some respect or other, without pointing out the degree; so that supposing a whole class were given to one variety, and that the best exhibited, still Mr. M. would be as far off as ever from accomplishing his purpose, inasmuch as that variety might be below the true standard, and therefore only second-rate. I must confess that the more I think about the new theory, and the regulations by which to work it, the more I seem perplexed. He then proceeds as if he had forgotten the invariable rule which holds at all exhibitions, and says "the opinions I promulgated were to the effect that any restriction preventing the best flower from winning in the classes, was mischievous in its tendency," \&c. Now, I am not aware that there ever was such 
a regulation, nor do I believe that any society ever had sucis a regulation as that of preventing the best flower from winning in the classes. If this be what Mr. M. means, and all that he means, our views are identical,- he retracts in January, 1852, what he published in July, 1851 ; but if he mean something different from what he here states, and that the same variety is to take all the prizes in the class, he will, in future, in vain look for that beautiful variety which characterized the great exhibitions, of which the one at Derby was the last.

And now a word with friend Dodwell, who puts this fair and sensible question, "Does the rule restricting judges to the placing a variety once only in its class, lead to the cultivation of secondary varieties, and is the cultivation of secondary varieties beneficial to floriculture ?" The answer to this question ought to contain the whole puint at issue. Mr. Dodwell must agree with me that the standard of perfection has not yet been attained, that there never was any specimen to which something ideal might not be added as an improvemer:t; it therefore follows as an indubitable fact, that varieties which are termed first or second-rate, are so only in degree, all falling short of that ideal perfection, which has been laid down for the regulation of societies, and sanctioned by florists of the most refined and enlightened views. Mr. Dodwell must therefore see that though the prizes in a whole class might be won by one variety, still (though first-rate compared with flowers of the same class) it might be second, third, or fourth-rate compared with perfection; and so the expression first-rate, according to Messrs. M. and D., means no more than the best of its class, and that all prizes shall be awarded to it so long as it continues so. But Mr. Dodwell seems to think that the allowing the same variety to win all the prizes in a class would not have a bad effect, that it would not remove from the stage flowers intrinsically interesting. But how does he come to this conclusion? If he knew to a certainty (for it is almost reduced to that) that it was quite useless taking any flower to an exhibition, but such as are termed first-rate, would he take those of second-rate pretensions simply for the trouble's sake and a little expense besides? I confidently believe he would not. In the next sentence, as if feeling that his position was untenable, he adds, "But should it still be questioned that an interesting variety would be absent from our exhibitions, what have we to do but to offer prizes for dissimilar varieties?" This is the true principle of class showing, and all that I contend for. I come therefore to the same conclusion at which I arrived in my former paper, that both Mr. Marris and Mr. Dodwell have published, without due consideration, opinions that cannot fail, if acted upon, to be injurious to the true interests of floriculture.

January, 1852.

RICHARD DIXON. 


\section{NOTES ON HOLLYHOCKS.}

Perhaps a few notes on what appears likely again to become a favourite flower may prove acceptable to some of your readers. I allude to the hollyhock, which, though some years past it was neglected for the gorgeous splendour of the dahlia, appears now to have regained public favour. I grew a few last season, and must say that I was highly pleased with the majority of them.

Chater's Queen of England is a noble flower, with stout wellformed petals; a beautiful deep rose. The centre is well up. This, I think, was the best of this colour.

Napoleon. - There are two of this name, but widely different in character. This one (Chater's) has large well-formed guard petals, buff and crimson, but is deficient in the centre; whilst the other, a Scotch flower, is very singular and pretty, a plum or purple colour, margined with white, the centre well up, double, and of good form.

Duke of Wellington, also a Scotch flower, was remarkable for its vivid and beautiful shade of light crimson. This is a most attractive sort, and very good.

Black Prince.-There are several varieties of the same name, Barron's and Gibbons's are both rich dark marone, nearly black, forming, with those previously described, a beautiful contrast.

Pitho.-Singular deep lilac shade; the guard-petals are large, too large in fact for the centre; nevertheless, it forms a nice contrast.

Miss Wedderburn is a fine variety of the rose class; guardpetals well formed, with good centre.

Model of Perfectron. - This is indeed a finely formed flower, creamy white, slightly shaded at the lower part of the petals.

Charles Barron is somewhat in the same style, shaded salmon, a very attractive sort.

Belladonna, which I had of you last year, bloomed well with me, and is a very desirable white; it flowers thickly on the stem, and there are few better.

Climax is a deep rose, with me rather more dwarf in habit than some others, but very pretty.

Formosa (Foulis).- Something in the same style, and wholly different from another Formosa, which is dark claret; a dis. tinct and neat variety.

I have several more which, though under different names, are very similar to others in the rose class; 
they have been raised from seed in distant parts of the country, and thus unintentionally cause confusion. Magnum Bonum (Barron) is a large and fine flower, glossy and dark.

Queen is a pretty rose, though apt to come out of character on poor land.

Watford Surprise (Long).-A beautiful and novel variety, splendid form, pure white, or nearly so, with a dash of purple at the lower part.

The above I grew in good style last season, and though perhaps no very great judge in such matters, I still feel confident they will please any person who may grow them. They should be staked early, placing a support to each spike. I gave mine occasional doses of liquid manure, which agreed with them very well.

JAMES SMITH.

\section{A FEW GOOD PICOTEES.}

I SEE there is a disposition in a certain nameless quarter to run down everything which comes from the midland counties, but I am glad to say that there are many, very many florists in Lancashire who admire the quiet and kind manner in which you have conducted the Midland Florist, during the past five years, and earnestly do we hope that you will continue your labours in the same style. I was in the sonth of England during last blooming season, at the house of a clergyman, who grows a very extensire collection of carnations and picotees; I also visited Mr. Turner's Nursery, at Slough, and in both these collections I saw most of the best flowers in cultivation. Your correspondent, Z . has described many of the sorts I saw there, but in looking over $m y$ notes, I cannot resist sending you the names of a few that I also thought particularly good.

Prince Arthur (Fellowes) is a delightful heavy-edged purple; large and of good substance. 
Grace Darling (Marris), raised I suppose by your correspondent at Leicester, is a fine bold broad-petalled flower, reminding one of Lovegrove's No. 5, alias Willmer's Princess Royal. It is a heavily-edged rose, and a decided acquisition.

Jeanette (Marris) was also very beautiful, I think the best of the two. It is not so full of petal as some, but it is very stout, and the heavy edging remarkably well defined. This also is in the rose class, and I am sure will be a favourite down here.

Duke of Rutland (Hollyoake).-This, I was informed, was also a Leicester flower. Very constant. I saw numerous pots of it, and the flowers were very similar in quality, heavy-edged purple, and evidently a first rate sort for exhibition.

Ganymede (Fellowes) has been before described in your pages, but it will bear talking about. The flowers were like waxwork, so stout, and yet so delicate; the margin, of deep purple, was well defined. In fact, it was a beauty!

Mrs. Norman (Norman). - A south country flower, of sterling quality, heavy-edged red. Fame had not belied this fine variety, undoubtedly one of the best heavy-edged reds in existence.

There was another heavy red which stood near it that I marked as XX, and that was

Costar's Christabel. - Grows very tail, of good form, and I am confident will be a favourite wherever shown.

I find that I also have

May's Ophelia marked as very fine. This really was a most excellent colour, dark purple, broad petal, and beautifully and evenly laid on.

I have some others, but they must do for another communication; and in conclusion, I will candidly say, that there is nothing so good as these let out or raised in this neighbourhood. I friend of mine, who resides a few miles from here, flowered some promising seedlings last year, but they were very late, and had not that attention given them which they required; the layers, however, did well, and I trust that he will be in a position to forward you blooms the coming season, that you may be enabled to compare them with the best sorts grown.

Manchester.

I. H. R. 


\section{PLANTS FOR MASSING.}

THESE beautiful additions to our gardens are now become an absolute necessity, and wondrous indeed is the variety produced by our seedling raisers. With these an amazing display of floral beauty is made in erery garden of any pretension throughout the kingdom. For our own part, we have a great predilection for the massing of colours, and we wish our friends who have not yet adopted the system would give it a trial. We have no doubt that many of our readers have small grass plots, with, most likely, a large bed in the middle, raised in the centre, and filled with a variety of plants, perennials, evergreens, and deciduous sbrubs, forming a most glorious intermixture. In the summer time, perhaps there is a perennial lupin near the verge, that overtops a mule pink behind it; or there may be a Delphinium grandiflora of three feet high placed before a potentilla of one, and the shrubs straggling here and there; in short, displaying no arrangement whatever. This great bed may have been planted years

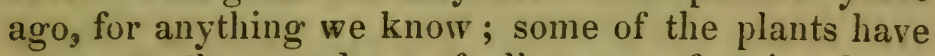
consequently spread out of all reason, forming large unmanageable patches. The bed too is so wide that it cannot be weeded without setting the feet on it to reach here and there; indeed, this great bed " is a great ugly thing." Now we think we hear some of our friends say, What shall we do? We reply, "Do" away with it altogether; and as your grass plot is "snuall," have a few "small" beds, "well crranged and rell filled," instead. We are not now talking to those who have lawns by the acre, but to those who may possess a square or oval of grass, ten yards by tell, or twenty, as the case may be. Instead of having this excrescence in the centre, which can only be approached by the female part of the family in dry weather, except at the risk of damp feet and their concomitants, we would have our beds in small circles, near the margin of the walk, but not all at MIARS:H-VOL. VI. 
the same distance, because that would appear formal. These beds should be two feet over. If the soil is not good, it should be taken out, and the space filled with appropriate compost. We do not say rich compost, because we have no notion of our hetiotropes, geraniums, \&c. making shoots like willows, and affording but little bloom. Their luxuriance is all well enough, but we have plenty of green on the grass plot, and we want flowers. We therefore advise the compost to be rather sandy than otherwise. Now suppose some of our friends have followed our advice, and have these nice little circular beds made, they will not be annoyed by anyone saying "Oh what a funny bed!" "W What a queer shape!" as when, in the simplicity of their hearts, they may have perpetrated a bed with as many sinnosities as a piece of ginger, or delighted themselves with the idea of having a facsimile of some uninterpretable hieroglyphic. No; not even when the bed is merely cut out, without a plant, and only the soil and rough edge of the turf to be seen, can anybody, with propriety, find fault with that which is perfect of itself. Mr. Glenny acted wisely when he took a perfect circle to be the standard of flowers; for though perhaps in some cases difficult to obtain, still it is a point beyond which we cannot go, being in itself perfection of form. So with our little beds. The next question is bow to fill them. We will talk first to those who may not have the means or wish to go to the expense of buying bedding plants at four shillings a dozen, though that is by no means an extravagant price. Well then, suppose there are twenty circles, some of them twelve inches from the margin of the grass plot, others twenty-four, we would keep those that are nearest for the lowest things, and we will see how we can make a beautiful display during the summer, for twopence each bed. We would advise our friends to go to the nearest respectable seedsmen, and obtain twenty packets of seeds at the above price. In most cases this would 
prove sufficient, for annuals are generally sown too thick. If the stalks of beans, cabbages, and other vegetables touched each other, to say nothing of the tops and leaves, no great produce would be expected, and it is equally essential that annuals should have room to develope themselves and show their beauty. Two pennyworth of seed then, we hold, would be amply sufficient. If the party accepting our advice would take the trouble of sketching an outline of his grass plot, and with a pair of compasses drawing twenty circles, he might then, to ensure the most agreeable contrast to his own eye, fill in the beds with various colours, red, blue, yellow, pink, dic. leaving two or more unpainted, to represent white. Thus he would have everything arranged to his mind before he committed the seed to the ground. Now if we were going to a seedsman, to fill ten of our beds nearest the edge, the first thing we should ask for would be Nemophylla insignis, a beautiful blue, with white eye. Then we should like Clarkia pulchella, with its singular and pretty pink flowers. The gaudy Escholtzia crocea, with heautiful foliage and bright yellow flowers, we could not possibly omit; or the other sort of nemophilla, called maculata, from the points of its petals having a large blue blotch on them. Then there is that beautiful showy annual with a singular name, Sphenogyne speciosa, buff, with a ring of black round the centre. For a very low plant, there is Nolana atriplicifolia, with neat blue flowers. Mignonette we must positively have for one bed, for though not remarkable for its appearance, still it is so general a favourite that a place it must have. Iberis umbellata (the Crimson Candytuft), and the White Rocket Candytuft, are two firstrate things for our plan, very showy; and Sanvitalia procumbens will also answer our purpose. For the beds that stand further from the verge we would have taller plants, and Convolvolus minor mist celtainly be one. The Erysimum Perowskianum, with rich orange blossoms, will form a fine mass; but the beauty of the whole would not be complete without a 
bed of scarlet Ten-week Stocks. Double Dwarf Larkspurs should not be forgotten, and the French Marigold too makes a beautiful clump. One or two of the beds might have neat wire trellises round them, removable in winter, and on these the beautiful Convolvolus major, or Tropœolum canariense, might be trained with nice effect. Collinsia bicolor would do very nicely, and Malope trifida, though full tall enough for the purpose, might be added; also Zinnia coccinnea, with large scarlet flowers, or in its place, mixed China Asters.

We have now mentioned twenty sorts of annuals, easily procurable, and of great beanty. We are certain that the adoption of the plan would prove highly satisfactory. In our next number, we will pursue the subject, with what are termed bedding plants, or those which have been wintered in frames or greenhonses, as it will be all in good time to procure them, and in the meantime our readers can make the necessary preparations for their reception.

\section{COPPICEANA:}

No. XX.

WE are happy to know that this part of our labour meets with the approbation of many friends, though we were somewhat amused the other day by seeing in reference to it the following question in print:"What have florists to do with oaks?" We hope that there are many, aye very many florists in the United Kingdom who can admire other beauteous. productions of nature beyond what are strictly termed florists' flowers. We should be sorry indeed were it not so; for, independent of the veneration that Englishmen have for what has been, and what must be, the chief defence of our insular situation, "The wooden walls of Old England," they (the oaks) have a picturesque beauty which we are sorry our kind hoarted critic is apparently unable to appre- 
ciate. Florists-true florists we mean-can estimate beauty of forin and harmony of colouring, whether in leaves of trees or petals of flowers. We hold a very high opinion of the influence which the cultivation of flowers has on the mind, though, it is true, there are exceptions to all rules. The next family growing here which we shall endeavour to describe is that of the Ribes. Under this head come the gooseberry and currant, but as it is only the ornamental with which we now have to do, we shall begin with

Ribes Sanguinea.-This very beautiful plant we believe was introduced from North America by the late David Douglas, to whom we are indebted for many beautiful plants and trees. We well recollect it being sold out at one guinea each for small plants. It had a great sale, and was nicely figured at the time in the Transactions of the Horticultural Society. Blooming, as it does, in early spring, its numerous pendent crimson flowers are very attractive. It certainly is one of the most gay shrubs grown. It is propagated easily by layers of the young wood, or by cuttings of the old, or it may be raised from seed, which it produces in great profusion. From this source several varieties have been originated. For instance, there is $R$. sanguinea pallida, with flowers paler, and $R$. sangumea atrosanguinea, much darker than the species. There is also a very nice white or cream coloured sort.

R. Sanguinea Alba.-This has precisely the same habit as the R. sanguinea, and contrasts beautifully with that sort. They ought to be grown together; or perkaps a curious bush might be made, if we took two young plants, the thickness of a goose-quill, and just above the ground, to a height of six inches cut away the wood to the centre in two long strips, then fit the edges together, bind with matting and plant; an adhesion would take place, and thus form one bush, and make: a " union" Ribes. It would have this advantage, too the amateur who had only room for one bush, would thus be able to enjoy the beauty of two varieties in the space otherwise occupied by one.

R. Sanguinea Flore Pleno (The Double flowering) has not realised the expectation formed of it. The bunches are short, and the colours of the flowers dull; they are, however, excessively double, and as a variety it is interesting.

$\boldsymbol{R}$. Beatonii is a shrub more diffuse in its habit than the preceding. From its character, it appears a hybrid, between the $R$. sanguinea and the $R$. aureum. The bunches are slender, and an intermediate shade of red and yellow. 
R. Grandiflora has a robust growth, with large mallow-lik: foliage. The flowers are produced in very long bunches: they are, however, green, and as far as colour goes, inconspicuous; still their large size renders it desirable in the mixed. shrubbery.

\section{RoBInIA.}

There are numerous varieties of this interesting family.

Robinia Pseudacacia was brought prominently before the public about thirty or forty years ago, as the Locust Tree, and under this fresh name many thousands were sold. It is a tree of fine foliage, bearing white pea-shaped flowers. The wood is said to be very durable, but the tree in a growing state is apt to be disfigured by high winds, in consequence of the brittleness of its branches.

R. Tortuosa. (The Twisted-branched Acacia.)-This is a most remarkable tree, the branches in many instances growing like corkscrews. The foliage is beautiful and massive. A tree well adapted for lawns.

R. Pendula. (The Weeping Acacia.) -Apparently a variety of the common acacia. This must not be confounded with the $R$. inermis, as its branches grow horizontally, drooping at the points. It requires to be grafted standard high, and then it makes a very ornamental tree.

R. Aurea.-This also is a variety of the species. The foliage, however, is bright yellow, thus affording a singular contrast to others of its family.

R. Bessonii. - A robust variety, with upright branches and stout foliage. Very distinct.

$\boldsymbol{R}$. Salicifolia. (The Willow-leaved.) - A very neat small-leaved sort. It forms a nice standard.

R. Hispida. (Rose Acacia) -A splendid shrub, seen to most advantage when trained against a wall. Its large bunches of béautiful pea-shaped blossoms are produced in great profusion, and certainly have a beautiful effect, materially heightened by its fine bold foliage. We have seen a plant reach to the top of an eight-feet wall.

$\boldsymbol{R}$. Inermis is a shrub in its natural state, but when grafted on the common acacia, it forms a remarkably handsome roundheaded small tree. It is grown extensively on the Continent, and if it were seen here more frequently, it would be appre. ciated as its merit deserves.

$\boldsymbol{R}$. Florabunda.-A variety of the R. glutinosa, having sticky branches. It flowers more freely, whence its specific name.

R. Umbraculifera.-A fine variety, with thicker branches and larger foliage than $R$. inermis. Like it, it requires to be seen to be more extensively planted. 


\section{羽art 狂E。}

\section{NEW, RARE, OR GOOD FRUITS, FLOWLPS, PLANTS, TREES, AND VEGETABLES.

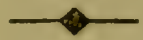

F R U IT S.

The Alberge Apricot.-This makes a first-rate preserve, but the fruit is small. Mr. Rivers says of this variety, "It is grown very extensively on the Continent, as far north as Belgium, forms a beautiful pyramid, and with annual root-pruning may be made a very prolific tree for small gardens, as such trees can easily be protected from spring frosts, by four stakes placed round them, a piece of calico being nailed to the top of the stakes, and calico being brought round and tacked to them, learing a space between the side covering and the top for the air to circulate. It is also well adapted for pot culture."

Several fine plums have been raised in Scotland, and we should suppose them to be of hardy constitution. Some have been previously noticed in our pages, but the following are new and of first-rate quality :-

Guthrie's Aunt Ann.-Green, mottled with russet when ripe; extremely luscious in flavour, and of large size.

St. Etienne.-Rather small, but of excellent flavour, and at the same time very handsome. Its colour is yellow, but deeper than most others. A foreign variety, lately introduced, but from its precocity worth inquiring about.

\section{HARDY TREES AND SHRUBS.}

Eugenia UGNi.-Another new evergreen, intruduced by Messrs. Veitch, of Exeter, to whom the floricultural world is so much indebted. The flowers 
are in the form of pendent bells, and are white, tinged with rose. The habit, foliage, \&c. bears some resemblance to the common myrtle.

Ilex Altaclarense (Urquhart).-This is a very beautiful addition to our ornamental hollies. It is not variegated, but has bold and very fine distinct foliage.

Cerasus Lusitancus Ormistonensis.-A very singular Portugal laurel. The leaves are rounder and smaller than the species. An interesting evergreen.

Ilex Balearica Variagata (The Minorca Holly) is a splendid evergreen, with large comparatively smooth leaves. A variety blotched with gold has lately been introduced from the Continent, and will make a fine addition to this popular class of shrubs.

Ilex Macrophylla.-A very fine evergreen oak, with broad and large leaves. Comparatively scarce yet, but will be much in demand when better known.

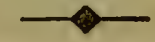

PERENNIALS.

Ranunculus Cortusefolia.-This very beautiful crowflower, or buttercup, is not quite hardy. The flowers are a peculiarly fine orange yellow, and two inches across. During severe frosts, some leaves or other protection should be placed over it.

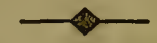

NEW BEDDING PLANTS.

Petunias.-As plants for bedding, we prefer the dark crimson varieties. Last year, we flowered Young's Crimson King most satisfactorily for this purpose. The contrast of its rich colour was well set off by its black throat. Grandis also, raised by Mr. Parsons, is well adapted for the same purpose; 
it is more inclined to purple than the preceding. Amongst newer sorts, there is Young's Ajax, a very large flower, fine rosy jurple; whilst for contrast and beauty of form, we can strongly recommend Parson's White Giant. Good white bedding flowers are comparatively scarce, this will therefore be found highly acceptable.

Mr. Smith, of the Tollington Nursery, Hornseyroad, Islington, London, is one of the most successful raisers of seedling verbenas in the country. We are glad to see that he stands up for " native production," as he offers to show his seedlings, during the corning summer, against all foreigners, for ten pounds. As this may appear a bold challenge, we shall give the names and colours of the varieties which Mr. Smith thus backs against "all comers," that our readers may see the advance made in this very beautiful tribe.

National. - Shaded red, splendid form, very large.

Virginius. - Very fine bluish purple, very large truss, pips large and circular, first-rate.

Orlando. - Lilac blue, very large, something like Mrs. Mills.

Purple Rival.-This, with the others, obtained a certificate of merit. White, with deep purple eye, very attractive. Alba Magna.-A very large fiower, extra fine form.

Eliza Cook. - A most excellent variety. Form first-rate, makes a large truss of purple flowers, with crimson eye.

Standard.-This is also a striking and distinct sort, nearly salmon-coloured, the centre pure white, surrounded by a darker shade.

Mr. Turner, of the Royal Nursery, Slough, has a beautiful variety, called Ormsby Beauty, to let out. This, we understand from Mr. 'Turner, is very distinct, colour bright rosy purple, with a white eye.

FLOWERS, ETC. RECEIVED SINCE OUR LAST REPORT.

R. S.-Your seedling hepatica is simply larger than the generality of single red ones. We would advise you to sow seed again from this. 
W. M.-Your polyanthus is out of season, and out of character. You say it was good last spring. Puil off the blossoms immediately, and we have no doubt your farourite will appear in its proper dress in due season.

W. S. M.-It is the Primula altaica, introduced from the neighbourhood of Constantinople, by C. Darbrishire, Esq. Rivington, near Bolton. It flowers abundantly and very early in the open ground, with us so early as the first of January.

T. W.-Your three very beautiful plants are, No. 1. Rhododendron dauricum. No. 2. Andromeda florabunda. No. 3. Daphne mezerion.

R. M.-Evidently a seedling from Rhododendron arborea. Unfortunately this class usually flower so early that late frosts destroy their beauty. We cannot say that yours is an improvement on existing varieties ; in fact, it wants more of the black spots in the throat, and rounder lobes of the petal, to make even a second-rate sort.

W. C.-The seedling apple grown at the Hermitage, near Hexham, Northumberland, is of a very handsome conical form, yellow, with stripes and blotches of red next the sun, and of medium size. It is of peculiar flavour, having a perceptible quincelike taste, which we should imagine would be desirable in a kitchen apple. We think it worth propagating for culinary purposes, and from its handsome appearance, it will doubtless prove a good market apple.

Cineraria.-Frances.-Pretty in colour, but we fear too narrow in petal to take a place with the improved varieties of the present day.

\section{EXTRACTS, HINTS, AND RECOLLECTIONS.}

I kNow the interest you take in all things floricultural, and therefore I know you will be delighted to hear that a floral reading and discussion society has been started here, on the suggestion of Mr. Joseph Lakin, who is elected secretary. The object of which is, the diffusion of knowledge on horticulture and floriculture, by means of reading, friendly discussion, and an examination of subjects, whether of flowers, plants, or vegetables, which its members are invited 
to produce "for general notice and criticism." At its last evening meeting, Mr. Naylor's remarks, at page 34 of your last issue, on "Tulip Judging in the Midlands," were read by a member, and it was the unanimous expression of the meeting (a large one) that the anomaly pointed out by Mr. Naylor was a most grievous one, and the lesson administered to us well deserved. It was just as unanimously the wish of the meeting that this should be publicly recorded; with it stating the regret felt, that $\mathrm{Mr}$. Naylor should have added to his remarks his feeling that had Edgar heen " a midland seedling, it would have been at the top of the class." Some little difference prevailed as to whether Sancta Sophia, stated to be, here, a pure strain of Washington, was or was not completely pure. It is evident that public attention has been recently excited on these points (questions of purity in the tulip), and a determined resolution to tolerate nothing short of absolute purity expressed. I trust this will show Mr. Naylor we are not the captions self-sufficient body of mien we have been described, but that we can feel the value of instruction, even when conveyed in the shape of reproof.

And now that I have my pen in hand, perhaps you will give me space to offer a word of censure and reproof to a "Southern Florist," who, at page 13, so far forgets what is due to himself and the gentlemen of the Birmingham committee, as to declare that if a certain system of showing be adopted, he shall not subscribe. I do not deny the right of the "Southern Florist" to decide for himself, or to offer suggestions to the Birmingham committee, but I do deny his right, and question the propriety, of his calling upon the Birmingham gentlemen to take a certain course, accompanied with a threat. Mr. Marris offered suggestions to the Birmingharn committee, but $\mathrm{Mr}$. Marris did not say, if you don't accept them, "I wont subscribe." I have no doubt the Birmingham gentlemen will give the threat the precise regard it is worth, and no more; but I deeply regret that any 
"southern florist" should have given utterance to such an undignified remark.

I do not propose to enter into a controversy with the gentleman, but perhaps I may be permitted to ask of him, where, after disqualifying all "dirty" flowers, "and the aliases of every description," he will find his seventy-two varieties, each of which shall be distinct, and with so much of "intellectual improvement" as shall make it "intrinsically interesting ?" Where also will he find the "juvenile florist" (query, read inexperienced) who can decide the exact "rank of the older flowers," and who, by consequence, is able to decide the "exact worth of a seedling?"

Derby, Feb. 9th, 1852.

E. S. DODWELL.

STRICTURES ON MR. WILLISON'S MODE OF MASSING COLOURS.

Your correspondent, Mr. Willison, writes in praise of massing colours in tulip beds, and describes his land of tulips with much fervour. That his method of field culture may save a great amount of labour is true, but surely he is not serious, when recommending his field practice to amateurs in general. Mr. W. talks of the great strides the "fancy" is taking, but assuredly the most remarkable stride yet taken is that of a tulip bed six feet in width. Now, for a moment, let us imagine thirteen flowers in a row, six inches apart, you want to see into the cup of a middle-row flower, what sort of a stride is necessary to accomplish this? The brazen Colossus alone could compass it. Again, let us look at the stage work necessary for protection, and without which tulips are never seen to advantage. Did Mr. W. ever witness the effect produced by a well-selected and well-arranged bed of tulips, as seen by the subdued light under a stage? I trow not, or he had 
never penned the article in question. Under the old regime all is harmony; the heights are well regulated, the colours blend even in the contrast, the golden cups of the one add lustre to the pearly whiteness of the other, while the black markings of some variety are beautifully softened by its rosy neighbour; the whole forming a glowing transparency, which is unequalled by any other of Flora's beauties. That a blaze of colour may be produced by massing, I do not deny, and it way be suitable to the surplus stock of large collections ; indeed, excepting the breeders, the plan is generally pursued in the south; but who wonld plant choice flowers in such a mass?

57, Elizabeth-street, Hackney-road, London.

H. WOLFE.

[Our friend, Mr. Wolfe, will see that it is yet, as it ever was, "so many mell, so many minds;" and though we may not think as others do, yet a candid opinion should be kindly met, and by fair and legitimate arguments, our endeavonrs should be to elicit the best way and the truth.-ED.]

\section{R E V I E W S.}

Turneris Florist, Fruitist, d Garden Miscellany. No. 50.

THE illustration is three beautiful epacrises, Rosea alba, Ingramii, and Elegans, raised by Mr. Ingram, of Frogmore. From MIr. Appleby's excellent paper on the cultivation of the above plants, we give the very judicious remarks on the soil most suitable for them. "The soil best suited for this handsome genus is peat. By this term the soil found in swamps, and often called peat, is not meant, we call that bog soil. The right kind is that found MARCH-VOL. VI. k 
on our moors, where the common heath thrives luxuriantly. This, mixed with a small portion of loam and leaf mould, and a liberal addition of silver sand, will suit them well. No one need attempt to grow them without this peat or heath mould, as it is sometimes called. They will grow in it alone, but not quite so well as with the above additions. The peat should be carted home, and put in a place where the sun and frost can act freely upon it. It should be broken up into fragments, but not so small as to approach a powdered state. Too fine a soil is injurious to them, excepting when very young. At the time of potting, a sufficient quantity shonld be taken from the heap, and all extraneous matters, such as large stones, living lumps of turf, or fern roots, or twigs of heath, all these may be picked out with the hand. By no means sift the peat, unless, as remarked before, for young plants. There is nothing so injurious to plants, heaths not excepted, as soil made too fine: it soon runs together in a solid mass, is then impervious to water, and becomes sour, and then destroys the young fibrous roots of the epacris, and in the end causes the plants to turn yellow and die." This is a fair sample of the style of the work, and it abounds in good and useful articles. There is also, A Plea for the Pansy-Seed Sowing-The Auricula-Fancy Pelargoniums, \&c. forming altogether a cheap shillingsworth.

\section{非art JEJE。}

\section{QUERIES.}

We are asked, can we give the genealogy of the Cradley Pet, S.F.? (Our correspondent means what raised from.) Will our friend, Mr. Wallis, kindly inform us?

We have a communication for $I$. H., who sent us a fine seedling S.B., from the neighbourhood of Halifax, for opinion. Will he kindly favour us with his address? 
Will you please give me, in your next number, a list of six or nine of the best and most esteemed varieties of carnations and picotees in each class, which will do well in the midlands? I have lately removed here from the west of England, and wish to commence their cultivation.

Coventry.

A. $\mathrm{H}$.

E. B., in the Scottish Gardener, for February, article-Chat about Tulips, says, Pilot, like all the rest of the Chellastons, "is narrow at the base." I was certainly surprised at this remark, for with all that can be said against the Chellastons for their sportiveness, and the immense number of bad strains which have been put into circulation, in which I heartily join, I was unprepared to hear that they are " narrow at the base," more especially Pilot, which I have repeatedly heard described as a very model of form. Will you oblige me by giving your opinion on this, and pointing out what flower is superior in the form of the base, so as to guide me in future selections? I have always considered it would bear a comparison with Hamlet, Musidora, Albion, \&c.

A Southern Florist.

Will you allow me, Mr. Editor, to ask you a question? I have noted the discussion which has taken place as to the merit or demerit of the restrictive rule in class showing, and I think the whole matter may be summed up in a line. We, here, have no class showing-that is, showing of single blooms-we are not, however, wanting in variety, nor are we supposed to be much behind the rest of the world as to our productions. I will suppose, then, the northerns dropped class showing. Would they, in such a case, put their Vestas and Dolittles into a stand with the slightest chance of success? If they would do so, this present system does no harm; if they would not (and I say they would not), then this system is bad.

\section{Another "Southern Florist."}

I shall feel much obliged by your noticing in the next number of the Midland Florist, the propagation of tree pæonies. If from seed, where can I obtain it? Where can I obtain seeds of the Camellia conchiflora, \&c., of the Cedar of Libanus and Deodar, and of other evergreens and flowering shrubs, and at what price? I should wish to raise some of them for myself, more particularly as the state of my finances will not allow me to purchase all I should wish to possess.

\section{A Mid-Staffordshire Subscriber.}

[In reply to our correspondent, we may observe that the tree pæony is propagated by grafting, by layers, by cuttings of the old wood, and from seed. We do not know where seed is to be obtained, simply because it is so rare that those who are fortunate enough to raise anv, will certainlv sow it themselves. A friend of ours has lately raised several seedlings from P. Banksia. Camellia seed is often advertised by the 
Continental nurserymen. Seeds of the Cedar of Lebanon and Cedrus Deodara may be obtained of the principal seed merchants in London. American tree seeds, consisting of raple, hiccory, liriodendron, \&c. can also be bought from the above-named parties; and we doubt not that rhododendron and azalea seed might be got from some of the extensive American plant growers in the neighbourhood of Bagshot and Woking.]

\section{ANSWERS TO CORRESPONDENTS.}

In reply to your correspondent G. $R$., relative to the propaga. tion of the dahlia, where a quantity is required, I send you the following plan, which $I$ have practised for the last three years, with great success. About the beginning of January, I plunge the dry roots into a forcing bed, of about seventyfive degrees temperature, giving water sparingly until they make a start. I then give it more freely, and in about four weeks, the cuttings are long enough to take off ; then bare the bud, taking care not to injure it. Put them into a pan of river or silver sand, well saturated with water, and plunge it into the same heat as the old roots, and in a week or two they will be sufficiently rooted for potting, taking care to employ soil of the same temperature as the house; and in about three weeks they may be hardened off for sale or otherwise.

W. C. N.

Carnations and Picotees.-Lady B.-The period of bloom varies very much with the state of the plant. If very vigorous, it will be much earlier than when weakly. The best early-blooming varieties in this locality are,-S.B.s, Omnium Primus (Kaye) and True Briton (Hepworth); C.B.s, Count Pauline (Holmes) and Caliban (May; ; P.B.s, Lady of the Lake (Hale) and Prince Albert (Puxley); P.F.s, Lord Byron (Taylor) and Premier (Millwood); S.F.s, Hero of Middlesex (Willmer) and Queen Victoria (Simpson); R.F.'s, Romeo (May) and Lorenzo (May). Picotees-Red-edged, Duchess of Sutherland (Burroughes), Ne plus ultra (Matthews), Mary (Dodwell), and Prince of Wales (Marris); Purple-edged, Beauty (Shaw), Portia (May), Prince Arthur (Fellowes), and Lady H. Moore (Turner); Rose-edged, Mrs. Barnard. Those which bloom late are-Lord Lewisham (Bunn), S.B.; Jenny Lind (Puxley), C.B. ; Rev. J. Bramhall (Clark), R.F.; and Duke of Devonshire (Barringer), S.F. There are but few late picotees-Green's Queen Victoria (heavy rose-edged) is of this class. All the above are fine growers. Add freely 
good fresh loam to the border they are to be planted in. The best and most select collection in the world is grown by Mr. Charles Turner, of the Royal Nursery, Slough. In the north, fine collections are grown by Mr. John Holland, Middleton; Mr. R. I. Kaye, Bury ; Messrs. Schofield \& Son, Leeds; and Mr. Benjamin Ely, Rothwell Haigh.

E. S. D.

W. D. and I. M.-Get your friends to join you, and obtain the following. You need have no fear as to your place in the town's competition. Jenny Lind, Faulconbridge, and Black Diamond, C.B.s. Picotees-Heavy red, Christabel, Giulio Romauo and Mrs. Norman; Light red, Mary; Heary purple, Duke of Rutland, Prince Arthur, King of Purples, and Lord Nelson; Light purple, Ganymede and Ophelia; Heavy rose, Grace Darling and Jeanette. These are the best of those coming out we saw last season. $\quad$ E. S. D.

W. C.-Your plants are evidently infected with the "spot," a deadly curse, when engendered. It is produced by overpotting, late-potting, loose potting, want of air, and excess of moisture, all which are evils of the most pernicious character. Remove the worst at once from the frame, and give air constantly to those left, standing the plants as wide apart as possible. Brush the plants clean, and cut off all the infected foliage. The remedy for this horrible plasue is to get the plants well established early in the autumn, well firming the soil when potting, and giving abundance of air at all times when in their winter quarters. Plenty of air cannot be given, if there be not plenty of space.

H.- The best scarlet bizarre of Mr. Kaye's is Lamartine. Splendour we saw extra fine in 1850 . We have not seen Magnet or Comet. The person referred to has not, and cannot obtain Mrs Norman. You must apply to Mr. Turner for Mary. We have no interest in it. The vituperation you denounce will but increase the sale. Will it be news to you that the person in question never has seen the flower, notwithstanding he informed the public, in 1850, that Mary was the best of its class? Reproaches from such a quarter are praise.

E. S. D.

T. B. asks are the spirits of seedling raisers dashed, because the highest honours were not awarded to them during the past season? Certainly not. A thousand things may have prevented their productions being properly seen, and amply justified the verdict of the censors; but we know, with such flowers as Duke of Rutland, Ganymede, Ophelin, Prince Arthur, Victoria Regina, Jeanette, General Monk, Faulconbridge, \&ic. the raisers may with confidence wait the verdict of the country; and as to what we may expect, why we hear, and from "sure hands," of fine S.B.s in the neighbourhood of Birmingham. The same from Halifax. Mr. Ely sends 
out one which is to distance our old favourite, Admiral Curzon; "Warrior" is to come from Lancashire; some fine things are in the hands of an esteemed friend of ours in this neighbourhood; Mr. Fellows has a batch, Mr. May a second; and to crown all, Mr. Puxley has a batch of sixty for trial, in addition to twenty first-rates waiting only for stock. Is there any room for despondency here? E. S. D.

\section{CALENDAR OF OPERATIONS,} FOR MARCH.

\section{GREENHOUSE.}

Every attention should be given to large plants of pelargoniums, calceolarias, cinerarias, and other specimens Let them have plenty of room, and be frequently turned round, that all sides of the plant may derive the same advantage from the light.

When water is required, give plenty, and let it be of the same temperature as the house in which the plants are growing. As the pots become filled with roots, weak manure-water may be given once a week.

Repot such camellias as require it, if they have done flowering, using two parts of good turfy loam, one part peat, with a little well-rotted manure, silver sand, and a good sprinkling of charcoal. Let the pots be clean and well-drained. As soon as the p!ants are repotted, place them in the warmest part of the house (or a much better situation for them would be a vinery, if at work), let them be frequently sprinkled over the foliage with a fine rose or syringe, give but little water at the roots until they have commenced growing, when it may be given plentifully. The young growth of creepers should be carefully trained in time, as much of their future well-doing depends upon the attention given to the young shoots.

Many New Holland and other hard-wooded plants will be about beginning to grow ; let them be well examined, and those requiring larger pots be at once carefully repotted. See that the ball is in a proper state of moisture; if too dry, soak it for a few hours in a pail of soft water, but be sure to let it drain well before potting. Use the compost in a moderately dry state, and pot firmly.

Many of the tender annuals are useful for decorating the greenhouse during the summer months, such as balsams, cockscombs, globe amaranthus, portulaccas, thunbergias, \&c. A sowing should be immediately made, where not already done. 
A small soning of the Chinese primrose may now be made, for flowering early. Give plenty of air in fine mild weather, early in the morning, closing the house while the sun is on it in the afternoon.

J. BAYLEY.

VINERY.

The buds in the late-house will now be about breaking; attend to disbudding in good time; directly you can see the fruit, remove the weakest and ill-placed ones. Keep a moist atmosphere, and the house perfectly clean. Give air on all favourable occasions, shutting up early in the afternoon.

J. BAYLEY.

\section{FLOWER GARDEN.}

More than ordinary diligence will now be required to get completed all alterations and such operations as have been hindered by the late excessive rains.

Anemones and ranunculuses, if not planted last month, should be done immediately the beds are in a fir state to receive them. Look well to stock; and if there is any deficiency, propagaie without delay such sorts as are wanted. Keep a sharp lookout for the greenfly, and fumigate immediately on its first appearance. Hoe and stir the soil amongst bulbous and other plants now above the ground. Plant out from the reserve border biennials sown last summer, and such herbaceous plants as were then propagated. Calempelis scaber, Tropœolum adureum or Canariense, Cobca scandens, maurandias, \&c., may be sown in large pans, and placed in a warm frame. Sow also plenty of Rodanthe Manglesii, for planting out in May. Abrut the middle of the month, if the soil is moderately dry and in gond condition, make a good sorring of the most showy hardy annuals ; in doing so, pay attention to the arrangement of their heights and colours.

Cuttings of chrysanthemums may now be put in. Dahlia roots, if not already put into excitement, should be lone as early as possible. Seeds should also be sown, and placed in a hotbed frame until up.

J. BAYLEX.

Carnations and Prcotees. - If the weather remain open, commence potting for bloom at once. The size of the blooms and anything like a considerable increase so entirely depend on the plants being well rnoted into the new soil before spindling, that we consider a much earlier potting out than has been generally practised in this district imperative. At the same time, to expose the plants to the cutting winds, severe night frosts, and frequent drenching rains which occur at this season, without any protection, is an almost certain method of rendering futile all the care which has hitherto been given to them. Some protection we consider absolutely necessary, and this we 
give by hooping over the plants, and covering them with Haythorn's hexagon net, which we have found most satisfactory, we therefore heartily recommend it. Commence of course with the strongest plants, give plenty of drainage, and well firm the soil as it is placed around the ball of the plant. When completed, cover the top of the soil with oyster-shells, small and cleau pebbles, or sniall pieces of charcoal; the value of such a procedure will be found as the season progresses. In turning out the plant, the utmost care must be taken to prevent the slightest injury to the root. We have seen plants dug from their winter quarters, put into a hole in the soil, or loosely placed in a pot, and then the pot having been gently shaken once or twice, the operation has heen completed. Such a course is simply barbarous, about as kindly as it would be to cut off a limb from a patient, and then remove him from a good shelter he had previously enjoyed. Some discretion is necessary in potting the different varieties, many requiring plenty of room, and others suffering from over-potting. Of the former class is, Alfred, Prince of Wales, Duke of Rutland, and Portia; of the latter, Garratt's King of Purples, Green's Queen, and Willmer's Princess Royal. Where one sized pot only is used, the desired result may be obtained by placing one, two, three, or four plants in each, according to the strength of the plants. Attend constantly to watering the plants, so long as left in the small pots.
Derby.
E. S. Donwell.

In the rose garden, perpetuals should be pruned, and the surface of those beds which contain clumps of roses be well mulched with rotten manure. Fresh beds may be made. Where stocks were budded last season, it will be necessary to remove the ligatures; and in cases where the bud has perished, the shoot operated upon should be cut close back to the stem, leaving a bud to make a shoot for a fresh trial next budding season. Ranunculuses should be planted immediately, if not already done; auriculas and polyanthuses top-dressed, and more water given; tulips netled over, and covered with mats if the frosts are excessive; and all out door operations, such as transplanting, forming edges, parting perennials, \&c., rapidly progressed with, whenever the weather is favourable. Look to hardy climbing plants, whether on walls, trellises, or on stakes. Cut out dead and superflnous wood, and nail or tie in, as the case may require. Turn over and prepare borders or beds, for the reception of half-hardy things in May. Make every disposition as regards the heights and colours of the things intended to be put in. It is a bad plan to plant by guess or chance when the time comes. Those flower gardens are generally most effective, the management of which has been previously well studied. 


\section{那art $\mathfrak{F}^{2}$. \\ ORIGINAL COMNUNICATIONS.}

LIST OF TULIPS.

I NOTED a few of the best tulips, which particularly took my fancy, during my stay in the vicinity of London; and if it will suit the pages of the Midland Florist, I will give four in each class, all of which I consider first-rate, and such as will please the midland growers.

Apelles.-A third-row flamed bizarre, feathered and flamed with a reddish brown, on a rich yellow, bottom and stamens pure, cup the Hardy standard. It stands well up, which gives it a finished appearance.

Guido. - A third-row flamed tricolor, of fine form. The marking on this tulip is what I call perfection; it is a dark brown, with a dense unbroken feather of the same colour. Cup good, bottom and stamens first-rate. My objection is its being a tricolor.

Lucullus (Clark).-A third or fourth-row flamed bizarre, strong leathery petals, cup above the average, bottom and stamens pure, of fine form. It is what I call a pencilled flamed bizarre.

Marcellus (Baron).-A pale lemon-coloured feathered bizarre, with feather nearly black, cup good, and stamens pure. Its place is in the first row.

Lord Bloomfield.-A third or fourth-row flamed byblomen, of the finest form, fine large cup, and stamens of extra purity. A real gem.

Othello (Battersby).-A second or third-row heavy-plated feathered bybloemen, the feathering nearly black; cup a shade above the average, but of transcendent purity. A gem of the first water.

Rubens.-A second or third-row flamed byblømen, flamed with a dark purple, and feathering nearly black ; cup.and stamens good. A good show flower.

Violet Quarto(Storm).-A fine fourth-row feathered byblomen, feathered with dark purple; cup and stamens of extra purity. A good strain of this is truly valuable.
APRIL-VOL. VI. 
Aglaia.-This is a second-row feathered rose, of superlative form, feathered with dark red about a quarter of an inch on each petal. It opens very creamy, but when well bleached, a superb flower. I have had fourteen or fifteen Aglaias, but none equal to this.

Countess of Blessington.-A second or third row feathered rose, cup and stamens of extra purity, and form first-rate; it is feathered with bright carmine, on strong leathery petals. A gem.

Dutch Ponceau.-A second-row feathered rose, of great purity, feathered with reddish crimson, cup short, and stands well. It has a fault in missing feathering round the petals; with this exception, it is first-rate. Scarce.

Rosina.-A first-row feathered rose, of great purity; the feathering is well laid on, and is nearly of the colour of Rose Lac. My root was unfortunately eaten through by a wireworm, and I have not been able to procure another.

Lucullus, Marcellus, Lord Bloomfield, and Countess of Blessington, perhaps, may be procured from $\mathrm{Mr}$. Nornan, of Woolwich, Kent. The others I cannot answer for.

Stony Stratford, Feb. 1852.

J. ORCHARD.

\section{BEST TULIPS IN EACII CLASS.}

Havivg asked for a list of six of the best tulips in each class, irrespective of new or old, high priced or low, from several of the principal growers in Britain,-in the first instance for a private purpose, but in the course of those applications, it having been suggested to me by some of the friends who have kindly acceded to my request, that it would be for the public good, were I to publish the returns, I therefore send them for insertion in the Midland Florist.

Now, as it is a declaration in man's infallible guide, "Holy Writ," that in the mouth of two or three witnesses every word may be established, and as I have obtained the witness of eight or ten of the most respectable and extensive growers of the tulip in Great Britain, to establish the claims of this list,it is true $I$ have not had returns from all $I$ could have 
wished, though some have liad the opportunity who have not contributed-it is, perhajs, as useful a list as any that has of late been published, either for the guidance of the young amateur, for whom it is especially intended, or for the no less advantage of the veteran florist.

I shall, therefore, without further comment, give the lists as I have received them, forming a table of the whole, showing at one glance what we may safely add to our collections, if we do not already possess them; that is, provided we can lay hold of a good strain, as nearly all our success in exhibiting, and vur satisfaction in growing the tulip, depends on this important point.

Floner-gate, Whitby, Feb. 1852.

$$
\text { WILLIAM WILLISON. }
$$

\section{MR. LIGHTBODY'S LIST.}

BIZARRES.

Phœnix (Headley), flamed Orion (Headlev), flamed Marshal Ney (Headley), flame. Everard (Bowler)

Polyphemus (Brown)

Crusader (Lightbody) BYBLEEMENS.

Salvator Rosa, feathered

Duchess of Sutherland (Goldhaw)

I hope the annexed will be considered satisfactory.

Dear Sir, yours most nbediently,

Falkirk, 10th January, 1852.

MR. HEPTON'S LIST.

\begin{tabular}{l|l|l}
\multicolumn{1}{c|}{ BIZARRES. } & \multicolumn{1}{|c}{ BYBLaMENS. } & \multicolumn{1}{c}{ Roses. } \\
Duke of Devonshire & David & Triomphe Royale \\
Polyphemus & Salvator Rosa & Momntain Sylph \\
Don Cossack & Musidora & Goldham's Maria \\
Charles X. & Superb en Noir & Camuse de Croix \\
Pilot & Thalia & Catalini \\
Aglaia & Vau Amburgh & Aglaia
\end{tabular}

My Dear Sir,-Enclosed you have the names of eighteen tulips, and I must confess I have been compelled to leare out 
several valuable acquisitions even to the most select collections, but you have my choice in those named.

Dear Sir, yours truly,

York, Jan. 12, 1852.

WiLLIAM HEPTON.

\section{MR. J. EDWARDS'S LIST.}

WACE COTTAGE.

Dear Sir,-In responding to your application, I do so most cheerfully. I have seen the following at one time or the other, in good condition.

Yours very truly,

London, Jan. 13, 1852.

JoHN EDWARDs.

BIZARRES.

Hamlet, or Polyphemus, or Ulysses, or Albion, and many other aliases

Duke of Devonshire

Selina

Fabius

Strong's King

Vivid

\begin{tabular}{|l|l}
\multicolumn{1}{|c|}{ BYBLGMENs. } & \multicolumn{1}{|c}{ Roses. } \\
Byzantium & Aglaia \\
Musidora & Bijou \\
Pandora & Lac \\
Princess Royal & Camuse de Croix \\
$\quad$ (Gibbons) & Triomphe Royale \\
Salvator Rosa & Dutch Ponceau tres \\
General Barnavelde & Blanc \\
&
\end{tabular}

\section{MR. SAMUEL BROMLEY'S LIST.}

FEATHERED BIZS. Duke of. Devonshire Surpass Catafalque Charles X. Lord Lilford

Cotterill's Elizabeth San Joe, or Apelles Sir Sidney Smith, or Magnum Bonum

FLAMED BIZARRES.

Polyphemus

Cbarbonnier

Donzelli

Garrick, or Shak. spere

Pilot (Gibbons)

Griswend's Morning Star
FEATHERED BYBS.

Gibbons's Maid of Orleans

Gibbons's Sable Monarch

Gibhons's Maid of Athens

Cotterill's Guido

Violet Quarto

Queen of the North FLAMED BYBS.

Gibbons's Princess Royal

Gibbons's Grace Darling

Gibbons's Queen of Violets

Bromley's Sable Queen

Raven Superb

Salvator Rosa

Bacchus
FEATHERED ROSES.

Heroine

Scarnell's Bijou

Rosy Gem

Rosy Queen

Cotterill's Mrs. Meynell

Naylor's Joan of Arc

Duchess of Suther. land FLAMED ROSES.

Triomphe Royale Aglaia

La Vandicken

Rose Camuse

Alexander du Roi

Slater's Kate Con-

nor 
Sir,-T hope this list, when compared with others, will affurd some information. I remain yours, \&c.

Macclesfield, Jan. 19th, 1852.

Sameel Bromley.

MR. DIXON'S LIST.

FEATHERED BIZS. Royal Sorereign Lord Lilford Magnum Bunum Hamlet

Ulysses

Inperator

Enterprise

Sphinx

FLAMED BIZARRES. Charbonnier Noir

San Joe

Polyphemus

Thomas Brown

Pilot

Shakspere

Pompe Funebre

Lord Collingwood

\begin{tabular}{|l} 
FEATHERED BYBS. \\
Lonis XVI. \\
King Robert Bruce \\
Maid of Orleans \\
Marmion \\
Violet Alexander \\
David \\
Incomparable Sur. \\
passant \\
Hereward \\
FLAMED BYBS. \\
Salrator Rosa \\
Thalia \\
Wallace (Brown) \\
Sarah Ann \\
Princess Koyal \\
Democrat \\
Napoleon \\
Lueen Charlotte \\
Superba
\end{tabular}

FEATHERED ROSES.

Bion

Lac

La Vandicken

Geraldine

Lady Jane Grey

(Gibbons)

Princess Maud

Maria

Dutch Ponceau

FLAMED ROSER.

Binn

Rowena

Heroine

Mrs. Dixon

Gem

Claudiana

Mozambique

Bijou (Scarnell)

Dear Srr,-Having given you the abure, I can have no objection to your publishing it.

Yours truly, RIChARD DIXon.

9, Bury New-road, Manchester, Jan. 19th, 1852.

\section{MR. HENRY GROOM'S LIST:}

\begin{tabular}{|c|c|c|}
\hline BIZARRES. & BYBLCEMENS. & ROSES. \\
\hline Duke of Devonshire & Addison & Aglaia \\
\hline arrick & Claude & Catalina \\
\hline arshal Soult & Michael Angelo & Claudiana \\
\hline $\begin{array}{l}\text { (Gronm) } \\
\text { Polyphemus }\end{array}$ & $\begin{array}{l}\text { Mentor, or Reine de } \\
\text { Sheba }\end{array}$ & $\begin{array}{l}\text { Countess of Wilton } \\
\text { (Groom) }\end{array}$ \\
\hline $\begin{array}{l}\text { Prince of the } \mathrm{Ne} \text { - } \\
\text { therlands }\end{array}$ & $\begin{array}{l}\text { Victoria Regina } \\
\text { (Groom) }\end{array}$ & $\begin{array}{l}\text { Duchess of Suther- } \\
\text { land (D.) }\end{array}$ \\
\hline William IV. & Violet Alexander & Emily \\
\hline
\end{tabular}

Sin,-Agreeably with your desire, I have marked six fine flowers in each class.

I am, Sir, your obedient servant,

Clapham Rise, Jan. 20th, 1852.
H. Groom.

\section{2}




\section{MR. J. F. WOOD'S LIST.}

FFATHERED BIZS.

Royal Sovereign

Polyphemus

Sir Sidney Smith, or Magnum Bonum Surpass Catafalque Earl Douglas (Delaforce)

Vivid (Saunders)

FLAMED BIZS.

Captain White

Polyphemus, or Hamlet (Brown)

King (Strong)

Pilot (Gibbons)

Charbonnier Noir

Caliph (Gibbons)
FEATHERED BYBS.

Maid of Orleans Kosciusko (Light- , body)

Snowdon (ditto)

Violet Alexander (Barr)

Chellaston Beauty (Gibbons)

Maid of Athens(do.) FLAMED BYBS.

Thatia

Queen Charlotte

Princess Royal

(Gibbons)

Salvator Rosa

Violet Brun

First-rate (Spencer)
FEATHERED ROSES.

Joan of Arc(Naylor)

Lady Clifton (Jackson) .

Heroine

Bion (Dixon)

Mary Iamb (Zuill)

Rbea Sylria (Dixon)

FLAMED ROSES.

Mountain Sylph

(Holmes)

Triomphe Royale

Aglaia

La Vandicken

Geraldine (Dixon)

Catherine (Gibbons)

Believe me very faithfully yours, \&c.

The Coppice, Nottingham, Jan. 19th, 1852.

$$
\text { J. F. WooD. }
$$

\section{MR. WILLIAM SMITH'S LIST.}

BIZARRES.

Surpass Catafalque

Charles X.

Polyphemus

Pilot, for shape exquisite

Captain White

Glencoe

$\mid \begin{aligned} & \text { BYBLGMENS. } \\ & \text { Buckley's Beauty } \\ & \text { Princess Royal } \\ & \text { (Gibbons) } \\ & \text { David, the best, but } \\ & \text { very tender } \\ & \text { Salvator Rosa } \\ & \text { Violet Brun } \\ & \text { Friend (Lawrefce) }\end{aligned}$

ROSES.

Triomphe Royale

Princess Maud

Cerise a Belle

Forme

La Belie Nannette

Heroine

Catalini

Dear Sir,-I enclose you a list of the best I have in my collection, that we may compare notes.

Yours respectfully,

Alpine Cottage, Darlington.

William Smith.

MR. WILLIAM WILLISON'S LIST.

BIZARRES. Surpass Catafalque King (Willison)

Napoleon

Polyphemus

Duke of Devonshire Charles X.
BYBLCEMENS.

Thalia

Maid of Orleans

(Gibbons)

Princess Royal (do.)

David

Queen of Violets

(Gibbons)

Sahle Monarch (do.) Heroine
ROSES.

Aglaia

Catherine (Gibbons)

Cerise a Belle

Forme

Claudiana

The Gem(Willison) 


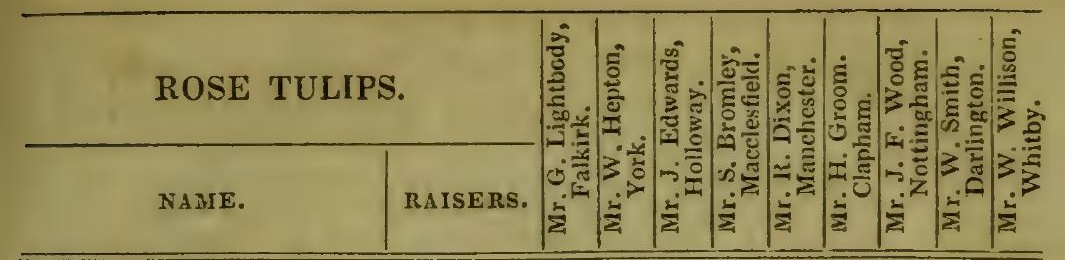

\begin{tabular}{lllllll|l|l|l|l|l|l|l|l|l}
\hline Aglaia & $\cdots$ & $\ldots$ & &. & $\ldots$ & $\ldots$ & $\cdots$ & 1 & 1 & 1 & $\cdots$ & 1 & 1 & $\cdots$ & 1
\end{tabular}

Alexander du Roi

Bijou

Catherine $\quad . . \quad$.. Gibbons

Camuse de Croix

Catalini .

Cerise a Belle Forme

Claudiana

Countess of Wilton

Duchess of Sutherland

Dutch Ponceau tres Blanc

Emily

*Exquisite

Geraldine

*Gem

Heroine ..

Joan of Arc

John Zuill

Kate Connor

Lac

La Belle Nannette

Lady Clifton

Lady Jane Grey

La Vandicken ..

Maria

Mary Lamb

Mountain Sylph

Mirs. Dixon

Mrs. Meynell

Mozambique

Princess IIIaud ..

Rhea Sylria

Rose Camuse

Rosy Gem

Rosy Queen

Rowena...

*Sylph .

The Gem

Triomphe Royale

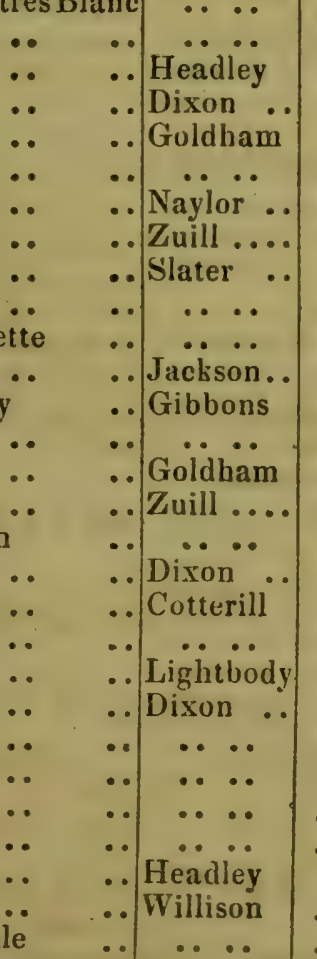

․

Dixon

-. . . .

$\cdots+\cdots$

$\because$ Groom

Groom . 


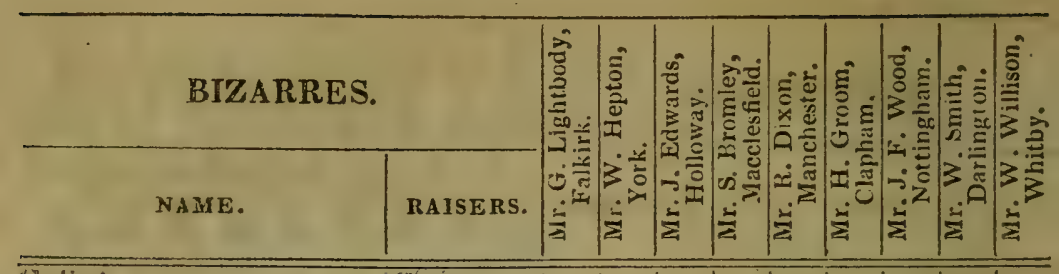

Caliph :.. ... ..Giobons

Captain White... ..

Chas. X. or Royal Sovereign

Charbonnier Nuir

Crusader.. ..

Cyclups ... $\quad .$.

Don Cossack

Duke of Devonsbire

Donzelli..

Earl Douglas

Elizabeth

Enterprise

Everard ..

Fabius

Glencoe ..

Imperator

King

*King

Lord Collingwood

I,ord Lilford

Magnum Bonum, orSirSid.Smith

- Marshal Ney

Marshal Soult ..

Mornirg Star ..

Napoleon

*Urion ..

*Phœnix.. ..

Pilot

..Lightbody

Pompe Funebre

Prince of the Netherlands

\section{$\mathbf{p}$}

Polyphemus ... .. Brown ..

San Joe .. . .

Selina

Shakspere, or Garrick .. Lairrence

Sphinx

Surpass Catafalque

Thomas Browu..

Vivid

William $\ddot{I V}$.

Dickson

..Delaforce

.. Cotterill

.. Buwler..

.. ....

Strong ..

..Willison

$\because \quad \therefore \quad \cdots$

Headley

.. Groom ..

.. Griswood

.. Headley

.. Headley

.. Gibbons

.....

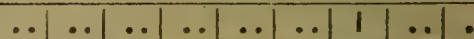




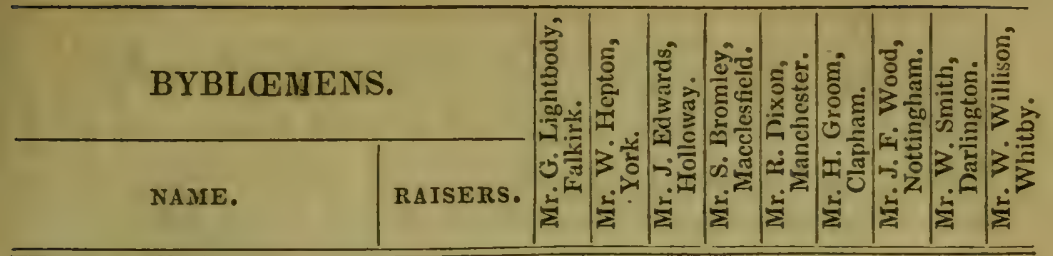

\begin{tabular}{|c|c|c|}
\hline Addison ... & . & \\
\hline Bacchus .. & & .. \\
\hline Beauty .. & .. & ..Buckley.. \\
\hline Byzantium & $\cdots$ & \\
\hline Chellaston & uty & .. Gibbons \\
\hline $\begin{array}{l}\text { Claude .. } \\
\text { David .. }\end{array}$ & $\cdots$ & .Groom ... \\
\hline $\begin{array}{l}\text { David .. } \\
\text { Democrat }\end{array}$ & $\cdots$ & 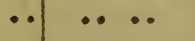 \\
\hline Democrat & $\because$ & $\because \quad \because \cdots$ \\
\hline
\end{tabular}

*Duchess of Sutherland Groldbam

First-rate

. Spencer..

Friend .. . . . . Lawrence

General Barnevelde

Grace Darling ..

Guido ...

$\because$ Gibbons

Hereward

.. Cotterill

Incomparabie Surpassant

*King Robert Bruce

Lonis XVI.

Maid of Athens..

Maid of Orleans

Marmion

Mentor, or Sheba

Michael Angelo..

Musidora

Napoleon

Pandora..

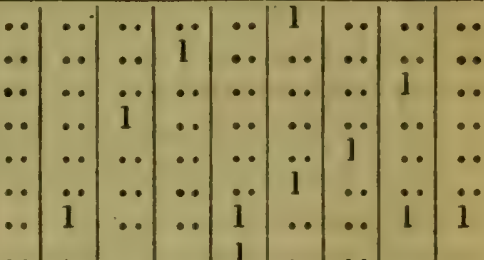

Prince Charles Edward Brown ..

Princess Royal ..

Queen Charlotte

Queen of the North

Queen of Violets

Raven Superb ..

Kosciuslso

Sable Monarch ..

Sable Queen

Salvator Rosa .

Sarah Ann

Snowdon

Lightbody

Superha ..

Superb en Noir..

Thalia

Van Amburgh ..

Victoria Regina..

Violet Alexander

Violet Brun

Violet Quarto

Wallace ..

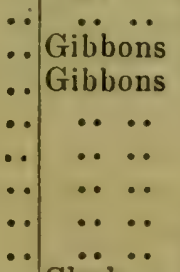

Clark....

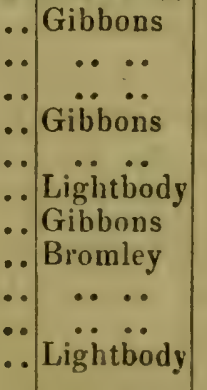

$\begin{array}{lllllllll} & \ldots & \ldots & \ldots & \ldots & \ldots & \ldots & \ldots & \ldots\end{array}$

$\ldots$

$\ldots \ldots$

$\ldots \begin{array}{lllllllll}\ldots & \ldots & 1 & \ldots & \ldots & \ldots & \ldots & \ldots & \ldots\end{array}$

$\ldots \begin{array}{llllllllllllllll} & \ldots & \ldots & 1 & \ldots & \ldots & \ldots & \ldots & \ldots\end{array}$

$\ldots \begin{array}{lllllllllll} & \ldots & \ldots & 1 & \ldots & \ldots & \ldots & \ldots & \ldots\end{array}$

$\cdots$

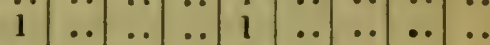

$\ldots \begin{array}{llllllllll}\ldots & \ldots & \ldots & \ldots & 1 & \ldots & \ldots & \ldots & \ldots\end{array}$

$\ldots \begin{array}{llllllllll} & \ldots & \ldots & \ldots & 1 & \ldots & \ldots & 1 & \ldots & \ldots\end{array}$

$\begin{array}{lllllllllllll}\ldots & \ldots & \ldots & 1 & 1 & \ldots & 1 & \ldots & 1\end{array}$

Brown

Gibhons

.. Groom

.. Barr

Brown 


\section{ON THE CULTURE OF THE BROCCOLI.}

BY. MR. J. H. KNIGHT, BATTLE.

Bring an extensive grower of the above esteemed and valuable vegetable, and being so far successful in its culture as to have it in perfection throughout the whole of the year, my experience may perhaps not be altogether uninteresting to the readers of the Midland Florist; therefore I venture to enclose the following observations, hoping they will be found useful and interesting.

To grow the broccoli in perfection, plenty of manure is required, as the plants, like all the other varieties of the Brassica family, require a large amount of nourishment to produce them in perfection. Liquid manure, judiciously applied during dry weather, and particularly for the summer and autumn crops, proves of very great benefit, as it keeps them cool and in a growing state, and tends materially to the prevention of premature heading, or buttoning, as it is commonly termed. But however rich may be the ground, and however great the attention given to the crop, vexation and disappointment will ensue, if the seed is not true, and saved under proper management; and indeed so great is the competition anong seed growers of the present day, that anxiety to produce an article at a certain price, has in nine cases out of ten resulted in bringing forth seed of inferior quality, and incleed it is difficult in many instances to obtain certain kinds true and genuine. The following, with the time of growing each, are the six sorts of broccoli which I find to answer the purpose of succession better than any others arnong the many varieties now in existence, all, or nearly all, of which I have grown. In point of succession, I will commence with the time when the August-sown cauliftowers have gone out of season,- - say the end of July, and throughont August and September. The best kind that I have found fur this purpose is Rendle's 
Improved Walcheren, which, to all appearance, is very little inferior to the finest cauliflower. To have this kind in succession thronghout the above months, a little seed should be sown in a warm sheltered situation, early in March, and again the second week in April, and under proper management, this cannot fail to produce a useful and valuable crop. During the time that this crop is growing, plenty of water should be given, to keep the plants in a healthy growing state, and mulching with short manure will serve to keep the ground about the roots moist and cool, which is the great art in producing close and firm heads. To succeed this, in October and November, the best kind is Hammonds's White Cape, the seed of which should be sown about the middle of A pril. To succeed this, in December, January, and February, the following sorts will prove the most useful:- Snow's Imperial White Cape, Grange's White, and Adams's White. For March, use Rendle's Improved Willcove; and for April and May, Elletson's Mammoth will be found most useful. 'I'he seed of all these should be sown about the first or second week in April.

Battle, Feb. 12tk.

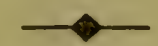

\section{CLASS SHOWING.}

Whatever may have been the feeling of the readers of the letter on this subject, addressed by Mr. Dixon to ourselves, in the last number of the Midland Florist, whether favourable or adverse to the views therein expressed, we believe these will be none who will not concede to the writer a thorough earnestness of purpuse. This earnestness alone is sufficient to entitle Mr. Dixon to a careful reading, and cunsideration, from everyone, but most of all from us, and this we certainly hare given to his paper.

Feeling, how ever, that Mr. Dixon bas utterly failed to show any cause for the retraction on our parts of the opinions we have adsanced, we think it right to state our reasons for such a conclusion, and having been addressed collectively, we think it will be most convenieut, and least trenching on the valuable space of the Midland Florist, for vur reply to be in that form. 
Mr. Dixon having informed us that he "cannot admit the force of arguments advanced rather for the purpose of maintaining a simply assumed position, than of proving its propriety and advantages," and his expectation that if he heard anything more on the subject "it would be illustrated in such a manner as to leave no doubt that the system as at present practised, was injudicious and injurious to the true interests of floriculture," and that in this he had been disappointed, we having taken a simply negative course, states,

Ist. That class showing is a competition of varieties, and in order to improve the classes in the true sense of the word, that is in form. purity, and marking, the practice of giving prizes at exhibitions to a certain number of the best varieties in each class was generally agreed upon as the surest means to that end.

2nd. That this method, up to the present, has been almost nniversally acted upon, and with the most satisfactory result, because as new and improved varieties were introduced, the inferior gave way, and thus by a method at once simple and just, floriculture has been advanced and improved, to the entire satisfaction of all.

3rd. Assuming an exhibition to take place, based on unrestricted showing, "the whole of the prizes in the several classes would be awarded to one variety only," thus affording "not only an insurmountable barrier to the admission of second-rate seedlings, but also of all others," and is this the way, says Mr. D. "to encourage the growth of seedlings, and consequently the improvement of the classes?" and continuing his remark, he says, "I repeat it would have the effect of throwing out of cultivation nearly all the present varieties, nithout the slightest chance of supplying their place with better."

Lastly. Granting that the answers to the "fair and sensible" question, "does the rule restricting judges to the placing a variety once only in its class, lead to the cultivation of secondary varieties, and is the cultivation of secondary varieties beneficiai to floriculture?" "ought to contain the whole point at issue," Mr. Dixon states, "that the standard of perfection not having been attained, there never was a specimen to which something might not be added ;" therefore it follows, "that varieties termed firstrate or second-rate, are so only in degree, all falling short of ideal perfection," and therefore, "though first-rate as compared with, others of the same class, as it may be second, third, or fourth-rate as compared with perfection, the expression first-rate means no more than best of its class."

We have thus given in a concise form the points on which Mr. Dixon founds the assertion, that we have "published without due consideration, opinions new and impracticable to any good result," and which "cannot fail, if acted upon, to be injurious to the true interests of floriculture," and if we fail to show that Mr. Dixon has promulgated this opinion without any sufficient warrant, it will certainly not be "from 
want of means, but the ability to do it." In commencing our remarks, we beg first cordially to express our appreciation of the desire shown by Mr. Dixon that the points at issne should be thoroughly understood-and though we had thought ourselves quite aware of what constituted "a class," we thank him for his definition. With respect to his first proposition we have also but little to dissent from, merely saying that that which has never been adopted by a large portion of the floral community, can hardly be said to have been "generally adopted ;" but granting that it were "generally" adopted, this is no proof of its soundness or propriety. We could readily instance many laws which hare been generally accepted, but which, with adrancing intelligence, have been still more generally discarded. This point, howerer, is one of little moment to contest. Witis the second point the case is widely different, and here we are totally at issue. Not to waste words as to whether it has or has not been universally acted upon, we emphatically deny that it has been followed with the "most satisfactory result," or that it is a system at nnce "simple and just," and one by which "floriculture has been adranced to the entire satisfaction of all." We say that it is not "satisfactory" to rerrard not only mediocrity but gross inferiority - that it is not " just" (however " simple" in one sense it may be) to expose the inexperienced to the danger of paying high prices for flowers greatly inferior to others of known character and standing-that a system which keeps a large number of varieties in cultivation, the majority being necessarily secondary, does not advance, but positively retards floriculture-and finally, that it has not been to the "entire satisfaction of all," our own humble protest, were it necessary, would be ample proof, but far beyond this, we point to the growing dissatisfaction as to the rule, the eminence of the dissentients from it, numbering among others, the editor of the Florist; and stili begond this, the stringent condemnation given to it by Mr. Wood, at page 260 of last year's volume of the Midland Florist, and page 231 of the volume for 1849 . Let Mr. Dixon, if he can, support his theory of "entire satisfaction to all" against a denunciation such as follows:- "There was also Rose Unique and Vesta, finely marked flowers, with Crown Prince and Lnstre de Beauties, and scores of others which we might name, that formerly stood high, but are now consigned to oblivion here, and if their names ever appear in a prize list, it is where a variety is allowed to win only once, thus keeping these old and worthless sorts before the public, dragging out a miserable existence in the latter part of a class, and affording their owners neither profit nor credit; and sure we are that this system very much retards the ouward course of perfection in florists' Howers." With respect to Mr. Dixus's assumption that the removal of the restrictive clanse would iustantly cause the whole number of prizes to be awarded to APRIL-VOL. VI. 
one variety, we have only to remark, that we are entirely at issue with him. So evenly are several varieties balanced in the majority of the classes of those flowers we are conversant with, that we do not believe it possible, certainly never probable, that at any exhibition open to a considerable body of competitors, one variety would monopolize ten places.*

But Mr. Dixon, continuing his assumption, says, "not only thus would an insurmountahle barrier to the admission of second-rate seedlings be created, but even of ALL oTHERS." "I repeat," says he, "it would bave the effect of throwing out of cultivation nearly all the present varieties, without the slightest chance of supplying their place with better." Is it necessary for us to do more than repeat these expressions, to convince every nne of the fallacies conveyed? Need we refer to the manifest contradiction implied in the assumed rejection not only of second-rate seedlings, but eren of all others? Have we,- that we are to lose nearly all our present varieties, without the slightest chance of supplying their place with better,-bave we, we ask, a finality in fioriculture? Has a Canute arisen, to say, thus far shalt thou go? or has the race of florists become so suddenly degenerate, that all are cuntentedly striving after mediocrity, hopeless of excelling that which yet is so secondary to perfection? We believe in nothing of the kind; we have an earnest faith in the many devotees of Flora, and a strong confidence in their perseverance. If intelligence and perseverance have accomplished much in the face of great obstacles, more will be realized when freed from the evil of rules which offer a direct preminm to the cultivation of inferior models.

We come now to the closing point of Mr. Dixon's objections, to his reply to the question described by him as "fair and sensible," and the answer to which " should contain the whole point at issue." What then is this answer? Not that the rule restricting judges to the placing a variety once only in its class, does not lead to the cultivation of secondary varieties (that is, varieties three, four, and five removes from the best known)not that the cultivation of secondary varieties is beneficial to floriculture; -on these points $\mathrm{Mr}$. Dixon quietly allows judgment to pass by default;- - but simply that as perfection never yet has been attained, the terms first-rate or second-rate, are sn ouly in degree, and though first-rate as compared with others of the same class, as it may be second, third, or fourth-rate as compared with perfection, so the expression first-rate means no more than best of its class.

A more utterly insufficient answer could not be imagined.

* But an instant and unfailing test may be applied to this speculation. If one variety will inevitably monopolize the whole of the prizes in the respective classes, of course the first prizes have hitherto invariably been tatcen by the same variety. (Of course it will be borne in mind no restriction has ever been applied to the first prize, it is only when that has been awarded, the winning variety has been refused a second place.) This has not been the case-so there is an end at once to Mr. Dixon's speculation and exclamation. 
Putting the argument into the strongest form for Mr. Dixon, be says, all varieties being secondary to perfection, all are secondary. This is neither logically nor literally correct. Mr. Dixon knows as well as we do that the degrees of comparison are as easily applied now, as they would be were perfection our superlative-he knows we have our good, better, best, and our bad, worze, worst-he expressly tells us we have rarieties first-rate as compared with others of the same class-he knows that if we had perfection, that would mean no more than the best of its class-be knows that between the best, which being "intellectually improved," is intrinsically interesting, and the worst, which is wanting in that "intellectuality," there is a vast difference-and he would know, if be would divest himself of that prejudice which be imputes to us, that to REwarD THE worse to the DISPLACEMENT OF THE BETTER, is neither consistent with good taste, good sense, or a regard to the adrancement of the flower. Will Mr. Dixon presume to contend that the advancement of the flower "in the true sense of the term, that is in form, purity, and marking," is secured by rewarding flowers imperfect in colour, ungraceful in proportion, and of scandalous impurity? To adopt the sarcasm of Mr. Punch, does Mr. Dixon think such a course "marks the superiority of the florist over the tasteful ignorance of the uninitiated?" Is it an "abundant cuurse for self-gratulation?" Because Mr. Dixon cannot see in unrestricted showing any prospect of seouring dissimilarity, he denies the possibility of its attainment. The justice of such a cause we will leave to others to comment upon. Many probably will remember how easily Columbus solved the simple problem, so impossible to the courtiers, of making the egg stand on end.

A few more brief remarks and we have done. When Mr. Dixon informs us, he "cannot admit the force of arguments advanced rather for the purpose of maintaining a simply assumed. position, than of proving its propriety and advantages," we know that he commits an unintentiunal error, as we know be will not impute to us that we have factiously supported a factitious proposition. Still it is due to ourselves to note and protest against the remark.

As to Mr. Dixon's complaint that we contented ourselves with a simply negative course, we have no inclination to cavil about words. We are, however, quite unable to understand how a course can be negative, which comprises a question, the answer to which "should contain the whole point at issne," and which shewed (and rather conclusively as we think, for our friend quite evidently shrinks from its iteration) the utter fallacy of his one great fact. True, our friend still insists that our opinions are new and impracticable, but it is no longer with the bold, unblenched front, which announced the astonish. ment of the "whole floral community;" and as our friend has awakened to the fact that the restrictive rule has excited the 
notice and obtained the condemnation of others far beyond our humble pretensions, and as we have in this a tacit acknowledgment that he had published without due consideration, may we not hope that with a little more reflection, and when freed from the perplexity which now encumbers him, our friend will take his place in the ranks of those who hold "that any system which keeps a large number of rarieties in cultivation, the majority being necessarily of secondary properties, cannot but be injurious, and tend greatly to postpone the adrance of the flower"?"

With reference to the assertion that class showing is an offering of prizes for dissimilar rarieties, we have simply to say, we have never yet seen it so stated in schedules, nor do we think it has been observed in practice. Names bave certainly been rewarded, but not distinct varieties. But this is worth nothing more than the passing comment that the purchase of dissimilarity, at the sacrifice of every primary property, is utter!y opposed to good sense. Dissimilarity, to be desirable; must coexist with form, and purity, and regularity of colour and markings.

Our remarks in reply to $\mathrm{Mr}$. Goodall must be very brief. We are duly sensible of the compliments he pays us on our victory, \&c. but he must really excuse our sayiug we cannot surrender victories for mere complinent.

Mr. Goodall sees only in unrestricted showing an exclusive benefit to the seedling raiser. Mr. Dixon denies the possibility of admission not only to second-rate seedlings, but even of all others. Mr. G. contends that because Don John was a failure (we dor't grant this, but there is no necessity for raising the question), and he has not heard of the Duke of Devonshire. unlimited showing must be an error. Now if $\mathrm{Mr}$. Goodall will turn to page 372 of the Midland Florist for 1851, he will find a sufficient reason for the privacy of the Duke-"Duke of Devonshire is a well-marked flower, of good average form, but late." We will not, however, cavil with Mr. G.'s premises. but we tell him that not one error of judgment, nor two, can invalidate a system. How many errors of the same kind have resulted under the restrictive system? We cannot regard the "intermediate" with the favour Mr. G. accords to it. We think it fundamentally wrong. Ist. Because it regards, rather a distribution of prizes, than the production of the better flowers. 2nd. Because it will evidently lead to the cultiration of many (so called) varieties, rather than a selection of the best. 3rd. Because it offers great temptation to persons of weak principle, to place one variety, in different stages of growth, under different names : a most pregnant source of evil. And lastly, because such restrictions inevitably tend to make exhibitions meager, and consequently unsatisfactory. Had not the "intermediate" something to answer for in this xay at the last exhibition of carnations and picotees, in Northampton? two 
flowers only being placed in five of the eleven classes, though three prizes appear to have been the minimum. Mr. G. will find at page 26 of the Midland Florist for last year, what Mr. Wood thinks of restriction. But Mr. G. seerns to think it a great bardship that one exhibiter should get five prizes in a class with one rariety, and calls upon the "trade" to note the effect of this. We really don't think the "trade" will be much disturbed by the fact, though the same result, so far as the flower is concerned, may take place uncler the intermediate system. But suppose the "intermediate" had obtained at Derby last year, the first and second prizes having passed to Admiral Curzon, the third might bave bees awarded to a seedling, which, as the event proved, was unequal to the sixth best Admiral Curzon.

We have said enough, and must now leave to an intelligent public to determine whether we have so illustrated the subject as to leave no doubt that the restrictive rule is injurious to the true interests of floriculture, - whether it be the fact that such a rule unduly promotes the cultivation of a large number of varieties, the majority being necessarily of a grossly secondary character, six, eight, and ten degrees removed from the best,and whether there be any truth in the testimony of our most eminent seedling raisers, our Becks and Hoyles, Mays, Matthewses, Puxleys, and Felloweses, that no advance will be obtained by seeding from an inferior parent. For ourselves, we beliere a modification of the rule is imperative, and that it is not our suggestions, but a perseverance in that which is wholly unsuited to the altered character of the times, which "cannot fail, if acted upon, to be injurious to the true interests of floriculture."

March, 1852.

ROBERT MARRIS. E. S. DODWELL.

\section{CARNATIONS.}

IN answer to the query in the February number, respecting Hepworth's President, \&c. I beg leave to hand you the following remarks on a few of the novelties that have come under my observation during the past season. First $\mathbf{l}$ will take the two varieties mentioned.

Hepworth's President.-Of this flower, the raiser, who ought to be a good judge, has a very high opinion. It is some. what in the style of Paul Pry, but decidedly an improvement 
on that old favourite; the colours are more brilliant, and the petals broader and smoother. The raiser, who has grown it three years, informed me that he had never had a bad flower from it. Whether it will beat Jenny Lind, time alone must decide; but, as she has been grown and shown here, it is a most decided beat on her.

Hepworth's Comet (not Superior) is a variety I think that will make some noise when more generally out. It possesses the finest of petals, good white, and the ribboning bold and brilliant.

Marsden's Ringleader (S.B.)-Now for a beat on Admiral Curzon. This flower has been submitted to most of the principal judges in the West Riding, and it has been pronounced by all to be a beat on the Admiral. They have been grown side by side two years together, and they have been exhibited together, and in every instance Ringleader has beat Curzon. It has a stouter petal than the Admiral, better white, the scarlet is as brilliant, the bizarre colour is blacker, and the stripes are more regular and boldier. It was let out last October, by the raiser, James Marsden, of Brighouse, the stock being only twenty pairs.

Netherwood's Companion (P.F.)-This promises to be a firstrate variety. It has a fine stout petal, good white, well ribboned with a rich purple. It has only been exhibited twice, and in each instance has been placed first in its class.

Jackson's Mr. Jepson is a flower somewhat in the style of Ely's Mango, or Milwood's Premier. It has a broad well-formed petal, beautifully ribboned with a rich purple. It is also a large flower, and will prove a teazer to many out.

I will now let you know the opinion of the florists here respecting the favourites of the midlands and the south. There must be some difference between our judgment and yours. For instance, May's Lorenzo was pronounced $A$. 1 of its class, and relying on the strength of the opinion given by your correspondent, "Z्Z." I applied to procure it, but I have been informed by different parties, that it is not worth the trouble of layering, -it has no character about it, either for colour, form, or marking. Jenny Lind, as I have seen it, no better; and what is worse, being a late variety, we cannot get it into bloom before September. 'The same with Dodwell's Alfred. Haines's Black Diamond is an unsteady variety, and I think it will be difficult to catch a good flower or so in a season. Such sorts as Ely's William Caxton, 
Summerscale's Nulli Secundus, Brierly's Music, Hepworth's Leader, and Yorkshire Hero, are far more admired here, because they are to be depended on: they are steady markers, and it is such we want.

GEORGE BAILDON.

Shrogg's Bottom, near Halifax, Feb. 1852.

[We think our correspondent should have grown Lorenzo. Its colour is pale truly, but in form, size, and narking, we think with " Z." that it is good. As we have said before, it is a difficult matter for florists to agree on every point.-ED.]

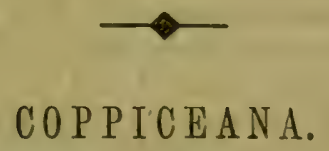

No. XXI.

The lilac is indeed a well-known shrub, - the common one at least,--and though called the Syringa vulgaris, or Common Lilac, we must not therefore suppose, that from being plentiful, it is necessarily unworthy of our regard. Its heart-shaped foliage is handsome, the flowers are produced in large and bold spikes, whilst its fragrance is almost overpowering. Our object is now to describe some sorts not generally known. New varieties from abroad are being constantly added to our collections; in fact, without the common surts, we grow twenty-two distinct varieties. Of these, the most desirable are the following :-

\section{Syringa.}

S. Saugeana.-A variety of the Siberian, with comparatively narrow foliage and slender flexile shoots. The heads of flowers are large, and produced in great profusion; they are of a reddish lilac, whence, in some gardens, it is called the Red Siberian Lilac.

S. Persica Alba.-Rather more delicate in habit than the preceding; the foliage is also narrower, and the flowers, which are creamy white, are smaller. 
S. Valletteana.-This we have flowered very finely. The foliage is stout and heart-shaped, the buds, during the winter season, very dark, and the flowers are not only large, but appear variegated, from the circumstance of the colour varying from rosy to purplish lilac. It is a distinct and well-marked variety.

S. Nana Alba. (The Dwarf French-white Lilac.)-This is shorter and more compact than most other sorts, with good foliage and white flowers.

S. Nana Rubra.-Similar in habit, but with reddish purple blossoms.

S. Emodi.-This is so different from all the other lilacs that few people not botanically acquainted with it, would suppose that it belonged to the family. The shoots are very stout and erect, and the foliage from six to seven inches long, by two and a half wide. The flowers are white, and rather small in proportion to the robust character of the plant. It ought to be in every collection of hardy shrubs.

S. Duchess de Nemours. - One of the most beautiful, having immense trusses of flowers, which are individually large, and of a delicate peach bloom, shaded with creamy lilac as they age; the trusses are produced in rich profusion; the foliage and habit of the plant are distinct and weli marked.

S. Vulgaris fol. Aurea Variegata.-This is the Gold-striped Common Lilac. When grown from layers it is very apt to run off, or degenerate, the foliage becoming green. The best plan for perpetuating the "sport," or variegation, is to bud from a variegated shoot, on a common lilac. The contrast of colour is very good, some of the leaves being exactly half green and half rich orange, whilst others are mottled or variegated with many stripes.

There is also another variety, the

Silver-striped, but the foliage of this is narrower, and is apt to twist and become distorted, independent of evincing a great disposition to become altogether green. We cannot say much in favour of this sort.

S. Jossike.-A singular dwarf variety, with narrow pointed foliage. The flowers are produced in erect pannicles, rather small, and of a dark purple colour. This plant is well adapted for the front of a shrubbery, its habit being neat and compact. It was discovered, we believe, in Hungary, by the Countess Jossikæ.

S. Prince Notger.-Very distinct, the flowers inclining more to blue than lilac.

S. Charles $X$.-A very robust variety, with large and compact spikes of flowers, inclined to dark red. This sort produces seed freely, and though very handsome in itself, we use it to bud and graft greater novelties on. 


\section{皳art 䄳。}

\section{NEW, RARE, OR GOOD FRUITS, FLOWERS, PLANTS, TREES, AND VEGETABLES.}

\section{F R U I T S.}

Purple Filbert.-The foliage is as dark as the purple beech, the husks of the fruit partake of the same character, and are highly ornamental for the dessert. 'The fruit itself is of excellent fiavour.

Belle Magnifique Cherry.-A most beautiful large cherry, something in the way of the Morello, but larger, and not quite so acid.

Even so far north as Nottingham, with judicious management and a proper selection of varieties, grapes may be grown with success on open walls. We have seen, last season, a large vine covered with ripe fruit. Amongst very hardy new early sorts, which appear to us adapted for this purpose, are the following:-

Pique Poule Noir.-This is a fine sort, very sweet, the berries above the average size, and of a nice purple colour.

Early Malingre.-A French variety, very early, and consequently a desirable wall grape. White.

Purple Fontainbleau.-A most excellent purple sort, bears most profusely.

Scotch White Cluster.-A very desirable white grape.

The sorts adapted for pot culture (and we do not see why one or two pots might not be grown in any of the small greenhouses of which we have so many in this neighbourhood) are,

August Muscat.-Of most excellent flavour, dwarf in its mode of growth, very prolific, fruit black.

Black Alicant. - A similar description may be given of this sort; the fruit is large and handsome. 


\section{PLANTS.}

Tigrida Canariensis.-Many people admire, and with much reason, the splendid 'Tigrida pavonia and Tigrida conchiflora. Little progress has been made in adding fresh varieties. Mr. John Morgan, of Torquay, however, is the successful raiser of the beautiful plant above named. It is bright yellow, gorgeously spotted with crimson. It will prove a valuable addition to our hardy bulbs.

Heliotropitu Voltatrianum Nanum.-Of extremely dwarf and compact habit, fine foliage and very prolific in flowers. Either for pot culture or for bedding purposes it will be highly desirable.

Jennings's King Pansy.-A very beautiful dark purple self, petals of good substance, and excellent in form.

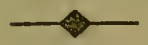

\section{VEGETABLES.}

Imperial Batavian Endivf.-All who are fond of salads (and who are not?) will appreciate this improved variety. It blanches remarkably well, and forms a fine solid heart.

Red Ash-Leaf Kidney Potato.-Bears well, and is very early and handsome.

The Reading Grant Broccoli.-We believe this fine sort was originated by Messrs. Sutton, of Reading, and we learn that linst season they exhibited a head which, when all superfluous leaves and the stem were removed, weighed seventeen pounds.

The Reading Giant Asparagus.-Good cultivation, and favourable soil and situation, most certainly have a great deal to do in the production of fine asparagus; but it is no uncommon thing for bunches of one hurdred heads to weigh twenty-five pounds. 


\section{THE EDITOR'S RECORD.}

"These things we would buy ourselves, and therefore recommend them."

WALKER'S RUSSET.-This is a seedling, raised by Mr. Walker, of Packington, near Ashby-de-laZouch, Leicestershire. The fruit is conical, one side covered with russet, and the other rich bronzy red. It is what would be termed a first-rate market apple, for independent of its other excellent qualities, the fruit is now (Feb. 2lst) perfectly sound and in good condition. It has to us a peculiarly grateful flavour, partaking in some degree that of the quince. It bears profusely and in a young state; added to which its growth is upright and luxuriant, a point of considerable importance.

\section{EXTRACTS, HINTS, AND RECOLLEC'IONS.}

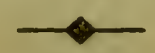

NOTE OF FINE TULIPS,

BLOOMED LAST SEASON, BY MR. GEORGE LIGHTBODY, FALKIRK.

[From the Scottish Gardener.]

Bournonville.-Pure, with rich black feather.

Irlandois. - A fine cup, and feathered with rich purple.

Groom's Claude.-Very prettily feathered, but rather long in shape.

Eveque d'Amboise.-Very rich flamed byblœmen, but slightly specked in the base.

Kosciusko (Lightbody) was very fine. There was one with a very rich hlack feather, others were flamed.

Zuill's George Glenny has a fine shape, quite pure, with a beam through each petal, wanting feather.

In roses,

Dixon's Bion.-Heavily feathered.

Dixon's Virginia. - Lightly feathered, inclined to be creamy.

Jeffery's Elizabeth.-Rich colour, and beautiful flame, rather narrow in the cup.

Lady Colville.-Flamed, truly a beauty. 
Mr. Lightbody bas three seedling byblœmens of surpassing excellence.

Snowdon-A dark, almost reddish brown feather.

Ceour de Lion.-Fine in colour and form, pure, and a noble fourth-row.

King Robert Bruce.-A brown purple feather, on a pure white ground.

Pandora, south country flame, was also well done.

Everard was first-rate in colour, form, and purity, though a red flamed bizarre.

Pilot is described as a finely-marked bizarre, but narrow in the base. This, we confess, we were not prepared to see; and the petals of nearly all the Chellaston seedlings are said to be twisted!

Crusader.-A seedling, marking like Polyphemus, but shorter in the cup.

To Preserve Carrots from Wireworms.-As the season has now arrived when most gardeners are preparing ground, by "digging and trenching," for different sorts of culinary seeds in spring, I would recommend those who have lately failed in the culture of carrots, to adopt the following mode, which I have seen practised with success, and which, I have no doubt, will be found a preventive against the wireworm. Trench the ground two spades deep (throwing it up in the ridge manner), allow it to remain so until the time that it is prepared for the reception of the seed, then level the ridges and give them a very slight cast of pigeon's dung all over, which should be pointed and worked well into the ground; sow the seed, and cover it in the usual manner; afterwards top-dress the ground with sand, well saturated with spirits of tar. By so doing, I am sure that those who adopt the plan will, when the plants are taken up, be gratified to find that the roots will not present the slightest trace of the wireworm. This I have seen practised more than once, and the result always proved satisfactory. The quantity of spirit of tar used was a gallon and a quarter to every eighty square yards.-A Ross-shire GarDENER, in the Gardeners' Chronicle. 
We see that the great national or northern tulip show, which is this year to take place at Birmingham, will be held in the town hall, on the 27th of May. From the spirit manifested, as well as the central situation of the town, we have no donbt there will be an immense gathering of florists. We have just seen the schedule of prizes, and we must here record our unqualified approval of the liberality with which the committee have devoted fifty pounds and upwards to rectified tulips only, as well as their adopting a class for simple beam or flamed flowers. Evidently they are desirous of reconciling conflicting opinions, and we trust that the plan will have a fair trial ; and as we know that many northern as well as midland growers have flowers of this description, we hope to see a strong contest in this class, as well as in the others. Let us hope that florists will make no delay in forwarding their subscriptions to $\mathrm{Mr}$. Job Cole, 28, Bennett's Hill, Birmingham.

Prizes For $W_{\text {ax }}$ Flowers. - We have lately seen many very beautiful specimens of flowers manufactured in wax, and as this art is becoming very fashionable and much practised by ladies, we think that at our floral exhibitions, not the least attractive feature would be a competition amongst the fair sex for an appropriate prize offered by the society. For instance, we would have single specimens, and also groups of six flowers. These should be staged the same as natural productions, ard judged by the same rules. The prize being awarded to the most perfect imitation, of course it would be advisable that " professors of the art" should compete together, and the lady amateurs separately. The national tulip show, to be held at Birmingham, would be a good time to try the experiment, and we think the bachelors of the neighbourhood would display their gallantry by offering a series of prizes to be competed for by their fair countrywomen. We have not the slightest doubt that this adjunct to the attractions of the day would be highly and deservedly appreciated. 
Allow me to correct what would appear to many of your readers to be an error, in the February number of the Midland Florist. In an article headed Tulip Judging in the Midlands, it would appear, as there stated, that I meant to say Washington and Sancta Sophia were the same sort. Now I did not say so, but that the Sancta Sophia shown at Derby and Nottingham was nothing but Washington,--the the true Sancta Sophia (Dixon's) being a distinct and superior sort, with better cup, and pure bottom and stamens; the colour darker, almost approaching to black, marking something in the style of Duc de Bordeaux.-JOHN NAYLOR.

\section{R E V I EW S.}

The Scottish Gardener, a Magazine of FloriculTURE AND Horticulture.

No. 2 is brimful of horticultural and floricultural matter. The articles comprise treatises on British Plants as Subjects of Cultivation-Protection of W all Fruit-Chat about Tulips-Street Gardens-Strawberry Forcing, \&c. These are only a few of the numerous valuable papers which grace its pages. If carried on as it is begun, and of this we have no reason to doubt, it will take a prominent position in the garden literature of the day.

British Pomology. Parts 3 and 4. By Robert Hogg. London: Groombridge \& Sons.

$W_{E}$ have previously noticed this very interesting work. The two parts now before us give evident proof of the research and painstaking of the author.

Taking great interest ourselves in all that pertains to orchards and their produce, their perusal has afforded us unmixed satisfaction. One sort described carried our mind vividly to "scenes gone by" many 
years. We allude to the Isle of Wight Pippin, mentioned at page 117. We used there to call it the Orange Pippin, and can add our practical testimony to its excellence. It is a small apple truly, but quite first-rate as a dessert fruit. Mr. Hogg says of it, "This is a very old variety, and is no doubt the Orange Apple of Ray and Worlidge. According to Mr. Knight, it is by some supposed to have been introduced from Normandy to the Isle of Wight, where it was first planted in the garden at W rexall Cottage, near the Undercliff, where it was growing in 1817 . There are several other varieties of apples known by the name of Orange and Orange Pippin, but they are all very inferior to this." -There are several other apples we have marked-Harvey"s Wiltshire Defiance, Pope Apple, Striped Beefing, \&c. but for further information, we most cordially refer our readers to the work itself.

The Garden Companion and Florists' Guide. Part 2.

IN this number there are two plates, one of a beautiful spike of Wellington Gladiolus, and two blooms of Von Gagern and Prince Albert, Dutch varieties of the same flower. The other is Ipomea palmata, a beautiful new climbing plant from Australia; and Dillwinia scabra, from the same locality. The chief articles of interest are, On the Hybridization of Plants-Glazed Promenades and Glass W alls--The Sikkim Rhododendrons, \&c.

The Faruer and Cottager's Guide. By Alizemiler Campbell. London: Groombridge of Sums. For allotment farmers this book will prove wi quisition. Labouring men do not usually lind -. much time to read as we wish they had. Here thich we have the pith and marrow of good cultivation written in an easy and unpretending style, ani much compressed, that its contents might everi learnt by heart in a short time. We think wouka in? 
this kind are calculated to do immense good, and we are glad to see that this is the fourth edition, revised and enlarged.

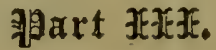

\section{QUERIES AND ANSWERS.}

Can you, or any of your correspondents, tell me, through the medium of the Midland Florist, the name of the yellorr picotee, a drawing of which is given in the fifth edition of Hogg's work on the carnation?

C. W.

Carnations and Picotees. - A. H., Coventry.-The following we think the best of those out, in their several classes :SCARLET BIZARRES.

Admiral Curzon (Easom)

Bardolph (May)

Bolingbroke (May)

Duke of Sutherland (Elliott)

Lord Lewisham (Bunn)

Lord Rancliffe (Holliday) CRIMSON BIZARRES.

Black Diamond (Haines)

Duke of Bedford (Ely)

Duncan (May)

Horsa (Puxley)

Jenny Lind (Puxley)

Lord Milton (Ely)

Lamartine (Kaye)

Prince Albert )Puxley)

Sir Robert Peel (Broughton)

Splendid (Martin)

True Briton (Hepworth)

$$
\text { PINK OR PURPLE BIZARRES. }
$$

Faulconbridge (May)

Henry Kirke White (Taylor)

Princess ('Taylor)

Prince Albert (Puxley)

Sarah Payne (Ward)

PURPLE FLAKES.

Beauty of Woodhouse (Mansley)

Earl Spencer (Barringer)

Lord Byron (Taylor)

Mayor of Oldham(Hepworth)

Cradley Pet (Wallis) SCARLET FLAKES.

Duke of Devonshire (Barringer)

Firebrand (Hardwick)

Hero of Middlesex (Willmer)

Perfection (Puxley)

Premier (Milwood)

Squire Trow (Jackson)

Squire Meynell (Brabbin)
Queen Victoria (Puxley)

Thomas Hewlett (Holliday)

Vivid (Hepworth)

William IV. (Wood) 
ROSE FLAKES.

Antonio (May)

Ariel (May)

Flora's Garland (Brooks)

Lorenzo (May)

Lady Ely (Ely)

Lady Gardiner (Ely)

Lovely Ann (Ely)

Madame Sontag (Puxley)

Princess Royal (Puxley)

Romeo (May)

PICOTEES.

RED-EDGED-LIGHT.

Duchess of Sutherland (Burroughes)

Ernest (Edmonds)

RED-EDGED-HEAVY.

Christabel (Costar)

Elizabeth (Robinson)

Giulio Romano (Fellowes)

Hogarth (Marris)

Isabella (Wildman)

Gem (Youell)

Mary (Dodwell)

Miss Holbeck (Kirtland)

| King James (Headley)

Mrs. Norman (Norman)

Prince of Wales (Marris)

Sebastian (May)

Ann Page (May)

Beatrice (May)

Circe (Matthews)

Ganymede (Fellowes)

Jupiter (Matthews)

Juliet (May)

HEAVY-EDGED PURPLE-NARROW.

Alpha (Dodwell)

PURPLE-EDGED-LIGHT.

Duke of Rutland (Hollyoake)

King of Purples (Garratt)

Lorina (Burroughes)

Lady H. Moore (Turner)

Minerva (Matthews)

Ophelia (May)

Surprise (Read)

Willoughby (Matthews)

Fanny (Dodwell)

Jessica (May)

Lady Harewood (Schofield) Viola (May)

Prince Arthur (Fellowes)

Prince Albert (Marris)

Portia (May)

HEAVY-EDGED PURPLE-BROAD.

ROSE AND SCARLET-EDGED-LIGHT.

Countess Howe (Marris)

| Mrs. Barnard (Barnard)

ROSE AND SCARLET-EDGED-HEAVY.

Alice (Dodwell)

Grace Darling (Marris)

Jeannette (Marris)

Miss Rosa (Merryweather)

(Princess Royal (Willmer)

Queen Victoria (Green)

Venus (Headley)

The above are a selection from upwards of three hundred and fifty varieties of which we have had experience, and we believe will be found to contain almost all, if not all, that is desirable of variety, combined with well-formed flowers, distinct colours, and well-defined markings; and with a few duplicates of each (with such attention as is necessary to their proper growth), we are satisfied not only will $\mathrm{A}$. $\mathrm{H}$. obtain a fine display on the home stage, but may also take his place with the best on the exhibition tables. E. S. D. 
The preliminaries of the towns meeting are being rapidly matured, and we hope to be able to state them, from our friend, Mr. Hollyoake, in the May issue. Meantime it has been suggested that Mr. Turner and Mr. Wood, Mr. S. Moreton, of Birmingham, and Mr. Benjamin Ely, of Rothwell Haigh, should be elected censors. Our friends at Leeds underrate their own ability very much, when they express an opinion that they cannot successfully compete with the more southern localities in the growth of these flowers, as the following extract from a letter written by an eminent cultivator in the neighbourhood of Edinburgh, will show:- "The bloom here was very good, some enormously large-perhaps too much so. I had Romeo over four inches and a quarter in diameter, and perfectly clean; but if we can get size, of course we can get other qualities by proper management." Another remark by the same gentleman so entirely accords with our own feelings, that we cannot help giving it. "Nothing, I am sure, will more tend to create a proper feeling among growers, and do more to remove a narrow-minded district jealousy, which is so apt to mar the interest which right-thinking people otherwise would feel in contributing to, and attending floricultural exhibitions, than such a meeting as the one you propose to hold, and with this view I shall do what I can to bring the growers here forward." E. S. D.

Two or three questions addressed to us on firm versus loose potting, the propriety of covering the soil with oyster shells, or charcoal, \&c. must stand over. This is potting month, and our evenings are thoroughly engaged. $\quad$ E. S. D.

\section{CALENDAR OF OPERATIONS, FOR APRIL.}

\section{GREENHOUSE.}

THIs structure is frequently too much crowded at this season, especially where there are not pits, or frames, to receive some of the hardier sorts of bedding stock; and as nothing tends so much to the ruin of plants as overcrowding, it is most desirable that a temporary structure should be erected, to relieve the greenhouse of such things as shrubby calceolarias, lobelias, and many other plants intended for the flower garden, that might be protected by mats.

Any plants making vigorous growth should have plenty of light, be carefully but plentifully watered, and often, in fine 
sunny weather, be syringed or sprinkled over head with a fine rose.

Use the knife freely to those epacrises and ericas that have done flowering, and repot, tabing care to have the pots quite clean, and not too large. Good peat, with plenty of silver sand, will suit each genus. Attend to the repotting of young stocks, and pinch out the ends of the shoots, to make them bushy. Calceolarias, cinerarias, pelargoniums, \&c. will require a plentiful supply of water, with an occasional dose of weak manure water. Examine them closely, and if any greenfly appear, fumigate with tobacco immediately.

Roses in pots will also require every attention; the rose maggot makes sad work, if not well looked after.

Attend well to balsams, schizanthuses, thunbergias, \&c. for summer decoration. Give air freely in fine weather, and see that nothing suffers for want of water.

J. BAYLEY.

\section{VINERY.}

Give air early in the morning, on all favourable occasions, but be particularly careful to avoid all sudden checks, by opening the lights too much at a time. The temperature may be allowed to rise by sun heat to sixty-five or seventy-five degrees, but the night temperature should not much exceed fifty-five degrees. Throw down plenty of water on the paths, in fine weather; close the house early in the afternoon, and syringe freely every part of the house. Keep the house a little warmer and drier while the vines are in flower. Attend well to stopping, and rub off all superfluous shoots; stop at the first joint above the bunch. Lools well to the leaders, that they do not meet with any obstruction that may canse them to break; tie loosely as they advance in growth.

J. BAYLEY.

\section{FLOWER GARDEN.}

If any alterations yet remain unfinished, let them be immediately completed, as mowing will now soon be on, and bring with it much extra work. Early mowing of lawns should be more practised, it has a tendency to keep down those stronggrowing grasses that so much disfigure some lawns.

Beds intended for massing may be forked over, using a little quick lime, to destroy insects. Rake and dress borders, at the same time sowing a good quantity of mignonette. Plant out hollyhocks, antirrhinums, phloxes, and any biennials not yet in the place where they are intended to flower.

Any herbaceous plants which send up many shoots will require to have them thinned, staked, and neatly tied.

Propagate plentifully such plants as salvias, mimuluses, scarlet and ivy-leaved geraniums, heliotropes, \&c. Sow a suc. 
cession of annuals. Seeds of biennials and perennials may also be sown now.

J. BAYLEY.

Carnations and Picotees.-Lose not a moment in getting any plants still in their winter quarters into the blooming pots or open ground. Well secure all tall growers by means of small sticks, to prevent injury by rocking from the wind. Arrange all the stock in classes, and alphabetically, so that at any moment you can refer to every variety. Elevate the pots a few inches from the ground, on strips of wood, leaving the drainage free, and preventing the ingress of worms; and particularly see that every individual pot is level, so as to allow of an equal distribution of water when required. Sow seed in fine soil, and place in gentle heat. Give plenty of air, and be very sparing of water, as the plants break through - the critical time with them. I have known hundreds lost by damping off. To allow of a thorough circulation of air, elevate the pans on strips of wood.

Derby.

E. S. DopweLL.

Dahlia seed should now be sown in pans. Place them in a dung bed. Continue to put in cuttings. These will root easily and quickly in a brisk bottom heat.

As for pink beds, it will be necessary to top-dress them with rich compost. Put neat sticks to the plants. It will be advisable to do this now, rather than at a later period, because no plant ought to have its fibres or feeders bruised or disturbed when in a growing state. Pinks may be potted now, in halfpeck pots, precisely in the way of carnations.

Gently break the surface soil of tulip beds, and put over the hoops Haythorn's hexagon netting. This will be found an effectual defence against the ravages of hailstorms.

Polyanthuses. - There requires more variety in these neat and beautiful florists' flowers. Crimson and scarlet grounds are much wanted. Addis's Kingfisher is a great improvement in this class, and seed from it should be carefully saved. Give more water to plants in frames. Gentle showers will also prove acceptable.

AURiculas. - These very beautiful spring flowers will now require abundant attention,-air, water, freedom from greenfly, must all be carefully atlended to. As the trusses rise, if too crowded, the smaller or misshapen pips should be cut out with a pair of sharp-pointed scissors. In collections, certain sorts are later than others; these should be placed in the warmest part of the frame. Small hand-glasses are nice things to place over the trusses; three small forked sticks, stuck round the sides of the pot, will support them. The amateur must be careful not to get his plants drawn, for nothing looks worse than long gawky stems.

JohN WILLIAMS. 


\section{嗮art}

\section{ORIGINAL COMMUNICATIONS.}

THE BEST METHOD OF ARRANGING A TULIP BED.

No. II.

In the hurry with which I wrote, when addressing you last, on the best method of arranging a tulip bed, I omitted to notice the second method, which is now becoming very general, and which, I think, $\mathrm{Mr}$. Glenny denominates " the herring-bone fashion." It is this, and may be briefly described as follows :- Instead of planting rose, byblœmen, and bizarre, rose, byblomen, and bizarre, crosswise, throughout the whole bed, as described in my last, the arranger of the bed must begin and complete his middle row with fourth-row flowers, to the length he means to extend his bed-say, first, a rose ; second, a byblœmen; third, a bizarre, and so on through the whole length. Then, to complete his first row, a pair of bizarres of the same variety must be put into the third and fifth compartments, a pair of byblœmens into the second and sixth, and a pair of roses into the first and seventh. This completes the first row. The second row, having a byblomen in the centre, requires a pair of roses in the third and fifth places, a pair of bizarres in the second and sixth, and a pair of byblœmens in the first and seventh. The third row, having a bizarre in the centre, requires a pair of byblœmens in the third and fifth places, a pair of roses in the second and sixth, and lastly, a pair of bizarres in the first and seventh places, and so on throughout the whole bed.

When the stock of the amateur is too limited to admit of carrying out the arrangement in pairs, then

MAY-VOL. VI. 
a couple of varieties must be selected to match as nearly as possible, so that remarks and comparisons may be made the more readily during the season's growth. Disputed flowers may thus be more easily compared with each other than when grown in different parts of the bed, and their appearance and character studied more carefully during the whole period of their bloom.

A good bed arranged in this manner, must be adinitted by all who have had the gratification of such a sight, to have a grand effect. In the first style of arrangement, described before, the lines of unbroken colour extend in a sloping manner, from one side of the bed to the other, whereas, by this arrangement, the line of one colour extends from the side row to the centre, through three rows, and then strikes off again from the centre to the side, at the same angle, and through the same three rows on the opposite side, (like the angle of incidence and the angle of reflection in the science of optics.)

This may be very simply iepresented by the following copy of ten consecutive rows from the tulip book of Mr. Thomas Bromfield, of Felton Mills, who grows his flowers in this manner.

TWENTY-THIRD ROW.

1 Walker's Coronation

2 Dutch Ponceau

3 Joseph Strutt.

4 Headley's King Richard

5 Zuill's Sir Robert Peel

6 Dutch Ponceau

7 Walker's Coronation TWENTY-FOURTH ROW.

1 Lady Lilford

2 Lawrence's Patty

3 Alexander's Monarch

4 Atkinson's fine Rose

5 Duke of Devonshire

6 Lady Exeter.

7 Lady Lilford TWENTY-FIFTH ROW.

1 Headley's Amyntas

2 Shakspere (Lawrence)
3 Lady Wilmot

4 Violet Grand Monarch

5 Lady Crewe

6 Shakspere

7 Amyntas

TWENTY-SIXTH BOW.

1 Duke of Wellington

2 Beteral's Brulante Eclatante

3 Brown's Salvator Rosa

4 Royal Sovereign, XX

5 Hooker's Salvator Rosa

6 Beteral's Brulante Eclatante

7 Duke of Wellington TWENTY.SEVENTH BOW.

1. Triomphe Royale

2 Parmegiano

3 Pompe Funebre

4 La Vandikken

5 Pompe Funebre 
A bed of tulips grown in any style is a delightful solace from the cares and anxieties of life, for the tulip is now admitted by nearly all to be the queen of flowers. But as the tulip blooin is again fast approaching, it is the duty of all florists of any experience to try to induce the young fancier to look round him during the season of 1852, so that he may adopt that style of growing his favourites which best pleases his fancy; and if he does not adopt either the one plan or the other which I have noticed, and totally discard the "grouping system," then many have arranged and laboured in vain.

I heartily agree with Mr. Willison that the tulip fancy has made rapid and gigantic strides during the last few years. But in the bizarre class the adrance has been the greatest. The magnificent bizarres raised by Lawrence and others, such as Damascus, Shakspere, Hamlet, Glencoe, Marcellus, Sheet Anchor, Polydora, \&c.; and the superb sorts broke from Clark's breeders, such as Dixon's Duke of Devonshire, and many others, were, till late years, entirely unknown in the north of England. When I became a tulip grower, the veterans of our society grew an old sort under the name of "Gold Bunteliffe," which used to carry all before it; but where is this Californian beanty now? Alas! how are the mighty fallen! It is gone to the tomb of all the Capulets, and is now quietly consigned to oblivion.

In the byblœmen class less advance seems to have been made, for many of the good old sorts are as "pure as the snowflake ere it falls," and consequently bad to drive from the field. Yet they in a few years must be abandoned, and driven from the stage, when such flowers as Glenny's Duke of Northumberland (which Mr. Wood said last year would please anybody), Lawrence's Patty (h.fi.), Friend (h.f.), Addison (fine f.), Pandora (XXX, when right), and Byzantium (b. fl.), Brown's Salvator Rosa (h. fl.), and the older favourites, such as Grand Monarque, Im. peratrix Florum, Jeffrey's Royal George, \&c. lately 
introduced into the neighbourhood, shall have become more plentiful; for they are varied in their different styles, and grand indeed.

Good roses also seem very scarce, for except Madame Vestris, I know of no flamed rose fit to compare with our old friend, Triomphe Royale, and its aliases, for it is supposed to have many in Northumberland; while feathered roses are admitted by all to be exceedingly scarce. Set aside Rosa Blanca, Lawrence's fine strain of Lady Crewe, Clark`s Portia, Lilas Rose (supposed to be from a young root of Triomphe Royale), and Heroine (supposed to be the same thing), and what else have we really valuable? Dolittle and its compeers belong to an age now gone by. Anastasia seems very promising, but it has been only once seen here. Arlette is truly beantiful, but apparently too shy a thriver ever to become plentiful in the north.

Let all true lovers of nature, then, unite in trying to promote a recreation so pure and unalloyed as the cultivation of a tulip bed. To all classes of society it has a fascination not to be found in any other branch of floriculture, but to the hardworking tradesman and the solitary student, who spend much of their time within doors, perhaps the charms of a tulip bed are greatest. From early morn to dewy eve, they are never forgot by amateurs of this description, when half an hour's leisure admits of a visit to the bed. During the period of bloom, the amateur sees the consummation of his fondest hopes, lives in a fairy land of his own, envies not the monarch his crown, or the miser his hoards, but sees, in the variously-tinted picture before him, the handy work of the Mighty Architect who planned the universe, and feels in the tranquil delight which the scene affurds him, a foretaste of that happiness destined for the just in a better world, "when care and sorrow have fled away." He can turn out in the early morning, and exclaim with Adam, in the beautiful language of Milton, 
" These are thy glorious works, Parent of good, Almighty! thine this universal frame, 'Ihus wondrous fair; thyself how wondrous then! Unispeakable, who sitt'st above these heav'ns, Tn us invisible, or dimly seen

In these thy lowliest works; yet these declare

Thy goodness beyond thought, and power divine."

WM. HARRISON.

West Thirston, near Felton, Northumberland, March 23rd, 1852.

\section{REASONS FOR GROWING PINKS IN POTS.}

Some years since, on first coming to the place at which I at present reside, I was told that I should find great difficulty in getting flowers of certain descriptions to grow in the borders; indeed I was warned that the soil was so much infested with "6 the wurm," that nothing but those plants which were not susceptible of injury to any great extent from it, or those which were unpalatable to the pest, would have any chance of long surviving the risks to which they would be exposed t $\omega$, if planted out.

In those days, being less acquainted with the nuisance than I have had good reason to become at the present day, I suppose I was either oversanguine or incredulous as to the amount of injury so small an enemy can inflict, so having long been a carnation and pink fancier, and having just before had to deal with a soil in which such injury was unfelt, one of the first things which was done was to fill a border with a good stock of the former, and to plant out a considerable number of the latter. In less than a month my carnations were almost annihilated, and before the season was over the pinks were all wellnigh gone too. To give you some idea of the amount of this pest, I may add, that by setting the usual trups, such as potato and turuip slices, we caught at the rate of over one hundred wireworms per day, for many days, in one border, not fifteen feet by eight. 'This was not confined to one purtion of the 
flower garden : all parts were more or less affected; so to grow either of these descriptions of flowers in the open border was out of the question. In the case of carnations the remedy was simple. Growing them in pots was common enough, and the details of the practice to be pursued were easily accessible, even if I had not, as I had already done, grown a good part every season in this way. But to grow pinks in pots some years ago, was very unusual, if indeed it was ever practised to any extent. However there was nothing else to be done. They might not do well in pots-they were sure to be killed in the border.

In thinking over the matter, there appeared to be no reason why they should not be grown in this way; if carnations did best in pots, why not pinks also? Moreover, if I had a scarce variety, or one which from any cause I was more than commonly anxious should do well, the recommendations were to keep such in pots through the winter, in frames, and this I had been in the habit of following, and in doing so had frequently remarked that the so cared-for plants were more healthy in appearance, and began the seasun of growth stronger in constitution than those which had been exposed to all the vicissitudes of wind and weather, during the previous winter. In addition to this, although in the garden in which I had been in the habit of growing them the soil was naturally well suited to them in character, being a loam, such as that in which pinks delight, the new ground was quite of an opposite nature, being poor and sandy in texture, and such as did not hold out any reasonable prospect of satisfactory success, without the addition of a large quantity of more adhesive soil to mix with it. To get this in sufficient amount for the purpose would be no easy matter: after it had been procured, even if it was to be had at all, to cart it home was no inexpensive one. Here was another argument for the trial of pot culture. A cartload would last in the one way for a season or two-in the other, such a quantity would make no 
sensible difference, when mixed with the contents of a whole border.

The plan was tried the first year with, if I recollect rightly, some two dozen pairs. These succeeded so well, that the next year the number was increased, and lately, one who could not otherwise have grown pinks at all, has been able to grow them to any extent desired, through the success which follows a proper mode of pot culture. And here is a strong argument for the recommendation of this mode-it places the cultivation of that flower within the reach of almost everyone; for, as was said above, filling a border is one thing, enough for a few pots is quite another. You, Mr. Editor, know privately with what success the pink has been grown here in pots. I only allude to it to show that they will not only grow well, but that they will flower in good character when so grown. And speaking of exhibitions leads me to mention another great advantage which pot culture presents. It enables the intending exhibiter, either by remuring a pot into some shady and cool place, to keep back his flower, or on the other hand, if a variety seems likely to be too late, to forward it considerably, by placing it in a warm situation and exposure. In the necessary tying and disbudding, and suchlike operations, pot culture has a decided advantage; at least it will be felt to be so by some of your less supple readers, who object to the cramping process which attention to them in the ordinary way necessitates. There is much more comfort in handling a plant on a bench before you, than there is in doing this while stooping over a border, and it is likely to be far better done in the one case than the other. Of late seasons, I have been in the habit of blooming from eighty to one hundred pairs in pots. An ordinary visiter might not recognize that they were so grown, for the pots are always plunged in a bed previously prepared for them, merely the rim showing above the surface. The bottom of the bed has a thick layer of cual ashes, strewed orer with soot, to present the entry into the pots of worms, whether 
wire or others. The soil in which the plants are grown is of the character quoted by Mr. Hogg, in his treatise, the Pinguisitem qua sit tellus:-

\section{"What soil is rich by this last rule we learn : Never, when tost about from hand to hand, Rives it, but pitchwise to the fingers sticks, Clammy with handling."}

In other words, a good stout loam. This has an addition of one-third cow dung, rotted into a mould, and ore-third leaf mould, which has been kept thoroughly sweetened, and which has been well exposed to the action of frost during the previous winter. As the plants require a great amount of water during the flowering season, much care is taken that the pots are well drained. The potting time is commonly early in the present month. Should any of your readers who may not yet have done so, be inclined to make a trial of pot culture, they should at once provide themselves with plants which have been wintered in pots,-removing those which may be in the border I should doubt the success of, as disturbing the roots of pinks at this season is injurious to the lacing. These should, without delay, be potted into their flowering pots. 'The size used here for this purpose is either nine or ten inches in diameter, and a pair or sometimes three plants are placed in each pot. When shown in pots, they have a very pleasing effect, and there are gond reasons, in my upinion, for encouraging this method of exhibiting them. I may, one of these days, send a few lines on this subject, if they will be acceptable.

\section{A N.B. AMATEUR.}

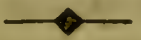

\section{THE JAPAN IILY.}

\section{(Lilium Lancifolium.)}

THIS beautiful, fragrant, free-growing and hardy bulb ought to be in the hands of every lover of flowers, who has either a staircase or parlour window to 
spare, or who can command the greater luxury of a cold frame or greenhouse.

The management is perfectly easy, and may be varied without much disadvantage, so as to suit various accommodations. I have grown them in the parlour window, in a greenhouse, in a cold frame, and exposed to the trials of a severe winter, without any protection whaterer, and I can say that any of these modes will do, even the latter, if necessary; though in that case an exception must be made in respect of the species Punctatum, which being much earlier than the others, will have its flower buds destroyed, unless the season happen to be remarkably mild.

But though great latitude may be allowed in the mode of cultivation, there are certain conditions which should always be attended to, and hoping that my remarks may be of service to some of the readers of your most useful little work, I proceed to give you that mode of management which I consider the most judicious.

The soil generally recommended is turfy bog and sand, but any rongh light rich garden soil will do, and the finest plants I have ever seen were grown in a rich compost of turfy loam, leaf mould, old rotten dung, and sand, with a small aliowance of hen dung. or domestic guano.

They require plenty of pot room, and when not put into full-sized pots at first, care must be taken not to delay the repotting too long : the roots should not get matted together. Let them have plenty of drainage, and let the bulbs be placed from two to four inches below the surface of the soil, according to size.

After potting, they may be put away in any convenient place, till the stems make their appearance, when they should be brought to the light and moderately watered, increasing the supply as the growth increases-ocasionally syringing them overheadgiving them always abundance of fresh air, and keeping them shaded from a scorching sun. 
This general treatment may be pursued till the flower buds are developed, when they should be brought into warmer quarters, if they have been out of doors, watered once or twice.a week with weak manure or guano water, and the stems neatly staked.

From the time, however, that they are attaining the height of eighteen inches or so, there are two points which should be attended to. ' First and foremost as to the greenfly. The head of the stem, containing the embryo buds and young leaves, forms a very attractive and secure harbour for that little pest, and if it is allowed to make a lodgment, the top leares will be punctured and curled, the flowers deformed, and all the future beauty destroyed. Search carefully for them, therefore, and get rid of them as soon as detected, either by smoking, or by the aid of a peg of soft wood, moistened with saliva, so as to make them adhere.

The other point refers to the peculiar habit of this lily in regard to the formation of its roots. Besides the ordinary ones at the bottom of the bulb, a very copious growth issues from the stem, when it has acquired a due degree of maturity, the object of which, no doubt, is to provide a larger amount of nutriment for the foliage and flowers than the bulb alone could give. 'This habit points out the necessity for the surface of the soil being kept moist, a provision which for most bulbs is not requisite.

Judicious treatment at this period of their growth I consider to be peculiarly important. If too much forced, or exposed to too powerful a sun, the leaves will be apt to flag, and if that is allowed to occur often (as it inevitably will if they are subjected to too great a drain upon their powers before the sub. sidiary roots get firmly established), the lower leaves will fall off, or become yellow and withered, and the beanty of the plant will be materially diminished.

From this period till the blooming season, they will only require attention to watering and shading; all danger of injury by the greenfly may be con- 
sidered as past, and if they are more frequently syringed overhead, and get a more liberal application of weak manure water, they will be fully satisfied, and the cultivator himself will be abundantly rewarded for all his trouble. At any rate, let him only succeed in producing a well-grown specimen, with its foliage fresh and full, rising like a verdant column from the surface of the soil, and crowned with a branching head of fragrant flowers, pure white, or tinted with rose of different shades, and numbering from ten to twenty and upwards on a single stem, and I am certain that if he is not satisfied, he ought to be.

When fairly in flower, the chief duty is freely to enjoy their attractive beauties, which I recommend to be done every morning, or oftener, as time or inclination dictate. The assiduous student will generally find, in addition to the charms of form, colour, and fragrance, a daily secretion of the sweetest honey hanging on the petals, ready for his use.

At the close of the season, less water will be necessary, and they may be put out with advantage, in some corner of the garden open to the sun, but sheltered from heavy and continued rains. Here they may remain till potting time, which 1 prefer taking in October or November, a month or two after flowering is over. It is not necessary to wait till the stem is entirely decayed, as that sometimes does not occur till after Christmas, and the roots for the following year will then, in most cases, be in full growth.

In preparing them for potting, let all the old soil be shaken away, the old bottom roots carefully removed, without injuring the new ones, and the stems cut off close to the bulb, which will bring away all the superficial roots, and leave room for the new bud to push up, without resistance.

The propagation is either artificially, by taking off some of the outside scales of which the bulb is composed, and planting them in sandy soil, when small 
bulbs will be formed at their base the following year; or by the natural growth of offsets on the stem, at the surface of the soil, or below, hidden among the superficial roots spoken of before, which should always, therefore, be carefully examined before being thrown away. The old bulb also frequently divides, putting up a second or third flowering stem, and may, at the potting season, be either separated into as many distinct plants, or not, according to the taste and wants of the grower.

I have now brought my remarks round to the point from which I started, and trust your readers will see no difficulty which need deter them from the cultivation of this charming flower.

Before concluding, I will mention the different species which I grow.

1. Album, or white.

2. Punctatum, slightly tinged with rose.

3. Speciosum, of a deeper colour.

4. Cruentum, or Rubrum, the deepest of all. This is the true Speciosum, as figured in the fifth volume of Paxton's Magazine of Botany; and in the same volume No. 2 is figured under the name Roseum.

How No. 3 has got possession of the name truly belonging to No. 4, I know not; perhaps it is a seedling from that variety, though I doubt it, as it is invariably earlier with me, both in coming up and in flowering, if both are treated in the same way. It is also of a stronger growth, makes larger bulbs, and requires more pot room than No. 4 . The shape of the leaf also differs. Punctatum (No.2) and Speciosum (No.3) are generally in flower at the same time, thongh the former appears above ground two or three weeks earlier. Album and Cruentum are three weeks later.

The general flowering season is from the middle of August to the middle of October, but it will be forwarded or retarded to the extent of three or four weeks, according to the early treatment. Last year, 
I kept my stock plunged in a border of coal ashes from the time of potting, and it was the middle of October before Cruentum began to open.

D.

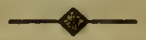

\section{BEDDING PLANTS.}

THE month of May will be the proper time to put out what are usually termed bedding plants. These are generally half hardy, and have been kept in frames or greenhouses through the winter. We will then suppose, that instead of annuals, as described in our March number, a selection of these plants is required to fill up the round beds on the grass plot. Verbenas will be very useful for our purpose, and of these there is now an immense variety. Let us then, for one, take Robinson's Defiance, with its large trusses of brilliant scarlet flowers. By judicious stopping, or pinching off the ends of the shoots, and pegging down with leaden pegs, such as we use for layering carnations, these plants will make a bed of amazing beauty. Another nice plant, that will suit us very well, will be the dwarf Lobelia dentata, a remarkably neat plant, with a very great quantity of small blue flowers. We must then find a good white amongst verbenas, and Perry's Wonderful will be the sort we would select for the next bed. Then some of the bright yellow shrubby calceolarias, such as C. amplexicaulis, for instance, would do very well. This is brilliant and very suitable. Woodcock's Magnificent is a large well-shaped pink verbena, which makes an admirable mass of this colour. Then there is Anagallis Monellii major, a very attractive bright purple. When the sun shines on these flowers, they are indeed beautiful, and are produced in great profusion. Being of a prostrate habit, this plant will not require pegs. Some of the petunias make splendid beds. We prefer the 
crimson, with dark throat, for this purpose, taking care to select sorts with stout petals, rather than large and loose ones. A bed of double nasturtiums, both of the orange and scarlet sorts, would be very desirable. They grow well, and produce a profusion of blossoms. Salvia patens, when well managed, is very effective. It requires pegging down and repeatedly stopping; it then throws up spikes of rich blue flowers. OEnothera riparia is of pretty dwarf habit, with yellow flowers; and CEnothera taraxifolia will afford a most striking and effective bed of white. These plants will do for our beds nearest the path: for the others it will be advisable to have rather taller plants. Of course there should be a bed for scarlet geraniums, either Tom Thumb, Queen Victoria, or Trentham Scarlet; but by no means put different plants in the same bed; the habit and mode of growth ought to be similar, otherwise the bed will appear defective. It will also be advisable to have a mass of variegated geraniums : they have much improved within the last few years. Flower of the Day is one of these, but perhaps too expensive yet to purchase in quantity. Dandy is very neat and compact, and makes a pretty mass; whilst the Variegated Pink and Variegated Scarlet are cheap, and both adapted for the purpose. A bed of heliotropes is absolutely indispensable. Though not particularly showy, yet their fragrance is so great, and the flowers are produced in such quantity, that they may be cut freely for bouquets. Triomphe de Liege is larger than most others, delicate lilac, with white eye. Corymbosum, which is dwarf and bushy, will answer the purpose well. Another plant, of rather taller growth, very neat and desirable, is Ageratum Mexicana, which bears light blue flowers in abundance, and is good for bouquets. We must not forget the antirrhinum. Two beds of these will be advisable; one rich crimson, such as Apollon, or Boule de Feu; the other white or yellow. Of the latter, California and King of Yellows are the best. Perhaps one of 
the prettiest things than any we have yet enumerated is the Cuphea platycentra. This must be grown. The flowers are crimson and black. Bouvardia splendens too, with its scarlet flowers, like a Trumpet Honeysuckle, is a most excellent bedding plant. 'Then there is choice amongst pentstemons. Album, for a white bed; and $M \bullet E$ Ewenii is a dwarf and bushy rosy crimson, capitally suited for summer flowering. We must have two beds for fuchsias; one lightcoloured, the other scarlet. Amongst the former, Napoleon and White Perfection; and in crimsons, Sir John Falstaff (Globe), Splendida, and Voltigeur are beautiful and brilliant. Gallardia picta, yellow, with crimson, will be very suitable; and Lantana crocea will accord capitally with the rest. We have now pointed out what, with common attention, will make a splendid show during the summer and autumn months; and should the amateur be possessed of a small greenhouse, he will find much amusement during the summer months, in striking cuttings for his next season's display, as well as attempting to hybridize or cross-breed some of the plants that may flower with him. We would also direct especial attention to the propriety of saving all seed which may be matured. 'I'hose who have not yet experienced the delight and gratification of raising a first-rate seedling plant, have, we can assure them, a treat in store; for while they may thus gain in a pecuniary point of view, they will also enjoy what is to most minds of far greater importance, the feeling of having contributed to the pleasure of the great floricultural brotherhood.

\section{DEUTZIA GRACILIS VERA.}

Tris beantiful ornamental shrub was introduced by Mr. Van Siebold, who sold it to Mr. Baumann, of Ghent, by whom it has been shown in great perfection, at the late exhibition there. Some plants which 
Mr. B. exhibited, measuring five feet across, presented one mass of beautiful clear white fiowers. From its profuse blooming and free growth, it will prove one of the best plants ever introduced into this country, either for early forcing or as an ornamental shrub. It is perfectly hardy, and will be a desirable addition to our ornamental gardens. It blooms at a very early age, as plants in this nursery (nine inches high) are, at the present time, covered with its beautiful white flowers, hanging gracefully from every lateral. Some fine specimens were exhibited by Mr. Baumann, grafted standard height, on the Philadelphus grandiflorus, which, no doubt, will be generally practised, where high plants are required. It requires similar treatment to others of its class, when forcing, a pot moderately drained, and a mixture of one-half rich loam and one-half good leaf mould. When making its growth, a little liquid manure, judiciously applied, will be found greatly to assist the plant, both in its growth and flowering.

Clapton Nurseries, London, March 24, 1852.

\section{T. CAPARN.}

\section{非art 秘。}

\section{NEW, RARE, OR GOOD FRUITS, FLOWERS, PLANTS, TREES, AND VEGETABLES.}

\section{NOVELTIES OF SPRING, 1852.}

\section{PHLOX.}

Drummondii Thompsonii.-A very rich marone crimson, with purple centre. There are now several varieties of this very pretty phlox, but as they sport much from seed, it will be necessary to perpetuate each sort by cuttings, which strike root readily. 


\section{DELPHINIUM.}

Hendersonii.-This extremely beautiful and interesting distinct hybrid was raised by $\mathbf{M}$. Chauviere, of Paris, from Delphinium Chinensis crossed with Delphinium elatum splendens, and partakes much of the fine branching character of the former, and large laciniated foliage of dark glossy green; flowers of large size and well formed, with very broad ample petals, of rich deep azure blue, finely contrasted with a bold white eye, which renders this plant very conspicuous indeed.

From the above description, and its appearance as depicted in the Maguzine of Botany, we should not be surprised if Delphinium Hendersonii and Delphinium magnificum, raised by Mr. Goodwin, of Collycroft, near Ashbourn, were of very similar character.

\section{ANTIRRHINUMS.}

Primrose Perfection (Edwards).-A most excellent variety of a pretty hardy plant. The spikes are large and compact.

Hendersonii.-Raised by Mr. George Parsons, of Brighton, and purchased by Messrs. E. G. Henderson \& Son, who describe it as the greatest novelty that has appeared in this tribe for years. Tube and ground colour white, distinctly marked throughout each petal with broad bands of deep carmine. The stripes and ground colour are so evenly balanced, that each flower is an exact counterpart of every other on the plant.

Novelty (Smith).- Has a dark rose tube, upper lip pure white, lower deep rosy purple, with yellow centre.

\section{CHRYSANTHEMUM.}

Hendersonii.-We should imagine, from the following description, that this will be found a good thing:- "The plant is of dwarf habit, two feet in height, belonging to the Chinese class, and so dense a flowerer that every morsel of young wood is thickly clustered with flower buds; indeed the whole plant is one mass of well-formed orange flowers. By having the branches neatly pegged down in the beds, the whole would look like a fine bed of ranunculuses, during the autumnal months."

\section{CALCEOLARIAS.}

The following are new calceolarias, peculiarly adapted for bedding out:-

Henderson's Wellington Hero.-Colour deep and rich golden yellow, producing very large trusses of flowers. It was 
awarded a label of commendation at the National Floricultural Society.

Henderson's Tom Thumb.-Dwarf and compact habit, flowers deep crimson. Without exception, the best dark variety in cultivation, for bedding purposes.

Smith's Beauty of Montreal. - This also is of a rich crimson colour, and desirable compact habit.

\section{GERANIUMS.}

Giant Scarlet Defiance.-This splendid sort is a great improve. ment on the Shrubland, often producing as many as a hundred flowers in a truss. It is suitable for a trellis, or, in fact, for bedding purposes, as one plant will cover a large space.

Jewess is a pretty fancy geranium. There is much contrast in the flower, the lower petals being white, with violet spots, whilst the upper ones are rich crimson, edged with white.

Hendersonii.-The foliage similar to the scarlets, but flowers white. Certainly a very distinct and desirable novelty. The truss of flowers is large and handsome.

Extravaganza.-A singular and curious hybrid. This fine variety possesses flowers of good size and substance. Large bold trusses of deep crimson. Each of the five petals has a large dark marone blotch, nearly covering the whole of it. A fine bedding plant.

Odoratissima Grandiflora (Henderson).-A very fine lemonscented hybrid, of strong and very compact habit of growth, with large trusses of flowers, in the style of the fancy class, splendid foliage, and highly scented. Colour rosy purple, veined with dark blotches in the upper petals.

\section{BEDDING FUCHSIAS.}

Globosa Perfecta. - A complete globe in form, with a remarkably small and slender tube. The habit is dwarf and spreading, which renders the plant very attractive, especially when covered with its hundreds of graceful pendent balls of rich crimson, with deep purple corolla.

The Darling.-A miniature plant, covered with an immense quantity of reflexed flowers, of brilliant scarlet and purple. It does not exceed eighteen inches in height, and is of neat and branching habit.

The Pet.-Of darker colour than the preceding; of much the same habit and form of flower.

Splendidissima.-A first-rate show flower. The sepals reflex, tube crimson, corolla deep purple.

Exquisite.-This is described by Messrs. Henderson as being a perfect model in shape; flowers of middle size, with bright scarlet tube, and riolet purple corolla; the sepals fall grace- 
fully backward, which, combined with its perfect proportions, render it peculiarly attractive.

Hendersonii.-A novel, distinct and very double variety; tube and sepals deep crimson, beautifully reflexed; the corolla a globular mass of purple petals. 'The semi-double varieties at present in cultivation, in contrast with this, will bear no comparison.

Beauty of Deal (Banks).-Tube white, corolla bright vermillion, flowers produced in profusion, habit excellent.

Cortona (Banks).-This is a most distinct new sort, the corolla being extremely dark, the tube and sepals rich crimson.

Gaiety (Banks). - Here we have something out of the common line in this family of plants. Tube and sepals pink, the corolla purplish lilac. A lively pretty sort.

PANSIES.

Schofield's Village Maid.-Pure white ground colour, with solid and bold eye, the five petals laced with a beautiful lilac.

Schofield's Magnum Bonum. $\rightarrow$ A rich chocolate colour, eye surrounded and shaded with rich crimson, quite smooth and of excellent form.

\section{DAHLIAS.}

Sir Richard Whittington (Drummond).-Ruby puce, compact and full, a large and deep flower, of extra fine quality.

Morning Star (Turner).-Extra fine form, brilliant orange scarlet. Obtained six first-class certificates. Indispensable.

Lizzy.-Raised by Mr. C. J. Perry, of Birmingham. Beautiful form, ground colour pure white, strongly tipped with cherry. This will be a most attractive sort.

Miss Ward (Turner).-Beautiful yellow, tipped with white.

Rawling's Dr. Frampton.-Splendid form, white, with purple edge, rather below the average, but very beautiful.

Spary's Absalom.-Excellent form, colour clear amber. Novel in colour, and will contrast well in a stand.

Green's Scarlet King. - A most beautiful and desirable scarlet, in form equal to the Duke of Wellington. All exhibiters should have this fine flower.

Bob (Drummond).-Another fine scarlet. Very rich, constant, and good.

\section{VERBENAS.}

We noticed a new verbena (A merica), which was raised by Mr. Hovey, of Boston, United States. We have just received further information of some other fine sorts, let out last April, and which our correspondent, who is a good judge of these flowers, states 
to be first-rate. No donbt they will find their way to the old country. 'They are,

Republic (Hovey).-Very delicate pink, distinctly ribboned with crimson.

Orb of Day (Hovey). - Said to be a beat on Robinson's Defiance, inasmuch as the colour is even more beautiful than that fine flower. Its habit is more dense and compact, and both trusses and flowers larger.

Diadem (Hovey).- Splendid purple, large, and of fine form; the texture of the petals of a peculiar velvetty appearance.

Nectar Cup (Hovey,.-This flower will be a great favourite, if it were for nothing more than its powerful fragrance. The colour is a beautiful pink, with a light centre and dark eye.

Our correspondent promises us a description of other new seedlings, for an early number.

\section{RETROSPECTIVE CRITICISM.}

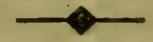

\section{CARNATIONS AND PICOTEES.}

Perhaps you will give me space to thank Mr. G. Baildon for the information he gives us in your last number, and to ofier a brief comment on the remarks he makes upon varieties esteemed in this district.

I cannot think with Mr. Baildon that "there must be some difference ir our judgment;" on the contrary, Mr. Baildon's own remarks satisfy me that there is none. It is true, Mr. Baildon, after remarking on Lorenzo, Jenny Lind, Alfred, and Black Diamond, and pointing out very grave faults in these varieties, says, "such sorts as Ely's William Caxton, Summerscales's Nulli Secundus, Brierly's Music, Hepworth's Leader, and Yorkshire Hero, are far more admired here, because they are to be depended on ; they are steady markers, and it is such we want." But when Mr. B. introduces Ringleader to us, it is not with the remark, now for a beat upon Heprorth's 
Leader, but " now for a beat on Admiral Curzon;" clearly conveying the idea that not Leader, but Admiral Curzon, has been the crack flower of the West Riding, as it is with us and the southerns. Very certainly the midlanders have no appreciation for flowers uncertain in their character, unsteady in their markings, wanting in colour and form, and not to be depended upon.

But Lorenzu is subject to none of these disabilities. I believe I may claim as much experience of the variety as any cultivator in the midlands, and $I$ unhesitatingly pronounce it, with your correspondent, Z. thus far, as the A. 1 of its class. It is, when in proper charaster, faultless in outline, and without a rival for its splendid petal. In colour it is scarcely a perceptible shade paler than Lovely Ann, and quite as distinct as that old favourite variety; in fact, there is no poverty of any kind about it.

Jenny Lind is certainly a few days (from three to seven) behind the height of the bloom; and this is against it for some places, but not in all. In every other respect, $\mathbb{I}$ know nothing ou to oupose it ; and I cannot but suppose some great lack on the part of the cultivator, for "Jenny" to have been seen without character, either for " colour, form, or marking." I have known it since 1849, and have never so seen it.

Haines's Black Diamond is certainly sportive; but so is Lord Milton, and Black Diamond is, in my estimation, qnite up to Milton in every respect; and I apprehend Milton, in its best cloth, would take rank before either Caxton or Nulli Secundus, in the West Riding. Like every other variety, these flowers require fair growth, and the stock to be in good health, before their merits can be fairly estimated; and without impugning the skill of our West Riding friends, I must take leave to believe their condemnation has proceeded from the absence of one or the other of these requisites.

As for Alfred, it would, perhaps, be unbecoming in me to say what it is. It is, however, not a late 
variety, as a reference to the Midland Florist for 1850, page 268, will show I exhibited it at Slough, on July 24 ; and last season, I saw it in the collections of two exhibiters (pots in bloom), at Chiswick, on July 19th. To show Mr. Baildon that we have a strong faith in the merits of varieties described by you as fine in this neighbourhood, and for no other purpose, I will show Alfred at our next exhibition, on August 4th, against every picotee of every class raised and grown north of Derby,-Mr. Baildon having my full permission to cull his blooms from any quarter he may think proper, north of this town, and on these terms, viz. that I shall pay to $\mathrm{Mr}$. Baildon, if he beats Alfred, all the expense he has incurred in obtaining his blooms, and travelling here to exhibit them; but if he should not succeed in defeating Alfred, that then Mr. Baildon shall simply bear his own expenses, paying me nothing; and against this expense, he will have the gratification of seeing a variety in better character than he had given it credit for, and the enjoyment of the towns' meeting; and I trust I shall have the pleasure of seeing him and many other friends on that occasion.

E. S. DODWELL.

To secure Mr. Baildon, I will at once deposit any necessary sum in the hands of any respectable man he may indicate; and any other preliminary I will leave to his arrangement.

Derby, April, 1852.

E. S. D.

Mr. G. Balldon, in the last number of the Minland Florist, lias given his opinion on certain carnations and picotees, and adds, that he thinks there still must be some difference in opinion between the southerns, midlanders, and the north : i.e. that the south and midland fiorists have a different standard from the florists further north. To this opinion I cannot 
subscribe; and will show Mr. Baildon that he has formed an erroneous opinion of several varieties. Dodwell's Alfred is named as a late variety. It is neither early nor late, but comes in at the height of the bloom, the best time possible it could flower; and is a steady variety. As a proof it is not late, two pots of it were shown at Chiswick, on the 19th of last July. This is not like catching a chance bloom, but must be pots of plants in full flower; and being the first season of its being sent out, speaks very much in favour of it; as neither the raiser nor myself were among the exhibiters, it therefore was shown from a;small stock.

Lorenzo is said to have no character about it, and not to be worth layering. Jenny Lind no better, with the drawback of being late; therefore the natural conclusion is, that bad as Lorenzo is, Jenny Lind is of still less value. Jenny Lind, I grant, is rather late, which is against it in some localities, but in its favour in others. But speaking of the merits of the flower, it is the most perfect carnation yet sent out. As regards Lorenzo, this flower, well done, is the best rose flake out under Mr. May's name. Prince Arthur, Ariel, Antonio, and Romeo, have all been seen fine; but Lorenzo will wear them all out. King John, of Mr. May's, will beat it, being both bright and fine.

I am the more surprised that Mr. Baildon does not appreciate the good qualities of the above, as he does not seem hard to please, seeing that such flowers as Music, Yorkshire Hero, William Caxton, Nulli Secundus, \&c. are highly esteemed by him. Whether Hepworth's President, so highly spoken of, will beat Paul Pry, or not, I cannot say; but doubt if the flower is raised yet-out of Mr. Puxley's stockthat will beat Jenny Lind; and I shall prefer seeing Ringleader, before I decide that it is a beat on Admiral Curzon.

Slough.

CHARLES TURNER. 


\section{R E V I E W S.}

Groombridge:s Farm and Garden Essays. No. 7.

The Garden Frame. How to construct, how to use, and how to make the most of it.

A vERY useful little book, and well worth the moderate price charged for it. There are many amateurs who are anxious to have a frame, but when they get one, it often proves a failure with them, or at the best, is not half managed. 'This little work will in a great measure obviate so serious a matter ; and if properly studied, will render the success of the artizan and amateur gardener comparatively certain.

Kidd's Own Journal. A Literary, Scientific, and Instructive Family Paper.

THIs is a periodical in which we take much interest, a cheap publication on natural history being much wanted. Here we have anecdotes of birds, animals, plants, \&c. We see that Mr. Kidd intends to publish in his pages Dr. Gall's splendid work on phrenology. We should much like to see a skeleton calendar of natural history published monthly: it would be a great boon to many young naturalists and botanists. Extracts too, from expensive works, on subjects bearing on the beautiful pursuits in counection with natural history, would be highly desirable. But we believe $\mathrm{Mr}$. Kidd to be able to make as agreeable and instructive a book as any man in England. We hear it bas a great sale, and it deserves it.

Turneris Florist, Fruitist, \& Garden Miscellay. New Series. No. 16.

A MORE than usually interesting number (if such a thing is possible), cummencing with the "Rhododendron Javanicum," accompanied by a nice plate of this

MAY-VOL. VI. 
fine plant. "Shading the Dahlia"_-"The Tulip. No. 2." We think the idea here expressed, that there should be a collection of tulips grown at Chiswick, or Regent's Park, a good one. We should say, have a first-rate bed at each place, cultivated, arranged, and covered in the best manner. This, we are sure, would be a very great source of attraction, and we believe would be the means of increasing in a material degree the number of cultivators of this fine flower. The other most interesting papers are British Plants-Pompon Chrysanthemums-Cultivation of the Epacris-Daphne Indica Rubra-The Camellia-On Bedding Autumnal Roses, \&c.

The Scottish Gardener, and Magazine of Horticulture and Floriculture. No. 4.

A TRULY practical work. Amongst many good papers, there is one on Raising Seedling Carnations, by Mr. Dodwell, of Derby; and Pink Notes, by Mr. James Lightbody, of Falkirk. From the latter, we will give the following extract:-

"Costar's Romeo is evidently a seedling raised from Alfred Morrison, and much in the same style of build and colour. The same raiser's Juliet is very like the above, but as these were only planted by me late in the spring, I could not so well judge of their merits.

“ Costar's Prince Arthur was scarcely so well built as either of the above. The petals tolerably smooth, but not well laced.

“ Hooper's Charmer is a most beautiful variety. Very heavy dark purple lacing, with fine petal. Has also the additional merit of always coming constant in character.

"Hooper's Mrs. Hooper is rather thin for most tastes. The petals are broad, smooth, and well laced with red.

"Garrett's Sportsman is also rather thin but will be an invaluable variety to cross with, as it produces abundance of pollen, and the petal is broad and smooth. It is very constant in lacing; the colour a brownish purple.

"Read's Countess Rossi and Kate are beautiful varieties, well built, with finely cupped petals, showing the white outer margin, the colour purple. I think they have been raised from Willmer's Laura, as the habit of the plants partakes much of that variety. 
"Smith's Huntsman, in habit of growth, is quite of the same straggling nature as most of this grower's seedlings. It is, however, a deciued acquisition, being a well built flower, with good petal, laced with rich rosy purple.

"Colcutt's Sappho has finely-formed petals, the colour dull red, rather faintly laid on. It is quite thin enough to come up to the standard. I may add, this variety is a free grower.

"Looker's Princess Helena, in shape of petal, approaches Sappho. The ground is of great purity, the lacing beautiful purple. This is a charming flower, and one, I think, which would please the most fastidious.

"Among other varieties, which I have described before, but are really worth adding, are, Willmer's Comet and Surplice, Burman's Mrs. Burman, Keynes' Hon. Mrs. Herbert, Costar's Lola Montes, Elldridge's Pickwick, Maclean's Criterion, and Read's Jenny Lind."

The Gardener's Record, and Amateur Florist's Companion. By 1. T. Neville. London: Groombridge of Sons.

This little work is extremely well got up, and we have no doubt it will obtain a fair share of public favour. 'The article on the tulip, by C. L. Crook, Esq. promises to be very interesting; and from that gentleman's knowledge, we expect full information of the very many splendid flowers grown in the south, which we northerns are comparatively unacquainted with.

\section{毁art JEEE.}

\section{QUERIES AND ANSWERS.}

Would you, or any of your numerous readers say, in an early number of the Midland Florist, what is the hest treatise on hot water-heating of greenhouses?

R. D.

[Our correspondent will find everything he requires in the pages of the Gardeners' Chronicle.] 
Carnatrons and Picotees.-S. Taylor. - We trust you foIlowed our advice; and if so, you will have had illustration of the advantages of firm potting, by this time. These may be briefly described, as preventing the severe saturation of the soil by heavy rain, and its opposite evil of great drought; to both of which a loose soil is inevitably subject. Plants firmly potted, are stouter in their growth than those in a loose soil, shorter jointed, and have a much more fleshy root. Long-experienced cultivators say, that successful cultivation depends upon the nearest realization of an equable temperature-gradually increasing according to the necessities of the plant-and the avoidance of sudden changes from heat to cold, and drought to moisture; and firm potting, as compared with its opposite, goes far to realize these conditions. You may illustrate firm and loose potting thus:-Take a sponge, and expose it a few hours to a strong wind. It will be dry as dead leaves. In that state pass it rapidly through a vessel of water, and you will find it is still dry-its surface only shewing a few drops upon it. This is the passing shower upon a loose soil. But plunge the sponge again and for a longer period, and you find it filled-gorged. Just so is the loose soil after drenching rain. Now, to try what firm potting is, wring out the sponge, compress it firmly (that is, firm it), and pass it into the waterno matter how long you retain it there, it adds nothing to its moisture; and nearly the same result attends the exposing of it to the air. As a soil well adapted for the growth of plants should, in its mechanical condition, bear a close affinity to a sponge, the analogy is not imperfect, and the experiment will fairly test the advantage of "firm putting." Covering the soil with oyster shells, or charcoal, is a carrying out of the same principle (the equalization of temperature), and is also further advantageous, inasmuch as it preserves the soil from the waste which repeated floodings and rapid evaporation engenders, and guards the tender roots from injury by the same agents. If the shells are now examined, the roots will be found lying out on the surface of the soil, and thus the cultivator has a prompt command over the energies of the plant. We take a great pleasure in looking to these results, and offering to these delicate mouths a gentle supply of the food they so much delight in,-that is, a mixture of about equal proportions of loam, sweet leaf mould, and thoroughly decomposed manure; proportioning the supply in all cases to the strength of the plant, and thoroughly firming the dose administered. And no one willing to take this little trouble will go unrewarded. $\quad$ E. S. D.

Z. complains he has had plants from Yorkshire so diminutive and dirty, that they seemed as though they had spent the 
winter in some old-fashioned chimney. They were also so reduced, for want of water, of which they seemed to have been innocent for at least three months, that it would require weeks to get them into the condition of well-to-do plants. Our own experience tallies very much with our friend, $Z$. and in all kindness, we must take leave to say to our friends of the West Riding, that a little more attention to keeping their plants clean in the winter, and a more liberal application of water during March, will rewald them with much finer plants, and, as a consequence, an earlier and superior bloom. No doubt we may be told, that if they are excited to growth, they are much more liable to injury from spring frosts, and unquestionably if left utterly uncared for, they would be injured by them; but why should they be left uncared for? Why is hooping, netting, and all the covering up to be given to the tulip, and none to the carnation and picotee? Let the carnation be fairly treated, and it will reward the cultivator for his labour, and want nothing in popularity.

We are unable to obtain from Mr. Marsden the parentage of Ringleader, Mr. M. having mixed his seed saved from several varieties. It was first bloomed in 1849, and was sold out last autumn, the stock then being under twenty pairs. We are afraicl it is not a vigorous grower. Blooms were sent to Mr. Wuod, whose opinion (a very flattering one) will be found at page 279 of last year's volume, under the initials H. I. Flattering, however, as his opinion is, we have the assurance of one of the leading cultivators of the West Riding, that "it (Ringleader) is nothing to Ely's seedling" (Sir Joseph Paxton, sent out last season, by Mr. Ely), so our expectation, in common with many friends, is not a little excited.

Mir. Hepworth informs us he has never yet had the pleasure of seeing Jenny Lind, or Lorenzo. This, coupled with the belief that Jenny has "no character, either for form, colour, or marking," sufficiently accounts for the supposition that President surpassed her. If spared, we shall look with much pleasure to the prospect of seeing President; but we must candidly say, without the slightest expectation of its surpassing Jenny. We know of nothing at present to touch it, unless it be General Monk, which we see has been described as being "rather rough," a very great delusion, in our opinion. We have too, seen a letter from that eminent veteran raiser and father of the "carnation" fancy, Mr. Puxley, in which he says, "The seedling which opened last, last year, I expect to be something very good. It is rather thin, but its qualities in other respects are admirable. The white the purest possible, the pink and purple most brillinnt, and the flakes the 
most distinct and regular ever seen." Coming after Jenny, what must we not expect? Mr. Puxley also says, speaking of Madame Sontag (R.F.), which excited quite a furor last season, "I think you will find much better rose flakes amongst my seedlings of last year." And very welcome they will be, say we.

E. S. D.

Perhaps some of our friends whose correspondence is not probably of a very extensive character, will permit us to remind them that it is quite unnecessary, when addressing private cultivators of flowers, to append "Florist" to their addresses. We do not mention this because the term is disliked, but simply that it is unnecessary and inappropriate. Who would think of writing to a geutleman known to be fond of music, as "Musician?"

E. S. D.

\section{CALENDAR OF OPERATIONS,}

FOR MAY.

\section{GREENHOUSE.}

Most soft-wooded plants (as geraniums, calceolarias, cinerarias, \&c.) are very liable to atlacks of greenfly, at this time; and as the beauty and luration of their flowers depend so much on being entirely free of this pest, every attention must be paid to ensure its destruction. This should be done by fumigating the plants well, hefore their flowers begin to expand.

Encourage by every available means a fine growth in such things as fuchsias, balsams, browallias, cockscombs, amaranthuses; \&cc. Chinese azalias, that have done flowering, should be encouraged by repotting, syringing, and freely watering; as their flowering next year depends on the attention now given.

Elevate upon pits all fine specimen plants, that they may get the light on all sides.

Cuttings of chrysanthemums may yet be put in.

Give air early in the morning. Water plentifully all plants thut are growing freely. In hot weather, pour water upon the paths; the plants will be much benefitted by so doing.

J. BAYLEY.

\section{VINERY.}

Constant attention to tying in and stopping the young shoots will be necessary; and where the fruit is set, thinning may be 
proceeded with. Be careful to avoid touching the berries with the hands, or allowing the hair to rub against the bunches, while thinning. Take care the vines are not overloaded. Let the strength of them guide you as to the number of bunches to be left on. A good soaking of liquid manure, now and then, will greatly assist the swelling of the berries. Frequently pour water upon the paths, in hot weather, and syringe freely the walls and other parts of the house, when closing, early in the afternoon.

J. BAYLEY。

\section{FLOWER GARDEN.}

If the beds intended for massing with half hardy plants were well attended to last month, they will now be getting in good order for planting; and should the weather be favourable about the middle of the month, some of the hardiest varieties may be got out, providing they have been well and carefully inured to the open air; but if this has not been attended to, it will be better to defer planting for a few days. I have generally found from the 18th to the 24 th to be the best and most safe time for this locality. Give a good watering to the plants, as they are put out ; and when the earth is settled about their roots, let them be carefully pegged down, to prevent their being rocked about by the wind.

Roses will be much benefitted by a plentiful watering with liquid manure several times during this month. Keep a sharp look out for the rose maggot.

Cuttings of allyssums, wallflowers, iberises, phloxes, \&c. may now be put in, and covered with hand glasses. Plant runners of the Neapolitan, tree, and other violets, for a supply of flowers during next winter and spring. Annuals may be thinned and transplanted in favourable weather.

J. BAYLEY.

Carnations and Picotens. - The blooming sticks should be placed to these at once. Wherever protected by netting, thrown over hoops, as in our own collection-we beg pardon, selection-a shorter stick should be placed temporarily for the support of the plant. Watch carefully for the greenfly, and every species of vermin, and proclaim war to the knife with them. As the old grass decays, carefully remove it with the help of a pair of sharp scissors. Wherever fairly attended to, however, the grass will attain to a green old age, and will fall frou the stool, gently displaced by the young shoots-an illustration of what we may expect a few years hence, when a new generation of carnation growers shall arise to push us from our stools, and very possibly smile at some of our antiquated notions. As the weather gets warm, a liberal supply of water will be requisite; and a free use of the syringe in the evening. will tend greatly to promote vigorous health in the plants, and 
afford in their appearance a most delightful treat to the ardent cultivator, covered, as they will be, in the radiant morn, with dew drops, glistening like orient pearls. Calendar writing is proverbially of so prosy a character, that the introduction of radiant morn and orient pearls, will most likely be received as a grave innovation. However, as I will guarantee the result to all who will follow my advice, I see no reason why these figures of speech should be denied to me. By the last week in the month, some of the earliest and most vigorous varieties will be improved by top-dressing, or a gentle application of manure water; but the latter must by no means be supplied unless there is a thoroughly healthy action at the root, and should be very weak. A gond breadth of seed has been sown in this neighbourhood, and is now (April 15) rapidly breaking through.
Derby.
E. S. DODWELL.

'This month will be a busy one amongst florists, the May tulip shows coming off towards the latter end. All accounts agree that these flowers are remarkably strong and healthy, and everything promises well for a splendid bloom. As soon as the buds begin to show colour, get the top cloths on, giving abundance of air at the sides, to prevent the stems being drawn. The flowers will require steadying. This is best done by procuring some nice peeled osiers from the basket maker, cutting them to the required lengths, and inserting them so that with four pieces of strong metallic wire, each stick will support four Howers-one end of the wire being round the stick, whilst a loop, like that at the end of a skewer, clasps the stem. During the bloom, attend to impregnation and cross-breeding. Let your experiments in this way be confined to flowers of the best form and greatest purity. Do not cross bizarres with byblomens or roses, but keep each class to itself.

Ranunculus beds must be watched. Fill up all cracks on the surface, and keep the beds perfectly free from weeds. The hot weather during April, has been against these flowers, which delight in a cool and shady situation.

Look over the trusses of flowers which are now declining, and p!uck out the decaying petals. Take care that seedlings which have shown any good properties, are properly marked and numbered.

Auriculas should remain on the stage to which they have been removed when in bloom. In default of such convenience, they may be placed in an eastern, or north-eastern, sheltered situation, standing the pots on ashes, or perhaps what would be better, on a border laid with asphalte, or gas tar.

Pinks will require their sticks to be placed forthwith. Where plants put up more stems than their apparent strength ill support, they must be reduced. Old stools, or last year's plants, will be found hest to save seed from. 


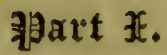

\section{ORIGINAL CONMUNICATIONS.}

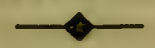

\section{NOTES ON RASPBERRIES.}

Nor having seen a notice in your valuable periodical of that very useful and desirable fruit the raspberry, I am induced to send you a few notes of sorts which I cultivate, trusting that they may be of service to some of your readers. In this neighbourhood they are grown extensively for market, and on wellmanured land produce abundantly, the demand for the red sorts being very great. I may observe, that in the market gardens here they are planted in rows, east and west, about four feet asunder; the shoots are bent or arched over, so as to meet each other, and tied with a willow twig. This leaves the centre of the plant open, and gives room for the shoots to rise without interfering with those of the previous year, which are in bearing. In the autumn, the usual plan is to cut the dead shoots away, fork orer the land, remove the suckers, and top-dress with good rotten horse dung. The bearing shoots for next year are thinned and tied as before. I will now attempt to describe the sorts I grow. Of yellow or white ones I have only two, the Yellow Antwerp, which is decidedly the best, and

The Magnum Bonum.-A most robust grower, throwing up an infinity of suckers. It is well flavoured, and both it and the Yellow Antwerp are much used for dessert.

The Red Antwerp, also known as the Red Prolific, was raised, if I recollect right, thirty years or more ago, in your county, and came up accidentally, amongst a quantity of the Yellow Antwerp. This I find of very good flavour, fine colour, and bears well.

JUNE-VOL. VI. 
Cornuall's Victoria.-Originated, I believe, at Barnet, near London. Of very robust growth, splendid colour, fruit large and remarkably juicy. One of the best I cultivate.

Ratter's Giant Raspberry is no giant at all. It is red, and bears well, but I am much disappointed in the sort. I have now given it three years' trial, but shall discard it after the next fruiting season.

Northumbrian Fillbasket.-This I admire very much, and if I am not mistaken, it will supersede most other red varieties. The fruit is large, of fine colour, and not so acid as other sorts. The canes are very large and distinct, so as easily to be distinguished from any other sort, some of mine, this year, being as thick as my thumb, and fully seven feet in height. It also has the property of bearing late in the autumn.

The Fastolff or Filby Raspberry has been much praised, but certainly, as far as my experience goes, it does not equal the preceding sort. Nevertheless, it bears abundantly, is a strong and vigorous grower, sells well in the market, and is extensively cultivated.

Rogers's Victoria.-I only notice this so say that I shall discard it, "root and branch," if possible, this season. It is a " weedy thing," the fruit acid, sometimes almost tasteless, a double-bearing autumnal sort, but good at neither season.

Monarch.-This I had from your neighbourhood, and find it a most prolific and good-flavoured sort, very dark red, and the fruit more conical than previous sorts named. It bears carriage better than any other variety I am acquainted with.

Scalter's Victoria is not very large, but of good flavour, and will be useful as a dessert fruit, in conjunction with the Yel. low Antwerp.

I have one or two other new sorts to try this season, and if worth recording in your pages, I will forward my notes on them.

JAMES WILSON.

WAX FLOWERS.

Havisg seen a remark in your number for April, respecting the exhibition of wax flowers at horticultural shows, I am tempted to say a word or two, founded on the result of a few years' experience. Six years ago, I suggested to the committee of the Handsworth and Lozells Horticultural Society 
(under whose auspices the national tulip show was held), that wax flowers would be a pleasing addition to the usual attractions of a floral exhibition. My proposition was promptly met, and from that time to the present, have beautiful and interesting collections of wax flowers always graced the tables. Occasionally have papier mache writing cases, desks, \&c. been presented to the successful competitors, but handsome books, consisting of poems, travels, dc. are the usual rewards. When single specimen flowers are exhibited, without glass covers, and arranged similar to natural ones, the deception is so complete that many visiters notice and frequently speak of them as collections of cut flowers.

Although the art of making wax flowers has arrived at great perfection in this neighbourhood, I have never yet seen, what I consider would be of great service to many amateurs, viz. models of what our florists' flowers should be. If perfect wax models could be shown of such flowers as the tulip, dahiia, carnation, auricula, pink, \&c. and be approved by competent judges, how much writing and quibbling might be saved. I hope, in a year or two, to see this idea carried out.

One great difficulty has generally arisen,-that is finding persons sufficiently competent to judge the specimens. The plant and flower judges invariably look frightened at them, as if they were something dreadful to encounter; and no doubt they have good reasons so to think when they come to be appealed to by the ladies, and questioned as to the reasons why such a collection was placed before another. The only answer they can give is, "Such a collection approaches nearest to nature." Then they are at once met with the remarks, "This collection is composed of difficult flowers, which have rarely been attempted, and although perhaps not quite equal to the natural ones, are far more creditable than simple flowers, which a beginner could make." The fact is, a judge of wax flowers should be a maker, and likewise an 
individual thoroughly conversant with flowers of every kind. Until you can find such a person to officiate, I would not advise you to commence the task, well knowing from experience, that on several occasions, more trouble and unpleasantness have fallen to my lot from exhibiters in this one class than from the whole body of exhibiters of natural productions.

C. J. PERRY,

HON. SEC. TO THE HANDSWORTH

HORTICULTURAL SOCIETY.

\section{NOTES ON A FEW GOOD POLYANTHUSES.}

Early in May last, we paid a visit to Ironville, a little town in Derbyshire, so named from its proximity to the ironworks of the Butterly Company, and which have in fact called it into existence, being inhabited by the workmen there employed. Our visit was not exactly to view the gigantic blast furnaces and the stupendous machinery, with which we were highly gratified and amazed; nor did we forget to look at the spacious infant and other school rooms, most substantially and excellently built, the beautiful church, the mechanics' institute, \&c. all of which redound to the honour of Messrs. Wright \& Jessop, the proprietors of these extensive works. The latter of these gentlemen has been by an all-wise Providence removed from his sphere of usefulness, and his mortal remains had been interred only the day before our visit, followed to their last resting place by fifteen hundred sorrowing workmen, whose improvement, comfort, and happiness, he, during a well-spent life, had so sedulously promoted. Our visit was to an old friend and florist, Mr. H. Godwin, who cultivates most florists' flowers extremely well, and that within half a mile of the extensive furnaces we before alluded to. If we were gratified with what we had previously seen of man's perseverance and ingenuity, here we had cause to admire an assemblage of floral 
beanties most delicately and elegantly formed by the the Master Hand who likewise formed the universe; and we must say that Mr. G. had, in this bleak and rather sterile part of Derbyshire, succeeded in blooming one of the finest beds of hyacintls we ever remember to have seen. The collection was in full flower, and covered with a nice awning. A seat was placed at the end of the bed, and here we sat and admired the beautiful forms and colours, whilst an indescribable perfume filled the air which floated round us. Certainly we would advise our readers who have not yet planted a bed of hyacinths to do so. They may be purchased at a very moderate rate, and with a little care will afford an immense amount of gratification.

Mr. Godwin's polyanthuses too were very strong. and in fine bloom. They were grown in large pots, plunged up to the rim in sawdust. Amongst the sorts which were particularly fine, were Hufton's Lord Lincoln, a really splendid sort, and when well grown, comes very nearly up to the standard of a perfect polyanthus. We have seen this fine sort very well done this season by onr friend, Mr. Samuel Hammond, of Radford, near Nottingham. As a red variety, certainly the very best was Addis's Kingfisher. This we noticed favourably, when sent to us as a seedling, for an opinion, and we are glad to find it still maintains its reputation. It trusses remarkably well; we have seen it this season with fifteen fully expanded pips, fit for any exhibition. Croshaw's Exile was also very good, though in its oharacter partaking somewhat of Hufton's Earl Grey, a slight foxiness being perceptible between the ground and body colours. Cheshire Favourite was extremely well bloomed, and certainly must hold a high position, being a very steady and well-laced dark flower. There were several pots of Bullock's Lancer, a lively crimson variety, nicely laced, but not so large as Kingfisher. Buck's George IV. was very strong and luxuriant, but what it gains in size it loses in neatR 2 
ness; still we should say that this would be a good parent, crossed with such sorts as Lord Lincoln and Cheshire Favourite. Amongst others, there were some strong.plants of Alexander, an old sort, which is not often seen in this part of the country. Its rich dark velvet ground colour and bright yellow lacing make it very attractive, but it wants smoothness of lacing and a sumewhat better form. Ordoyno's or Bowley's Bolivar was large but coarse. The ground colour of this flower is too large in proportion to the yellow, as was the case also with Lakin's George Canning. Mr. Godwin gave us to understand that his plants were grown in one-half decayed turf, the other half being rotten leaves and sharp sand, in equal proportion. He considers that they should be kept from the direct rays of the sun as much as possible; and when expanding their blooms, an occasional dose of weak liquid manure, made with sheepdung, he finds of great service. Simple as these directions are, his flowers were amazingly fine, and the plants in the most robust health imaginable; and we are convinced that much of the imaginary difficulty of growing these plants in the south of England would vanish, were his method followed.

\section{RESULT OF AN EXPERIMENT IN RAISING SEEDLING ROSES.}

I CANNOT, conceive anything more congerial to the wishes and taste of an individual, high or low, young or old, who has got the organ of philoprogenitiveness largely developed, than the raising of a batch of seedlings of any kind. This seems to create hope where there is none, and give cheerfulness where melancholy would have reigned rampant. The carefulness in hybridizing, and selecting the seed; then the time of sowing, soil, and situation; again, the peeping up of one seed after another. Indeed the 
various stages of the process are so numerous and interesting that a volume might be written on it.

At last comes the blooming season, and oh what anxiety. Great hopes are entertained of this or that plant, because when he looks at the mark put to it, if a rose, he finds that it has been obtained from seeds of Paul Joseph, Acidalie, or some other fine Bourbon, or perhaps from no less fine hybrid perpetual, as Geant des Batailles, or Duchess of Sutherland; if a tea, oh this was raised from seeds of Elise Sauvage, or Moire; or if a tulip, he says this was from Polyphemus, or Salvator Rosa; and so on. If his attention has been turned to the auriculas, those chaste and lovely flowers of spring, he is no less delighted in watching and looking at them, for he is heard to say, those 1 raised from Dixon's Matilda, or Unique, and so on, through as many groups as you wish to run.

Now, as I have shared perhaps as largely in this pleasing pursuit as most individuals, and am not tired of it yet, if I make two or three remarks on what I have observed, and give you a specimen or two, to prove my statement, and show my success in raising seedling roses, I trust they may not be altogether without interest to your readers.

It will be remembered that last spring I gave a paper on my success in raising the rose seeds $I$ had sown, and those who were rose fanciers would, no doubt, have their desires excited to know what new rarieties would be obtained from them. I therefore send a bloom or two from those plants raised last spring. One from Geant des Batailles, very vivid and a fine foliage. This will improve when grown a year or two-(a remarkable fact, noticed by Mr. Rivers, in his Rose Guide, that the rose half double when a seedling will by and by become full double.) The one from Ruga is a very sweet and promising noisette. 'The little double white is from Madame Laffay, very different to its parent. That from Emilie Courtier is very promising, the seedling plant being only like a straw yet. The one from Yellow 
Tea will, by cultivation, become more double. One from Fulgens is rery vivid and singular in its large leafy calyx. That from Armosa is very much like the Curled Provence, and will prove a nice variety.

Here you will perceive how great the resemblance to the parent in some, but yet how very dissimilar in others, proving to a demonstration that no one is warranted in saying what any rose has been obtained from, unless he has gathered and marked the seed. It may be interesting to know that from the seeds of summer roses I have raised some of the most decided perpetuals; and from climbers, roses of the opposite habit, and of a different blooming season. So diversified were a large batch of seedlings from the old China rose, which I gathered and sowed with my own hand, a month or more after I liad sown all my other seeds, so that I was certain no mixture could possibly occur. From this I have sometimes felt inclined to question if there be a native rose like the one originally introduced, and to ask myself, may it not be only a variety, like many of the plants sent us from China? As a reason for my entertaining such an idea, I will give a short description of the batch I have above alluded to. 'Two or three of them, to all appearance, were boursaults; two were what we call hybrid Chinas-one as dark as the old Tuscany, but too thin; the other, a very interesting rose, with short petals, I call Willison's Shell Rose. Another, which would class with Riego, very globular and of the inost delicious scent, I call the Governor. 'Two of them were very dwarf and bushy, most like sweetbriars, and the flowers were worthless. 'Two or three, which have not yet bloomed, are evidently of the class we call hybrids. The rest were much like the parent, excepting that two or three were almost spineless white noisettes, of no particular merit. Such was the strange brood.

As those few sent were the first to bloom, when the others, many of which are very singular and promising, flower, you shall see or hear of them. 


\section{积art XF。}

NEW, RARE, OR GO0D FRUITS, FLOWERS, PLANTS, TREES, AND VEGETABLES.

Great accessions have been made to American seedling camellias, which already dispute the palm of excellence with the finest of the Belgian and Italian varieties. Mr. Kurtz, an amateur, of Baltimore, has raised two very fine seedlings; one is a blush, distinctly striped with pink, and finely imbricated to the centre; and the other a deep rich rose, double, and finely imbricated. Messrs. Hovey \& Co. have produced several splendid sorts, particularly distinct, and entirely new in colour. One is a pure white, elegantly flaked with crimson, with a petal as entire and perfect as can be imagined, and imbricated to the very centre; another a dark marone, and a third a crimson scarlet-both remarkable for form and colour. Mr. Wilder has a fine new one, of similar colour to Wilderii, but larger, and much fuller and better formed, though not so good a petal. He has others of less merit, but far superior to many of the foreign kinds, which have had a high reputation. Messrs. Winship \& Co. have also a seedling, very handsome, something in the way of Duchess of Orleans, but rather better, being a free bloomer.

In hardy trees and shrubs we have not much to communicate. Pavia purpurea (the Purple-leaved Pavia, or Horse Chestnut) is singular, and worth inquiring about. Just now, one of the handsomest small trees in our nursery is the Genista purgans. Grafted standard high on the laburnum, it is really a beautiful object, having a complete head of innumerable gold-coloured flowers. The seedlings from the 
Pink Persian Broom will very often come correct, but sometimes revert to the White Broom. Some that we have now blooming have a large blotch of deep rose at the back of the upper petal. Pince"s Queen Victoria rhododendron ought to be grown by everyone who can manage this tribe. The flowers are produced in trusses of deep claret, or crimson purple. It is magnificent. R. Albertus too is very good. French white, with large black spots in the throat. R. campanula picta is splendid, being very delicate lavender, with deep purple spots. We have, this last spring, added at least fifty named sorts to our collection.

In hardy herbaceous plants, Dielytra spectabilis is certainly one of the most beautiful. At Wood Hall, Norfolk, it has stood in the open border, covered only with cinder ashes, in a south east aspect, in very heary soil. It is two feet and a half high, with seventeen spikes of flowers, and is one of the most showy plants imaginable.

A new turnip, called the Orange Jelly, is talked about; rather a singular name, but it is highly recommended for quick growth and excellent flavour.

\section{FLOWERS RECEIVED SINCE OUR LAST REPORT.}

AUriculas.-R. W. R. - No. 18, a very fine green-edged flower; paste dense and circular, body colour very dark, of large size. No. 4 , a nice lively flower; the paste beautifully white, the ground colour dark, and well laid on. These are both firstclass flowers. Name them forthwith. No. 1, white-edged, the colour breaks through to the margin, faded. No. 9. shrivelled up when received.

Polyanteuses. - W. S.-Your flower has certainly some pretensions : the ground colour is rich velvety crimson, the lacing good, and broader than usual (we have seen Nicholson's Gold Lace as broad), but it is defective, inasmuch as it breaks, or is not continuous. Still, for its very fine colours and good form, we should keep it as a stock plant, to seed from. Something good would most surely result. 
W. T.-Yours certainly is Pearson's or Lee's Alexander, a good old sort, but in a great measure superseded.

R.- Yes; Buck's George IV.

Cinerarias. - Nemo. - A beautiful flower. You should have sent its intended name.

R.-Pixie Queen is hardly fairylike, being coarse and inferior to many of a similar character out.

Tulips.-A Beginner. - Your six flowers are-No. 1. Lord, Milton, broken originally by us, at Chilwell, and sold out by the late Mr. John Pearson. We do not consider it more than a second-rate flamed bizarre. It was shown at the Corn Exchange, Manchester, in 1850, under the name of Lord Stanley. No. 2 is evidently Chellaston Beauty, a shortcupped feathered bybloemen, and when in good character, a nice thing. With regard to your query, whether it is a feathered Countess of Harrington, we are unable positively to say, though those who profess to know more about these flowers than we do, declare it is. No. 3. Duke of Clarence, a tricolor, useless at present as a show flower, in the northern and midland counties, but makes a noble fourth.row bed flower. Keep it, by all means. No. 4. Heroine, a fine strain of Triomphe Royale, one of the best feathered roses we have, and no bed of any pretensions should be without halfa-dozen specimens of it. No. 5. Osiris, a lively flower. Examine it, and you will find it is stained, and therefore useless. No. 6. Bienfait. This, although a very pretty flower, is slightly stained at the base ; nevertheless, the strain is so good, being certainly one of the best we recollect ever to have seen, we would advise you still to find a place for it on your bed.

Calceolarias -J. S., Blackburn.-No. 7 (Conqueror) is of good form and pretty, the white is pure, and the plumcoloured markings distinct. It wants size; but as you say that you have grown them in poor soil, and that they have suffered severely from greenfly, it will probably improve with better cultivation. Under those circumstances, we should like to see it again. Nos. 1, 4, 6, and 3 we would try again. The rest yuu may throw away.

Scarlet Pelargoniums.-X.X.-Queen of May. We wish we could say your flower was like your signature, double $\mathrm{x}$. It is of good colour, but wants form.

W.M.-A flower of the Lucia Rosea class. Like the preceding one, it wants outline.

Miscellaneous.-Rector.-Your shrubs, of which you send specimens, are-No. 1. Cercis Canadensis (The Canadian Judas Tree). Perfectly hardy. Singular, from the circumstance of its flowers being produced before the foliage. It will look well trained against a wall. No. 2. A small shoot of the Pinus insignis, one of the most beautiful of the pine 
tribe. Quite hardy. No. 3 is Glycine sinensis, a splendid plant for verandahs, trellises, or similar situations. It will sometimes remain for a year or two without moking much progress, but when established, it makes shoots of a great length in a season. No. 4 is unknown to us, but looks like one of the syringas. It is evidently of that family, but we cannot speak positively to its name.

\section{RETROSPECTIVE CRITICISM.}

\section{GROUPING OF COLOURS IN A TULIP BED.}

Being led to suppose, from your note at the foot of Mr. Wolfe's remarks on my paper, in your January number, you had anticipated my nonresistance principles, which was perfectly correct, having said to a friend, with a smile, when I read over what had been said by my friends, Mr. Wolfe and Mr. Harrison, I shall not take any notice of this; but thinking it only right to thank you for your kindly and appropriate remark, and to show my friends who differ with me that I can do so, afford to do so, and on my part perfectly agree to do so, I would not dogmatize, nay, I would not be thought to have such a wish, if I could prevent it, I so much detest it. You have well said, " many men, many minds," therefore as one of the men in the north, perhaps not so highly favoured as our southern brethren, I gave my mind, not at all wishing to mislead any young beginner, and I think if fairly looked at, the scope of my paper will show that it did not apply to a small collection. One especial advantage arising from my mode of planting, I might have noticed in my last, was that of bringing doubtful varieties side by side, so as to compare foliage, height, shape of cup, colour, bottom, stamens, \&c. Now, were I inclined to wage a war of words, or show a bad feeling towards those who differ 
with me, I might say much, and never be done with it, and say what would hare been far better unsaid, as is too often the case in matters of this kind.

Now, as I do not want to be hard on any, in my proposal, I do not intend testing my friends in the way Moses Roper, the runaway American slare, did, who, while in England, I think in the south, was showing the cruelties practised on the South American slaves, and exhibited, among other implements of torture, the immense whip of the driver. He was opposed publicly by a Tertullian orator, who said that it was not possible that any man could wield at arm's length, over head, this huge weapon, from fifty to one hundred times, without being exhausted. Moses, not expecting to meet so eloquent an opponent in a land where he had hoped all were friends, rose in reply, stating that as he was not such a master in English terms as his opponent, he wonld not engage in a conflict of words, but make a simple proposal and then leave it for the audience to judge of the fairness, which was this, that if the said gentleman would go out of the meeting and allow him to make proof on his back of what he had stated, he had no fear of proving the truth of his statement to a demonstration; if, however, he should fail he would allow himself to undergo the flagellation. This appeared so clear and so satisfactory to the gentleman, that he was completely silenced, and the lookers on quite satisfied. My proposition is this, that if my friends will only be kind enough to pay my tulip bed a visit when in bloom (and I assure them I shall be very happy to see them, even those who differ with me-I think we should understand each other better when we met), and they find it not as I have described, they shall publish my error; but if, on the other hand, it be so, they shall have courtesy enough to acknowledge that my plan would at least do when applied to my bed.

Now, in respect to Mr. Harrison's remarks : although we do not agree in opinion, I can thank lim for the mild and inoffensive way in which he has JUNE-VOL.VI. 
treated the subject in hand; indeed, I have often felt pleased at the useful and friendly papers written by him. It would be well if all the writers in your pacific little magazine would follow his example. How much better would it be in scientific, as well as in theological matters, were we sometimes to see how near we agree, rather than how far we disagree. I am sure by the first of these we should make more friends; and as man is, after all his acrimony and contradiction, a social being, ought we not rather to adopt the first. I am fully persuaded that this would increase the readers of the Midland Florist as well as other monthlies, and might induce many to give the experience of accumulated years; but fearing that some ruthless hand would exhibit to public gaze any little defect in expression, or otherwise, instead of acknowledging the thanks due to them for their valuable information, they are afraid to make the attempt. I hope these few remarks will be as kindly taken as they are given.

WILLIAM WILLISON.

Flower-gate, Whitby, March 12, 1852.

\section{CARNATIONS AND PICOTEES.}

Notwithstandivg the remarks in your last number, I am still convinced that there is some difference in our opinions and yours respecting carnations and picotees, and that many varieties raised in the south and midlands will never do for the north. This is evident from the description given by your correspondent, Z, in the last year's volume, pp. 291 and 369. Many described there as the best in their respective classes are but little esteemed here. This arises in some measure from the florists of the midlands and south having a taste for large full flowers, whilst, on the contrary, we would rather see a thin flower than a very full one. We consider from twenty to twentyfive petals quite sufficient to constitute perfection, and 
if a flower has only fifteen or eighteen good sized petals, we admire it more than one with sixty or seventy, many of which are only the size of what a single stripe of colour ought to be. Any one will admit that the larger the petal, the more space for displaying the marking. Then we do not admire pale rose flakes and pink and purple bizarres. Duchess of Devonshire and Lady Ely are considered quite pale enough for rose flakes, and Lord Milton for a crimson bizarre. Showing on cards is another system which we can never agree with; flowers that are not compact enough to do without cards to hold them up will never do for us.

Mr. Dodwell has misunderstood me with regard to Leader, William Caxton, \&c. My meaning was not that they were the crack flowers here; but that they were steady varieties, and that they were admired for their steadiness. Neither did I intend to convey the idea that Admiral Curzon was our crack flower. Undoubtedly it is a first-rate sort, but there are varieties which are considered equal to it bere. Music surpasses it in form; Lord Rancliffe is considered by many to be superior to it, and I must say that I have seen Rancliffe as good as ever I have yet seen Curzon. At our horticultural show, at Halifax, last year, Ringleader was at the head of the class, and Music next to it, and there were plenty of good Curzons exhibited there.

I must still say that Lorenzo will not do for the north. I made many inquiries respecting it, of parties who have grown it, and they all assure me that it is worthless. I have never yet seen the flower, but I have it from persons upon whose judgment I can rely. A friend of mine, who grew two pots of it, last season, would not take the trouble to layer it, because he did not consider it worthy. Mr. Dodwell may say that the stock was not healthy; but such was not the case, and they had the same attention, if not more, paid to them that the other varieties had. 
With such assurances, whatever may be the opinions of Mr. Dodwell, Mr. Turner, or Z. I am bound to believe that it will not do here.

Jenny Lind I have seen, and the opinion which I expressed of the flower I saw, is correct. But I am inclined to think that it was a premature bloom; that is, that the layers had spindled before the proper time, as they frequently do when overgrown. Still I think it will be of little use here; for a friend of mine could not bloom it before the middle of September, not even with the aid of a hand-glass, and the plants were in good health. No doubt it will do for the south, where the climate is more suitable for blooming late flowers than the bleak hills of Yorkshire. Alfred could not be got into bloom before the beginning of September, and in some situations not so soon. It may have been exhibited on July 19, but how were the plants grown? perhaps in a conservatory, or a tent. Now we do not believe in making carnations and picotees into greenhouse plants. According to our ideas, they are hardy plants, blooming at a time when there are no frosty nights, no hail or snow storms to protect them against, and therefore need no tents or conservatories to defend them. We believe it is more injurious than otherwise to the plants to bloom them in this manner. All the protection we give them is to place a board, about a foot square, over the blooms, to keep them from the sun and rain, and that is all they require.

As to Mr. Dodwell's challenge, it would be folly in me to accept it; and the reason is simply this, that on the 4th of August, not one-tenth part of the carnations and picotees, either in Yorkshire or Lancashire, will be in bloom. It is well known that even in the most forward situations, in the West Riding, the general bloom is not before the 12 th or 16 th, and in my situation, not before the 20th. It cannot, therefore, be considered a fair trial, as Mr. Dodwell will, most likely, have twenty or thirty pots of Alfred 
in full bloom at that time. I hope, therefore, that Mr. Dodwell, on these grounds, will excuse me from accepting the challenge. If 1 can make it convenient, $I$ will be at Derby on the 4 th of August, when I hope to see the flowers in question in good style.

GEORGE BAILDON.

Shrogy's Bottom, near Halifax, April 19, 1852.

Mr. BaILdon having sent the above paper to me, I will at once offer a few remarks upon it. And first, 1 must assure him he commits a grave error when he assumes as a fact, that the florists of the midlands and of the south have a " taste for large full flowers," containing "sixty or seventy petals." In the April number, I gave a list of those varieties most esteemed by us. Can Mr. Baildon name one of those which has "sixty or seventy petals," many of them not larger than the "stripe of colour should be in a good flower?" Quite as erroneous is Mr. Baildon's conviction that there is a difference of opinion between us; that is, as I am bound to assume from the context, that we are content with deformity-placing a large full flower, inferior in colour and imperfect in delineation, before one which may be faultless in outline, spotless in purity, and of the most brilliant colour, but containing a lesser number of petals. We require that the flower shall be the nearest possible approximation to a hemisphere - that the outline shall be broken as little as may be-that the white or ground colour shall be of unblemished purity - that the colour (of whatever shade) shall be rich and distinct, and unbroken in its delineation - the petal of good substance, gently cupped, and without the slightest serrature on the edge. Will Mr. Baildon point out wherein the cultivators of the West Riding differ from this?

Colour is a subject on which tastes may legitimately differ. Our friends may therefore arcept or reject a pink and purple bizarre, or a pale rose flake, at their pleasure. Yet, perhaps they will permit me to say, with no feeling of pedantry or discourtesy, that when their tastes are more cultivated, they will find in these just as legitimate grounds for acceptance as in flowers with darker and stronger colours. Form alone is primary, and cannot be dispensed with. Colour is secondary, and may be of an infinity of shades, always providing that it be rich and distinct, and unbroken in its delineation.

Showing on cards is not practised here because our flowers are not "compact," or able to dispense with that assistance. Mr. Baildon will learn this when we have the pleasure to see him. Then too, Mr. B. will find that we do not describe s 2 
flowers as " best of their class," or desirable, which have " no - character about them, either for form, colour, or marking." And when he has becume acquainted with our culture, he will no longer suppose that we make "greenhouse plants" of them, or attempt to grow them in "conservatories or tents." But after having bestowed upon our pets a twelve months' care; after having rested them during their period of rest, and with painstaking trouble watched and guarded them so as to keep up a continuous growth when growth has naturally commenced -after having done this, and attained the threshold of that climax of a florist's joy, a fine bloom, Mr. Baildon may come to the conclusion that there is no more harm in placing them under a glass roof appropriately shaded, or a neat awning, every cloth of which may be remored in five minutes, than in putting over them a board, a foot square; and that the former, whilst it thoroughly protects from sun, rain, and wind (the latter being by far the most destructive element), at a time when protection is imperative, affords every opportunity for constant inspection, and a minute noting of varieties in every phase of their development; being, in fact, a daily exhibition, from the bud to the bloom, and yielding an enjoyment and an experience in one season, which it would take seven of the board system to realize.

What Mr. Baildon now says of Lorenzo, and what he said in his former communication, is very different. It may be that Lorenzo will not do in the West Riding. Being without ex. perience, I cannot determine this. But what Mr. Baildon said in the April number, was, simply, "There must be some difference between our judgment and yours. For instance, May's Lorenzo was pronounced A 1 of its class, and relying on the strength of the opinion given, I applied to procure it, but I have been informed by different parties, that it is not worth the trouble of layering; it has no character about it, either for colour, form, or marking :" ergo, the midlanders had pronounced

- varieties without character, either for colour, form, or marking, as best of their class!

Of course I can make no objection to Mr. Baildon's decining the trial proposed; but if Alfred can only be bloomed in proper season by a course of "greenhouse" treatment, such treatment being so injurious to the plants, and consequently to the bloom, I cannot possibly understand how it could only be "folly" in Mr. Baildon to accept it; or how, even though one-tenth only of the flowers of Yorkshire and Lancashire were in bloom, it could not be considered a "fair trial." I mention this only to show the anomalous position assumed by Mr. B.-a position, in fact, from which he instinctively recoils. To prevent misapprehension as to my stock of Alfred, perhaps I may as well say, it is just half the quantity assumed.

E. S. D. 


\section{EXTRACTS, HINTS, AND RECOLLECTIONS.}

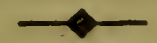

\section{WALLFLOWERS.}

THESE are general favourites; and as far back as I can recollect, were as much esteemed as now. I have endeavoured to make a collection, and forward you the names of those I cultivate. They are easily raised by slips or cuttings. These, placed in the open border, under a bell-glass, speedily take root. I should much wish to see a prize given at our floricultural shows, for the best pair, or the best six distinct varieties; for these, with stocks and hollyhocks, are some of the oldest, and at the same time, greatest ornaments of cottagers' gardens throughout the kingdom.

The Manchester Green Top is a large light yellow, with double flowers, remarkable from having a quantity of unexpanded green buds, forming a flat crown, whilst the lower ones on the spike are fully expanded. A very distinct and remarka. ble sort.

The Negro Boy.-Sent out by Mr. Charlton, of Wall, near Hexham. Very dark, but rather small. A fine contrast.

The Double Purple.-This I believe to be of foreign origin. Double singular pinkish purple flowers, very fragrant, and a distinct and good variety.

The Silver-striped. - The foliage of this variety is very prettily edged with white, flowers like the common Double, from which it is evidently a sport.

Splendidissima.-This I flowered for the first time last season, and consider it one of the best out. The-spike is large and finely formed, the individual blooms are of good size, deep rich orange, thickly pencilled with narrow brown stripes.

The Orange Wallfower.-Beautiful in colour, splendid deep golden yellow, lirge spikes, powerfully fragrant, and should be grown in every flower border. Quite first rate in its family.

Independent of these, I have four other double ones, the Common, the Small-flowering Yellow, the Bronze, and the Dark Blood-coloured. There are also sereral sorts of single walliowers deserving of 
cultivation, and from a single packet of German seed a dozen different varieties may often be got. I cannot dismiss these very nice border plants without alluding to two cheiranthuses, which make very beautiful bedding plants, dwarf and compact in habit, and extremely handsome. I allude to Cheiranthus alpinus (the Alpine Wallflower) with deep strawcoloured heads of blossoms; and Cheiranthus Marshallianus, sold out by Mr. Stark, of Edinburgh, deep orange, with a beautiful violetlike odour, one of the prettiest hardy plants I grow. Both these last are as easily propagated, and in the same manner as the others.

R. S.

PRESERVATION OF GRAPES.

You were pleased to make mention of some fresh Isabella grapes I sent you the lst of this month. To-day (March 17, 1852) we have eaten the last of fourteen boxes, each containing between one and two pecks of fruit, which I put down in October last. They retained their plumpness (except here and there a bunch which appeared a little withered), and their delicious flavour, very nearly, if not equal to what they possessed at the time of gathering. In most of them the stems had not lost their verdure. The luxury of having Isabella grapes not only all winter in great abundance, but so late as the middle of March, is worth enjoying to all lovers of that delicious fruit. The experiment having been so successful, and the method of preserving them so simple, many of my friends have asked me to describe the process, for their benefit. I have done so, and now send it to you for publication, if you feel so disposed, that the benefit, if any, may not be confined to a limited circle. In July and August, I procured a quantity of ash sawdust, from Messrs. Eaton, Gilbert, \& Co.'s coach and rail car manufactory. Ash, be- 
cause it imparts no taste to the grapes, and because it is usually obtained dry. I then sifted it, to take out the fine powder, which heretofore I found difficult to remove from the grapes, when taken out to use.

After thus preparing it, I kept it under cover until I wanted to use it, when it was sufficiently dry. When the grapes were fully ripe, in October, I picked them, and immediately packed them away in boxes (old soap and candle boxes, without covers), putting in first a layer of sawdust about half an inch thick, then a layer of grapes in bunches, the bunches as close together as they could be placed without crushing them; then a layer of sawdust just thick enough to cover them, and so alternately a layer of grapes and sawdust until the box was full, the boxes containing four and five layers. After packing them, I piled the boxes one on top of the other, the bottom of one box forming the only cover of the one underneath. I kept them in one end of my wood shed (enclosed) until it became freezing weather, when I removed them to the cellar, in the same order. None of them have been mouldy, none of them musty. In removing them from the boxes, for use, all that we found necessary, by way of cleaning them, was to use a small dust brush, which very soon removed every particle of sawdust, and left them at once fit for use.

\section{Troye.}

THOMAS W. BLATCHFORD.

[We think this plan of keeping grapes will be of immense use to the cottagers and other growers of hardy grapes in the Isle of Wight and the south and west of England. If enabled to preserve them in two-gallon kegs (which we should prefer to soap or candle boxes, and which were plentiful in that locality in our youthful days), they would get a good price for them about Christmas. Could not Golden Drop and other plums, nectarines, peaches, \&c. be thus preserved? We wish some of our readers would try, and report progress.] 


\section{ON THE PROPAGATION OF FANCY PELARGONIUNS.}

BX J. ROBINSON, PIMLICO.

I AM unacquainted with any class of florists' flowers that stands more in need of a few practical hints as regards proper cultivation than the abore. Few plants are more interesting, or, when well managed, greater favourites, either while in bloom, or in a growing state, when fine and healthy. A small greenhouse will accommodate a great many different varieties; if only fifteen feet by ten, it will hold twenty fine specimens, and if the latter are in sixinch pots, you may grow forty. Being a successful cultivator of this variety of pelargonium for several years past, I will give the young amateur or gardener the benefit of $\mathrm{my}$ experience as respects the methods I adopt for propagation and making good plants.

I know of no better season than the present (February) for taking cuttings. Select some good tops from the very best sorts that are out, get as many thumb-pots as you will require for the purpose, fill them with rich turfy monld, and put one cutting into each pot; but previous to filling the pots, let them be well drained with broken charcoal or oyster shells, either will do. Then with your pencil, or a piece of round stick, make a hole an inch deep, fill the said hole with silver sand, then put in the cutting, and give the pot a slight blow on the potting board, to settle it firmly in the soil ; dip a piece of stick, or your pencil into some water, and hold it downwards, in order that three or four drops may fall from the same, close to the side of the cutting; this will set the whole closely together, and the quantity of water will be quite sufficient for three or four days; after that, add a little more, in a similar way, or with a fine-rosed watering-pot, as may be thought needful. When you have finished this part of the work, let all the pots be plunged into a slight bottom heat, say 
from sixty-fire to seventy degrees; give a little air in the day-time, to prevent the cuttings from damping off; and as soon as they are rooted, they are established plants; not like some of the nurserymen's poor sickly things, from which it is impossible to make a specimen fit for exhibition, and which you must grow along in the best manner you can, till you can get a cutting from them, at a great loss of time.

I do not recommend the practice of putting a great quantity of hard-wooded cuttings into one pot; two out of three will take root, when you spoil several in getting them apart; strong cuttings struck singly in pots, as directed, and well managed after they are rooted, will make fine specimens by $\mathbf{J}$ une or July the following season. I have exhibited plants in July, two feet in diameter, that were taken off the parent plant shewn at Chiswick in July the previous year; but you will not find many of the sorts do this; most of the varieties will, however, make good specimens by the time stated.

In a future number, I will give a few practical hints on their general culture and management, and also respecting the soil I have proved from long experience to be most suitable for them. In the meantime, I trust that what has been written above may be found of some service.

\section{Turner's Florist.}

Kate Conyor 'Tulip.-Of course we have a reason for everything we do or say, at least we hope we have. At the Manchester show, in 1850, we saw the above flower with seven or eight petals, and though out of character, we spoke approvingly of it. We have not had an opportunity of judging of its merits since, though our friend, Mr. Chippendale, broke it finely feathered, which we duly recorded, and from his information, we suppose it to be a good sort. In supplying Mr. Willison with a list of tulips, we mentioned those only which we had seen good, leaving those which we had only heard about 
till a future time, promising them ample publicity in our pages, when their merit was established. The question is, who raised Kate Connor? We know a gentleman who has at least twenty bulbs and offsets of the breeder, and who seerns inclined to claim the honour of its parentage. Perhaps some of our friends will give us its history.

Ardsia Crenulata.-In the conservatory of $\mathrm{Wm}$. Cartledge, Esq. of Woodthorpe, near Nottingham, we saw early in March, two beautiful specimens of this plant. They were compact pyramids of scarlet berries, set off with rich green foliage. This plant ought certainly to be grown in every warm greenhouse. As a fine contrast to this, we have just heard that M. V. Houtte, of Ghent, has plants on sale, at 12s. 6d. each, of Ardsia crenulata fructu albo, or the White-berried Ardsia. It was obtained from M. V. Siebold.

Ceanothus Rigidus we saw at Derby arboretum, a short time ago. It is an erect, compact, and beautiful hardy shrub. Dr. Lindley says "it is the hardiest and best of the Californian ceanothes."

The Double White Peach, from China, is stated by the same authority to be very showy, and a great acquisition. The red variety is very brilliant, but is most handsome when not fully expanded. We have no doubt these will make a beautiful display, with our other early-blooming hardy plants.

In the Horticultural Society's garden, at Chiswick, near Losdon, there are large bushes of camellias growing on the north side of a wall. It appears the flowers require some protection. Why cannot we have walls covered with these beautiful plants? If these were built so that we might have fitted to them an iron framework, filled with rongh plate glass, to slide in grooves, thousands of flowers would be thus produced, which would pay abundant interest for the first outlay. 
Hydrangea Hortensis. - A most splendid hardy plant in the sonth of England, with immense heads of pink flowers. By adopting a certain mode of treatment, which Mr. Florendine has described in a previous volume, these flowers may be made blue. We have seen fine specimens at Clifton Hall, near Nottingham. In this character it is a most gorgeous greenhouse plant. A very fine new variety has been raised by the brothers Rovelli, of Palanza, the leaves of which are mottled with pure white, in the way of the Aucuba Japonica.

\section{R E V I E W S.}

The Gardener's Record. By Mr. I. T. Neville. No. 3, May,

Contains a continuation of the interesting article on the tulip, by C. L. Crook, Esq. A Description of a few Carnations and Picotees (varying from that of Mr. Newhall, in the April Number), to which, with all our "non-intervention" ideas, we are obliged to make an exception. For instance, Admiral Curzon is neither a shy grower nor delicate, here; so we must suppose that there is something beneficial to flowers, as well as to human beings, in native air. We quite admire, however, Mr. Proctor's anxiety to improve Mr. Newhall's list. How far he has succeeded, his brother florists will be the best judges. There is nothing like diversity of opinion, and the consequent discussion, to arrive at the truth. The number, as usual, is good, and, as we have before observed, got up in very nice style.

The Horticulturist. By A. I. Downing, Newbury, United States.

WeLL got up and well written. The first is a very clever article on the Improvement of Vegetable Races, 
which we hope to profit by some day. Diseases of the Peach Tree; and then a sketch of the largest dessert pear, the Duchess d'Angouleme, a perfect monster. It weighed exactly one pound nine ounces, was of a deep golden yellow, with reddish brown specks on the surface of the skin, and of excellent flavour. The following remarks are on Fortune's Five-coloured Rose. Speaking of roses grown at Rose Hill, near Waltham, United States, the writer says, "From the specimen there presented in full flower, we are very much inclined to pronounce it a complete humbug. The bud in embryo is just like a monstrosity very common in the rose family, and when fully expanded, is little else than a cluster of half-developed leaves, struggling for the light."

There is also an account of the Snake plant of South America, extracted from Dickens's Houseloold Words, written, we should say, from its style, by Charles Waterton, Esq.; with an article on the Preservation of Grapes, which our readers may consider worth knowing, and which we have given in another page. We consider the Horticulturist a sterling work of merit.

The Magazine of Horticulture. By C. M. Hovey, Boston, United States.

The Americans "go ahead" with new fruits, and this work is a faithful record of novelties of every description. The first article is, Notes on some New Varieties of Fruits, including strawberries, cherries, pears, and apples. Amongst cherries, Bigarreau Noir Tardiff is said to be very good. The darkest coloured, perhaps, of all the black cherries, and of good size, sweet, and ripening about the middle of July. Promises, both on account of its beauty and flavour, to be an acquisition. There are also descriptions and engravings (outlines) of select varieties of pears, and we are proud, as an Englishman and a F.H.S. to see that our late lamented president's seedling pears are beginning to be appreciated 
amongst the thousands of the United States. In alluding to the Dunmore (Knight), it is stated, that the additional experience of four years has afforded a better opportunity to test their quality, "and we may now say that the Dunmore proves to be one of the finest kinds which Mr. Knight produced, excelled only, if excelled at all, by the Monarch."

There is a good article, On the Flower Garden, and on the Principles of Grouping Colours, in which is the following simple method of finding the opposite of any colour we may wish to employ:- " Form any number of concentric circles, divide the first into three parts, the second into six, the third into twelve, and so on indefinitely; then in the first place the three primary colours, red, blue, and yellow, and the same in the adjoining spaces in the second circle; in the alternate spaces of the second place the mixtures as above mentioned, which will then contain red, purple, blue, green, yellow, orange, and it will be found that red is opposite to green, purple to yellow, and blue to orange. By continuing the same process through another circle, we shall have twelve different shades of colour, and so on indefinitely." Here is something for our friends who are fond of massing their flowers to think about.

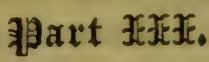

\section{ANSWERS T0 CORRESPONDENTS.}

Your correspondent, Z. complains of the carnations and picotees received from the West Riding of Yorkshire being "so dirty and diminutive that they appear as if they had passed the winter in some old-fashioned chimney." We, in our turn. must complain of the plants received from the midlands and the south. They are so tender, and of so pale a green, that they appear as if they had passed the winter in a stove or greenhouse. The first breath of cold wind withers them like hay, and it is with the greatest difficulty that we can 
rear them, so as to make them do well. We would rather have a hardy stiff layer, though it appear a little dirty (which is caused by the factory chimneys by which we are surrounded), than those which resemble tender stove plants more than anything else. I think we can produce plants as fine, either for size, strength, or healthiness, as any county in England.

George Baildon.

\section{CALENDAR OF OPERATIONS,}

FOR JUNE.

\section{GREENHOUSE.}

THrs house will now be relieved of many things; some removed to make gay the borders in the flower garden, and others to a sheltered situation. More space may now be alluwed to such plants as boronias, pimelias, polygalas, eriostenuons, \&c., and every attention given that will encourage a fine growth. Place ericas in the most airy part of the house; see that they are carefully but plentifully watered with rain water. Repot young plants and such as have done flowering, as they require it. Cuttings may yet be put in. Those cinerarias whose flowers are beginning to fade, may be planted out in a sheltered place.

\section{J. BAYLEY.}

\section{VINERY.}

Continue to thin the berries, observing the cautions recommended last month. Examine the ties to see that none of them are pinching the shoots. Five air early in the morning, and keep down plenty of water on the paths, while there is air on the house. Close early in the afternoon, and make all growth you can now. Do not syringe the berries after this time. Should red spider make its appearance, paint the pipes or flues with sulphur.

J. BAYLEY.

\section{FLOWER GARDEN.}

Complete planting out verbenas, calceolarias, heliotropes, scarlet geraniums, anagallis, and other half hardy things, without delay; and as they are put out, water them freely with water that has been well exposed to the sun and air. This will settle the soil about their roots. Rake over the beds as soon as the soil is dry enough, and proceed at onee to peg down all such as require pegging. The plants will then be secured from being blown about by the wind, and will root much sooner than if left even for a day or two unpegged. Carefully thin out and 
transplant annuals; much of their beauty depends on this being well done. Too frequently do we see them so closely crowded, that not only is the babit of the plant destroyed, but their duration of flowering much shortened. Stake and tie dablias and hollyhocks, and if the weather continues dry, water them plentifully. Frequent applications of liquid manure will greatly assist roses in developing their flowers. Look well after the maggot. The greenfly is also troublesome at this time. Syringe the plants with soap-suds and tobacco water, or dip the ends of the shoots in a basin of tobacco-water. Bud roses towards the end of the month. Cuttings of Erysimum Marshallii, Allyssum saxatile, wallflowers, and other early-flowering plants, may be planted under a hand glass on a shady border. Roll, mow, and sweep lawns and wallis, and attenci to neatness in every part of the garden.

J. BAYLEY.

Carnations and Picoters. - Tie the flowering stenus neatly and securely (not tightly), as they advance. Stop all shoots running for bloom, except the leading stems. Some cultivators remove these entirely from the plant: our practice is merely to pinch out the shoot, and we thus obtain a large accession to the increase. Top dress with equal parts of sound loam, sweet leaf mould, and well-decomposed manure. Watch continually for greenfly, and remove them with a small brush; if the points of the shoots are much infested, moisten the brush with a little tobacco-water, as needed. Syringe frequently, and water liberally when required. A liberal application of the syringe will not only promote a vigorous growth, but greatly aid in keeping. the plants free from thrip and greenfly, either of which, ir allowed to get ahead, is certain destruction to a fine blnom. Remove any decaying foliage on the plant; it is unsightly, and harbours all kinds of destructive insects. Disbud as soon as the young buds can be conveniently removed. Some discretion is necessary in this operation, and the number of blooms to be left must depend on the variety, whether full or thin in the flower, and whether for exhibition or for bearing seed. We have much interest in getting seed, and disbud scarcely so hard as we should for exhibition only. As the buds swell, a gentle application of weak manure-water will greatly assist them. In the next number we will give a list of the thinner varieties, specifying the number of buds we leave. Old stagers need none of these specialities ; but we don't write for " old stagers." We remember, when we were a beginner, how grateful we felt for such hints; and we believe there are hundreds now where a few years back there were tens only. With new varieties, if quite in ignorance of their character-not ofien the case with the ready means for diffusing information now-a-days - we feel our way, watching for the appearance of the bud, and being guided by that, and by the state of the plant, as to the number to be left. A little careful observation will soon inform the 
veriest tyro, and such attention as he may give will be repaid a thousand fold.

Hitherto (May 15) in this neighbourhood we have had a most trying season. An almost total absence of rain for over three months, has not been compensated by a double allowance of east winds, biting night frosts, and bright burning sun. Still the plants are generally looking well, and we hear from both north and south very cheering accounts of their appearance. One of the best cultivators in the neighbourhood of Leeds informs us, his plants are very strong, and the bloom will be quite ready for the 4th of August, the day fixed for the towns meeting.

Derby.

E. S. DoDWELL.

Tulips.-As soon as the bloom is over remove the awning, and place sticks to those flowers which have been impregnated, and from which it is desirable to save seed, in order that a board may be placed over the pericarp. Break off the seedvessels of others. which will tend to strengthen the root.

Auriculas. - Keep in a cool shady part of the garden. Beware of the drip from trees. Water liberally, and particularly attend to cleanliness.

Dahlias. - If not already done, let them be put out forthwith, staking them at the same time, and watering well. The care during the month will be to give abundance of water, and to prevent their being hroken by the wind.

Pinks must be carefully attended to. Disbud according to the strength of the plants, water liberally, and mind that they are well tied to neat sticks.

KANUNCULUSES.- Take care that the awning is ready. Draw the weeds carefully from between the plants, and give an occasional watering between the rows. Water from a pond or tank exposed to the full sun is best. The cuckoo spit, or cicada spumaria, is apt to attack the rising buds of the ranunculus, and a long green caterpillar is also troublesome. These should be carefully exterminated.

J. F. W.

In the artizan's vegetable garden, if he have a patch of ground vacant, he may make a sowing of Cape broccoli. This will give him heads towards the latter end of the year. Celery plants should be carefully attended to; they may be pricked out on beds composed of rotton leaves and manure, giving them a liberal supply of water. Peas to come in autumn, may now be sown. Knight's Marrow is good for this purpose, not being so apt to mildew as some others. Towards the middle of the month sow endive; and for early-hearting cabbage or coleworts, a small quantity of Waite's King, to come in the autumn. Stone, Swan-egg, or Snowball turnip, small salading, \&c., may be got in. Towards the end of the month, make trenches for celery. Dig in a good quantity of manure, and plant out whenever the weather is favourable, recollecting that abundance of 
water is requisite for its well doing. Attend to hoeing, sticking peas, \&c. As the tall sorts reach the ends of their sticks, pinch off the tops; this will cause them to throw laterals, and bear much longer.

JoHn WiLLIAMS.

\section{FLORAL EXHIBITIONS.}

\section{AURICULA SHOW.}

At the Golden Cock Inn, Kirk.gate, Leeds, April 27.

Premier Prize.-Lee's Colonel Taylor, W. Dobbings.

Ist Pan.-Imperator, Complete, Hallamshire, Oddy's Rest, I. Watson, Esq. 2nd. Colonel, Complete, Catherine, Othello, W. Dobbings. 3rd. Standard, Complete, Regulator, Ned Lud, Mr. Cawthorn.

\section{Green-edged.}

1 Colonel, W. Dobbings

2 Lovely Ann, I. Watson, Esq.

3 Standard, Mr. Cawthorn

4 Prince of Wales, W. Dobbings

5 Lord Nelson, I. WVatson, Esq.

6 Imperator, J. Bramma Grey-edged.

1 Complete, 1. Watson, Esq.

2 Ne plus ultra, T. Titley, Esq.

3 Seedling, I. Watson, Esq.

4 Conqueror, ditto

5 Mary Ann, Mr. Cawthorn

6 Privateer, J. Bramma White-edged.

1 Catherine, W. Dobbings

2 Favourite, ditto

3 Unknown, I. Watson, Esq.

4. Regulator, Mr. Cawthorn

5 Venus, 1. Watson, Esq.

6 Lord Chancellor, T. Titley, Esq. Selfs.

I Othello, W. Jobbirgs

2 Ned Lud, Mr. Cawthorn

3 Squire Mundy, I. Watson, Esq.

4 Blue Bonnet, Mr. Cawthorn
5 Oddy's Rest, I. Watson

6 Seedling, J. Fryer

$$
\text { Alpines: }
$$

1 Seetling, I. Fryer

2 Ditto, ditto

3 Barstow's Seedling, W. Dobbings

4 Rosamond, I. Watson, Esq.

5 Conspicua, Mr. Cawthorn

6 Seedling, I. Fryer

\section{POLYANTHUSES.} Dark Ground.

1 Alexander, I. Fryer

2 Lord Rancliffe, ditto

3 Seedling, Mr. Kearsley

4 Ditto, ditto

5 Ditto, ditto

6 Ditto, ditto

Red Ground

1 Seedling, Mr. Kearsley

2 Laura, I. Fryer

3 Seedling, Mr. Kearsley

4 Telegraph, I. Watson, Esq.

5 Seedling, Mr. Kearsley

6 Ditto, I. Fryer

\section{AURICULA SHOW,}

At the house of Mr. E. Wilkinson, the Woodman Inn, Gower-street, Leeds.

Premier Prize.-Sykes's Complete, W. Chadwick.

Ist Pan. - Lovely Ann, Complete, Lord Chancellor, Blue Bonnet, W. Chadwick. 2nd. Lady Ann Wilbraham, Privateer, Bright Venus, Othello, E. At. kinson.

\section{Green-edged.}

1 Lovely Ann, W. Chadwick

2 Lady Ann Wilbraham, E. Atkinson

3 Waterloo, W. Chadwick

4 Barlow's King, T. Wainman

5 Ne plus ultra. W. Chadwick

6 Pollitt's Standard, E. Atkinson Grey-edged.

1 Complete, W. Chadwick

2 Privateer, ditto

3 Conqueror, E. Atkinson
4 Beauty of Wydham, T. Wainman

5 Ringleader, J. Boshell

6 Mary Ann, ditto White-edged.

1 Lord Chancellor, W. Chadwick

2 Lord Hallamshire, ditto

3 Bright Venus, J. Bcshell

4 Taylor's Glory, E. Atkinson

5 Taylor's Favourite, T. WVainman

6 Pillar of Beauty, E. Atkinson 
Selfs.

1 Blue Bonnet, W. Chadwick

2 Seedling, ditto

3 Ditto, ditto

4 Ditto. ditto

5 Ditto, ditto

6 Ditto, ditto

Alpines.

1 Seedling, T. Wainman

2 Ditto, ditto

3 Ditto, ditto

4 Ditto, ditto

5 Ditto, W. Chadwick

6 Ditto, ditto
POLYANTHUSES.

Dark Ground.

1 Elizabeth, W. Chadwick

2 Lord Rancliffe, ditto

3 Cox's Regent, T. Wair.man

4. Beauty of England, ditto

5 Alexander, W. Chadwick

6 Sovereign, J. Boshell Red Ground.

I Cox's Regent, W. Chadwick

2 Red Rover, ditto

3 Seedling, 'T'. Wainmar

4 Bullock's Lancer, ditto

5 Seedling, ditto

6 Beauty of Over, ditto

HALIFAX AURICULA SHOW,

At the Shoulder of Mutton Inn, May the 4th.

Premier Prizes.-1. Leigh's Colonel Taylor, W. Baildon. 2. Sykes's Com. plete, R. Summerscales.

Green-edged.

1 Litton's Imperator, W. Baildon

2 Booth's Freedom, E. Pohlman

3 Yates's Morris Green Hero, R. Summerscales

4 Leigh's Colonel Taylor, E. Pohlman

5 Barlow's King, W. Baildon

6 Buckley's Jolly Tar, R.Summerscales

7 Pollitt's Ruler of England, ditto

8 Pollitt's Highland Boy, W. Baildon Grey-edged.

1 Sykes's Complete, R. Summerscales

2 Fletcher's Ne plus ultra, ditto

3 Fletcher's Mary Ann, ditto

4 Oliver's Lovely Ann, E. Pohlman

5 Grime's Privateer, ditto

6 Rider's Waterloo, R. Summerscales

7 Waterhouse's Conqr. of Europe, do.

8 Thompson's Bang-up, ditto White-edged.

I Simpson's Lord of Hallamshire, W. Baildon

2 Cheetham's Countess of Wilton, $\mathbf{R}$. Summerscales

3 Summerscales'Catherina, W.Baildon

4 Ashworth's Regular, E. Pohlman

5 Lee's Bright Venus, R.Summerscales

6 Taylor's Favourite, W. Baildon
7 Seedling, R. Summerscales

8 Potts's Regulator, ditto Selfs.

1 Netherwood's Othello, E. Pohlman

2 Martin's Mrs. Thurock, ditto

3 Martin's Eclipse ditto

4 Headly's Royal Purple, ditto

5 Lighthody's Admiral of the Blues, do.

6 Clegg's Blue Bonnet : ditto

7 Kenyon's Freedom ditto

8 Berry's Lord Lee, R. Summerscales Alpines.

1 Conspicua, E. Pohlman

2 Fieldhouse's Fair Rosamond, $\mathbf{R}$. Summerscales

3 Hoyles' Queen Victoria, E. Pohlman

4 Mellor's JennyLind, R.Summerscales

POLYANTHUSES.

1 Summerscales's Warrior, R. Sum: merścales

2 Ashworth's Elegant, '. ditto

3 Seedling, ditto

4 Gibbons's Royal Sovereign, ditto

5 Crownshaw's Exile, ditto

6 Craiggy's Highland Mary, ditto

7 Crownshaw's Invincible, ditto

8 Nicholson's Bang Europe, ditto

\section{NATIONAL FLORICULTURAL SOCIETY.}

May 13.

First-class certificate to National pansy, white ground, with narrow purple belt, and excellent form. Also to Fearless pansy (Messrs. Schofield \& Son), chrome yellow ground, margined with dark purplish marone, stout, and of fine form. Also to Mr. Epps, of Maidstone, for two beautiful seedling ericas, namely, E. jasminiflora rubra, fine long tubular flowers, in large clusters; a nice sort. E. tricolor Eppsii, colour scarlet, shading into white, truss large, the tube of the flowers short and stout; ' a very handsome variety.

Certificates of merit were awarded to the following :-Sir J. Paxton pansy, (Mr. C. Turner) straw-coloured field, edged with purple. Joe Miller pansy, dark self, remarkably large and fine.' Erica tricolor splendens (Mr. Epps). Cinerarias Lord Stamford and Picturata (Messrs. E. G. Henderson \& Son). 


\section{刕art 开。}

\section{ORIGINAL COMMUNICATIONS.}

\section{NOTES ON THE GREAT NATIONAL TULIP SHOW,}

At Birmingham, Mar 27, 1852.

BY THE EDITOR.

$W_{\mathrm{E}}$ promised in our last to give some account of this really very splendid exhibition. The only fear we have is that we shall be unable to do it justice; for without disparagement to those which have preceded it, certainly this was one of the best. The arrangements were of first-rate character, and though, perhaps, the committee may alter some of the minor details, when the exhibition is held at Nottingham, we certainly consider our Birmingham friends carried it out in first-rate style. Of course we cannot precisely say in what way the Nottingham will differ from the Birminghan, but as far as our own views go, we would have a good premier prize in each class, both feather and flame, allowing the same variety to win again once in the same class; the prizes to run, with the premier, seven in length. By this means, inferior rarieties would be excluded, and consequently, if not winners, their cultivation would soon be discontinued. 'Then again we would have stands of breeders-two bizarres, two bybloemens, and two roses; for thongh a first-rate breeder may break to an inferior marking variety, its form and purity should be encouraged. 'The pans should be exhibited on stands, similar to those at Birmingham, and the single flowers in bottles; thus giving the judges a better opportmity of comparing flower with flower. In the stands of twelve, we think that two of each JULY-VOL. VI. 
class, feathered and flamed, would be advisable. These are only a few hints, on which we shall be glad to hear the opinions of our friends; for though we have but one voice in the committee, still we are sure the Nottingham florists, with ourselves, will be thankful for any kind suggestion that may be given. We will now proceed with our memorandums.

We arrived in Birmingham late; but at the Turk's Head, where Mr. Cole had kindly provided us with excellent quarters, we found some of the most eminent fiorists in the kingdom assembled, and enjoyed a very agreeable evening. In the morning, all were on the qui vive, and as much business had to be done, in the way of arranging flowers, \&c. we took a turn through the markets and principal streets, till we were called upon to commence our duties. We may observe of the market-place in the Bullring, that it is spacious and excellent, covered in and well lighted. Here the nurserymen and fruiterers have their stands, and we could not help drawing a comparison unfavourable to our own town; for though Nottingham has perhaps the finest provincial market-plare in the kingdom, yet, exposed as we are to all weathers, our plants and seeds, as well as ourselves, suffer to a considerable degree. Then we greatly admired King Edward's schrool, in Highstreet, where there are nearly eight hundred scholars; and as we neared the town-hall, we were struck with its massive proportions, and its bold and noble character. We were glad to find that some old houses had been pulled down in its immediate vicinity, so that it now stands out prominently in all its grandeur. If we admired the building, we were equally struck with its contents. The conp d'oeil, on entering, was imposing in the extreme, the tables being filled with the choicest specimens of hot and greenhouse plants, mingled with rhododendrons, hardy perennials, \&c. We have not room to particularise these, but we are sure that the highest encomiums are richly deserved by the amateurs and professionals of Birmingham 
and its neighbourhood. The tulips too were in very strong force, and of excellent quality. Soon after ten, the judges (Messrs. Lawrence, Bromiley, Orson, Mlorton, and ourselves) commenced their, certainly arduous, undertaking. In looking through the stands the first time over, we found that most of them contained a Captain White. It seemed to be the opinion that they were stained, but we must confess, that if they were so, it was infinitessimally, and we should be sorry to see this fine old flower put in the back ground. Certainly flamed Polyphemus had a dark tinge at the base of the flame, much more objectionable than that in the Captain, and in our opinion, it must be a very good flower indeed that will supersede him. We were also sorry to see a fine stand of flowers, belonging to Mr. Thorniley, disqualified. The base of one flower was pure, but the stamens were "awfully black," and as perfect purity was requisite, the judges, with great regret, were obliged to put it aside. Had it not been for this drawback, the stand would have run both the winner of the medal and the first cup very hard. Mr. Houghton, of Nottingham, won the gold medal, though for a long time it was a question whether $\mathrm{Mr}$. Godfrey should not have that piace. It was a creaminess about the base of Van Amburgh which decided the matter, and gave the palm of victory to the former. The list of prizes will be found with the register of other shows, we shall therefore confine our comments to those varieties which took our fancy.

The flowers of Mr. Houghton were all well-known and established favourites of the midland counties, except Coup d'Hebe, which certainly was the worst flower in the stand. It savours too very strong of the Chellaston parentage. In Mr. Godfrey's stand there were four flowers similar to Mr. Houghton's, with Van Amburgh and Maid of Orleans-the former a fine-formed and good-marking flower, which requires much bleaching to make passable; the latter 
a black feather on pure white, but unfortunately very sportive and capricious. The second prize was gained by Mr. 'Turner, of Slough. Lord Denman, a midland flower, a light fiamed byblœmen, very pure, beautifully marked, and the petals well formed. Its drawback is a slight inclination to what a veteran florist of our acquaintance terms, more truthfully than euphoniously, "tundishy." Still it was very much admired. The other noticeable flowers in this stand were Arlette and Polyphemus. The third stand was that of Mr. Adams, of Derby. In this was a short-cupped byblœmen, heavily feathered, and of first-rate form. It was labelled "s unknown." We fancied it a Chellaston Beauty; but Mr. Adams did perfectly right in labelling it as he did, rather than giving it a new and perhaps wrong name, and thus perpetuating the confusion in which these flowers are involved. Mr. Marsden, Derby, was fourth. Here was La Belle Nannette, certainly nothing more than a feathered Royal; and Lady Jane Grey, a very beantifully-marked flamed rose, pure, and rich in colour, but in length rather above the standard.

We now come to the stands of twelve dissimilar blooms, four of each class, and strange to say, no less than six or seven were disqualified by having a wrong number. Some had five bizarres, others the same number of byblœmens or roses; and thus, for want of a little care, throwing away their chance. The first, a very good stand, was that of $J$. Willmore, Esq. of Birmingham. Amongst them were seven or eight south country flowers. Thalia was very beautiful, with its fine-formed cup, purity, and light flame. Strong's King, fiamed bizarre, also good, and perfectly clean. Camuse de Craix and Lawrence's friend were in good style. Mr. Turner again came second. In this stand was a most delightful flower, Scotch, we believe, named after Mr. George Glenny. It was a delicate flamed byblœmen, and very pretty. Pilot was fine; in fact, a fine flower of this variety takes a great deal of beating. 
Mr. J. Edwards was third. Priam, a flamed bylbœmen, and Hamlet, a bizarre, one of the Polyphemus family, were the most noticeable. Mr. Lymbery, of Nottingham, fourth. These flowers were fresher, and at the close of the day stood better than those which had the precedence, and we heard strong opinions stated that the censors had made an error in judgment. On this point we shall make no further remark than whether it were so or not, we believe they all tried to do their duty. In this stand was a seedling, named Mrs. Lymbery, rather inclines to be long, but beautifully pencilled with black. Lord Sandon, in the way of Duke of Devonshire, black feather, on yellow; and a very good La Vandicken were the most prominent.

In class $\mathrm{C}$, nine dissimilur blooms, Mr. Houghton was again first. Here were two flowers which some thought similar, namely, Victory and Royal Sovereign. We think we recollect the former being let out some years ago, at the Apple Tree Inn, Manchester, a breeder and a rectified flower, for something like thirty shillings; and as the other flowers were good, he had the benefit of the donbt. We should be glad to hear from Mr. Cotterill, the reputed raiser, something about it. Mr. Parkins, of Derby, the second, had in his stand the best and cleanest WValworth we have seen for some years; and a good flamed Violet Alexander, or, as it is sometimes called, La Bien Aimee. Mr. Adams was third, Pilot, Maid of Orleans, and Captain White being the best of his flowers. The fourth was Mr. C. Turner, of Slongh, and in the stand of nine dissimilar blooms, were five Chellaston seedlings.

Class D was a prize for the best feathered flower in each class, or, as we call them here, premiers. We should hare liked prizes to have been given for flames also. The first feather was a most excellent Charles X., and after sampling it against all others in the classes, as well as Magnum Bonums, it deservedly gained its position. The other two were 
obtained by the Rev. S. Creswell, of Radford, near Nottingham, with a very pretty feathered rose, called Agnes Creswell, and Prince of Wales, a short-cupped, pure, and rather heavily flamed byblœmen. 'This last was broken some years ago, by Mr. J. Spencer, of Adbolton, from the same batch of seedlings as his First-rate. Mr. Spencer did not raise them liimself from seed, but purchased them of the widow of Mr. Creswell, of Stanton, who was famous for ranunculuses, as well as raising seedling tulips.

In the classes, amongst feathered byblœmens, Mr. Thorniley, of Heaton Norris, was placed first, with a very excellent Maid of Orleans. Victoria Regina we certainly did not much like. The others, unless we except a Salvator Rosa, belonging to Mr. Ackerley, do not require particular comment. The flamed byblœmens were good, Mr. Houghton winning first, with a Princess Royal, beating, after a long discussion as to their merits, amongst the judges, a very nice Queen Cliarlotte. Mr. Hartland's General Bournonville (true) was a rich and good flower; whilst Lord Vernon, Rubens, and Surpasse le Grand, each good in its respective style, brought up the rear.

In feathered bizarres, Mr. Dixon was first, with an excellent Charles X. Mr. Thorniley second, with Vivid, a London flower, said to be the best bizarre in cultivation. Mr. Parkinson's Magnum Bonuin was the best out of many, being not quite so heavily plated as its antagonists. Colbert was new to us, and has some promising points about it; and the same may be said of Prince Arthur, though placed last. Flamed bizarres were a good class. Captain White gained the first place, closely, very closely, run by Pilot. Both were very good flowers. Mr. Frearson's Lord Milton was fine, but rather past its best. Strong's King, shown by Mr. Edwards in very pretty style, was next. Donzelli, though full long enough, was in good character. Polyphemus was last.

Feathered roses, always a scarce class, was, however, very fairly done. Mr. Chas. Spencer's Heroine, 
or feathered Royal, was a beautiful specimen of this favourite rariety; whilst the Rev. S. Creswell's Napoleou, though rather small, was a perfectly clean, well-feathered, and bright flower. Mr. Dixon's Baguet, placed in this class because (as shown) it was more of a rose than a byblœmen. 'The same gentleman gained the fourth place with his Bion, a flower which, when in good character, will certainly eclipse most, if not all, existing feathered roses, excepting only one that we whispered about last year, but more of this at a fitting season. Mr. Ackerley was filth, with a nice Anastasia; and Rebecca, a promising seedling of the Rev. S. Creswell's, was the sixth. In flamed roses, the Rev. S. Creswell was placed first, with a very nice bloom of Vicar of Radford, a seedling. 'This is short-cupped and beautifully marked. It is a tall fourth-row flower, and singularly enough, last rear it was a perfect feather, thus afiording another instance of the caprice of tulips. Mr. Parkinson's Aglaia and Triomphe Royale were both very good; and Mr. Lymbery's Grand Rose Desire was certainly nothing more than a fine strain of La V andicken. He purchased it under the first-named designation, at the sale of the late Mr.J. Thackeray's tulips.

In simple flames little can be said, except that it was the worst class exhibited, Mr. G. Mills's Holmes's King being the only purely simple beam. It was beautifully formed, and deserved its position. Oriflamme is a Chellaston, good cup, pure, and striking, in the style of Saunders's Enterprise. As for the others, perhaps " the least said is soonest mended."

We must not omit to mention a feathered bybloemen sent by Mr. Forman, of Chellaston. It had a cracked leaf, and was entrusted to us to show to the growers, who expressed but one opinion of it- "the very best of its class." Of full size, excellent form, dazzling purity, with broad well-defined black feather, and the anthers bold. We believe it to be Chellaston Beauty in her best dress; in fact, we do not see how 
she could be better. 'There were several flowers not for exhibition, and amongst others one called Sancta Sophia. Be it what it may, it certainly is not the same as Mr. Dixon's, and though this was perfectly pure, it much resembled a good $W$ ashington. A few seedlings, both in the breeder and broken state, were exhibited, but not of sufficient quality to require any particular notice from the censors.

Amongst the results arising from the Birmingham gathering, we may say that the idea that there was great difference of opinion between the sonth and the north is exploded. The judges then assembled were all for form, purity, and marking, taking, as they believed, those which complied best with these requisites. That many flowers will be thrown out of cultivation we are sure; full as many from southern as northern collections. We say this advisedly; for having grown many this season, and never having had a better bloom, to our surrow, we found that many, very many, were wanting. To use a term from the vocabulary of "our ancient friend," the beds want purging; and in fact, they must be " purged," with a vengeance, to meet the requirements of the progressive style of floriculture.

After some discussion, it was finally agreed that the exhibition for 1853 should take place at Nottingham. We may just say here, that the National Society cannot be handed over from one provincial society to another. If such a plan were adopted, there would be never-ending jealousies, and it would be a bad precedent. As we received it at the hands of the Birmingham and other tulip growers, assembled on the occasion, it was for the tulip growers, and them only, of the neighbourhood in which the exhibition was to take place, to decide on what steps to adopt; and if they found it advisable, and conducive to the interests of the national tulip show, to combine with any horticultural exhibition in their neighbourhood, of course they were at perfect liberty so to do. We were happy to find that Mr. Cole and 
Mr. Perry worked independently of each other-one for the florists, the other for the horticulturists, - but at the same time with such a hearty good will and perfect unanimity, as to realize the excellent exhibition which it was our good fortune to see, and is our pleasure to record in our pages.

\section{TULIP SHOWING.}

There has been a great deal said of late respecting the system of tulip showing and class showing, but I do not see that any party is near bringing the subject to a close, nor do I think they are likely, as long as the system adopted by the southern growers is so widely different from that adopted by the midlanders, and with your permission, I will try to explain how tulips are shown in and around the metropolis. I am a midlander, but having resided in the neighbourhood of London the last four years, I have had opportunities of seeing both their collections and their exhibitions. In the first place, form always takes precedence. 'Their stands consist of twelve tulips, an equal number each of byblœmens, roses, and bizarres, or tricolurs; the last to be classed, as they can arrange them either byblœmen or bizarre, so that the greater the dissimilarity in the blooms, the better the chance of winning. As respects feathered bizarres, they are by no means particular in having them decidedly feathered, but will allow stripes, or pencilling, or breaks in the feather, and the less feathering the better, so that you can just discern the colour, and then the term fine is applied to the flower. For instance, the Mundi yellow, and the Mundi white, are very great favourites with them. Then there is Holmes's King, with no feather at all, and the flame only an inch long, by a quarter of an inch wide. I have heard them extol bis Majesty up to the skies, but they could never get me 
into their way of thinking, as I never would have it in my collection. As respects roses, they will not allow a fine feathered Aglaia and a coarse flamed Triomphe Ruyale to be shown in one stard, as they say they are too similar for competition: or, vice versa, a fine feathered Triomphe Royale or Heroine, and a flamed Aglaia. For instance, I saw, last year, a most beautiful stand thrown out, the flowers in which consisted of a feathered Platoff, San Joe, Polyphemus, and a seedling tricolour, flamed bizarres; the byblœmens were Ruscins, feathered $\mathbb{M}^{x}$ aid of Orleans, General Barneveldt, and a very fine Addison; the roses, a fine Aglaia, Claudiana, flamed Triomphe Ruyale and a seedling flamed rose, darker than Gibbons's Catherine; and what was the consequence? the party boxed his flowers immediately, and left the room in disurust. But the best remains to be told. He had to show the next day, at another place, against the party who came in first after his pan was set aside, when the disqualified pan was placed first and the other second. so mach for good censors. I believe, Mr. Editor, you are personally acquainted with the parties who acted as censors on the last oecasion; and alluw me, through your pages, to ask, what similarity is there in the afore-named flowers? I cannot see any. I forbear to mention names, as it might engender ill feeling, and I do not write with that intenc.

And now a wurd or two with Mr. Caparn, of Newark. Granting him all that he suggests, I should like to know where we are to get the flowers from. I confess, in all my travels, I have seen but Holmes's King and one or two others. Mr. Davidson makes mention of one or two, and perhaps half-a-dozen might be found, if well sought up. In fact, I think, that instead of adding to the beauty of a bed, they detract from it, and, I for one, shall give my veto against that, and, with your permission, Mr. Editor, will make an amendment. There shall be two classes for pans: the first for dealers and large 
amateur growers, whose collections consist of more than fifty rows; and each member's pan to consist of twelve dissimilar blooms, so that they can introduce flamed flowers without any feather into their pans, which will be the means of reducing the number of flowers on the class principle, as well as meeting the sontherns half way. 'The second class pans shall be the production of amateur growers whose collections do not comprise fifty rows; and the flowers to consist of six in each pan, and to be judged according to the midland system of showing. The small amateur growers to show in the first class, on paying an extra fee, say two shillings and sixpence. I would also recommend the keeping up of the present system of class showing, as, for instance, Platoff, Charles X. with Polyphemus and San Jue, being so numerous, would sweep off the first two classes; besides I think it adds a stimulus to the procuring of new varieties, as well as keeping the chance open for disqualified pans, so that parties may get some remuneration for their trouble, as I am well aware that all cannot win. Should the above remarks meet your approbation, yon are welcome to them, and I hope they will be taken as they are given, without any ill feeling.

JOHN ORCHARD.

HOW TO GET RID OF SNAILS.

THE present fine rains, after the long dronght, has brought out these mischievous creatures, wherever they exist. A year or two ago, my peas, cabbages, \&c. were half devoured by them, but by steadily pursuing a very easy plan, 1 arn now freed from their ravages. That plan is to carry about with me a pair of sharp-pointed scissors, and to use them whenever I meet with a delinquent.

The best time for hunting is the feeding time, which begins as the dews fall in the evening, and continues till morning. 
When I first began, I was not content with the morning and evening attacks upon the enemy, but took an occasional excursion at midnight, killing from two to four hundred at a foray. I went out last night, and had some difficulty in finding half-adozen.

If the gardener will only provide himself with the useful instrument I have mentioned, and keep it alnays abont him, using it whenever he has an opportunity, and looking for the opportunity also, especially the first thing in the morning and the last at night, not forgetting to visit the rubbish heap, I will guarantee the total destruction of the present generation of the vermin in a few days; and if he will keep watch for new comers, bearing in mind that one killed in the spring, before it has laid its eggs, is worth more than a score killed in the autumn, I am confident that the most infested place may be thoroughly cleared in the course of a year.

May 20, 1852.

D.

NOTES OF THE GREAT METROPOLITAN MEETINGS.

THE following, being a letter to an esteemed correspondent, has been placed at our disposal, and as containing many excellent hints of novelties which may be of use to our readers, we gladly give it a place in our pages. It will be seen it was never intended for publication, but we have little doubt our readers will agree with us that the absence of that formality which is so frequently found in effusions intended for the public eye, is a charming recommendation, and we trust it will shew to many valued, but over-scrupulous friends, how much more easy a matter it is to address our "dear public" than they suppose.-Ev.

"I think I promised you a few 'jottirgs' if I went to the Park ( $\mathbf{J}$ une 9 th), and though the weather was 
so wretched, pouring all day, yet as Phil was compelled to take that day, or lose his tickets, we went, the wet notwithstanding. As the Times says, 'there wefe few there, beyond those interested, and those ardent amateurs, whom nothing can keep away.' So far as fine company is concerned I care nothing, still it was depressing to know how much of enjoyment was marred by the relentless wet. Somebody has said, somewhere, 'that the desire for knowledge is only equalled by the wish to impart it to others. And thus it is perhaps with me, that the pleasure such an exhibition affords is much enhanced by conreying to you the particulars of $\mathrm{my}$ enjoyment. Hence my excuse for this. Having premised this, however, and taken my pen for the purpose, I really feel nonplussed, and think how presumptuons in me to say anything on what I understand so little-indeed barely enough to teach me I know nothing. The 'Duke's' answer also occurs to me, when asked by a lady to describe one of his great battles: 'Really, madam, there was so much going on everywhere, that it is impossible to say what was going on anywhere.' Well then, with such an authority as the F.M. I think it will be prudent in me to follow his example, but then I should not redeem my promise, and that wonld be a serions matter. Serious or not, however, I can only say I feel wholly incapable, therefore you will forgive me my rashness, if I give you one or two things more in my way, that struck my eye in passing.

"Of course the orchids and miscellaneorts plants are quite ont of my pale-altogether beyond me-but they were gorgeously imposing, producing sensations of wonder and admiration so intimately blended, it was hard to say which predominated. Ericas and azaleas were must grand, and in great profusion, but you wont want me to euter into a detail of them.

"Pelargoniums, my especial favonrites, though such a novice, were in wonderful numbers; and though I did not observe the names of any growers who got JULY - VOL. VI. 
the leading positions, yet I was particularly struck with the appearance of such a mass of bloom, and such a profusion of plants. It was most difficult to select, all were so good, still I noticed as those to my ere most striking and prominent, Ganymede, Magnet, Mokanna, Cristine, Dion, Lagouna, Portia, Oscar, Leonora, Astrea, Enchantress, and Optimum, the latter the very best. Ambassador is a larged-trussed flower, but appears 'leggy' in habit, and not very thick in the petal. The above struck me as being peculiarly beautiful, whether they are new or not I cannot say; some of them I never heard of before. I dare say, when the "critiques" appear, I shall find myself much beside the mark, but I don't care, the above pleased me, and I am a - still.

"In fuchsias there were few worth anything, Kossuth and Dr. Smith being, as I consider, the best present. 'There was one, however, a seedling, called Banks's Glory, the very best I have evel seen, and I think the best out. It was something between Story"s sorts (viz. Elegantissima, \&c.) and Kossuth, in habit of growth and foliage, with a splendidly reflexed crimson-scarlet sepal, and densely purple corolla, of good size, and well hanging out from the plant. Good foot-stalk. 'This will be a great favourite, or I am out. It was shown by Smith. There was also a light one shown by 'Turner, called Banks's Express, something, as it looked to me, of the Fair Rosamond and Pearl of England breed, but better than either-similar colours and habit, but reflexing better;-a fuchsia must reflex to find favour with me. Some of them remind me with their half-expanded sepals, turning down instead of up, of chickens with the 'pip' on a wet day. To go on, however, there were a few stands of pansies, but nothing particularly calling for notice-they were all good. Verbenas, of Smith's, called National, Orlando, \&c. \&c. were very fine indeed. I am told he has challenged the world with them, and they must be wonderful indeed to beat these. One stand each of ranunculuses, anemones, 
and pinks (Willmer's), but nothing to speak of. Calceolarias were in great profusion and beauty, but I cant notice them, except one of the shrubby kind, for bedding;-it will be a great acquisition, having the colours of Kentish Hero, but larger, and will doubtless make the Hero retire when it becomes plentiful. It is named Model. 'There was also a very nice pearl white geranium for bedding, apparently dwarf in habit, with the horseshoe marking, and is very tidy truss of flowers. This we much want. Miss Emily Field they called it. Likewise a beantifully variegated-foliaged one, very striking, named Attraction, with a good truss of orange scarlet flowers. The habit of this, I am afraid, is not very first-rate, and I fear too it is a slow grower; still, notwithstanding this, as soon as it is at all come-at-able, I shall, in all likelihood, procure it, as it pleases me much more than Flower of the Day, or Golden Chain, which they are making such a stir about just now. There was also a scarlet Unique, but the truss was not su compact as the old crimson one. And now I think I have given you enough of my scrawling, my facts, and iny opinions; but I must just add that the fruit made one's month water, which was quite unnecessary, as there was water enough without that. Of roses there was a great deficiency, and the least said about them the better; but the 'Americans' were in full beauty, and a more gorgeous sight you cannot well imagine. The rain, however, came through so freely that it made it dangerous to one"s health to stay long, and therefore any examination of their indiridual claims was out of the question, especially as we had our dear wives with us. 'There was one thing, however, which struck me, viz. the worse than negligence in the growth of the plants in the stand of the Society. I an sure there were plants there that would have disgraced any old woman's window; - I mean as regards the method (or rather want of method) of growing them. Do we not look to these societies for instruction? If 
so, I pity the poor mortal who looks to receive any benefit from them. This ought to be remedied (and they cannot plead ignorance, with the splendid exaniples of skill before them), and as you are in the way of giving certain editors hints, just gently remind them upon this head. Tell them ignoramuses notice it, and what then must others do?"?

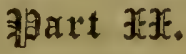

\section{FLOWERS RECEIVED SINCE OUR LAST REPORT.}

Auriculas. - W. T.-Your seedling, No. 5, is fine in colour, and large, but rather coarse; the colour too, breaks through to the edge. No. 1. Grey edge, good form, colour well distributed. Will do.

Tulips.-J. Battersby, Mansfield.-Camilla.-A splendid flamed rose, won at Derby in 1851. Again in good character, the flame as well as feather beautifully laid on. In the flower sent, a delicate violet tinge was apparent at the base of the flame. Base and stamens pure.

Gem.-Pure short-cupped rose. If this comes with distinctive character, either flame or feather, it will be worthy of its name. Broke in 1851.

Herald-A fine lemon-ground bizarre, of large size, perfectly pure, nicely and correctly feathered with reddish brown. If it avoids quartering, wlich we hope it will, the bloom sent being old, it will take a high place in its class. Broke 1852.

Regulator, also broke in 1852. A pure and very correctly feathered bizarre, the pencilling coming well down the sides of each petal. Very beautiful.

Warclen.-Feathered bizarre, broke in 1851, the marking, which is very black, rather lightly laid on. Very pure, both in base and stamens.

Warden, in a flamed state. Very dark feather, with light flame. There is a slight cloudiness below the marking, but not more so than in a flamed Polyphemus.

R. MarRIs, Leicester.--Antagonist, bizarre breeder, the seed from Polyphemus, crossed with Optinus. The nearest approach to the Hardy standard we have yet seen. It is perfectly pure and of first-rate form. 
B. S.-You are right; the flower is decidedly Salvator Rosa, certainly somewhat out of character; but this flower is rather capricious. A first-rate grower in one of the eastern counties informs us that it alternates with him, one year good, the next bad or indifferent. The bizarre is Leonidas, a fourth-row flower, not much grown as yet in the northern and midland counties, but we agree with you that it wants to be better known. The feathered bizarre is an Optimus. There are several strains of this flower. We have seen Surpass Optimus good; the one sent is somewhat like it, but the several breaks in the feather detract from its merit.

T. W.-.The seedling breeders sent have black stamens. We fear this defect will not " break out," that is, become pure, when rectified. Under these circumstances, we should recommend our correspondent to plant them on an outside bed, if he can spare the room, but we can assure him we have not much faith in them.

W. H.-The byblomen from somebody's Duke of Hamilton is good: it promises well as far as niarking and purity go. Reid's Thomas Maxwell we have not before seen. Beautifully marked flamed byblœmen, pure in every respect, but too long by an inch. We cannot say much of the flower which was placed second at the exhibition named; if it merited its place, we are quite certain those behind it were very sad ones. Seedling 103. Clean thick petals. Good breeder and broken flower. Chellaston Beauty, for though small (as sent), yet it deserves its name.

War. Harrison, Felton. - The feathered byblomen is Chellaston Beauty. 'The other three-Felton Hero, good cup, and pure, the marking not so good this year as last. The same may be said of Pegasus, though the yellow is dull, and as we judge, the marking inferior, one of the petals having a broad streak of the breeder colour in it. Patriot, flamed bizarre, we liked best. Each petal was alike, pure and of rood form.

Pansies.-Milessrs. Schofield \& Son.-Your pansy is a bold rich variety. Deep yellow, belting nearly black, strong eye. It is well named Fearless.

Shylock is a nice flower Yellow ground, with rich bright eye. W. B.-Maid Marian.-A fine white ground flower, with heavy purple belt and large dark eye. Better than scores in the same class.

C. S., Berwickshire.-No. 1. Large dark plum-coloured self, with a ray of blue round the centre, a fine flower of its class. No. 2. This we like best of the two. The petal is thicker, of excellent form, the colour a dense and uniform bronzy plum, with small yellow eye, a good flower.

J. L.-Joe Miller, bronzy yellow, good form, with distinct and good eye, upper petals edged with greenish purple, the $\mathrm{x} 2$ 
sides and lower one with a narrow belt of same colour. We should say a very distinct and useful flower in a stand. Miss Lakin, finely formed, good eye, well belted with purple, a very desirable variety, rather rough on the margin, but we think this will improve.

T. Y. C.-Your pansy, Duke of Sutherland, is a splendid dark self. It will please anybody.

Nemophilla Maccuennir.-A very pretty variety. Plumcoloured ground, with darker centre, the margin being pure white. This will make a nice addition to our hardy annuals.

C. K. S., Edinburgh. - The cineraria bloom is excellent. Very pure circle of white, with heavy shaded purple margin. Quite first-rate. We want a name.

Querist, Devonshire.-Cloth of Gold Rose, a splendid variety when well done. Yes; it will take well on the Manetti stock. A greenhouse, or a warm situation against a wall, appears indispensable for its well doing.

Calceolaria.-I. C.-Your seedling is very bright in colour, of tolerable form, a pretty variety, but we are afraid it is too much like several that are out. If there is anything in its habit, or style of flowering, to recommend it, we should say by all means propagate it; but of this we are not able to judge by single blossoms.

W.W.- Your apple (seedling), received the 3rd of June, was in a good state of preservation, but had become rather mealy. The form is conical, regular, and handsome; colour bright yellow. We should, if nothing unforeseen happen, like to have a fruit earlier next season.

\section{R E V I E W S.}

Turner's Florist, Fruitist, \& Garden Miscellany. No. 54 .

$\mathrm{W} E$ have in this excellent periodical a very well executed plate of Lightbody's Sir Joln Moore auricula, and a most beautiful variety it is. There are many interesting papers, consisting of Culture of Achimenes-New Plants--Cultivation and Management of the Verbena, \&c. We must give an extract:"The Pedigree of Flora's Garland Rose Flake Carnation.-This old and esteemed variety was raised by Mr. Brooks, a small amateur grower, and cooper by 
trade, living at Baptist Mills, St. Paul's, Bristol. It bloomed for the first time twenty-eight or twentynine years ago. This fact of itself speaks much in its favour. Look at the number of flowers it has had as competitors, which it has seen one by one drop off to be forgotten; and good as some of its contemporaries are, we do not know one in its class of the present day that will wear it out. But who is there that does not know Flora's Garland? - what need have we to extol it? The only complaint we ever heard respecting it was, 'we cannot keep it.' Every grower has in turn been teased by its fickle. ness and its beauty. The most remarkable thing connected with this remarkable flower is, that it was raised from a yellow picotee, Louis XVI. ;" but there is some doubt about this. Lancashire Lass has been mentioned, "which we think by far the most likely parent." The number is altogether a good one.

The British Winter Garden : being a Practical Treatise on Erergreens, showing their Cieneral Utility in the Furmation of Garden and Landscape Scenery, and their Mode of Propagating, Planting, and Removal, from one to fifty Feet in Height, as practiseả at Elvaston Castle. By William Barron, Head Gardener. London: Bradbury \& Evans.

T'нE above title will give a good idea of the contents of this raluable little book. We have read it over several times, and each time found fresh canse to admire it. The style and spirit of the work is excellent. It is embellished with a frontispiece, being a portrait of the large Araucaria inbricata, at Elvaston Castle; also with the various carriages and instruments for removing large trees, engravings of remarkable yew trees, and a series of examples of the mischief arising from allowing plants to remain in pots for a long time previons to planting out, by which the roots become strangled and the plants are ruined. We perfectly agree with the remarks of 
Mr. Barron on the excellence and superiority of holly hedges, and was much interested in all his remarks on removing large trees, \&c, ; for we have had practical evidence of the excellent manner in which they were transported from awkward situations, and removed with perfect facility to their final destination, twenty years ago. But we must revert to this subject again. In the interin, we would recommend all who admire the graceful beauty of the deodar, the stately grandeur of the araucaria, the diversified elegance of junipers, cypresses, hollies, pines, \&c.-in fact, all who would see the lawns, the hills and slopes, the pleasure grounds and gardens of our beautiful country, still more beantiful, to procure this book, and we are certain they will, after its perusal, thank us for drawing their attention to it.

The Scottish Gardener; a Magazine of Horticulture and Floriculture. No. 6.

OuR northern contemporary still pursues the even tenour of its way, giving us each month an excellent idea of the progress of horticulture in that part of the world. Amongst the most useful and interesting articles are, Cottage 'Trellising--Theory of pruning Fruit Trees-Cnlture of the Indian Azalea-Mural Gardening-Plants adapted for Bedding, \&c. We wish it all the success which so well conducted a periodical deserves.

Letters to Farmers. By James Haywood, of Western Bank, Sheffield. London: Simpkin, Marshall, \& Co. Worksop: Robert White.

We are extremely gratified with the above very excellent publication, and earnestly wish that it could be read by every agriculturist in the United Kingdom. It treats most lucidly and in a popular style of a multitude of things connected with the soil and its produce. We have, the Action of Frost on Soils and Manures-Springs-Natural and Artificial Drain- 
ing-Evaporation and Condensation of MoistureAmmonia: its Nature and Artificial Production; Quantity yielded by various Manures-On the Formation of 'Butchers' Meat, and the Feeding and Rearing of Stock, \&c. We have marked several passages for extraction. The following will give some idea of the work:- "A good cow, for instance, will fatten when exposed to the worst kind of weather, providing she have a sufficient quantity of cake, or other fattening food. But then, on account of her expending a great deal of heat, in evaporating the rain which falls upon her, she will tatten very slowly, and will require much more food than if she had been kept warm and dry. Nothing, indeed, can be more unfavourable to the formation of fat than frequent exposure to rain. In the evaporation of a pound of water, for instance, from the skin of an animal, as much heat is consumed as would (if concentrated to oue point) be required to make six pounds of iron red hot. Now it is possible that the animal may have no heat-producing elements to spare for this purpose; and we shall probably be within compass, if we estimate the loss of two ounces of fat for every pound of water driven off:"

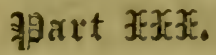 \\ QUERIES AND ANSWERS.}

Will you be kind enough to explain to a novice the difference between a carnation or picotee and a pink? I mean more particularly during the winter months, when, to my unenlightened mind, they appear very much alike.

A Mid-Staffordshire Subscriber.

[We readily perceive that our correspondent is not a florist in the strict sense of the term, but, we make no doubt, in its general acceptance, as a lover of all that is beautiful and lovely, our friend ranks high. We will endeavour to enlighten the matter. The Dianthus family, to which the carnation, picotee, and pink belong, is a very extensive one, for here we 
have the sweetwilliam, and perhaps fifty or sixty species besides. There are some pinks which have strong foliage and robust habit, though generally speaking they are weaker in the grass (foliage) than the carnation, and by the practical flurist are easily distinguishable. The carnation is striped with various colours, on a white ground; whilst the picotee is margined with various shades of scarlet, rose, and purple, on white or yellow grounds. The pink has invariably a dark or red centre, in some cases without edging or lace round the margins of the petals, whilst others are laced with purple, red, or marone of various shades.]

G. D.-The situation of your bed immediately in front of your greenhouse is not desirable, but the season must bear the chief blame for the "weakly spindling" of your plants, complained of. On no account give guano water; it would increase the evil. The "prepared stuff, good turf, loam, and rotten dung," in which they are planted, is quite sufficiently exciting ; indeed, from your description, we should suppose it a participis in the evil bewailed, leading as it certainly would to a strong root-action, whilst the arid condition of the atmosphere forbad the swelling of the flower stem; hence its weakly elongation. If the situation cannot be altered in future seasons, we recommend your using a loam of a more retentive character, and mulching the surface with manure, instead of mixing it with the compost. Carnations delight in a cool strong soil.

I. S. \& Son.-You are quite right; blooming under glass is not new, and has been practised by the best cultivators for more years than we can look back upon. Circumstances must determine you as to the best erection for blooming your collection under. If expense were no object, no doubt a glass structure, fitted so as to command an unlimited supply of air, would be preferable to all others. For ourselves we have a light tent framing, over which is stretched thin canvass or calico cloths, and we have found this quite ample to keep off the strong winds, rain, and sun. We also use the spare lights from our frames, secured on strong posts, say five feet in front and seven feet at the back, giving to them such an inclination as will rapidly throw off rain; and we have found this structure of the greatest use, not only in blooming our plants, but also in ripening seed. The tent should not exceed ten or twelve feet in width. The former allowing three rows of plants to be arranged on either side, with a walk four feet in width in the middle; the latter, four rows. Its length must be determined by the extent of the collection. We recommend the opponents of such a means of success, and such a means of enjoyment, to take advantage of this month, and visit the maguificent collection to be seen at 
the Royal Nursery, Slough, and we stake our existence, after such a visit, they will no longer be opponents.

S. L. S.-Ies; a judicious thinning of the increase, where very thick, will be advantagenus for the bloom, and give you at the same time a supply of pipings; but do your thinning as Ariel did his spiriting, "gently." The particulars of the "Towns Exhibition" are given in ar advertisement, in this number. A circular resperting Mr. Hollyoake's conditions is in the press, and shall be sent when ready.

We beg to invite the attention of all whom it may concern to the evil complained of by Mr. Baildon, at page 189 of the last number. When we accepted the invitation of our esteemed friend, the editor of this work, to offer from month to month, brief suggestions on the culture of these flowers, we did so with the determination, through evil and through gond report, to point out, according to our experience and ability, the evils to be avoided, as well as the means which lad resulted in a large measure of success. With this view, and because we were persuaded that our friends in the West Riding could produce "plants as fine, either for size, strength, or healthiness, as any county in England," and because we had heard much, hoth publicly and privately, of the impossibility of obtaining a bloom in that district earlier than the 20 th of August, and because with plants such as we have received, we knew here we could not attain an earlier bloom, we gave unhesitating expression to the complaint of our friend, $\mathrm{Z}$; and we trust that those of our friends to whom it applied, will receive it in the spirit of kindly regard in which alone it was uttered. So too we trust that those of our friends in this district and in the south, who are open to the censure of Mr. B. will for their own sakes, and to ensure a thousandfold more of enjoyment, at once aniend their ways; for sure we are, that cultivation productive of such results, can never obtain for them, either here or in the south, even a third-rate place on the exhibition table.

E. S. D.

\section{CALENDAR OF OPERATIONS, FOR JULY.}

\section{GREENHOUSE.}

As the beauty of the cineraria and the calceolaria declines, it will be found necessary to remove them to other quarters. Free then of greenfly, dead leaves, and flower stems, and plant them out-the cinerarias in a tolerably rich border, where they 
will make fine robust plants for potling. The calceolaria will be the better for being planted in a shady part of the border.

Give but little water to those pelargoniums that have done flowering, preparatury to their being cut down. When the wounds have healed over, a little more may be given, until they have pushed shoots about an inch long; they may then be shook ont, the roots carefully pruned, and repotted in smaller pots. If they can be placed in a close frame until they have again begun to grow, so much the better. Cuttings of the nost desirable sorts may be planted in the open border.

Those plants tbat have been removed from this house to the open air, should receive every attention in stopping, training, and particularly in watering-stand them on strips of wood, to prevent worms entering the pots; it will also serve better to drain them and offer less inducement to the roots growing through the buttoms. Look carefully over the heaths, and if mildew has made its appearance, immediately dust with flowers of sulphur.

Cultings of azaleas and many other greenhouse plants will strike readily now, if placed in a mild bottom heat.

\section{J. BAYLEY.}

\section{VINERY.}

Attend well to late grapes. Keep a little fire, and plenty of minsture, during the day. Fret them ripenell before the season is too far advanced; they will keep better and be much better flavoured. Continue to stop laterals. See that the ties are not pinthing any of the shoots. Give abundance of air where the berries are beginning to colour, with rather less moisture.

J. BAYLEY.

\section{FLOWER GARDEN.}

The late heavy rains will have so saddened the beds as to render it necessary to stir them deeply with a Vernon hoe, or some such implement, taking care not tn injure the new roots, which are spreading in all directions. If any vacancies occur, through accident or otherwise, let them be immediately filled up from the reserve stock. Peg down verbenas, salvias, heliotropes, and other things intended to cover the beds, as they advance in growth. Tie dahlias, hollyhocks, and other rapirdgrowing plants frequently. Use strong matting, that the plants be not blown from the stakes by sudden gusts of wind. Train creepers, and attend to neatness in every part of the garden. Cuttings of some of the best antirrhinums, phloxes, helianthe. mums, \&c., may now be put in, in sandy soil. Cover with a hand-glass. Brompton stocks may now be sown. Divide polyanthuses and double primroses, and plant deeply, at the end of the month. Bud and layer roses. 
Carnations and Picotens. - Disbud constantly as the laterals rise; a proper atiention to this is most important to ensure a strong and early bloom. With reference to the number of flowers each plant should carry, Mr. Turner, in the last number of the Florist, page 117, says, "Our plan is simple: in the case of small flowers or a weakly plant, we leave one bloom only; all others have two to a plant." We should pursue a precisely similar course; but the necessities of our exhibition consume so many of our flowers (we have repeatedly, from necessity, dressed and put up from 150 to 200 blooms), that to obtrin seed we are obliged to leave an additional hud where practicable. We submit to this only as to a disagreeable necessity, and by no means advocate quantity at the price of quality. The varieties with smaller or thin flowers are :-Carnations: Admiral Curzon, Capt. Edwards, Knowsthorpe Pet, Lamartine, Sir Robt. Peel (Broughton), Omnium Primus, Splendid. Black Diamond, Lord Milton, Thos. Hewlett, Earl Spencer, Premier, Perfection, Africana, Cradley Pet, Bishop of Gloucester, Firebrand, Lady Ely. Picotees: Lady Gardiner, Guilio Romano, Gem, King James, Fanny, Lorina, Viola, Surprise, Alice. These we reduce to one or two buds, according to the strength of the plant. On varieties like Puxley's Prince Albert, and others of similar habit, we leave three buds, removing the leader when just bursting into bloom, thus obtaining two fine side blooms without any of that coarseness we have heard lamented by some. The interested cultivator will speedily detect those varieties requiring the whip, and those which need the rein, and by the time this is in his hand the race will be deepening in interest every hour. Be fully prepared for the climax, and see that every requisite is clean,-tent cloths, hand-glasses, and blooming cards. Of these latter, those made by Mr. Meek, of Crane-court, Fleet-street, London, are so superior to any others we have seen in use that we cannot hesitate about recommending them. We consider the mode of attaching a card or heavy piece of pasteboard to a bloom, by means of its pressure on the pod, to be prejudicial in the highest degree, and many a fine bloom have we seen utterly prostrated under such barbarous treatment. The cards used by us do not touch the pod at all. They aro supported in their place by a circle of thin paper merely, and of so light a character that no disturtion of the pod can arise. These matters may seem to some of very trivial regard, but it is on attention to such minute observances that success is based; and we desire success to be more the rule and less the exception than we have known it; and when the effect of the card and its proper application is more understood, we shall have less cause to smile at the idiosyncracies which are uttered respecting it. As the buds progress they will require tying. We have found a piece of soft bast matting preferable to any other substance for the purpose. India rubber bands are quite JULY-VOL.VI. 
worthless. Trap earwigs incessantly, and watch for and destroy every class of destructives-slugs, greenfly, \&c. Varieties which start early for bloom, such as Lorenzo, Mary, Prince Arthur, \&c. and which are consequently liable to be prejudiced by the drying winds of early spring, should be extensively piped, and now is the time for the operation. Some cultivators - do this in the open ground, we prefer a gentle hotbed. Carefully shade the cuttings, after putting them in. Keep them clean, and remove the moisture from the glasses from time to time, as needed.

\section{Derby.}

E. S. Dopwelit.

In other floricultural matters not previously treated of, we may observe, that pipings of pinks and pansies should be put in; they will strike readily in the open ground, under a handglass, though a slight hotbed for the former is preferable. Towards the latter end of the month ranunculuses will require getting up. We would advise their being then divided, in preference to a later period, when the roots are dry. Auriculas and polyanthuses will require but little care. See that seedlings are kept clean and free from weeds and filth of every kind, Tulip roots will also be ready to take up at the latter end of the month. It is advisable to do this as soon as the foliage assumes a yellow tint. Be careful in taking up seedlings, as they have a great propensity to strike down and form a bulb at a considerable depth. Store them away in a dry, airy, and shady place. If the grower has a cabinet, or drawers, they may be put in their proper places as they are taken up, leaving the fibres to be removed at a more convenient opportunity.

\section{KITCHEN GARDEN.}

Look broad beans over; it is a good plan to pull or cut off their tops; the proper time is easily ascertained, when the young beans are apparent. Sow a sprinkling of early Stone or Snowball turnip. Perhaps some of our readers are fond of tomatoes or love apples :-if they have any, they must attend to thinning and stopping the shoots. Towards the 20th, we would sow early cabbage. Most certainly the earliest and best that we have seen this year is Waite's King; it is much esteemed in this neighbourhood; but see Mr. Knight's advertisement, in the present number, for a description of a new sort. Where other varieties are desired, we can strongly recommend the Nonpareil and Enfield Market Cabbage. Celery should be all planted by this time; the month of June has been a very favourable season for the operation; it delights in liquid manure, but care must be taken that it is not overdone. Small seeds, such as cress, lettuce, turnip radish, endive, \&c. may still be put in. 


\section{FLORAL EXHIBITIONS.}

\section{CAMBRIDGE FLORISTS' SOCIETY TULIP SHOW.}

May 20th, at the Lion Hotel.

Premier Prize.-Osiris, Mr. Ready.

Feathered Bizarres.

1 Platoff, Mr. F. B. Smith

2 Charles X. Mr. Ready

3 Pass Polyphemus, ditto

4 Holmes's Globe, Mr. Coulden

5 Platoff, Mr. F. B. Smith.

6 Abercrombie, Mr. Lenton Flamed Bizarres.

1 Osiris, Mr. Ready

2 Loril Munster, ditto

3 Duke of Bedford, ditto

4 Rachael Ruish, ditto

5 Rachael Ruish, Mr. F. B. Smith

6 Osiris, Mr. Ready Ferthered Byblomens.

1 Lawrence's Friend, Mr. Ready

2 Imperatrice, Mr. F. B. Smith

3 Ditto, ditto

4 Ditto, ditto

5 Mr. R. Headly

6 Imperatrice, Mr. F. B. Smith
Flamed Byblomens.

1 Rubens, Mr. Ready

2 Cleopatra, ditto

3 Imperatrice de Maroc, Mr. F. Smith

4. Boadicea, Mr. Catling

5 Roi de Siam, Mr. R. Headly

6 Ditto ditto Feathered Roses.

1 Madame Vestris, Mr. Ready

2 Heroine, Mr. F. B. Smith

3 Rosa Blanca, Mr. R. Headly

4 Heroine, Mr. F. B. Sinith

5 Mr. R. Headly

6 Heroine, ditto Flamed Roses.

1 Brilliant, Mr. R. Headly

2 Seedling, ditto

3 Triomphe Royale, Mr Ready

4 Triomphe Royale, Mr. Catling

5 Dido, Mr. Ready

6 Rose Guerre, ditto

\section{ECCLES UNITED TULIP SOCIETY.}

At the house of Mr. Joseph WVright, Dyers' Arms, Eccles, May 22.

Maiden Prizes.-1. Trafalgar and Sancta Suphia, J. Shawcross. 2. Firebrand and La Belle Narene, J. Thompson.

Premier Prizes.-1. Sovereign and Bienfait, M. Fogg. 2. Sovereign and Violet Wallers, P. Daine. 3. Trafalgar and Sancta Sophia, J. Shawcross.

1 Sovereign, T. Preston

2 Waterloo, ditto

3 Crown Prince, C. Wych

4 Magnum Bonum, P. Daine

5 Surpass Catafalque, J. Cordwell

6 Royal Gem, M. Fogg

7 Unknown, C. Wych

8 Duc de Savoy, M. Fogg Flamed Bizarres.

1 Lustre, T. Preston

2 Polyphemus, J. Shawcross

3 Cat. Superior, M. Fogg

4 Albion, J. Cordwell

5 Lord Milton, M. Fogg

6 Lacantique, J. Harrison

7 Sovereign, J. Shawcross

8 Careless, $\mathbf{P}$. Daine Feathered Byblocmens.

1 Bienfait, T. Preston

2 La Belle Narene, ditto

3 Unknown, M. Fogg

4 Washington, J. Shawcross

5 Mango, P. Daine

6 Antony, M. Fogg
7 Violet Winner, J Shawcross

8 Adelaide, J. Thompson Flamed Byblocmens.

1 La Belle Narene, C. Wych

2 Tout, M. Fogg

3 Bienfait, $T$. Preston

4 Surpassant, ditto

5 Unknown, M. Fogg

6 Adelaide, P. Daine

7 Siam, J. Cordwell

8 Washington, H. Pearson Feathered Roses.

1 Lady Crewe, T. Preston

2 Latiy Grey, P. Daine

3 Newcastle, T. Preston

4 Dolittle, J. Shawcross

5 Comte, ditto

6 Andromeda, M. Fogg

7 Lady Lilford, ditto

8 Duc de Bronte, T. Preston Flamed Roses.

1 Unique, T. Preston

2 Vesta, J. Shawcross

3 La Vandicken, C. Wych

4 Aglaia, J. Shawcross 
5 Lord Derby, M. Fogg

6 Newcastle, J. Harrison

7 Lord Hill, P. Daine

8 Comte, M. Fogg

Cato, J. Shawcross
Mango, P. Daine

Unknown, C. Wych

Selfs.

Min d'Or, J. Shawcross

White Perfection, P. Daine

\section{AMATEUR TULIP SOCIETY,}

Ninth Annual Exhibition, at the Horns Tavern, Kennington, May 24.

1st prize was awarded to the Rev. T. Jephson, Hanworth House, for Holmes's King, Gibbons's Princess Royal, Lalla Rookh, Polyphemus, Surpasse Pompe, Vivid, Cerise Belleforme, Catalani, Lachesis.

2nd prize to Mr. G. F. Delaforce, Kentish Town, for General Bouruonville, Royal George, Triomphe de Lisle, Dickson's Duke of Devonshire, Marcellus, Brown's Ulysses, Rose Brilliant, Count Vergennes, Claudiana.

3rd prize to Mr. Wallace, Petersham, for Holmes's King, Juc de Bouffleurs, Roi de Siam, Dickson's Duke of Devonshire, Marcellus, Cenotaphium, Rose Camuse, Aglaia, Lady Jane.

4th prize to Mr. C. L. Crook, Brixton, for Gibhons's Princess Royal, Bloemart, Royal George, Polyphemus, Vivid, Strong's King, Crook's Fanny, Madame Vestris, Fleur des Dames.

5th prize to Mr. Charles Williams, Kennington, for Victoria Regina, Law. rence's Friend, Gibbons's Princess Royal and Pilot, Albion, Marshal Soult, Madame Vestris, Aglaia, Lucetta.

The following stand, exhibited by S. Sanders, Esq. of Staines Villa, was pronounced by the censurs to be the best in the rooin, but was disqualified for nnt containing the requisite proportion of roses:-Franklin's Victory, May's Sir H. Smith, Sanders's Lord Hardinge, Salvator Rosa, Polyphemus, Cerise Belleforme, Gibbons's Pilot, Rose Brilliant, Bloemart.

Prizes were also awarded to the three best flowers exhibited, as follows :-

To the Rev. Thomas Jephson, for the best byblcmen, Gibbous's Princess Royal. To Mr. Delaforce, for the best bizarre, Dicksori's Duke of Devonshire.

To Mr. Lane, of Wycombe, for the best rose, Cerise Belleforme.

And for tricolors, as under:-

1st. To Mr. Delaforce, for Lord Melhourne, Lucullus, and Lady Lascelles.

2nd. To Mr. Bushell, for Smith's Duke of Wellington, Ariadne, Black Duke.

3rd. To Mr. Wallace, for Duke of York, Lucullus, and Carlo Dolce.

A scedling prize was awarded to Mr. Crook, for a byblœmen, broke this year, called Champion.

\section{MIDLAND HORTICULTURAL SOCIETY.} At the County Hall, Derby, May 26.

TULIPS.

Collections of Six.-1. Royal Sovereign, Maid of Orleans, Heroine, Captain White, Van Amburgh, Triomphe Royale, Mr. Godfrey. 2. Royal Sovereign, Baguet, Heroine, Polyphemus, Lord Denman, Triomphe Royale, Mr. Spencer. 3. Platoff, unkrown, Duchess of Sutherland, Captain White, Queen Charlotte, Triomphe Royale, Mr. Adams. 4. Pass Perfecta, Baguet, Heroine, Captain White, Princess Royal, Aglaia, Messrs. Lakin. 5. Royal Sovereign, Maid of Orleans, Lady Middleton, Pilot, Queen Charlotte, Catherine, Mr. T. Storer.

\section{Flamed Bizarres.}

1 Pass Perfecta, Mr. Parkins

2 Royal Sovereign, Mr. Godfrey

3 Magnum Bonum, Mr. Forman

4 Catafalque, Mr. Spencer

5 Optimus, ditto.

6 Duc de Savoy, Mr. Allestree Flamed Bizarres.

1 Captain White, Mr. Godfrey

2 Pilot, Mr. Adams

3 Oriflamme, Mr Lakin

4 Polyphemus, Mr. Spencer

5 Pass Perfecta, Mr. Adams

6 Duke of Devonshire, Mr. Forman
Fealhered Byblowrens.

1 Maid of Orleans, Mr. Adams

2 Sable Monarch, Mr. Parkinson

3 Unknown, Mr. Adams

4 Seedling, Mr. Allestree

5 Baguet, Mr. Spencer

6 Wonder, Mr. Parkinson Flimed Byblocmens.

1 Queen Charlotte, Mr. Adams

2 Princess Royal, ditto

3 Lord Denman, Mr. Parkins

4 Purple Perfection, ditto

5 Queen $6 \mathrm{f}$ Violets, Mr. Storer

6 Britannia, Mr. Parkins 


\author{
Fenthered Roses. \\ 1 Heroine, Mr Forman \\ 2 Comate de Vergennes, Mr. Godficy \\ 3 Walworth, Mr. Parkins \\ 4 Hero of the Nile, ditto \\ 5 Aglaia, Mr. Parkinson \\ 6 Midland Beauty, Mr. Allestree \\ Flamed Roses. \\ 1 Aglaia, Mr. Parkinson \\ 2 'Triumphe Royale, Mir. Godfrey \\ 3 Lady Jane Grey, Mr. Parkinson \\ 4 Rose Camillus, Mr. Lakin \\ 5 Catherine, Mr. Parkinson \\ 6 Fanny Cerito, ditto \\ Bizarre Breeders. \\ 1 Pilot, Mr. storer \\ 2 Merit, Mr. Parkins \\ 3 Hamilton, ditto
}

4 Polyphemus, Mr. Parkins

5 Seedling (R. Cobdien), Mr. I:ırkinson

6 Larl of Radnor, Mr. Parkins Bybl emen Breeders.

1 Grace Darling, Mr. Lakin

2 Van Amluurgh, Mr. Parkinson

3 Violet le Grand, Mr. Storer

4 Model of Perfection, ditio

5 Princess Royal, Mr. Adams

6 Britannia, Mr. Parkinson Rose Breeders.

1 Catherine, Mr. Storer

2 Lady Stanley, Mr. Lakin

3 Lady Jane Grey, Mr. Adams

4 Lady Leicester, ditto

5 Anastasia, Mr. Parkins

6 Fanny Cerito, Mr. Parkinson.

\section{PANSIES.}

Twelve Dissimilar Blooms.-1. 'Thompson's Priam, Cruikshanks, Thompson's Elegant, Hooper's Juventa, Rngers's Nelson, Hussey's Master Lacon, Lakin's Oxford Blue, Queen of Eng!and, Turner's Euphemia, Thompson's Sylvia, Turner's Blanche, Fellowes's Diadem, Messrs. Lakin. 2. Queen of England, Mary Jane, Mr. Beck, Climax, Elegant, Joseph Hunt, Hunt's Ellen, Uttoxeter Hero, Duke of Norfolk, Mrs. Beck, Lucy Neal, Pliny, Mr. John Lowe. 3. Mir. Milwood.

\section{NATIONAL TULIP SHOW, \\ Birmingham, May 27.}

The National Tulip Society's gold medal, value $\mathfrak{E} 7 \mathrm{7s}$. for the best six rectifier flowers, was awarded to T. Houghton, Hemshall, Nottingham, for Royal Sove. reign, Coup de Hebe, Capt. White, Qucen Charlotte, Heroine, Triomphe Royale.

Six Rectified Flowers, one of each Class,-1. Mr. Godfrey, Chellaston, for Captain White, Van Amburgh, Royal Sovereign, Maid of Orleans, Heroine, and 'Triomphe Royale. 2. C. Turner, Slough, for Lord Nerman, Arlette, Polyphemus, Queen Victoria, Triomphe Royale, and Royal Sovereign. 3. T. Adams, Derby, for Captain White, unknown, Queen Charlotte, Heroine, and Triomphe Royale. 4. W. Marsden, Derby, for Captain White, seedling, Ambassador, Sarah Ann, Lady Jane Grey, and La Belle Nannette.

Twelve Dissimilar Flowers, four of each Class.-1. J. Willmore, Esq. Edgn baston, for Lady Flora Hastings, Strong's King, Clark's Thalia, Earl Douglas, Triomphe Royale, Heroine, Duke of Devonshire, Aglaia, Washington, Water1oo, Camuse de Craix, and Friend. 2. C. Tumer, Slough, for 'Thalia, Madame Vestris, Pilot, Duke of Devonshire, Triomphe de Lisle, King, Claudiana, Maid of Orleans, George Glenny, Polyphemus, and Heroine. 3. J. Edwards, Hol. loway, for Purple Perfecta, Junius Brutus, Triomphe Royale, Priam, Violet le Grand, Kose Astonishing, General Bournonville, Catalani, Princess Royal, Miss Catherine, and Hamlet. 4. W. Lymbery, Nottingham, for Captain White, Lord Milton, Donzelli, Lord Sandon, seedling, Mrs. Lymbery. Mantua Ducal, Baguet, Prince Eli, Ia Vandicken, Sarah, Bacchus, and Polyphemus.

Nine Dissimilar Flowers - l. T. Houghton, for Heroine, Abercrombie, Princess Royal, Emperor of Austria, Victory, Queen Charlotte, Royal Sovereign, Triomphe Royale, and First-rate. 2. J. Parkins, Derby, for Walworth, La Bien Aimee, Denman, Heroine, Venus, Aglaia, Sovereign, Britannia, and Shakspere. 3. 'T. Adams, Derby, for Royal Sovereign, Heroine, Maid of Orleans, Pilot, Triomphe Royale, Enchantress, Captain White, Princess Royal, and Cornelius. 4 C. Turner, Slough, for Princess Royal, Midland Beauty, Glory of Abingdon, Lady Stanley, Triomphe Royale, Purple Perfecta, Glencoe, Gibbons's No. 2, and Albion.

Best Feathered Flower in each Class, selected from the Classes.-Bizarre, J. Parkins, Derby, Charlps X. Byblcmen, Rev. S. Creswell, Radford, Prince of Wales. Rose, Rev. S. Cresivell, Agnes (seedling). 
Feathered Bizarres.

1 Charles X., K. Dixon, Manchester

2 Vivid, J. Thorniley

3 Magnum Bonum, Parkinson, Derby

4 Colbert, R. Dixon

5 Chellaston, Mr. Spencer, Chellaston

6 Catafalque, Rev, S. Creswell Flaned Bizarres.

1 Captain White, Mr. Godfrey

2 Pilot, W. Astle, Melbourne

4 Lord Milton, Frearson, Nottingham

4. King, J. Edwards, London

5 Donzelli, J. Willmore, Esq.

6 Polyphemus, Rev. S. Creswell Feathered Bybloemens.

1 Maid of Orleans, J. Thorniley

2 Princess Royal, T. Adams

3 Victoria Regina, C. Spencer

4 Sarah, Rev. S. Creswell

5 Salvator Rosa, Mr. Ackerley

6 Kosciusko, Rev. S. Creswell Flamed Bybloemens.

1 Princess Royal, T. Houghton

2 Queen Charlotte, C. Thorniley

3 General Bournonville, J. Hartland
4 Lord Vernon, Mr. Parkinson

5 Rubers, R. Dixon

6 Surpasse le Grand, J. Astlee, Derby

Feathered Roses.

1 Heroine, C. Spencer

2 Napoleon, Rev. S. Creswell

3 Baguet, $R$. Dixon

4 Bion, ditto

5 Anastasia, Mr. Ackerley

6 Lady Crewe, Rev. S. Creswell Flamed Roses.

1 Vicar of Radford, Rev. S. Creswell

2 Aglaia, Mr. Parkinson

3 Triomphe Royale, J. Parkins, Derby

4 Grand Rose Desire, W. Lymbery

5 Triomphe Royale, Mr. Godfrey

6 Carnilla, J. Astlee

Flame or Beam.

1 Holmes's King, G. Mills, Alderly

2 Oriflamme, S. Lakin, Derby

3 Pilot, ditto

4 Gibbons's No 4, C. Turner, Slough

5 Lord High Admiral, J. Willmore

6 Duke of Clarence, Mr. Ward, Not. tingham.

\section{MOTTRAM TULIP SHOW.}

At the House of Mr. H. Patchetts, Tollemache Arms, Mottram, May 29.

Premier Prize.-Charles X., W. Hilton.

Feathered Bizarres.

1 Charles, J. Shawcross

2 Surpasse Catalque, J. Bradley

3 Crown Prince, T. Penkathman

4 Trafalgar, ditto

5 Juc de Savoy ditto

6 Waterlow, T. Summers Flamed Bizarres.

1 San Joe, J. Barratt

2 Catafalque, ditto

3 Lacintique, T. Penkathman

4 Lustre, ditto

5 Liberty, ditto

6 Charles, ditto Feathered Byblomens.

1 Bienfait, J. Bradley

2 Violet Winner, T. Penkathman

3 Incomparable, W. Hilton

4. Mango, J. Barratt

5 Wasnington, T. Penkathman

6 Unknown, T. Summers

Flamed Bybloemens.

1 Bienfait, J. Barratt

2 Violet a Fond Noir, ditto

3 Gibbons's Seedling, ditto

4 Competitor, T. Penkathman

5 Gibbons's Seedling, J. Barratt
6. Tout, T. Penkathman Feathered Roses.

1 Comte de Vergennes, J. Shawcross

2 Dolittle, J. Bradley.

3 Heroine, J.'Barratt

4 Andromeda, ditto

5 Lady Crewe, J. Shawcross

6 Unknown, J. Bradley Flaned Roses.

1 Rose Unique, J. Barratt

2 Rose Vesta, T. Summers

3 Roi de Surrey, T. Penkathman

4 Unknown, T. Summers

5 Lady Crewe, J, Shawcross.

6 Holden's Rose, T. Penkathman Bizarre Breeders.

1 Gibbons's Seedling, T. Penkathman

2 Unknown, J. Bradley Byblomen Breeders.

1 Unknown, J. Barratt

2 Unknown, J. Bradley Rose Breeders.

1 Unknown, T. Penkathman

2 Unknown, ditto

Melfs.

Min d'Or, J. Bradley

White Flag, J. Shawcross

\section{BOLTON TULIP MEETING.}

June 1.

Young Growers' Prize._Lady Crewe and Waller's Vivlet, J. Turner.

Feathsred Bizarres,

1 Lord Lilford̉, J. Morris

2 Magnum Bonum, ditto

3 Grand Duke, ditto
4 George IV., J. Turner

5 Lord Melbourne, J. Morris

6 Crown Prince, J. Turner

7 Danicl O'Connel], W. Shippobotham 


Feathered Bizarres.
1 San Josef, J. Morris
2 Charles X., ditto
3 Lord Milton, ditto
4 Albion,
5 Shakspere, J. Barlow
6 Lustre, W. Yates
7 Polyphemus, R. Dunderdale
Feathered Byblomerus.
1 Baguet, J. Morris
2 Favourite, T. Walsh
3 Bienfait, J. Hardman
4 Mango, W. Yates
5 Purity (seedling), J. Morris
6 Grand Exeter, ditto
7 Washington, J. Barlow
$\quad$ Flamed Byblomens.
1 Atlas, J. Morris
2 Bienfait, J. Turner
3 Waller's Violet, ditto
4 Sable Rex,
5 Eagle Noir, J. Morris
6 Incomparable, W. Shippobotham
7 Alexander Magnus, R. Dunderdale

Feathered Roses.

1 Heroine, J. Mlorris

2 Lady Crewe, ditto

3 Comte de Vergennes, R. Dunderdale

4 Duchess of Newcastle, ditto

5 Bion, J. Morris

6 Hurst's Rose, ditto

7 Andromeda, J. Barlow Flamed Roses.

1 Rose Unique, J. Morris

2 Triomphe Royale, ditto

3 Aglaia, ditto

4 Ponceau Brilliant, W. Yates

4 Camillus, J. Morris

6 Matilda, T. Walsh

7 Seedling, ditto Breeders.

Best Bizarre, Pilot, J. Morris

Best Byblœmen, unknown, J. Barlow

Best Rose, No. 12, J. Morris Selfs.

Min d'Or, T. Walsh

White Flag, ditto

\section{FALKIRK HORTICULTURAL SOCIETY.}

June 1.

Judges.-Mr. John Waterston, florist, Paisley; Mr. John Milligan, Denny ; and Mr. John Ferguson, Larbert.

Six Blooms, three Feathered and three Flamed.-1. Alexander's Sysigambis (feathered rose), La Vandickel (flamed rose), Read's Tam O'Shanter (feathered byblomen), Prince Ferdinand (flamed by blomen), Waterloo (feathered bizarre), Calman's Polyphemus (flamed bizarre), A. Johıson, Falkirk. 2. Zuill's Mary Lamb (feathered rose), Montona (flamed rose), Reid's Prince Albert (feathered byblœmen), Bacchus (flamed byblœmen), Waterlon (feathered bizarre), Albion (flamed bizarre), D. Draper, Falkirk. 3. Aglaia (feathered rose), l'erle Brilliant (flamed rose), Rodney (feathered byblœmen), Queen Charlotte (flamed byblœmen), Waterloo (feathered bizarre), Albion (flamed bizarre), J. Rennie, Falkirk.

Twelve Blooms.-Heroine, La Vandicken, Goldham's Maria, Norna, Davey's Queen Charlotte, Lawrence's Friend, Reid's Prince Albert, Diana Bruin, Dickson's Duke of Devonshire, Waterloo, Pizarro, Polyphemus, D. Draper. 2. Hebe, Triomphe Royale, Iphigenia, La Vandicken, La Belle Narene, Prince Elie, Rodney, Queen Charlotte, Surpass Catafalque, Platoff, Albion, Waterloo, J. Rennie.

Feathered Bizarre-Surpass Catafalque, A. Johnston.

Flamed Bizarre.-Lawrence's Polyphemus, ditto.

Feathered Byblœmen.-Baguet, ditto.

Flamed Byblomell. - Prince Elie, ditto.

Feathered Rose.-La Belle Nannette, ditto.

Flamed Rose-Cerise Primo Superb, ditto.

Premier Tulip.-Calman's Polyphemus, ditto.

First.class certificates were awarded to $\mathrm{Mr}$. Lightbody, for the following seedling tulips:-Kosciusko (feathered byblœmen), Irene (feathered rose), Saracen (flamed bizarre), Redgauntlet (flamed bizarre), Lochnagar (feathered bizarre).

\section{HALIFAX TULIP SHOW.}

At the Shoulder of Mutton Inn, June the 2nd.

Feathered Bixarres.

1 Comte Platoff, J. Jackson

2 Rising Sun, G. Baildon

3 Monarch, J. Jackson

4 Seedling No. 4, J. Hinscliffe, jun.

5 Grand Duke, J. Fletcher.

6 Firebrand, G. Baildon
7 Salamander, J. Hinscliffe

8 Surpass Catafalque, J. Jackson

Flamed Bixarres.

1 Brown's Hamlet, J. Hinscliffe

2 Donzelli, A. Hartley

3 George IV., J. Hinscliffe

4 Polyphemus, G. Baildon 
5 Charhornier. J. Fletcher

6 Seedling, J. Hinscliffe

7 Sanzio, J. Fletcher

8 Sir Joseph Bankes, J. Jackson Feathered Bybloemens.

1 Bienfait Incomparable, J. Hinscliffe

2 Baguet, J. Fletcher

3 Gibbons's Duchess of Sutherland, J. Jackson

4 Hepworth's Queen of the North, J. Hinscliffe

5 Violet Winner, J Rushworth

6 Lewold, G. Baildon

7 Gibbons's Sarah Ann, J. Jackson

8 Maitre Partout, G Baildon Flamed Bybloemens.

1 Czarinne, J. Rushworth

2 Voerhelm's Incomparable, J.Fletcher

3 Grand Cid, J. Rushworth

4 Gibbons's Qu. of Violets, J. Jackson

5 Bienfait, J. Fletcher

6 Gibbons's Seedling, G. Baildon

7 Violet Brun, ditto

8 General Barnevelde, ditto Feathered Roses.

1 Lady Middleton, J. Rushworth

2 La Belle Nannette, J. Hinscliffe

3 Comte de Vergennes, ditto

4 Walworth, G. Baildon

5 Lady Crewe, dit to

6 Duchess of Newcastle, J. Rushworth $\mid 4$ Prince Albert, J. Rushworth

\section{TULIP SHOW,}

At Mr. J. Binns's, the Morning Star, Bridge-street, Staley Bridge, June 5.

Feathered Bizarres.

Premier.-Charles X., T. Perkins

1 Watcrloo, T. Summers

2 Trafalgar, T. Penkathinan

3 Duc de Savoy, ditto

4. Liberty, T. Shawcross

5 Pearson's Wellington, ditto Flamed Bizarres.

Prem.-Surpass Lacantique, T. Perkins

1 Beauty Parfait, J. Barratt

2 Polyphemus, T. Penkathman

3 Magnifique, T. Perkins

4 Lustre, T. Summers

5 Liberty, T. Perkins

Feathered Bybloemens.

Premier.-Ambassador, J. Shawcross

1 Bienfait, J. Collier

¿ La Belle Narene, S. Marsland

3 Washington, T. Summers

4 Mungo, J. Shawcross

5 Incomparable, J. Muirs

Flamed Bybloemens.

Premier.-Groashaw, J. Shawcross

1 Violet a Fond Noir, T. Penkathman

2 La Belle Narene, J. Muirs

3 Tout, T. Penkathman

4 Sable Rex, T. Perkins

5 Gadsby's Magnificent, J. Shawcross
7 Hero of the Nile, J. Jackson

8 Heroine, G. Baildon

Flamed Roses.

1 Aglaia, G. Baildon

2 Clark's No. 4, J. Hinscliffe

3 Mantua Ducal, ditto

4 Triomphe Royale, J. Rushworth

5 La Vandicken, G. Baildon

6 Unique ditto

8 Tord Hill, $G$. Baillife Bizarre Breeders.

1 Poly $\star$ Leopold, J. Fletcher

2 Charbunnier, J. Hinscliffe

3 Pilot, J. Rushworth

4 Hepworth's No. 14, J. Hinscliffe Bybloemen Breeders.

I Sancta Sophia, J. Rushworth

2 Gibbons'sLady F. Hastings, G.Baildon

3 Cibbons's : No. 12, J. Rushworth

4 Pearson's No. 3, J. Jackson Rose Breeders.

1 Lady Leicester, J. Jackson

2 Gibbons's Seedling, J. Rushworth

3 Fairy Queen, G. Baildon

4 Glaphra, J. Jackson Selfs.

1 White Flag, J. Fletcher

2 Min d'Or, J. Rushworth

3 Cotherstone, J. Jackson 


\section{剓art \\ ORIGINAL COMNUNICATIONS.

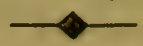

ON RAISING SEEDLING CARNATIONS.

ON turning over the pages of one of the numbers of the present year's Midland Florist (long may it continue to flourish), I cast my eye on an article written by Mr. Dodwell, on the carnation, in which he advises seed to be sown on a gentle heat, and to be sparing of water.

What need there can be for bottom heat to facilitate the growth of seed that will vegetate in nine or ten days, I am at a loss to conceive.

The same result, as is well known, will often occur to the small salad herbs grown on heat. Yet I never knew mustard, rape, dc. to damp off in the natural ground, and carnation seed will germinate in almost as little time.

Twenty-five years ago, when I first sowed seed, I was advised to sow nearly half an inch deep, without heat, and plants so raised, for the most part bloomed next year. I continued for some few years to sow in the same way, with perfect success, as far as raising plants was the question; and the list of dealers, seventeen or eighteen years ago, will show some flowers of mine considered good.

A lapse of many years occurred before I again began seedling raising. In the spring of 1850 , having saved a considerable quantity of seed in 1849 , and supposing that the custom of using heat and shallow sowing must in that interim have been discovered to be an improvement, I adopted it, and found it produce exactly the result described by AUGUST-VOL. VI. 
Mr. D., namely, that hundreds dimped off, or "shanked."

In 1850, I saved but a single pod of seed, and returning to my old system of deep sowing and a northern aspect, I shall this year bloom every plant so raised, every seed having, I believe, produced a plant.

Last year, I again sowed a rather large portion of seed, which has produced a two-light box full of plants; and these were sown in pots and pans, fully exposed to the atmosphere, and carefully kept out of the influence of sun heat, in a northern aspect, where, at least, they received no more than the early and late rays of that luminary, keeping the surface soil constantly moistened, the pots, \&c. being carefully and efficiently drained, so that no superfluous moisture might remain long in the soil.

Plants so raised will be found to drop their cotylidons almost on the surface of the soil, and give not the least trouble to the raiser.

It is, perhaps, unnecessary to inquire too curionsly into the cause of their shanking, when by a simple mode of culture it is to be avoided : but may it not be produced by the tender stalk being unnaturally forced above the surface, when naturally it remains below it? I attribute half the calamities to which Dianthus caryophyllus flore pleno is subject, from the cradle to the grave, to unnatural treatment. I may further add, that much of the seed sown this year by me, had not attained above half its size, and was perfectly colourless, yet it has vegetated more or less freely. I should also explain that I mean a two-light frame full of pans and pots; and that this protection has only been afforded them a day or two since, in consequence of the continued heavy rains, until which they had no shelter whatever, yet have bravely withstood the late long spell of easterly winds.

J. W. NEWHALL.

Woolwich, June 21st, 1852. 
DESCRIPTIVE REIIARKS ON ABOUT ONE HUNDRED VARIETIES OF THE TULIP.

Taken during the Blooming Season of 1852.

BY MR. WM. HARRISON, SECRETARY TO THE FELTON UNION OF FLORISTS AND HORTICULTURISTS.

What bliss beside the bed to stand, As silently they preach,

And tell us of His wondrous hand?

The atheist they might twach.

Talk of the painter's brush ! tis vain

To match the wondrous hand

Who fashioned them, created us,

And yon bright systems planned.

As a continuation of my remarks on the best method of arranging a tulip bed, I beg to hand you the following notes on about one hundred rarieties of the tulip, which were taken while the flowers were in bloom. I an much indebted to the kindness and urbanity of Mr. Bromfield, of Felton Mills, who afforded me every facility in making remarks on the new and scarce flowers in his magnificent bed; and as such opportunities do not often occur, I offer you the following notes, hoping that, as they were taken with great care and deliberation, and with the strictest impartiality, they may be of some use to future purchasers. I am aware they may not please all parties, but as they are faithful remarks on the varieties mentioned, as they have bloomed here this season, I offer them "withont fear or farour," and shall at once proceed with the

\section{BIZARRES.}

C'herles $X$. - This old variety was very fine, possessing a pure bottom, good cup, fine feather and slight flame, and in every respect perfectly pure.

Lawrence's Glencoe.-This striking flower has a fine delicate feathering of black, on a rich yellow ground, and is generally characterized by bold black flashes of rich flame.

May's King has a fine rich orange ground, and a slight black feather, but the stamens are a little stained at the top.

Smith's Victory. - This is a very grand flower indeed, having a rich yellow ground colour, fine wide low cup, a delicate dark 
brown feather, and totally destitute of flame. It is a new and great acquisition.

Dickson's Duke of Devonshire. - This continues a grand middlerow bizarre, and ought to be in every good bed. It is now ten years since I first saw it in Mr. Bromfield's bed, and it certainly is a star of the first magnitude. The cup is of great strength, and the yellow ground seems as if varnished over with a fine glittering yellow, with a feathering and flaming nearly black. 1t is truly a magnificent and beautiful variety.

Lawrence's Milton.-This is another grand cupped flower, with a heavy black feather, and slight flaming about half way down the petals; very similar in character to the Duke, but does not stand so long.

Slater's Curion.-This is a very fine feathered bizarre, ground colour rich, cup fine, slightly feathered with dark brown, and a decided acquisition.

Lyde's Lord Strathmore has a very fine low cup, slightly and irregularly flamed, richer in the outside of the cup than the Duke, and evidently one of the same family. A fine flower. Alexander's Monarch.-This is said by many to be the same as the Duke, but it is decidedly different. Its ground colour is a richer orange, feathered with a lighter brown, and a little inclined to be stained at the top of the stamens. It is a very rich-looking feathered bizarre, with a slight beam down the middle of each petal.

Solon.-This is a rather pale lemon yellow ground, very striking flower, quite pure, and a distinct variety; feathered and slightly flamed.

Marcellus.-A fine cup, pure bottom, feathered and slightly flamed with very dark brown.

Apelles.-A fine rich bizarre, good cup, fine feather, and very heavy flame.

Clarli's Leonidas.-This is another grand flower, heavily feathered and flamed with rich dark glossy brown. An extra fine variety.

Waterston's Midas.-A good first-row bizarre, fine bottom, and feathered and flamed with light brown.

Allan's Queen of Bizarres.-A fine dark feathered bizarre, but pale on the outside of the cup, like the Duke of Clarence.

Darl's Dangerous.-A rich fine flower, light feather and little flame. A fine first-row flower.

Bowler's Everard.-A fine pure bottom and good cupped flower, with a rich yellow ground colour and a deep rich crimson feather and flame.

Finlayson's Hampden.-A very rich-looking bizarre, finely feathered and flamed with a very dark brown. The fine flaming of this flower runs a long way down, yet leaves the bottom quite pure. A very attractive flower. 
Polyphemus.-As usual, in various strains, some heavy and others light, but all clean and fine.

Leopold. - A fine feather and flame, on a lemon coloured ground. Very pretty and distinct.

Albion-Fine, but heavy, like a heavily flamed Polyphemus.

Tyso's Polydora.-This is a grand flower in every respect. 'The general character of Polydora is feather and slight flame, with the colour of the outside of the petals nearly as good as the inside, which gives it a superiority over many of even the finest bizarres. It is certainly a grand flower, and ought to grace every bed.

Tyso's President. - This flower has a good cup and pure bottom, but retains much breeder colour about the beam, and is not so good as any of the foregoing.

Slater's Northern Hero is distinguished by its rich orange ground, and feathered with a dark brown, when free from the breeder colour. Stained.

Norman's Royal Albert.-A fourth-row bizarre, good cup, pure bottom, with feather and rich starry fiame.

Norman's Sir Edward Knatchbull.-A second-row bizarre, fine short cup, pure bottom, bright yellow, and deep scarlet feather and flame.

Norman's Sir Genrge Whitmore.-A fine bizarre, with rich brown feather and pillared flame.

Walker's Coronation.-A fine second-row bizarre, with colours and marking similar to Strong's King.

Bromfield's Sir George Grey.-This is a fine pure good-cupped flower, rather delicately feathered with rich brown; a decided acquisition, and second to none. It is a break of this year.

Lawrence's Bolivar possesses a gocd cup, pure bottom and stamens, fine reddish brown feather, and slight flame; a very good flower indeed.

Delaforce's Earl Douglas. - This is a very fine flower, perfectly pure bottom and stamens, very rich yellow ground, fine dark heavy glossy feather, and beautifully pencilled flame. Too much cannot be said in praise of this fine flower.

Walker's King. - A pretty thing. When from a small root, it comes with the most delicately pencilled feather imaginable, no flame, and perfectly pure bottum, but the stamens are a little stained at the top.

Lord Munster.-Very fine rich yellow inside, perfectly pure bottom and stamens, large bold black arthers, and fine bold heavy brown feather, with slight flame. It is, however, rather pale on the outside of the petals.

Ophir.-A very fine rich clear bizarre, with a fine brown feather and slight flame.

Scotia.-A very beautiful rich yellow ground colour, and a slight red jencilled feather; cup and stamens perfectly pure. 
Albion (Slater's strain).-A long cupped richly flamed flower, but stained in the bottom, and worthless.

old Catafalque. - Good cup, fine heavy dark feather, but stamens rather stained.

Prince Albert.-This is a beautiful rich feathered bizarre, the cup being exceedingly rich inside, and the feathering a fine dark brown; but the cup is always narrow at the top, and bad to get open. It is supposed by many to be the same as Surpass Catafalque, but this variety is quite pure, while the upper half of the stanens of Prince Albert is stained.

Lawrence's Shakspere has been very fine this season. It is finely feathered, and the flaming beautifully pencilled out to the feather ; colour nearly black, on a rich yellow ground. Though apt to come heavy, when in right trim, it is most beautiful, and generally admired.

Lawrence's Ostaide.- This is a pretty thing, and perfectly pure. It has a fine broad feather, but unfortunately the ground colour soon bleaches very pale.

Lawrence's Damascus. - This has long been a great favourite of mine. It is a magnificent variety, cup extra, ground fine, and feathering and flaming quite black. It is a very dear and scarce flower, and still in fer hands. It is a distinct and striking flower, and ought to be in every good bed.

Strong's Hero.-This is another very pretty variety. Rich yel. low ground, feathered and flamed rather irregularly, but still a pretty and desirable flower.

Lawrence's Paul Potter has this year been very fine. It possesses a fine clean cup, ard has this season been correctly feathered with dark brown. When in this state, it is a most desirable flower.

Lawrence's Donzelli.-Whis is another very fine and attractive flower. Ground colour rich, with a fine bold dark feather and very slight flame. It well deserves to be generally cultivated.

[The byblomens and roses in our next.]

West Thirston, near Felton, July 1, 1852.

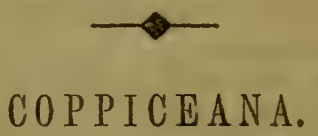

No. XXII.

AT the earnest desire of many of our friends, we resume the description of trees and shrubs growing in our grounds, premising that we conclude the present 
series in another number or two. We will, tleu, attempt to describe

The Salisburia Adianthafolia. (The Maiden-hair Tree.)-Certainly most singular in its foliage, which is angular, having the base divided into two lobes, forming a fanciful resemblance to the parted hair on the forehead of a child. It is deciduous, and perfectly hardy in England, though we understand that it requires some protection in the northern parts of Scotland. It is usually raised from layers, in this country; but plants raised from seed are sometimes offered for sale on the Continent.

The Spirceas are now becoming an extensive fanily, principally deciduous, though one or two are subevergreen. 'They are easily propagated by suckers or layers. Some, however, are of a weedy character, and throw up suckers in all directions. They vary extremely in appearance; some have small and rounded foliage, whilst others are of the size and form of the ash.

S. Arctica is of dwarf habit, seldom rising more than twelve or eighteen inches, bearing dense corymbs of white flowers in great profusion. Well adapted for small beds, or the front position in a shrubbery. 1s.

S. Bella.-Tall, with wandlike shoots. The flowers are pretty pink. A distinet variety. 6d.

S. Douglasii, with spikes of pinkish flowers, rather pretty, but monopolizes much space with its creeping roots. It would be a nice thing for the border of rides through extensive plantations, and might make a good thing to mix with other undercover for game. $6 \mathrm{~d}$.

S. Lindleyana.-A strong-growing shrub, but one of the most handsome, both in flowers and foliage. The former are white, and produced in long drooping racemes of a light feathery appearance. The foliage is pinnate, or ashlike, forming a bold and attractive bush.

S. Prunifolia Pleno.-This has double white flowers, somewhat similar to single blossoms of the double white hawthorn, thickly studded on its curving slender branches. It was introduced into Belgium by Dr. Von Siebold, and first sent to this country by Mr. Van Houtte, of Ghent. It may now be procured at a cheap rate, and should be in every garden where shrubs are grown. Is.

S. Reevesii.-This is nearly evergreen, and of pretty habit. The flowers are white, and produced in clusters. A very nice addition to dwarf hardy flowering shrubs.

S. Rotundifolia, with small foliage and white flowers. A very handsome and interesting variety. Is. 


\section{SYMPHORICARPOS. (The Snowberry.)}

S. Racemosus. - A shrub with small and rather inconspicuous flowers, succeeded by white snowlike fruit, about the size of large peas. Readily proparated by suckers, and now become common. $3 \mathrm{~d}$.

S. Racemosus Variegata.-A dwarf dense bush, the leaves blotched with yellow. A very handsome variegated deciduous plant, and will grow in any common garden soil. 1 s.

Syringa. (The Lilac.)

A very farourite family with us, consequently we have a tolerable collection.

$S$ Flore Purpurea Pleno.-A light bluish lilac flower, extremely pretty, and double.

S. Charles $X$., with large closely set flowers, purplish red. A stout grower, ani very handsome.

S. Duchess de Nemours. - A very fine sort, flowers large, bronzy pink, and produced in great profusion. One of the best.

S. Princess Marie.-In the same style as the foregoing, with rather more of a lilac cast.

S. Emodii has large lance-shaped foliage, and white flowers. The wood is strung, making shonts somewhat like the ash. A very distinct species from the Hinyala.

S. Saugeana.-A red variety of the Siberian, very handsome. Shoots slender, foliage lance-shaped, and dark green. Forms a beautiful standard for a lawn. The trusses of flowers are large in proportion to the shoots and foliage.

S. Jossikce.-Of dwarf habit, very distinct, flowers dark purple, produced in whorls. A nice sort where space is an object.

'The Taxodinms are remarkable for the beauty of their foliage. 'The most conmon and best known, though not seen half so often as it onght to be, is

T. Distichum. (The Deciduous Cypress.) - The tree is uf hand. some pyramidal habit. foliage very narrow and of a lively green. In the autumn it dies off a reddish brown tint. To mix with other trees of bolder foliage, it is very appropriate, flourishing most in rather moist situations. It is raised from seed, and may be obtained, according to size, from Is. to $5 \mathrm{~s}$. T. Distichum Pendula. (The Weeping Deciduous Cypress.) This requires to be inarched on the previous variety. Foliage similar, but the branches have a drooping habit, and it is not of en met with.

T. Pinnatum, or Hugelii. (Baron Hugel's Deciduous Cypress.) -A very pretty simall tree. The character is less robust than T. distichum, but though to the botanist and collector most desirable, yet from the circumstance of it not being quite so harcy, and to the casual observer undistinguishable, we should recommend T. distichum for all general purposes. 
T. Sempervirens. (The Evergreen Taxodium.) - A very beautiful and comparatively new tree, throwing out its branches clothed with fine dark foliage horizontally, and assuming a pyramidal form. It is of rapid growth, and a fit associate for the Deodar, Pinus insignis, \&c. In fact, for a conspicuous position on a lawn, there are few trees so desirable. From 2s. $6 \mathrm{~d}$. to $10 \mathrm{~s}$.

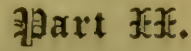

NEW, RARE, 0R G00D FRUITS, FLOWERS, PLANTS, TREES, AND VEGETABLES.

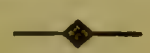

\section{HARDY PERENNIAL HERBACEOUS PLANTS.}

Lilium Colchicum.-A rery attractive plant, and will be first-rate for hybridizing. It is of neat growth, and has large bright orange flowers.

Beauty of Charonne Delphinium. - Another addition to the beautiful family of perennial larkspurs, and forms a splendid border plant. It is in the way of D. magnifica, and is highly desirable.

Pentstemon Esteril.-A novel and rery pretty blush variety. The habit of the plant is good.

Lychis Diolca Alba Plexa.-A double-flowering white catchfly, of dwarf growth, and very attractive.

In the Horticultural Society's garden, at Chiswick, a new cross-bred aquilega, or columbine has been obtained, by impregnating a species from California with the Aquilega fragrans, from the Himalaya mountains. The flowers are beautiful, being deep purple and yellow. Onr readers will please to mark this. A new perennial herbaceous plant, like the one just named, is raluable. What has been done there may also be accomplished elsewhere. 
Prinula Undulata.-From Russia. Throws up a slender flower stalk, the summit being crowned with small starlike lilac blossoms.

Gallardia Semiplena.-A very showy perenial, with semidonble flowers, the rays being yellow, with dark shade at the base.

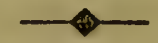

\section{VERBENAS.}

So wonderful indeed is the improvement of this favourite and beautiful plant, which is adapted alike for bedding purposes and for pot culture, that we are at a loss to imagine what combination of colour will be next produced. We made notes of some very beautiful varieties we saw last seasun, and which, we believe, are now letting out by the trade.

Marianne.-A continental variety, of extra fine form, compact and neat in its mode of growth. Its colour is a beautiful dark rose, dashed with purple, having a fiery crimson eye.

Belle Melanie. - This is a very striking variety, beautiful in habit, flowers white, with deep marone eye

George Sands is one of the scarlets, of which there are now so many. It will, however, bear favourable comparison with the best out, having a deep crimson centre, and altogether is very attractive.

Goethe bears a very fine truss; the flowers also are individually large, fine blue, with distinct purple centre.

Cornelia.-This took our fancy much, being white, with a large and beantiful purple centre. The contrast was very striking. It is a brilliant flower.

M. Paquin.---Rich plum colour, with large pure white centre. This we considered really a first-rate sort.

GREENHOUSE PLANTS.

Brachysema Acuminata. - A very beautiful climber for the conservatory. The flowers are bright scarlet.

Pelargoniums.-At the National Floricultural Society"s rooms were exhibited, on the 27th of May, 
the following seedlings:-Empress (Beck), the form of the flower was tolerable, the colour vermillion scarlet, with a rich shaded crimson spot; very distinct and desirable. A first-class certificate was awarded to it. At the same time, a fancy variety, raised by Mr. Ambrose, had a similar reward. The upper petals deep purplish crimson, the lower ones pencilled and shaded with rich violet. It is a stout good formed flower.

Calcholarias.--These are so easily raised that great improvement ought to be the result of the immense quantity grown. On the 3rd of June, were exhibited by Messrs. Henderson, of the Wellington-road Nursery, the following seedlings, for which labels of commendation were awarded :-

Heywood Hawkins. - A beautiful half-shrubby dwarf kind. The flowers have a clear yellow ground, regularly broken with dark crinson markings. It is very showy, producing large trusses of flowers, in great abundance.

Fascination.-A new colour, described as a shaded flamed red, of good habit and tolerable form.

Araminta. -The form of this is good, rather deficient in habit, heavily marked with richly shaded crimson.

Fireball.-Fine orange scarlet, on yellow. Desirable for its novel colour.

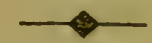

\section{NEW SHRUBS.}

New Perpetual Roses.-An eminent amateur of roses hast sent us the names of the following, which he states to be extra fine:-

Madame Andry. - A very stout and good formed flower. Petals well arranged, the colour a peculiarly rich and striking rose. Diodore.-Hebe's cup over again, except that it gives autumnal flowers.

Eugene Sue--Immensely large flowers, perhaps the largest yet raised. Colour bright rose.

Joseph Decaisne. - One of the very best formed flowers. Colour bright rose. Its shape will make it a favourite, though there are several very similar in colour already in cultivation. 
Louise Odier.-This is a Bourbon of exquisite form, quite a first-rate rose, deep pink.

Beauté Lyonnaise. - A peculiar colour, nearly a true lilac, large, and will make a line sort for exhibition.

Peonia Montans, or Tree P.eonies-These have, during the last few years, made considerable progress, not only in number of varieties, but also in size and abundance of petals. We understand that those introduced by Mr. Robert Fortune, to the London Horticultural Society's gardens, have bloomed finely this season. Amongst them, P. moutan globosa, is a very fine white one, of more compact habit and better form than many others. P. moutan picta is salmoncoloured, large, and very handsome.

Most people who are fond of evergreens know the Garreya elliptica, with its long pendulous male flowers or catkins. In spring, it is one of the most interesting evergreens we possess. It appears that - all the plants introduced by the late D. Douglas were catkin-bearing, or males. We are, however, glad to hear that there is a female plant in the Horticultural Society's gardens, now bearing fruit, and from which we trust plants will be raised.

NEW TREES.

Weeping Variegated Moun'taln Ash.-This variety, lately introduced from the Continent, has with us long flexile branches, the leaves strongly blotched with yellow. It will form a good addition to our hardy ornamental trees.

The Hemp Palm.-This has been living for some years in the Royal Gardens, at Kew, and some hopes are expressed in the Gardeners" Chronicle, "that this fine tree may eventually be seen growing on our hill sides, as it does in Northern China, particulariy in the milder parts of England, Ireland, and about 
Edinburglı. We sincerly hope it may, for independent of its beauty, "it produces large quantities of the brown fibre on its stem, which is probably intended by nature to protect it from cold." "These trees are very valuable to the natives, who remove a quantity of fibre from them every year. Its fibre is converted into ropes, cables for junks, and brushes; hats and cloaks are also made of it, and worn in wet weather, by the agricultural labourers and others. It makes excellent bottoms for beds and couches, and is used in many other ways."

\section{FLOWERS RECEIVED SINCE OUR LAST REPORT.}

Pansies.-R. R. O., Birmingham.-Ajax.-Good form. Very dark purple upper petals, approaching to black, heavily belted with the same; yellow ground, chrome eye, which nearly touches the belt of the lower petal. This is rather against it, otherwise it is a striking and fine flower.

Brilliant. - Rather small, but very rich in colour, with plum top petals and belting, yellow ground, eye distinct and good.

Miss Jane. - A large flower, white ground and purple belt, with lighter shade on the inner margin. Not first-rate, but better than many of a similar colour.

Owen Glendower.-Rich heavy purple-belted flower, with a strong well-defined eye. This we like best.

Eldorada.-Rich orange, bronze eye, distinct, and very pro. mising.

Mrs. Oswald.-Purple belt and upper petals, in the way of Mrs. Beck. The above, as a lot, are higher than the average of what are usually submitted to us.

SeEding Ranunculus.-I. M. - Of good build, creamy white, slightly dotted and edged with crimson. Apparently a nice sort.

R. M.-The pink, Diadem, has beautifully formed petals, very pure, and well laced with dark purple. It will be a favourite.

DABLIA. - R. R. O.-Your seedling, Pandora, is very like its parent in form, and is well up in the centre. We think it very likely to make a good show flower.

Fuchsia.-M.R.-Not much. There are half-a-dozen others of the same colour, but better, already out.

Rose. - A seedling hybrid perpetual, raised by a florist of Nottingham, has been submitted to us. It is of good form, colour rich carmine, like Col. Foissy Bourbon. It is one of AUGUST-VOL. VI. $2 \mathrm{~A}$ 
the best English-raised roses we have seen. It is to be immortalized with the raiser's name, adding thereto the prefix of, we understand, his ancestor, David. Blooms will be forwarded to some of the best judges in and round the metropolis, and if their opinion tallies with ours, it will be propagated and sold out, under the designation of "David Garrick."

\section{EXTRACTS, HINTS, AND RECOLLECTIONS.}

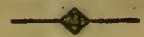

THIRD ANNUAL RHUBARB SHOW,

At Mr. J. Gregory's, Fox and Grapes Inn, Sutton, June 12.

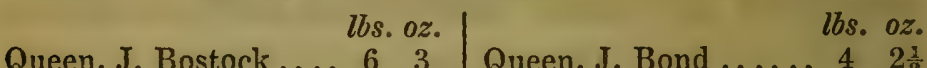

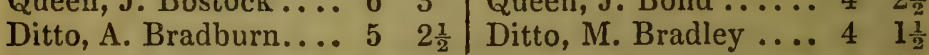

Ditto, J. Lovatt ...... $552 \frac{1}{2}$ Ditto, J. Warburton .. $313 \frac{1}{2}$ Ditto, J. Gregory $\ldots . .444$

Hardy Aquatic Plants.-A friend asks us what plants are most suitable for a small sheet of water, which lies at the base of a hill, on which his bouse is situated. He wants hardy and not expensive ones. Perhaps a list may be serviceable to others of our readers, therefore we subjoin a few :-

Nymphce Kalmiana.-Floating habit, fine foliage, yellow flowers. Nymphcea Stellata.-Floating habit, fine foliage, blue flowers. Nymphcea Advena.-Floating habit, fine foliage, yellow flowers. Limnocharis Humboldtii._Floating habit, fine foliage, pale yellow flowers.

Butomus Umbellatus.-Erect habit, fine pink flowers.

Sagittaria Sagittifolia.-Upright, white flowers.

Sagittaria Sagittifolia Flore Pleno.-Handsome double white flowers, upright.

Villarsia Nymphchoides.-Floating foliage, handsome yellow flowers.

Menyanthus Trifoliata.-Erect habit, white flowers.

Richardia Ethiopica.-Erect habit, large white flowers, and handsome foliage.

Aponogeton Distachyon.-Floating foliage, white flowers.

Iris Foetidissima. - Erect habit, with livid blossoms.

Iris Pseud Acorus. - Upright, yellow flowers.

Alisma Plantago.-Erect fine foliage, pink and white flowers. 
A Splendid Tree Peony.-There is now (the early part of $\mathbf{J u n e}$ ), in the grounds of Miss Stapleton, Grey's Court, Oxfordshire, a moutan, which is five feet eight inches in height, measures thirty feet in circumference, and has two hundred and two blossoms on it, one of which was measured, and found to be two feet round. It is most beautiful.-Gardeners' Chronicle.

We are sometimes asked for rules for the formation of societies in connexion with floriculture. We lay the following "Rules of the Florists' Conversational Society" before our readers :-

1. That this be called the "Florists' Conversational Society," having for its object the advancement of floriculture, by means of social intercourse.

2. That the meeting nights be the second and fourth Mondays in each month, at the Cock and Castle Tavern, Elizabethstreet, Hackney-road; the chair to be taken at eight o'clock in the evening, and vacated at halfpast ten.

3 . That a contribution of sixpence per quarter (payable on the first meeting night in January, April, July, and September) constitute a member. That all moneys received on account of the society be strictly applied to the object in question.

4. That the business of the society be conducted by six officers, viz. chairman, vice-chairman, secretary, and a committee of three members; the same to be chosen annually, on the first meeting night in January. That all officers be honorary.

5. That all the members be requested to aid in promoting the object of the society, by forwarding specimens of plants or flowers (seedlings or otherwise) for the inspection of the members. That the secretary register an account of all such plants or flowers, with the name of the exhibiter (who shall state whether they be his own production or otherwise); and if, in the opinion of the majority of the members present, any specimen be considered of superior merit, entry shall be made accordingly.

6. That in the event of any premiums being offered by the society, notice of the same shall be posted in the club-room one month previous. That three judges be chosen for the occasion, from among the members present on the night of appointing the show.

7 . That on the receipt of a requisition, stating the object, and signed by one-fourth of the members, or by two of the committee and four members, the chairman shall call a general meeting, giving three days' notice of the same. 
Summer Dessert Apples.-Our correspondent, W.W. who sent us a seedling apple, requests the names of a few early sorts, adapted for the table. Apples are often known by different names in various localities, but we can safely recommend the following:- The Improved Eve Apple, Egglestone Summering, Lord Lennox, J uneating, or Jeannetting.

To procure Early Sweet Peas.-The plan of sowing peas on turf, in heat, and tben planting thein, sod and altogether, has often been adopted with success, and an early crop thus ensured. The other day, we saw several yards of turf, about as wide as a mignonette box, placed on narrow boards, on the greenhouse floor, grass side downwards, and sweet peas inserted among the turfy roots. The peas were four to six inches high, and could thus be carried and planted out when convenient; or a piece of turf, six inches long, with its crop of sweet peas, would form a patch, over which a wire guard, three feet high, could be placed, and they would grow up inside and thus form a most beautiful object.

PINks.-I beg, Mr. Editor, to offer you a few remarks on showing pinks. The Lancashire and Yorkshire growers prefer those which have the dark lacing quice to the edge: the southerns, with Mr. Glenny and the best cultivators in that quarter, say, a white edging outside the dark. Why not meet half way, and make the classes of pinks seven? Let us have three classes, red, purple, and dark lace, with the colour to the margin; then three more classes, red, purple, and dark lace, with a white margin, and a class for black and white. What harm would be done if Lancashire, Yorkshire, Oxon, Staffordshire, Derbyshire, Notts., Middlesex, Bucks., and all other localities were to discard their prejudices in favour of this or that system, and to adopt a comprehensive plan similar to the one I suggest, for one or two years? 'Then, if it was not found to work well, let 
them all turn back to their own plans. But, I think, if once adopted, it would give everyone a chance, and from Landsend to John o' Groats, florists would be able to show together, and know what they were about. If any of your correspondents will furnish a better way of reconciling conflicting opinions, I am sure they will confer a benefit on the floral community, and on no individual more than your yet "incog." correspondent.-H. S. M.

To propigate the Dielytra Spectabilis.-They may be put into bottom heat the same time as dahlias, and started in a similar manner. 'Take off the young shoots and put them into sand; they will soon strike root, when they may be potted off and hardened, preparatory to planting out in May, after which they may be treated like any other hardy herbaceous plant.

Hardy Passion Flower.-The Passiflora cœrulea is a very beautiful climbing plant, but owing to its not being quite hardy in this part of the world, it is not often seen. Mary years ago, we used to admire a very fine plant that covered the front of a cottage at Nettlestone, near Ryde, in the Isle of Wight. It fronted the sea, and was called "The Fort." The festoons of flowers, which garlanded the cottage windows were beautiful in the extreme, and since that time we hare sighed in vain for so fine an ornament for our own house. In our February number of the Midland Florist, we mentioned a seedling which has been raised by Mr. Wasnidge; This has elicited information about another, and thankful indeed are we for it; for by this means we hope to bring into notice seedlings of all descriptions, which might otherwise have remained unknown, except in their own locality. Our correspondent, Mr. William Charlton, of the Hermitage, near Hexham, Northumberland, writes us as follows :-." I raised some seedlings a few years ago, and planted them out, one of them having rather a better place 
than the rest, much hardier, and blooms more freely than the old sort, though there is not much difference in the appearance of the flowers." Now here are two points gained, greater hardiness, and a more profuse bloom. 'The next is to improve the colour; this could be done by obtaining farina from some of the crimson greenhouse varieties, and impregnating the hardy one therewith. Who among our readers will lend a helping hand to originate fresh varieties?

Restoring Bloom to Plums, Cucumbers, etc. INTENDED FOR Exhibition.-A correspondent has asked our opinion on the legality, as well as the feasibilty, of adopting artificial means to give a better appearance to fruit, \&c. intended for exhibition. We must say at once that it is very unfair, and were we judging, we should disqualify the articles. As well might a florist stick in a carnation petal, or do any other thing to deceive. We well recollect, some years ago, seeing the drawing of a machine for this purpose. It was, if we recollect right, a small box, in which the fruit or cucumber to be operated on was placed; through a hole in the side, the nozzle of a powder puff was introduced, and a very fine powder, either brimstone, or hair powder, we forget which, was discharged into the box. This settled down in the form of "a fine bloom" on the fruit. The writer, we believe, suggested another "artful dodge," namely, if the flower had dropped from the end of a cucumber, that another might easily be stuck on with gum, and thus give it the appearance of rapid growth. We trust our correspondent will never try these disreputable methods of endeavouring to deceive censors and cheat brother horticulturists.

Lady Clifton Tulip was raised from the seed of a flamed Triomphe Royale (grown or gathered in 1834), fertilized by the pollen of Queen Boadicea, with a view to obtain the rounded petal of the latter with the clean base and stamens of the former, and this flower 
is thought to be the best of the sowing that has ever bloomed. Having grown under unfavourable circumstances, it might be 1841, or later, before it produced its first flower, and blooms of it, in the breeder state, were seen in Nottingham in 1845, in the flaned state in 1847 , and in the feathered state in 1851, after which the raiser disposed of three bulbs, two feathered and one breeder. The raiser's name is Jackson, a mechanic by occupation, and a native of Nottingham, but has been residing at Belvoir, in the county of Leicester, during the raising of this flower.

In the June number of the Birmingham and Midland Magazine, I find a remark on the judges being in error, in not discovering that two of the flowers in the second stand in class C., at the National Tulip Show, which appeared under the names of Walworth and Heroine, were one and the same flower. I feel surprised that any florist should make such a remark, when one was creamy in the bottom and the other pure white. The Walworth I exhibited at the horticultural show, the previous day, and took the third prize in feathered roses; and it was seen growing by Messrs. Dodwell, Parkinsun, and Wood, a few days before the show, when they remarked that they had not seen so good a Walworth for some years. I should not have been surprised if the reniark had been made on the first stand in Class C., where Victory and Royal Suvereign were both placed, and most florists know that they are the same flower, or both from one breeder.-James Parkins.

Tomato Figs.-A new mode of preparing the tomato like figs has been suggested. A sample deposited in the patent office, in the United States, is said to be of superior quality. From the taste, it is supposed that all the gond qualities of the fruit are retained. In appearance, the drum of tomatoes resembles one of the figs very nearly. The following recipe is given for the preparation:- Take six pounds 
of sugar to one peck (sixteen pounds) of the fruit; scald and remove the skin of the fruit in the usual way; cook them over a fire, their own juice being sufficient, without the addition of water, until the sugar penetrates, and they are clarified. They are then taken out, spread on dishes, flattened, and dried in the sun. A small quantity of syrup should be occasionally sprinkled over them whilst drying; after which, pack them down in boxes, treating each layer with powdered sugar. The syrup is afterwards concentrated, and bottled for use. 'They keep well from year to year, and retain surprisingly their flavour, which is that of the best quality of fresh figs. The pear-shaped or single tomatoes answer the purpose best.-Gardeners' Chronicle.

The Garden.-Gardens are amongst the most delightful things which human art has prepared for our recreation and refreshment. To say nothing of the common-places, that a garden was first constructed by God himself,-that in the shades of a glorious garden our first parents were placed by him,-that our Saviour delighted to walk in a garden,-that in a garden he suffered his agony, and that in a garden he was buried; there are a thonsand reasons why gardens should be highly valued, especially by those who are fond of the country. Lovers of nature cannot always stroll abroad to those beauties and delights which lie scattered far and wide; the physical impediments of time and space-the severities of winter, the dews, the hasty storms, and the strong heats of summer, lie between them and their enjoyment, especially if they be of the delicate sex. But into a garden-a spot into which, by the magical power of science, taste, and adventurous enterprize, the sweetest and most beautiful vegetable productions, not only of our own country, but of the whole globe, are collected, they may step at all hours, and at all seasons; yes, even through the hours of night, when many glories of nature are to be wituessed; her 
sweetest odours are poured out; her most impressive and balmy quiet is sent upon earth. 'There, fearless of any "pestilence that walks in darkness," the gentlest and nost timid creature may tread the smootl path of the garden, aud behold all the calm pageantry of the glittering host of stars, of moonlight and of clouds. The bowers of a good modern garden invite us from the fierce heat of noon to the most delicious of oratories, in dry summer eves, to the most charming place of social enjoyment. A garden, with all its acompaniments of bowers, secluded seats, shrubberies, and hidden walks, is a concentration of a thousand pleasant objects, and the field of a multitude of animating pursuits. The rarest beauties of the vegetable world are not only there congregated, heightened in the richness and splendour of their charms, but there many of them are actually created. The feeble invalid and feebler age, they who cannot lay hold on nature in her amplitude, though they may anxiously and intensely thirst to renew, on heath and mountain, the enchantments of past days, can there grasp a multitude of her delights at once. The sedentary man there finds the most congenial relaxation, the most restorative exercise ever at hand. The lover of all bright hues and graceful forms, of all delicate and spicy aromas, of curious processes and wonderful phenomena, of all that is soothing to the mind, and pleasant to the vision and the taste, there walks in a fairy land of his own creation. There the sun shines tempered by the coolness of whispering branches; the breeze blows softly, charged with fragrance, the dews fall to refresh and awaken sleeping odours, and birds bring from their wilder haunts their melodies.Howitt's Book of the Seasons.

Landscape Gardening in New England.-We extract from Downing's Horticulturist (American), the following beautiful observation, and we are sure it will be read with pleasure by many of our friends. 
"Even so small a spot as half an acre may be made one little snug home scene of rural beauty. Abandoning all ideas of a kitchen garden, to men occupying such places, generally a thing of no pecuniary value, let the entire ground be filled with groups of ornamental trees and shrubs, and flowers, upon a groundwork of smooth grass. Let woodbine, honeysuckle, and climbing roses here entwine themselves round a column, and wreath themselves there over a window. Here place a rustic seat, half hid amongst the shrubbery; there lead a short walk, carelessly curving towards a little vine-clad arbour. How trifling the expense ! 'The cost of a single article of extravagant furniture will defray it. How permanent and beautiful the result! how gratifying not only to the occupant, but to the passing traveller! and more than that; for whatever tends to cultivate a refined taste, improves the heart and elevates the better nature of man."

\section{弱art XEFEE。}

\section{QUERIES AND ANSWERS.}

I was very much interested on reading over your notes of a few good polyanthuses, particularly in your reference to the cultivation of that flower in pots. It would give me and other parties I am acquainted with great pleasure if some of your cultivators would give, in your pages, the routine of their method. I have seen so much said against the practice, that I scarcely dare attempt it, although I have several reasons which urge it upon my attention.

Dera.

[Perhaps our friend, Mr. S. Hammond, will respond to this.-Ev.]

Mr. Lightbody, of Falkirk, is the gentleman who possesses a stock of Kate Connor tulip. Napoleon feathered rose tulip is not one of Mr. Thackeray's seedlings. It is also known 
to be in more than two collections, namely, in those of Messrs. Creswell, Wylde, Marshall, Gibson, Mart, Lymbery, and Wood. It was broken by Mr. Mart, from a breeder obtained by us, some sixteen years ago, from Mr. R. Dixon, of Manchester.

Trro.- It is imperative that the colour on the margin of a picotee should be uniformly distributed. It is not recessary nor desirahle that the colour of the carnation should be uniformly distributed, the same on every petal. Mr. Glenny does say of the picotee, "It is not necessary that the feather should be of the same width all the way round." But before we criticize this, we should bear in mind the state of the flower at the time those properties were promulgated, and the apparent hopelessness of ever seeing it other than with the colour deeper in the centre of the petal than elsewhere. So far indeed from taking exception to the many excellent standards put out by Mr. Glenny, we think it a subject of congratulation they are so free from blemishes, and that $\mathrm{Mr}$. G. succeeded in getting so far away from the bias of the times in which he wrote. To understand fully why uniformity in the distribution of the colour on the margin of a picotee is necessary, and why uniformity in the distribution of colour in the carnation is neither necessary nor desirable, we must refer to the leading characteristics of these flowers. In the one case, the picotee, we find the colour distributed in curves, forming, by a combination of the petals, a circle, more or less perfect. "Iota," in his Essays on the Philosoplyy of Florists' Flowers, published in the Florist for 1849, says, "A curve is a line the direction of which is deflected at every point ac. cording to a fixed law; whence its effect is to disperse instead of concentrating force. And the impression produced by it will be that of gracefulness, gentleness." It becomes thus necessary, imperative, that the marginal colour should be uniform, inasmuch as irregularity in it would destroy the harmony needed to create the sensation of "gracefulness, gentleness." In the carnation we find the lines of colour disposed longitudinally, the same way with the length of the petal, and at right angles with the outline of the flower. In the same essays, "Iota" says, "lines at right angles are necessarily harsh." And again, "a straight line is one the direction of which is always the same; whence its effect is to accumulate force upon a point. And the impression produced is that of asperity, brilliance, grandeur, power." Now this asperity, harshness, would be aggravated, and made positively painful, by an exact distribution of colour, and its uniform arrangement in every petal. The eye cannot rest with pleasurable emotion on such an arrangement; it needs relief, and this we find in its charming variety, in the fact that, "without violence to its general unity, it has no two petals, 
and no two stripes on the same petal, alike in the form of their colours." Much of what we have here set forth has been taken, as it will readily be perceived, from the essays in question, and we commend to our young friend with all our heart, a careful reading and study of them throughout. In them he will find described, in elegant and forcible language, and in an easy perspicuous style, the principles un which the points of excellence in florists' flowers are based; and we believe he will rise from such study with the conviction well expressed by the writer at the close, viz., "I do not scruple to avow before the most fastidious, that it (the florist's) is a pursuit not unworthy of a wise man, nor unbefitting a good one : it is elegant, instructive, scientific, and full of results. And the reader of his bible may see, and grow wiser by seeing, in it another instance of the tenure on which he holds his portion on earth; that the ground and the things which grow out of it do not yield their advantages without the labour of his bands, and the exercise of his intelligence." These essays - and the paper on "Perfection of Form in the Tulip," published in the first volume of the Midland Florist, from the able pen of G. W. Hardy, Esq., the latter being a masterly application of exact principles to the construction of the tulip - should be in the hands of every florist of every degree, should form their manual, and, after their bibles, their books of chiefest study, for on these all their present greatness as a body depends, and a superstructure a thousand-fold more vast may be erected.

E. S. D.

\section{CALENDAR OF OPERATIONS,}

FOR AUGUST.

\section{GREENHOUSE.}

WHILE the weather is 30 excessively hot, constant attention must be paid to the things in this house, and see that a plentiful supply of water be administered to all free-flowering and free-growing plants. If plants are once allowed to suffer for want of water, their duration of flowering is much shortened, and considerable injury to the foliage will be the consequence. Cut off all decaying flowers as they appear (except such as have been hybridized for seed), being left on after they have faded, produces an unsightly appearance, and injury to the plants. $\mathrm{Pe}$ largoniums that have begun to make fresh growth after being cut down, may he attended to as directed last month. Cut down others as they go out of flower, and put in cuttings of the 
most desirable sorts. Sow seeds as soon as ripe. Calceolaria seed may also be sown as it ripens, and the old flower stems cut off. Make a good sowing of mignonette in pots, for flowering in the winter. Attend to young primulas. Pot chrysanthemums in their flowering pots, using a rich compost. Nice dwarf plants may be produced by layering the ends of the shoots of such plants as are planted in the borders, or reserve garden. Attencl to creepers, and see that they do not obstruct too much light.

J. BAYLEY.

\section{VINERY.}

Give abundance of air, and let the house be kept as sweet and clean as possible. Continue to remove all superfluous shoots. In damp weather, light gentle fires, to dispel moisture. If any cracked or bad berries appear, let them be immediately removed. A little fine netting over the ventilators, will be found useful to keep out wasps and fies. J. BAYLEY.

\section{FLOWER GARDEN.}

Now, while everything here is gay, will be the best tinıe to determine upon your arrangement for the next year; and such plants as are most desirable may be propagated forthwith, if cuttings can be got. Pipings of pinks may yet be put in; and those already rooted planted out in a good rich border or bed. See that dahlias, hollyhocks, and other strong-growing plants are properly secured to good strong stakes. If the dry hot weather continue, give an abundant supply of water. Use every means to entrap earwigs. Neapolitan violets may be transplanted upon their flowering beds, keeping them shaded for a few days. Put in plenty of euttings of China roses, pentstemons, antirrhinums, \&c. Gather seeds as they ripen, and remove the dead flower stems. Attend to neatness in every part of the garden. J. BAYLEY.

Carnations and Picotres.-Proceed with layering, without a moment's delay. Use light sandy soil, and peg them securely. When completed, they should be shaded for a few days, and carefully attended to with water. Attend to the impregnation of every fine bloom not absolutely required for exhibition. Leave nothing to chance. The extreme heat of the season is likely to promote an abundant supply of pollen, and we trust it will be sedulously used. It is impossible to describe the many crosses from which successful results may be expected, or predicted. We can only suggest to beginners, to combine with a healthy growth the greatest possible refinement, the broadest and stoutest petal, and the most distinct and best defined colours. In our own case, we shall endeavour to obtain combinations of the following, or any of them, viz. S.B.s : Admiral Curzon, Bardolph, Lord Lewisham, Omnium Primus, Sir Robert Peel
AUGUST-VOL. VI.
$2 \mathrm{~B}$ 
(Broughton), Splendid, True Briton. C.B.s: Black Diamond, Duncan, Favourite, Jenny Lind, Milion, Queen Victoria. P.B.s: Falconbridge, H. K. White, Sarah Payne, Prince Albert. P.F.s: Beauty of Woodhouse, Earl Spencer, Perfection, Premier, Squire Trow, Squire Meynell. S F.s : Cradley Pet, Firebrand, Queen Victoria. R.F.s: Ariel, Lorenzo, Lovely Ann, Lady Ely, Antonio, Haidee, Magnificent, Madame Sontag. Picotees. Red edged: Mary, King James, Elizabeth, Mrs. Norman, Isabella, Giulio Romano, Mrs. Bevan, Sebastian. Purple-elged: Alfred, Duke of Rutland, Ganymede, Juliet, Fing of Purples, Lady Harewood, Lady H. Moore, Lord Nelson, Mrs. Turner, Ophelia, Portia, Prince Arthur. Rose-edged: Mrs. Barnard, Miss Rosa, Grace Darling, Jeanette, Princess Roynl, Qieen Victoria, Venus. We shall also freely use any good seedlings we may have of our own, or others entrusted to us, as we find young life so much more vigorous and prolific, and therefore at all times of much easier management.
Derby.
E. S. Dodwell.

Darucias. - Well watering, thinning shoots, disbudding as the sorts require it, staking out and tying the laterals, trapping and destroying earwigs, \&c. is the requisite attention which must be given to these flowers.

Pinks. - Attend to pink pipings. It is soon ascertained when they have made a start, by the centre of the young plant elongating. Have a bed, or beds, according to stock, for their reception, made of loam, leaf soil, rotten manure, and river sand. Let them be planted out when ready, choosing showery weather, if possible.

Auriculas and Polyanthuses.-Strictly attend to watering, weeding, \&c. Repot young plants, toward the middle of the month, in a more genial compost; it will materially add to their strength during their autumnal growth.

Amateurs who are fond of trying what they can do in the way of budding roses, should now try their hands. Always. bud as close to the main stem as possible. We subjoin a few names of varieties which should be worked by all means:Geant des Batailles, Paul Ricaut, Souvenir de Malmaison, Baron Prevost, Baron Hallez, and Souvenir d'un Ami.

In the kitchen garden, sow cabbage seed for early crops immediately. Many, of coxurse, have already got their seed in; it is, however, all in good time. As early potatoes, peas, \&c. are removed, manure, dig, and replant the land with savoys, Brussells sprouts, and other winter greens. Sow Black Spanish radish. Train tomatoes. Sow peas, for the chance of a late crop. Water lettuce during very dry weather: it will prolong its season. Top kidney beans, and when these are gathered, always get them clean, for if pods are left on to ripen seed, it always deteriorates the crop. 


\section{FLORAL EXHIBITIONS.}

The annual open auricula and polyanthus show was held on the 26th of April, at the house of Mr. Jnhn Harrison, che Masons' Arms Inn, Middleton, near Ma:)chester, when the judges (Mensrs. Jnseph Clegg, W'm. Chadwick, and E. Fallows) awarded the prizes as follows .-

Best Pan.-Freedom, Lancashire Hero, Venus, Blue Bonnet, C. Ball, Esq.

Best Bunch. - Lancashire Hero, D. Jackson.

1 Freedom, J. Buck Green-edged
J. Buckley

2 Imperator, E. E. Efliott

3 Prince of Wales, J. Buckley

4 Colonel Taylor, D. Jackson

5 Lord Lynedoch, J. Holland

6 Morris Green Hero, ditto

7 Shakspere,

8 Lord Nelson, C. Stoit Grey-edged.

I Lancashire Hero, D. Jackson

2 Sykes's Complete, C. Ball, Esq.

3 Mary $A n n, J$. Heap

4 IRingieader, C. Ball, Esq.

5 Conqueror, C. Stott

6 Privateer, W. Kent

7 Newton Hero, J. Heap

8 Fair Flora, R. Lancashire White-edged.

1 Venus, C. Stott

2 Favourite, J. Buckley

3 Countess of Wilton, C. Ball, Esq.

4 Regular, E. Elliott

5 Wood's Delight, C. Stott

6 True Briton, R. Lancashire
7 Smiling Beauty, J. A shworth

8 Catherina, J. Holland Selfs.

1 Othello, C. Ball, Esq

2 Blue Bonnet, J. Ashworth

3 Primate, E. Ellintt

4 Queen Ann, J. Holland

5 Ned Lud, J. Buckley

6 Apcllo, R. Lancashire

7 Desdemona, D. Jack on

8 Admiral of the Biue, J. Holiand

POLYANTHUSES.

1 Lord Lincoln, R. Lancashire

2 Alexander, W. Kent

3 Exile, R. Lancashire

4 Beauty of England, J. Heap

5 Sovereign, C. Ball, Esq.

6 Seedling, J. Bucklev

7 George IV., C. Ball, Esq.

8 Cheshire Favourite, W. Kent

9 King, J. Buckley

10 Princess Royal, W. Kent

11 Lord John Russell, R. Lancashire

12 Unknown, W. Kent

\section{FELTON UNION OF FLORISTS AND HORTICULTURISTS.}

The members of the Felton Union of Florists and Horticulturists held their annual exhibition of auriculas, polyanthuses, byacinths, and vegetabies, being their first show for the season, on Monday, the 3rd of May, at Mrr. Leighton's, Co.sch and Horses Inn, Felton, when the prizes were awarded as follow :-

\section{AURICULAS.}

Green-edged.

1 Page's Duchess of Oldenburgh, G. Cockburn, Esq. Alnwick

2 Page's Champion, ditto.

3 Oliver's Lovely Ann, J. Thompson, Esq. Morpeth

4 Dormand's William IV., B. Burn, Linden

Grey-edged.

1 Ashworth's Newtown Hero, G. Cockburn, Esq.

\section{POLYANTHUSES.}

Best Seedling - Gowen's Ann, A. Gowens.

1 Buck's Geo. IV., J. Thompson, Esq. I4 Pearson's Alexander, J. Thompson, Esı

2 Thompson'sLord Morpeth,J.Crossling

3 Thompson's G. Glenny, J. Thompson

SINGLE HYACINTHS.

1 Grootvoorst, K. Richard:on, icton

2 Waterlon, J. Hudson, Felton

3 Mliss Kitty, J. Black, Linden

\section{Nicholson's King, J. Crossling}

6 Black and Gold, ditto
2 Warris's Union, J, Crossling, Felton Park

3 Fletcher's liary Aun, G Cockburn, Es.

4 Cheetham's Lancashire Hero, J. Crossling

White.edged.

1 Popplewell's Conqueror, J. Thompson, Esq.

2 Taylor's Glory, G. Cockburn, Esq.

3 Tavlor's Favourite, J.Thompson, Esq. 4 Cheetham's Countess of Wilton, clo.

\section{DOUBLE HYACINTHS.}

I Grand Vainqueur, .I. Black

2 I'Amic de Cour, R. Richardon

3 Vulcan, 'T. Dawson 


\section{VEGETABLES.}

Best cauliflower broccoli (Mammoth), W. Harrison ; 2nd and 3rd. J. Hudson. Best leeks (Large Flag), T. Dawson; 2nd. Ditto; 3rd. J. Hudson.

Best radishes, J. Hudson; 2nd. T. Dawson.

An extra prize was awarded to Mr. Mack, for Victoria rhubarb : and another to Mr. Thompson, of Acklington Factory, for Howick Improved cabbage.

Secord Exhibition, at Mr. Appleby's, North Briton Inn, June 7. TULIPS.

1 Harrison's Pegasus, W. Harrisun

2 Prince Albert, T. Dawson

3 Lawrence's Milton, W. Harrison

4 Old Catafalque, ditto

5 Demetrius, ' $\mathrm{T}$. Dawson

6 Pass Catafalque, A. Gowens Flamed Bizarres

1 Harrison's Felton Hero, W. Harrison

2 Captain White, J. Crossling

3 Catafalque, ditto

4 Felton Hero, W. Harrison

5 Royal Sovereign, ditto

6 Felton Hero, ditto Feathered Byblomens.

1 Grand Marvel, T. Dawson

2 Washington, $J$. Crossling

3 Triomphe de Lisle, $T$. Dawson

4 Bienfait, W. Scott

5 Triomphe de Lisle, W. Harrison

6 Chellastor Beauty, ditto
Flamed Byblaemens.

1 Le Grande Monarque, W. Harrison 2 Violet ma Favourite, A. Goweus 3 Pearl Blanche, T. Dawson 4 Lawrence's Friend, J. Crossling 5 Alexander Magnus, A. Gowens 6 Duc de Florence, ditto Feathered Roses. 1 Heroine, T. Dawson, Acklington 2 Cerise Triumphant, A. Gowens 3 Lilas Rose, ditto 4 Cerise Triumphant, J. Crossling

5 Triomphe Royale, $T$. Dawson 6 Globertine ditto Flamed Roses.

1 Triomphe Royale, T. Dawson

2 Duchess of Clareuce, ditto

3 Amadis, W. Scott, Felton

4. Rose Hendrica, ditto

5 Rose Cerise Primo, ditto

6 Amadis, A. Gowens

\section{PANSIES.}

Best Stand of Six Varieties, J. Crossling, Felton Park, Duke of Norfolk, Ophir, Mrs. Crossling, Helen, Dr. Vernon, and Zabdi ; 2nd. J. Crossling, Mrs. Crossling, Ophir, Lord Jeffrey, Zabdi, Mrs. Beck, and Duchess of Rutland; 3rd. A. Gowens, Felton, Youell's Supreme, Riddell's Conqueror, Golden Guage, Aurora, Mrs. Beck, and Nymph.

\section{VEGETABLES.}

Best rhubarb (Victoria), A. Gowens; 2nd. Mr, Mack; 3rd. W. Harrison. Best cabbage (Howick Improved), J. Cookson; 2nd and 3rd. W. Scott.

Third Exhibition, at Mr. Cookson's, Red Lion Inn, July 5.

\section{RANUNCULUSES.}

1 Romeo, T. Dawson

\section{Variegated.}

2 Flora Mac Ivor, ditto

3 La Singulier, W. Harrison

4 Tyso's Dilectis, ditto

5 lighthody's Victor Hugo, ditto

6 Lightbody's Dr. Horner, T. Dawson

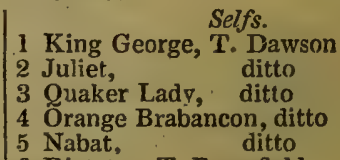

PANSIES.

Best Stand of Six Varieties, Mr. Black, Linden House, Zabdi, St. Andrew, Isabella, Ophir, Nevills, and Lucy Neal ; 2nd. J. Crossling, Crossling's Orion, Zabdi, Rainbow, Caroline, Mrs. Crossling, and Lord Jeffrey ; 3rd. Mr. Black, Ophir. Zabdi, Rainbow, Emma Gray, Caroline, and a seedling ; 4th. J. Crossling, Mrs. Crossling, Golden Guage, Duchess of Rutland, Mrs. Beck, Zabdi, and Berryer; 5th. T. Dawson, Ophir, Duchess of Rutland, Zabdi, Duchess of Northumberland, Supreme, and Conqueror; 6th. T. Dawson, Golden Guage, Aurora, Mrs. Beck, Nymph, Supreme, and Duchess of Rutland.

The prize for the best seedling pansy was awarded to J. Crossling, for a very fine variety, named Crossling's Mrs. Burdon.

\section{VEGETABLES.}

Best lettuce (Belleabone), W. Harrison; 2nd, W. Harrison; 3rd. W. Scott. 
Best twelve kidney pntatoes (Ashtop), J. Cookson; 2nd. T. Dawson; 3d. J. Cookson. Best twelve round ditto (Foster's Seedling), T. Dawson; ind and 3rd. J. Cookson.

Extra prizes were awarded to W. Scott, for some very fine early turnips, and to J. Cookson, for a very fine dish of peas.

\section{PETER EATON'S TULIP MEETING,}

At the Sign of the Cotton Plant, Bedford, near Leigh, May 22.

Maiden Prizes.-1. Charles X., Catafalque, Crown Prince, Lady Crewe, Andromeda, and Maugo, R. Davis 2. Charles X., Crown Prince, 'Trafalgar, Duc de Bronte, Andromeda, and Dolittle, J. Leather.

Premier Prizes.- 1. Charles X., San Jue, Biciffait, Wallers, Count, Unique, J. Postlethwaite. 2. Charles X., Dutch Catafalque, Bienfitit, Queen Charlotte, Heroine, and Rose Unique. R. Mort. 3. Crown Prince, Lustre, Bienfuit, La Belle Narene, Heroine, and Unique, IV. Postlethwaite. 4. Charles X., Lacan. tique, Mango, Bienfait, Lady Crewe, and Unique, R. Prescutt. 5. Pass Catafalque, Dutch Catafalque, Mango, Criterion, Heroine, Unique, J. Belshaw. 6. Charles X., Albion, La Bebrenn, Bienfait, Dolittle, and Unique, J. Eaton. 7. Waterloo, Duke of Leeds, Mango, Suwarrow, Duc de Bronte, and Lady Lilford, P. Rosbotham. 8. Duc de Savoy, Lustre, Mango, Bienfait, Dolittle, and Unique, J. Monks. 9. Charles X., Carlus, Bienfait, ditto, Heroine, Unique, J. Leather.

1 Charles X., J. Leather

2 General Blucher, J. Postlethwaite

3 Crown Prince, R. Prescott

4 Duc de Savoy, ditto

5 Magnum Bonum, P. Hilton

6 Goud Beurs, J. Eaton

7 Trafalgar, G. Mort

8 Catafalque, ditto

y Firebrand, J. Thompson

10 Seedling, J. Leather Flamed Bizarres.

1 Albion, J. Thompson

2 Lustre, $P$. Hilton

3 San Joe, J. 'Thompson

4 George IV., R. Mort

5 Pass Lacantique, J. Thompson

6 Polyphemus, $\mathrm{P}$. Hilton

7 Carlos, J. Leather

8 Dutch Catafalque, J. Eaton

9 Unknown, J. Turner

10 Charbonnier, J. Eaton Feathered Bybloemens.

1 Bienfait, J. Postlethwaite

2 Lancashire Hero, ditto

3 Mango, R. Mort

4 Beauty, J. Postlethwaite

5 Violet Winner, R. Prescott

6 La Belle Narene, R. Mort

7 Fonce Fonce, ditto

8 Baguet, J. Postlethwaite

9 Washington, T. Hardman

10 Seedling, J. Eaton

I Sable, J. 'Thompson

2 Bienfait, J. Belshaw

3 Siam, ditto

4 Lancashire Hero, J. Yostlethwaite

5 Atlas,

6 Tout, R. Mort

7 Wallers, P. Hilton

8 Witenberg, J. Eaton

9 La Belie Narene, P. Hilton

10 Grotius, J. Belshaw
1 Heroine, R. Mort

Feathered Roses.

2 Lady Crewe, R. Davis

3 Seedling, R. Mort

4 Count, J. Eaton

5 Dolittle, R. Prescott

6 Andromeda, G. Mort

7 Hero of the Nile, J. Leather

8 Walworth, R. Davis

9 Bagley's Rose, R. Prescott

10 Duc de Bronte, P. Hilton Flamed Roses.

1 Unique, T. Belshaw

2 Vesta, J. Belshaw

3 Ponceau, R. Prescott

4. Roi de Siam, P. Rosbotham

5 Rose Ann, P. Hiltors

6 Rose Regina, R. Prescott

7 Newcastle, J. Postlethwaite

8 Aglaia, ditto

9 Andromeda, R. Prescott

10 Lady Lilford, J. Leather Bizarre Breeders.

1 Cluarbonnier, G. Mort

2 Dutch Catátalque, J. Belshaw

3 Unknown, ditto

4 Truth, T. Belshaw

5 Seedling, J. Eaton Byblomen Breeders.

1 Godet Parfait, J. Thompson

2 Orleans, K. Davis

3 Unknown, E. Green

4 Lady Flora Hastings, J. Belshaw

5 Unknown, J. Yostlethwaite Rose Breeders.

1 Lady Lilford, I. Mort

2 Lord Derby, J. Monks

3 Village Maid, J. Thompson

4 Newc.stle, J. Belshaw

5 Lady Crewe, R Prescott Selfs.

Min d'Or, J. Monks

White Perfection, J. Leather 


\section{TULIP SHOW,}

At Mr. Wm. Cork's, Queen's Head Inu, Burslem, Staffordshire, May 22.

Hill.

Best Feathered Flowe:-Comte de Vergennes, T. Boot.

Best Flamed Flower.-Surpass Charbonnier, T. Morrey.

1 Trafalgar, 'T. Morrey

Feathsred Bizarres.

2 Firebrand, C. Bradshaw

3 Sultana, T. Morrey

4. Duke of Wellington, ditto

5 Duc de Savoy, ditto

6 Grand Patriarch, T. Boot

Flamed Bixarres.

1 Gibbons's Pilot, 'I'. Boot

2 Lord Milton, '1. Morrey

3 Bromiley's Truth, W. Wright

4 Goud Beurs, C. Bradshaw

5 Lord B:ougham, ditto

6 Charles X, T Morrey Feathered Bybloemers.

1 Bienfait, T. Morrey

2 Baguet, T. Boot

3 La Belle Narene, T. Morrey

4 Washington, T. Boot

5 Unknown, 'T. Morrey

6 Maitre Partout, C. Bradshaw Flamed Byblomens.

1 Bienfait, T. Morrey

2 La Belle Narene, T. Boot

3 Baguet, C. Bradshaw
4 Violet Wallers, T. Morrey

5 Roi de Siam, ditto

6 Czarine, C. Bradshaw Feathered Roses.

1 Comte de Vergennes, C. Bradshaw

2 Dulittle, W. Wright

3 Lady Middleton, $\Gamma$. Boot

4 Aglaia, C. Bradshaw

5 Claudiana, T. Boot

6 Lady Crewe, W. Wright Flamed Roses.

1 Aglaia, T. Boot

2 Triomphe Royale, ditto

3 Anastasia, C. Bradshaw

4 Lord Morpeth, '1'. Morrey

5 hose Unique, 1 . Boot

6 Lady Crewe, W. Wright Breeders.

1 Chellaston Bizarre, C. Bradshaw

2 Gibbons's Catherine, T. Bout

3 Maid of Orleans, ditto Selfs.

1 White Perfection, C. Bradshaw

2 Min d'Or, ditto

\section{TULIP SHOW,}

At the House of Mr. E. Wade, near Longton, May 22:

Premier Prize.-Baguet and San Joe, A. Shaw.

1 Charles X., A. Shaw

2 Victory, T. Cooper

3 Waterloo, A. Shaw

4 Magnum, ditto

5 Patriarch, ditto

6 Rufus, ditto

1 Duke of Devonshire, A. Shaw

2 San Joe, ditto

3 Polyphemus, T. Cooper

4 Charles X., A. Shaw

5 Rufus, ditto

6 Paul Pry, G. Mountford

1 Bienfait, A. Shaw

2 David, T. Cooper

3 Grand Turc, ditto

4 La Belle Narene, E. Poulson

5 Violet Quarto, A. Shaw

6 Grotius, A. Shaw

1 Lucy Neal, A. Shaw

2 Queen Charlotte, ditto

3 Addison, ditto

4 Monarque, E. Poulson

5 Superb en Noir, G. Mountford
6 Prince Albert, E. Poulson

1 Comte de Vergennes, A. Shaw

2 Lady Midảleton, ditto

3 Heroine, T. Cooper

4 Lady Crewe, E. Poulson

5 Boadicea, T. Cooper

6 Bacchus, ditto

1 Aglaia, A. Shaw

2 Andromeda, ditto

3 Boadicea, D. Brown

4 La Vandicken, A. Shaw

5 Princess Royal, ditto

6 Clarke, E. Poulson Breeders.

1 Devonshire, T. Cooper

2 Pilot, A. Shaw

3 Dentonian, D. Brown

1 Godet Parfait, A. Shaw

2 Clarke, 'T. Cooper

3 Unknown, E. Poulson

1 Giblons, T. Cooper

2 Seedling, D. Brown

3 Catherine, ditto 


\section{CARRINGTON TULIP SHOW.}

At the House of Mr. H. Daine, Windmill Iun, Carrington, May 24.

Jutges. - Messrs. J. Clegg, R. Taylor, J. Boardman, and Holland.

Sovereign, H. Daine (kettle); Sovereign and Albion, J. Thorniley (kettle); Edgar and Violet Wallers, Mr. Nunnerley (kettle); Walworth and Triomphe Royale (ket!le).

\section{Feathered Bixarres.}

I Sovereign, J. L. Richardson

2 Magnum Bonum, P. Daine

3 Surpass Catafalque, Mr. Nunnerley

4 Crown Prince, J. L. Richardson

5 Duke of Devonshire, Mr. Nunnerley

6 Firebrand, J. L. Richardson

7 Goud Beurs, C. Wych

8 Duc de Savoy, ditto

Flamed Bizarres.

1 San Joe, T Hollinsworth

2 O'd Dutch Catafalque, ditto

3 Surpass Catafalque, J. L. Richardson

4 Lustre de Beauty, J. Ackerley

5 Albion, E.. Dean

6 Charbonnier, $\mathrm{T}$. Hollinsworth

7 Duke of Devonshire, ditto

8 Charles X., J. L. Richardson Fruthered Bybiansens.

1 Bienfait, E. Dean

2 Mango, J. L Richardson

3 Lewold, T. Hollinswor? h

4 Duc de Bordeaux, J. I. Richardson

5 Giblons's Seedling, J. Thorniley

6 Violet Quarto, Mir. Nunnerley

7 Maid of Athens, ditto

8 Grotius, ditto

Flaned Byblomens.

I Incomparable Surpassant, Nunnerley

2 Queen Charlotte, P. Daine

3 Bienfait, E. Dean
4 Duc de Florence, Mr. Nunnerley

5 Roi de Siam, E. Dean

6 Violet Wallers, $H$. Daine

7 Pyramid of Egypt, P. Daine

8 Baguet, J. L. Richardson Feathered Roses

1 Lady Crewe, Mr. Nunnerley

2 Heroine, ditto

3 Comte de T'ergennes, J. Ackerley

4 Lady Gray, E. Dean

5 Dolittle, ditto

6 Duchess of Newcastle, Mr. Nunnerley

; Walworth, J. L. Richardson

8 Duc de Bronte, ditto Flamed Roses.

1 La Vandicken, C. Wych

2 Rose Unique, J. Thorniley

3 Rose Vesta, J. L. Richardson

4 Triomphe Royale, Mr. Nunnerley

5 Aglaia, ditto

6 Rose MIonti, ditto

7 Groom's Iphigenia, J. Thorriley

8 Lord Hill, J. L. Richardson Breeders.

Polyphemus (bizarre) Mr. Nunnerley. Sir H. Pottinger (byb.) P. Daine Anastasia (rose). J. Smith Selfs.

Min d'Or, J. L. Kichardson

White Perfection, P. Daine

\section{TULIP SHOW,}

At Mr. Wm. Postlethwaite's, the Queen of Flowers, Leigh, May 24.

Maiden Prizes-1. Charles X., Surpass Catafalque, Crown Prince, Lady. Crewe, Andromeda, Mango, R. Davis. 2. Charles X., Crown Prince, Trafalgar, Andromeda, Unique, Duc de Bronte, J. Leather.

Premier Prizes - I. Charles X., San Joe, Bienfait, Wallers, Comte, Unique, J. Postlethwaite. 2. Charles X., Polyphemus, Bienfait, Wallers, Comte, Unique, J. Mort. 3. Charles X., Dutch Catafalque, Bienfait, Mango, Heroine, Rose Unique, J. Buckley. 4. Charles X., Unknown, Bienfait, Wallers, Heroine, Rose Unique, J. Boardman. 5. Surpass Catafalque, Dutch Catafalque, Mango, Siam, Heroine, Rose Unique, J. Belshaw. 6. Crown Prince, Lustre, Bierfait, La Belle Narene, Heroine, Rose Unique, W. Postlethwaite. 7. Charles X., Lustre, La Belle Narene, Sable Rex, Comte, Rnse Unique, A. Belshaw. 8. Charles X., George IV., Lancashire Hero, Wallers, Hurst's Rose, Unique, w. Battersby. 9. Charles X., Albion, Washington, Sable Rex, Heroine, Emperor, J. Thompson. 10. Charles X., Genrge IV., Mango, Siam, Village Maid, Rose Unique, J. Leather. 11. Charles X., Albion, Mango, Bienfait, Duc de Bronte, Rose Unique, R. Tongue. 12. Magnum Bonum, Polyphemus, Mango, La Belle Narene, Duc de Bronte, Unique, $P$. Hilton. 13. Charles $X$., Albion, Mango, Bienfait, Dolittle, Rose Unique, J. Eaton.

1 Charles X., J. Leather

\section{Feathered Bizarres.}

2 Crown Prince, J. Mort

3 Southern, R. Tongue

4 Trafalgar, ditto
5 General Biucher, J. Postlethwaite

6 Duc de Savoy, J. Eaton

7 Waterloo, J. Smith

8 Surpass Catafalque, J. Leather

9 Gigantic, ditto 
Flained Bizarres.

I Surpass Lacantique, J. Thompson

2 Lustre, T. Belshaw

3 San Joe, J. 'Thompsnn

4 Albion, J. Mort

5 Unknown, J. Boardman

6 Lord Stanley, J. Mort

7 Unknown, J.' Buckley

8 Carlos, Joseph Leather

9 George IV., J. Leather Feathered Bybloemens.

1 Bienfait, J. Postlethwaite

2 Lancashire Hero, ditto

3 Eager, W. Battersby

4. Mango, J. Boardman

5 Seedling, T. Boydell

6 Beauty, J. Postlethwaite

7 La Belle Narene, J. Eaton

8 Fonce Fonce, W. Battersby

9 Baguet, J. Postlethwaite Flamed Byblomens.

1 Adelaiile, W. Battersby

2 Wallers, ditto

3 Bienfait, J. Belshaw

4 Siam, J. Leather
5 Atlas, J. Postlethwaite

6 A Fond Noir, J. Leather

7 Tout, J. Belshaw

8 Criterion, ditto

9 Baguet, J. Eatnn Feathered Roses.

1 Comte, W. Battersby

2 Andromeda, J. Mort

3 Hurst's Rose, ditto

4 Heroine, J. Postlethwaite

5 Lady Crewe, R. Davis

6 Dolittle, T. Belshaw

7 Walworth, R. Davis

8 Village Maid, J. Thompson

9 Dac de Bronte, $T$. Belshaw Flamed Roses.

1 Rose Unique, J. Buckley

2 Vesta, W. Battersby

3 Lady Crewe, T. Boydell

4 Aglaia, J. Belshaw

5 Roi de Serries, T. Boydell

6 Guerrier, J. Postlethwaite

7 Walworth, T. Boydell

8 Ponce:u Brilliant, J. Leather

9 Rose Anu, P. Hilton

\section{CAMBRIDGE HORTICULTURAL SOCIETY.}

The second exhibition for the season was very superior to the corresponding one of last year, and evinced the skill with which the various articles had been raised. This remark applies to every department, whether plants, vegetables, or florists' flowers. Messrs. Chater's (Haverhill) twenty-four pansies were considered the finest ever exhibited, and elicited general admiration, as did also a pair of seedlings from the same establishment.

Six Tulips.-1. 'Citian, seedling, Naomi, Mary Headly, and two seedlings, $R$. Headly. 2. Aglaia, Felicia, Lawrence's Friend, Violet Alexander, Osiris, Duke of Bedford, Mr. Ready.

Three Tulips - - . Three seedlings, R. Headly. 2. San Josef, Madame Vestris, Cleopatra, Mr. Ready.

Twenty.four Pansies.-l. Vulcan, Chater's Rotunda, Magnificent, Chater's Sparkler, Orlanda, Aurora, Lady Carrington, Duke of Perth, Barron's Perfec. tion, Bellona, Master Lacon, Maid of Athens, Elegant, Pandora, Madonna, Androcles, Chater's Climax, Thisbe, Beauty of Ilaverhill, Jennings's King, France Cycole, Flora Superbe, Juventia, Messrs. Chater.

\section{OXFORD FLORAL SOCIETY.}

The annual pink show of the above society took place on Monday, July 5 , at the house of Mr. T. Davis, Cockpit Inn, Hollywell, when the prizes were awarded as follows :-

1. Looker's Regulator, Looker's Oxford Rival, Lonker's Eclipse, Looker's Beauty of Oxford, Smith's Huntsman, Maclean's Criterion, and Burman's Mrs. Burman, T. Looker.

2. Read's Mary Aun, Carter's Rose Empress, Willmore's Laura, Bunkle's Queen, Carter's Clementine, Kirtland's Albert, and Carter's Dean of Christ Church, H. Carter.

3. Harris's King of Purples, Willmore's Laura, Kirtland's Albert, Lord Gough, Hodges's Mars, Smith's Whipper-in, and unknown, G. Davis.

4. Kirtland's Albert, Maclean's Criterion, Roberts's Izaak Walton, Will. more's Laura, Hodges's Mars, Hand's Pilot, and Young's Double X, D. Roberts.

5. Harris's King of Purples, Kerr's Harriet, Smith's Harkforward, Willmore's Laura, Eldridge's Prima Donna, and a seedling, H. Bell.

Some very fine seedlings were shown by Mr. Looker, one of which was awarded the first seedling prize, and named R. Smith, Esq. The stock, we understand, has been purchased by Mr. C. Turuer, of the Royal Nursery, Slough. 


\section{弱和。}

ORIGINAL COMNUNICATIONS.

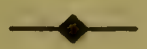

\section{CULTIVATION OF THE RANUNCULUS.}

FindiNG that the ranunculus, comparatively speaking, has little or nothing said or written to encourage its growth, or sing its justly-deserved praise, I trust that a few lines in your magazine will prove useful to somebody.

Which of all Flora's gems can compare with it? True, some prefer the flour of oats, and some of barley, but most of finest wheat, to all creation's flowers; whilst others quite as lustily crv, of all the garden flowers, the cauliflower for me. Now, if I might choose in wide creation's round, with leave to take but one, the flower that gives a smile to the cotter's fireside, when the cares and toils of day are over, would be mine.

But to return again to Floras garland. How just the remark, what so graceful as the fuchsia, or so gay as the geranium? ray, what so chaste as the auricula, or what so lovely as the rose? and most of all magnificent, the dahlia? Qualities and names have been assigned to others, as sweetness and humility to the violet; whilst the title of Queen of the Garden has been justly given to the tulip. But what, shall we ask, has been reserved for the subject of this paper, that cannot with equal propriety be assigned to any other?-most certainly symmetry. The ranunculus, for symmetry, truly surpasses every other flower, and, doubtless, gives us the true idea of form in every double flower.

Now, if, after I and many of my neighbours had given up growing the ranunculus for some years, in SEPTEMBER-VOL.VI. $2 \mathrm{c}$ 
consequence of repeated failures, I give a description of a small plot and the treatment of them, and some of your readers should be induced to give them a second trial, and succeed, as I have done, I am sure they will be highly gratified.

Before doing this, I may here say that the ranunculus, anemone, and iris, were grown by me, with considerable success, more than thirty years ago. Those being the favourites of $\mathrm{my}$ youth, great care I took of them, and often were they admired, and I dare say justly so, but never had $I$ anything like, nor ever have I seen anything like the batch I wish to describe to you, giving you the treatment, which I consider the entire cause of their uncommon vigour and beauty.

Last autumn, writing to my friend, Mr. Lightbody, on business matters, he offered me some of his fine ranunculuses. I said to him that myself, with many other persons, had given them up entirely, it being so difficult to get a fine bloom. In his reply, he said that he would make it a very easy thing, if $I$ would attend to the following directions, which were very simple and very kindly given. Those directions being quite free from any perplexing nostrums, I at once agreed that he should send me a few of the very best he had. Those I soon received, forty in number, according to his catalogue price, amounted to nearly eight pounds.

But what were the accompanying directions? As near as I can recollect, they were these: "The ranunculus must have something to live upon. In the autumn, I throw out a trench, from one foot to eighteen inches, according to the depth of the soil, putting at the buttom some well-rotted cow dung or old hotbed manure, filing it up again with the same soil. In the month of February, rake it very fine, plant exactly an inch and a half deep, destroy all weeds and vermin, press the soil firmly about the necks of the plants, and I have no doubt you will have what will gratify you. One of the most im- 
portant things to be attended to is not to let the roots remain in the ground after the foliage has changed in colour. If you want any other information, $\mathbb{I}$ shall be most happy to give you it." Being then in possession of those valuables, I thought I must once more try my skill : I therefore made choice of a bed two yards from a south wall, throwing out the soil as directed, and collecting a few baskets of well-seasoned dung from a cow pasture, I put it at the bottom, sixteen or eighteen inches below the surface, covering it up with the soil thrown out. In the month of February, I made the surface fine and even, by raking the soil; I then drew off the soil to the depth of an inch and a half or two inches, marking the place where each root should be planted by putting down a small pinch of silver sand, in which I inserted each root; and now, in order to carry out the directions given me, and that I might not cover them over much, or too little, I stuck in a few pegs, leaving just two inches out of the ground, so that I might cover them very exactly, and when the soil had settled, they would be just an inch and a half deep.

Thinking that ranunculuses often suffered from droughty weather, I tried to obviate this by setting up a thin screen of branches, six or eight feet high, on the south side of the bed, partially to break the rays of the sun, but not altogether to exclude them. This done, they lay still for some weeks, when all came up, except No. 1, which, like the bubbles on the river after which it is named, had glided for ever out of being. The weather now being dry, I occasionally sprinkled them over with water; and being fairly up, in order to compress the soil around the necks of the plants, I carefully walked through and through. Under this treatment, they grew most luxuriantly, raising my expectations every time I inspected them, especially as all who saw them declared they never beheld such plants. At length they nearly all came into bloom; but now comes my 
task of giving a correct description of their beauty and growth.

Mr. and Mrs. Archibald Johnson were amongst the giants of the bed, most beautifully formed and sweetly marked, Archibald looking over the head of his fair lady full four inches, she having raised her lovely face no less than seventeen inches high. Those are gems of the first water. Near by, were the lovely Jenny Deans and Nydia, with delicate red edging, on pale yellow ground, rising to the height of seventeen or eighteen inches. Roxalana, quite as stately, very large and showy, but not quite so chaste as those above. Petrel, seventeen inches high, certainly more like an eagle, with gold-tipped wings, rising to meet the sun, than a bird of storm, was brilliant yellow, tipped with red, of the finest form. Felican, rising to the same height, exquisite in form, with a clear rose edge, on white ground. Phroine, William Bradshaw, Aboukir, Zebina, Cyra, Prince of Wales, and Commodore Napier, with Thomas Hood, and Little Nell, all attained to fifteen inches, and formed an assemblage of beauty rarely equalled. Liffey, Sultana, Delphos, Ashwelthorpe, Baritola, and Hon. Robert Wilson fell an inch lower than the above group, still they were equally beautiful. Philomel, Charybdis, and Claudiana, beautiful, especially the last, were thirteen inches. Emily, Dr. Horner, and the lovely Anne Hathaway were one foot. And now, to end this long and, I am afraid, tedious description, I shall just notice the lowest, rising only to eight inches here, Mackenzie, the author of "The Man of Feeling," seems to stoop to those chaste, lofty, and beautiful personages around him, to adore and admire. I may just add, that although the flowers were not very much larger than usual, there were those amongst them of the finest form and colour, from two to three inches over, while some had stems a quarter of an inch, or more, thick.

Now, if by this account of my little plot of ranunculuses, and the simple directions here given, I induce 
some one to adopt the plan and succeed as well as $I$ have done, I shall consider my time not entirely lost. Here it may be well to state, for the convenience of those who may wish to obtain a collection of roots to begin with, that Mr. Lightbody, of Falkirk, and Messrs. Tyso \& Son, of Walling ford, from whom priced catalogues may be had, are among'st the best growers in the kingdom.

WILLIAM WILLISON.

Flower-gate, Whitby, July 21st, 1852.

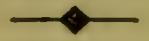

COP PICEANA.

No. XXIII.

OUR next family of plants will be the Arborvitæs, beautiful pyranidal evergreen trees, generally extremely hardy, and propagated by cuttings, seeds, and the more choice sorts by grafting on the American and Siberian varieties. The foliage has a most powerful odour. We are not aware that it is used in medicine, but well recollect, many years ago, it being recommended as a cure for the ague. The application was singular. It was to place a layer of the foliage inside the shoe, and the patient was then to walk or run sereral miles, in order to induce perspiration. The effect on the system was so powerful that the breath of the person would smell strongly of the plant. We have now got a tolerable collection, and though some of them are but small, still we consider them highly interesting; and as they increase in value yearly, we recommend them strongly to all who are interested in ornamertal planting. The scientific name of the family is Thuja, and

T. Occidentalis (The American Arborvitæ) is the most common and perhaps the most ordinary looking of the group. It is raised easily from seeds, which are imported in large quanti. ties from its native country, America. As an evergreen for hiding unsightly objects it is very useful. It makes also a good screen, or hedge, and bears clipping well. It is cheap, 
from 6 d. to $2 \mathrm{~s}$. $6 \mathrm{~d}$. A plant six feet high can be obtained for the latter sum.

T. Occidentalis Variegata. (The Variegated American Arborvitæ.) - A sport only, and one which is soon apt to loose its distinctive character. We have had it from the continent, but it soon became green on our strong soil, and on two occasions we have discovered variegated branches on plants growing in our nursery. It should be planted on poor soil, where it might retain its varigation, but we cannot say much for its beauty.

T. Siberica. (The Siberian Arborvitæ.)-More dwarf and compact in habit than the preceding, also darker in colour, a very hardy and nice sort, roots very freely from layers or cuttings; it also bushes much, so that plants may be taken up, divided, and replanted. $6 \mathrm{~d}$. to $1 \mathrm{~s} .6 \mathrm{~d}$.

T. Orientalis. (The Chinese Arborvitæ.)-A most beautiful variety, very distinct in character, well adapted for the centre of a bed, where such plants are required. We find it, however, apt to die and become disfigured on a rather wet and cold soil, whilst on sandy loam, in rather warm situations, it makes a splendid tree. $1 \mathrm{~s}$. to $5 \mathrm{~s}$. We have several varieties, all very handsome.

T. Orientalis Aurea.-Very distinct, originated by Mr. Waterer. When we first had it, we were rather disappointed, and expressed ourselves so, but as our plant has gained size, it has increased in beauty. We now make the amende honorable, and advise all our evergreen-loving friends to procure it. In winter it is a lively green, but in spring and early summer it has the most attractive golden tint possible.

T. Orientalis Empetrifolia, somewhat in colour like the preceding, but smaller in all its parts. The plant is yet young, but it promises to be a very interesting variety.

T. Orientalis Sieboldii. (Siebold's Arborvitæ.)-Extremely distinct and very beautiful. A darker purplish green than others of the family. Of this we have a great opinion that it will make one of the best. Scarce, but no doubt will be extensively planted, when more common.

T. Orientalis Tartarica. (The Tartarian Arborvitæ.)-Of rigid habit, dark green, hardy and ornamental.

T. Orientalis Hybrida.-A seedling of very distinct character, originated here, the branchlets being horizontal and perpendicular alternately. Our plant, which is now about three feet high, is extremely interesting. It appears to partake of the character of both Orientalis and Siberica.

T. Flagelliformis. (The Whiplike-branched Arborvitæ.)-This is new and distinct, throwing out its branches (which are pendulous at the ends) horizontally. We have no doubt this will prove highly ornamental, and will be a fit companion for the Deodar and plants of similar habit. 
T. Gigantea. (The Gigantic Arborvitæ.)-Something in the style of foliage like the Siberian, but strong.growing and pyramidal. It attains a great height in its native country, and will doubtless prove a valuable addition to our hardy evergreen trees.

T. Filiformis. (The Weeping or Thread-branched Arborvitæ.) -A singular and rather elegant form of the family. Slender drooping branches. With us it assumes a brown tint in winter, but regains its colour in the spring and summer.

T. Chilensis. (The Chili Arborvitæ.)-Should this prove sufficiently hardy to withstand our climate, it will be one of the most attractive evergreens we possess. The branches are thrown out horizontally and flat, as in the Cedar of Lebanon, the colour of the foliage is a peculiar and delicate green, and perfectly distinct from any previously enumerated.

A FEW GOOD HOLLYHOCKS.

We have a nice bloom of these noble flowers, and will give our readers the result of our notes on them this season. We think our opinion of the varieties will be borue ont by those who bave already grown them, and thus we hope to guide those who are desirous of becoming cultivators next year.

Aurora.-A very rich crimson, good and flat guard petal, centre well up.

Napoleon.- Of this we have two sorts, the one yellow and scarlet, of moderate form; the other purple, with white margin, and a full and high centre. Very attractive and pretty.

Rubens.-One of the most interesting, being a delicate salmon colour, of good form, and the centre full.

Walden Gem.-Dark crimson scarlet, extra form, flowers produced thickly on the spike, quite first-rate.

Black Prince (Gibbons).- This was raised at least twenty years ago at Bramcote, near Nottingham, and the original plant is yet in existence. Amongst all the Black Princes and dark ones, we think this the best, though only known out of its immediate locality within the past few years. It makes a noble spike, and is extremely glossy and rich.

Queen Victoria. - A large and bold flower, light rose, very full, and of first-rate form; splendid.

Premier. - Nice habit and of good form, beautiful light crimson, a very lively and attractive flower. 
Charles Turner (Black).-Quite up to the mark. Rich rosy crimson, extra fine form. Indispensable.

Sulphurea.-Light yellow, a pleasing variety.

Rosy Queen.-Very delicate pink, smooth guard petals, nice form, and pretty habit.

Captain Peat.--A Scotch flower. Rich pink, very flat, smooth and round guard petals, high centre, very good.

Miss Wedderburn.-Also Scotch. One of the most attractive, forming a close and beautiful spike. The colour is a lively pink, excellent habit. Must be seen to be appreciated.

Sir $D$. Wedderburn. - Fine dark brownish crimson, large and full. First-rate.

Formosa.-Dark chocolate, an interesting variety, foliage also distinct and handsome.

Belladonna.-This we raised from seed. Its ault is, the guard petal is thin; nevertheless, it is a most beautiful sort. It comes very true from seed, and we would advise our friends to endeavour to obtain a seedling with stouter guard petals.

Sovereign.-Raised from Black Prince, forming a magnificent spike of marone-coloured flowers, which are of the largest size, and produced very close on the stem.

\section{CULTIVATION OF THE POLYANTHUS.}

IN complying with your request, I must confess to having much more confidence in cultivating the polyanthus than in writing an article for the press. But if any remarks, given in my plain humble way, can be found at all interesting to the readers of your widely-extended and justly-esteemed useful publication, I shall be most happy in communicating all and every particular connected with my simple mode of cultivation and management, feeling, as I do feel, most anxious to see this much neglected, though deserving flower brought into a more extensive and healthy state of cultivation.

I regret much to hear such repeated complaints of failure in the cultivation of the polyanthus, which I find much easier, and much less trouble and expense than most other florists' flowers. Three things necessary to the insurance of success are, first, the purchase of good plants, from a healthy stuck; 
second, proper soil and situation to grow them in; third, regular attention;-the latter being required to a much greater extent in pot than bed cultivation, therefore I should not advise those who are about to commence, or whose gardens are far from home, to attempt growing them in pots.

But to commence forthwitb, as there is no time for delay, select a spot open to the sun throughout the winter, and free from overhanging and drip of trees, mark two feet in width, any length required, allowing eighteen or twenty inches for path-one end of the bed to point east, inclining a little south, the other end will be, of course, west, the same inclination north, which will give the required aspect. Measure the length marked out, and procure some fir poles, four inches thick and five feet long, have them sawn down the middle, and thus each will make two posts, one of which will be required to every three feet your bed is in length, and one over. Provide also some strips of red deal, one inch thick and two broad, for edging the bed in front and at both ends; and a few stakes, one foot long and two inches thick, to be driven down about three feet distant, to the extent of the bed, and the strips nailed on outside, next the path; also four pantile laths, the full length required frorr end to end. If the ends of the posts, stakes, and strips of deal are brushed over with hot gas tar, mixed with one-fourth of linseed oil, a few days previous to being put down, they will last much longer. All being in readiness, stretch a line, three feet six inches high, from end to end, to the extent of the back or south side of the bed; then put down the posts, till the tops are even with the line, and fasten them firmly; then nail thereon the pantile laths, commencing six inches from the surface of the bed for the first, and the rest following with equal space to the top. Dig out all the soil a foot deep, clear and regular, and put in a layer of any decayed regetable refuse, such as hedge clippings, rotten sticks, or the like, that will admit 
of pressing down equally all over with the back of the spade, till about three inches thick. Upon this a moderate quantity of soot should be sprinkled regularly all over with the hand. Then a stratum of well-decayed cow or pig manure, the same thickness as the vegetable refuse. This also must be sprinkled with soot, but very slightly, or it will injure the plants. It is to prevent worms rising, which often make sad havoc in a newly-planted bed, by rooting up the plants and dragging them into their holes. If on cold clay land, use sheep manure, mixed with one fourth of sandy turf. Fill up the bed to within an inch of the top edge of the strips (which may now be put down for border or edging for the bed) with fresh fibrous loam that will easily divide with the fork or hand; then rake all over carefully, and put on a riddling of nice light soil, free from manure, one inch thick. This completes the bed ready for planting, which must be finished by the end of this month. Three plants in a row, across the bed, and eighteen inches between the rows, will be quite thick enough. Betwixt every two rows may be planted the double blue and red hepatica, alternately with gentinella and double primroses. In February, a root of the red and white turban, and ranunculus in varieties may be dibbled in betwixt every plant. These I find to bloom much better here than in open exposure. When these, that is the turbans and ranunculuses are past flowering, they must be taken up, and a few ten-week stocks put two in a row, about three feet apart. They will do no harm at this season of the year, but rather good, by keeping the plants cool. As it will be necessary for the bed to be made much larger than will be required for the few polyanthuses got in the first season, this will be found a desirable plan for making use of spare room, and will render the bed gay and attractive during the hot summer months, and thereby draw attention towards the polyanthuses, so essentially necessary in summer, with respect to watering, \&c. It will be 
advisable to nail some calico, canvass, or matting, froin the top lath to the bottom one, to shade the plants till they have taken root. Two or three weeks will be sufficient, when the shade may be taken off, and some good strong plants of the double flowering currant planted at the back or south side of the laths, two feet distant. Blooming with the polyanthus, it adds much to the beauty of this early "treat," affords good shade in summer, and losing its foliage in winter, gives access to the sun's rays, and is in all respects the best thing I know of for the purpose.

I think I have now shown that the polyanthus border may be rendered as ornamental and attractive as any part of the garden; and should these few remarks be found worthy of insertion, I shall endearour to give a few more next month.

Alfreton-road, September, 1852.

S. HAMMOND.

NOTES ON A FEW PLANTS \& FLOWERS EXHIBITED AT THE ROYAL SOUTH LONDON SHOW.

THE fuchsias were most of them old varieties, but well done. The newest were,

Kossuth.-Small crimson tube, with light purple corolla.

Psyche.-A splendid variety. Light tube, with crimson centre. Bianca. - Flesh-coloured tube, with vermillion centre.

Fair Rosamond.-Very large white, with deep pink corolla. A striking and pleasing variety.

Dr. Gross. - Extra fine flesh-coloured tube, vermillion corolla.

There was also a seedling of Mr. Harrison's, of Darlington, called

The Pride of England. - White tube, with crimson corolla, beautifully reflexed. A first-rate thing.

In roses,

Viscomte de Cazes was most beautiful, and being in good cha. racter, was widely different to what it is usually seen.

Narcisse.-A good-formed straw-coloured flower, quite XX. 
Reine des Fleurs.-Very splendid hybrid perpetual. Deep pink. Should be in every collection.

Devoniensis and the favourite sort, Geant des Batailles, were exhibited in very first-rate trim.

Prince Albert (Bourbon) was also very striking, much after the style of H.P. Standard of Marengo, but fuller and deeper in colour.

Frederick II.-Hybrid Bourbon. A very nice dark variety, but rather thin.

In verbenas,

Exquisite.-Deep pink, with white centre. A very fine flower.

Croesus, violet purple, and Joan of Arc, bright deep pink, were excellent; but

Monsieur Paquin, deep violet purple, with white eye, was certainly the most beautiful variety there.

There was also exhibited a seedling, called

Camberwell Beauty.-Deep pink, very large, and good in form. Also

Elizabeth, a promising white one.

In hollyhocks,

Bragg's Cream of the Valley was a fine and delicate variety, and the best seedling there.

\section{THE TOWNS EXHIBITION OF CARNATIONS AND PICOTEES}

Drd not disappoint either the public or the florists who came from a distance to witness the friendly competition. For ourselves we never recollect to have taken part in a more interesting meeting. The season certainly has been an untoward one for these flowers, but we think the eminent success of our friend, Mr. Dodwell, who, like Mr. C. Turner, of Slough, and the leading cultivators of the south, blooms his flowers under an awning, thus preserving them in a great measure from the vicissitudes of the weather, will induce others to follow the example; indeed we heard more than two or three florists who had visited Mr. Dodwell's collection, estirnating the cost of a similar erection, and expressing a determina- 
tion, before another season, to have one for their own flowers. Now this is as it should be; it takes a good deal of writing and argument to convince people of what they do not feel an inclination to try,--but let them witness the successful result of the selfsame system, and they are immediately impressed not only with its propriety, but its necessity. And we appeal to all florists who visited Mr. Dodwell's collection, whether he has written one iota which he does not practice, and successfully; and glad shall we be to see that our friends, at the next "towns meeting;" have improved on their previous systems, and done their best to take the lead in so laudable an emulation. For the season, the flowers were very good, and produced in great profusion. As our space is too confined to particularize at great length, we shall endeavour to give our readers a description of some of the best in each stand. They will, if they are admirers or cultivators of these beautiful flowers, glean something of service from our notes, and if so, our trouble will not be in vain. Before doing so, however, we must express our unfeigned delight at the cordiality and truly happy florist's feeling which pervaded every breast. We do not say appeared, because we are sure that such sentiment was perceptible on every side; and we are equally certain that the florists from Yorkshire, Cheshire, Lancashire, Lincoln, Leicestershire, W arwickshire, Notts. \&c. fully appreciated the exertions of our Derby friends in catering for their gratification. Most gratifying was it to us also to note that our friends from Yorkshire and Lancashire, Messrs. Baildon, Bower, and others, were the first to express their cordial approval of arrangements which previously they had only imperfectly understood, and their conviction that the opinions which had recently appeared in our pages as to the merits of Lorenzo, Alfred, \&c. were fully warranted. Such candour was most creditable, and we believe we express the unanimous SEPTEMBER-VOL. VI. $2 \mathrm{D}$ 
feeling of every enthusiastic florist in the midlands, when we say, we are most glad to be set right, if we fall into error. A more striking illustration of the truth of the opinion we gave on the cover of our last number, viz. that since we have known what floriculture was, never has there appeared so much unanimity and good feeling amongst florists, could not have been desired; and never before was there a stronger proof that assumed differences of opinion, magnified into mountains whilst space divides us, vanish into thin air, when we come face to fase, with the subject before us to illustrate our remarks.

There was a marked difference in the flowers from varions localities, and certainly we were most agreeably surprised to see so well-grown and splendid a stand of flowers sent from Edinburgh. These were the production of C. K. Sievewright, Esq. and did him infinite credit. They would have held a very prominent position, but from the circumstance of the crimson bizarre having a run petal, and several others having no dark stuipe in them. The fiowers were the largest in the exhibition, and were also extremely well matched.

Amongst seedlings, the most noticeable were a scarlet bizarre, rose flake, and a heavy-edged purple picotee, flowers of great promise, raised by Mr. John Bayley. General Monk, a superb crimson bizarre, produced by Mr. Charles T'urner (not for competition), and a pink bizarre of Mr. Dodwell's, \&c. dc.

The following took our fancy much in the respective stands. Derby took the lead. Here was the scarlet bizarre raised by Mr. Bayley. Both form and ground colour were good, the scarlet appeared rather dull, apparently from the age of the flower. Flora's Garland was in excellent trim. When well done, it distances most competitors. Lord Milton (C.B.), Admiral Curzon (S.B.), Cradley Pet and Firebrand (S.B.) were also excellent; and Squire Meynell, though small, from its purity and distinot 
ribboning, reminded us of what we have seen this flower in times gone by, certainly when in character, A 1 of its class.

The stand from the hardrare village, yclept Birmingham, was placed second, though the flowers were rather small, but neat and well marked, and apparently to the day. Here were two flowers raised in that quarter, that were fine, namely, Lord Lewisham, a very high-coloured scarlet bizarre, and Black Diamond, equally distinguished by its fine marking in the crimson class. 'Then there was old Lydia in her best dress, and Lord Pollitigton in beautiful character, the ground colour and bizarre being nearly balanced. Lovely Ann, a scarce and attractive rose flake, aided most materially in giving contrast as well as quality to the stand.

Nottingham ran a good third. In this stand were two promising seedlings,-Taylor's Lucia, with fine white and distinct broad flakes of lively pink, and a scarlet flake of Mr. Cooper's, with broad, stout, and gently-cupped petals : it appeared, however, rather overgrown, as the ground colour was hardly of so pearly a whiteness as last year. Faulconbridge, a pink and purple bizarre, was in very excellent character; and $M^{x}$ ilton also was very fine. Another flower also, now rarely met with, was one of the best, namely, Ely's Lady Gardiner, distinguished for its stout petal, fine form, and excellent marking.

Leeds stood fourth. 'The flower par excellence of this stand was Schofield's Magnificent, a first-rate rose flake, which we had occasion to notice as a seedling. It still maintains its character, and is certainly very fine. It was, however, very closely run by that first-rate flower Ely's Lady Ely. Then there was Justice Shallow (S.F.), and the good old C.Bs. Lord Milton and Paul Pry. Firebrand and Ariel were both pretty.

The fifth place was taken by York, and thongh not very forward, still the style in which our old friend, Merryweather, brought his flowers to the 
mark, did him much credit. Here was a nice scarlet bizarre, rather small, but beautifully marked, called Knowsthorpe Pet. This should have only one flower on a plant: if size could be obtained by this means, it would take some shaking off. Lord Rancliffe and Lydia were again fine, and Martin's Splendid noticeable for the extreme purity of the white. 'True Briton was also in fine colour, but there was a roughness about the edge incompatible with a first-class flower. The other flowers were of average merit, but certainly we thought this stand showed rather better dressing than any other.

Wakefield was sixth. The flowers small in comparison with some others, nevertheless, very prettily marked, including Beauty of Brighouse, a highcoloured scarlet flake, and Hepworth's Leader, remarkable for its neat and distinct marking, but it is sadly undersized. There were several unuamed seedlings, which we hope to see when named, under more favourable circumstances.

Leicester was seventh. Our friends' was the post of honour reversed, but by no means dispirited, they intend to have another trial for a better position next year. It certainly was too late for them, their best flowers having been exhibited a week or ten days before. In this stand was our old "friend," Gladiator, really very resjectable, for a wonder! Brisies, a beautifully-marked rose flake; Queen of Purples (P.F.); Earl of Leicester (S.F.), being a late flower, was the best in the stand. Independent of these, there was a purple flake of good quality, but little known, called Hudson's Duke of Rutland.

The picotees were generally very good. Derby again first. Our readers will please to mark the sorts, in the detailed account of the show, in another page. The flowers we allude to here, we record as especially deserving of notice. First, then, was Mrs. Norman, a splendid heavy-edged red, and Duke of Rutland, of the purple class, quite equal in merit; Ganymede (light purple), Venus (heavy rose), and 
Mrs. Barnard (light rose), as lovely as can be imagined; and then a heavy purple (the seedling of Mr. Bayley's), without a name (since called Duke of Devonshire), was excellent. But we must entreat our friends to name their flowers, so that they can be referred to, for what reference can be made to "seedling," without name or number. Ophelia, light purple, was beantiful, and is every way first-rate; and Prince of Wales was exquisite.

Birmingham took second place. King James, heary red, was as well done as we have seen it this season. Green's Queen and Headly's Venus, heavy rose-edged, very pretty and clean. Alfred, Elizabeth, and Mrs. Barnard we will warrant to maintain their character as first-class flowers; in fact, every one who saw them were satisfied as to their respective good qualities.

The third place was assigned to York. Lady Franklin, a light-edged purple, was very good; Miss Rosa, a medium-edged rose, very attractive, and should be grown by every one; Mrs. Wood, light, and Mary Ann, heavy red, were also distinguishable for their purity and good marking. In this stand was the best Dodwell's Alfred in the exhibition; it certainly was a beantiful flower, and would have pleased the most fastidious.

Nottingham took fourth. Norman's Lord Nelson, heavy purple, was very beautiful; so was Marris's Prince of W ales, heavy red, and Youell's Gem, light red, which, with Mrs. Barnard and Green's Queen, were the elite of the stand.

Leeds fifth. Regina, Lady of the Lake, and Mrs. Barnard, were amongst the best; whilst flowers befure enumerated, such as King Janes, Duke of Rutland, and Mrs. Norman, with Ann Schofield, Christabel, and Prince of $W$ ales, were in very fair trim.

Leicester sixth. 'The best were Duke of Rutland, Prince Albert, Mrs. Norman, Lord Nelson, and Gem, which, though small, were neat, and very prettily marked. 
Our readers will perceive, from the notes, that the best flowers in cultivation were brought together in competition, and we have no doubt the gathering will be attended with very beneficial results. We have but little room for further remark, but hope to recur to the subject before the year is out. The flowers belonging to the members of the Derby society were shown at the same time, and were most excellent. The plants, fruit, \&c. as is always the case, were first-rate; and last, though not least, a stage of prize gooseberries attracted great attention, not only for the beauty of the fruit, but also the nice stage on which they were shown. It was of mahogany, the berries being placed in cups, turned neatly, of the same wood, with the name and weight of each attached.

A large company, comprising the influence and intelligence of the neighbourhood, testified the interest taken in these exhibitions; and we are sure, wherever they are as well carried out, the patronage of the public will not be wanting.

\section{非art 和E。}

\section{FLOWERS RECEIVED SINCE OUR LAST REPORT.}

Double Antirrhinum.-D. W.-Will make a nice border flower.

SEEDLING Fuchisias. - I. W.-The small one is very prettily reflexed, and a good contrast. No. 1 is a stout flower, equal to many of its class, but not sufficiently distinct or superior to guarantee its being sold out.

I. R.-Your fuchsia, named Captivation, is pretty, certainly, but we should only mislead you by raising extravagant hopes as to its value. There are too many like it already to allow of its being sold out as a distinct variety.

J. B.-Your picotee is very pretty. We want the name, then we will say something more about it.

H.-Petunra.-Pink, with dark throat, having a broad and well-defined green margin, like a green-edged auricula. Very handsome. Propagate it by all means, and if it comes in the same character next year, it will sell. 
W. W.-Rose.-Dropped as soon as the box was opened. Colour good, but we cannot say anything about its form.

R. M.- Your pinks, Theresa and Angelina, we thought we had before noticed. By all means let them out, they will give satisfaction we are quite sure. Adelaide and Beatrice are very attractive, but a little uncertain; still, when in good trim, they will beat very many that are now thought highly of.

Carnatron.-Captain Franklin, crimson bizarre. A uice flower. White very good, and the stripes of marone and pink distinct and bold. This will make some of the crack sorts look about them.

J. B., Leeds.-Miss H. Boshell Picotee.-Heavy-edged purple. A very promising flower, as far as three tiers of finelyformed leather-like petals go. Surely some small ones had been pulled out of the centre. The purple is novel in colour, and very evenly laid on. If it crowns well, it will take a prominent place in its class.

Yellow Picotees and Selfs.-No. 1. Yellow, with red edge, slightly barred. Pretty. 2. Canary coloured, dark purplish margin. A fine and full flower, very promising. Of coures these two are layered. 3. Singular bronze colour. Worthless, except for its novelty. The rose self is large, and will make a good border flower. The purple is serrated, and will not do.

Delphinioms.--W. Werton.-No. 11. Double white, tinged with green. Very singular and pretty. 5. Very good double shaded purple. 4. Double purple. A nice sort. Magnifica pleno: fine broad petals. Good. 9. Single blue, tipped with crimson. The other varieties sent were faded, and a fair opinion could hardly be given of them.

James Merryweather, York. - The light purple picotee, placed first at the York Horticultural (Aug. 12), is as rough on the edge as a circular saw, -not a petal without the serrature, most of them with deep indentations, and in our judgment, very inferior to the two blooms of Lady Franklin, accompanying it, stated by you to have been placed second and third. The first, as sent, is worthless.

\section{RETROSPECTIVE CRITICISU.}

Mr. Newhall, at page 227 , finds grave fault with the brief directions of my April calendar. From Mr. Newhall's position as an old florist, I presume I 
must offer something in vindication of my heretical doctrine.

First, then, I recommend gentle heat, because it more surely promotes the germination of the seed (rather an important point), and because in my experience I have found quite as many plants have damped off out of gentle heat, as in it; added to which, hundreds of seed, out of heat, have perished. Surely Mr. Newhall, with his twenty-five years of experience, has heard of such things as the loss of salad crops, of onion seed perishing after germination, of rose-buds and fruit-buds untimely nipped, and other such evils as form the stock-in-trade of floricultural grumblers. Surely too, he must have some little knowledge of the English climate, and the vicissitudes of an April day. Yet he writes as if he could not have too much of it, and the only thing to do was to "keep in the shade." I cannot agree with him. I tried the "northern aspect, fully exposed to the atmosphere" system, and obtained two plants from upwards of seven hundred seed, such seed being, according to the opinion of two of the oldest florists in this neighbourhood (Messrs. Parkinson and Lakin), the best they had ever seen, and certainly as finely ripened as any 1 have had since. Then, upon the advice of my triend, Mr. Bayley, I tried a little heat-giving plenty of air, and being sparing of water-and with such satisfactory results (full particulars of which Mr. N. shall have, any day he will favour ine with a call-the history of the seed, the number sown, how many germinated, \&c.), that I could not hesitate to recommend the practice to $\mathrm{my}$ friends; and Mr. N. must forgive my telling him it was not the system, but his neglect, which produced the damping off he describes. Would Mr. N. think it quite fair for me to impute to his system any evil which might have arisen to his plants had he not protected them froin the "continued heavy rains?" Did he not then guard them from damping off? and, if it is not inquiring " too curiously," wherein is that 
mode of culture more simple, than the recommendation of mine, "give plenty of air and be sparing of water ?" I recommend the use of gentle heat, because it is more certain in its results, - because it is no more trouble to " give plenty of air, and be sparing of water," than it is to "carefully keep the seed from the influence of sun heat, and the surface soil constantly moistened," - and because, whatever may have been Mr. N.'s mistakes, I have found no difficulty in getting plants raised in gentle heat, "to drop their cotylidons almost on the surface of the soil." "Unnatural treatment" is indeed a pregnant source of evil, but before Mr. N. can sit in judgment on my brief directions, he must fairly show wherein " gentle heat, plenty of air, and a sparing application of water" is more unnatural than "pots and pans, carefully kept out of the influence of sun heat;" he must demonstrate, in fine, precisely what is natural, and whether florists may accept that as quite consistent with their vocation is a question which may then be raised.

E. S. D.

Nicholson's Ajax Strawberry.-Very large, and new, often weighing two ounces each.

Nymphea Gigantea, a beautiful new blue water lily, has been introduced from New South Wales. The flowers are about twelve inches over, whilst the foliage attains twice that size. It requires the temperature of a greenhouse. Will not this be the parent of some hybrids, with blue flowers, which will be sufficiently hardy to stand our winters. In fact, we see no reason why this should not: it will be far out of the reach of frost at the bottom of ponds or lakes. But then the price just now (seven to fifteen guineas each), almost precludes the experiment. We hope, however, the gentlemen who have introduced it will give one of the tubers a trial. 


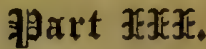

\section{ANSWERS T0 CORRESPONDENTS.}

Mid-Staffordshire- You may put in the cuttings now. Gentle heat is desirable. We do not imagine that it will be of any service to your plant to cut it down. We would advise that only part of the cuttings be taken off. You may sow seeds now of lothospermums, eccremocarpos, cobra, maurandya, and rhodochiton. These will require greenhouse protection during winter, and will bloom beautifully in the open air, next summer. You will thus gain a season.

\section{CALENDAR OF OPERATIONS, \\ FOR SEPTEMBER.}

\section{GREENHOUSE.}

If this house is not already thoroughly cleaned and prepared for the reception of the plants which have been standing in sheltered places during the sumner months, let it be done immediately. The plants mav also be well cleaned and carefully examined, to see that none are suffering through imperfect drainage. If there be any appearance of worms in any of the pots, it will be most importani that each plant be turned out, the ball carefully looked over to see that none remain, and the drainage (if the least choked) be readjusted. Tie neatly all that require it, wash the pots, remove from the surface any moss or weeds, and top dress with a little fresh soil; let everything be quite ready for housing the plants whenever the weather may set in wet and coid. The calceolarias and cinerarias that were planted in the borders (as recommended to be done in the July number), will now be growing freely; detach the offsets, and put in small pots, using a light rich soil. Seedlings should also receive attention, and be potted as soon as large enough to get hold of. Be sure to keep them free from insects. Look over tropæolum bulbs, and if any have begun to grow, let them be immediately potted, give them but little water, and let them be kept, in a cool place. Other bulbs, such as hyacinths, narcissus, tulips, \&c., may now be potted, and plunged four or five inches deep in old tan, coal-ashes, or sand; they may remain here until wanted for gentle forcing. Shift on young plants of the Chinese primrose, and pinch out any flower stems that may at present appear. Frequently water chrysanthemums with liquid manure, and see that they do not at any time want water, or loss of foliage will result. Give rather less water to those 
plants which have made their growth, but let them have as much light and air as possible. J. BAYLEY.

VINERY.

When the grapes are quite ripe, leep them as dry and airy as possible. In dam $p$ weather gentle fires will be necessary cluring the day. If any berries get injured by wasps or other iusects, remove them at once, or whole bunches will soon be destroyed. Those not yet ripe may be assisted by a little fireheat, which will also help to ripen the wood. All superfluous growths inust be at once removed.

J. BAYLEY.

\section{FLOWER GARDEN.}

Continue to propagate all the most desirable plants as fast as cuttings can be obtained; such things as verbenas, anagallises, shrubby calceolarias, heliotropes, cupheas, \&c., will strike readily now. The success in wintering these things greatly depends on their being well established in pots before the long, cold, wet nights come upon us. In fine dry weather, gather seeds of the different annuals and perennials as they ripen, and carefully mark each sort with its name, height, and colour of Hower; this will be found useful in sowing time. Some of the hardy annuals, auch as erysinum, Peroffskianum, Nemophylla insignis, Clarkia pulchella, \&c., if sown on dry and rather poor soil, will stand the winter, and will be found useful in the spring. Plant out pinkpipings, Erysimum Marshallii and alpinum, and the different varieties of al iyssum, for early spring flowering. Cuttings of China roses strike freely now, if placed in a little bottom heat.

J. BAYLEY.

Carnations and Picotees. - The whole stock being layered and thoroughly clean, the early part of this month will be one of comparative leisure, during which the enthusiaslic florist will find a grateful and profitable employment in conning over his notes of the past and former seasons, and drawing out a list of those varieties which will form the most complete selection: marking against each variety the number of plants to be grown. These being checked oft as "potting up" for wintering proceeds, the cultivator has a prompt idea of his stock before him. We commence this latter operation about the third week in the month, using good sweet sand loam, with the addition of a fifth or sixth part of sweet leat mould, and such well-washed sand or pounded crocks as may be needed to ensure a free percolation of air and water. The soil may be prepared at once, and should be kept dry. Various sized pots should be used, according to the strength of the plants. Over-potting is a great evil. When potted, place in a cold frame, and keep close for some days, shading from bright sun. Water sparingly. Badly-rooting varieties will be greatly aided with a little gentle bottom heat. We shall be glad to hear from our friends as to the quantity of seed harvested, as opportunity may serve.

\section{Derby.}

E. S. DODWELL. 


\section{FLORAL EXHIBITIONS.}

\section{TULIP SHOW,}

\section{At. Mr. E. Wilkinsor's, Woodman Inn, Leeds, May 27.}

Premier Prize.-Platoff, I. W. Bower.

Ist Pan.-Platoff, Polyphemus, Bienfait, Baguet, La Belle Nanette, Triomphe

Royale, and a breeder, I. W. Bower. 2nd. Charles X., Polyphemus, Baguet,

Alcoran, Walworth, Triomphe Royale, and Catherine, W Chadwick.

\section{Feathered Bixarres.}

1 Platoff, I. W. Bower

2 Sovereign, W. Chadwick

3 Bolivar, ditto

4 Magnum Bonum, G. Foster

5. Waterloo, I. W. Bower

6 Beurs, ditto

Flamed Bizarres.

i Hero of Slough, G. Foster

2 Polyphemus, G. Chadwick

3 Leopold, I. W. Bower

4 Donzelli, ditto

5 Sanzio, W. Chadwick

6 Carlo Dolci, T. Wainman Fealhered Byblamens.

1 Bienfait, I. W. Bower

2 Baguet, W. Chadwick

3 Elegance, $\mathrm{T}$. Wainman

4 Trulotta, I. W. Bower

5 Ely's Victoria, W. Chadwick

6 La Belle Narene, I. W. Bower Flamed Byblomens.

1 Baguet, W. Chadwick

2 Alcoran, ditto

3 Magnus, G. Foster
4 Voerhelm's Incomp. W. Chadwick

5 Ely's Victoria ditto

6 Voerhelm's Incomparable, ditto Feathered Roses

1 Lady Middleton, I. W. Bower

2 La Belle Nanette, ditto

3 Walworth, W. Chadwick

4 Duchess of Newcastle, T. Wainman

5 Lady Crewe, I. W. Bower

6 Duc de Bronte, ditto Flamed Roses:

1 Triomphe Royale, W. Chadwick

2 Aglaia, G. Foster

3 Lord Hill, W. Chadwick

4 Rose Ruby, ditto

5 Emperor Alexander, G. Foster

6 Cerise Primo, T. Wainman Selfs.

I Min d'Or, I. W. Bower

2 Seedling, W. Chadwick

3 Cothersione, G. Foster

4 Seedling, W. Chadwick

5 White Flag, T. Wainman

6 Min d'Or, W. Chadwick

TULIP SHOW,

At Mr. Joseph Gregory's, Fox and Grapes Inn, Sutton, May 28.

Premier Prize.-Baguet and Violet Wallers, W. Swindells.

\section{Feathered Bizarres.}

1 Charles X., W. Swindells

2 Charles X., C. Pimlott

3 Rising Sun, J, Goodwin

4 Rufus, T. Salt

5 Spencer's Duke, J. Boston

6 Surpass Catafalque, W. Swindells

7 Sysigambis, J. Brocklehurst Flained Bizarres.

1 Lustre, T. Salt

2 San Joe, ditto

3 Surpass Catafalque, J. Brocklehurst.

4 Albion, C. Pimlott

5 Polyphemus, ditto

6 Waterloo, W. Swindells

7 Unknown, ditto Feathered Byblomens.

I Ia Belle Narene, J. Brocklehurst

2 Dolittle, T. Salt

3 Bienfait, ditto

4 Baguet, W. Swindells

5 Ambassador, J. Brocklehurst

6 Washington, T. Salt

7 Unknown, J. Brocklehurst
Flamed Byblcemens.

1 Violet Wallers, W. Swindells

2 Bienfait, ditto

3 Lucy Neal, T. Salt

4 Violet Wallers, J. Goodwin

5 Voerhelm, W. Swindells

$6 \mathrm{H}$ and $\mathrm{B}, \mathrm{J}$. Goodwin

7 Roi de Siam, T. Salt Feathered Roses.

I Lady Crewe, J. Bostock

2 Dolittle, C. Pimlott

3. Hero of the Nile, W. Swindells

4 Comte, T. Salt

5 Lady Crewe, J. Goodwin

6 Enterprize, ditto

7 Duc de Bronte, C. Pimlott Flamed Roses.

1 Unique, $T$. Salt

2 Unique, $W$. Swindelis

3 Aglaia, C. Pimlott

4 Celestial, T. Salt.

5 Camillus, J. Goodwin

6 Rose Aspasia, T. Sait

7 Triomphe Royale, ditto 
Preeders.

Countessus (bizarre), J. Goodwin

W. Swiudells
Lady Jane Grey (rose) T. Salt

Selfs.

White Flag, W. Swindells

Min d'Or, ditto

\section{TULIP SHOW,}

At Mrs. Kitchen's, Orange Tree Inn, Butley, May 28th.

Premier Prize (silver cup) - Charles X., Bienfait, Comte de Vergennes,
Lustre, Buckley's Beauty, Unique, D. Potts.

Best Pan of Breeders.-Sunbeam (bizarre), Britannia (byblœmen), and Lady

Leicester (rose), M. Grimsditch. Feathsred Bizarres.

I Charles X., J. Davenport

2 Charles X., P. Hibbert

3 Surpass Catafalque, J. Davenport

4 Spencer's Duke, D. Potts

5 Magnum Bonum, Mrs. Barnshaw

6 Sysigambis, Mrs. Wrigley

7 Perfecta, Mrs. Kitclien

8 Duke of Devonshire, G. Chadwick

9 Trafalgar, Mrs. Wrigley

10 Seedling, G. Clarke Flamed Bizarres.

1 Polyphemus, Mrs. Kitchen

2 Lustre, M. Grimsditch

3 Surpass Catafilque, D. Potts

4 San Joe, P. Hibbert

5 Polyphemus, ditto

6 Flamme de Guerre, Mrs. Kitchen

7 Catafalque, G. Chadwick

8 William IV., D. Potts

9 Unknown, P. Hibbert

10 Beaute Parfaite, ditto Feathered Bybloemens.

1 Bienfait, P. Hibbert

\section{Bienfait, J. Davenport}

3 David, D. Potts

4 Washington, J. Davenport

5 Lady Flora, Mrs. Wrigley

6 La Belle Narene, G. Chadwick

7 Maitre Partout, G. Clarke

8 Duc de Bordeaux, Mrs. Kitchen

9 Ambassador, Mrs. Wrigley

10 Elegant, J. Davenport Flamed Byblomens.

1 Louis XVI., Mrs. Wrigley

$2 \mathrm{H}$ and $\mathrm{B}$, M. Grimsditch

3 Lawrence's Friend, D. Potts

4 Siam,

ditto

5 Violet Wallers, ditto

6 Bienfait, ditto

7 Prince Albert, ditto
8 Washington, Mrs. Kitchen

9 Pyramide d'Egypte, D. Yotts

10 Sable Rex, M. Grimsditch Feathered Roses.

1 Comte de Vergennes, P. Hibbert

2 Duc de Bronte, Mrs. Wrigley

3 Heroine, ditto

4 Walworth, J. Davenport

5 Comte de Vergennes, G. Chadwick

6 Claudiana, J. G. Winterbottom

7 Dolittle, D. Potts

\& Lady Crewe, Mrs. Wrigley

9 Aniromeda, J. Davenport

10 Rose Mignione, D. Potts

1 Unique, D. Potts

2 Aglaia, ditto

3 Vesta, G. Chadwick

4 La Vandicken, J. Davenport

5 Cerise Superior, D. Potts

6 Andromeda, G. Chadwick

7 Unique, J. Davenport

8 Walworth, Mrs Barnshaw

9 Camillus, D. Potts

I0 Rose Ruby, M. Grimsditch Bizarre Brceders.

I Unknown, P. Hibbert

2 Polyphemus, J. Davenport

3 Sunbeam, M. Grimsditch Bybloemen Breeders.

1 Democrat, D. Potts

2 Godet Parfait, ditto

3 Patriarch. ditto Rose Breeders.

1 Portia, D. Potts

2 Lady Leicester, M. Grimsditch

3 Lady Lilford, J. Davenport Selfs.

Min d'Or, D. Potts

White Flag, ditto

\section{TULIP SHOW,}

At Mr. George Williamson's, the Turner's Arms Inn, Bollington, May 29.

Premier Prize (silver cup). - Surpass Catafalque, Edgar, Walworth, Lustre, Perle d'Angleterre, and Unique, Mrs. Wrigley.

Best Pan of Breeders.-Unknown (bizarre), Rowland (byblœmen), Newcastle (rose), P. Hibbert.

Feathered Bizarres.

1 Charles X., P. Hibbert

2 Surpass Catafalque, T: Oldfield

3 Charles X., D. Potts

4. Perfect, Mrs. Wrigley

5 Trafalgar, ditto

SEPTEMBER-VOL.VI.
6 Duc de Savoy, Mrs. Wrigley

7 Lord Lilford, T. Oldfield

8 Duke of Devonshire, J. Hayes

9 Rufus, J. Hooley

10 Magnum Bonum, Mrs. Wrigley

$2 \mathrm{E}$ 
Flamed Bixarres.

1 San Joe, D. Potts

2 Charles X., G. Chadwick

3 Polyphemus, P. Hibbert

4 Albion, J. Hardern

5 San Joe, J. Mellor

6 Fullyson's Hampden, P. Hibbert

7 Lustre, ditto

8 Charbonnier, ditto

9 Duke of Devonshire, J. Hooley

10 Rufus. ditto Feathered Bybloemens.

1 Bienfait, P. Hibbert

2 La Belle Narene, T. Otảield

3 Bienfait, G. Chadwick

4 Washington, T. Oldfield

5 Surpassant, D. Potts

6 Tout, J. Hayes

7 Ambassador, J. Mellor

8 Unknown, J. Honley

9 Violet Winner, J. Hayes

10 Duc de Bordeaux, $\Gamma$. Oldfield Flamed Bybloemens.

1 Bienfait, $T$. Oldfield

2 Tout, J. Hayes

3 Violet Wallers, D. Potts

4 Pyramide d'Egypte, G. Chadwick

5 Lord Vernon, D. Potts

6 Lucy Neale, J. Hayes

7 La Belle Narene, P. Hibbert

8 Voerhelm, ditto
9 Unknown, Mrs. Wrigley

10 Bloemart, D. Potts Feathered Roses.

1 Heroine, P. Hibbert

2 Comte de Vergennes, ditto

3 Walworth, G. Chadwick

4 Heroine, Mrs. Wrigley

5 Lady Crewe, J. Hayes

6 Hero of the Nile, I. Potts

7 Dolittle, J. Mellor

8 Lady Stanley, J. Hooley

9 Duc de Bronte, ditto

10 Seedling, J. Hayes Flamed Roses.

1 Vesta, G. Chadwick

2 Thalestris, ditto

3 Vesta, ditto

4 Unique, J. Hayes

5 Camillus, Mrs. Wrigley

6 Rose Ann, J. Hayes

7 Cerise Superior, D. Potts

8 Unknown, Mrs. Wrigley

9 Walworth, J. Hayes

10 Ponceau Brilliant, D. Potts Breeders.

Dutch Catafalque (biz.), T. Oldfield

Clegg's No. 5 (byblœmen), D. Potts

Portia (rose), Selfs.

White Perfection, Mrs. Wrigley

Min d'Or, D. Potts

TULIP SHOW,

At the Red Gate, near Longton, May 29.

Premier Prize.-Rising Sun and San Joe, E. Eardly.

1 Charles X., T. Couper

2 Charles X, A. Shaw

3 Platoff, ditto

4 Magnum, ditto

5 Washington, ditto

6 Rising Sun, E. Poulson

7 Antony, E. Eardly

1 San Joe, A. Shaw

2 Polvphemus, ditto

3 Charles X., E. Poulson

4 Lord Hawke, A. Shaw

5 Sunbeam, E. Eardly

6 Catafalque, A. Shaw

7 Rufus, ditto

1 Grace Darling, A. Shaw

2 Washington, ditto

3 La Belle Narene, E. Poulzon

4 Maid of Orleans, ditto

5 Gibbons, A. Shaw

6 Comte de Flanders, E. Poulson

7 David, A. Shaw

1 Monarque, A. Shaw

2 Roi de Siam, E. Poulson

3 Princess Royal, A. Shaw

4 Violet Wallers ditto

5 Queen Charlotte, ditto
6 Queen Charlotte, A. Shaw

7 Prince Elie, T. Cooper

1 Anastasia, A. Shaw

2 Heroine, ditto

3 Comte de Vergennes, T. Cooper

4 Walworth, A. Shaw

5 Lady Middleton, ditto

6 Gibbons, ditto

7 Lady Crewe, E. Poulson

l Aglaia, E. Poulson

2 Triomphe Royale, A. Shaw

3 Triomphe Royale, E. Eardley

4 Rose Monti, A. Shaw

5 Rose Baguet, D. Brown

6 Iphigenia, A. Shaw

7 Unknown, D. Brown

Breeders.

1 Charbonnier, E. Poulson

2 Dentonian, ditto

3 Polyphemus, D. Brown

1 Gibbons, T. Cooper

2 Godet Parfait, ditto

3 Gibbons, ditto

1 Gibbons, T. Cooper

2 Ditto ditto

3 Catherine, E. Poulson 


\section{CHEETHAM HILL, IANCHESTER, TULIP SHOW. May 29.}

Best Stand of Three Breeders.-Atticus, Gibbons's Catherine, and another Chellaston seedling, W. Lea.

Best Stard of Six Rectified Flowers.-Charles X., Bacchus, Guido, La Van. dicken, Captain White, and Rosy Queen, S. Bromley.

Feathered Bizarres.

1 Charles X., W. Prescoit

2 Lord Lilford, W. Lea

3 Sidney Smith, ditto

4. Surpass Cat, R. Nunnerly

5 Crown Prince, $\mathrm{P}$. Leather

6 Catafalque, J. Hinscliffe

7 Duc de Savoy, P. Leather

8 Duke of Devonshire, IV. Lea

9 Catafalque Superieure, L. Ashmole

10 Firebrand, J. L. Richardson Flamed Bixarres.

1 San Joe, J. Holland

2 Polyphemus, P. Leather

3 Albion, ditto

4 Charles X., J. Ackerley

5 Lustre, J. L. Richardson

6 Charbonnier, W. Lea

7 Shakspere, J. Hinscliffe

8 Don Cossack, J. L. Richardson

9 Strong's K'ing, J. Thorniley

10 Lord Milton, J. Holland Feathered Bybloemens.

1 Buckley's Beauty, J. Holland

2 Naylor's Edgar, S. Bromley

3 Bienfait, P. Leather

4 Louis XVI., W. Prescott

5 Baguet, P. Leather

6 Lancashire Hero, W. Prescott

7 Washirgton, P. Leather

8 Lewold, $R$ Dixon

9 Mango, J. L. Richardson

10 Premier, S. Bromley Flamed Byblomens.

1 Bienfait, P. Leather

2 Queen Charlotte, ditto

3 Bacchus, W. Prescott

4 Violet Wallers, J. Thorniley

5 Roi de Siam, W. Lea

6 Alexander Magnus, W. Prescott

7 Gibbons's Seedling, J. Thorniley

8 Adelaide, W. Prescott
9 Baguet, J. Hinscliffe

10 Incomparable, J. Haigh Feathered Roses.

1 Heroine, W. Lea

2 Lady Crewe, ditto

3 Seedling, P. Leather

4 Comte de Vergennes, J. Hinscliffe

5 Queen Eleanor, R. Dixon

6 Bion, ditto

7 Hurst's Rose, P. Leather

8 Dolittle, ditto

9 Andromeda, ditto

10 Aglaia, J. Thomiley Flamed Roses.

J Unique, W. Prescott

2 Triomphe Royale, R. Nunnerley

$\$$ Vesta, L. Ashmole

4 La Vandicken, R. Dixon

5 Aglaia, W. Lea

6 Camillus, ditto

7 Rose Elegans, J. Thorniley

8 Mantua Ducal, W. Lea

9 Catalani, J. Holland

10 Lady Crewe, J. Snithies Bizarre Breeders.

I Charbonnier, S. Bromley

2 Red Gauntlet, J. Slater

3 Seedling, L. Ashmole

4 Seedling, J. Haigh

5 Polyphemus, P. Leather Byblomen Breedcrs.

1 Princess Royal, J. Ashton

2 Gibbons's Seedling, IV. Lea

3 Godet Parfait, S. Bromley

4 Seedling, J. Haigh

5 Catherine, J. Ashton Rose Breeders.

1 Willison's Juliet. S. Bromley

2 Unknown, L. Ashmole

3 Jeanette, S. Bromley

4 Anastasia, J. Ashton

5 Posy Queen, S. Bromley

\section{TULIP SHOW,}

At Mr. W. Duncalf's, Smallthorn, near Burslem, Staffordshire, May 29.

A handsome china tea service was awarded to T. Boot, for the best pan of six rectified flowers, containing Duc de Savoy, Bienfait, Lady Crewe, Royal Sove. reign, Bienfait, and Aglaia.

1 Charles X., J. Morrey

Feathered Bizarres.

2 Trafalgar, W. Wright

3 Duc de Sávoy, J. Alorrey

4 Charles X., W. Wright

5 Duke of Wellington, C. Bradshaw

6 Catafalque, J. Morrey

1 Pilot, T. Boot Hlamed Bixarres.

2 Polyphemus W. Wright

3 Goud Beurs, C. Bradshaw
4 Magnum Bonum, T. Boot

5 Charles $\mathrm{X}$, J. Morrey

6 Albion, C. Bradshaw Feathered Byblomens.

1 Grotius, J. Morrey

2 Baguet, ditto

3 Maitre Partout, W. Wright

4 Washington, T. Boot

5 Mango, C. Bradshar

6 La Belle Narene, J. Morrey 
Flamed Bybloemens.

1 La Belle Narene, J. Morrey

2 Unknown, T. Boot

3 Maitre Partout, W. Wright

4. Washington, J. Morrey

5 Baguet, C. Bradshaw

6 Buckley's No. 46, T. Boot

Feathered Roses.

1 Walworth, C. Bradshaw

2 Dolittle, ditto

3 Lady Middleton, ditto

4 Heroine, T. Boot

5 Hero of the Nile, C. Bradshaw

6 Lady Crewe, W. Wright

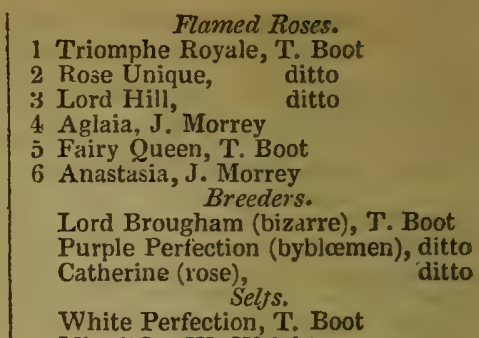

Min d'Or, W. Wright

\section{TULIP SHOW,}

At the Lomax Arms, Great Harwood, May 29.

Premier Prizes -1. Charles X., R. Birtwistle. 2. San Joe, T. Chippendale. 3. Bienfait, T. Whalley. 4. Bienfait, E. Hodgson. 5. Lády Crewe, J. Birtwistle. 6. Unique, J. Bedson.

Feathered Bizarres.

1 Charles X., E. Hodgson

2 Catafalque Superior, ' $I$. Whalley

3 Waterloo, T. Gibson

4 Duke of Devonshire, T. Chippendale

5 Trafalgar, $\boldsymbol{R}$. Holding

6 Seedling, J. Birtwistle

7 Surpass Catafalque, R. Holding Flamed Bizarres.

1 San Joe, T. Chippendale

2 Charbonnier, ditto

3 Paganini. ditto

4 Charles X., ditto

5 Pilot, T. Whalley

6 Lord Crewe, J. Bedson

7 Surpass Catafalque, T. Whalley Feathered Byblocmens.

1 Bienfait, T. Whalley

2 Lewold, ditto

3 iVinner, T. Gibson

4 La Belle Narene, T. Whalley

5 Winifred, T. Chippendale

6 Ambassador, T. Whalley

7 Duchess of Lancaster, $T$. Whalley Flamed Bybloemens.

1 Bienfait, T. Chippendale
2 Violet Cook, $\mathbf{T}$. Chippendale

3 Davis's Queen Charlotte, ditto

4 La Belle Narene, ditto

5 Gigantum, ditto

6 Pucella, R. Birtwistle

7 Incomparable, ditto Feathered Roses.

1 Comte, ' $\Gamma$. Gibson

2 La Belle Nanette, T. Chippendale

3 Crewe, T. Whalley

4 Hero of the Nile, T. Gibson

5 Andromeda, R. Birtwistle

6 Dolittle, E. Hodgson

7 Newcastle, T. Chippendale Flamed Roses.

1 La Vandicken, T. Gibson

2 Aglaia, T. Whalley

3 Lady Crewe, T. Chippendale

4 Bell's Best Rose, T. Whalley

5 Vesta, ditto

6 Unique, T. Chippendale

$7 \mathrm{Du}$ Roy, T. Whalley

Breeders.

I Seedling, T. Chippendale

2 Kate Connor, ditto

3 Polyphemus, ditto

\section{GREAT NORTH CHESHIRE TULIP SOCIETY.}

The fifth annual exhibition was held at Mr. John Shepley's, Sportsman's Inn, Hyde, May 30 . The judges were Mr. R. Taylor and Mr. W. Bentley.

A silver cup, value $£ 5$ 8s. was awarded to J. Peacock, for the best pan of six rectified flowers, viz. Charles X., Charles X., Bienfait, Bacchus, Alpha, and Triomphe Royale. 2nd. Surpass Catafalque, Polyphemus, Lewold, Incompara ble, Jupiter, and Aglaia.

Maiden Prize - Charles X., Z. Peacock, Esq.

Feathered Premier - Charles X., J. Turner, Esq.

Flamed Premier, - Polyphemus, J. Sidley. Feathered Bizarres.

1 Charles X., J. Turwer, Esq.

2 Magnum, J. Thorniley

3 Surpass Cataf 1 lque, J. Sidley

4 Lord Melbourne, I. Peacock

5 Waterloo, $\mathrm{H}$. Parsonage

6 Paul Pry, G. Green

7 Duke of Devonshire, J. Sidley

8 Duke of Richmond, R. Peacock, Esq. 8 Charles X., J. Sidley

Flamed Bizarres.

1 Polyphemus, J. Sidley

2 San Joe, I. Mather

3 Pilot, W. Peacnck, Esq.

4 Duke of Devonshire, G. Green

5 Albion, J. Thorniley, Esq.

6 Lustre, T. Leech

7 Surpass Catafalque, R. Peacock, Esq. 
Peathered Byblomens.

1 Bienfait, W. Peacock, Esq.

2 Sir H. Pottinger, ditto

3 Lancashire Hero, I. Mather

4 Edgar, I. Naylor

5 Baguet, ditto

6 Lewold, J. Sidley

7 Apollo, I Naylor

8 La Belle Narene, ditto

Flamed Byblomens.

1 Sable Monarch, S. Ardem, Esq.

2 Flora, W. Peacock, Esq.

3 Bienfait, R. Peacock, Esq.

4 Violet Wallers, G. Green

5 Incomparable, J. Sidley

6 Alexander Magnus, ditto

7 Grace Darling, I. Peacock

8 Baguet, W. Peacock, Esq. Feathered Roses.

1 Jupiter, J. Sidley

2 Lady Crewe, I. Mather

3 Comte, J. Turner, Esq.

4 Alpha, I. Peacock

5 Heroine, I. Mather

6 Newcastle, R. Peacock, Esq.

7 Seedling, I. Wilde

8 Little, I. Buckley

Flanned Roses.

1 Unique, W. Peacuck, Esq.

2 Triomphe Royale, I. Shepley
3 Aglaia, W. Peacock, Esq.

4 Vesta, ditto

5 Guerrier, I. Buckley

6 Vainqueur, I. Mather

7 Thalestris, I. Naylor

8 Hill Du, R. Peacock, Esu. Bixarre Breeders.

1 Charbonnier, R. Peacock, Esq.

2 Hamilton, I. Peacock

3 Grace Darling, H. Parsonage

4 Athelstan, T. Leech

5 Unknown, I. Shepley

6 Seedling No. 6, I. Peacock Byblaemen Breeders.

I Sancta Sophia, J. Turner, Esq.

2 Princess Royal, W. Peacock, Esq.

3 Unknown, H. Parsonage, Esq.

4 Rubens, W. Peacock, Esq.

5 Countess of Blessington, $\mathbf{J}$. Turner

6 Countess of Blessington, J. Sidley

Amelia, T. Leech

2 Juliet, 1. Naylor

3 Gibbons, W. Peacock, Esq.

4 Ditto, ditto

5 Newcastle, T. Leech

6 Lady Jane Grey, I. Mather Selfs.

Min d'Or, 1. Buckley

White Perfection, J. Sidley

\section{GREAT SOUTH "LANCASHIRE TULIP SOCIETY.}

The twentieth annual exhibition was held at the Nottingham Castle Inn, Denton, June 6. The Judges were Mr. R. Taylor, Glodwick; Mr. W. Bentley, Royton; and Mr. W. Alsup, Stockport.

A silver cup, value $£ j$, was awarded to $\mathrm{IV}$. Matley, for the best pan of $\varepsilon$ ix rectified flowers, namely, Charles X., San Joe, Bienfait, Bienfait, Lady Crewe, and Triomphe Royale.

Best Pan of Breeders.-Duke of Hamilton, Van Amburgh, and Anastasia, J. Naylor.

Maiden Prize.-Queen of the North, Z. Peacock, Esq.

Feathered Premier.-Polyphemus, H. Parsonage.

Flamed Premier.-Violet Wallers, J. Sidley

Breeder Premier.-Nimrod, J. Naylor.

Feathered Bixarres.

1 Polyphemus, H. Parsonage

2 Sidney, W. Matley

3 Charles $\mathrm{X}$., ditto

4 Lord Lilford, .J. Turner, Esq.

5 Surpass Catafalque, J. Sidley

6 Rufus, J. Turner, Esq.

7 Crown Prince, H. Parsonage

8 Paul Pry, W. Batty, Esq. Flamed Bixarres.

1 Charbonnier, J. Sicley

2 Polyphemus, R. Peacnck, Esq.

3 San Joe, ditto

4 Lustre, w. Matley

5 Charles X., I. Peacock

6 Surpass Catafalque, I. Shepley

7 Albion, W. Matley

8 Rufus, S. Ardern Feathered Byblomens.

1 Baguet, W Matley

2 Edgar, J. Turner, Esq.

3 Maid of Orleans, 1. Peacock

4 Bienfait, J. Naylor
5 Catherine, Z. Peacock, Esq.

6 Incomparable, J. Turner, Esg.

7 Harrington, J. Naylor

8 Washingtor, ditto Flarned Byblomens.

1 Violet Wallers, J.Sidley

2 Bienfait, I. Peacock

3 Alexander Magnus, W.Peacock, Esq.

4 Van Amburgh, T. Leech

5 Lord Vernon, J. Naylor

6 Incomparable, J. Sidley

7 Grotius, S. Ardern

8 Roi de Siam, ditto Feathered Roses.

I Heroine, J. Naylor

2 Lady Crewe, 'T. Leech

3 Alpha, I. Peacock

4 Arlette, W. Peacock, Esq.

5 Duke of Newcastle, J. Naylor

- 6 Amelia, ditto

7 Andromeda, W. Matley

8 Lady du Fayel, J. Naylor 
Flamed Roses.

1 Unique, W. Peacock, Esq.

2 Triomphe Royale, I. Peacock

3 La Vandicken, J. Sidley

4 Aglaia, ditto

5 Vesta, ditto

6 Queen Philippa, J. Peacock

7 Mason Matilda, W. Matley

8 Guerrier, R. Peacock, Esq. Bizarre Breeders.

1 Polyphemus, W. Matley

2 Duke of Hamilton, ditto

3 Seedling No. 9, I. Peacock

4 Cato, J. Sidley

5 Pilot, W. Matley

6 Lord Cobham, J. Turner, Esq.
Bybloemen Breeders.

1 Nimroc, J. Naylor

2 Gibbons, I. Peacock

3 Van Amburgh, J. Naylor

4 Seedling No. 27, I. Peacock

5 Britannia, ditto

6 Maid of Orleans, J. Naylor Rose Breeders.

1 Lady Stanley, W. Peacock, Esq.

2 Anastasia, W. Matley

3 Lady Leicester, I. Peacock

4 Alice, T, Leech

5 Alpha, Z Peacock, Esq.

6 Lady C. Gordor,, J. Turner, Esq. Selfs.

Min d'Or, W. Peacock, Esq.

White Perfection, J. Naylor

\title{
PINK SHIOW,
}

At Mr, Lewis Greaves's, Red Lion Inn, Newcastle-under-Lyme, July 3.

Judges.-Mr. H. Penson, Hanchurch, near Trentham, and Mr. D, Brown, Newcastle-under-Lyme.

Purple-laced.

Premier.-_'laylor's Mango, H. Eaton

I Jones's Huntsman, ditto

2 Taylor's Mango, ditto

3 Bradshaw's Greensides, R. Moorley

4 Faulkner's Duke of St. Albans, H. Bradshaw

5 Pearson's Professor. R. Moorley

6 Beauty, H. Bradshaw

7 Slater's Lady A ntrobus, R. Moorley

S Kay's Advancer, ditto

9 Seedling. W. Griffiths

10 Norris'sBlackeyed Susan,H.Eaton Red-laced.

Premier.-Etchell's Susanna, W. Griffiths

1 Lee's Joseph Sturge, ditto

2 Etchell's Susanna, ditto

3 Williams's Thirsa, E. Barker

4 Jackson's Criterion, H. Eaton

5 Unknown, H. Bradshaw
6 Brundret's Sir William,R.Moorley

7 Parker's Dr.Hepworth, W. Griffiths

8 Slater's Lady Antrobus, R.Moorley

9 Pearson's Professor ditto

10 Unknown, H. Bradshaw

Black and White.

Premier.-Millman's Lillia, R. Moorley

1 Ditto, ditto

2. Bradshaw's Margaret, E. Barker

3 Millman's Lillia, ditto

4 Kay's Mary, R. Moorley.

5 Fairbrother's Beauty of Blackburn, W. Griffiths

6 Whalley's Beauty of Clayton, $R$. Moorley

7 Norris's Blackeyed Susan, ditto

8 O'Brien's Virgin Queen, W. Griffiths

9 Parry's Union, H. Bradshaw.

10 Smith's White Rose, ditto

\section{MIDLAND HORTICULTURAL SOCIETY.}

\author{
At the County Hall, Derby, August 4.
}

Judges.-Mr. J. F. Wood, F.H.S., of the Coppice, near Nottingham, and Mr. Charles Turner, F.H.S., Royal Nursery, Slough.

\section{ROSES.}

Best Twelve Cut Bunches.-Jacques Lafitte, Souvenir de Malmaison, Earl Talbot, Reine des Fleurs, Duchesse de Montpensier, General Cavaignac, Madame Verdier, Dupetit Thouars, Geant des Batailles, General Negreier, and Paul Joseph, Mr. Allestree

Best Twelve Single Blooms.-Baronne Prevost, Souvenir de Malmaison, La Reine, Devonensis, Duchesse de Galliere, General Cavaignac, Duchesse de Montpensier, Dupetic Thouars, Madame Trudeaux, Geant des Batailles, and Reine des Fleurs, Mr. Allestree. 


\section{CARNATIONS.}

Six Blooms - - Fl. Flora's Garland, Premier, Lorenzo, Cradley Pet, Admiral Curzon, and Lord Milton, Mr. Dodwell. 2. Black Diamond, Prince Arthur, Lord Milton, Premier, Admiral Curzon, Hero of Middlesex, Mr. J. Fisher. 3. Five seedlings and Lord Milton, Mr. J. Bayley. 4. True Briton, Jenny Lind, Lord Milton, Premier, Lady Ely, Admiral Curzon, Mr. Merryweather. 5. Seedling, Squire Trow, seedling, Lady Gardiner, William IV., Brutus, Mr. W. Parkinson.

Best Flower of any Class.-Admiral Curzon, Mr. Dodwell.

Scarlet Bizarres.

] Admiral Curzon, Mr. Dodwell

2 Ditto,

3 Seedling, ditto

4 Sir Joseph Parton, ditto

5 Duke of Sutherland, ditto

6 Spleudid, Mr. Merryweather

Crimson Bizarres.

- Lord Milton, Mr. Dodwell

2 Ditto, ditto

3 Ditto, ditto

4 Black Diamond ditto

5 Ditto,

6 Ditto,

Pink Bizarres.

ditto ditto

1 Princess, MIr. Dodwell

2 Seedling, ditto

3 Lady of the Lake, ditto

4 Princess, ditto

5 Falconbridge, ditto

6 Lady of the Lake, ditto
Purple Flakes.

1 Premier, Mr. Fisher

2 Perfection, Mr. Dodwell

3 Premier, ditto

4 Bealty of Woodhouse, ditto

5 Premier, ditto

6 Miss Thornton, Mr. Merryweather Scarlet Flakes.

1 William IV., Mr. Dodwell

2 Seedling, Mr. Bayley

3 Firebrand, Mr. Dodwell

4 Cradley Pet, ditto

5 William IV., Mr. Merryweather

6 Cradley Pet, Mr. Dodwell

Rose Flakes.

1 Seedling, Mr. Bayley

2 Magnificent, Mr. Dodwell

3 Lady Ely, Mr. Merryweather

4 Seedling, Mr. Bayley

5 Lorenzo, Mr. Dodwell

6 Lovely Ann, ditto

\section{PICOTEES.}

Six Blooms.-1. Mrs. Norman, Alfred, Prince of Wales, Venus, Mrs. Barnard, Green's Queen, Mr. Dodwell. 2. Elizabeth, Venus, Duke of Rutland, Mrs. Turner, Mrs. Barnard, Seedling No.7, Mr. Bayley. 3. Prince of Walex, Mrs. Barnard, Alfred, Venus, Elizabeth, Gem, Mr. Fisher. 4. Elizabeth, Alfred. Lady Franklin, Mr. Barnard, Green's Queen. Mrs. Wood, Mr. Mierryweather. 5. Princess Alice, Prince of Wales, Isabella, Youell's Gem, Mrs. Barsard, Northampton Bride, Mr. WV. Parkinson.

Best Flower of any Class.-Mrs. Norman, Mr. Dodwell.

\section{Heavy-edged Red.}

I Julio Romauo, Mr. Dodwell

2 Mrs. Noiman, ditto

3 Prince of Wales, ditto

4 Mrs. Norman, ditto

5 lizabeth, ditto

6 Prince of Wales, ditto

$$
\text { Light-edged Red. }
$$

1 Prince ot Wales, Mr. Parkinson

2 Gem, Mr. Dodwell

3 Ditto, ditto

4 Ditto, Mr. Parkinson

5 Ditto, Mr. Dodwell

6 Ditto, ditto

Heavy-erlged Purple.

1 Alfred, Mr. Merryweather

2 Alfred, Mr. Dodwell

3 Lady Harriet Moore, ditto

4 Alired, ditto

5 Alfred, Mr. Merryweather

6 Lord Nelson, Mr. Dodwell
Light-edged Purple.

1 Ophelia, Mr. Dodwell

2 Lady Franklin, Mr. Merryweather

3 Ophelia, Mr. Dodwell

4 Alfred, Mr. Fisher

5 Lorina, Mr. Dodwell

6 TVilloughby, ditto

Heary-edged Rose.

1 Venus, Mr. Dodwell

2 Venus, Mr. Fisher

3 Queen Victoria, Mr. Dodwell

4 Venus, ditto

5 Grace Darling, ditto

6 Seedling, ditto

Light-edged Rose.

1 Mrs. Barnard, Mr. Dodwell

2 Ditto, AIr. Fisher

3 Ditto, Mr. Dodwell

4 Ditto, ditto

5 Ditto, ditto

6 Ditto, Mr. Parkinson 


\section{GRAND "TOWNS" EXHIBITION.}

Judges.-Mr. J. F. Wood, F.H.S.; Mr. Charles Turner, F.H.S.; and Mr. John Rhodes, of Leeds.

\section{TWELVE DISSYMILAR CARNATIONS.}

1. Denky.-Seedling (S.B.), Flora's Garland, Premier, Firebrand, Lorenzo, Lord Milton, Admiral Curzon, Magnificent, Cradley Pet, Princess, Squire Meynell, seedling.

2. Brrmingham.-Premier, Lord Rancliffe, Brisies, Admiral Curzor, Ariel, Miss Thornton, Pollington, Lydia, Black Diamond, Lord Lewisham, Lady Rhodes, Lovely Ann.

3. Nottrngham.-Taylor's Lucia, Hale's Albert, seedling, Lady Peel, Earl of Leicester. Falconbridge, Admiral Curzon, Lord Ryron, Lord Milton, Lady, Gardiner, Firebrand, Oberon.

4. LEeDs.-Lord Milton, Magnificent, Great Northern, Rainbow, Firebrand, Ariel, William IV., Lady Ely, Rose Helen, Admiral Curzon, Paul Pry, Justice Shallow.

5. YoRK.-Miss Thornton, Lord Rancliffe, William IV., Admiral Curzon, Ariel, Knowsthorpe Pet, Lydia, Briton, Splendid, Rainbow, Squire Meynell, Brilliant.

6. WAKEFIELD.-Seedling No. 2. Beauty of Brighouse, Admiral Curzon, Lady of the Manor, Hepworth's Leader, Lord Rancliffs, Nulli Secundus, seedling, Lord̉ Milton, seedling, Squire Meynell, Patriot.

7. Leicester.-True Briton, Duke of Rutland, Prudence, Earl of Leicester, Gladiator, Brisies, Black Diamond, Squire Meynell, Lorenzo, Hamlet, Queen of Purples, Princess Royal.

A fine stand from Edinburgh was disqualified, containing a self petal.

TWELVE DISSIMILAR PICOTEES.

1. Derby.-Mrs. Norman, Duke of Rutland, Ganymede, Green's Queen, Mrs. Barnard, Venus, Alfred, Ophelia, Bayley's Seedling, Mary, Prince of Wales, Isabella.

2. Birmingham.-Audrey, Prince of Wales, Alfred, Green's Queen, Elizabeth, Mrs. Brown, Duchess, Delicata, Venus, Amethyst, Mrs. Barnard, King James.

3. YoRk.-Alfred, Green's Queen, Lady Franklin, Miss Rosa, Ked Rover, Mrs. Wood, Elizabeth, Portia, Delicata, Mary Ann, Mrs. Barnard, King James.

4. Notтingham.-Princess Royal, Elizabeth, Juliet, Green's Queer, Gem, Lord Nelson, Prince of Wales, Duke of Rutland, Enchantress, Alfred, Isabella, Mrs: Barnard.

5. Leeps.-Mrs. Barnard, Elizabeth, Lady of the Lake, Prince of Wales, Regina, Ann Schofield, Alfred, Christabel, Cerise Blanche, Mrs. Norman, Duke of Rutland, King James.

6. Lercester.-Prince of Wales, Duke of Rutland, Nina, King James, Lord Nelson, Youell's Gem, Bates's Seedling, Mrs. Norman, Prince Albert, Jenny Lind. 


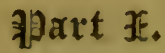 \\ ORIGINAL CONINUNICATIONS.

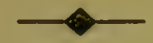

DESCRIPTIVE REIIARKS ON ABOUT ONE HUNDRED VARIETIES OF THE TULIP.

TAKen DURING the Blooming Season of 1852.

BY MR. WM. HARRISON, SECRETARY TO THE FELTON UNION OF FLORISTS AND HORTICULTURISTS.

[Continued from page 232.]

BYBLCEMENS.

Tiolet Superb. - This possesses a fine cup, and is a finely fiamed flower; it is, however, a little creamy at opening, but soon bleaches.

Morris's Light Cup.-A lovely delicate flower, cup and stamens perfectly pure, with slight feather and flame. A truly beautiful variety.

1.awrence's Friend.-This is a grand acquisition to any bed, its heavy black feather and slight flaming on a snowy white ground, rendering it a striking object in any collection.

1.e Grand Monarque.-This is another beautifully pure and clear flower, fine cup and bold black anthers, and slightly feathered and flamed with a fine rosy purple. It is a real gem, and should be in every bed.

Imperatrix Florum.-This is a very prettily-feathered flower with me, and sometimes a little flamed. Stamens quite pure, feather very dark purple, and petals a little pointed at the top, but still a very fine flower.

Buckley's Beauty.-This possesses a good cup and beautiful feather, but the bottom cannot be said to be quite pure.

Triomph de Lisle.-This is really a fine old byblœmen, possessing a fine cup, perfectly pure, and feathered and slightly flamed with nice violet. It still ought to be generally cultivated.

Holmes's King.-If every one get his due, this must be considered a lovely delicate flower, and fit for a place in any bed, especially among the heavily-flamed varieties, for the sake of contrast. I can conceive nothing prettier than itis, wi h its snowy bottom, its pretty pale pillar, and branches, and its OCTOBER-VOL. VI. 
fine cup, when planted near such heavily-flamed flowers as George Glenny, Lawrence's Patty, or Duke of Northumberland, for certainly it then appears truly beautiful, and, in my opinion, ought to be in every bed. Sometimes it feathers also, but this is very poor.

Roscius possesses a fine short cup, with a fine feather and flame, but the bottom is not quite pure.

Young Roscius is finer than the foregoing, but still the bottom will scarcely bear the scrutiny of the present day.

Gibbons's Queen of the Violets is a large noble flower, feathered and flamed with a rich dark purple. It is one of the best Chellastons that I have seen.

Ambassador is a very fine low-cupped flower, with a rich dark purple feather, and no flame. It is a little creamy, but bleaches out.

Glenny's Duke of Northumberland.-This variety possesses a model of a cup, and is generally heavily feathered and nicely flamed with a rich dark glossy purple, on a snowy white ground. It is a diamond of the first water, and ought to be in every collection. Nearly the whole of the stock of this flower is in the hands of Mr. Bromfield, of Felton Mills, who bought it some years ago. A bloom of this byblomen was suhmitted to Mr. Wood, in 1851, who truly said that "it would please anybody."

Duke of St. Albans. - A southern flower. A very distinct byblomen, the marking generally a slight beam, with a fine feather of dark purple. An extra fine flower.

Violet Alexander. (Barr's strain.)-A finely-cupped flower, slightly flamed and feathered with lightish pus ple. A sweet and delicate variety.

Violet Quarto (the finest strain of Violet Alexander.) -This is a most beantifully.feathered flower, the feathering finely pencilled round the top of the petals with a lightish purple. It is one of the most beautifully feathered bybloemens that I have as yet seen.

David. - The feathered strain of David is a real gem. The cup is grand, the bottom pure, and the fine solid feather nearly black. This strain is rare and valuable, and is bad to fall in with. Mr. Uromfield's was very fine this season.

Reid's William Tell. - A clean but long-cupped flower, pillared up the middle of the petal, with a fine slight feather of darkish purple.

Malibran-This is a beautiful flower indeed, feathered and slightly flamed with a very dark glossy purple, almost black, on a fine white ground.

Lawrence's Patty.-This is a very grand fourth-row flower, finely feathered and regularly flamed with a nice rosy purple. A grand acquisition as a middle-row flower, and ought to be in every good bed. 
Superb en Noir.-A fine clean flower, heavily flamed with a dark rich glossy purple. A very desirable variety.

Godet Parfait. - A fiower of Dutch origin. A finely-flamed flower, rich dark feather and pillar, but the bottom creamy and difficult to bleach.

Smith's Sir Robert Peel bloomed here heavily flamed, but quite blue in the bottom of the cupl, although favourably noticed in some of the periodicals last year. Stamens pure.

Reid's Prince Albert is a very magnificent blyblœmen, finely feathered and flaned, perfectly pure, and the marking a brownish purple. This, as it bloomed at Felton Milis, last year, seems a very grand variety.

Holmes's Lalla Rookh.-This seems a very distinct, and attractive variety, with an exceedingly delicate feather and very little flame, on a ground of uncommon purity. It is a most attractive flower, and should be more generally known. Cup tine.

Slater's Sir Henry Pottinger.-This is a very fine delicate-looking flower, with fine pencilled feather and little flame. A very delicate and desirable flower.

Zuill's George Glenny. - A very clean and fine variety, pillared and imperfectly feathered and flamed.

Reid's Flora Mac Ivor.-A fine feathered byblømen, perfectly clean, and very beautiful.

Gibbons's Princess Royal. - Fine pure bottom, large cup, evidently lightly marked, but much overrun with breeder here, this year.

Ellis's Lord Blomfield.-A rich noble-looking flower, finely feathered and flamed with rich dark purple. Bottom perfectly pure, and cup fine.

Reid's Macdonald.-A very fine byblomen, with a broadish feather and very little flame. This stands in bloom a long time, and is very beautiful.

Gibbons's Countess of Harrington.-A very finely-shaped petal, with slight feather and flame. A pretty and clean flower.

Bijou de Amateurs.-A very pretty variety, finely feathered and slightly flamed, perfectly pure, and in every respect fine.

Gibbons's Prince Albert.-A large fine feathered and flamed byblomen, marking rich purple, but the bottom rather creamy.

Addison is always fine, and a star of the first magnitude, with his grand cup, snowy ground, and dense broad black feather. What can equal it except the best strain of David?

Gibbons's Van Amburgh.-This seems a really fine flower, with a fine bold feather, pillar, and grand pencilling in the flame. The marking very extra, as grown here this year.

Gibbons's Elegance.-A fine rich dark feather, and perfectly pure. A beautiful and noble flower.

Gibbons's Midland Beauty has rather a long petal, but fine rosy brown feather, cup quite clean, and, although long in the cup, is an attractive variety. 
Bromfield's Mrs. Bromfield.-This is a very beautiful and delicately-marked flower, the feathering slight and of a fine dark purple, the ground colour exceedingly pure through all its stages, and the cup fine. This flower is a decided and valuable acquisition. It broke some years ago, and the whole stock is in the raiser's hands.

Headly's Director.-A noble-looking flower, finely feathered, and a pillared flame; cup perfectly pure, colour a dark pur ple, and white fine.

Reine de Sheba. (Tyso's strain.)-This is one of the most lovely gems that I have yet seen. When opening, it seems both narrow and creamy, but after it gets open, it forms a handsome cup, the little yellow in the bottom soon bleaches out, and becomes as pure as snow. This, surrounded by a pale lilac feather, renders it a real gem, and no bed should be without it. This fine strain, however, is tender, and does not thrive well so far north as Northumberland.

Gibbons's Chellaston Beauty. - This broke with me last year, and is a very fine feathered byblœmen, good cup, perfectly clean, and a heavy feather round the top of the petals.

Prince Elie.-This variety is gexerally very finely marked, the feather and flaming being nearly perfect, and the cup fine, but the bottom not quite pure.

Constant is a very beautiful byblœmen, finely feathered and slightly flamed. It needs no bleaching, being as pure as satin, and fit for any exhibition in the kingdom, the moment it expands. Like some other fine sorts, it is a very shy propagator, so that the stock of it increases but slowly.

Louis $X V I$. - We cannot do better than close this long list, for the present, with Mr. Bromfield's new-broke strain of this old favourite. It is a grand feathered flower, and perfectly pure, both in the bottom and stamens, and finely feathered with a very dark purple, nearly black. This strain is truly beautiful, and very rare.

\section{ROSES.}

Rose Triomphe Royale.-An old favourite. Pure bottom, good cup, and generally feathered and flamed. One of the best show flowers extant.

Rose Amadis.-Like Triomphe Royale, and supposed by many to be the same, but the flame generally much heavier.

Globertine.-Something similar to the foregoing, but more lightly flamed.

Minerva.-This is a real gem, perfectly pure in every respect, very delicately feathered with a fine pillared flame. Totally distinct from all others, and truly beautiful.

Grand Rose Imperial.-A very good-cupped flower, feathered and slightly flamed with very dark rose; rather creamy at opening, but soon bleaches out. 
Comte de Vergennes.-A fine pure middle-row rose, generally beautifully feathered, but the shape of the cup only indifferent. Aglaia.-A fine clean flower, generally finely feathered, and a distinct pillared flame. Quite distinct from the Triomphe Royale tribe, and a lovely flower.

Cerise Triumphant. - A very grand, clean, feathered and slightly flamed rose, very beautiful indeed, and supposed by many to be a fine strain of Triomphe Royale.

Lilas Rose.-A very fine pure flower, generally feathered, with little or no flame. It is a pure and attractive flower, and similar to the foregoing.

La Vandicken.-A perfectly pure and good-cupped flower, but very irregularly feathered and flamed with a purplish rose colour. From several years' experience of the flower, I shculd say that it is a very uncertain variety.

Lady C'r we (Lawrence's fine strain.) - Whatever may be said of this fluwer, it is perfectly pure in the bottom, and a beautifully feathered variety, but the stamens are a little stained at the top.

Claudiana.-This is an old-established favourite, and highly esteemed by some, though it is a most uncertain Hower with me. The character of the flower is a fine cherry feather, but I have grown it for about ten years, and must say that I have never had it in showable trim yet. On looking over ali the tulip meetings reported in the Midland Florist, this season, it seems only to have won twice, viz., at Burslem and Butley, which surely does not say much for it as an old, well.circu. lated variety; while at the Manchester meeting, where one might have expected to have found it first-rate, it seems to have stood as low in the estimation of the judges as it does in mine, for it did not win at all, apparently. Well may the floral luminaries of the day, then, agree with me, and in their writings describe it as " a sporting variety."

Glenny's Grand Rose.-The correct name of this is uncertain, but it is a lovely thing, being feathered and slightly flamed with a fine blood red, on a beautiful white ground. The bottom is a little creamy at opening, but it soon bleaches quite pure. It is quite distinct from the Triomphe Royale family, and a valuable acquisition to any bed.

Rosa Bianca.-.. The finest strain of this is very grand indeed, quite a bold rosy feather, on a brilliant white ground, and cup as pure as snow. Sometimes it is a little flamed also, but in either character it is a grand middle-row rose.

Heroine.-A lovely gem indeed, perfectly pure, with as near a perfect feather as possible, and a splendid cup. It is certainly a grand feathered rose, and wherever plentiful, must always win.

Chellaston No. 17.-This I broke from the breeder last year. It is rather long in the cup, and requires hot weather to get 2 F 2 
it open, but is beautifully and heavily feathered with a fine darkish scarlet, and much freckled or ponncy on the outside of the petals. Will any of the growers of the Chellastons give me its correct name? Its stem is weak, and it generally droops.

Zuill's Mrs. Waterston.-This is a beautiful flower, with a fine cup, slightly feathered and flamed, but the bottom is only middling, and the stamens stained at the top.

Zuill's Flora. - This is an exceedingly fine rose, beautifully feathered, and dies off a bybloemen.

Zuill's Mary Lamb. - A rich coloured looking flower, heavily feathered with darkish scarlet, and perfectly pure, but evidently too long in the petal, and upon the whole, no acquisition for strict competition.

Zuill's Mrs. Zuill._A fine-feathered and heavily-flamed flower; a very distinct and pretty variety.

La Belle Nanette. A $\mathrm{A}$ grand feathered flower, this year, in $\mathrm{Mr}$. Bromfield's bed, and as pure as the strictest judge could wish. It is equal to any Heroine that ever was grown.

Clark's Portia.-This is another beautifully-feathered rose, but very little known in the north. It possesses a fine cup, with a beautiful dark rosy feather, and cup perfectly pure.

Gibbons's Anastasia was a very finely-feathered rose with me, last year, but this year has been irregularly flamed.

Arlette.-'The first time I saw this, it was newly-broke, in Mr. Bromfield's bed, and was in every respect perfect. The cup was fine, the bottom pure, and the feather splendid, and without a fault. When in this state, it may safely be pronounced first-rate.

Cerise Blanche.-This is another beautifully-feathered rose, and in every respect clean and fine.

Dutch Ponceau is another very grand rose, fine delicate feather, petals wide at the top, forming a fine wide cup, bottom pure, and altogether first rate.

Madame Vestris. - Last, though not least, comes Madame Vestris, one of the most beautifully-flamed roses known. It is in colour quite distinct from the Triomphe Royale family, and is generally finely feathered and flamed. The anthers are rather nieagre, but the cup pure and fine, and no amateur can grow too many roots of Madame Vestris.

Having now trespassed very considerably on your space this season, I shall take my leave of "s the Queen of the Garden," for the present; and if these notes, which, I must repeat, were carefully taken, should be the means of assisting young amateurs in their future purchases, I shall be amply repaid. I find that there are many favourite varieties omitted, 
but these may form the subject of a future article, next year. And now, Mi. Editor, thanking you for the space which you hare kindly allowed me, I take my leave, and heartily wish you and your readers good-by.

West Thirston, near Felton, September 1, 1852.

\section{CULTIVATION OF THE POLYANTHUS.}

BY MR. S. HAMMOND, RADTORD, NEAR NOTTINGHAM.

[Continued from page 266.]

In a fortnight after planting, the surface of the burder should be stirred an inch deep, but not too near the plants, which must be pressed firmly all round, close and well up to the foliage, and more soil added, if any of the fibres are exposed. I wish particular attention to this, it being, in my opinion, a very important consideration. The latter end of this month, some long soft moss will be required, which, previous to being used, should be exposed on the hearth, to a brisk fire, an hour or two, and a little soot sprinkled all over it. The foliage of each plant must be gathered close together in the hand, and the moss put all round, pressing it firmly to the foliage, and of sufficient thickness to keep the plant perfectly upright through the winter. Provide a sufficient number of stakes, a foot long, and an inch thick, and the same number of pieces of glass, four inches square, to allow one of each to a plant. The stakes must be pointed at one end, and a saw-gate cut twothirds through at the other end, or top, in which to fix the piece of glass. The stakes must then be pressed down three inches from the plant, in a slanting direction, so as to bring the centre of the glass directly over the heart, and let them remain through the winter, which will prevent wet lodging in the hearts, and be a great protection from frost. This completes, for the present, the simplest and best mode of cultivation for small growers, of which I 
believe there are many, who have neither time nor convenience to grow for exhibition, but nevertheless feel interested in cultivating a few, for their own private amusement. To such I can confidently recommend it as being equal to the more expensive and troublesome mode of pot cultivation, with one exception-they will probably be from a week to ten days later in blooming.

I shall now attempt to give a few hints on pot culture, which are quite late enough, and where any plants have been left for potting, they ought not to be deferred beyond the first week in this month. Having grown polyanthuses nearly thirty years, I find the best of all time for propagating, is the last week in July and the first week in August; and for potting, or getting them into order, from the middle to the end of September. If examined, on taking them up for propagation, at the period above stated, each heart will be found to have formed for itself a new joint, or base, from which fresh fibres are produced, and the main root almost fibreless, and fast approaching decay. The main root must be removed, hy taking hold of the lower end and turning it upwards till it breaks off, which, if the new root is properly matured, will be at the above-named joint, and is far preferable to cutting. I find them to succeed much better in pots after having six or eight weeks' growth in the border; then potting them when divided, and choosing the strongest and best plants for that purpose. In potting, I use fresh fibrous loam, and would, if convenient, have it cut not more than three weeks previous to using it. It should be well broken up, and laid on a board or mat, and exposed to the sun. After being well divided, a moderate quantity of charred vegetable matter, or wood ashes, may be added, and well rubbed together. In a fortnight, if kept dry, it will be fit for screening. I also use decayed cow manure, mixed with oneeighth of charred vegetable matter, and one-eighth of shingle, or coarse grit sand, exposed and prepared in the same manner as the loam, but kept separate 
until potting commences, which may be proceeded with in the following manner :-First place an oyster shell hollow side downwards, and resting on a few bits of broken pot, to ensure free drainage; then lay some pieces of rotten stick, broken small, crossways, about an inch thick, and a thin piece of fibrous turf over them; then add full two inches in thickness of the manure. In putting in the loam, form it much the highest in the middle, and regularly sloping to the sides. Observe the height required to bring the lower tier of leaves to within an inch of the top of the pot, when finally planted. Then take the plant, carefully dividing the fibres, so as to be equally distributed all round, place it in the centre, and fill up with loam, pressing it firmly, till within two inches of the top. Finish with one inch of fresh light soil, leaving, from the surface to the top of the pot, one inch clear space, which will be required hereafter. Place them in the shade, and give a moderate watering daily, for a fortnight, should the weather prove dry, when they may be allowed the morning sun until November, when further particulars will be given, as to wintering, \&c.

To those who have not yet made their selection, I would recommend the following, where only a dozen are required, as being certain to give satisfaction :-

Hufton's Lord Lincoln

Hufton's Traveller

Hufton's Earl Grey

Addis's Kingfisher

Ollier's Cheshire Favourite

Barrenger's Prince of Wales
Buck's George IV.

Bullock's Lancer

Crownshaw's Exile

Pearson's Alexander

Brown's Freebloomer

Nicholson's King

DESCRIPTIVE LIST OF HYACINTHS.

BY ALPHA.

No. II.

Auricula's Eye. (Single Blue.)-We have here a name appended, indicating something strikingly attractive, and to the admirers of that beautiful flower, the auricula, doubly enticing; and if the substitution of novelty in colour is to 
be considered as an equivalent for its resemblance to the eye of that flower, I suppose we have no alternative but to accept it as such. However, as it is, the flower possesses a fine bold well-shouldered bell of dull dark plum or puce colour. It also has the merit of trussing well, but here our praise of it terminates. The bells are extremely pendulous, and consequently, to a certain extent, obscure the white tube of the flower, from which ridiculously faint resemblance, we suppose the idea of "auricula's eye" originated. It is of mediocre appearance, and does not warrant the price charged for it. It much resembles that old and well known variety, Emicus, but is of a different colour, and has a trifling advantage over that variety in the size of its bells.

Camper. (Single Blue.)-This is a very deserving flower, and although it does not truss equal to others of its class, has a strong claim to be kept in cultivation. It has well-formed bells of bright azure blue, and is a vigorous grower, when grown in glass. Its colour is a delicate pale azure.

Charles Dickens. (Single Blue.)-This is a flower of modern introduction, and is one of those varieties in which the point of size, in the eyes of the exporters, appears to take the precedence of the usual standard points of excellence. It is a bold-trussing flower, the colour bright blue; the bells, however, are too long, and the footstalks project further than is desirable. . It is much in the style of Emilius and Lord Nelson, and appears in advance of those sorts only in the size of its flowers.

Diebitch Sabalskansky. (Single Red.)-The preponderating feature here is colour. When cultivated in water, it exhibits a most heautiful rose tirt, combined with density of truss; but when cultivated in the ground, it might readily be taken for another variety, as it then appears a bright cherry rose, and presents a striking contrast to the paler flowers. The bells are rather diminutive, and fall short of the required standard; its beautiful tints will, however, cause it to be cultivated for some time.

Garrick (Double Blue) is a flower that is not in general cultivation (judging from its name not appearing in several of the catalogues). It is a semidouble variety, of a dark lavender shade, and trusșes tolerably well. When at its best, it has a pretty appearance, but will not bear comparison with Blocksberg, and others approaching to the same colour.

Duchess de Parma. (Double Red.)-This is a common variety, selling at a moderate price, and generally produces a pretty truss of flowers. It is a late sort, possesses a good dark eye, and forms a pleasing diversity of colour. The bells stand out well in an horizontal position.

Gumal. (Single Dark Blue.) - Its colour, a resplendent indigo, is fairly described in the catalogues, and it seems to be a good trussing variety. The flower stem does not appear to 
rise well out of the ground, it has medium-sized bells, and is a very desirable flower.

Galitzin (Single White) is a meritorious sort. The bells are of fine form and good size, besides exhibiting great purity. It is rather deficient in trussing, yet is worthy of a place in select collections.

Gloria Florum Suprema. (Double White.)-Another flower maintaining a high price. It is a late blooming sort, producing bells below the average size, rather starry in appearance and not reflexing well. The colour is a waxy white, and it has an exceedingly attractive mulberry-coloured centre; the bells stand out horizontally from the stem, but are too far apart, and in consequence, the truss does not produce a good effect. It is evidently not up to the mark as a class A flower, which the price seems to indicate, although, for effect, it may be safely introduced into any collection.

Johana Christina. (Single Red.)-This is a pleasing variety; at first opening it is a pale pink, slightly shaded with orange, which soon disappears and is succeeded by a deeper shade of colour, when it becomes an attractive flower. It is a fair trusser, and only loses ground in the size of the bells.

La Belle Africane. (Single Black.) - A dark indigo of sombre appearance, with but indifferently formed bells, narrowing excessively below the shoulder. It may be kept for contrast in colour, but is deficient in general good properties, although the bells are larger than many others in this class.

La Guirlande. (Double Red.)-This variety has been extolled as a fine flower, far beyond its merits. It is in the style of Waterloo, but inferior to that sort in trussing. In colour alone it takes the precedence, and is worth cultivating. It has the appearance of being a delicate sort.

Laaiy Sale. (Double Yellow) -An insignificant variety with which to perpetuate the name of this heroic lady. It is a semidouble flower, many of the bells presenting only an additional petal in the centre to remove it from the single class. I by no means recommend it for general cultivation.

Nimrod. (Single Blue.)-This, for glassing and growing in pots, is an estimable flower, the dense truss and bright colours secure it a place for general culture. A remarkable feature in this variety is the expansion of the bells before the truss has fully emerged from the foliage, and when the flower stem has only partially arisen; yet it ultimately throws its stem well up, and eventually becomes a very prepossess. ing sort.

Spheri Mundi. (Double White.)-A magnificent flower, of long standing, and worthy of an extended cultivation. I know of no flower having so pure a white, and in which pale blue florets, imparting a remarkably chaste appearance, are so delicately blended; unfurtunately, however, the bells are 
so pendulous, that to obtain a distinct view, the flowers must be held up. I think an artificial support might be devised, to remove the defect.

Victor Hugo. (Single Yellow.)-The yellows, as a class, are evidently very deficient, the majority are not clear yellow, but of a buff shade. This variety is an improvement on many of the sorts annually enumerated, yet is far from being a distinct yellow. It has medium-sized bells, standing out horizontally, the stem rises well above the foliage, and it deserves a place in any collection.

Each succeeding year confirms my opinion of the utility of descriptive lists, particularly with regard to the hyacinth; and should the trade feel annoyed at their flowers being closely criticised, they must also recollect that where a variety coming under notice is entitled to praise, it is not withheld. It may probably lead cultivators to select certain varieties, and so also in a corresponding ratio will the demand for sterling sorts be increased.

绿art JEE。

NEW, RARE, OR G00D FRUITS, FLOWERS, PLANTS, TREES, AND VEGETABLES.

THE following plants and flowers have received firstclass certificates, at the National Floricultural Society, during the present year :-

Countess of Ellesmere Camellia, - Of first-rate form, with large and broad petals; colour blush white, delicately striped with pink. Raised by Messrs. Jaskson \& Son, nurserymen, Kingstone.

Erica Jasminif Lora Rubra.-This beautiful heath has long rosy red tubes, produced profusely in large trusses.

Erica Tricolor EpsiI.-The tube short and stout, fine scarlet, shading to white. 
Banks's Glory Fuchsia.-The tube short, brilliant crimson, with very dark purple corolla; the sepals reflex well.

\section{HARDY PLANTS.}

Colchester Cardinal Pink.-Raised by Mr. I. Norman, of Colchester. This is stated to be by far the best of its class. Pod good, petal broad, smooth, and pure, well laced with purple.

Antirrhinum Modestum.-Cream-coloured tube, throat yellow, cup and lip regularly striped, a bold and fine flower. From Messrs. Garraway \& Mayles, Bristol.

Charles Lidyard Hollyhock. - Excellent form, with broad and smooth guard petals, and high and compact centre; colour rosy salmon.

Creali of the Valley Hollyhock.-A new and distinct colour (rich cream), with large, smooth, and well-formed flowers. Both from Mr. Bragg, of Slough.

Sir I. CathCart Pansy.-A fine and rich flower, raised by Mr. C. Turner, Royal Nursery, Slough. Deep yellow ground, with beautifully even bronze edging.

Fearless Pansy.—Raised by Messrs. Schofield \& Son, Knowsthorpe, near Leeds. Yellow ground, margined with dark purple. Of excellent form and substance.

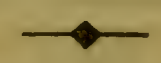

\section{THE EDITOR'S RECORD.}

"These things we would buy ourselves, and therefore recommend them."

Often, as our readers well know, we have adro. cated the propriety of amateurs devoting a certain space in their gardens for raising and blooming seedlings of every description of ornamental plants. Very many of the beautiful and improved races of OCTOBER-VOL. VI. 2 G 
plants have been raised in gardens belonging to the humble artizan, as well as the more wealthy amateur. In a former volume, we noticed a phlox of very peculiar and beautiful habit, raised from seed of the tall-growing $\mathbf{P}$. speciosissima. At that time, we thought that a very appropriate name would be P. speciosissima nana, owing to its diminutive stature, as it does not rise more than eighteen inches. It was raised by a well known florist in the neighbourhood of Nottingham, named Spencer, and in consequence, is by some called P. Spencerii. As it was not regularly sold out, but plants and cuttings of it given away, no emolument has arisen from it to the raiser. We are glad to find, however, that its beauty has been appreciated in the metropolis, for at a late meeting of the National Floricultural Society, it was exhibited in first-rate style, by Mr. C. Turner, of the Royal Nursery, Slongh, and gained a first-class certificate, which it certainly richly deserved, the truss of fiowers being extremely large, well formed and compact, fine rose colour, with a well-defined light centre. We are sure that our readers will thank us as much for bringing this plant under their notice as they did for making them acquainted with Delphinium magnificum.

There are yet two other seedling perennials raised here, which we must introduce into our Record, namely, Cheiranthus Daftii, a very decided improvement on the well-known and deservedly-appreciated Cheiranthus Marshallianus. It has more rounded and thicker petals, the colour being a rich dark orange, and is as delightfully scented as its progenitor. The other is Aquilega fragrans spectabile, a most beautiful plant. The flowers are round, thick, and of a most peculiar waxlike appearance; and instead of having the pendulons character of the parent, they stand erect, in the style of the double purple Aquilega Siberica. Both these, when attainable, will be appreciated by all lovers of perennial herbaceous plants. 
Frowers recerved since our last.-Purple Picotee, Purity.-H. I. D.-A really beautiful flower, most aptly named. Perfectly smooth petals, substance good, and the appearance of polished ivory, nicely and evenly margined with a bright tint of violet purple. No spot or bar perceptible.

Retrospective Criticisu.-Kate Connor and Guido TuliPs.-Mr. Slater, in his periodical for September, comments on these tulips. He says, having seen a flamed Kate, which was cut too young, that had it been a matured bloom, he believed there was not a rose tulip in existence that could bear comparison with it. Guido, except being pure, had all the faults of Edgar. Now I feel confident that had Mr. Slater been as favourably disposed towards Guido as he was towards Kate, he might with as much propriety have said, had Guido been matured, it would have been a byblœmen of the first order. I doubt not but the Kate referred to was grown in the same garden as Guido. Guido is quite short cupped, with thick fieshy petals, round on the top and smooth on the edges, ground pure white, feathered with a rich dark purple, almost approaching to black. I never had but two blooms of Guido, one in 1851, and the one referred to in the stand. Now had Mr. Slater have seen the matured bloom of 1851, his decision must have been vice versa.-SAML. Bromley, Macclesfield.

\section{EXTRACTS, HINTS, AND RECOLLECTIONS.

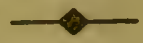

REMINISCENCES.

Anovgst other fruits which have highly pleased us this season is the Beurré de Capiaumont pear. Seven years ago, we planted in our orchard some pyramidal 
pears we had of Mr. Rivers, of Sawbridgeworth. Amonget them were Knight's Monarch, Brougham, Broom Park, Louise Bonne of Jersey, King Edward's, Beurré d'Aumalis, Easter Beurré, Beurré Rance, \&c. 'These were put in with a view of ascertaining how far the varieties were suitable for Nottinghamshire. Most of them have borne fruit this year, and in a future number, we hope to say something about them; but it is with the Beurre de Capiaumont we have now to do. We have planted the Hessel pretty extensively for a market pear, but the former variety has, this season, quite eclipsed it. Our two small trees (pyramids), not more than twelve feet from the ground to the topmost branch, have borne fifteen pecks of fine pears, which we have sold in Nottingham market, at three shillings per peck. The fruit was well distributed over the trees, and very good. We are so far satisfied with this variety, that we shall plant a row of seventeen across our pyramidal orchard, feeling certain that it will pay well.

Agnes Dahlia.-Our friend, Mr. Edwards, of Nuttall, near Nottingham, has raised a very nice white dahlia, named as above. The outline is circular, petal excellent, and colour good. Of course, it is not perfection, being rather low in the centre; but this is not the case with all the blooms. We understand the Nottingham Horticultural Society have awarded it a first-class certificate. Even with the drawback alluded to, we shall be surprised if it does not stand pre-eminent among the whites, next season.

Encouragement to sow Rose Seed.-We give the following extract from a communication from Mr. Willison, of Whitby, which accompanied a specimen of a beautiful dark purple, extremely double, and highly fragrant Bourbon rose :-_' I send you the present bloom, which is a strong-growing Bourbon seedling of 1851 , not only because it is promising, but on account of circumstances con- 
nected, and as a confirmation of what I have already stated, that if we are to expect really good varieties, we must breed from first-rate sorts. In the month of April or May, last year, when pruning a plant of Paul Joseph, I observed a deformed seed-vessel, and on examination, found one seed. I deposited this at once in a small pot. A few weeks after, the little plant raised a pair of 'cotyledons,' when very ready I was to wish it good speed to flowering. To a friend, a rose lover, when looking on with me, I remarked, "There, a sovereign would not buy that little thing with two leaves.' 'This appeared to him extravagant, but the flower sent (although an indifferent specimen), and a look at the plant, will show how far 1 was right or wrong in my expectations of it."

WEIGHT OF GOOSEBERRIES EXHIBITED DURING THE PAST SEASON, 1852.

RED.

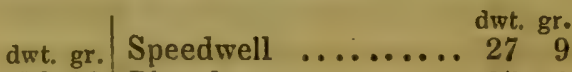

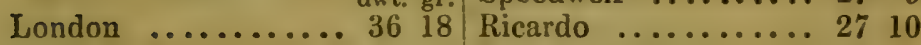

London .......... $37 \quad 7$ Red Seedling ........ 292

Companion .......... 3111 GREEN.

Conquering Hero .... 27 16 Thumper.......... 2813

Slaughterman ....... 30 0 Turnout .......... 2621

Wonderful ........ 31 0 Weathercock ....... 2812

Wagnet .......... 28 0 Gretna Green....... 2715

Dan's Mistake....... 298 Randonı Green ..... 2515

Lion's Provider ..... 2610 Green River........ 2522

Highlander........ 2723 Green Wonderful .... 2710

Lumper .......... $31 \quad 7$ Telegraph ......... 294

Flixtonia ......... $27 \quad 15$ Little Wonder....... 2813

Old England ....... 292 Tom Joiner........ 2711

Clayton .......... $28 \quad 18$ Queen Victoria ...... 266

Useful ........... 31 2 Overall........... 276

Banger........... 26 0 Brotherton ......... 2614

Monarch .......... 24 5 Great Britain ....... 2414

Fermley give it a Name 2720 General .......... 2714

Red Robin ........ 2810 Rough Green ....... 2719

Napoleon le Grand.... 2619 Dean Swift ........ 2320

King Cole .........26 26 Peacock ..........27 6 
dwt. gr.

Thunder .......... 260 Gipsy Jack .........23 1

Peover Ranger ...... 27 6 Morton Hero ........ 266

Sweepstakes ........ 2311 Hue and Cry (unsound) 284

Providence ......... 25 0 Golden Hero ....... 255

Green Prince ........ 254

YELLOW.

Catherina.......... $32 \quad 8$

Leader............... $27 \quad 3$

Lord Rancliffe.......27 12

Drill................. 28 i5

Peru............... $30 \quad 0$

Broom Girl......... 2812

Two-to-One......... $28 \quad 8$

Comet............ $26 \quad 4$

Pilot $\ldots \ldots \ldots \ldots \ldots .29 \quad 6$

Game Cock.......... 2814

Hue and Cry .......227

Go.by ............ 2512

Great Western ..... 2622

Oldham ........... 2523

Goldfinder $\ldots \ldots \ldots \ldots 26 \quad 16$

Railway ......... $26 \quad 4$

Dublin............ $26 \quad 6$

Lightning $\ldots \ldots \ldots \ldots 27$

Freedom .......... 2815

Lady Leicester ...... $30 \quad 4$

Lady Stanley ........25 18

Queen of Trumps .... $30 \quad 0$

Antagonist ......... $31 \quad 14$

Snowdrop $\ldots \ldots \ldots \ldots 34 \quad 5$

Snowball........... 2512

Snowdrift.......... $23 \quad 3$

Jenny Lind ......... 2618

Miss Walton ........ 2510

Alice Hawthorn ..... $25 \quad 3$

Tallyho ........... 2618

Coppice Lass ........ $26 \quad 17$

Taire Stant ........ 2421

Swallow ........... 2314

Woodlady ......... 243

Cossack ............ 2818

Flora ........... 257

White Hare........ 2617

Oakmere..........2 $25 \quad 4$

\section{ROYAL NURSERY, SLOUGH.}

WE visited this nursery the other day, chiefly with a view to inspect the large collection of dahlias which is grown here, with so much care, by Mr. Turner. 'The plants are cultivated in "quarters" of convenient size, each plant standing six feet asunder one way, and five feet apart the other; and at present, although the height of the bloom is certainly past, they are exceedingly gay. A remarkable fact connected with dahlias grown for exhibition here is, that as a whole the plants are gayer than those that have not undergone the process of thinning of the shoots, and disbudding, operations essentially necessary for the production of large flowers. Owing to the immense size of the individual blooms, the plants are still as 
gay as if no shoots had been taken away; but Mr. T. informed us that after a certain period, say the 20th of August, all young shoots are removed, which, up to that time, had only been judiciously thinned. Among new varieties we remarked Sir J. Franklin, a buff of exquisite form and good habit, and the flowers appeared to come very true ; Grand Duke, bluish lilac, large, and ratber coarse, yet a full constant flower, and one that must become popular; Drummond's Bob, a new scarlet, having the same shade as Lee's Bloomsby, a flower never grown now, on account of its deficient form; this was in the best possible condition, the petals being neat, small, well-formed, and finely imbricated. There was a large number of blooms of this fine variety, all of which appeared to be equally good. Plantagenet, a shaded purple, is also one of the most approved form. Of those most recently distributed by the trade may be mentioned Annie Salter, which was particularly fine, being a delicate peach, with white at the base of the petals; Dr. Frampton, good in shape and habit, but rather small, white, edged and mottled with crimson; Sir R. Whittington, a noble crimson; Donglas Jerrold, a yellow, tipped with red, but not of the best form; Triumphant, a good-shaped ruby crimson, and possessing a noble habit; Scarlet King, lake, but too flat to match with the fine flowers now out ; Sir C. Napier, a model in form, and certainly the best red, or heavy scarlet, in cultivation; Queen of Beanty, white, tipped with rose, very beautiful, but uncertain; Sir R. Peel, bright vermillion, with small yellow tip, extremely fine in form. Morning Star, a fiery orange, not the best in form, but very attractive and constant. Queen of Dahlias, a flower of bad habit, and very inconstant, yet it had some noble blooms on it, as had also Andromeda. In whites there appears to be still a defciency; Queen of Whites, although rather coarse, is the best; Kant is a good-shaped flower, but it soon becomes thin ; Bar-maid, Mr. Seldon, Mrs. Seldon, Sir F. Bathurst, Mr. Herbert, Miss Spears, George 
Villiers, and the old Essex Triumph, each exhibited the good efferts of high cultivation. In fancy varieties, Princess Charlotte is a first-rate addition. Mrs. Hansard maintains her character as the best of the yellnw-ground class, and Emperor de Maroc as the best dark fancy. Lochner's Claudia is a good new variety, purple, tipped with white; Spectabilis, striped; Glorie de Kain, also distinctly and beautifully striped; Laura Lavington, Miss Ward, Racbel, and Kossuth, are tipped varieties of good shape.

In the glass houses there is at present little to record ; it may, however, be worthy of mention, that the pelargoniums for the May shows have just received their last shift, and are already staged. The plants for later exhibitions are also housed, and although in small pots, are looking vigorously. Those for J une will be finally repotted about the end of October. The fancies have " broken" very regularly, and are encouraged to make a good start with a little warmth at night. The young stock is coming on fast, and is strong and healthy.

Pinks are being planted in their blooming beds. Of carnations and picotees there are immense numbers here, all exhibiting the very best of health; the first layered are being removed from the stools to be repotted for wintering. Auriculas, which are very fine, are exposed night and day when it is not likely to rain, and even then the back and front of the frame are left open.

A bed of the new phlox, called Spencerii, was in bloom; it has the best habit of any we have seen. The colour is rose, or rosy lilac, with a white eve, and the flowers are of average shape, but in habit it surpasses most of this numerous class, having a very large head of blossoms, and being only about one foot high, on stout stems requiring no support.

It may be interesting to know that the old crown glass received considerable damage here a short time ago from a severe hail-storm. 'The remainder of this glass is now fast disappearing before the modern sheet, 
none of which was broken by the storm alluded to. We had almost forgotten a new scarlet pelargonium, named King of Scarlets, whose habit is a little stronger than that of Tom Thumb, but it has broad petals, forming a circle, and is certainly an acquisition to this very useful class of plants.

Gardeners' Chronicle.

\section{THE HOLLYHOCK.}

IN a notice of Mr. Paul's little pamphlet entitled $A n$ Hour with the Hollyhock, in p. 663, 1851 , we promised to return to the subject at a fitting opportunity; we now proceed to redeem our pledge, and commence with some remarks on form. Our opinion is, that for every half-inch in height of ball there should be an extension of one-eighth of guard-petal beyond the ball, and we would liave the height of the ball to be one-half its diameter; thus a flower an inch and a half high should possess three-eighths of guard petal, the florets forming a diameter of three inches, and, with the guard petals, a whole flower of three inches and three-fourths in diameter. Larger flowers should possess similar proportions, smaller ones are scarcely to be tolerated, for we have varieties now very nearly approaching our proportions, and of little less than six inches in diameter. Then, as respects the guard petals, all admit that "they should be thick, dense, whole on the edges, and entirely free from fringe or serrature;" in other words, "perfectly smooth and even," " neither ridgy, serrated, nor curled." To require the guard petals to be "flat," is to require an absolute contradiction of all previous notions relative to the standard of perfection in fiorists' flowers. As well might we desire the guard petals of pinks, picotees, and carnations to be flat; whereas the gentle cupping of the guard petals constitutes the charm and grace of the flower, and so it must be 
with the hollyhock. We deem it, therefore, a sine qua non that the guard petals do gently cup, a term well known to florists. Of the texture of both guards and florets, no difference of opinion exists ; the freer from a crape-like appearance the better-solid, dense, and velvety. So in regard to the florets, they must be " compact and closely arranged, free from pockets, the anthers not to be seen," and as respects colour, " clear and decided." In striped, veined, mottled, or shaded flowers, the ground and overiying colour should be distinct and well defined, free from all confusion. We have as yet only touched on the quality of flower; let us now advert to habit and arrangement of flowers on a spike. There are many varieties which produce so great a profusion of flowers that a crowded and confused appearance is the result. Others, again, on the contrary, are scarce of bloom ; and for this there is little compensation, while, as regards the former, the cultivator can thin so as to please himself. One point hitherto overlooked is a propensity which some sorts have of drooping, not the spike but the flowers; hence it is necessary that the footstalks be strong, and of a length proportionate to the size of the flower, so as to display it withont materially overlapping its neighbour. The larger the bloom therefore the stronger must the stem be. Some diversity of opinion exists respecting foliage being permitted to be seen between the flowers forming the spike in a cut state for exhibition; but we bold that a clean and healthy leaf of moderate size, and not too prominent, cannot but be regarded as assisting in the display of those natural beauties for which the hollyhock is so famous. Thus to rob them of their foliage is to deprive them of much of their charm. We are of opinion that a collection of eleven spikes is highly improved when some few leaves are retained, and those near the base, and particularly on spikes which are placed at the corners of the show-board. With pansies, pinks, picotees, carnations, dahlias, roses, \&c., uniformity in the mode of exhibiting has been se- 
cured; may we suggest that some such regulation is needed with spikes, for although during the agreeable " hour" previously alluded to, we are told how to take spikes to an exhibition, nothing further is stated, the want of which is fully exemplified, when common ginger-beer bottles are used for holding flowers, detracting of course greatly from the neatness which should obtain at every well-ordered exhibition. We would propose that they be formed in two lines of a given distance from each other, say a board of fifteen inches from back to front; the back row of six holes to be three inches from the edge and nine inches apart; the front row of five holes to be also three inches from the front edge, and alternating with the back row of holes. The invitation of eleven spikes, required by this plan, may at first read somewhat odd. In the case of twelve, two lines cannot well be carried out to display all to the best advantage; some have set twelve up in three lines-the front with three, the centre four, and the back with five spikes; but this arrangement does not produce so agreeable an exhibition as we seem to see by the two lines. Again, as regards uniformity of heights, if with flat boards the back row of stems may be eighteen, and the front row fifteen inches long, or if the stems be all of one height, and eighteen inches seems the popular measurement, then the board should be raised six inches higher at back than at front. 'The metropolitan dahlia measurement suits the purpose admirably, and no other should be tolerated. Let us hope that the plan now suggested may meet with similar approral.

Gardeners' Chronicle.

We are very glad to find that the Horticultural Society of London have established a series of exhibitions to be held at their rooms, Regent-street, during the autumn and spring months, for flowers, fruits, and vegetables which are not usually exhibited at their shows at Chiswick. Amongst other things, 
we see chrysanthemums, celery, autumn heaths, hardy annuals, winter flowering plants, camellias, Chinese primulas, hybrid rhododendrons, hyacinths, cyclamens, vegetables, \&c.; and also a very excellent idea, namely, "Fruit or vegetables preserved whole by private persons, for family use, without sugar or vinegar, shown in bottles of white glass, one bottle of each kind, accompanied by a written account of the manner in which they have been prepared." Here will be a chance, we hope, for some of our fair readers who are clever in such matters, of winning one of the society's medals. We think the American method, detailed in the Midland Florist, some time ago, or some modification of it, would answer the purpose well.

Lord Suffield Apple. -We have plants, two years from the bud, with a dozen fruit on each, clustering round the last year's wood like a rope of onions. A specimen, which weighed nineteen ounces, was grown last year. It is as early and as great a bearer as the Keswick Codlin, and at the same time much larger, heavier, and handsomer.

The Forsythia Viridissima is a most excellent plant for training against a wall, flowering early in the season. We have seen a plant in the nursery of Mr. Fox, of Newark, covered with its bright yellow flowers.

\section{羽art JEJEE。}

\section{QUERIES AND ANSWERS.}

I shall feel greatly obliged if you will answer the following queries in the next number of the Midland Florist:-1. Is it possible, by sowing carnation and picotee seed immediately, to 
raise plants that will flower next summer? 2. Can you furnish me with the name of any florist in the south of Germany? Hogg, in his work on the carnation, speaks of some yellow picotees which he obtained from that country, and which were remarkable for what he calls their bizarrerie or mixture of tints. I have rot been able to procure anything similar here, and have therefore been induced to trouble you on the subject.

A Subscriber.

[To the first question, we think it too late. Secondly, the German yellow picotees, thuugh generally singular in colour, are extremely rough and clouded. Any respectable London seedsman would procure you seed. It is often advertised. We would advise you to get some few pairs of the best yellow picotees raised in England, such as those of Messrs. May, Hoyles, Turner, or Bragg. Save seed from these yourself; you will be much more likely to get good flowers. At the same time, raising seedlings is the most delightful part of floriculture.]

T. Q. - The name of your plant is Davallia Canariense, or harefoot fern. 1t grows freely, potted in sandy peat, with a few potsherds mixed amongst it, placed in a warm and shady situation, and kept tolerably moist at the root.

\section{CALENDAR OF OPERATIONS,}

FOR OCTOBER.

GREENHOUSE.

IN this house many things, such as balsams, thunbergias, coxcombs, and other summer-flowering plants, will be fast declining in beauty, and may, as seed is matured, be consigned to the rubbish.heap, to make room for camellias, salvias, epacrises, chrysanthemums, \&c., whose swelling buds give cheering hope of beauty during the dreary winter months. All plants requiring the protection of the greenhouse, should be thoroughly cleaned and placed there without delay. Let them have abundance of air at all favourable opportunities; and should there be any indication of frost, shut up the bouse early in the afternoon; by doing so, fires will be less likely to be needed. Water must be given more sparingly to all plants that have completed their growth, and morning will be found the best time; the house will then have time to dry before closing. Prune and tie in climbers, that they may not obstruct any light. 


\section{VINERY.}

Keep the house where grapes are yet hanging, dry and cool. An occasional fire during the day, with plenty of air, will be necessary, to keep the berries plump and free from damp. Remove all laterals, and cut back the shoot to the bunch; this will give more light, and will greatly tend to the ripening of the wood.

J. BAYLEX.

\section{FLOWER GARDEN.}

Cuttings of verbenas, cupheas, anagallises, and other bedding plants that were recomm nded to be put in the last and preceding month, will, in most cases, be well rooted, and may be potted off. Where there is not much room, several plants may be placed in a pot; they may then be put into a frame and kept close until they have begun to grow, when plenty of air may be given during fine weather. Shrub!y calceolarias will strike freely this month, if placed in a gentle bottom heat. Remove from the borders all annuals, and the stems of such herbaceous plants as have done flowering, at the same time filling some of the vacant places with allyssums, wallflowers, double primroses, hepaticas, and other early spring-flowering plants. As soon as the beds, which have been massed with summer-flowering plants, are cleared, let them be dug and put in urder for the winter; and where bulb, are not to be planted, small bushy evergreen shrubs may be dotted over the surface. Atten.l to any repairs the lawns may require. Transplanting evergreens may be advantageously proceeded with during this month.

J. BAYLEY.

Carnations and Picoters. - Complete the potting for winter without a m ment's delay. Too much stress can scarcely be laid on giving attention to this important operation, for on getting the plants well and vigorously established, depends the whole success of next season's bloom. Carefully clean the plants from dead or decaying foliage, dust dirt, or insects, and keep the frames close for a week after potting. Water sparingly, and only if needed, to prevent the plants from flagging. Should water be required, air must be given until the foliage is dry, keeping the plants effectually sheltered from strong winds. When fairly started, give air abundantly day and night, guarding from the saturating rains usual at this period. Remember, the first blow for the York cups must now be struck, and whoever neglects these preliminaries, will find it is a knock-down blow for him. Nothing more surely promotes disease than a thorough saturation at this season, and it requires to be guarded against both before and after the removal of the layers from the parent stool. Firm potting, is of course. 


\section{FLORAL EXHIBITIONS.}

\section{LEICESTER SOCIETY OF AMATEUR FLORISTS,}

At the Wicliffe Rooms, Leicester, May 24.

TULTPS.

Pans of Six.-1. Baguet Primo, Optimus, Empress, Captain White, Comte de Vergennes, and Rose Brathel, J. D. Hextall, Ashbi-de-la-Zouch. 2. Hep. ton's Sarah, Gibhons's Princess Royal, Triomphe Rnyale, ditto feathered, Pilot, and Optimus, R. Marris. 3. Triomphe Royale, ditto feathered, Duke of Devonshire, Optimus, Bagnt and Lawrence's Friend, G. Evans. 4. Triomphe Royale, ditto feathered, Victory, Captain White, Violet Aiexander, and Amhassador, W. Mitchell 5. Bagot, Magnum Bonum, Queen Charlotte, Lord Milton, Triomphe Royale, G. Hudson.

Pans of Three.-1. Pilnt, Queen Charlotte, and Comte de Vergennes, R. Marris. 2. Triomphe Royale, Magnum, and Bagot, J. D. Hextall. 3. Triomphe Royale, Pilot, and Lawrence's Friend, J. Cooke. 4. Captain White, Bagot, and Comte de Vergennes, G. Evans.

Three Seedling Breeders-R. Marris.

Feathered Bizarres.

1 Victory, W. Mitchell

2 Victory, Mr. Lane

3 Magnum, G. Hudson

4 Governante, J D. Hextall

5 Polypliemus, W. Mitchell

6 Optimus, J. D. Hextall

7 Polyphemus, Mr. Lane

8 Seedling, ditto Flamed Bixarres.

1 Polyphemus, J. D. Hextall

2 Jitto, ditto

3 Duke of Devonshire, G. Evans

4 Polyphemus, G. Huison

5 Unknown, W. Mitchell

6 Polyphemus, R. Marris

7 Captain White, G. Hudson

8 Polyphemus, ditto Feathered Byblamens.

1 Bagot, J. D. Hextall

2 Ditto, ditto

3 Bagot, Mr. Lane

4 Gibbons's unknown, G. Hudson

5 Duc de Bordeaux, J. D. Hextall

6 Gibbons's unknown, $J$. Cooke

7 Violet A lexander, F. W. Hollyoake

8 Grand Turc, J. D. Hextall
Flamed Byblamens.

I Gibbons's Prince Albert, R. Marris

2 Duchess of Sutherland, ditto

3 Violet Alexander, ditto

4 Grand Turc, J. D. Hextall

5 Grand Monarch, R. Marris

6 Grand Monarch, J. D. Hextall

7 Princess Royal, R. Marris

8 Bagot, J. D. Hextall.

Feathered Roses.

] Celemine, J. Evans

2 Ditto ditto

3 Triomphe Royale, R. Marris

4 Triomphe Royale, G. Hudson...

5 Bagot, G. Evans

6 Triomphe Royale, R. Marris

7 Lady Crewe, J D. Hextall

8 Hero of the Nile, ditto Flamed Roses.

1 Gibbons's Lady Stanley, R. Marris

2 Anastasia, J. Cooke

3 Aglaia, ditto

4 Triomphe de Flora, W. Mitchel!

5 Unknown, ditto

6 Vinlet Wallers, ditto

7 Triomphe Royale, G. Evans

8 Triomphi Royale, J. Cooke

\section{Wednesday, July 7 .}

\section{ROSES.}

Pans of Six.-2. Charles Duval, Glorie de France, Geant des Batailles, Double-margined Hip, Tricolor de Flandres, Souvenir de la Malmaison, R. Marris.

Paiss of 'Three.-1. Stadtholder, Kean, and Baron Prevost, J. D. Hextall. 2. Boule de Nantieul, Mrs. Flliott, and Smith's Yellow Noisetie, R. Marris. 4. William Jesse, Clementine, and Madame Laffay, W. Mitchell. 5. Orpheline de Juliet, Clementine, and Geant des Batailles, F. W. Hollyoake.

\section{PINKS}

Pans of Six.-1. Marris's Diadem, Theresa, Angelina, Bestrice, Turner's Optimus, and Cant's Criterion, R. Marris. 2. Marris's Angelina, 'Theresa, Costar's Lola Montes, secrling, Kirtland's Albert, and Keyıe's Hon. Mrs. 
Herbert, G. Hudson. 3. Seedlings, W. Mitchell. 4. Marris's Angelina, Will. mer's Elizabeth, Lightbody's No. 55, Keyne's Hon. Mrs. Herbert, Marris's Damon, and Willmer's Laura, J. D. Hextall.

Pans of Three.-1. Marris's Theresa, Angelina, and Costar's Lola Montes, R. Marris. 2. Seedlings, W. Mitchell. 3. Read's Countess Rossi and two seed. lings, F. W. Hollyoake. 4. Read's Jenny Lind and two seedlings, G. Hudson. 5. Marris's Emmeline, Etna, and Willmer's Laura, J. D. Hextall.

\section{Purple-laced.}

1 Hands" Pilot, W. Mitchell

2 Ditto, ditto

3 Beauty of Clayton, R. Marris

4 Marris's Emeline ditto

5 Hand's Pilot, W. Mitchell

6 Seedling, R. Marris

7 Read's Jenny Lind, G. Hudson

8 Ditto, ditto

Red-laced.

1 Marris's Angelina, R. Marris

2 Ditto, ditto

3 Ditto, ditto

4 Ditto, ditto
5 Marris's Angelina, R. Marris

6 Ditto, ditto

7 Marris's Adelaide, ditto

8 Seedling, ditto

Black and White.

1 Looker's Rosalind, R. Marris

2 Marris's Beatrice, ditto

3 Ditto, ditto

4 Seedling, G. Hudson

5 Gregson's Lady Boldhaughton, J.

6 Ditto, D. Hextall

7 Seedling, W. Mitchell

ditto

Wednesday, July 28.

CARNATIONS.

Pans of Six.-1. Ely's Lovely Ann, Brooke's Flora's Garland, Easom's Admiral Curzon, Haines's Black Diamond, Wallis's Cradley Pet, and Ely's Lady Ely, R. Marris. 2. Aiterton's Fanny Gardner, May's Poor Tom, Lodge's True Briton, Hudson's Vanguard, Wallis's Cradley Pet, and Jackson's Squire Trow, J. D. Hextall.

Pans of Three.-1. Tongue's Prudence, Brabbin's Squire Meynell, and Colcut's Brutus, G. Hudson. 2. Taylor's Kirke White, Wallis's Cradley Pet, and Puxley's Princess Royal, R. Marris. 3. Lodge's True Briton, May's Duncan, and Addenbrooke's Lydia, J. D. Hextall. 4. Hardwick's Firebrand, Twitchett's Don John, and Ely's Lady Ely, W. Mitchell. 5. May's Bardolph, Duncan, and Justice Shallow, F. W. Hollyoake.

Scarlet Bizarres.
1 Atterton's Fanny Gardner, Hudson

2 Hale s Prince Albert, ditto

3 Hepworth's Hamlet, J. D. Hextall

4 Easom's Admiral Curzon, Hollyoake

5 Ely's Lord Pollington, G. Hudson

6 Holliday·s Lord Rancliffe, J. Hextall

7 Hollyoake's Rienzi ditto

8 Lodge's True Briton, G. Hudson Crimson Bizarres.

1 Mav's Durican, J D. Hextall

2 Hoimes's Count Paulina, G. Hudson

3 Ely's Lord Milton, J. D. Hextall

4 Slater's Gladiator, G. Hudson

5 Count Paulina, ditto

6 Gladiator, ditto

7 Elliott's Victory, ditto

8 Bates's Titian, ditto

Scarlet Flukes.

1 Wallis's Cradley Pet, F. Hollyoake

2 Hardwick's Firebrand, J. D. Hextall

3 Ditto,

4 Marris's seedling, P. 49, ditto

Purple Flakes.

1 Jackson s Squire Trow, G. Hudson

2 Brabbin's Squire Meynell, ditto

3 Millward's Premier, R. Marris

4 Squire Meynell, F. W. Hollyoake

5 Mansley's Beauty of Woodhouse, J. D. Hextall

Rose Flakes.

1 Tongue's Prudence, G. Hudson

2 Sir George Crewe; H. Bates

3 Prudence, $W$. Mitchell

4 Prudence, G. Hudson

5 Ditto, ditto

6 May's Antonio, J. D. Hextall

7 May's Ariel, ditto

PICOTEES.

Pans of Six.-1. Norman's Mrs. Norman, Headly's Venus, Dodwell's Alfred, Costar's Christabel, and Marris's Jeanette and Grace Darling, H. Marris. 2. Robinson's Elizabeth, Burroughes's Mrs. Bevan, Wond's Princess Alice, Lightbody's Seedling, Hudison's Exquisite, and Dodwell s Mary, J. D. Hextall. 3. Marris's Hugarth, Mrs. Barnard, Robinson's Elizabeth, Willmer's Princess Royal, Norman's James II., and Holland's Lady Fair, G. Hudson. 4. Marris's Alexander and Prince of Wales, Burroughes's Lady Alice Peel, and three seedlings, Mr. Bates. 
Pans of Three-1. Marris's Prince of Wales, Headly's Venus, and Smalley•s Omega, R. Marris. 2. Matthews's Enchantress, Hudson's Exquisite, and Hol. lyoake's Duke of Rutland, W. Mitchell. 3. Fellowes's Ganymede, and Hollyoake's Rutland and Nina, F. W. Hollyoake. 4. Hollyoake's Duke of Rutland, Marrib's Princess Royal, and seedling, Mr. Bates. 5. Fellowes's Prince Arthur, Norman s Lord Nelson, and Marris's Seedling, Z, J. D. Hextall. 5. Hollyoake's Duke of Rutland, Headly's Venus, and Marris's Hogarth, Mr. Cox.

Heavy-edged Purple.

1 Hollyoake s Duke of Rutland, W. Mitchell

2 Lady Rowena (seedling), F. Hollyoake 3 Turner's Lady H. Moore, J. Hextall 4 Seedling, H. Bates

5 Marris's Iphigenia, ditto

6 Wood's Princess Alice, W. Mitchell Light-edged Purple.

1 Marris's Alexander, R. Marris

2 Hudson's Exquisite, J. D. Hextall

3 Hudson's Exquisite, $\mathrm{H}$ Bates

4 May's Ann Page, J. D. Hextall

5 Seedling, $H$. Bates

6 Marris's Seedling. A. 50, J. Hextall

7 Hudson's Exquisite, ditto Heavy-edged Red.

1 Smalley`s Omega, R. Marris
2 Costar's Christabel, F. W. Hollyoake

3 Norman's Mrs. Norman, ditto

4 Robinson's Elizabeth, R. Marris

5 Bates's Seediing, IV Mitchell

6 Wildman's Isabella, J. D. Hextall Light-edged Red.

1 Dodwell's Mary, J. D. Hextall

2 Youell's Gem, ditto Heavy.edged Rose.

1 Marris's Regina, G. Hudson

2 Ditto, ditto

3 Marris's Jeanette, dicto

4 Headly's Verius, F. W. Hollyoake

5 Ditto, ditto

6 Ditto, ditto

7 Ditto, ditto

Light-edged Rose.

1 Barnard's ilrs. Barnard, G. Hudso'

THE COTTAGERS' SOCIEYY.

Wednesday, May 25, in the Market Hall, Leicester.

TULIPS.

Pans of Six.-1. Gibbons's Pilot, Feathered Triomphe Royale, Polyphemus, Magnum, Captain White, and Royal sovereign, D. Toon. 2. Lord Mlilton, Captain White, Prince Albert, Violet Alexander, Grace Darling, and Andromeda, R. Hawley. 3. Lawrence's Friend, Hero of the Nile, Aglaia, Magnum, Royal Sovereign, and Sir Sidney Smith, Mr. Battison. 4. D. Toon, with sorts similar to those in the first pan.

Pans of Three -1. Captain White, Gibbons's Pilot, and Triomphe Royale, D. Toon, 2. Captain White, Bagot, and Gibbons's Queen of Scots, R. Hawley. 3. Aglaia, Cenotaph, and Charbonnier, Mr. Battison.

\section{'TULIP SHOW,}

At Mr. Nelson Warren's, Snipe View Gardens, Ashton-under.Line, May 29.

Maiden Prize,-Bienfait, J. Newton.

1 Charles X., A. Leech Feathered Bizarres.

2 Magnum Bonum, ditto

3 Apelles, T. Schofield

4 Rising Sun, ditto

5 Paul Pry, R. Whittaker

6 Surpass Catafalque, J. Wild

7 Cruwn Prince, W. Woller

8 Trafalgar, W. Chadwick Flamed Bixarres.

1 Albion, H. Cowburn

2 Polyphemus, W. Chadwick

3 San Joe, ditto

4 Lustre, R. Whittaker

5 Charles X., A. Leech

6 Pilot, J. Newton

7 Grace Darling, ditto

8 Lacantique, R. Whittaker Feathered Bybloemens.

I Bientait, J. Newton

a Catharina, W. Walker

3 Baguet, J. Wild

4 Sir Henry Pottinger, R. WWittaker

5 Duc de Bordeaux, iv. Chadwick

6 Maid of Urleans, $J$. Wild

7 La Belle Narene, J. Yarwood

8 Grotius, J. Wild

1 Racchus, A. Leech Flnmed Byblomens.

2 Wallers, $\mathbf{R}$. Whittaker

3 Bienfait, $A$. Leech

4 Baguet, R. Whittaker

5 Princess Royal, J. Wild

6 Gibbons"s Catherine, J. Newton

7 La Belle Narene, $R$ Whittaker

8 Ashtonian, W. Butterworth

1 Lady Crewe, J. Wild

2 Heroine, W. Woller

2 Comte de Vergennes, ditto

4 Dolittle, J. Moss

5 Andromeda, J. Wild 
6 Newcastle, R. Whittaker

7 Arlette, James Wild

8 Lady Grey, J. Hollingworth Flamed Roses.

1 Vesta, A. Leech

2 Unique, W. Woller

3 Lady Ashley, H. Cowburn

4. Aglaia, W. Chadwick

5 Lord Hill, H. Cowburn

6 Lady Crewe, ditto

7 Camillus, W. Chadwick

8 Triomphe Royale, ditto Bizarre Breeders.

1 Old Dutch Catafalque, I. Yarwood

2 Dreadnought, W. Chadwick
3 Charbonnier, J. Wild Byblcemen Breeders.

i Unknown, R. Whittaker

2 Verpoort, W. Chadwick

3 Catherine, W. Butterworth Rose Breeders.

1 Lord Derby, J. Newton

2 Marchioness of Waterford, W. Chadwick

3 Newcastle, J. Wild Selfs.

I Min d. Or (yellow), W. Butterworth

2 Stadtholder (yellow), J. Wild

1 White Flag (white), J. Wild

2 White Perfection, W. Chadwick

PINK SHOW,

At D. Barker's, Travellers' Inn, Broomhill, near Sheffield, July 5.

Best Blonm.-Cant's Criterion, H. Barker.

Maiden Prizes.-Mango (kettle), J. Martin; Mango (cup), S. Tomlinson.

Purple-laced.

Premier.-Mango, W. Benn

1 Mango, J. Martin

2 Airdale Beauty, C. Colton

3 Coronation, J. Simmonite

4 Beauty of Deighton, ditto

5 Greensides, H. Barker

6 True Blue, S. Tomlinson

7 Ruby, H. Barker

8 Professor, W. Benn

9 Merry Monarch, J. Simmonite Red-laced.

Premier.-Susanna, H. Hydes

1 Susanna, S. Pryor

2 Adam Smith, H. Hancock

3 Sturge, J. Simmonite

4 Louis Tasso, H. Hancock
5 Lady Antrobus, W. Benn

6 Dr. Hepworth, G. Brassington

7 Little Wonder, F. Benn

8 Prince Albert, J. Simmonite

9 Dreadnought, T. Oxley

Black and White.

Premier.-Lady Frost, .J. Simmonite

1 Beauty of Home, F. Benn

2 Kay's Mary, S. Pryor

3 Lady Frost, H. Hydes

4 Beauty of Blackburn, J. Simmonite

5 Blackeyed Susan, H. Hancock

6 Miss Jessop, H. Barker

7 Lady Boldhaughton, S. Pryor

8 Beauty of Clayton-le-Moor, S. - Tomlinson

9 Virgin Queen, H. Barker

\section{SOUTH LANCASHIRF PINK SHOW,}

At J. Grundy's, Spread Eagle Inn, Stamford-street, Ashton-under-Lyne, July 5.

Judges.-Mr. James Heap, Stake Mill, near Middleton; Mr. Joseph Dicken and Mr. Joseph Ingham, A shton.

Pans of 'Three.-1. Huntsman, Sturge, and Mary, J. Beswick, Midilleton. 2. Coronation, Susanna, and Snowball, C. Grundy, Ashton. 3. Huntsman, Susanna, and Kay's Mary, A. Matley, Ashton. 4. Mango, Sturge, and Mary, J. Turner, Bolton. 5. Mango, Susanna, and Mary, T. Mellor, A shton. 6. Huntsman, Susanna, and Beauty of Hotne, S. Raynor, Middleton. 7. Mango, Susarna, and Snowball, W. Taylor, Middleton. 8. Huntsman and two seedlings. R. Norris, Penthoram.

Maiden Prizes. -1. Mango, Susanna, and Mary, T. Mellor. 2. Huntsman, Susanna, and Blackeyed Susan, R. Hope, Pendleton.

$$
\text { Purple-laced. } \quad 5 \text { Dr. Hepworth, R. Hope }
$$

1 Huntsman, T. Mellor

2 Coronation, J. Leigh, Rochdale

3 Greensides, J. Beswick

4 Duke of St. Albans, J. Grundy

5 Mango, R. Norris

6 Seedling, R. T'eebay, Preston

7 Richard Cobden, J. Beswick

8 Kay's Advance, R. Hope Red-laced.

I Susanna, J. Beswick

2 Sturge, J. Turner

3 Seedling, R. Norris

4 Sir William, T. Mellor

6 Brutus, J. Beswick

7 Richard Cobden, S. Raynor

8 Dreadnought, R. Teebay Black and White.

i Virgin Queen, J. Turner

2 Kay's Mary, W. Taylor

3 Snowball, W. Taylor

4 Superior, A. Matley

5 Beauty of Clayton-le. Moor,S. Raynor

6 Lady Boldhaughton, R. Hope

7 Fair Flora, J. Leigh

8 Beauty of Blackburn, R. Hope 


\section{NORTH STAFFORDSHIRE AND MACCLESFIELD PINK SHOW,}

At Mr. D. Porter's, Leopard Inn, Tunstall, Staffordshire, July 10.

Judges.-Mr. H. Penson, Hanchurch, near Trentham, and Mr. S. Etchells, Stockport.

A gold medal was awaried to R. Mnorley, for an excellent stand of three flowers, one in each class, viz. Jones's Huntsinan, Etchell's Susanna, and Fairbrother's beanty of Blackburn.

\section{Purple-laced. \\ Premier.-Jolies's Huntsman, R. Moorley}

1 Bradshaw's Greensides, J.Hambleton

2 Jones's Huntsman, ditto

3 Taylor's Mango, C. Bradshaw

4 Willshaw"sCheshire Hero, W. Ward

5 Pearson's Professor, J. Hambleton

6 Faulkmer"s Duke of St. Albans, R. Moorley

7 Bow's Suwarrow, J. Hambleton

8 Sambo, S. Bromley

9 Normington's Airdale Beauty, R. Moorley

10 Howard's Beauty of Rochdale, $\mathbf{T}$. Whitehouse Red-laced.

Premier._Etchell's Susanna, J. Hambleton

1 Etchell's Susanna, J. Weston

2 Brundrett's Sir William, R. Moorley

3 Lee's Joseph Sturge, J. Hambleton

4 Parker's Dr. Hepworth, S. Bromley
5 Hand's Pilot, R. Moorley

6 Jacksun's Criterion, ditto

7 Trickett's A. Smith, J. Hambleton

8 Champion, R. Moorley

9 Mloorley's Dorothy, ditto

10 Slater"s Lady Antrobus, ditto Black and White.

Premier._Miss Newbold (seedling), S. Bromley

$10 \cdot$ Brien's Virgin Queen, W. Wright

2 Barker's Fairy Queen, $\mathrm{C}$. Bcote

3 Bradshaw's Margaret, R. Moorley

4. Kay's Mary, ditto

5 Norris"s Blackeyed Susan, T. Whitehouse

6 Beauts of Home, S. Bromley

7 Millman's Lillia, S. Bromley

8 Fairbrother's Beauty of Blackburn, T. Bonte

9 Rawsthorn's Superior, W. Ward

10 Whalley's Beauty of Clayton, $R$. Moorley

\section{Second Meeting, at Mr. W. Johnson's, the Gardeners' Tavern, Common, Miacclesfield, Juls 17.}

A gold medal was awarded to S. Bromley, for a stand of three flowers, one in each class, viz. Taylor's Mango, Lee's Juseph Sturge, and Miss Newbold (seed.)

Maiden Stand - Taylor's Mango, Lee's Joseph Sturge, and Norris's Blackeyed Susan, W. Ward.
Purple.laced.
Premier.-Jories \& Huntsman, $\mathbf{R}$. Moorley
1 Attractive, T. Boote

2 Howard's Beauty of Rochdale, $R$. Moorley

3 Hand's Pilot,

4 Faulkner's Duke of St. Albans, do

5 Bradshaw s Greensides,

6 Jones's Huntsman, J. Hambleton

7 Taylor's Mango, ditto

8 Bow's suwarrow, ditto

9 Sambo, T. Buote

10 Lodge's Enterprize, J. Hambleton Red-laced.

Premier,-Etchell's Susanna, C. Bradshaw

1 Lee`s Joseph Sturge, C. Bradshaw

2 Etchell's Susanna, J. Hambleton

3 Trickett's Adam Smith, ditto

4 Slater's Lady Antrobus, R. Moorley

5 Parker's Dr. Hepworth,

6 Jackson's Criterion,
7 Moorley's Dorothy, R. Moorley

8 Pimblott's Seedling (Jane), S. Bromley

9 Richard Cobden, C. Bradshaw

10 Williams"s Thirza, S. Bromley Black and White.

Premier.-Norris's Blackeyed Susan, S. Bromley

I O-Brien's Virgin Queen, R. Moorley

2 Gregson's Lady Boldhaughton, C. Pimblott

3 Norris's Blackeyed Susan, C. Bradshaw

4 Smith's White Rose, S. Bromley

5 Baker's Overall, R. Moorley

6 Fairbrother's Beauty of Blackburn, ditto

7 Millman's Lillia, ditto

8 Kay"s Mary, S. Bromley

9 Whalley's Beauty of Clayton, $\mathbf{R}$. Dionrley

10 Bradshaw s Margaret, ditto 


\section{PINK SHOW,}

At Mr. E. Barker's, Joiners' Arms Inn, Newcastle-under-Lyme, July 10.

Purple-laced.

Premier-Jones's Huntsman, T. Bailey

1 Jones's Huntsman, T. Bailey

2 Norris's Blackeyed Susan, H. Eaton

3 Bradshaw s Greensides, 'T. Bailey

4 Faulkner's Duke of St. Albans, D. Brown

5 Howard's Beauty of Rochdale, $\mathrm{H}$. Eaton

6 Normington's Airdale Beauty, $R$. Moorley

7 Norris s Club-ace, H. Eaton

8 Teebay s Thunderer, ditto

9 Taylor's Mango, H. Bradshaw

10 Tilistone's RichardCobden, E. Barker Red-laced.

Premier.-Lee's J. Sturge, E. Barker

I Etchell s Susanna, E. Barker

2 Lee's Joseph Sturge, ditto

3 Brundrett's Sir William, R.Moorley

4 Seedling, D. Brown

5 Parker's Dr. Hepworth, W.Griffiths
6 Lightbody's Louis Tasso, T. Bailey

7 Jackson's Criterion, H. Eaton

8 Moorley's Dorothy, R. Moorley

9 Williams's Thirza, T. Bailey

10 Prince Albert, H. Faton Black and White.

Premier-Norris's Blackeyed Susan, H. Bradshaw

1 Norris"sBlackeyed Susan, R.Moorley

2 Gregson s Lady Boldhaughton, W. Griffiths

3 Millman's Lillia, E. Barker

4 Whalley's Beauty of Clayton, $T$. Bailey

5 Fairbrother's Beauty of Blackburn, R. Moorley

6 Bradshaw's Margaret, E. Barker

7 Parry's Union, 'I'. Bailey

8 Baker's Overall, W. Griffiths

9 O.Brien's Virgin Queen, ditto

10 Kay's Mary, E. Barker

\section{PINK SHOW,}

\section{At the Albion Inn, Lemon-street, Leeds, July 12.}

Pans.-1. Huntsman, Mrs. Chadwick, Boshell's Gem, Kay's Mary, and Deception, W. Chadwick. 2. Blackeyed Susan, Greensides, Dr. Hepworth, Lady Boldhaughton, and Laura, T. Wainman. 3. Huntsman, seedling, John Nixon, Blackeyed Susan, and seedling, I. W. Bower.

Premier Prize.-Seedling (Harriet), J. Boshell.

Purple-laced.

1 Mrs. Chadwick, W. Chadwick

2 Ditto, J, Boshell

3 Huntsman, I. W. Bower

4 Blackeyed Susan, $T$. Wainman

5 Seedling, I. W. Bower

6 Mrs. Chadwick, I. Boshell Brown.laced.

1. Kelsey's Surplice, I. W. Bower

2 Greensides, 'I'. Wainman

3 Mrs. Chadwick, ditto

4 John Nixon, C. Benton

5 Pilgrim, I. Boshell

6 Mrs. Chadwick, ditto Red-laced.

1 Seedling, I. Boshell

2 Joseph Sturge, ditto

3 Joseph Sturge, C. Benton
4 Dr. Hepworth, T. Wainman

5 Boshell's Gem, W. Chadwick

6 Joseph Sturge, ditto Dark.eyed.

1 Lady Boldhaughton, $\mathrm{T}$. Wainman

2 Kay's Mary, W. Chadwick

3 Kay's Mary, T. Wainman

4 Blackeyed Susan, C. Benton

5 Blackeyed Susan, J. Boshell

6 Blackeyed Susan, J. W. Bower Red-eyed.

1 Seedling, I. W. Bower

2 Criterion, W: Chadwick

3 Laura, C. Benton

4 Laura, T. Wainman

5 Criterion, C. Benton

6 Criterion, W. Chadwick

\section{DERBY GARDENERS' AND FLORISTS' DISCUSSION SOCIETY.}

At Mr. S. Newbold`s, Star and Garter Inn St. Mary*s.gate, Derby, July 12.

1st Stand of Twelve Pinks.-Looker's Oxford Rival, Lola Montes, Regulator, Gaylad, Prince Albert, Duke of Wellington, Whipper.in, Sappho, Lord John Russell, Sturge, Optimus, and Dr. Barnes, Mr. Lakin.

Ist Stand of Six Pinks.-Maclean, Criterion, Sappho, Lola Montes, Achilles; Rival, and Diana, Mr. Dodwell.

Ist Stand of Twelve Roses.-Luchess of Sutherland, Bremus, Earl Talbot, Jaques's Lafayette, Souvenir de la Malmaison, unknown, Geant des Batailles, Reine de la Guilleterie, La Reine, Madame Laffay, Prolific Moss, and Madam Hardy, Mr. J. Lowe.

Best Carnation.-Premier, Mr. Lakin.

Best Picotee--Prince Arthur, Mr. Dodwell. 


\section{嗮art $¥$.}

\section{ORIGINAL CONMUNICATIONS.}

THE "TOWNS" EXHIBITION OF CARNATIONS AND PICOTEES.

ADMONITION, if offered in a spirit of kindly regard, and if the result of careful observation and experience, is as valuable, and to the earnest student, often as grateful, as the hearty applause which greets a successful labour. Will you, Mr. Editor, allow me, as an old florist, to offer a few remarks on the above exhibition, and a word of advice to $m y$ esteemed friends who took part in it? I need not go over ground which you have well occupied, either to dwell upon the cordial feeling, or unanimity, which was found so truly to exist among us, or to dilate upon the beautiful flowers presented, and the skill displayed. Of these you have well spoken, and with but one exception--your approval of the Lady of the Lake picotee, in the Leeds stand-I concur heartily in your criticisme. Much indeed there was to praise and to clwell upon only as earnest, enthusiastic large-hearted florists can praise and dwell upon. But there might have been improvement-as thus. The editor of the Florist says, "The two Derby stands were good specimens of growth and quality combined, each stand possessing excellent variety." The remark is made with the editor's usual sound discrimination, and was deserved, all the more that provincial cultivators, and judgres too, need lessons on the necessity of contrast and variety; but a minute examination showed many of the flowers NOVEMBER-VOL. VI. 2 I 
with petals more or less split on the edges, in dressing, and $I$ am sure $I$ shall have the thanks of $\mathrm{my}$ Derby friends for drawing their attention to this, and telling them it must be obviated. The flowers had been well preserved, thanks, doubtless, to the mode adopted in protecting the bloom, as I saw them evidently quite up to their best eight or nine days before the day of exhibition. Birmingham, with its clean and bright flowers, came into the second place easily, though far away from the first. Here the fault was want of size, a failing aggravated by the flat mode of dressing adopted; and our friends will do well to bear in mind, that in any future competitions, at least one-third should be added to the size of their specimens. Bright colours, clean grounds, and well-defined markings are indeed essential, but they are attainable without any sacrifice of noble proportions-indeed they are only realized in their best, in specimens of superior culture. Nottingham, so necessitated, doubtless, had in its stands, a mized lot: soxne of fine growth, others inferior. Its chief failure was in the spotted and flushed appearance of the flowers, evidencing imperfect protection. I have often wondered that a protection so obvious as a good tulip awning should have been so generally overlooked by my carnation-loving friends. The flowers from Leeds were small, and many of them appeared to have been kept too close, so that there was an absence of stamina in them (for flowers, to be firm in texture, must have plenty of air); but the chief fault was in the flat dressing. The same faults were apparent in the specimens from Wakefield. Will my friends allow me to tell them that form is the first property, and that this is incomplete, if it does not closely approximate to a hemisphere? Flowers of that form, or so treated by the art of the florist, offer quite as fair a field for the display of colours as one stretched and flattened like a pancake; and have the additional recommendation, that the eye rests upon and takes in at the same moment, a larger 
surface, with greater ease and more delight. York puzzled me more than all the other's put together. Growth was not wanting, and its artistic style of dressing, though not as complete as it might have been in every specimen, was a good lesson to every competitor there. Yet there was a peculiarity in the colours of the flowers-a staleness or dead appearance, which I could not account for, whether arising from the shade being too dark, from dirt or natural colour, or from the soil, or the water used. But whatever the cause, if rectified, our friends will be formidable competitors. 'The flowers from Leicester I will not criticise. It was evident ther were contributed from a determination to take a part in the competition, though the place might be the last. But the fine stand from Edinburgh, disqualified as it was, must have some notice. In growth, after the first stands, it had no competitor. It failed only in the adoption of too many of the pale-coloured varieties, Lady of the Lake, Sarah Payne, Favourite, Romeo, Flora's Garland, and one or two others, and the consequent absence of those striking colours which give contrast and variety, - after form, the next essentials for the attainment of a picture, and points, in $\mathrm{my}$ opinion, far too lightly regarded by the majority of florists. How can florists bope to draw attention to the lorely subjects of their care,--almost of their creation-whilst overlooking the effect of contrast, or the advantages of combination? How display their admirable variety? Failing in this prime necessity, the stand must have been placed much below its apparent merit,-such, at least, was my judgment. And now, Mr. Editor, will my friends condemu me as a croaker, or hold my remarks worth a moment's consideration? Will they think with me, we met for instruction as well as recreation? and determine that whilst we applaud and emulate the good, it is the part of wise men, and good florists, to notice and avoid the bad? 


\section{NOTES ON VARIOUS KINDS OF RHUBARB.}

WE noticed, some time ago, a few sorts of rhubarb which we cultivated. The second and third years have given us an opportunity of testing their merits more closely. We shall extract from our note book a few memorandums, which we trust will be of service. The sorts we grow are Mitchell's Prince Albert, Lee's Seedling, White Perfection, Bailey's Wonder, Bailey's Monarch, Fox's King Alfred, Linnæus, Victoria, Sanguinea, Jamesii, Mammoth, Magnum Bonum, and Scarlet Giant. We can say but little in favour of the first. It is early, but considered here as great a "drop" as the Beehive strawberry. Bailey's Monarch and Fox's King Alfred are both infinitely superior to it; in fact, they are excellent. The first is rather the earliest of the two, quite as forward as Prince Albert, erect in habit, handsome both in foliage and stem, much hardier, and of exquisite flavour. Fox's King Alfred is ten days before Linnæus, and is ready to pull when Victoria is peeping out of the ground. It is of beautiful colour, and very large; the grain of the stems appears very fine, and it is excellent for cooking. It is somewhat singular that these two very early rhubarbs were raised in Staffordshire, - the first at Longton, by Mr. Bailey, manufacturer; the latter by Mr. Fox, nurseryman, Cliff Vale, near Leek; both cold and late localities. Lee's Seedling is not worth growing, being thin and without any good quality. Sanguinea, as its name implies, is of a fine blood colour, rather iate, but the stems are well formed, and it forces well. Though not very large or early, still we shall cultivate this for its beautiful appearance and flavour. Jamesii is thin and certainly not worth growing. White Perfection, on further trial, does not appear to possess any particular good quality. The foliage has a singular hoary appearance, and the stems are of medium size and good quality. Bailey's Wonder is in the way of Victoria, 
but certainly not a beat on that fine variety. The leaf stems are shorter; they are, nevertheless, thick, but we should not plant it to the exclusion of the sort named. Mammoth has been grown for some time at Mansfield, and is evidently a seedling from Victoria. Having a rather peculiar upright growth, it will attain a large size, is handsome, and of fine flavour. In the Giant Scarlet we have been disappointed, as it was more frequently green than red. The young leaf stems are high coloured, but as they age, become green. We shall discard it. Magnum Bonum we shall give a further trial to; at present it promises well, is large and of good colour. Linnæus is now tolerably well known, and is a very productive high-flavoured second-early sort. It is not so large as Victoria, but gets to a fair size, forces well, and is of fine colour. Myatt's Victoria is superseding most other sorts for size and quality. It is immensely large, and of fine flavour, and will be grown by everyone who has room for it. The rhubarbs are all gross feeders, and will well repay attention, such as watering with liquid manure, \&c. As very many of our readers have not much room for plants of this kind, we will give a selection of four, which will succeed each other, and are decidedly the best we know. Bailey's Monarch, Fox's King Alfred, Myatt's Linnæus, and Myatt's Victoria.

\section{JOTTINGS ON FLOWERS AND PLANTS,}

Made during a Commeroftal Tour, in the Summer of 1852. Br R. S.

Having, during the past summer, visited many of the principal nurseries in the kingdom, as well as the gardens of some of the nobility, I was enabled, from the nature of my profession (a commercial traveller), to notice most of the new and striking things connected with floriculture. It would be invidious in 
me, perhaps, to mention names, as I might, in some way or other, give offence, even when least intended; but as I made copious notes during the time I was out, and having lately looked through and arranged them under their different families, I thought I would send them to you. It is now some years since we have seen each other, yet, for "auld lang syne," and the interest I take in the success of your periodical, I would willingly do all in my power to aid in rendering it even more useful, if possible, than I believe it to be. Should my jottings pass your "editorial sanctum," I shall, most likely, claim a space in your pages, very often. I see you mention some hollyhocks which you have grown: they are certainly most of them good, but some splendid varieties have come out this season, and improvement in these beautiful and stately flowers is rapidly progressing. The yellow varieties are scarce, at least good ones. Bircham's Yellow Model is one of the best. It is of excellent form, primrose, the lower part of the petals being strongly shaded with dark brown. Sulphurea perfecta is good, and is one which you name, but it is beat by one of Chater's, in the same style, but of better form. Triumphant (Parsons) is novel and fine, but tall in habit; colour primrose, though not always so, as $I$ have on several occasions seen it shaded with pink. Amongst the very new ones is Cream of the Valley (Bragg). I see you have noticed it before, but it will bear repetition. It is a distinct and good sort, not pure white, but there is a richness about its stout and well-formed flowers that makes it very attractive. Poupre de Tyr is a flower of sirgular beauty: there is nothing that $\mathrm{I}$ have yet seen of the same colour. The blooms are close set on the spike, well formed and large, and of a rich purple, shot with a shade of pink. This will be a fine contrast with the preceding sort. Then there is Saffrano, another of Mr. Parson's, but, like most of his sorts, tall. This I take to be a great novelty and a fine sort; the guard petals are buff, while the centre is 
deep salmon. I expect these sorts are yet high in price, though from the ease with which the hollyhock is propagated, they ought soon to be within the reach of the florist of even moderate means. One of the most attractive, and in fact, the newest in character, is Mrs. Mouldey (Turner), a nice white-ground, margined in the way of a picotee, with bright pink. 'This, I assure you, will be a favourite with all lovers of this flower; and so will Joan of Arc (Parsons), a delicate blush, a sweet pretty thing. But in scarlets or crimsons, Bircham's Meteor is, to my fancy, firstrate. It is indeed a splendid sort, that will be noted a hundred yards off. I shall now turn over a leaf or two in my memorandum book, and see what I have got in pansies. These are greatly patronized in Scotland, where I have seen some very good ones. First and foremost then, I jotted down Roval Visit (Dickson). This, I believe, has been raised several years, and it really is a most beautiful sort. The ground colour is pure as drifted snow ; it is of good form, the top petals have nothing weak about them, there is no crimping in the margin, or washiness in the colour; on the contrary, the flowers are smooth and flat, the colour is rich purple, the eye good, and the belting broad and continuous. Downie \& Laird have a nice sort, called St. Andrew, which took my fancy. It is a self, as rich as velvet, dark, and of fine substance; and Handyside's Duke of Perth, though comparatively old, still holds a prominent place amongst both northern and southern flowers. When well grown, it is a grand dark purple. As for yellow grounds, their name is legion. The Duke of Norfolk appears, from strong family likenesses, to be the progenitor of many of the beautiful sorts now out. I was much pleased with several which I saw in a southern nursery. Sir J. Paxton (Betteridge). The form good, the ground colour not so rich as some, but uniform, a light shade of yellow; the top petals and belting were of the same shade (an indispensable requisite). This colour was more of a 
purple than bronze, very rich and attractive. Then there was Sir I. Cathcart (Turner), distinct, the colours being rich and glowing. There wants (as in this flower) something different to the constant yellow and bronzy purple. Here there were top petals fast verging to dark crimson, belting same, broad and well laid on. If I do not mistake, this will be the forerunner of a more lively class of flowers. Wheeler's Marchioness of Bath will find many admirers, from its lively colours and well-defined centre. The petals are stout, banded with a narrow margin of blue, top petals the same. This, from its fine form, will be a good one to seed from. So will National (Turner), which is a very pretty variety, white ground, with narrow belt of purple, excellent in form, and remarkably smooth. When in the neighbourhood of Wolverhampton, I saw a fine self pansy, raised by a man in somewhat humble circumstances. Whether he has made anything of it I know not. I thought it, as selfs go, very good, and superior to many I had seen in the north. I think he called it Duke of Sutherland. It was a fine rich purple, and quite first-rate in form and texture. I have yet some remarks to make on this beautiful family, but perhaps I have written enough for the present, and therefore will say good-by, promising, if you wish it,* a continuance of my memoranda.

* Most certainly we do._ED.

\section{CULTTVATION OF THE POLYANTHUS.}

BY MR. S. HAMMOND, RADFORD, NEAR NOTTINGHAM.

[Continued from page 299.]

The pots should now be filled up with moss, prepared and applied in the same manner as directed for the border. A place for wintering them may be constructed at triffing cost, and with comparatively 
little, if any, waste of ground, under a hedge, facing the south, or south-east, by boarding up the back fourteen inches, and the front ten inches, allowing sufficient width from back to front to contain two rows of pots. The shutters for the top should be made of three-quarter inch deal, six feet long, and sixteen inches wide, cross-stayed in the middle and at each end with hooping iron, which looks neater than wood, and hung on at the back with small hooks and bands, that they may be remored with little tronble. A post will be required at the back, in the centre of each shutter, two feet six inches high, a hook, six inches long, and two small staples, one in the post, the other in the back or upper side of the shutter, to fasten it when turned up. This will leave the shutters a little inclining over the plants, which will be better than if they were thrown wholly back, as it will prevent the drip from the hedge falling on the plants. But as this situation will only be fit for them until the beginning of March, it will be adrisable to form slots in the posts, so that the boards will slide down at each end, and thereby answer a double purpose, affording convenience for removing them to the opposite side of the garden, which will be much better for blooming, and save expense of materials for an extra place. In my opinion, there is no other mode of arrangement. when in bloom, in which they show to so much adrantage as in this. In putting in the pots, great care should be taken to prevent worms getting in, by placing under each pot a piece of slate, the size of the bottom, and covering it with soot, to the depth of half an inch. The spaces betwixt the pots may be filled up with sawdust, or poor light sandy soil. Although the plants are more liable to injury by frost, in pots, than in the border, they are often rendered much more so by shutting them up and excluding air. I do not fear a slight frost, but rather consider it beneficial, as they are then more hardy, and consequently less liable to be cut off in bloom. It also checks them in throwing up winter 
blooms, which some varieties are very apt to do when kept closely confined. I have at this time a hundred of my pots plunged in a boarded frame, with no other protection at top than strong calico lights, brushed over several times with a solution of alum, which renders them in a great measure waterproof and very durable. Some of them have been in use seven years, and are yet whole and sound. In extreme frost, I throw a mat or two over them at night, but in all weathers, except heavy rain, they are fully exposed through the day. All fiower stems that appear from this to the end of January, should be pinched off just below the pips, when they have made an inch growth. During the winter, I collect some good loamy leaf mould, from hedge bottoms, and prepare for top-dressing, by mixing it with onethird of well-decayed cow dung, frequently turning it over, and keeping it dry, by covering in wet weather. I think this all that is necessary, until February, at which time, if spared, and the patience of your readers is not already exhausted, I shall feel pleasure in resuming the subject.

Alfreton-road, Oct. 7th, 1852.

COPPICEANA.

No. XXIV.

Amongst deciduous trees, the lime holds a prominent position. It is planted extensively for avenues, and is a quick-growing, ornamental tree. There are numerous varieties, many of which we grow, and shall now attempt to describe. One of the most beautiful is the

Tillia Alba Pendula. (The Weeping Lime Tree.)-The foliage is broad and ample, with a silvery appearance beneath; the branches weep gracefully. This tree should be extensively planted. It is grafted standard high on the common lime tree, and plants are worth from 1s. to $2 \mathrm{~s} .6 \mathrm{~d}$., according to the age. 
Tillia Europa Laciniata (the Cut-leaved Lime) is a very singular sport, the plant being of more diminutive growth than the species. The leaves are so varied, that no two are anything near alike. When raised from layers, as it sometimes is, it forms a diminutive tree of singular appearance. It is, how. ever, usually grafted four or five feet high. Is. each.

Tillia Laciniata Variegata. (The Variegated Cut-leaved Lime.) - This we received from the Continent, last autumn. The foliage is cut or laciniated quite as much as the preceding, but larger in all its parts. Each leaf has a strong yellowish bar down the centre. Should it retain its variegation, it will prove a very interesting variety.

Tillia Maerophylla. (The Large-leaved Lime.)-A most bold and striking sort. The foliage is very large, being three times the size of that of the common lime tree. It is not much known yet, but as it becomes more common, will doubtless be extensively planted.

Tillia Vitafolia. (The Vine-leaved Lime.) - This is well-named. The foliage is very distinct, and extremely similar to that of the grape vine. Well worth inquiry. About 1s. each.

Tillia Aurea. (The Golden-branched Lime.)-The young branches of this variety are rich yellow, and the beauty of the tree is apparent, from this circumstance, as well in winter as summer. This tree should be planted with such things as the scarlet dogwood, with its rich crimson shoots, the snakebarked maple, the golden willow, and other trees of a simiar character, for when their leaves are fallen, they impart a tone, by their rich and lively colour, to the otherwise dreary and cold appearance of deciduous trees in vinter.

Tillia Maculata. (The Spotted-leaved Lime.)--Also recently from the Continent. Our plants had the foliage very distinctly veined and mottled with yellow.

Tillia Longifolia Dentata. - A very distinct and good variety. Foliage rather large, long, and toothed, as its specific name indicates. Should be in every collection of hardy ornamental trees.

We have also the following new sorts, but must see a little more of them before we describe them, namely, Tillias platiptica, oblongata, oblica, macropoda, bicuspidata, and bigoniæfolia. There is one of the new varieties, however, which promises to niake a very ornamental tree. That is

Tillia Apiculata.-The foliage is large and very stout, deeply indented, and of an intense dark green. They are borne closely on the shoots, which are stout and dark red.

We now come to a very different class of plants, of sombre appearance, hardy in their constitution, and ornamental in character. The yews are very 
varied, and whether they stand as single trees, or form hedges, or are cut into singular and fantastical shapes, they have numerons admirers. Some new species have of late years been introduced, and are known by the designation of Cephalotaxus ; but it is to the common yew and its varieties we would first direct attention. These varieties are many of them well marked.

Taxus Dovastoni, we recollect to have read of, years ago; it was introduced into notice hy a Mr. Dovaston, of West Felton, and is a weeping variety. When struck from cuttings, the branches stretch themselves horizontally on the surface of the soil. The best way is to get grafted plarts, with stocks from four to six feet. It forms a good companion for the weeping holly.

Taxus Adpressa.-A singular small tree, with short shining leaves. This should be grafted on tall stems of the common yew. These, with well-formed heads, would be very beautiful and valuable trees for lawns.

Taxus Fastigiata.-Better known as the Irish yew. Of upright growth, forming massive pillars of dark green foliage. There are magnificent specimens, forming avenues, in the beautiful grounds of Lord Harrington, at Elvaston. A highly appropriate tree for cemeteries, or to mix with round-headed evergreen shrubs, breaking the monotony of the outline in the same manner as the Lombardy poplar amongst forest trees.

Taxus Fastigiata $\mathrm{J}^{\top}$ ariegala. - This is a variety with the foliage marked with yellow. Our plants are not iarge enough yet to say much about their beauty as variegated plants; still they are promising.

Taxus Baccata Aureis (the Golden Variegated Common Yew) is a very beautiful plant indeed, being remarkably distinct, and in winter, showing to great advantage. No collection of evergreens should be without several specimens of this really interesting and handsome tree.

Taxus Baccata Argenteis. (The Silver Variegated Yew.)Equally handsome with the preceding, but in a different style, the leaves being striped with white.

All these sorts will strike readily from cuttings, but they are of slow growth. They are to be obtained of a tolerable size in most large nurseries, and planters must recollect that trees of this description increase greatly in value as they age, fine specimens being much sought after, and high prices are often given for them. 


\section{非art 狂。}

FLOWERS, ETC. RECEIVED SINCE OUR LAST REPORT.

W. M.-Seedring Apple. - Of good size and tolerable flavour. It had every appearance of being a good cooling and market apple, but it will never do for the dessert.

I. R. - The seedling potato, which you intend to name Invincible, we have had cooked. It was mealy, white, and well-flavoured. We cannot pretend to say whether, as a seedling, it will escape disease another season. Experience goes to prove, that both old and new sorts are liable to it. It appears to us to be a variety highly deserving of cultivation.

B. \& H., York.-Ageratum Auredm Folits Variegata.An extremely pretty variegation, and likely to become a favourite with those who admire this class of plants.

I. B. - The juniper is the $J$. communis pendula. The pears are unknown to us.

W. M.-It is almost too late to decide on the merits of your seedling daisy. We have seen, this season, a white, of large size, centre well up, and altogether better than yours; but then this was in its proper season. Send yours next year, and we shall then be able to come to a better conclusion as to its worth.

\section{EXTRACTS, HINTS, AND RECOLLECTIONS.}

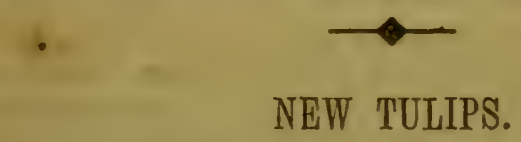

DESCRIBED BY MR. JAMES LIGHTBODY, OF FALKIRK.

ROSES.

Flora Mc. Donald (Reid).-A second-row, fine shape, stout petals, and hard to expand, feathered and heavy flamed, opens creamy at bottom of cup. This variety is first-rate.

Z.auly of the Lake (Reid). - Rather long, tight cup, clean at bottom, very steady in character, and comes with a most beautiful feather, stands long in bloom, and attracts attention in the bed. Secund-row.

Jenny Lind (Reid). - A second row, cup rather long, pure, comes with a brilliant scarlet feather.

NOVEMBER-VOL. VI. $2 \mathrm{~K}$ 
Mrs. Dixon (Dixon).--Third or fourth-row, good shape, pure, and rather hard to open, feathered.

Naomi.-Beautiful shape, and pure, comes with a rosy beam only. First or second-row.

Duchess of Rutland (Jackson).-Third-row, fine compact cup, quite long enough, pure, and finely feathered and flamed. This variely will be a great favourite, when better known.

Frincess Miaude (Lightbody).-Pure and finely-formed cup, comes beautifully flamed and ferthered, quite long enough, thick fleshy petals, hard to expand; as a specimen of a fine fiamed rose, second to none.

Rhea Sylvia (Dixon).- Third-row, feathered and flamed with rich crimson, pure, and good shape. Will be a favourite.

\section{BYBLEMENS.}

Prince Charles Edward (Browne).-Beautifully pure, with a compact cup, feathered with rich dark purple, incleed almost black. Was greatly admired during bloom.

Irlandois (Clark), alias Prince Georye (Jeffiey), Wonder, Browne's Mrs. Butler.-This is a second-row, at times comes only with a very heavy dark purple feather, and sometimes also with a strong beam; the cup is short, and the petals at the top are inclined to curve inwards. It is a pity to see such a fine variety with so many aliases; it is also sometimes called $L a$ Belle Irlandois.

Gavazzi (Zuill.) - A lilac purple feather. and flame, large cup, pure, and rather loose in shape.

Index (Dixon).- Third-row, fine pure cup, with a delicate lilac purple feather. Will be found an acquisition in the most select collection.

Kosciusko (Lightbody).-Pure cup, and finely feathered with rich dark purple. One break of this variety came with a beam only.

King Robert Brice (Lightbody).-Fourth-row, pure and fine cup, with feather of rosy purple; rather late in blooming.

Lord Byron (Reid).-Also late in blooming. In its best dress, has a most striking appearance; the feather is heavily laid on, the jetals very thick and hard to open, pure bottom and stamens.

\section{BIZARRES.}

Signor Mario (Zuill).--This variety was broke this season only. It has a short cup, with rich ground colour, and intense heavy feather.

Napier (Steir).-The deepest orange colour I have seen, and equal on the outside to the inner petals; delicate feather and beam of a reddish brown, very pure in cup, and quite a beauty of a bizarre. 
Redgauntiet (Lighthody').--Perfect in shape, massive petals, and rich yellow ground, with fine brown feather.

Champion of England (Lyde). - This is an old friend with a new name (everyone having a breeder of the late Mr. Clark's in their possession, when they break it, must tack their name to $\mathrm{it}$, as if it were a seedling), the same as the Dulie of Devonshire, alias Lall Singh, MIajestic, Munro, Lord Strathmore, Lyde's Napoleon, Browne, \&c.

Sphinx (Sanders) I believe to be also a break from the same breeder as Devonshire. It is, however, only a second-row, and comes so steadily and finely feathered, that it is worth more than all the rest put together.

Scottish Gardener.

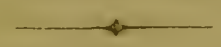

\section{SEEDLING GOOSEBERRIES.}

WE extract the following notice of new seedling gooseberries, exhibited at the fir $J_{0}$ ohn Talstaff Inn, Manchester, Angust 7, fiom the Gooseberry Groners" Register, published by Mr. Thomas Whittaker, of Blackley, a book which ought to be in the hands of every amateur of this useful and popular fruit.

Mr. Francis Oldfield's red seedling, Bedford, a long bright red berry, colour between Napoleos le Grande and Companion, but a longer-formed berry, very rough, and quite distinct.

Mr. Oldfield's red seedling, Roger, a darkish green, shading to red, very rough. The pricks on the berry were of a deep purple, and very strong. A stout square-formed berry, apparently late; fine, and quite distinct from any other sort.

Mr. Parry's red seedling, Help, short and round, in form of Highlander, open veined, quite smooth, and distinct.

Mr. James Elliott's red seedling, Champion, long, smooth, dark, and distinct.

Mr. Edward Forber's red seedling, a beautiful pink colour, a square-formed berry, with green reins, novel, and quite distinct.

Mr. James Winward's red seedling, between Conquering Hero and Provider, long, smooth, and distinct.

Mr. Skerratt's (of Shelton) red seedling, Star, bright and red, a little rough, something in the form of London, broad veins of a green colour. Apparently a cross between London and Companion. Quite distinct.

Mr. Joseph Leicester's red seeding, Prime Minister, a squareformed dark red berry, mottled with dark and light red, in form of a long three-veined London, rough, and quite distinct. 
Mr. George Oldfield's red seedling, a dark coloured red, between Wonderful and Conquerin $§$ Hero, a little rough, quite distinct. Mr. W. Bailey, of Cheadle.-Your berry was spoiled, we could neither describe the colour nor form.

Mr. Thomas Williams's yellow seedling, Fanny, a pale dull yellow, round form, resembling a Dublin. Quite distinct.

Mr. George Webster's yellow seedling, a long smooth berry, about the colour of Peru, and the form of Alexander. Quite distinct.

Mr. Joseph Leicester's yellow seedling, a dark mottled yellow, about the colour of Gunner, perfectly smooth, square form, and quite distinct.

Mr. Joseph Leicester's yellow seedling, first year of bloom 24 dwts. 4 grs. Form of Catherina, of a dull orange yellow, the veins and skin all one colour, unlike any other sort, and quite distinct.

Mr. Thomas Nichols's green seedling, Beetson Castle, a long three-veined berry, a bright dark green, smooth, and quite distinct. Shown in a match, for the best in its class, $27 \mathrm{drwts}$. first year of bloom.

Mr. John Bayley's (of Biddulph) green seedling, a dark smooth green, something in the form of Turnout, but a little longer. Quite distinct.

Mr. Joseph Weeldon's green seedling, long and smooth green, something in the form of a long two-veined Freedom, about the colour of Green River. Quite distinct.

Mr. B. Kenyon's green seedling, 1,apstone, resembles Gretna Green in colour and form, but unlike it in the veins, smooth and quite distinct.

Mr. Francis Oldfield's green seedling, Lofty, appeared again in good style, $25 \mathrm{dwts}$.

Mr. Thomas Nichols's seedling, Snowdon, colour between White Hare and Snowball. Quite distinct.

Mr. James Greenhalgh's white seedling, a long smooth berry, in form of Freedom, the veins showing white and clear, and from vein to vein shows a dark dull colour through the skin, unlike Freedom, or any other sort we have seen. Quite distinct.

Mr. Thomas Williams's white seedling, a smooth square-formed berry, something in colour of Flora, and quite distinct.

Mr. John Bayley's white seedling, a long rough berry, of a thick creamy white, with green veins. A beautiful berry, and quite distinct.

Mr. John Lockett's white seedling, Crystal Palace, a long berry, of a yellowish white, a little rough, and quite distinct.

Mr. Skerratt's white seedling, Citizen, 10dwts. a long darkish coloured white berry, a little rough. Quite distinct.

Mr. James Biddulph's white seedling, too much like the Ostrich. : Try it again. 
Mr. James Biddulph's white seedling, too far gone to give an opinion.

Mr. William Harpham's (Nottingham) white seedling, a smooth berry, in form of London in every respect, of a dull white colour, both the veins and the remainder of the berry. There were several berries, and all fine. Owe of the best seedlings shown, and, if we are not very much mistaken, will be a match for the best in its class.

Mr. E. Poulson.- We received your Clayton, Repea, and Speedwell. The berries were so spoiled, we can say nothing of them. We have seen the three soris, and they are all distinct.

Mr. Charles Dennis. - Your red seedling appears too much like Dan's Mistake. Try it again. The Speedwell berries received were fine and quite distinct.

Mr. John Thewlass's white seerlling, Pretty Lass, a long-formed smooth berry, something in colour of white Hare and Freedom. Quite distinct.

Mr. Joseph Leicester's yellow seedling, Stella, again appeared, $25 \mathrm{dwts}$.

We intended offering a few observations, last month, on the serious evil of garden robbing. When a poor and industrious man has his crop of apples, onions, cabbage, or other garden produce thus swept away, it is bad enough; but when, as in the case of our friend, Mr. Craiggy, whose advertisement appears in this month's number, a most valuable collection of flowers, the labour of a series of years - of a life, is stolen, no terms of reprobation which we can use are sufficiently strong to express our abhorrence of such practices. Mr. C. informed us that the parties were well known, but there was some dificulty (in law) in fixing them with the guilt. We would advise, in all cases of this kind, if there were a florists' society in the district where the suspected party lives, that the secretary of such society should request the supposed thief to attend a meeting of florists, who should be empanneled as a jury; the evidence should be adduced, the party having the Englishman's privilege of defending himself, and the jury should decide according to the evidence whether he were guilty or not. It would go far to repress this reprehensible practice, if all florists were to avoid the 
company of persons thus found guilty, who, though the law might not reach them, still would, we hope, have a salutary dread of such an exposure.

Spring-Flowering Scillas.-Very beautiful little plants are the spring-flowering squills, almost bearing company with snowdrops and crocuses, which generally form the whole array of garden flowers, to greet the approach of spring. With these too the prevailing cerulean hue of the scillas would form a fine contrast. Why is it then that they are so seldom seen ? for it is rare to meet with them, except in the gardens of the curious, and there not in profusion. I would most strongly recommend them to notice, as plants which should be grown as commonly as snowdrops and crocuses, in every garden where early spring flowers are sought for. 'They have many recommendations. Growing but a few inches high, and bearing for the most part blue flowers, they would form beantiful beds, or margins to beds, in situations where now such plants as crocuses and snowdrops are almost exclusively depended on for the earliest bloom. The snowdrop, as is well known, furnishes white blossoms only, and the crocus supplies various tints of orange, white, yellow, and purple; but in neither is the pure blue colour to be found. Those, therefore, who desire to render their gardens ornamental at the earliest dawn of spring, should procure and plant largely of the plants in question; and there are several kinds adapted for that purpose. I will just mention two or three. Scilla bifolia grows about three or four inches high, and when gruwing freely, throws up several flower scapes, each of which bears from four to eight blue flowers, during A pril and May. S. verna grows about the same size, and bears a roundish head of purplish blue flowers, in May and June. S. amœna is also about the same stature, and produces largish drooping light blue flowers, in April and May. S. Siberica, another of these dwarf species, has drooping blossoms, of a 
beantiful clear light blue, which are borne in April. Of $\mathrm{S}$. bifolia there are at least two very distinct varieties, one having white and another pink blossoms. 'They are all cultivated with facility:-Florist.

Packing Carnations and Picotees.-Perhaps while the matter is fresh on my mind, I may as well offer a word or two on this subject, which is, I fear, not well understood. During the past potting season, I have receired many parcels of plants, and all, with the exception of those from Mr. Charles Turner, of the Royal Nursery, Slongh, packed in damp, or more literally, wet, moss. In spring, I have received them as dry as dead bones. This is inrerting the order which a little reflection would suggest as best. Experience teaches us, that of all the evils the carnation is subject to, none is so deadly in its effect, or so insidious in its nature, as spot-a mildewing of the foliage, which, whether causing a dry or wet rot, is equally fatal in its result. Experience further teaches, that this clisease is generated by close stagnant air, and moisture, and is most rapidly developed in plants of an open succulent habit, or when the plants are succulent from rigorous growth; just as the decomposition of grass is more rapid than that of the dried hay. Now, when carnation layers are sent out in the antumn, they, haring been just removed from the parent stool, are usually in the most vigorous growth, and to pack them in wet moss at such a moment, is as sensible as it would be to plunge them in a dung bed. Heat, in either case, will assuredly be generated, and that heat is the prolific parent of disease. To travel without injury, the plants shonld have had no moisture for a week before their removal, and the moss for packing cannot be too dry or too clean. In the spring, from the different seasonal influences, a little moisture may not be objectionable.-Z.

APPLES.-We have been favoured by a very kind friend in Lancashire with specimens of three apples, 
Grenadier, Golden Spire, and Miss Manley. The former has weighed 15oz. 3dwts. All three varieties were large and fine looking apples, Grenadier taking precedence. If a good bearer, it will be an invaluable cooking apple; it is large, with a very nice brisk flavour. Golden Spire is rich yellow, rather long, apparently an early kitchen apple; it did not eat quite so firm as the Grenadier. Miss Manley, raised by a young lady, of that name, at a boarding school, at Rhodes Green, Middleton, near Manchester, is somewhat in the way of Greenup's Pippin, or Hawthorn Dean, cream colour, tinged with blush next the sun. All three varieties are highly deserving of cultiration. We may just observe here, that Lord Suffield apple, which came from the same neighbourhood, was raised from seed by Mr. Thomas Thorpe, Boardman-lane, Rhodes, Middleton.

"How to Plant Roses."-A Seasonable Hint.It may not be considered out of place here to offer a few brief remarks on the best system of planting roses. When they are to be placed out singly, on lawns, or in beds, amongst other plants, a hole should be made, about eighteen inches deep, and large enough to contain a good-sized wheelbarrowful of compost; two-thirds of this should be turfy loam (if it can be procured from an old pasture it is preferable), and one-third well-decomposed animal manure. These should be thoroughly mixed together. Should the ground be dry at the time of planting, or if it is done in spring, a liberal watering should be given before the soil is all filled in around the plants; and standards should be securely staked to prevent the winds from moving them, which is very injurious. When beds are to be planted, the ground should be deeply trenched, and afterwards a good dressing of manure should be applied. A small quantity of the compost recommended above may also be added around each plant. As roses seldom thrive well in 
soils that have previously grown them for a number of years, it is adrisable that when old beds are renewed, the soil should be removed to the depth of eighteen inches, and its place supplied with the above mixture. When a piece of ground is set apart for the exclusire cultiration of roses, the most open situation that is available should be selected. If wet, it should be drained. If it is inconvenient to use tiles, a layer of from four to six inches deep of brickbats, or any other coarse material, will answer the purpose. This done, the ground should be trenched as deeply as the nature of the soil will admit of. The beds may then be formed according to taste or circumstances, and the planting may be proceeded with as recommended above. Norember is the best month for transplanting, but it may be safely done from October to March. It is not advisable to prune at the time of, nor immediately after, planting. 'The first season the plants should all be headed back to two or three buds upon each shoot. This will ensure a rigorous growth. W Ood \& SoN, Maresfield.

NEw Fuchsis.-The editor of the Gardeners" Chronicle sars,_ " 'That must be a rery fine florist's flower that would induce us to introduce a notice of it into this part of our columns, which is usually reserved for discussions of higher interest. There is, however, no rule without an exception; and we feel obliged to bring forward as prominently as possible a new fuchsia in the way of Corallina, the beauty of which we can scarcely find adequate language to describe. Hlowers of the deepest rose colour, three inches long, with a deep purple corolla, stamens projecting an inch beyond the flower, the slender pale pink stalk of which is from two to three inches long; such is a single blossom. Every twig is loaded with from three to seren of these gorgeous flowers, so that the branches are forced downwards by the weight which they are unable to support. Add to this, that 
the leaves are firm, deep green, with bright reddish stalks, and that the yuung wood is of the same colour, and the mind may conceive what a magnificent effect is produced by this variety, which has been well named Fuchsia princeps by Messrs. Lucombe and Pince, of Fxeter, the raisers of it.

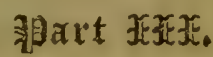

\section{QUERIES AND ANSWERS.}

Will the editor of the Midland Florist oblige me with an answer to the following query:-Will a single eye, taken from the young wood of the grape vine, bear a crop of fruit the same season it is planted? I have been told by several gardeners that it will, but cannot get an explanation. My employer likewise tel!s me he saw some vines this year, growing in pots and boxes, and bearing beautiful crops of fruit, and the gardener told him they grew and fruited them from single eyes every year, which is a mystery to me, knowing that a single eye only produces one shoot and one bunch of fruit, sometimes two, and if three, we consider it extremely fruitful, and I cannot conceive how a good crop can be obtained from a single eye.

A Sưbcriber from the First.

[A good crop of fruit cannot be obtained from a single eye of the grape vine, the same season it is planted. But by the follorwing method, single eyes may be prepared to bear, the next seasun, six or eight bunches of fine well-coloured grapes :Select well-ripened shoots, with round prominent eyes or buds, from vines which bear good crops of fruit, and in February cut the eyes with about an inch of wood on each side; insert them in four-inch pots, one in each, half an inch deep, using sandy turfy loam, with a little leaf mould; plunge them in a cucumber frame or pit, where a brisk bottom heat can be had. When they have begun to grow freely, a little air may be given. As soon as the pots are filled with roots, they may be potted at once in their fruiting pots, which should be about twelve inches wide, and thoroughly well-drained, using for this potting two-thirds of rich turfy loam, one-third well-rotted cow-dung, and a good sprinkling of ground bones or bone-dust. After potting, the plants should be placed in a house or pit where a temperature of from sixty to seventy- 
five degrees is kept up. Give but little water until they have begun to grow freely; but as the pots become filled with roots, the supply must be increased. As the shoots advance in growth, train them carefuliy immediately under the glass, that they may get all the light possible, and when they have attained the length of six or seven feet, stop them: the laterals must be stopped as they appear, except three or four at the top, left to prevent the principal eyes from breaking. As soon as the wood becomes well ripened the plants may be gradually innured to the open air, and may be placed against a south wall until frosts set in, they may then be placed in a cool vinery.]

Would you have the kindness to give me and a few other subscribers a list of what you consider twelve of the best gladioluses, and twelve of the best liliums?

An Old Subscriber.

[The best gladioluses and hardy lilies which have come under our notice are the following:-

GLADIOLUSES.

Professor Bhem.-A very large and showy flower; a good spilie, rich scarlet, striped with pure white.

Abd-el-Kader.-A fine orange scarlet and white.

Brenchleyensis. - Splendid scarlet.

Gandavensis Roseus. - Not so rich in colour as the preceding, but very handsome deep pink.

Louis Philippe.-Dark rose, feathered with white and purple.

Princess d'Orange.-Rich salmon, with a purple feather.

Lafayette.-Rich scarlet, pure white feather.

Dumont d'Urville.-Dark crimson, striped with white.

Elegantissima. - White, with a light blue feather. Very delicate and pretty.

Princess.-Blush pink, with a crimson stripe.

HARDY LILIES.

The varieties of Lilium lancifolium are perfectly hardy, and Mr. Groom, of Clapham Rise, grows them magnificently in the open air. Usually so far north as Nottingham they are cultivated in the greenhouse, of which they form one of the greatest ormaments. We would advise our corres. pondent to obtain Lilium lancifolium album, L. punctatum, and $L$. cruente. To these he may add $L$. superbum, orange, spotted with black, a tall-growing sort, which delights in peat soil ; as well as L. testaceum, also attaining the height of six feet, colour salmon, with very small and darker spots.

Lilium Brownii is a splendid hardy sort, with large tubular white blossoms, the exterior strongly marked with brownish purple.

Lilium Longifiomum.-Dwarf habit, with pure white trumpetshaped flowers. 
Then there are several varieties of $L$. umbellatum, which aro pretty; and of $L$. candidum, the double as well as the striped-florvered varieties, perhaps the less said the better, being floral curiosities only. Besides the above, there are Lilium croceum, concolor, atrosanguinea, pyramidale, pyrenaicum, and the Martagon and Tiger Lilies; in fact, there is immense variety in this very beautiful family.]

I have a fine wall of peaches, \&c. with a western aspect, which, some ten years ago, bore abundance of fine fruit. Since that time the trees have gradually become blighted, and ceased producing fruit of any consequence. Two years ago, I replaced six, with fine young trees, but they have shrivelled up, and gone off in the same way. Do have the kindness to tell me, in your next Midland Florist, of some remedial measure. I don't mind any trouble, or reasonable expense, which will give me a flourishing set of trees. I should thank you to say if you can supply me with trained peach, apricot, and nectarine trees, of approved kinds, true, this autumn. The trees were all properly planted on hard bottom. Alford, sept. 27.

LYDIA WILSON,

[We fear that your postscript reveals the mystery. If your border is not well drained, and wet accumulates at the roots of the trees, similar effects to those described will ensue. We will relate a case in point. Some years ago, a gentleman, residing in the vicinity of Nottingham, had the whole of his wall trees attacked in the way described by you. He was told that it was for the want of proper drainage, and in order to obviate similar disasters, he had his border excavated to the depth of six feet, six feet wide at the bottom. He had a quantity of broken bricks placed to the depth of a foot; over this he put grass sods, and filled in with good sound loam and a quantity of broken bones. He then replanted his wall. He mulches the border, during winter, with decayed stable manure, which is forked in early in spring, and light crops, such as radishes, and other small salads, are grown. Now he has beautifully grown trees, which bear profusely.]

[We regret that various replies, due last month, were too late for publication, our engagements preventing our placing them in the editor's hands earlier than the 20th. They are given beneath.-E. S. D.]

AN Ord Subscriber. - The evil you complain of, viz., the plants turning yellow at the lower leaves, followed by the dropping off of the young layers, is caused by the situation in which they are placed. The loss of the leaves first, and secondly the dropping off of the young layers, too debilitated any longer to maintain a struggle for existence, arises unquestionably from external causes; without doubt, from a 
constant precipitation of moisture upon the leaves, and consequent low temperature, precisely the result likely to follow from the locality described,- " a low part of the garden, rather damp, and protected from every wind." Remove them at once to the "situation much higher, dryer, and exposed on all sides but the north." The specimen sent mould have flourished under fair conditions; the sap is untainted with disease.

"—_ AN Old Friend."-We are certainly flattered that you, so much our senior in years and experience, should appeal to us for our opinion of the best to be accessible this season. Without assuming ourselves qualified to decide your question, we can say, we intend to look after the following, and believe they will not disappoint you :-

$$
\text { CARNATIONS. }
$$

General Mack (Puxley), C.B. Friar Lawrence (May), R.F. Acca (Puxley), S.F.

Benedict (May), R.F. Poor Tom (May), R.F. Magnificent(Schofield),R.F. PICOTEES.

Lady Macbeth (May), heavy-edged red.

Lavinia (May), medium-edged red.

Theodore (Buswell), heavy-edged red.

Ann (Schofield), ditto ditto.

Bianca (May), heavy P.E.

Bridesmaid (Matthews), light ditto.

Countess (Fellowes), heavy ditto.

Diadem (Fellowes), ditto ditto.

Haidee (Fellowes), light ditto.

Lady Franklin (Merryweather), light purple edge.

Calliope (May), medium rose edge.

Julia (May), heavy scarlet edge.

Rosalind (May), medium rose edge.

Unexpected (Marris), heavy rose edge.

Victoria Regina (Marris), heavy scarlet edge.

We pricle ourselves upon growing a selection, and we would not willingly introduce a second-rate into our stock. Some of the above are of the rarest magnificence, as may be readily imagined when we state, Lady Macbeth excels in splendour the far famed Mrs. Norman; and fine as the light purples at present in cultivation are, Ophelia, Ganymede, \&c., Bridesmaid and Haidee completely distance them. In heavy roses, Julia is exceedingly fine, and Marris's Victoria Regina, now at length, after our long patience, to be had, queen-like, leads the class. Of flowers out last season, add to your collection, Ringleader (Marsden), S.B. It is a "Curzon" flower, fine in form and texture, bright in colours, and well defined. Companion (Netherwood), P.F., a northern variety, and Warrior, C.B., a Lancashire flower, we have a good report of, but these we have not seen. 
H. - The National is surrendered to York for 1853, of course with the understanding that we have it in 1854 . It was the unanimous feeling here (Derby) that it would have been selfish in us to refuse to accede to the wish of our friends in York, as we of the midlands, and Derby especially, have been highly privileged with national and aggregate meetings during the few past seasnns. Moreover, it is but graceful that the society which first gave to the tulip meeting its present proud importance, should have the eclat of giving to the Carnation and Picotee Society an equal prominence; and we felt bound to defer, highly as we rate the honour. The days of exhibition (for being in connertion with a great horticultural fete, there will be more than one) are fixed for the 3rd and 4th August, and with this long notice, a district unparalleled in extent may send its representatives to the competing tables. Mr. Hepton guarantees $£ 30$ from the city of York alone, and it is more than probable that the amount offered in prizes will not only be without a precedent in the history of the carnation, but will also exceed the liberal sums offered at the tulip gatherings. Of course the officers and principal members of the society acceded to the arrangement. 'They welcomed the application, well knowing wherever the system of the "National" is once seen, there it will continue to be practised, to the creation of more lovers and cultivators of the flower.

B. V.-The National Carnation and Picotee Society is analagous to the Tulip Society, except that its system of showing the flowers is defined, and not subject to a merely local arrangement. A "towns" meeting for 1853 is being actively promoted by our Leicester friends. Mr. Cole, of Birmingham. suggests the contribution, by the various competing towns, of a handsome sum as entrance, to be distributed in a series of graduated prizes, or in a piece of plate,-such plate to be held by the winners, subject to challenge in future years, but held in perpetuity if won for two consecutive years. Is not the idea worth attention? Why not, as well as silver sculls or diamond oars. $\quad$ E. S. D.

\section{CALENDAR OF OPERATIONS,}

FOR NOVEMBER.

\section{GREENHOUSE.}

Grve to chrysanthemums, salvias, cinerarias, and other things now in flower, a tolerably good supply of water, with an occasional dose of weak liquid manure. This should be done early 
in the morning, that the house may get drv before closing in the afternoon. NIost other greenhouse plants will require to be very carefully watered. Keep them free from decaying leaves and owers, as these encourage mildew and dampness if allowed to remain. On the first appearance, f greenfly, le: the house be immediately fumigated with tobacco. Only sufficient fire to expel damp and keep out frost, will be necessary.

\section{J. BAYLEY.}

\section{VINERY.}

Remove all d caying leaves, and everything that has a tendency to create damp and mouldiness, were grapes are yet hanging. When the fruit is cut, the vines may at once be pruned, the loose bark cleaned off, and the house made ready to receive the scarlet geraniums and other plants which have been taken up out of the flo ie garden. When the border is dry, it may be covered a few inches thick with dry leaves or fern, and a little litter or soil scattered over, to prevent their being blown away. J. BAYLEY.

\section{FLOWER GARDEN.}

If any scarlet geraniums, ageratums, lobelias, calceolarias, \&c., yet remain out, let them be taken up without delay, and potted, using a sancly soil, and pots as small as the roots can be well got into. Plunge them in a gentle bottom heat, and they will immediately form new roots. If any bulbs yet remain unplanted, let them be attended to at once, as every day $t$ ey remain out of the ground after this time, will be to their injury. Take up dahlias, and tie the names or numbers to the stems with metallic wire. Attend to sweeping and rolling grass lawns and gravel walks, otherwise they will get unsightly with worm casts. Proceed with alterations while the weather is fine.

\section{J. BAYLEY.}

Carnations and Picotees.-By the time this is in the hands of our friends, the plants should be thoroughly established in their winter quarters; and the chief duty of the cultivator will he, to keep them thoroughly clean, provide them an abundance of air, and guard from the spturating rains usual at this period. Give plenty of room in the frame to every plant, remem e i $g$ that one vigorously established and well wintered, is worth, in the spring, more than three attenuated and sickly from confinement. Prevention is at all times better than cure, and the dreaded and destructive enemy, spot, may easily be kept at arm's length by thorough cleanliness, and an abundant suppiy of air. Frequently go over the plauts with the brush and scissors, removing all dust and decayed foliage. Draw off the lights on every favourable occasion, and in wet and wincly 
weather, tilt them both at back and front. Some little difference of opinion prevails as to the best aspect for the frames, for wintering. We prefer the north, as keeping the plants more at rest, and enabling us to leave them guarded with the lights (of course tilted freely) on questionable mornings, with more immunity frotn the gleams of sunshine which break out often unexpectedly in the autumn and winter months. Be sparing in the application of the watering pot, but wh n needed, let them have a thorough soaking, and in the morning.
Derby.
E. S. DODWELT.

\section{FLORAL EXHIBITIONS.}

NORTHAMPTONSHIRE FLORAL \& HORTICULTURAL SOCIETY.

At the Swan and Helmet Inn, Gold.street, Northampton, July 29.

\section{CARNATIONS.}

Best Six.-Earl Fitzhardinge, Lord Milton, William IV., Lady Ely, Squire Meynell, and Adiniral Curzon, J Carter. 2. Admiral Curzon, Lord Milton, Firebrard, Hill's Miss Ann, Beauty of Woodhouse, and Hale's Prince Albert, S. Hudson

Scarlet Bizarres.

1 Lord Rancliffe, B. Vialls

2 Admi culal Cun, E. Weston

3 Seedling, J. Carter Crimson Bizarres.

1 Gladiator, B. Vialis

2 Count Paulina, E. Weston

3 Lord Milton, S. Haddon Scarlet Flakes.

1 William IV., R. Vialls
2 William IV., E. Weston

3 Marris's Seeviling, B. Vialls Purple Flakes.

1 Squire Meynell, J. Carter

2 Earl Spencer, ditto

3 Miss Thornton, S. Haddon Rose Flakes.

1 Martin's Maria, E. Weston

2 Lady Ely, s. Haddon

3 Tomlyn's Brisies, B. Vialls

\section{PICOTEES.}

Best Six.-Gem, Alfred, Delicata, Malay Chief, Mrs. Barnard, and Mrs. Vialls (seedling), B. Vialls. 2. Duchess of Cambridge, Mr. Trahar, Delicata, Green's Queen, Mrs. Barnard, and Martin's Queen Victoria, J. Carter. 3. Sebastian, Mrs. Bevan, Portia, L'Elegant, Princess Royal, and Mrs. Barnard, S. Haddon.

$1 \mathrm{Mr}$. Trahar,

2 Mr. Trabar, J Carter

3 King James, B. Vialls Light edged Red.

1 The Gem, B. Vialls

2 'The Gem, J. Carter

3 The Gem, E. Weston He tvy-edged Purple.

1 Ely's Favourite, J. Carter Light.edged Purple.

1 Delicata, J. Carter

2 Delicata, B. Vialls

3 Delicata, S. Haddon
Heavy-edged Rose.

1 Green's Queen, E. Weston

2 Venus, B. Vialls

3 Ditto, ditto

Light.edged Rose.

l Mrs. Bernard, J. ('arter

2 Lady A lice Peel, B. Vialls

3 Mrs. Barnard, E. Weston Heavy-edged Yellow.

1 Martin's Queen Victoria, B. Vialls

2 Martin's Queen Victoria, J. Cai ter

3 Martin's Queen Victoria, E. Weston Lisht.edged Yellow.

1 Martin's Queen Victo. ia, S. Haddon

2 May's Malvolio, B. Vialls 
Fxtra prize, offered by F. Parlier, Esq. for the best two Prince Gecrge picctees, B. Vialls.

A pan of six seedling rose picntees (MIrs. Vialls) were also exhibited, but not for competition, and were higtily cominended by she judge.

\section{CARNATION SHOW.}

\section{Ounsdale, Aug. 2.}

Best Stand of Fight_-Curzon, Dinmond, A riel, Beauty of Woothouse, Lydia, Juliet, Duchess of Cambridge, and Mrs. Barnard, Mr. Acldis.

Best Single Bloom.-Tomlyn's Brisies, Mr. Baylis.

Best Seedling R.F.-Mr. I. Elliott.

1 Lord Rancliffe, Mr. Baylis

2. Curzon, ditto

3 Dr. Newton, ditto

4 Lord l.ewisham, ditto

5 Ditto, ditto

6 Curzon, Mr. I. Elliott

1 Duke of Bedford, Mir. Addis

2 Diamond, Mr. Baylis

3 Diamond, Mr. Addis

4 Duke of Bedford, ditto

5 J10 ditto

6 Diamond, Mr. Bavlis Scarlet Flakes.

1 William IV., Mr. Baylis

2 Potter's Champion, ditto

3 Lydia, Mr. J. Elliott

4 Lydia, Mr. Adis

5 Pntter's Champion, Mr. Baylis

6 King of Scarlets, ditto Purple Flakes.

1 William Penn, Mr. Baylis

2 Meynell, ditto

3 Squire Trow, ditto

4 Ditto, ditto

\author{
5 Premier, Mr. I. Elliott \\ 6 Excellent, Mr. Baylis \\ Rose Flakes. \\ 1 Larly Ely, Mr. Baylis \\ 2 Ariel, Mr Addis \\ 3 A riel Mr. Baylis, \\ 4 Lady Ely, ditto \\ 5 Flora's Garland, Mr. Addis \\ 6 Ariel, Mr. I. Elliott
}

\section{PICOTEES. Red.}

1 Durhess of Cambridge, Mr. I. Elliott

2 Duchess of Cambridge, Mr. Baylis

3 Ditto, ditto

4 Mrs. Barnard, Mr. I. Elliott

5 Duchess of Cambridge, Mr. Baylis

6 Prince of Wales, ditto

1 Juliet, Mr. Addis

$$
\text { furple. }
$$

2 Marchioness of Exeter, Mr. Baylis

3 Ditto, ditto

4 Pluperfect, ditto

5 President, ditto

6 May's Portia, Mr. I. Elliott

WEST RIDING CARNATION SHOW, At the Shoulder of Mutton Inn, Halifax, August 9.

Premier Carnation Prize.-Baildon's Constellation, J. Chapman.

Premier Picotee Prize.-Wood's Princess Alice, R. W. Foster.

Scarlet Bizarres

] Hepworth's Leader, J Jackson

2 Easom's Admiral Curzon, ditto

3 Marchan's Sir R. Peel, J. Fletcher

4 Thomas Brown (seedling), ditto

5 Brierley's Music, R. W. Foster

6 Schofield's Knowsthorpe Pet,Jackson

7 Summerscales's Capt. Fdwards, ditto

8 Elliott's Duke of Sutherland, Fletcher Crimson Bizarres.

1 Wakefield's Paul Pry, J. Sutcliffe

2 Ely's Lord Milton, ditto

3 Sir C. Napier (seedling), J. Wilkinson 4 Summerscale's Nulli Secundus, Foster 5 Seedling, T. Washington

6 Hepworth's Vivid, G. Baildon

7 Haines's Black Diamond, J. Jackson

$s$ Ely"s Hugo Meynell, ditto
Scarlet Flakes.

1 Hardwick's Firebrand, J. Sutcliffe

2 Els's King of Scarlets, R. W. Foster

3 Wilsen's W'illiam IV., ditto

4 Chadwick's Brilliant, J. Fletrher

5 Hepworth's Comet, G. Bdildon

6 Sir Joseph Paxton, J. Jackson

7 Wallis's Cradley Pet, ditto

8 Seedling, T. Washington Purple Flahes.

1 Netherwood's Companion, J. Sutcliffe

2 'Turner's Princess Charlotte, ditto

3 Holland's Earl Wilton, J. Jackson

4 Ely's Mango, J. Fletcher

5 Taylor's Lord Byron, G. Baildon

6 Zanga (secdling), J. Chapman

7 Haslam's Lady Peol, R. W. Foster

8 Jackson's Mr. Jepson, J. Fletcher 


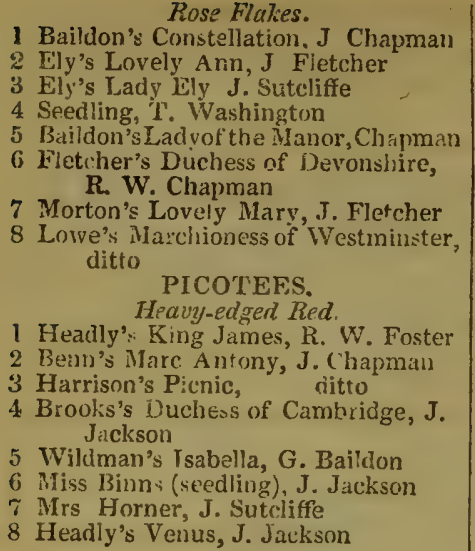

Rose Flaties.

2 Ely's Lovely Ann, J Fletcher

3 Ely's Lady Ely J. Sutcliffe

4 Seedling, $\Gamma$. Washington

5 Baildon's Ladvof the Manor, Chapman

R. W. Chapman

Morton's Lovely Mary ditto

\section{PICOTEES}

1 Headly': King James, R. W. Foster

2 Beun's Mare Antony, J. Chapman

3 Harrison's Picnic, ditto

5 Wildman's Tsabella, G. Baildon

6 Miss Bimn: (seedling), J. Jackson

8 Headly's Venus, J. Jackson
Light-elged Red. 1 Costar's Deiectus, R. W. Foster 2 Wonderful (seedling), J. Jackson 3 Yorkshire Hero, G. Baildon 4. Youell's Gem, J. Fletcher 5 Miss Bacon, J. Wilkinson Heavy-edged Purple.

I Wood's Princess Alice, R. W. Foster

2 Burroughes's President, J. Fletcher

3 Mitchell's Nulli Secundus, R. W. Fosier

4 May's Portia, J. Chamman

5 Holland's Countess Milton, J.Jackson

6 Hepworth's Mary Ellen, ditto

7 Nuli Secundus, J. Fletcher

8 Countess Milton, J Jackson Lisht-edged Purple.

I Seerling No. 27, R. W. Foster

2 Dodwell's Alfred, ditto

3 Holliday's Delicuta, ditto

4 Jack ${ }^{\prime}$ on's Lamartine, J. Jackson

5 May's Juliet, G. Baildon

6 Eliza Cook, T. Washington

\section{LEEDS CENTRAL FLORAL SOCIETY.}

At the Golden Cock Inn, Kirk.gate, Leeds, August 10.

Judges.-Messrs. I. Rhodes, I. Stevenson, and I. Bowers.

\section{CARNATIONS.}

Silver Cup-Curzon, Lord Miltun, Dule of Devonshire, Netherwood's Champion, Lovely Ann, Hepworth's Mary Ellen, and Headly's King James, E. Mitchell.

Ist Pan_-Curzon, President (Henworth), unknown, Mango, Hepworth's Rose Ellen, Hepworth's Cerise Blanche, and Mary Ellen, W. Grey. 2nd. Curzon, Paul Pry, Firebrand, seedling, Hepworth's Jenny Jones, Cerise Blanche, and Mary Eilen, I. Bramma.

1st Premium-Princess Charlotte, E. Mitchell. 2nd. Duke of Devonshire, E. Mitchell.

Scarlet Bizarres.

1 Hepworth's Leader, E. Mitchell

2 Seedling, G. Wood

3 Curzon, E. Schofield

4 Lodge's Briton, I. Watson

.5 Gameboy, I. Iramma

6 Curzon, E. Schofieid Crimson Bizarres.

1 Milton, E. Mitchell

2 Jenny Lind, G. Wood

.3 Hepworth's President, E. Mitchell

4 Paul Pry, E. Schofield

5 Fireorand, W. Grey

6 William IV., ditto Scarlet Flakes.

1 Hepworth's Tam O'Shanter, E. Mitchell

2 Ivanhoe (secdling), W. Chadwick
3 Wilson's William IV., I. Smith

4 Firebrand, W. Grey

5 William IV., ditto

6 Ivanhoe (seedling), W. Chadwick Purple Flakes.

1 Princess Charlotte, E Mitchell

2 Mango, ditio

3 Miss Thornton, I. Hopwood

4 Hepworth's Jenny Lind, E. Mitchell

5 Earl Spencer, E. Schofield

6 Jenny Jones, I. Bramma Rose Flakes.

1 Unknown (Hepworth), W. Grey

2 Lovely Ann, E. Mitehell

3 Lady Ely, E. Schofield

4 Lady of the Nanor. E. Mitchell

5 Hepworth's Rose Ellen, W. Grey

6 Lady Flora Hastings, Hopwood

\section{PICOTEES.}

Red.

1 Yorkshire Hero, $\mathrm{E}$. Schofield

2 Seedling, G. Wood

.3 Headly's King James, E. Mitchell

4 Hepworth's Cerise Blanche, ditto

5 Hepwurth's Seedling,

6 Unknown, I. Smith

\section{Purple.}

1 Hepworth's Seedling, E. Mitchell 2 Hepworth's Mary Helen, I. Bramma 3 Hepworth's Seedling, ditto 4 Alfred, E. Mitchell 5 Stephenson's Sir G. Goodman, Grey 6 Mary Ellen, I. Bramma 
LEEDS OLD FLORAL SOCIETY.

At the house of Mr. James Walker, Albion Inn, Leeds, August 13.

CARNATIONS.

1st Pan.-Ely's Joseph Paxton, Chädwick's Blue Peter (seedling), Chadwick's Ivauhoe (seedling), Chadwick's Earl of Harewood (seedling), Chadwick's Re. becca, Chadwick's King Charles (seedling), and Nulii Secundus, WV. Chadwick. 2. Sir R. Peel, Lord Milton, Boshell's Juseph Paxton, Mango, Rebecca, Mrs. Hormer, and Boshell's Seedling, J. Boshell.

Premier Bloom,-Chadwick's Blue Peter, W. Ch diwick. $^{-}$

Scarlet Bizarres.

1 Sir Robert Yeel, J. Boshell

2 Adimiral Curzon, $T$. Wainman

3 Ditto,

4 Seedling,

ditto

ditto

5 Leader, J. Boshell

6 Ely's Joseph Paxton, W. Chadwick Pink Bizarres.

I Blue Peter, W. Chadwick

2 Ditto, ditto

3 Lord Milton, J. Boshell

4 Seedling, T. Wainman

5 Hugo Meynell, J. Boshell

6 Seedling, 'T. IVainman

Scarlet Flakes.

1 Ivanhos (seedling), W. Charlwick

2 Ditto,

3 Ditto,

ditito

\section{PICOTEES.}

Purple.

1 Nulli Secundus, W, Chadwick

2 Boshell's Harriet, J. Boshell

3 Ditto,

4 Ditto, ditto ditto

5 Nulli Secundus, T. Wainman

6 Ditto, ditto
4 Ivanhoe (seedling), W. Chadwick

5 Ditto, ditto

6 Ditto, ditto

1 Rebecca, IV. Chadwick

2 Ditto, ditto

3 Rebecca, T. Wainman

\& Rebecca, J. Boshell

5 Ditto, ditto

6 Rebecca, T. Wainman Purple Flakes.

1 Mango, J. Boshell

- Sir John Beckett, T. VVainman

it Earl of Harewnod, W. Chadwick

4 Mango, J. Boshell

5 Charjotte, T. Wainman

6 Mr. Jepson, J. Boshell

Scarlet.

] King Charles, W. Chadwick

2 Mrs. Horner, J. Boshell

3 Yorkshire Hern, T. Wairıman

4 Adeline, J. Boshell

5 Ditto, ditto

6 Adeline, T. Wainman

\section{GO0SEBERRY SHOWS.}

\section{At Ounsdale, August 2.}

Four Heaviest Berries, Mr. Addis. dwt.gr.

London ......................... 31

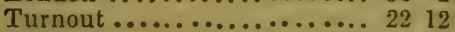

Catherine ............... 2626

Freedom............... 2019

Heaviest Single Berry, Mr. Addis.

London ..................... 321 Best Seedling, Mr. Elliott.

Topaz.................. 2319 RED.

Companion, Mr. Addis ..... 2916 London, ditto.......... 296 Champion, Mr. I. Flliott .... 273 Conquering Hero, Mr. Addis 2514 King Cole, Mr. I. Elliott .... 23 10 Lion's Provider, Mr. Aldis .. 2219 YELXOW.

Catherine, Mr. Addis ....... $27 \quad 7$

Two-to-one, ditto ........ 2t 8
Topaz (seedling), MIr. I. Elliott 2318 Drill, Mr. Addis ........... 247 Marigold, MIr. T. Elliott...... 23 11 Pilot, Mir. Adảis .......... 2220 GREEN.

Turnout, Mr. Addis........ 2523

Thumper, ditto ......... 242

Overall, ditto ............ 2322

Random Green, ditto........... 22

Bumper, ditto .........21 6

Seedling, Mr. I. Elliott...... 214 WHITE.

Lady Leicester, Mr. I. Elliott 247 Tallyho, ditto.... 2323 Cossack, Mr. Acidis.......... 23 6 Philip, ditto......... 284 Freertom, Mr. 1. Elliott ...... 230 Foley, Mr. Addis........... 2220 
At the Spotted Horse Inn, Victoria-street, Derby, August 3. Premier Prize, Mr. Lakin.

Drill $\ldots \ldots \ldots \ldots \ldots \ldots \ldots \ldots . \ldots \ldots 2513$

Gretna Green ............. 24

Fre $=$ dom.................24 16

Landlady's Kettle, Mr. R. Smith.

Mistake .................25 3

Catherine ...............2 2320

Peacock.................20 20

Snowball.................. 2512 Stewards' Prizes.

London, Mr. Storer........ $27 \quad 0$

Drill, Mr. Astle .......... 24

Thumper, Mr. Fletcher..... 22 23

Tallyho, Mr. Wild ......... 287 RED.

Slaughterman, Mr. Wild $\ldots .26 \quad 2$

Mistake, Mr. R. Smith ......25 5

Cumpanion, Mr. Wild.........25 4

Loudon, Mr. R. Smith ...... 2423

Guido, Mr. Salistury ..........20 2017

Lincoln, Mr, Astle .......... 207

Lion, Mr. Fletcher ......... 2n 6

Magnet, Mr. Storer......... 1912

Drill, Mr, Lakin .......... 2510
Catherine, Mr. Storer ........22 2218

Two-to-one, Mr. T. Smith.... 2211

Peru, Mr. Storer.......... 2122

Teazer, Mr. R. Smith........ 2116

Marigold, Mr. B. Smith...... 2112

Seedling, Mr. Spencer....... 2021 GREEN.

Queen Victoria, Mr. Salisbury 2216 General, Mr. Lakin......... 226 Overall, Mr. Wild .......... 2l 3 Gem, Mr. Storer ............ 208 Thumper, Mr. Spencer ....... 1923 Weathercock, Mr. Salisbury.. 1910 Green Wontlerful, Mr. Spencer 1812 Unknown, Mr. 'T. Smith .... 17 o. WHITE.

Seedling, Mr. Lakin ....... 2321 Queen of 'Trumps, Mr. Storer 2320 Lady Leicester, Mr. R. Smith 230 Eagle, Mr. B. Smith .......21 10 Sdowdrop, Mr. Salisbury .... 217 Antagonist, Mr. Spencer .... $21 \quad 5$ Snowball, Mr. Fletcher...... 1921 Snowdrift, Mr. Spencer....... 1912

At the Falstuff Inn, Market-place, Manchester (the largest show in England), August 7.

Maiden Prize, J. Holland. dwt.gr.

Catherine Ste.................

London, F. Oldfield........ 346

Old England, T. Chesters .... 292

Catherine, J. Holland....... 3112

Weathercock, J. Jones ...... 2812

Snowdrop, G. Walton........ 292

Dan's Mistake, Mr. Brundret 283

Drill, J. Daine ............. 2815

Overall, J. Leicester ....... 27 6

Antagonist, J. Oldfield ....... 289

Highlander, T. Nicholas .... 2723

I.eader, G. Oldficld ......... $27 \quad 2$

Telegraph, C. Leicester...... 2622

Freedom, J. Parry ......... 286 RED.

London, F, Oldfield.......... $34 \quad 5$

Ormskirk Buauty, T. Nicholas 2720

Seedling, F. Oldfield ........ $27 \quad 12$

Conquering Hero, T. Burrows 2710

Companion, J. Oldfield ..... 2622

Lumper, T. Pilkington ....... 2622

Wonderful, P. Daine .......2620

Dan's Mistake, S. Barlow.... 2619

Lion, J. Jones .............26 26

Lion's Provider, J. Parry ..... 2610 YELLOW.

Game Cock, F. Oldfield ...... $28 \quad 14$

Broom Girl, ditto ......... 2812

Drill, J. Oldfield ............ 2722

Catherine, W. Edwards...... 2714 dwt.gr.

Great Western, J. Oldfield.... 26.22 Two-to-one, T. Nicholas...... 2612 Peru, P. Daine............ $26 \quad 3$ Hue and Cry, T. Nicholas.... 2522 Oldham, C. Leicester........ 2521 Goldfinder, T. Pilkington .... 2516 GREEN.

Telegraph, F, Oldfield........ 294

Little Wonder, ditto ........ 2720

Turnout, C. Leicester........ 2620

Overall, T. Nicholas........... $26 \quad 17$ Green Wonderful, J. Oldfield 251 Green River, J. Jones ...... 2522 Thunder, T. Nicholas......... $25 \quad 2$ Thumper. J. Jones ........... $25 \quad 2$ Queen Victoria, T. Williams 2420 General, G. Walton......... 2419 WHITE.

Antagonist, F. Oldfield ...... 2812 Queen of Trumps, J. Leicester $28 \quad 6$ Snowdrop, ditto .. 286 Freedom, T Nicholas....... 27 10 Jenny Lind, T. Pilkington .. 2618 White Hare, S. Barlow ...... $26 \quad 17$ Laãy Leicester, F. Oldfield ... 2520 Lady Stanley, T. Pilkington... 2518 Snowball, T. Williams ...... 2512 Tallyho, C. Leicester ......... 254

London, B.B.B., J. Coppock. . 31 12 London, S.B.B., J. Park .... 2920 


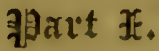

\section{ORIGINAL COMMUNICATIOITS.}

\section{REMINISCENCES OF THE CARNATION AND PICOTEE BLO0M.}

Admirable as are the many uses of exhibitions, forming, as they do, a focus of attraction, and starting points for renewed exertion,-fields for hopeful, inxious, eager, earnest emulation,--centres of skill and artistic effort-equally suggestive and corrective in their results, they are, from the accidents of time to which all are liable, comparatively partial in the experience conveyed, and for the fulness thereof, required by the ardent admirer of Flora, he will from necessity and by inclination, turn to the observation of his own and his friends' collections. There he will have all under his gratified eye-the early and the late, the weakly in growth and those most robust - the tall, the short, those high in colour, and those with less to excite attention-those full in their habit of bloom, and those which most attract by their lireadth of petal and beauty of delineation.

We purpose, therefore, to offer a brief reminiscence of the past season, and invite our readers to accompany us, as we revert to a little gathering, a humble floral " at home," we were privileged to enjoy during the past season. Many friends from various quarters have honoured us with their genial company, and after an irterchange of kindly greetings, and such temperate refreshment as our " mortal coils" require, we sally forth to our little garden. On our road, short though it be, we have discussed the prominent features of the season,- - the long drought, the extreme heat, and the horrible devastation of the thrips.

DECEMBER-VOL. VI. $2 \mathrm{M}$ 
Eloquent indeed are we in our denunciations of this dreadful pest, and eagerly we inquire, is there no remedy for its direful ravages? We get but slight consolation on this head, for, "absolute remedy there is none," says an old friend, " a good smoking in the earliest stage of the swelling of the buds, and shading from the fierce rays of the sun, by means of a thin, open, substance, which will admit plenty of air, is very useful, but for positive prevention, there is none." "Keep the plants cool, in short," says our old friend, "and give them plenty of air, and this is all that can be said about it." We agree with our friend, and pass on. Entering our humble tent, we turn eagerly to the examination of our pets, and soon our delighted gaze is rivetted on some one of their many beauties. After a panse, our old friends tell us, we have not attained our usual freedom of growth, and consequent richness of bloom, and we acknowledge the truth of their remarks. Can we give any reason for this? We think we can, - the plants were removed in mid-winter from a situation unusually confined and forcing to the hill we are now standing upon, and were therefore more than usually susceptible to the harsh drying winds which prevailed through the spring, and to the full influence of which they were exposed. But some of our friends think we have still much to enjoy, indeed they tell us they have never seen so delightful a show before; and though declining their kindly compliments, we agree it is wise to enjoy that which is left, rather than embitter a loss by vain regrets. Turning to the picotees, exclamations and notes of admiration abound. Spectacles are donned by our grey-headed friends, and some, zealously critical, bring strong magnifying glasses into operation. Look! look ! what a Venus! says one,-low delightfully pure in the white, how bright in colour, how fine she is this season! And here is King James, "Gentle Jamie." What solidity in colour, what pearly white-was it ever so good before? Well, we think it is finer than we ever 
remember to have seen it. And then there is Prince of Wales. How rich, how pure, how every inch a prince-was ever ivory so exquisite? And then Mrs. Norman. How grand, hew commanding, what noble proportion, what admirable colour, what firmness of texture, and inimitable refinement! And Giulio Romano, thin though it be, is a worthy reminiscence of the great painter. And what is that fair flower there? fine in form, exquisite in shape of petal; with its regular band of colour, it needs nothing but a more pearly white to dispute the palm with Mrs. Norman herself. That is Bayley's Esther, a seedling from Portia, and a most delightful flower it is. And here is Robinson's Elizabeth, large and fine in form, and blooming most luxuriantly, every pot having nine fully expanded blooms upon it, and all so nearly alike, it is hard to select the best. And Isabella, ancient as she is, claims our notice, and in her determination to vindicate herself, runs close up to Mrs. Norman. Another heary red, also a large and striking flower, Fellowes's Magnificent, something in the Middleton style, but more refined, will not be passed over; and noticing this, we indulge in a brief episode on the arrangement of the home stage, and the necessity for strong colours to produce contrast, bearing in mind always, that the extent over which the eye ranges, softens and subdues what, if concentrated in the narrow area of an exhibition stand, would be positively offensive. But speedily our friends and ourselves are called from our disquisition, to dilate upon that " noble purple." Whatever is it? It is Bayley's Duke of Devonshire, and noble indeed it is. Z. has well said, it will be second to none. Observe its splendid form, its large size, its broad band of locely purple, and strong growth. It is indeed every way noble, and worthy a noble name. Alfred is here too, though faint and weak, as after a long fight-and a long fight he has had, I can tell you. He went into action with one hundred and fifty buds of the finest promise, and now-let us count-yes, he has fourteen only left. Such are the 
ravages of thrips. Poor Duke of Rutland was even worse handled, of ninety buds not one escaped. But let us pass on. Portia is extremely good, seeming to improve as she grows in years, and carrying us in the flashing of a thought to the inimitable scenes of the Merchant of Venice. Vividly before us passes the "learned doctor of Padua," and the dulcet harmony of the moonlight scene is a fit association of flowers. Prince Arthur (Fellowes), with its lovely white and delightful colour, brings vividly to our memories the "pretty child," with his rough but geutle-hearted gaoler, Hubert. Its beauty will create poetry even in the hearts of the most unimpassioned. Lady Harriet Moore vigoronsly grown, is a fine heavy, constant, and of the finest form; and Lord Nelson, though small, is worthy the illustrious name it bears. But what is this light purple, with its broad petal and delightful colour so evenly laid upon the margin, a new flower, and so exquisite? Exquisite truly! May's Ophelia greets you,-and how can we describe these blooms before us! Come similies from fertile brains! A hemisphere of drifted snow, bounded with lovely violet. Will that describe our Ganymede? And so we proceed in our raptures. Princess Helena (Schofield) is delightful, but an old friend says it "saddles" so, a term some of us wish explained. But we are called on to sip new delights. Mrs. Barnard, in light roses, reigns supreme, and supreme indeed she is. A humourous Benedict of our party points out to our unmarried fair friends the vast improvement her matrimonial alliance has effected in her appearance, and the ill-looking thing she was, when Miss Desborough. Green's Queen lacks no admirers, and a delightful seedling of $\mathrm{Mr}$. Adams's is criticised with all the energy of a batch of florists, and can very well bear it. Princess Royal is rough and inferior in colour, and is passed with a shake of the head, and an assurance that "she is not what she ought to be." Mary, in light reds, holds her place, though we have to visit the beds where some late pipinge are blooming, to see her. Miss 
Holbeck is very pretty, but Gem has not donned her best dress. And so we turn to carnations. Here, paramount above all others, holding his place "against all comers," is the "Admiral." Curzon is the abbreviation in other localities, but here the "Admiral " is the designation, the man living in the minds of our old florists, whose productions he so much delighted in. Well! Admiral holds up his head to the most searching criticism, with the unblenched front of a British sailor, and our friends come unanimously to our own conclusion, that here he is without a rival. But where is Ringleader and Sir Joseph Paxton? Ringleader has been brought by Mr. Baildon, but not fully grown: when matured, our Admiral will have a formidable competitor for his honours. Paxton is before us, noble in growth, and a fine large flower; plenty of colour, and a fine petal, not quite so well crowned, or so clear as we like; but for this latter fault we think this burning sun must be arraigned, flushing the white and burning the colours, despite our utmost efforts to intercept his searching rays. Bardolph is bright and fine, Lord Ranclifie large and regularly marked, though a little more smoothness would be desirable. Lewisham is solid, full, and full of colour. Duke of Sutherland holds a good place in his class, and Broughton's Sir Robert Peel, small though he be, looks threateningly up to Paxton, conveying an unmistakable hint, that before he can come to blows with the Admiral, a slight set-to must be had with him.

Crimson bizarres come next. Jenny, "Superlative Jenny," leads the van. She is, however, but now unveiling her beauties, and to see her in all her magnificence, we must make another call. Lord Milton in lis finest dress, attends the bidding of her ladyship; and Black Diamond, smooth as the most polished courtier, and quite as gay, follows quietly, as ready to seize the slightest faux pas of his lordship as a stepping-stone into his place. Whatever may be said of his youthful follies, here at least he is 
constant, a virtue for which my Lord of Milton is not remarkable. Duncan, with his fine broad petal and noble striping, is a fit emblem of the kingly dignity; and Queen Victoria has arrayed herself as becomes our "English matron." Of minor satellites there are many, as the penny-a-liners tell us, "too numerous to mention."

Of the merits of pink bizarres some of our old friends are sceptical, yet what can be finer than Falconbridge, with his glowing colours so regularly delineated? what more delightful than the refinement of Sarah Payne? prettier than Princess? or more attractive than Prince Albert? How can a stand be complete, wanting the attractions of this delightful class? Arguing so emphatically, our friends half admit the "innovation," and we pass on.

Purple flakes are no exception to the rule,--none are so good as usual, and thrips and heat have done their work here as elsew here. Premier is, however, goorl in several places, fine in some; and Perfection, for its white and delightful colour, quite realizes its name. A bud of Squire Meynell excites the warmest approbation; Squire Trow, with its sweet white, fine form, and cheerful colour, is praised by all ; Beauty of Woodhouse is equally liked; and Rachel, a bantling of our own, a seedling from Squire Trow, but larger and with more colour, is reported worthy of a place in the best selections.

Scarlet flakes are numeronsly dotted round us, but all more or less flushed from the excessive heat. Cradley Pet, in our unarimots judgment, occupies the first place. Justice Shallow, usually supposed so inferior in the white, is much clearer than it has credit for, and is withont a rival for its splendid texture and smooth edge. Firebrand sets every florists' heart on fire, with its bright colour, regular marking, good white, and fine form. Queen Victoria, with its rich and bright colour, and broad petal, attracts the eyes of all, and will bear the criticism, despite its inclination to sport, and occasional serra- 
ture on the edge. King of Scarlets is admired for its texture, its regularity of marking, and good white, but the narrow petal is strongly objected to; and very nearly the same verdict obtains with William IV.

In rose flakes, Lorenzo occupies a prominent place, both in number and merit, but is waning, for he has been blooming for three weeks, and Mr. Baildon tells us at once the colour will do, and the petal is of the very best of shapes. Mr. B. tells us also, Lady of the Manor, like Lorenzo, is very early in bloom, has a petal of fine shape, and a colour of similar shade. Sontag, not like the Sontag ot the previous year, for the envious winds have robbed her of her luxuriance, yet Sontag shows us how distinct and delightful she can be. Magnificent is really magnificent. Haidee, hardly assanlted as she is with thrip, still shews us a petal of the broadest, a colour of the brightest, and a form most lovely. Lady Ely is as regular in the arrangement of her colours as the reriest martinet of the proprieties could require; and Lovely Ann is delightful enough to inspire the old, and intlame the hearts of the youngest florists. Floras Garland needs no notice-she is desired by all.

And so we come to the end of our inquisition, reducing to some little order, for the greater ease of our kindly readers, expressions and opinions uttered with many digressions and iterations. But as we sit for a moment, some of our party ask where is Comet, and President? so we take our friends to them. Comet, though run, may possibly make an acceptable flower; of President, sent with Comet direct from Mr. Hepworth, it would be difficult to speak too hardly; the petal was the narrowest we ever saw, the white spotted and pouncy, the colours coarse, and the whole flower without the shadow of a claim to favourable regard. But we will not libel an opinion we are satisfied was well warranted when given (for if our northern friends can point out the best flowers here, they can do the same at home, and we suppose the veriest stirrers-up of mischief will have little room 
for asserting this is flattery), because we were informed the flower in question, called President, when sent to us, was not the same which obtained the opinion formerly given in these pages, and that others had suffered a like imposition with ourselves.

A few brief remarks on the foolishness of chicanery, and we are trooping like merry school-hoys to our friend Mr. Bayley's. We are received with his accustomed cordiality, and speedily introduced to the objects of his skilful care. Now again, adjectives of every degree, positive, comparative, and superlative, are incessantly in requisition, and our friends point with delight to the vigorous and free growth of the plants so much excelling our own. We cordially endorse the opinion, and amidst a storm of exclamations of look at this splendid Curzon! look at this Duncan ! this Milton, this Black Diamond, this noble crimson bizarre, this rose flake, this scarlet bizarre, this scarlet flake, this Meynell, this Ariel, and this Lorenzo, we learn that Mr. Bayley's plants have had the advantage of a sheltered though airy situation, and have been kept gently growing through the season without a check, and unanimously agree that in this lies the secret of a fine bloom. Turning to the picotees, our enthusiasm grows rampant. Such noble blooms of the heary purple, such a Rutland (florists love to abbreviate), such a King of Purples,-and such a king it was indeed, we don't wonder at the name now,- - such bloorrs of Prince of Wales, such Barnards, Venuses, and King Jameses, such Elizabeths, Prince Arthurs, and Esthers (Bayley), greet us on every side, until we are positively surfeited with delight. We look up at the bright and burning sun, and earnestly invoke the aid of friendly clouds, so that these fine blooms may be spared for the "towns" exhibition. Wearied with the very excess of feeling, we rest ourselves on seats kindly provided, and drink in the full tide of beauty. We are, however, soon up again, for the day is drawing on, and we have to visit Quorndon, the Himalaya of the Derbyites, the residence of Mr. Adams. Taking Mr. Bayley in our train, we 
wend our way over pleasant fields, and rich undnlating grounds, diversifying our walk, now with admiration for the delightful scenery through which we are passing, and now with cheerful conversation and a general comparing of notes. A short hour brings us to our destination, and here a disappointment awaits us. Strange as it may seem, with a dry gravelly subsoil, a situation admirably sheltered from north and east winds, and with the flowers on the plants in the open ground, positively decaying, our friend's collection was wanting seven or ten days to its best bloom. After an examination into the why and wherefore of this anomaly, we came to the conclusion that the water supplied to the plants had been colder than the soil, when applied, and thus by incessantly reducing its temperature, had produced the result described. The man-servant stontly repudiated our theory, but we had good cause for adopting it, and we believe Mr. Adams entertained the same opinion. However, our speculations could not last for ever, and Mr. A., who is the very soul of hospitality, cut them short by insisting upon an adjonrnment to his house, where we found a most ample supply of the good things of this life with which to refresh exhausted nature. Pleasantly the hours fled under the presidency ef our estimable host, and long will the remembrance of that delightful evening live in the minds of those present. One incident is worth recording:-One of our northern friends, inspired doubtless by the occasion, proposed with hearty earnestness, "Good health and much success to the midland innovators," and then our host, in his own humorous way, whilst acknowledging the toast and the kindly feeling with which it had been proposed, stated that "both himself and his friend Mr. Bayley, innovators as they were, belonged to that very Lancashire whose sons had been invoked to put them down. But putting down," said our friend, "in this age is an impossibility, - the current of men's thoughts will be, and must be, onward. We, however, have no overweening opinion that we only are right; we concede to our friends the fullest right to differ 
from us, asking only that they will concede to us the merit of sincerity, and that whilst they freely dispute, they will as fairly test the opinions expressed."

The rays of the moon streaming through an open window, warned us it was time to depart, and our way home was enlivened by reminiscences of our day's delight, and active speculation on the beauties another season is to unfold. A list of those we think most worthy has been already given, and need not be repeated.

And now we make our bow to the readers of the Midland Florist, whom, in our humble way, we have tried to interest, if not to edify, for nearly twelve months. We believe our motives will be readily understood, and having made palpable how easy it is, even for the least to do something to advance a public good, we hope our example will induce many, more able, to occupy its pages, and thus win more to the study of a pursuit "full of results; elegant, instructive, and scientific; not unworthy of a wise man, nor unbefitting a good one." That the productions of the florist have been worthy the patronage of the year '52, we believe Duke of Rutland, Ganymede, Ophelia, Prince Arthur, Mrs. Norman, Jeannette, and many others will abundantly testify, and the "towns" exhibition loudly proclaims there is no lack of spirit in the floral community.

Derby, November, 1852.

E. S. DODWELL.

\section{$\multimap$ \\ COPPICEANA.}

No. XXV.

Our next notice will be of the furze, or gorse. Ulex Europea, the double-flowering variety of which, is a very beautiful plant, forming masses of rich golden flowers. It is extremely well adapted for high and exposed situations, making a barrier which neither men nor beasts are fond of penetrating. It is propagated by cuttings, and may be obtaine $d$ at from $6 \mathrm{~d}$. to $1 \mathrm{~s}$. each. 
Ulex Stricta, known as " the Upright Irish Gorse," is of peculiar habit. It does not bloom very freely, though a large bush in our nursery has been covered with flowers during the past season. We think this plant might be profitably cultivated in high and dry situations as food for cows, being of much smoother character than the common variety, which, when bruised, is well known to be greatly relished by them. It is easily raised from cuttings, and is a good nssociate with such plants as the Irish yew, juniper, \&c.

The elms are well known trees, and our limits will not allow of our describing the common sorts. We shall, therefore, confine ourselves to those which are peculiar in their beanty and distinctive character.

Ulmus Viminalis (The Twiggy-branched Elm) is a very neatgrowing compact tree, with small foliage. It is very orna. mental, and well adapted for the back part of shrubheries.

$U$. Viminalis Variegata. (The Variegated Twiggy-branched Elm.) - A variegated variety of the preceding. The branches are slightly pendulous. When grafted standard high, it is one of the prettiest trees imaginable for a single specimen. Our plant, which we have had for some years, occasionally evinces a disposition to revert to a green state.

U. Vminalis Incisa. (The Cut-leạved Twiggy-branched Elm.)Not su compact in habit as either of the foregoing, erect, with slender rodlike branches, and the foliage is more serrated. A very interesting small tree, but scarce at present.

U. Pyramidalis. (The Pyramidal Elm.)-This variety we had originally from the Continent. The foliage is broad, dense, and distinct. It would make a fine tree for avenues, or to plant with other round-headed varieties, and would be far preferrable in every respect to the Lombardy poplar. It is propugated by grafting on any of the common sorts.

U. Stricta Purpurea. (The Upright Purple-leaved Elm.)When young, the foliage is dark purple, in the way of the the Purple Beech. As the season advances, it becomes somewhat greener, but always retains a distinct and peculiar character.

$U$. Viridissima, as its scientific name implies, is remarkable for the dark and shining leaves, which are also somewhat curled at the margin. A very aistinct and ornamental small tree.

U. Pendula Superba. (The Superb Weeping Elm.) - A really beautiful pendulous tree, with very large foliage, and weeping in the same style as the Weeping Ash. One of the most ornamental of this tribe, and should be wherever this style of plants are desirable.

U. Montana Pendula Variegata. (The Broad-leaved Variegated Weeping Mountain Elm.)-Brought into notice by, and 
originated, we believe, in the nurseries of Messrs. Pontey, of Huddersfield, Yorkshire. The foliage is beautifully striped, and the branches pendulous. Quite a first-rate ornamental tree.

\section{VIBURNUM.}

Under this head are some of the most beautiful evergreens we possess. Take, for instance, the

$V$. Tinus. (The Laurestinus.)-Wherever shrubs are grown, this is invariably amongst them. Blooming at a season when there are few other flowers out of doors, either to interest or attract, no wonder it is so universally admired.

There are two variegated varieties: the silverstriped, which is propagated by grafting on the common sort; and the gold-striped. Both these sports, however, are inconstant, and on rich moist soils, lose their variegation.

V. Lucidum. (The Shining-leaved Laurestinus.)-A robustgrowing evergreen shrub, producing large corymbs of white flowers, hardly so profusely as the common sort, but, from its broad and shining foliage, may be classed quite as a firstrate plant.

V. Stricta. (The Upright Laurestinus.)-Very distinct from the preceding varieties, the foliage being rounder and more closely set on the branches. It has rather a sombre appearance; nevertheless it is a useful and desirable evergreen.

$V$. Suspensum is a new variety, with handsome evergreen foliage. Our plants are yet small, but apparently a fine addition to the family.

The common Gueldre rose is also a viburnum. In many localities, it is known as the "Snowball tree," and, though common, is justly admired. Of this, we have a variety with the foliage blotched with yellow, and another, styled V. purpureum, with narrow purplish leaves. They are not particularly noticeable.

\section{Vinca.}

These are the periwinkles, prostrate undershrubs, adapted, with ivy, cotoneasters, \&c. to cover the fronts of shrubberies, and to grow under trees, or in shady places. There are several varieties of the Vinca major. For instance, the gold-variegated, 
which is very handsome in poor soils; but with us, where it grows rapidly, there are generally as many green as variegated leaves. The Vinca minors are very neat for rockwork, \&c. the gold and silver-striped being nice plants, of very prostrate growth. Then there are others, with double pink and single white flowers, all worth growing.

YocCA.

These are singular evergreen plants, with long swordlike leaves. One of the most humble in growth is

Yucca Filamentosa. (The Thread-bearing Adam's Needle.)On dry banks, or in sandy soil, we have seen them flourish and bloom amazingly, throwing out stems bearing many pendulous cuplike flowers.

$Y$.Filamentosa Variegata is a variety of the above, the foliage heautifully striped with cream colour.

$Y$. Gloriosa. A stronger-growing plant. Of fine growth, and throwing up splendid spikes of large flowers.

$Y$. Recurvefolia has leaves which are not so stiff and erert as the preceding. It is very ornamental, and on mounds of prepared earth, it has quite an oriental appearance.

These plants are all well adapted as single oljects for lawns, and are highly deserving of extended cultivation.

Our description of the hardy plants grown here would not be complete without we included climbing plants. These are in such requisition, and so ornamental, that we are sure many of our readers will be glad to know something about them; for who has not got a house or cottage front to decorate? a trellis or arbour to ornament? a pillar or tree to entwine? and what so beantiful for this purpose as inany of the plants we shall briefly describe? Let us begin then with

Ampelopsis.

Ampelopsis Hederacea (The Virginian Creeper) is a plant very suitable for walls in the interior of towns, were few other things will grow It is deciduous, and its flowers inconspicuDECEMBER-VOL. V1. $2 \mathrm{~N}$ 
ous; the foliage is palmate (handlike), for which reason it is sometimes called the Five-leaved Vine. The leaves assume a scarlet hue in the autumn, and we much like to see it planted with the ivy. The front of a house we once resided in was so covered, and in the autumn, the scarlet foliage of the ampelopsis peeped from the dark green of the ivy, almost realizing at a distance the supposition that the ivy was a climbing plant bearing orange and scarlet blossoms.

\section{Aristolochia.}

A Sipho.-Near Stratford-on-Avon, years ago, we recollect a lodge covered with the magnificent foliage of this fine plant; and in the Derby and other arboretums, it forms, on properlyconstructed supports, a beautiful pillar of foliage. It should be in every collection of climbing plants.

A. Kempferii has narrow and singularly-formed foliage. It is not, however, as far as we can see of it, so hardy or so ornamental as the preceding.

A. Sempervirens is a very pretty variety, with lance-shaped evergrecn foliage, and bearing singular brownish flowers, looking like miniature horns. A most interesting and desirable plant.

These are all perfectly hardy, but, from their sleuder habit, should be grown by themselves, as the more robnst sorts are apt to overgrow them. Cultivated as greenhouse plants, either attached to rafters or trained to oval trellises, they are very ornamental, particularly the latter.

A. Alpina has blue flowers, which are produced in great profusion. It requires support, or training, and is very ornamental.

A. Macropetela.-Flowers very delicate, creamy white, and gauzelike. They are produced very early, and are often destroyed by spring frosts, in this part of the country.

Clematis.

C. Flammula-Bears small white sweet-scented flowers in great profusion, and is consequently a very general favourite. It is a hardy plant, and extremely well adapted for intermingling with honeysuckles, \&c. for covering arbours, \&c.

C. Florida has rather delicate stems and foliage. The flowers are large and single, greenish white, produced abundantly, and very ornamental.

C. Florida Pleno.-Similar in habit to the preceding, and bearing double greenish white flowers. 
C. Florida Sieboldii.-Introduced from Japan, by Dr. Siebold. More handsome than either of the preceding. Flowers large, single white, with purple stamens, giving them somewhat the appearance of passion flowers.

C. Montana.-A remarkably vigorous grower, with flowers like the single white wood anemone, having a slight fragrance of the heliotrope.

\section{JOTTINGS ON FLOWERS AND PLANTS,}

Made during a Commercial Tour, in the Sumarer of 1852. BY R. S.

So you say that an old friend of yours desires to claim acquaintance with me. I shall be delighted, when business calls me to Derby, to make his acquaintance. In the meantime, tell him I am flattered by his approval. I must not, however, forget that I have some memoranda to transcribe. I have a few about pinks. In one direction or another, during the season, I saw a great many, and as I take mucb interest in this sweet and delightful flower, I fancy I became thoruughly initiated into the various points of excellence propounded by the difierent florists in the extreme north, as well as the sunny south, not forgetting the opinions held by the gentlemen of " the Manchester school." I was somewhat amused by that indefatigable friend of yours, H.S. M. who appears so anxious that the vexed question should be settled. Why do you not tell him (for you know who is the real Simon Pure) to endeavour to get up "a national pink show" at Leeds or Manchester? Surely your "old friend" at the latter place would be delighted to take the initiative. But I do not see, if the colour is to cover the extreme margin of the jetals, how many growers could compete with them, unless H. S. M.'s suggestion were adopted. Truly I saw some very pretty flowers of this character in Lancashire, though in comparison with what I had 
previously seen in the sonth, they were small indeed. But to our pinks. Oxford, I find, has been very successful in sending out some fine sorts. Optima, purchased of the raiser, Mr. Hastings, was from that locality, and a splendid variety it really is. The lace is purple, and I was much struck with its fine contrast to the extremely pure white ground; smooth on the edge, and of excellent form, it certainly merits the double X I put opposite its name. Talking of donble $\mathbf{X}$, puts me in mind of a variety of that name, which I had seen some well done, years ago. On inquiry, I was given to understand that it is rather sportive in its character, and on being shown a specimen, I thought, if character it had, it certainly was a very bad one. Maclean's Criterion I positively fell in love with,-it was just my fancy. I saw it good in many places, and was glad to find its merits are appreciated by most, if not all, connoisseurs of the pink. Lord Valentia (Kirkland) is a striking heavily-laced flower. The white is very pure, and the margin a crimson marone; but I thought it too rongh, too coarse, in comparison with very many others. Gaylad is by the same raiser, and occasionally a very nice darkly-laced flower; but I noticed that almost all the pinks from Oxford had a strong family likeness in their mode of growth-" long and shanky:" Nevertheless, they are, as a lot, a fine batch of flowers. Take Sappho and Huntsman, for instance; the former purplish rose edge, and the latter nearly the same shade; both large and fine flowers. The former I liked best. Read, I believe, does not live in that locality, but his Jenny Lind I saw on several occasions, done in splendid style. I understand it has been out some years, but for smoothness of petal and general good points, there are few to beat it. I have a note that Narbro' Buck was XX; but amongst the galaxy of beauty which I saw at the Royal Nursery, Slough, where I had a two hours' inspection, I do not wonder at forgetting the Buck's appearance; but I should not have placed 
his name on record, had he not been worthy of such distinction. Mr. Turner had a few very promising seedlings, which were to be let out this autumn, therefore, I have no doubt, ere this, many of your readers have become possessed of them. Sarah I admired much, and you midlanders, and I think, the cultivators of such flowers as Greensides, Coronation, \&ow will also fall in love with her. She is a fine fiower indeed, of excellent form, good breadth of petal, the white peculiarly good, and the lacing dark and well laid on. Phœnix was not so large, but it was a gem, and had I the opportunity or time to grow pinks, this is one which, from its beautiful smooth edge and rich dark lace, I should save seed from. Harry was pointed out to me. This is a stout flower, of very excellent properties, and sure to become a favourite. The lace is dark purple, rich and distinct. Then there was Esther, perfectly distinct from any other; the edge was a rich pink, a fine contrast. This I am persuaded will be required, for in stand showing, were diversity is desirable, flowers with lacing of this shade will be found a great acquisition. I may just notice, that at this nursery I observed that pinks are struck by the thousand ; in fact, every sort of florists' flowers appeared to abound, and were propagated ad infinitum. Singlar enough, I did not observe any black and white or plain pinks which are favourites with you and the northerns. If plain yellow picotees (is not this a bull?) are shown, 1 see no reason why plain pinks should not be; but these mysteries of floriculture often mystify me, I assure you. Blackeyed Susan is one of this class, and quite a crack flower. I certainly admired it much in both characters, for it can be a beautiful purple-laced pink, and also a plain or black and white one. I was told in Lancashire, that when sold out, its character was the latter. Parry's Union is a large flower in the same way, but in very many of the blooms I examined, I could perceive a faint trace, a sort of incipient lacing, 
from the dark centre; it was small, truly, but sufficient, as I thought (I don't know what you judges think), to be a defect. Very many of the Lancashire flowers, particularly old sorts, are serrated, though I make no dunbt that growth exercises a material influence in this respect. Miss Jessop, though a neat flower, is defective. Some of the smoothest-laced flowers I saw were Kay's Mary, Lady Boldhaughton, Superior, and Beauty of Clayton. In red-laced flowers, I saw in the neighbourhood of Leeds, the finest blooms of Lee's Joseph Sturge I had ever beheld : they were beuutifully regular. As the flower ages, the petals reflex, but possibly a master hand, with a pair of tweezers, would counteract this apparent defect. Dr. Hepworth, Louis 'Tasso, Little Wonder, and Susanna, were all shown to me as good exhibition varieties. Neat they were, truly, but I wanted size also. In purple-laced flowers, I particularly noticed Jones's Huntsman, a delightfullyformed, well-laced, smooth-petalled flower. 'This I would grow. Greensides I thought laughably small, but it was perfect, or nearly so. Dr. Daubney I saw in one of the gardens here. This put me much in mind of some of the Oxford flowers. The party who grew it said he did not know who raised it, but that it was so coarse, he should not pipe it. Mango I liked very well ; it is a neat and pretty purple lace. I saw many seedlings: some perhaps equal to the best out. In fact, there appears, wherever I went, to be a determination to improve,-progression is the order of the day; and from what I could gather, particularly in the north, there seems an anxions wish amongst pink growers, that some universally-acknowledged standard shonld be immediately established. In conclusion, I do not know low far these rough notes may be acceptable, but at all events, as your periodisal is of so miscellaneous a character, they will, I trust, prove useful to some who may be as great admirers of them as vour friend. 


\section{NOTES OF A TULIP RAMBBLE.}

$W_{E}$ usually give a short description of the tulips grown in the midland counties, which come under our notice, during our rambles in the month of May. It is a treat we have enjoyed for years, and certainly should be sorry to forego it, even though it should prevent our being called on to act as censor of the flowers we may have seen; for the latter we would gladly give up, the former never, whilst we can walk and see.

We visited Derby a few days before the exhibition there and at Birmingham, and taken as a whole, the flowers were decidedly in better character than on prerious occasions. Our first call was on Mr. Parkyn. One of his most noticeable flowers was Lord Denman, a light flamed byblœmen, which has crept rather more into favour lately, owing to its purity, excellent marking, and good top to the cup, the petals being extremely uniform; still it is too narrow at the base. Walworth, feathered rose, was in first-rate character, and, as we have elsewhere observed, better than we ever recollect to have previously seen it : in fact, it was as pure as could be, and when in that state, is a very useful flower. Salvator Rosa, broken by a person named Allen (thongh one of Gibbons's), was a most excellent flamed byblœmen, of good form, pure, and finely feathered and flamed with intense dark purple. Pass Perfecta, or, as it is sometimes called, La Perfection, was a finely-marked feathered bizarre, somewhat in the style of Charles $\mathrm{X}$. but more dull on the exterior petals.

Mir. Parkinson's beds came next under inspection, and contained many very good flowers. The old favourite, Queen Charlotte, was in excellent trim; and we may remark, that the strain so much admired here is hardly known in the south, the best growers in tlat part being now anxious to obtain it. Another flower which will become a decided favourite is Lady 
Jane Grey, somewhat alove the standard in form, but everywhere pure, with rich heavy crimson beam, and darker feather. A fit companion for the Queen, in a stand of six. Surpass Optimus, feathered bizarre, was in its best character, and is a decided nice strain (known as Mr. Dixon's). Here was Jersey Wonder, very pretty indeed, black feather, on ground of ivory whiteness. We really think now it is not Addison, our flowers of the latter attaining a greater height by six inches. Irene, a novel and pretty flamed rosy byblœmen, was one of the gems of the collection; whilst Surpass le Grande, with its "grand" beam, extreme purity, bold anthers, and fine rich purple, was one of the most attractive of the flamed Chellastons. Anastasia, a fine heavy-feathered rose, was in good character, and Catherine and Lady Stanley figured well amongst the flames.

Messrs. Lakin's flowers were rather past their best, but were splendidly grown. Purple Perfection and Violet le Grand were both stately, pure, and finely flamed; and Princess Royal was in very excellent character, well marked, without being too heavy, and the beam not breaking broadly through the top, which is apt to be the case with this flower. 'Tricolor, or Oriffamme, is a bold and high-coloured flamed bizarre, something in the way of Saunders's Enterprize; but it will not do for northern or midland tastes, being often destitute of feather. The bed was rich in the best varieties of midland flowers, and here again were Lord Denman and Allen's Salvator Rosa, in fine style. Many good judges, who have seen Brown's Salvator, seem inclined to award the palm of excellence to the former. We hope this question will be fairly mooted at the national exhibition, at Nottingham, in 1853 , as very possibly both flowers will be there in their best character.

Mr. Marsden bad a splendid blooin. Here we were shown a seedling feathered bizarre, equal to a good Charles X. but so much like it that he did not think it advisable to name it. Amongst really finely 
marked flowers, we may mention Rouse's Princess Royal, a heavily feathered byblœmen, but unfortunately stained. Venus was a splendid flame, rather peculiar in its style of marking, nevertheless, a star on any bed. There was also a seedling raised by us, named Elizabeth, with excellent cup, pure, and heavily flamed with purpie. La Belle Nannette was very fine, and Sarah Ann, another of the Chellaston family, with short cup and fine flame, was conspicuous for its beauty. Here also was W agstaff's Apollo, a finely-marked byblœmen, but worthless, the base being as yellow as a buttercup. Finlayson's Hampden, black and yellow, strong flame, was much better than usual. The Captain Whites, in this garden, were in great force, and very rich in colour, being dark and glossy, and, as far as we could see, perfectly pure. His seedling, Annot Lyle, has not yet broken; but there was a red feathered flower, very pure and distinct, Allen's Edward, which will be likely to take a place in the class.

We next had a drive to Chellaston, and were rather surprised to find a long bed, which was said by Mr. Gibbons to contain three thousand Princess Royal breeders. If this was correct, here is the secret of the confusion amongst these flowers, for most certainly there were blooms in six or seven different characters. There was Maid of Orleans feathered, and Princess Royal flamed, Venus, Lord Vernon, \&c. but certainly very differenct. We fancy that some of $\mathrm{Mr}$. Gibbon's breeders are so much alike, that previous to becoming rectified, they are not to be distinguished from each other. His best bed was certainly not so rich as we have previously seen it; nevertheless, we were pleased to see Grace Darling in a new character, a rich and glossy heavy feather, nearly blark, the fine cup of this noble flower rendering it very conspicuous. Then there was Lady Flora Hastings, in similar character, with the slightest speck possible immediately below the anthers. Lord Vernon was a grand and pure flame. 
Britannia a very distinct feather, but in the same plight as Lady Flora. Glory of Abingdon was rather past its best, but we would advise our friends to look out for it. It is from Berkshire, and is a rich flamed bizarre, with a heavy plated black feather round the petals. This flower, we believe, was shown in good style at Birmingham, by $\mathrm{Mr}$. C. Turner. Chellaston Beauty, of which more anon, was also grand, certainly one of the best, when in character. Time prevented our making more copious notes, so we moved on to the village.

At Mr. Godfrey's, all the older varieties of tulips celebrated in the neighbourhood were grown in perfection, and in the best possible strain. Mr. G. appears to aim rather at a score of a good sort than a score of varieties. We noticed, however, a fine Van Amburgh, and a good Grace Darling.

At Mr. Forman's we had the treat of the day, in seeing perhaps the best Chellaston Beauty we ever beheld. But even here there was some doubt; Chelaston Beauty is supposed to be about a second-row flower, whilst this was certainly a third or fourth-row. A strong and healthy bulb, well grown, might make some difference., Mr. Forman, who broke it some years ago, from this circumstance, named it Sir I. Harpur Crewe. At that time we had a small bulb of it, but so indifferently had it bloomed with us during two years, that we had actually crossed it out, to throw away, but seeing this splendid flower, has given it a reprieve, and we shall try it again. The flower in question was all that could be wished. We took it to Birmingham, and gave it to Mr. Turner, the editor of the Florist, who has figured it in the August number of that periodical, and we must say, that beautifully though it is represented, still it falls short of the excellence of the flower, for "who can paint like Nature?" Magnet was larger than usual, with a heavy black feather, on a yellow ground; and Lady Evelyn was an extremely delicate and pretty new feathered rose. 
Proceeding onward, we passed through the property of Lord Harrington, at Elvaston. Here a great number of fine oaks had been felled, and, stripped of their bark, with their bare arms extended, they looked like prostrate giants. At the first day's sale of these noble trees, we understand, more than five thousand pounds was realized. The farmers will possibly be glad to be rid of them from their fields, whilst the lovers of the picturesque will regret their absence.

Our next stoppage was with our old friend, Charles Spencer, of Thulston. Here we saw Mr. Groom's crack byblœmen, Victoria Regina. We almost think fifty pounds has been asked for this flower. It has a fine cup, pure, and lightly feathered, opens rather creamy, but bleaches. There is not that boldness or richness so apparent in Chellaston Beauty, nevertheless, it is a much-admired flower in the south, and will be extensively cultivated here, when attainable. Here also was the best General Barneveldt we have seen, an intense dark purple flame, verging on black. 'The older varieties, such as Optimus, Lord Lilford, Bagot, \&c. were extremely well grown.

Another move brought us to Amberstone Ford, a passage across the river Derwent, our nearest way to Mr. Allistree's, of Draycott. The water was low, and our carriage passed through safely, though at this spot, a few years ago, Mr. Fletcher, of the Cavendish Bridge brewery, lost a team of very valuable grey horses, which were swept away by the impetuosity of the current. Mr. Allistree's flowers were past their best, but they had evidently been fine. Amongst the more conspicuous was Bowler's Everard, of which a good deal has been said at various times, in the Gardeners Gazette. It has a beautifully-formed cup, very pure, and well marked with a flame and feather of reddish brown. A most desirable variety. Jackson's Duchess of Rutland, originated by the same person, and from the same pod of seed as Lady Ciifton, was a pretty light 
flamed rose, though, as Mr. Lightbody says, rather long. Violet Brun and David were both good; and Triomphe de Lisle was in excellent condition. This last is a very different thing to the rose which formerly bore that name in the midlands, being a large and finely-cupped flamed byblœmen, though at the same time apt to come too short of feather to suit our northern taste. Lac, flamed rose, was splendid, and is a flower not seen erery day; this, and Gem, feathered byblœmen, raised by Mr. Abbot, of Stanton, were two of the gems of the collection.

Though last, we must not forget our friend, $\mathrm{Mr}$. Adams, at Quorndon, one of the prettiest and most healthy villages in Derbyshire. It is in the close vicinity of Keddlestone, the seat of Lord Scarsdale. The houses are built of stone, on each side of a very long hill, and most of them are ornamented with creepers. We noticed fine specimens of the broadleaved variegated ivy, crimson Chinese roses, honeysuckles, and jasmines. On the right of the ascent, is a very picturesque little church, with its diminutive tower and spire covered with ivy. From the summit of the hill, a most beautiful view of the surrounding country is obtained, and here our friend grows his flowers in first-rate style. They were just in their glory, and we saw the best collection of feathered flowers it has been our fortune to meet with during the past season. There was Maid of Orleans, Chellaston Beauty, Midland Beauty, Auastasia, and many of the flowers previously noticed in these memoranda, besides several unnamed seedlings of great merit, especially one with short and excellent cup, form and marking of Chellaston Beauty, only a rich rose, instead of purple feather. This, as an old friend from Sheffield says, will be a "top marker." Of flowers not previously noticed, was Enchantress, lilac purple, pure, with a splendid flame. Musidora, flamed, but in a very different style, short, pure, and beautiful. Then two well-feathered Pilots, flowers which will some day dispute the palm of excellence with 
Charles X. Alice Gray, a feathered byblœmen, pretty in marking, but decidedly too long. Duchess of Sutherland, a rosy purple, sometimes nearly a rose, was also very good. Champion of England took our attention, but surely it is nothing more than a good strain of Devonshire. Albion was in good character, but this also was Polyphemus. Model of Perfection, another low-growing Chellaston, is of good form, a feathered byblœmen, but very creamy on opening, and it is with great difficulty it bleaches out. Mr. Adams expressed his determination to root out all impure flowers, and certainly we believe his bed now to be the best in the county of Derby, though there are several others who are close up to him.

We must now close these memoranda, trusting they may be of service to our friends. At all events, they will enable growers at a distance to form some idea of what they may expect from this part of the world, at our national exhibitions.

\section{ON THE JERITS OF VARIOUS ROSE STOCKS USED FOR BUDDING AND GRAFTING.}

As it is plain that much, very much, depends on the stock from which anything-plant, or animal-lias descended, for vigour, constitution, and health, so also is it, that in plants, as much depends on the root on which they are budded or grafted. In treating on this all-important-I cannot call it anything less-subject, as it regards the well-being of a plaut, I do not intend to enter into any dispute on what may be called the vexed question of the rose stock, as I do not like a question because it has become a vexed one : to me it is a matter of regret. Yet, still I do not dislike a question solely becnuse it has become an angry or unpleasant one with some: this only proves, in many instances, the importance of attending more particularly to the subject, looking more closely into it than we have done, that we may

DECEMBER - VOL. VI. 20 
derive advantage from facts made known, even where the best feeling lias not been manifested.

I say again, I regret that the rose stock has become one amongst the many rexed questions of the day; and am truly sorry that our friends who liave done much towards the cultivation and present highly improved state of the rose, should have lost temper for one moment, or bave made use of the slightest expression that might have a tendeney to wound the feelings of others. Yet, in the midst of all my regrets, I thank them for the information communicated; and, from their cbservations, am more than ever convinced, that however good any stock may be in one locality, it will not succed equally well in another,-one soil being more congenial to the roots than the other.

The Manetii hes no mean claim to being a most valuable stock generally; whilst others, in certain parts of the country, have equal, if not superior claims. For my part, I atrach much importance to the treatment of proparation of stocks in the present day, and the capabiities or tendencies they have to sucker.

Stocks may be dividcd into two classes. Those very easily, or those cip rable of being disbudled, and those that it is difficult os disbad. By the first, I mean such as Mavettii, Victoria, \&ce.; the latter may be illustrated by the boumunlt, which, has, independent of its great number of eyes and a strong disposition to sucker, also a repuductive power, difierent to what I have observed in Manettii and Victoria, and which is the cause of the objection to it as a stock, -n that it is less healky than the others already wamed, or that it does not suit the nature of almost any rose, but its troublesome character in everlastingly producing suckers in one way or another. 'This, however, I may say of the boursault, that I lave not found any stock to furce like it, it is less affected by heat than any other, and is rarely known to die. 
It may be asked, do not all roses that are worked sucker more or less? 'To this I answer, if the stocks are properly treated (that is for drarf plants), they do not, as far as iny observation has gone. Now althongh it has been stated over and over again, it may be useful to some one to state it again, that this is prevented by taking ont the eyes of the cutting intended for a stock at the lower end, which will eventually become the root of the worked plant, sending all its flow of sap up this disbudded stem to the eye inserted in it.

As a reason for my thinking that Manettii, good as I believe it to be, has now a formidable rival in a safe disbudding rigorous stock, I send you the accompanying ten varieties, generally not the most vigorous growers, nor are these the effects of a bigh cultivation, for the cuttings, when planted, had no manure applied, and the ground had just been occupied by a crop of onions, and more than this, the cuttings nearly all grew. I may just state that - the plants of white moss, so very strong, more like Antwerp rasplerries in appearance than white moss roses, were taken from amongst fifty plants, all growing in the small space of fifteen feet. The following rarieties had also the same treatment:Bath White Moss, Mossy de Meaux, Curled Crested Moss, Madame Angouleme, Charles Souchet, Princess de Modena, Du Petit Thouars, Dr. Míarx, Triumphant Tea. I send this last because I have not been able to grow it at all on some stocks on which I have repeatedly tried. The above are all worked on the Victoria. It is just two rears, this month or the next, since the cuttings were planted, an inch or two apart, in lines, twenty inches to two feet asunder; they were budded last autumn (1851), and are now presented to you for your opinion of the merits of the stock.

Before closing, I would just state why I chiefly prefer Victoria to Manettii. Not becanse I had the honour of raising it from seeds of Rose ruga, about 
ten years ago, of which I am certainly proud, but for its being more quickly propagated. Such is the difference here, that were I to commence with one plant each, I have no hesitation in saying, that I could rear five hundred plants of Victoria before I had obtained one hundred of Manettii. This is one of the most important of the facts relating to the two stocks : in another district or soil, however, it might be vice versa.

Now, from the examples presented with this paper, and the established claims of Manettii as a stock, I think it will be very apparent that, by proper treatment of such stocks, we shall no longer find it a difficult matter to keep in health our fine delicate, but unrivalled Bath White Moss, Mossy De Meaux, \&c. hitherto so generally complained of as being short-lived. I trust that these few observations will prove useful to some of your numerous readers.

WILLIAM WILLISON.

Flower-gate, Whitby, Nov. 9th, 1852.

[The plants sent were indeed fine specimens of growth, the Victoria stocks being abundantly furnished with roots, in the way of a paradise stock, on which apples are budded. We have grown the Victoria for two or three years, and have budded some varieties which were shy growers; and from the results with which $\mathrm{Mr}$. Willison has so kindly furnished us, we shall grow it more extensively, for this purpose.-ED.]

Cuthill's Black Prince Strawberry.-The Black Prince is the best early Strawberry out, and for forcing none can beat it. I have forced five hundred pots of it each of the two last seasons, and never had such crops, and at the unusually early period of the Ist of February. They are beantiful while in flower, and attract notice, from the reddish tinge on the petals._C. M‘INTOSH, Dalkeith. 


\section{鼠art 㖘。}

\section{NEW PLANTS.}

\section{HARDY PERENNIAL PLANTS.}

Roi Lxopold Phlox.-This fine variety was raised by $M$. Rodigues. It forms a large head of flowers, extremely compact; the petals are smooth, and pure white, striped very distinctly down the centre of each with purplish rose.

\section{$\longrightarrow$ \\ GREENHOUSE PLANTS.}

Dictyanthls PavoniI.-A most singular climbing plant, with flowers of the form and colour of the stapelias. It was exhibited at Anvers, during the past season, and was universally admired.

Genethyllis Tulipifera. - This also has been recently introduced to the continental nurseries. As far as appearance goes, it is something in the style of Diosma fragrans; the blossoms are cup-shaped, striped and coloured like those singular flowers the parrot tulips. This will prove a fine plant for exhibition.

Habrothanues Elegans fol. var.- The plant, in its usual character, is well known in most conservatories, as affording many flowers during the winter season. This variety having its foliage very strongly spotted with yellow and white, will be a favourite with those who are fond of rariegated plants. It is to be sold out by M. Louis Van Houtte, of Ghent, and haring been raised by an amateur, it has been arranged that the profits arising from it are to be devoted to charitable purposes. 


\section{EXTRACTS, HINTS, AND RECOLLLETIONS.}

\section{$\longrightarrow$ \\ PROPOSAL FOR A CENTRAL INSTITUTION OF GARDENING.}

$W_{E}$ are happy to see an institution of this kind advocated by Mr. Fleming, of Broomhill, in the Scottish Gardener. We have long felt its absolute necessity, and are certain it would be of infinite advantage to the cause of horticulture in general. The preliminary education of the generality of gardeners and nurserymen, before their apprenticeship begins, hardly ever has reference to their future occupation. In fact, the class books used in public schools are of little service to the horticultural aspirant. We feel how little use to us was Casar's Commentaries or Virgil's Anead. The months and years we devoted to them, would have been far better employed in studying such works as the Revue Horticole, $V$ an Houtte's Flore de Serres et des Jardins 'l'Europe, or Lindley's School Botany; and as English reading books, Loudon's Arboretum, Linnceus's Lapland Tour, Humboldt's Travels, and works of a similar character. In truth, our faith in the histories of Rome and Greece has been somewhat shaken by the revelations made by recent writers, that the tale of Romulus and Remus being suckled by a wolf, the death of the latter by the hand of his brother, and many another singularly interesting record of early Rome, are but mere fictions. If this be so, much of the precious time of our youth was sacrificed; and to avoid this, we would advocate with all our energy, a horticultural college, on the principle of the Royal Agricultural College of Cirencester. We well know that to be a good gardener requires much experience, perseverance, devotion to the profession, and much learning; and though we also know that there are many first- 
rate men of this description, still nine out of ten are self-taught, as far as Latin, French, botany, chemistry, \&c. are concerned. What greater pleasure can there be for an employer, after the perfect culture of his plants and fruit, than to know that his gardener is acquainted with his profession theoretically as well as practically? And such a man is invaluable. We have known many men in our time who could scarcely write their owu names, were ignorant of mathematics, and could not tell you why the blood-flowered currant should be called Ribes sanguinea. Yet these men were excellent cultivators, but unhappily had no chance of improvement in their youth. To counteract effects of this description, on the Continent, the government of the King of the Belgians has taken the initiative, and afforded the horticultural portion of our community a good example. There is at Ghent, a practical and theoretical school of horticulture, under the direction of the well-known nurseryman, M. Louis $\mathbf{V}$ an Houtte. The rules are too long for us to extract, but we will give, according to the second article, what is taught there :-Mathematics, drawing, surveying and mapping, landscape gardening, the construction of horticultural buildings, arithmetic, writing, elements of physic and chemistry, botany, and horticulture, both theoretical and practical. Added to this, German, French, and English are also taught.

Our own view of the matter would be to establish a school where these preliminary studies could be entered into, in connection with the college, where the practical and scientific part of the profession might be taught to the advanced scholars.

Mr. Fleming says, "I would propose that a suitable piece of ground, say twenty or thirty acres, should be chosen, and on it, that walls should be built, vineries, greenhouse, and other erections of the same kind raised, all in the latest and best styles. On the walls shonld be grown the fruits proper to that situation; in the house, all the nseful species of foreign 
fruit might be cnltivated; and the surrounding ground might be laid out in fruit, kitchen, and flower gardens, in such kind of way as to present the greatest possible variety of all kinds of plants. One division of the space night be appropriated to the growth of native plants, where attempts could be made to bring under culture any that seemed suitable, and other similar experiments tried. Occasional lectures by professors of botany, and other useful sciences, might be provided for, much to the advantage of the young men."

With all this we most cordially agree, and we have no doubt that if the system is once got into operation, there are other things which will be deemed essential to be tanght, such as the principles of landscape gardening, pruning forest trees, measuring timber, \&c. a knowledge of which is highly desirable for gardeners who may become managers on large estates, \&c.

In the gardens of the Horticultural Society of London, a system somewhat similar is adopted. Young men are admitted, who go through a regular course of study, both in theory and practice; examinations take place, the same as in the government school of horticulture, at Ghent, and certificates of capability are granted to them, according to their respective abilities.

We trust this subject will be taken up seriously by influential parties; and most truly do we wish it success.

A JUNE VISIT TO THE AMERICAN NURSERIES AT KNAP-HILL AND BAGSHOT.

Those who have only seen American plants cooped together under canvass in the neighbourhood of smoky London, can form little idea of the grandeur and magnificence of the fields of rhododendrons 
azaleas, and kalmias, which have been planted and reared during years of care and solicitude, by Messrs. Hosea and John Waterer, at Knap-hill and Bagshot. Every season, about this time, many acres are studded with the lovely blossoms of these charming plants, and, notwithstanding the unfavourable spring which has just passed by, they are as fine at the present time as ever we remember to have seen them. It is true that the blossom buds of some of the early-flowering tender scarlet kinds have been killed by the late spring frost, but this is a circumstance less to be regretted, for, thanks to the skill of the Messrs. Waterer, we can now enjoy the beauty of the scarlet, or at least deep crimson rhododendrons, which flower sufficiently late to be out of the reach of such a calamity. 'This has been effected through years of judicious and repeated cross-breeding in the right direction; and it must be regarded as an acquisition of no ordinars kind, and one which cannot fail, in time, to materially alter for the better the general aspect of ornamental grounds; for once it shall have become generally known that the high-coloured rhododendrons exist, which will flower every year, without fear of disappointment, we shall have them scattered profusely over every lawn. And who shall not long for the event? for what can be compared with the beauty and effect of a fine specimen of the scarlet "rose tree" in bloom?

At Mr. Hosea Waterer's, at Knap-hill, whose extensive grounds are now one blaze of beautiful colours, of almost every shade, we noticed standard rhododendrons ten and twelve feet high, with clean stems five feet in length and six inches in diameter, bearing heads thirty feet round, and loaded with flowers. Trees of these dimensions are not uncommon here: and a knowledge of this fact alone, independent of the thousands of bushes and standards of less size, will serve to furnish lovers of American plants with some idea of the kind of treat a visit to these nurseries may be expected to afford. The 
scarlet, orange, and buff colours of the azaleas, too, form an interesting intermixture, which renders the whole striking, raried, and effective. The broadleaved kalmias, of which there are immense specimens here, were scarcely sufficiently in bloom when we saw them. Anong rhododendrons, perhaps the best of the newest kinds is Brayanum, a charming sort, with good shaped truss and flowers, which possess a colour about as fine as that of the Standard of Marenge rose. Barclayanum, a vivid crimson, was just coming into blossom, showing that it is really late. Atrosanguinenm is very dark, and Archimedes is one of the very best of bright rose colours. Brutus is desirable, and so is Desdemona. Nero and Onslowianum are two new and valuable kinds: as are also Maculatum nigrum and rubrum; the former having exchanged the spots which are usually on the upper petals for a blotch of deep chocolate, which gives it a distinct and striking appearance. Other fine kinds consisted of Rembrandt, Titian, Vandyck, Victoria, and Vervaneanum, to which must be added Currieanum. Fastuosum is a well-known double kind, which still maintains its good character. The following free-blooming and free-growing varieties of Catawbiense should be in every garden, viz. elegans, azureum, bicolor, ccelestinum, e. pictum, candidissimum, delicatissimum, ererestianum (an old but very fine kind), grandiflorum, purpureum elegans, roseum elegans, splendens, multimaculatum, and hyacinthiflorum. The latter has a lovely effect in the shape of a standard, and the flowers last longer in perfection than those of the single kinds. Of azaleas, one of the best scarlets is Coccinea major, but Cruenta is also a good one. Aurantiaca cupra is a fine orange, and Carnea delicatissima a pretty light pink, and a good trusser. Decus hortorum is rose, with the back petal yellow; and of buffs, none surpassed Pontica globosa. Of other fine kinds, of various colours, we remarked Gloria patria and mundi, Triumphans, Imperatrix, Monstrosa variabilis, Morterii, Ne plus 
ultra, Persoluta, Pontica imperialis, P. monstrosa, $P$. princeps, Prænitens, Crocea distincta, and Nilens. These are all first-rate kinds, in which no one need fear to be disappointed. Seedling azaleas and rhododendrons are very plentiful here, but it is only now and then that such gems as Brayanum and some others we have mentioned, can be picked from among them.

Mr. John Waterer's nursery, at Bagshot, is charmingly situated on two sides of a valley, over which a fine view can be obtained from the rising ground on either side; and, seen from such elevated positions, the scene presented at the present time is magnificent. Standard rhododendrons of no ordinary magnitude ornament the margins of the main walks, as well as the interior of the compartments into which the nursery is divided by arborvitæ hedges; and the fine broad, deep banks of azaleas, which exist here and there, are truly striking, and assist materially in setting off to adrantage their associates, the rhododendrons. In addition to the varieties of azalea mentioned above, all of which we saw here, we remarked some promising seedlings, the result of crossing the yellow Chinese kind with the large lightcoloured Viscosissima. Some of the produce from this cross looked as if they wonld be striped. Among high-coloured rhododendrons, none were more striking than Grand Arab, Soleil d'Ausierlitz, Blandianum, Vestitum coccineum, and Charles Truffaud. These are exceedingly bright and beautiful, and we trust that future experience will prove them to be sufficiently hardy to resist our sharp late frosts. Leopardi is a very fine spotted rosy lilac kind, and Towardianum has large very finely-shaped blossoins, which must ever render it a favourite. Captivation is worth attention, on account of its compact neat conical heads. Blatteum is a rery dark kind, with large trusses; and Nobleanum bicolor is good; as is also Mammoth. Lady Eleanor Cathcart is reported to be a very fine sort, but we were not fortunate enough to see it in bloom. Catawbiense splendens and grandi- 
florum make charming standards. C. album elegans and delicatissimum are certainly the best whites. Egregium makes a pretty standard; and Marriageanum is a fine kind, as are also Mirandum, Perspicuum, and Roseum elegans. We also remarked here a very excellent variety of Victoria.

Besides these fine rhododendrons and azaleas, there were abundance of nice bushes of the charming genus Kalmia. It may perhaps be worth recording, in conrection with this shrub, that the myrtle-leaved kind has been budded here on the broad-leaved sort, furnishing another means of increasing it besides layering and grafting.

At Knap-hill and Bagshot, conifers grow splendidly in the bog earth which prevails all over that district, and many fine examples of the leading kinds are to be found at both places. A tree of Pinus macrocarpa, at Knap-hill, is at least thirty feet high, and just now it is extremely handsome, on account of the bunches of orange blossoms with which every branch is terminated. Some time ago, it produced a large cone, from the seeds contained in which many plants have been raised. We also noticed a magnificent laburnum (Waterer's variety), forming a fine tree, clothed to the very ground with immense clusters of golden flowers. At the entrance of Mr. John Waterer's nursery, next Bagshot town, stands perhaps the largest weeping beech in the country. It is exceedingly pendulous and handsome. While speaking of conifers, we almost forgot to mention that plants of Funereal Cypress, both here and at Knap-hill, have had their leaders killed by the late frosts. Young cryptomerias, at Bagshot, have also suffered in a similar manner, whilst older plants have escaped. We therefore trust that the larger plants of the cypress, whose growth will be less succulent, will share a better fate.

Two propagating pits have been erected at Knaphill, each sixty feet long, with a path up the middle, and beds on either side, warmed with hot water, in 
two four-inch iron pipes, an arm of which is passed round the top, for surface heat. They are glazed with Hardy's patent rough plate. The roofs are fixed, and here and there a pane opens outwards, and means of ventilation are also provided at the sides.

\section{Gardeners' Chronicle.}

\section{PINK SHOW,}

At the house of Mr. Martin, the Red Lion, Coalpit-lane, Sheffield.

Young Growers' Kettle.-Mango, Mr. Martin.

Society Cup.-Mango, Mr. Martin.

Purple-laced.

Premier.-Mango, H. Barker

l Mango, H. Barker

2 Ruby, W. Benn

3 Greensides, W. Powell

4 Coronation, A. Knutt

5 Suwarrow, S. Tomlinson

6 Jenny Lind, W. Powell

7 Merry Monarch, J. Simmonite

8 Huntsman, H. Hydes Red-laced.

Premier.-Sturge, Mr. Martin

1 Beauty of Deighton, $\mathrm{H}$. Hydes

2 Criterion, W. Green

3 Adam Smith, w. Benn
4 Sturge, H. Barker

5 James Lang, S. Tomlison

6 Lady Antrobus, G. Brassington

7 Fanny, W. Green

8 Catherine, J. Sinmonite Black and White.

Premier.-Virgin Queen, A. Knutt 1 Lady Frost, H. Hydes

2 Miss Jessop, A. In nutt

3 Beauty of Home, ditto

4 Alfred Evelyn, ditto

5 Beauty of Blackburn, J. Simmonite

6 Kay's Mary, G. Brassington

7 Blackeyed Susan, Mr. Martin

8 Beauty of Clayton le-Moor, H. Hydes

\section{KATE CONNOR TULIP.}

I RECEIVED a copy of the Floricultural Review, for Septemher last, which only reached me on the 20th of October, too lale then to reply to Mr. Slater's attack upon me. In the said Review, Mr. Slater says, "The assertion that Mr. Lightbody raised Slater's Kate Connor is well known to be false." This is rather strong language for a man living in a glass house to use torvards me.

I will now state my reasons for claiming the credit of being the raiser of this so-much-bepraised rose tulip. When Mr. Slater got the loan of the lot of breeders from me, in 1842, he got a bull of the breeder of this flower among them. Fortunately for my own interest, I retained some of it. I did nut know that the celebrated Kate Connor of John Slater, of Cheethum Hill, near Manchester, was a seedling of mine, till last year, on my return home from Derby, I saw it in bloom, on the bed of a friend of mine, near Manchester. When I saw the flower, DECEMBER-VOL. VI. 
I certainly did claim it; and I now tell Mr. Slater that he has no more right to append "Slater" to this flower, than I have to appropriate another man's property to my own use.

Mr. Slater says this flower is very scarce. It may be so with him. But, notwithstanding Mr. Slater's assertion, that it is scarcely possible that I hold more than two blooming roots, and a few small pieces, if it will be any gratification to him, I will undertake to produce either twenty or forty blooms, which will be no difficult matter. According to Mr. Slater's history of the origin of this flower, it bloomed frst in 1844. I will simply ask, how can it be possible that I hold a stock of Slater's Kate Connor ? keeping in mind, that I never received a bulb of Kate from any person, and have been sending it out as a breeder for years past, and this year in the broken state, and at present have above eighty bulbs of all sizes. Yet Mr. Slater says it is so scarce that he has great difficulty in getting a small root.

I hope, from this statement of facts, that Mr. Slater will see he has made one "grand mistake;" and if he is not;satisfied, I may in all probability be obliged to say what may not he very pleasant to a man of his high principles of honour and strict integrity.

Falkirk, Nov: 6th, 1852.

GEO. LIGHTBODY.

RHUBARB SHOWS.

$W \mathrm{E}$ have often been asked if we knew of any rules and regulations for conducting exhibitions of this kind. Throngh the kindness of $\mathrm{Mr}$. George Geggie, of the Waterloo Gardens, Bury, we are now enabled to lay before our readers those which are in force at Bury and the neighbourhood. There are various rhubarbs exhibited there which have not yet come under our observation. We subjoin the names of those which were shown at the Cotton Tree, Bury, on the 5th of June last:- Victoria, Prince of $W$ ales, Napoleon (seedling), Old England, Chance, Fantail (seedling), Swindler, Sir R. Peel, Goliath, Washington, Carter's Whip, and Excellent. Besides these, there were shown Freedom and Hercules; and at other shows, Hector, Lady Downham, Vulcan, Robin Hood, Egyptian Queen, Lady Russell, Lady Derby, 
Ajax, Snowball, and Lord Duncan, in all, twentyfour varieties. These certainly are a great many, and we would advise our rhubarb-growing friends to be inquiring about them. In the meantime, we should be happy to receive a description of any of the sorts peculiar to that part of the country, from the growers, stating the colour, general appearance, flavour, whether early or late, dc. We are sure information of this kind wonld be highly acceptable to many of our readers, and gladiy shall we afford room in our pages for such communications. We may just observe here, that we have read the Rhubarb Book, published by Mr. R. I. Kaye, of Bury, on the same principle as the Gooseberry Growers Register. The heaviest entire stalk was shown by Mr.John Ridge, at Blackburn, and weighed Slb. Ioz. The best trimmed according to the regulation No. 10, was Victoria, and weighed 5lb. 4oz. by Mr. James Crossley, at Bury.

\section{RULES.}

1. No shower to win above one premier.

2. No grower to win above one prize with one sort, except a maiden grower.

3. Any sort having won a premier prize, is eligible to win again by anyone except the winner of the said premier.

4. Maiden growers to be entitled to show on equal terms, in every respect, with the older growers, without regard to their having won a maiden prize.

5. If three maiden growers enter, to be one prize; if six enter, to be two prizes; if nine enter, to be three prizes; and so on.

6. Any seedling winning a prize, if thought sufficiently distinct, must be named previously to the prize-money being paid. And any seedling deemed an improvement upon a named variety, to be distinguished, after being sold out, by the raiser's name being prefixed, thus - Hope's Goliath, Virtue's Victoria, \&c.

7. The number and value of the premier prizes to be fixed at the making-up meetings, by a majority of the members present; and also the number of the money prizes.

8. The judges to be appointed by vote, on the day of showing; who shall give their word to show no partiality, and to act according to the best of their ability.

9. Every shower to declare upon oath, if thought necessary, that what he is showing is of his own growth, and correctly 
named, to the best of his judgment; and any person found violating this rule, to forfeit his prize-money, and to be expelled.

10. The leaves to be cut to the length of ten inches from the centre of the crown of the stalk. Any crack or blemish more than skin deep to be deemed a disqualification.

11. No person to be allowed to show who is in arrears in his payments to any previous meeting.

12. No person to be allowed to show as a maiden grower off an old shower's plants, unless he has replanted such plants, after they came into his possession.

13. That three persons be appointed by a majority of the exhibiters of any show, to inspect the plants of any exhibiter, when deemed necessary to do so.

14. Any seedling, after having won for two seasons, cannot be'shown again until it has been let out, providing the growers are prepared to subscribe for twenty lots.

\section{PLANTING AND TRAINING WALL TREES.}

THE disappointment resulting from loss of blossoms every spring, even where trees are partially protected, has induced me to think that, in walled gardens the trees ought to be planted on the opposite side of the wall to that on which they are intended to bear fruit; that their branches should be led over the coping, and trained down the other, say south side. By so doing, we should have all our valuable borders to do as we liked with, and we could crop them up to the veiry foot of the wall. It has always been remarked by gardeners, that wherever trees have been planted on a north wall, and brought over and trained down the sonth side, the blossoms have escaped frost, unless, indeed, it has been very severe. This in a great measure would do away with spring covering; for by the present system of planting and training, we make the blossom a cup to hold water, sleet, or snow, as the case may be; and when morning frosts occur, the water freezes, and the organs essential to fructification perish. It is notorious that what blossoms do escape, are sure to be those on the undersides of the shoots, and which, of course, look downwards. The 
stamens and pistils being dry, are saved. When a tree is on the nortl side of a wall, the sun cannot act upon its stem, the sap, therefore, flows more regularly. The practice would also save muiching, watering, and many other annoyances; for in some places where I have been, even a cat must not be seen treading npon the south border. It has been noticed, that fruit gathered from trees planted after this fashion, has been of a better flavour than that from trees growing in the ordinary way. I planted a good many at Broom House, Fulham, in this manrier; and Mr. Knight, of the Exotic Nursery, Chelsea, a good authority in such matters, will perhaps say how they have succeeded. In addition to the above advantages, I may mention, that a tree trained down a wall is never so liable to red spider as one otherwise placed, on account of the undersides of the leaves being more exposed to rains and dews; neither is it so liable to mildew, on account of its main stem being protected from violent sun heat. One thing much against fruit trees is that the majority of gardens lie in the lowest parts of the park, where they receive the earliest frosts in antumn, and the latest and sererest in spring. No doubt some will object to planting on the outside of walls as they will be unable to make up those unnatural plum-pudding borders in which they so much delight. This, however, to a great extent, might be got over. It is a well known fact that the late Mr. Chapman, of $V$ auxhall, never made a border for his grape vines; they were merely planted against the wall; and in the present year, Mr. Chapman told me that in digging down he could not even find a root, they had passed under the wall to the other side, where gardens of other people abut; and for fruit from those same vines he has taken numerous prizes. Does anyone know where the roots of the famous vine at Hampton Court lave gone? And yet it is a fact, that upon these vines, over whose roots we have no: 
control, the berries are always better coloured than under ordinary circumstances. Do not, however, let me be understood as wishing to depreciate modern advances in fruit growing. I am only bringing forward cases in support of my plan of planting contrary to what at present exists; besides, those borders, if any, on the outsides of walls, might be abandoned, at least as far as a few stumps of cabbages and greens are concerned.

\section{Camberwell.}

JAMES CUTHILL.

\section{HYBRIDIZING PEONIES.}

Since the commencement of the Midland Florist, we have lost no opportunity of advising our readers to cross-breed any of our hardy showy perennials which admitted of such manipulation. We extract from the Gardeners' Chronicle an account of an experiment of this kind, on the plants above-named. "I must mention an attempt made by me to obtain a large double crimson garden pæony, shrubby, instead of herbaceous. The common garden pæony has its fine duplication made for it out of anthers. Its female part is undisturbed. I touched this with the dust of Moutan papavaracea ; plenty of seeds formed, and when sown in a pot, came up plentifully. When of right age, I planted them out in a border. Their foliage was very various-none like garden pæonies. So I had great expectations. At three years old, they flowered-all dull red, small, single, wild-looking flowers. In disappointment, I took them all up, but two, which showed a little like inclination to shrubbiness. The roots were as various as the foliagesome like moutans; some tubers, like garden pæonies; and others, the greatest number, something between fangs and tubers. From the variations in foliage, and the roots of the seedlings, and from the 
particular that the garden (old crimson double) pæony has no anthers, I believe the hybridization took place; but no shrubbiness resulted. Can it be, that the male being the shrub, and the female herbaceous, the mules must be the latter. It may throw some light on the philosophy of these things, in raising the suspicion that in mules between an herbaceous and a frutescent plant, of relation near enough to be hybridized together, the mule will be herbaceous or fruticose, according as its female parent is the one or the other."

We sincerely hope that this will lead others to make a trial. It is no rule, because these hybrids were wild-looking, small, and single, that all should be so: and why not endeavour to impregnate some of the double pæony moutans with farina from the single crimson tennifolia insignis? if the idea holds good, that the seedlings take after the female parent, perhaps the cross we suggest might be attended with better success.

FLowers.-Of all the minor creations of God flowers seem to be inost completely the effusions of his love of beauty, grace, and joy. Of all the natural objects which surround us they are the least connected with our absolute necessities. Vegetation might proceed, the earth might be clothed with a sober green ; all the processes of fructification might be perfected without being attended by the glory with which the flower is crowned; but beauty and fragrance are poured abroad over the earth in blossoms of endless variety, radiant evidences of the boundless benevolence of the Deity. They are made solely to gladden the heart of man, for a light to his eyes, for a living inspiration of grace to his spirit, for a perpetual admiration. And accordingly; they seize on our affections the first moment that we 
behold them. With what eagerness do very infants grasp at flowers! As they become older they would live for ever amonyst them. They bound about in the flowery meadows like young fawns; they collect heaps ; they sit among them, and sort them, and sing over them, and caress them, till they perish in their grasp. We see them coming wearily into the towns and villages with their pinafores full, and with posies half as large as themselves. We trace them in shady lanes, in the grass of far-off fields, by the treasures they have left behind, lured on by others still brighter. As they grow up to maturity, they assume, in their eyes, new characters and beauties. Then they are strewed around them the poetry of the earth. They become invested by a multitude of associations with innumerable spells of power over the human heart; they are to us memorials of the joys, sorrows, hopes, and triumphs of our forefathers; they are, to all nations, the emblems of youth in its loveliness and purity.-Howitt's Book of the Seasons.

American Aloe,-A specimen of this aloe (Agave Americana) is now in bloom, at Moreby Hall, York, where it forms a very stately and conspicuous object. It is grown in a box nearly three feet square, plunged centrally on the ground level of the spacious gravelterrace on the east wing of the mansion, in which position it has stood about ten years, protected during the winter season by moveable glass frame-lights, within which a small stove has been placed during severe weather, to exclude frost. Previous to the formation of the flower-stem, the leaves extended between forty and fifty feet in circumference, the heart or central part of the plant being up to the above period two and a half feet in diameter. The length of the leaves averaged from six to ten feet, and they were from twelve to sixteen inches wide at their lowest part in connexion with the stem. The flower scape is twenty feet in height; and at the elevation of about 
ten feet the side flower branches, which are tiwentyeight in number, commence diverging horizontally from the main column. These lateral flower-stemis are about eighteen inches in length, progressively shortening towards the top, thus forming an elegant candelabra-like pyramid or outline. Each of the side branches again branch off into three smaller ones, which immediately converge into one large, flat, umbel-like cluster of densely-crowded floral envelopes, from which issue numerous projecting yellow stamens, or male organș, surrounded by imperfectly developed floral leaves or sepals. It is calculated that the aggregate number of blossoms contained in the twentyeight fasciles is between four and five thousand. 'The excellent preservation of the plant for such a period, through all the vicissitudes of weather incident to such a situation, reflect credit upon the management. -W. Wood, Fishergate Nursery, York.

Winton's Parke's Steel Digging Fonks.-Our own experience has proved the paramount superiority of these forks over all others, particularly in digging heary gravelly or stony soils, uniformly retaining their proper shape and sharp points; and lowever large the stones pressing between the tines, they instantly spring into the uriginal form, without the least strain or bend, requiring no repairs, being uniformly and gradually reduced by wear from a long to a short-tined fork. Many persons have witnessed trials between workmen of equal power, and in every instance, the workmen using this instrument, at twenty-inch trenching, earned more money, with less fatigue, at task work, than those workmen using the broad biade fork-the former doing his work better and cleaner. In a recent match between two workmen, the man with a light fork earned four shillings, and the other only two shillings and threepence, the latter man having to pay sixpence for the repair of the bent and strained blades. It is calcu- 
lated that the workman with the light fork lifts in the course of the day five tons less weight than the worknan with the old heavy fork. 'The saving in repairs, in one fortnight, exceeds the cost of the light fork. For field, garden, yard, or stable use, and in hop and cane plantations, vineyards, \&c. their utility will exceed the most sanguine expectation. A very light fork is made, by the use of which children can with ease and comfort earn good wages at twelve-inch trenching.

In the last number of the Midland Florist, I saw an article on scillas, or spring bulbs. I have been in the habit of growing several beds of Scilla Siberica, for the last twenty years, and I think there is not anything mure beantiful. They pot up their pretty blue buds in February, sometimes in January, and keep flowering until May. They grow from nine inches to a foot high, and are so hardy, that no frost affects them. With a slight sprinkling of snow on the ground, they look quite dazzling. Scilla nutans rosea also makes a good show in May. It grows a foot to eighteen inches high, and a bud of it looks beautiful, with its roselike bells. The following few will be found good companions for the above:Leucajum vernum, Dens canis, Red and White Grape, Hyacinth (three varieties), Winter Aconite, Helleborus Nigra or Christmas Rose, Trichonima bulbicodium, Scilla Italica, \&c.-F. F.

Trees.-What can be more beautiful than trees? their lofty trunks, august in their simplicity, asserting to the most inexperienced eye their infinite superiority over the imitative pillars of man's pride! their graceful play of wide-spreading branches! and all the delicate and glorious machinery of buds, leaves, flowers, and fruit, that with more than magical effect burst forth from naked and rigid twigs, with all the rich and brilliant, and unimaginably varied colours 
under hearen; breathing delectable odours, pure, and fresh, and animating; pouring out spices and medicinal essences; and making music, from the softest and most melancholy undertones to the full organ peal of the tempest. I wonder not that trees have commanded the admiration of men in all nations and periods of the world. What is the richest country without trees? What barren and monotonous spot can they not convert into a paradise.-Honitt's Book of the Seasons.

Best W ater for Plants.-It is well known that rain water is far better than spring water for promoting the growth of plants. This is from the former containing that which is a necessary ingredient in their formation, viz., ammonia; and which is abundant in liquid manure. The efficacy of this may soon be developed by sprinkling one-half of a grass plat with spring water, and the other half with water in which pounded carbonate of ammonia (about one ounce to the gallon) has been dissolved. The former will keep it alive, but the latter will give it vigour and luxuriance.-The Builder.

I take the liberty of forwarding to you the size and weight of three sticks of celery, grown in the garden of the Rev. C. Whichcote, Aswarby: The three sticks, after being well washed and having the roots cut off, weighed $2 \tau \frac{1}{2}$ lbs. The largest weighed $10 \frac{1}{2} \mathrm{lbs}$. and measured eighteen inches and a half in circumference, in the solid part, and four feet seven inches in length. It is a seedling, between Seymour's White and a variety for which I have no name, except Broadstem. It is very firm and well-flavoured, and I feel persuaded, that with extra management, I can grow it near a stone weight another season.IV m. Haynes, Gardener to the Rev. C. Whichcote, Aswarby, Folkingham, Lincolnshire. 


\section{弱art JEEEE.}

\section{R E V I E W S.}

The Gardeners' and Horticulturalists' Almanack, FOR 1853. By Joseph Harrison. London: Whit = taker \& Co., Ave Maria-lane.

THIs, we should say, will be a successful candidate for public favour; for amongst the various good garden almanacks published now-a-days, it is one of the best, combining with abundant information of all that relates to gardens and gardening affairs, a most interesting monthly calendar of animated nature. It is also embellished with a large coloured plate of the Victoria regia, in its native habitat.

\section{QUERIES AND ANSWERS.}

Will you kindly inform me in your next number, whether I shall succeed in striking cuttings of hybrid perpetual roses? How shall I perform this operation, and when? J. F.

[Most hybrid perpetual roses, such as Geant des Batailles, La Reine, Duchess of Sutherland, \&c., will strike root, if cut clean across, immediately below a bud, or if the shoot is short, and has " a heel" (a portion of older wood) cut smooth, so much the better; put under a hand-glass in the autumn, they will callous and emit roots at spring.]

Grafting Cactuses. - W. M.-Yes; this is often done. If the portion to be grafted is cut at the lower part, like a wedge, and inserted in a cleft of the stock (a Pereskia, for instance), and kept covered with moss at the junction, it will readily take.

CockroACHes.-Zero.-Your house is certainly in a sad plight, but these insects may soon be removed. When you can procure some cucumbers, spread the peel on your kitchen floor, at bed time; repeat this a few nights, and the cockroaches will quickly be destroyed. 
Cedrus Deodara, Araucaria Imbricata, and Cryptomeria Japonica.-A Constant Subscriber.-Our friend who has an extensive lawn cannot do better than plant specimens of these very handsome and hardy trees. They are all of eminently beautiful character. We really advise all who are fond of distinct and splendid trees, to get those abovementioned; they are not very particular as to soil ; they will grow well in the peaty soil of Woking, as well as in ours, which is strong and retentive.

Kate Connor Tolip.-R. S. - We believe it to be a very good sort, though our two blooms, this season, were flamed, and certainly second-rate. Whenever we see it capable of beating Lady Clifton, or any other fine rose, it shall have from us the praise it will merit. It would appear, from Mr. Geo. Lighthody's letter, inserted in our present number, that Mr. . Slater has been guilty of naming Mr. Lightbody's flower, and calling it his own. R. S. must excuse our inserting his remarks. We do not wish to wound anyone's feelings, not even those of our worst enemy (if we have more than one). Conduct like that to which R. S. alludes, is certainly most lamentable, but all these things will find their level in time.

Pinks.-A Yodng Beginner.-Yes, you can grow these in pots as well as carnations and picotees. Plant them in the pots for blooming, about April, in rich compost.

Apples adapted for Small Gardens.-H. W.-We should advise them on the paradise stock, instead of the crab. The former emits more fibrous roots, and produces more fruit, without the tree attaining so large a size as the latter. For half-adozen, three table and three kitchen fruit, we would recommend our correspondent to procure, for dessert, the Eve Apple, Ribston Pippin, and Mannington Pearmain; for kitchen, Lord Suffield, Queen Caroline, and the Blenheim Orange. These will succeed each other, and be found ex. cellent.

Standard Filberts.-F. B.-Yes, they are ornamental, when grafted on the Spanish nut, which does not emit suckers. The Frizzled Filbert and Purple-leaved Filbert are well worthy of cultivation in this manner.

J. Colman, Esq., Stoke Holy Cross, Nomvich.-Companion (Netherwood) (P.F.) was sent to us by Mr. W. Baildon, Shrogg's Bottom, near Halifax, and by Mr. Thomas Bower, Durkill, Great Horton, near Bradford. Ringleader (S.B ) was raised by Mr. James Marsden, of Brighouse, near Halifax. The stock of Warrior (Slater) (C.B.) is almost exclusively in the hands of Mr. James Scholefield, of Mossley, near Ashton-under-Lyne, who informs us, he bought it to "preserve a fine variety from destruction." Mr. S. speaks DECEMBER-VOL. VI. $2 \mathrm{Q}$ 
very highly of it as a flower, but says it is a bad doer. Mr. $\mathrm{S}$. says further, that being an amateur, he is not allowed to advertise it. Most of our readers will doubtlessly agree with is that an "innovation" on such a rule would be an improvement. We have taken a very unusual course in giving these particulars, because we are anxious the good flowers of the north should have the prominence they deserve. We have been much delighted with the spirit which has been evinced by our northern friends during the past season, and have a grateful remembrance of many kindnesses spontaneously rendered to us, and we trust at the coming York show, they will claim and maintain a position worthy of their ancient fame. If we may add one word of parting advice, we would suggest a thorough revision of their picotees; in these they - certainly do not shine; of carnations they have a good array. The accounts of the quantity of seed saved are singularly variable in their tenor, but all very conclusively show that to obtain seed, hybridization is imperatively necessary, and we are quite satisfied that no advance will be obtained without a careful application of the same means. $\quad$ E. S. D.

\section{CALENDAR OF OPERATIONS,}

FOR DECEMBER.

\section{GREENHOUSE.}

FEw plants afford a more sure and ample reward than does the chrysanthemum, to those who have given it the necessary attention during the summer and autumn months. At this season of the year, when all other flowers are scarce, wellcultivated plants of the chrysanthemum furnish a profusion of most beautiful and durable flowers, of great variety of colour. Water may be freely given while they are flowering, and all decaying leaves or flowers should be removed as they appear. Camellias will now be rapidly swelling their flower-buds, and will require to be more liberally watered. An occasional sponging of the foliage with clean tepid water, will be of much benefit to the plants. They should now occupy a light and airy part of the house. Ericas should be frequently looked over, and if mildew appear, fimmediately dust the part affected with flowers of sulphur. Let them have plenty of air, and be carefully watered. Similar treatment for epacrises, boronias, pimelias, eriostemons, and most other hard-wooded plants. Pelargoniums, and other soft-wooded plants, will need but little 
water. Remove all fogged leaves, and fumigate on the first appearance of greenfly. Use no more fire than will be necessary to keep out frost and expel damp. Give plenty of air when the weather is favourable.

VINERY.

It has been a difficult matter to keep grapes during the last month, especially in houses containing plants. If any are yet hanging, cut them at once, with a piece of wood to each bunch, tie them upon rods, and hang them in a dry room, where they will be found to keep much better than in the house. The vines may then be pruned, the stems cleared of the loose bark, and afterwards coated over with the fullowing mixture, viz., to a quarter of a peck of lime add one pound of sulphur, and a quarter of a pound of soft soap, dissolved in as much warm water as will make the whole of the consistence of thick paint.

J. Bayley.

- FLOWER GARDEN.

The long-continued rains of last month having greatly retarded the operations in the out-door departments, we must now embrace every opportunity of favourable weather to get the flower garden well cleaned, the vacant beds and borders dug, the grass and box edgings thoroughly repaired, and any inequalities in the lawns or walks rectified and well rolled. If any bulbs, such as crocuses, snowdrops, tulips, narcissus, \&c., yet remain unplanted, let them be immediately got in. Prune and nail or tie creepers on walls and trellises. J. BAYLEY.

Carnations axd Pscotees.-The long-continued heavy rains will have sorely tried the patience of the cultivator, and have called for all his vigilance. Every effort must be made to guard against the evils such an excess of moisture is likely to en ender, giving at all times the freest supply of air possible. Keep the plants thoroughly clean, scratching the soil over from time to tiure, to prevent its becoming green, and carefully shield from drip. Frost will do no harm if the soil is properly dry ; but should it set in suddenly, with the plants in rapid growth, care must be taken to thaw them slowly. On all sides the note of preparation is being sounded for the coming season, York and Glasgow taking the lead; and it is gratifying to know that the spirits of florists never were more eager, or their unanimity of opinion so apparent, as they are at this moment of our completing our calendar.

Derby.

E. S. Dodrexi. 


\section{ADDRESS T0 0UR READERS.}

ANother year nearly passed has brought us to the close of the sixth of our editorial labours, and we assure our friends, that we are abundantly thankful for the generous sympathy, support, and help which our little periodical continues so liberally to receive on every side. With a cordial remembrance of the many kindnesses personally shown to us, and the repeated letters of commendation we have received, we shall commence our labours for 1853 with a determination to afford that information on floral and horticultural subjects, which we have the best of reasons to know has been hitherto acceptable to the great majority of our readers, - gladly acknowledging the large measure of assistance we have received from enthusiastic and able friends. Indeed, as our readers are well aware, much, very much, of the best of our periodical, has been the voluntary contributions of those whose only motive is to be found in their love for the cause of Flora and their desire to aid its progress. This assistance we shall continue to try to deserve, and our readers will, we believe, fully appreciate it. In rebutting (on our cover) the illiberal and false assertions which have disgraced the pages of a contemporary publication, we have simply performed a duty we owed to truth; and whatever influence we may possess, will at all times he devoted to the determined opposition of those who would disseminate discord amongst the floral community, and to the protection of the characters of those who otherwise might suffer the keenest injustice, without redress. The true florist is anything but an incendiary. The study of the beauteous forms of Nature leads to the very reverse of falsehood and chicanery; and while we are spared to conduct the Midland Florist, we trust we shall never be guilty of warping our public duty to the littleness of petty feeling. Frail we know we are, and therefore liable to errors of judgment. Corrections of these we shall thankfully receive; and whilst attempting to diffuse information, as becomes the place we fill, we shall be grateful for any communications to us, - for we every day feel an increasing pleasure in learning, and the vastness of the field for investigation.

Soliciting our friends for a continuance of their kind support, and their recommending us, as they find us worthy, to those who may not have seen our little work, we respectfully and gratefully make our bow, wishing our readers, one and all, a merry Christmas and a happy new year.

The Coppice, neak NotTingham, J. F. W. DeCENBER Ist, 1852. 


\section{N D E X.}

Address to our readers

American aloe

Americar High Bush Blackberry

American nurseries at Knap-hill and Bariot, $\ldots$...

and Bagshot, a June visit to the $386^{\circ}$

Antirrhinums, Soleil d'Or, Giantess, 20 ; Queen of the Whites 58

21; Primrose Perfection, Hendersonii, Novelty, 148 , Whites,

Apples, Isle of Wigt Pippir, 125 ; Lodestum 303

Grenadier, Golden Spire,

Apricot, Alberge

Aquilega, a new cross-bred

Ardsia crenulata ...

Asparagus, Reading Giant

Auricula, rot in the

Autumn and spring exhibitions of the Horticultural Society of
London

Azalias, Indica extranii, Indica magnifica $\quad \ldots 313$

Brachysema acuminata $\quad \ldots \quad \ldots 21$

Broccoli, on the culture of the.. $\quad \ldots-\ldots 236$

$\because \quad \ldots 108$

Butcher's meat, on the formation of $\quad \ldots \quad \ldots 120$

Calceolarias, Conway's Florabunda, Albiflora, 22 ; Wellington Hero, 49, 148; Henderson's Tom Thumb, Smith's Beauty of Montreal, 149; Heywood Hawkins, Fascination, Araminta, Fireball $\ldots$ alendar of operations, for January, 31 ; February, $\ddot{64}$; March

96; April, 1.28; May, 160; June, 190; July, 217; August, 248;

September, 280; October, 315 ; November, 348 ; December .. 404

Camellia, Countess of Ellesmere

Camellias seedling :.

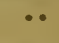

Carnation and picotee bloom, reminiscences of the

Carnation, Flora's Garland rose flake, pedigree of

Carnations

on raising seedling...

Carnations and picotees, packing

Carrots, to preserve from wireworms

Ceanothus rigidus ...

Celery, size and weight of three sticks of $\cdots$ -

Central institution of gardening, proposal for a

Cerasus Lusitauicus semis tomensis

Cherries, Belle Magnifique, 119 ; Bigarreau Noir Tardiff

Chrysanthemum, Hendersonii..
.. 302

$\therefore 1 \varepsilon 6$

60,171

.. 355

.. 212

.. 115

., 227

.. 341

.. 122

.. 186

.. 401

.. 384

$\therefore 86$

.. 188

49,148 
PAGE

$\begin{array}{lllllll}\text { Chrysanthemums } & \ldots & \ldots & \ldots & \ldots & \ldots & 41\end{array}$

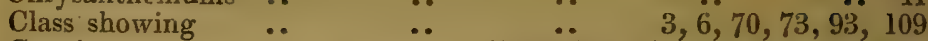

Coppiceana $\quad \ldots \quad \ldots \quad 17,46,82,117,232,263,332,364$

Dahlias, Sir Richard Whittington, Morning Star, Lizzy, Miss Ward, Rawling's Dr. Erampton, Spary's Absalom, Green's

Scarlet King, Bob, 150; Agnes $1 .$.
Delphiriums, Magnificum, 57; Hendersonii, 148; Beauty of

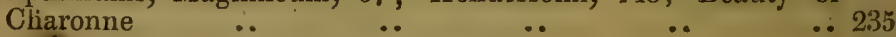

Derby floral reading and discussion society $\quad \ldots 88$

Deutzia gracilis vera $\quad \ldots \quad \ldots 146$

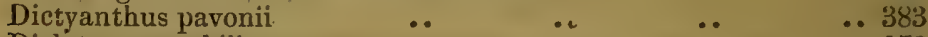

Dielytra spectabilis .. $\quad \ldots \quad \ldots 172$

Double White Peach propagate the $\quad \ldots \quad$.. $\quad$.. 243

Early sweet peas, to procure $\quad \begin{array}{llll}\text {. } & \ldots & \ldots & \ldots 186\end{array}$

Apple, Walker's Russet _. $\quad$. $\quad \ldots \quad$.. . . . 121

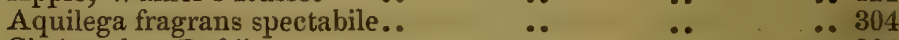

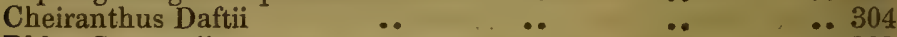

Phlox Spencerii .. $\quad \ldots . \quad \ldots \quad \ldots 303$

Endive, Imperial Batavian $\quad \ldots \quad \ldots \quad \ldots 120$

Epacrises, soil most suitable for $\quad \ldots \quad \ldots \quad \ldots 91$

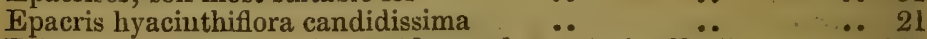

Ericas, longiflora, 21 ; jasminiflora rubra, tricolor Epsii $\quad$ _. 302

Erratum - Washington and Sancta Sophia tulips ... $\quad$.. 124

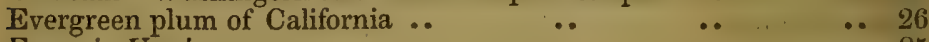

\begin{tabular}{llllll} 
Eugenia Ugni & $\ldots$ & $\ldots$ & $\ldots$ & $\ldots$ & $\ldots$ \\
\hline & $\ldots$ & $\ldots$ & $\ldots$ & $\ldots$ & \\
\hline
\end{tabular}

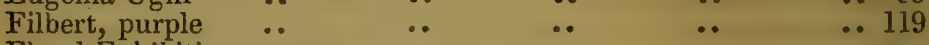

Floral Exhibitions-

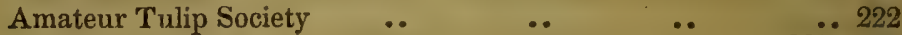

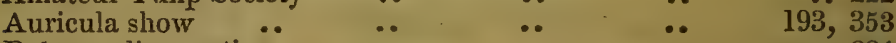

Bolton tulip meeting $\quad \ldots \ldots \quad$.. $\quad \ldots 224$

Cambridge Florists' Society, tulips _.. $\quad$.. $\quad \ldots 221$

Cambridge Horticultural Society, tulips $\quad \ldots 258$

Carnation and picotee show .. $\quad$. $\quad \ldots 351$

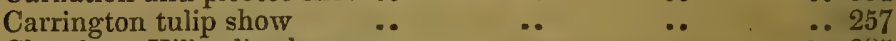

Cheetham Hill tulip show $\quad . \quad 0 \quad \ldots \quad$.. $\quad \ldots 285$

Derby Gardeners' and Florists' Discussion Society, piriks, roses 322

Ecclés United Tulip Society .. $\quad$.. $\quad$.. $\quad$.. 221

Falkirk Horticultural Society, tulips $\quad \ldots \ldots 225$

Felton Union of Florists and Horticulturists, auriculas, poly-

anthuses, hyacinths, \&c. 253 ; tulips, pansies, ranunculuses 254

Grand towns $\in$ xhibition, carnations and picotees .. $\quad$.. 290

Great North Cheshire Tulip Society . . $\quad$. . $\quad$..286

Great South Lancashire Tulip Society .. $\quad$.. $\quad$. $\quad$. 287

Halifax auricula show, 194 ; tulip show $\quad \ldots .225$

Leeds Central Floral Society, carnations and picotees $\quad$.. 352

Leeds Old Floral Society, carnations and picotees ... . ..353

Leicester Society of Amateur Florists, tulips, roses, pinks, $31 \ddot{7}$; carnations and picotees ... .. $\quad . .318$

Middleton Floral and Horticultural Society, carnations, picotees 34 Midland Horticultural Society, tulips, 222 ; roses, carnations,

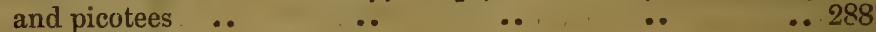
Mottram tulip show $\quad \ldots \ldots \ldots$. $\quad \ldots \quad \ldots 224$ National Horticultural Society $\quad$.. $\quad$.. $\quad$.. 194 National tulip show $\quad \ldots \quad \ldots 223$ Northamptonshire Floral and Horticultural Society, carnations 350 
Floral Exhibitions-

North Staffordshire and Macclesfield pink shows $\quad \cdots \quad$ PAGE.

$\begin{array}{llll}\text { North Staffordshire and Macclesfield pink shows } & \ldots & \ldots 321 \\ \text { Oxford Floral Society, pinks } & . . & . . & . .258\end{array}$

Peter Eaton's tulip meeting .. $\quad$.. $\quad$.. $\quad$.. 255

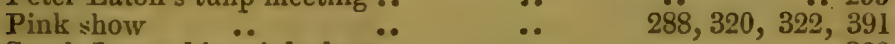

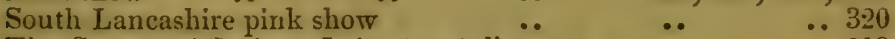

The Cottagers' Society, Leicester, tulips $\quad \because .319$

Tulip show $\quad \because 33,226,256,257,282,283,284,285,286,319$

Wakefield Floral Society, pinks, carnations $\quad$.. $\quad . .33$

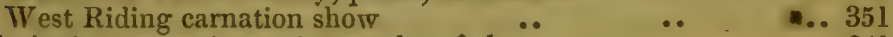

Florists' conversation society, rules of the.. $\quad$.. $\quad$.. 241

Flowers.. $\quad . . \quad \ldots 397$

Flowers and plants, jottings on, made during a commercial tour,

in the summer of $1852 \quad \ldots \quad \quad . \quad \quad \quad . \quad 327,369$

Flowers, \&c. opinions on $\quad \because . \quad 87, \ddot{1} 72,210,239,276,305,335$

$\begin{array}{lllll}\text { Forsythia viridissima } & . & . . & . . & 314\end{array}$

Fruits of the midland counties.. $\quad$.. $\quad$.. $\quad 14,4$

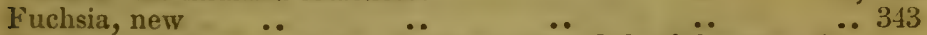

Fuchsias, Globosa perfecta, Darling, Pet, Splendidissima, Exquisite, 149 ; Hendersonii, Beauty of Deal, Cortona, Gaiety, 150 ; Banks's Glory

Gallardia semiplena

Garreya elliptica

Garden robbing

Garden, the

Genethyllis tulipifera

Genista purgans

$\because \quad \therefore \quad \quad . . \quad \quad \because 303$

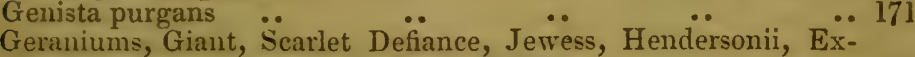
travaganza, Odoratisim Drandiflora

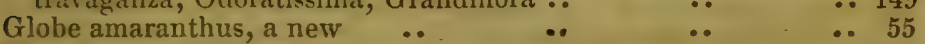

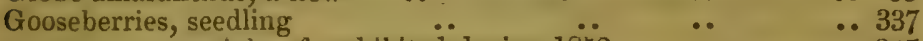
Gooseberry shows ... exhibited during $1852 \quad \quad . \quad 1 \quad \ldots 307$

Grapes, Pique Poule Noir, Early Malingre, Purple Fontainebleu, Scotch White Cluster, August Muscat, Black Alicant 119 preservation of $\quad . \quad \ldots 182$

Great national tulip show, notes on the, $19 \overline{9}$; errata.. $\quad . .245$

Greenhouse plants, cheap pit for $\quad$.. $\quad$.. $\quad$.. 22

Habrothamnus elegans fol. var. $\quad$.. $\quad$.. $\quad$.. 383

$\begin{array}{llll}\text { Hardy aquatic plants } & \because & & \end{array}$

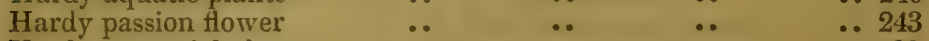

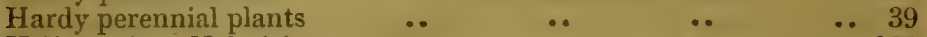

Heliotropium Voltairianum nanum $\quad \begin{array}{lll}\because & & \end{array}$

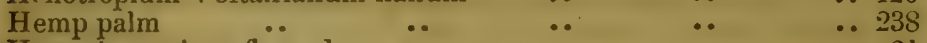

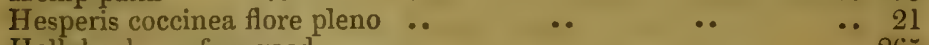

Hollyhocks, a few good $\quad \because . \quad \ldots \quad$.. $\quad \ldots 265$

Charles Lydyard, Cream of the Valley..$\quad \quad \ldots 303$

to improre the present breed of, by cross-breeding.. $\quad 25$

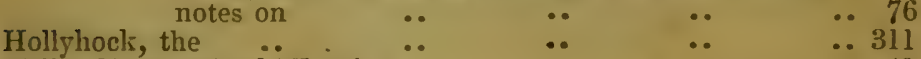

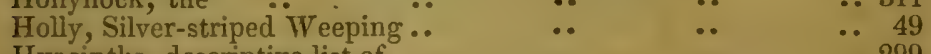

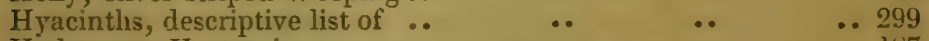

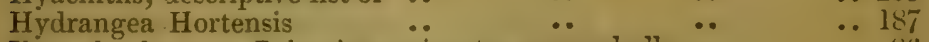

Ilex, altaclarense, Balearica variegata, macrophylla .. $\quad$.. 86

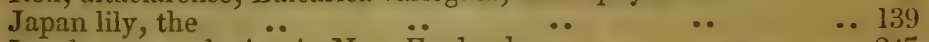

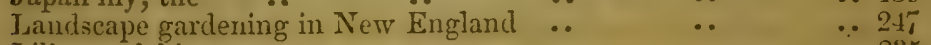

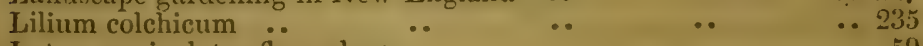

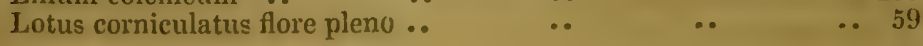


PAGE

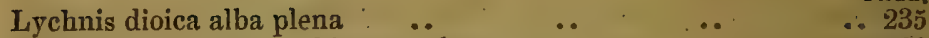

Mimuluses, elegans, rubinus perfecte $\quad \ldots \quad \ldots \quad \ldots 20$

Mountain Ash, Weeping Variegated $\quad \ldots \quad$.. $\quad \ldots 28$

Notes of the great metropolitan meetings.. $\quad$.. $\quad$.. 206

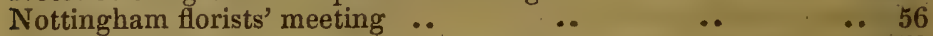

\begin{tabular}{lllll} 
Nymphea gigantea ... & $\ldots$ & $\ldots$ & $\ldots$ & $\ldots 279$ \\
\hline
\end{tabular}

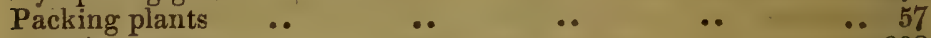

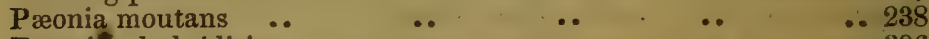

Pronies, hybridizing $\quad \ldots-\quad \ldots 396$

Pansies, Kossuth, Sir Joseph Paxton, $\ddot{\text { Duchess of Perth, }} \ddot{50}$; Jennings's King, 120; Schofield's Village Maid, Schofield's Magnum Bonum, 150 ; Sir I. Catheart, Fearless .. $\quad$.. 303

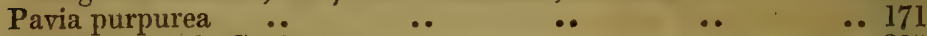

Pear, Beurre de Capiaumont .. $\quad$.. $\quad$.. $\quad$.. 305

Pelargoniums, Mount Hecla, Standart Bearer, Reine des Fleurs, 21 ; Optimus, Ariadne, 27; Rubens, Enchan-

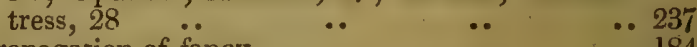

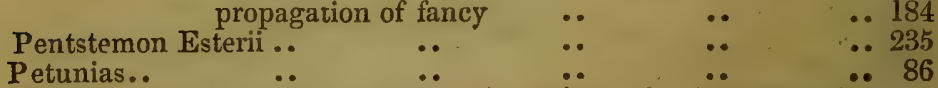

Phloxes, Roi des $\ddot{N}$ ains, Imperialis major, 20 ; $\ddot{\text { Drummondii, }}$

Thompsonii, 147 ; Roi Leopold $\quad$.. $\quad \ldots 38$

Picotees, a few good

Pink, Colchester Cardinal

Pink notes on wintering the

Pinks descriptive list of

reasons for grow
Plants for massing ..

Plums, Guthrie's Aunt Ann, St. Etienne..

Polyanthus, cultivation of the...

Hufton's Lord Rancliffe

Polyanthuses, notes on a few good

Potato, Red Ash-leaf Kidney ..

Primula undulata .. . .

Proposed national auricula show

Queries -

Apples adapter for small gardens ..

Asparagus, best time for planting ..

Cactuses, grafting

Cactuses, grafting

$\begin{array}{llll}\cdots & \ldots & \ldots 383 \\ \cdots & \cdots & \cdots & \ldots 77\end{array}$

$\because \begin{array}{llll}\cdots & \cdots & \cdots & \\ \because & \cdots & \ldots 303\end{array}$

$\because \quad \quad \because \quad \quad \ldots 303$

Carnations and picotees..

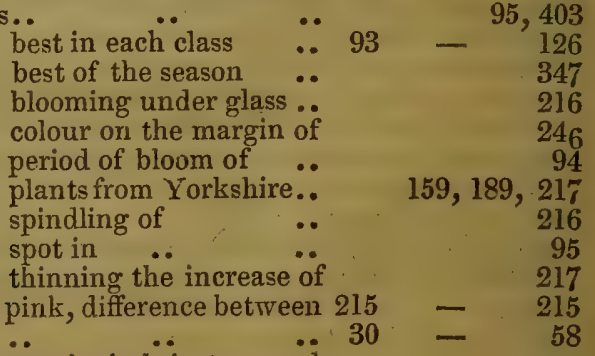

$\begin{array}{lllll}\text { Carnation, picotee, and pink, difference between } 215 & - & 215 \\ \text { Carnation seed } & . . & . . & \ldots & 30\end{array}$

Carnation seed Deodara, Araucaria imbricata, and

Cryptomeria Japonica

Cockroaches..

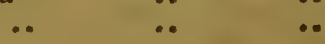


Queries-

Dahlia roots, striking and dividing..

Davallia Canariense

Firm versus loose potting $\quad$.

Gladioluses and lilies, list of $\quad \because$

Grape vine, fruit from a single ere of the $\because 345 \quad-\quad 345$

Grape vine, fruit from a single eye of the .. 344 - 344

Hepworth's President and Superior, merits of.. 63 - 115

Jenny Lind and Lorenzo $\quad$.. $\quad$.. $\quad 159$

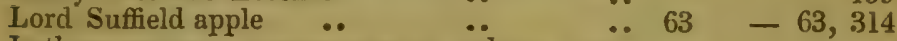

Lothospermums, eccremocarpos, cobæa, maurandia, and rhodochiton, sowing seed of

National Carnation and Picotee Society

National Tulip Society ..

Pinks

Polyanthuses, cultivation of

Ringleader ..

$\because \quad 281$

Roses, cuttings of hybrid perpetual $\ddot{0} \quad \quad \because 402 \quad-\quad 402$

Sowing carnation and picotee seed, German yellow picotees

Standard filberts

Towns meeting, the

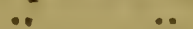

.. $\quad$.. $314 \quad-\quad 315$

.. $\quad \cdots$

Tree pronies, propagation of ..

Tulips, Kate Connor and Napoleon

Tulips, six of each class..

Wall trees, blighted $\quad .$.

$\because \quad 348$

848

$\therefore 63-63, \quad 89$

$\because \quad . \cdot$

.. $248266,297,330$

159

Ranunculus, Cortusefolia ${ }^{\circ} \quad \ldots \quad \cdots$

Raspberries, notes on cultivation of the

Raspberry, Belle de Fontenay..

Reminiscences

-. $\quad$.

$\therefore \quad 128$

- $\quad 31,93-31,93$

$\because 30 \quad-248,403$

Restoring bloom to plums, cucumbers, $8 \mathrm{c}$ Retrospective criticism-

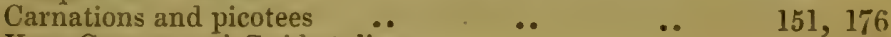

Kate Connor and Guido tulips

Raising seedling carnations ...

Tulip bed, grouping of colours in a

Reviews-

An Hour with the Hollyhock

British Pomology

Gardeners' Almanack for $18 \check{5} 2$

Groombridge's Farm and Garden Essays

Kidd's own Journal

Letters to Farmers

..

The British Winter Garden ..

The Farmer and Cottager's Guide

'The Garden Companion and Florists' Guide

.. 346

346

.. 86

.. 259

.. 163

. 20

.. 305

The Gardeners' and Horticulturalists' Almanack for $1853 \quad \ldots 402$

The Gardener's Record, and Amateur Florist's Companion, 15

The Horticulturist

The Journal of the Horticultural Society of London

$\because 181$

The Mlagazine of Horticulture

.. 62

.. 188

The Scottish Gardener $\quad . \quad \quad \because . \quad \ddot{6}, 121,150,214$

'Turner's Florist, Fruitist, and Garlen Miscellany 61, 91, 155, 212

Rhododendrons, Pince's Queen Vietoria, Albertus, Campanula

$\begin{array}{llllll}\text { picta .. } & \text {.. } & \ldots & \ldots & \ldots & \ldots 172\end{array}$

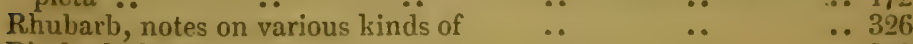

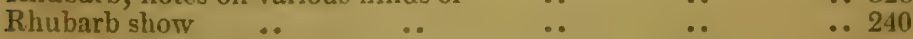

$\begin{array}{llllll}\text { shows } & \ldots & \ldots & \ldots & \ldots & \ldots 392\end{array}$ 
Rose seed, encouragement to sow

Roses, how to plant new perpetual raising from seed

$\therefore$ results of experiments in raising seedling
PAGE.

$\therefore 306$

.. 342

$\because 237$

$\therefore 50$

.. 168

Rose stocks used for budding and grafting, on the merits of various 379

Royal Nursery, Slough

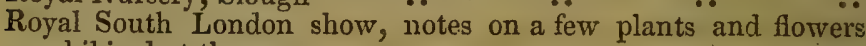

exhibited at the ..

Scillas, spring-flowering

Snails, how to get rid of

Silenton Floral and Horticultural Society...

Strawberries, Nicholson's Ajax, 279 ; Cuthill's Black Prince

Strictures ore Mr. Willison's mode of massing colours

Summer dessert apples

The polite gardener on the character of his bride

Tigrida Canariense..

Tomato figs

Towns exhibition of carnations and picotees, the

Tree pæony, a splendid

Trees

Tulip be $\ddot{d}$, grouping of colours in a remarks on the best method of arranging a $\therefore 308$

.. 269

340,400

$\therefore 205$

$\ldots 28$

.. 382

$\therefore 93$

$\therefore 242$

.6 60

$\because 120$

270,323

$\because 241$

$\because 400$

8

67,131

Tulip, descriptive remarks on about one hundred varieties of the,

$229 \quad \ldots \quad \ldots \ldots \ldots \ldots 291$

Tulip judging in the midlands ... $\quad \ldots \quad \ldots 54$

Tulip ramble, notes of a $\ldots \ldots \ldots 373$

Tulips, another word on the nomenclature of $\quad \ldots . \quad \ldots 37$

a word or two on the nomenclature of $\quad \ldots \quad \ldots . .16$

best in each class $\ldots \ldots 100$

Joan of Arc, Salvator Rosa, 29 ; Marshal Soult, 59 ; Kate Connor, 185, 391 ; Lady Clifton _.. .. 244

list of

list of new, described by Mr. J. Lightbody, of Falkirk $\quad \begin{array}{r}99 \\ 334\end{array}$

new, described by Mr. $\ddot{J}$. Lightbody, of Falkirk $\quad \ldots 334$

.. 99

Tulip showing note of fine, bloomed last season, by Mr. Lightbody

.. 121

$\because 203$

Turnip, Orange Jelly

a yoüng florists' opinion on

Verbenas, Dufoy's M. Paquin, Turner's B̈eauty, Louise Miellez,

$\therefore 35$

.. 172

La Nymph, Jules, 22; America, 60: National, Virginius,

Orlando, Purple Rival. Alba magna, Eliza Cook, Standard,

Ormsby Beauty, 87; Republic, Orb of Day, Diadem, Nectar

Cup, 150 ; Belle Melanie, Marianne, George Sands, Groethe,

Cornelia, M. Paquin

Wallflowers

Wall trees, planting and training

Water, best for plants

Wax flowers

prizes for

Winton's Parke's steel digging forks

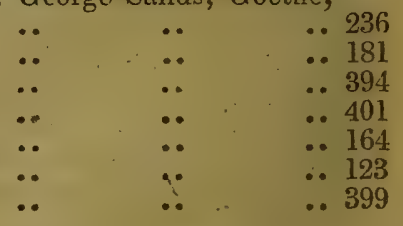

ERratum-Page 292, for "very poor" read "very rare." 







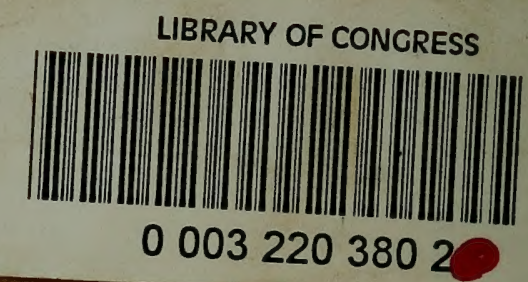

